BRONZE AGE FARMS AND IRON AGE FARM MOUNDS OF THE OUTER HEBRIDES

Scottish Archaeological Internet Report 3, 2003 www.sair.org.uk 


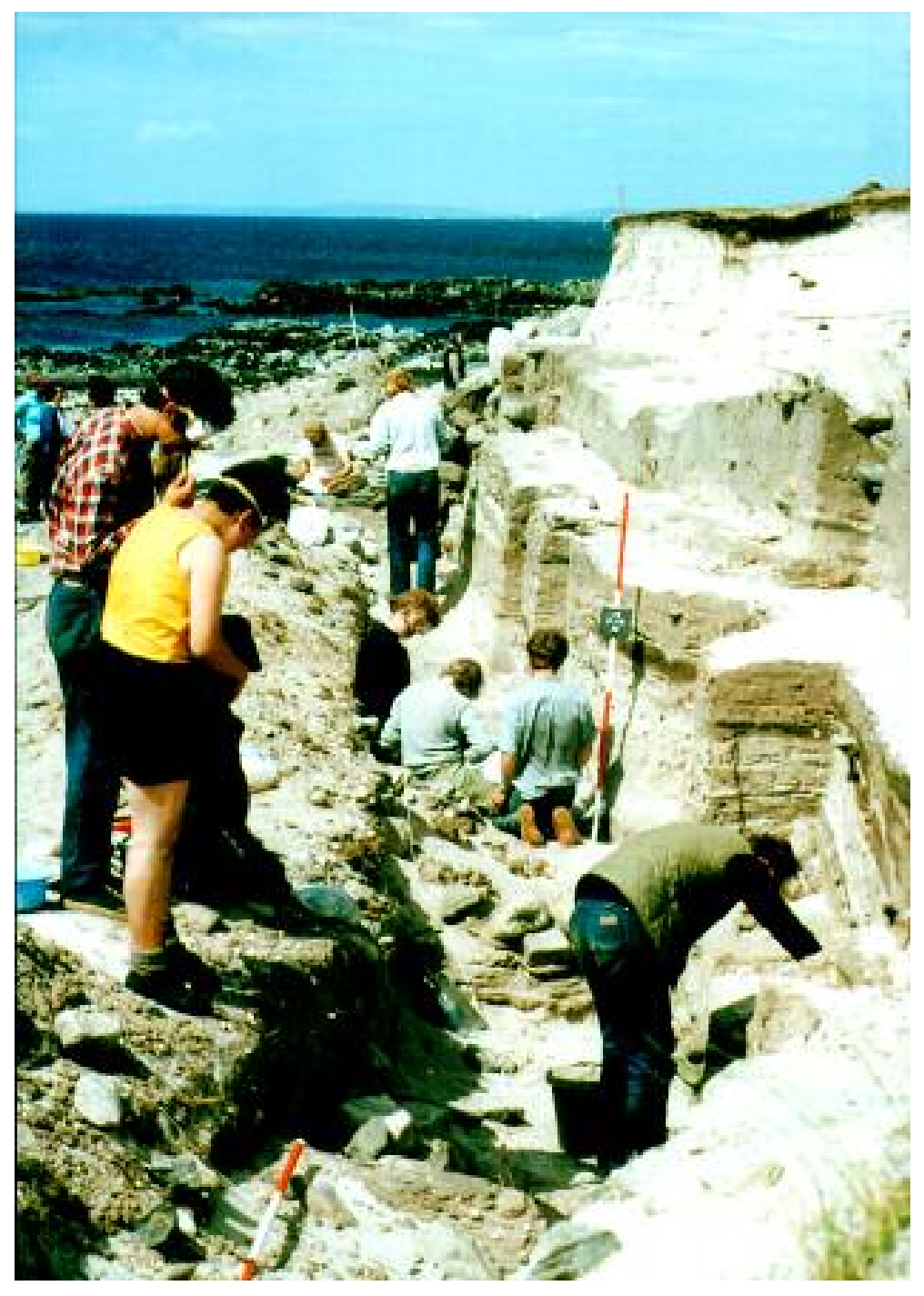




\title{
BRONZE AGE FARMS AND IRON AGE FARM MOUNDS OF THE OUTER HEBRIDES
}

\author{
by \\ John Barber \\ with contributions from;
}

Geoff Collins, Lisbeth Crone, Alan Duffy, Andrew Dugmore, Nyree Finlay, Will Forbes, Ann-Marie Gibson, Paul Halstead, Ken Hirons, Heather F James, Andrew Jones, Glynis Jones, Frances Lee, Daragh Lehane, Ann MacSween, Antoinette Mannion, Ian D Mate, Rod McCullagh, Simon Moseley, Andrew Newton, Chris Pain, Alix Powers, Jim Rideout, William Ritchie, Marian Scott, Dale Serjeantson, Andrea Smith \& Nigel Thew 
This page intentionally blank 


\section{ORGANISATION OF THE VOLUME}

In Chapters 1-3 the background to the project is presented together with a general introduction to the physical environment, the natural history and archaeology of the Western Isles. The results of the excavations are presented in Chapters 4-8 in a highly synthesised form, with field interpretation, post-excavation analyses and final archaeological interpretation summarised by Block (see Chapter 1.3.5). Chapters 9-18 contains the detailed results of the post-excavation analyses together with the conclusions of the project.

When original context numbers appear in the text, they are rendered in square brackets thus, [274]. Radiocarbon dates are presented either as raw radiocarbon determinations $\mathrm{BP}$, eg $2350 \pm 50$ uncal $\mathrm{BP}$, or as calibrated age ranges $\mathrm{BC}$ or $\mathrm{AD}$, eg 1500 to $1275 \mathrm{cal}$ BC. Where more general terms are used, as in 'the second millennium BC' the dates should be understood as indicating calendar dates, unless otherwise specified and if the context seemed to require it the phrase 'cal BC' or 'cal AD' has been employed. The term 'radiocarbon years' has been used to identify the intervals between the means of radiocarbon determinations, eg there are 100 radiocarbon years between $2350 \pm 50$ uncal BP and $2450 \pm 50$ uncal BP.

This monograph has taken many years in the making and consequently, many of the specialist reports were written some time ago. To avoid further delay in publication the original texts are published, with the date of their submission in brackets after the author's name.

\section{PREFACE BY COLIN WALLACE, MANAGING EDITOR OF SAIR}

The sharp-eyed reader will notice that SAIR 3 is different in appearance and concept to the other reports in the SAIR series. Bronze Age Farms and Iron Age Farm Mounds of the Outer Hebrides was welcomed by the SAIR Pilot as a parallel project, a long-running one with its own editor and publication history, that would find a home under the SAIR umbrella. It was not reasonable to impose further delays consequent on putting it in the hands of the Pilot Editor and entering it into another editing process, when the point of SAIR is to make the results of archaeological fieldwork available. Read on! 
Published by the Society of Antiquaries of Scotland with Historic Scotland and the Council for British Archaeology

Editors Anne Crone \& Ronan Toolis

Design \& pagesetting

M.C. Bishop at The Armatura Press

ISBN: 0903903725

ISSN: $\quad 1473-3803$ 
CONTENTS

CHAPTER I: BACKGROUND TO THE WESTERN ISLES PROJECT

CHAPTER 2: THE PHYSICAL BACKGROUND I2

CHAPTER 3: THE NATURAL HISTORY AND ARCHAEOLOGY 23

CHAPTER 4: EXCAVATIONS AT BALELONE HF James \& P Strong 32

CHAPTER 5: EXCAVATIONS AT BALESHARE HF James \& A Duffy

CHAPTER 6: EXCAVATIONS AT HORNISH POINT H F James \& R P J McCullagh 72

CHAPTER 7: EXCAVATIONS AT SOUTH GLENDALE H F James \& W Forbes I04

CHAPTER 8: EXCAVATIONS AT NEWTONFERRY HFJames \& J Rideout I09

CHAPTER 9: RESEARCH QUESTIONS AND METHODOLOGY II4

CHAPTER I0: THE ARTEFACT ASSEMBLAGES I26

CHAPTER II: THE HUMAN, ANIMAL, BIRD AND FISH BONE ASSEMBLAGES

CHAPTER 12: THE CHARRED PLANT REMAINS FROM BALESHARE AND HORNISH POINT G Jones

CHAPTER I3: POLLEN ANALYSES OF ORGANIC HORIZONS FROM THE BALELONE MIDDEN A Mannion I59

CHAPTER 14: THE MOLLUSCAN ASSEMBLAGE N Thew I63

CHAPTER I5: THE PHYTOLITH ASSEMBLAGE A Powers I78

CHAPTER 16: POLLEN AND DIATOM DIAGRAMS FROM LOCH SCOLPAIG AND BALELONE FARM,

NORTH UIST A M Mannion \& SP Moseley

CHAPTER I7: PRELIMINARY INVESTIGATION OF LAKE SEDIMENTS FROM THE MACHAIRS OF THE OUTER HEBRIDES $K R$ Hirons

CHAPTER 18: INTERPRETATION AND DISCUSSION

BIBLIOGRAPHY

INDEX

TABLES 


\section{ILLUSTRATIONS}

1. Location map

2. Results of the coring exercise at Baleshare

3. Hougharry: location map and plan of Site 1

4. Hougharry: plans of Sites $2-4$

5. The solid geology of the Western Isles

6. Models of machair evolution

7. Machair morphology and archaeological deposits

8. Ecological units on the Western Isles

9. Balelone: site location and survey

10. Balelone: main section showing Blocks

11. Block 3

12. Block 4

13. Block 5

14. Block 6

15. Block 7

16. Block 8

17. Block 9

18. Baleshare: site location and survey

19. Baleshare: main section showing Blocks

20. Block 2

21. Block 4

22. Block 5

23. Blocks 7, $8 \& 10$

24. Block 9

25. Block 11: section

26. Block 11: plans of Floor Levels 1, 2 and 3

27. Block 12

28. Block 14

29. Block 15

30. Block 16 
31. Block 17
32. Block 20
33. Block 21
34. Block 24
35. Block 26
36. Block 27

37. Hornish Pt: site location and survey

38. Hornish Pt: main section showing Blocks

39. Block 1

40. Block 2

41. Block 3

42. Block 4

43. Block 5

44. Block 6

45. Block 7

46. Block 8

47. Block 9

48. Block 11

49. Block 12

50. Block 13

51. Block 14

52. Block 16

53. Block 17

54. Blocks $15 \& 18$

55. Block 19

56. Block 20: section

57. Block 20: plan

58. Block 21

59. Block 22

60. Block 23: plan

61. Block 23: section 


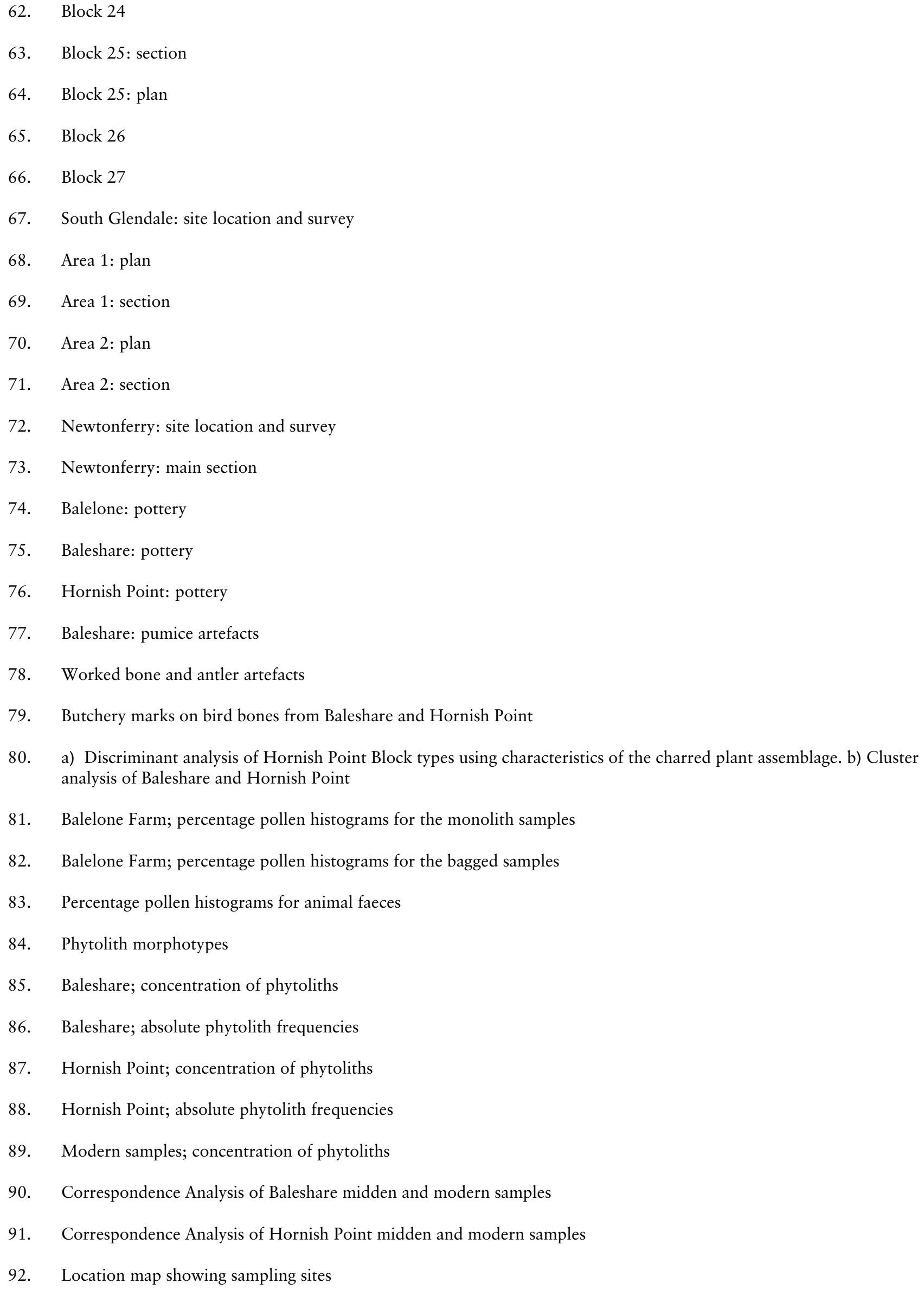

81. Balelone Farm; percentage pollen histograms for the monolith samples

82. Balelone Farm; percentage pollen histograms for the bagged samples

83. Percentage pollen histograms for animal faeces

84. Phytolith morphotypes

85. Baleshare; concentration of phytoliths

86. Baleshare; absolute phytolith frequencies

87. Hornish Point; concentration of phytoliths

88. Hornish Point; absolute phytolith frequencies

89. Modern samples; concentration of phytoliths

90. Correspondence Analysis of Baleshare midden and modern samples

91. Correspondence Analysis of Hornish Point midden and modern samples

92. Location map showing sampling sites 
93. Loch Scolpaig; a) pollen percentages b) concentration data

94. Balelone Farm; a) pollen percentages b) concentration data

95. Loch Scolpaig

96. Askernish; sediment characterisation

97. Askernish; chemical analysis

98. Differential thermal analyses traces

99. Askernish; pollen percentage diagram

100. Askernish; pollen concentration diagram

101. Balemore; sediment characterisation

102. Balemore; pollen percentage diagram

103. Margins of sites interdigitated with peat

104. Calibration of the marine effect

105. The major structural elements at Baleshare 


\section{PLATES}

1. Ceramic vessel the island of Ensay, Sound of Harris

2. Site of Paible, North Uist.

3. Sandcliffs at Baleshare, prior to excavation

4. Deflation surfaces on Ensay, Sound of Harris

5. Bucket augers

6. Lewissian gneiss

7. Machair plain at Ardkenneth, South Uist

8. Evidence for progressive drowning of the landscape

9. The domed structure of Baleshare midden viewed from the seaward side

10. Knock-and-lochan in North Uist

11. Cultivation marks at the base of the Balelone midden

12. Balelone

13. Balelone

14. Balelone

15. Baleshare

16. The entrance feature, Block 8

17. The quern, Block 18

18. Baleshare, Entrance passageway running into unexcavated sediments

19. Baleshare, Circular structure

20. Baleshare, ardmarks

21. General view of excavation in progress at Hornish Point

22. Hornish Point, Section

23. Hornish Point

24. Hornish Point

25. Hornish Point

26. Hornish Point

27. South Glendale

28. The tallard at Newtonferry

29. Newtonferry, midden deposits

30. Balelone sherd bearing impressed, ring-headed pin decoration 
31. Hornish Point, Human vertebrae

32. Sheep mandible

33. Baleshare, Distal tibia of extinct crane species 


\section{TABLES}

1. The maximum extents of the cored sites

2. Acidity $(\mathrm{pH})$ of a range of modern deposits from the Long Isle

3. The IHI values from the Baleshare Blocks

4. $\mathrm{CaCO}_{3}$ content of beach units

5. Baleshare, Pottery attributes.

6. Baleshare, Catalogue of lithic finds.

7. Hornish Point, Flint

8. South Glendale, Catalogue of stratified and unstratified lithic finds.

9. Baleshare, Unmodified pumice finds.

10. Baleshare, Minimum numbers of identified anatomical units in faunal assemblage.

11. Hornish Point, Minimum numbers of identified anatomical units in faunal assemblage.

12. Baleshare and Hornish Point, Age at death - wear of mandibular d4 and M3

13. Baleshare and Hornish Point, Age at death - postcranial evidence

14. Baleshare and Hornish Point, Sex structure of cattle and sheep.

15. Baleshare and Hornish Point, Fish species present.

16. Baleshare, Catalogue of fish bones.

17. Hornish Point, Catalogue of fish bones.

18. Baleshare, Bird species present.

19. Hornish Point, Bird species present.

20. Baleshare, Carbonised plant remains.

21. Hornish Point, Carbonised plant remains.

22. Baleshare and Hornish Point, carbonised plant remains

23. Balelone, Stratigraphy.

24. Balelone, Faunal groups and faunal associations.

25. Baleshare, Faunal groups and faunal associations.

26. Baleshare, Stratigraphic Blocks with faunal groups in chronological order.

27. Burnt and green-stained snails

28. Marine mollusca from Baleshare, Hornish Point, Newtonferry and Balelone

29. Ecological requirements of marine mollusca

30. Baleshare, Provenance of phytolith samples. 
31. Hornish Point, Provenance of phytolith samples.

32. Baleshare, Ranking of Blocks based on phytolith concentrations.

33. Baleshare, Blocks with significantly different phytolith suites.

34. Baleshare, Correspondence Analysis.

35. Baleshare, Cluster Analysis.

36. Hornish Point - ranking of Blocks based on phytolith concentrations

37. Hornish Point - Correspondence Analysis

38. Hornish Point - Cluster Analysis

39. Baleshare and Hornish Point, Ranking of Blocks.

40. Baleshare and Hornish Point, Cluster Analysis of material.

41. Characterisation of dune samples by concentration and types of phytoliths recovered

42. Loch Scolpaig, Core stratigraphy

43. Balelone Farm, Core stratigraphy

44. Balelone Farm, Radiocarbon dates from the pollen core

45. Loch Scolpaig, Summary of results for the $\mathrm{pH}$ spectrum

46. Loch Scolpaig, Summary of results for the ecological spectrum

47. Askernish, Core stratigraphy

48. Balemore, Core stratigraphy

49. Categories of deposits evidenced on the excavated sites

50. Radiocarbon dates from marine shell

51. Radiocarbon dates from bone and carbonised seeds

52. Baleshare, Pairwise analysis of the radiocarbon dates

53. Hornish Point, Period II, Pairwise analysis of the radiocarbon dates

54. Radiocarbon dates - the marine reservoir effect

55. Baleshare and Hornish Point, Approximate sedimentation rates

56. The absolute ages of the 'wheelhouse complex'

57. Block types from which worked bone and antler have been recovered

58. Baleshare and Hornish Point, Categories of worked bone and antler

59. Baleshare, Types of deposits with burnt stone 
Dr Noel Fojut was the Rescue Inspector at Historic Scotland when this project was undertaken and the writer is grateful to him for help and support with the project. This report has profited from the editorial input of other inspectors and I would particularly like to thank Ian Armit, Gordon Barclay and Patrick Ashmore for useful comment and discussion. Mike Parker-Pearson undertook a full review of the final draft and his advice and comments were unfailingly helpful.

I am grateful to the North Uist Estate and the South Uist Estate and their owners and factors and also to the Commons Grazing Committees and their chairmen for permission to survey and, or, excavate on sites under their guardianship. The site supervisors Peter Strong (Balelone), Rod McCullagh (Hornish Point), Alan Duffy (Baleshare), Jim Rideout (Newtonferry) and Will Forbes (South Glendale) also deserve my special thanks and I am happy to record my debt to them. In the year that Balelone was excavated, I was recuperating from a serious back injury and Mike Brooks undertook the administration of the excavation at that site, for which I am grateful to him. To all of the specialists who have contributed to this study I also extend my thanks.

During the excavation, off-site services were provided by; Jean Comrie (stratigraphical checking) Daragh Lehane (sample processing) Heather James (data manager) and Magaret Rodan (logistical support). During the post excavation process, Heather James acted as the project manager, a role adopted in varying degree also by Nyree Findlay, Anne MacSween and Anne Crone. I am happy to record by gratitude to them all.

Early work in bringing together the site reports and the overall report was undertaken by the site supervisors and by Heather James who also undertook the IHI calculations and the integration of the specialist's site-specific information. I am deeply grateful to Heather for her work and her support. Subsequently, Jenny Shiels continued this work. Illustrations were prepared by Peter Strong, Angie Townsend, Heather James and Anne Crone, as well as by individual specialists.

Finally, to my colleagues at AOC Archaeology who have had to suffer my absences from other labours to complete this report I extend my grateful thanks for their forbearance. I will I hope be forgiven for mentioning specially my wife, Dr Anne Crone, who edited and finally brought this report to completion and for expressing the hope that we may survive the experience.

It is my happy duty to express my gratitude to the excavators who worked on these sites. Exceptionally, in my experience of the West Coast, we were blessed with fine warm weather in which the greatest discomfort we suffered was that from wind blown sand that managed to get everywhere. No doubt this contributed to the making of a very enjoyable excavation. I would like similarly to extend my thanks to the people of the Long Isle with whom we enjoyed the most cordial of relationships. In particular I would like to mention Joan Campbell (now Mrs Joan Troughton), Willie MacAllister and Norman MacGaskill.

Historic Scotland funded the fieldwork and the post-excavation programme and also provided grant aid for this publication. 
This page intentionally blank 


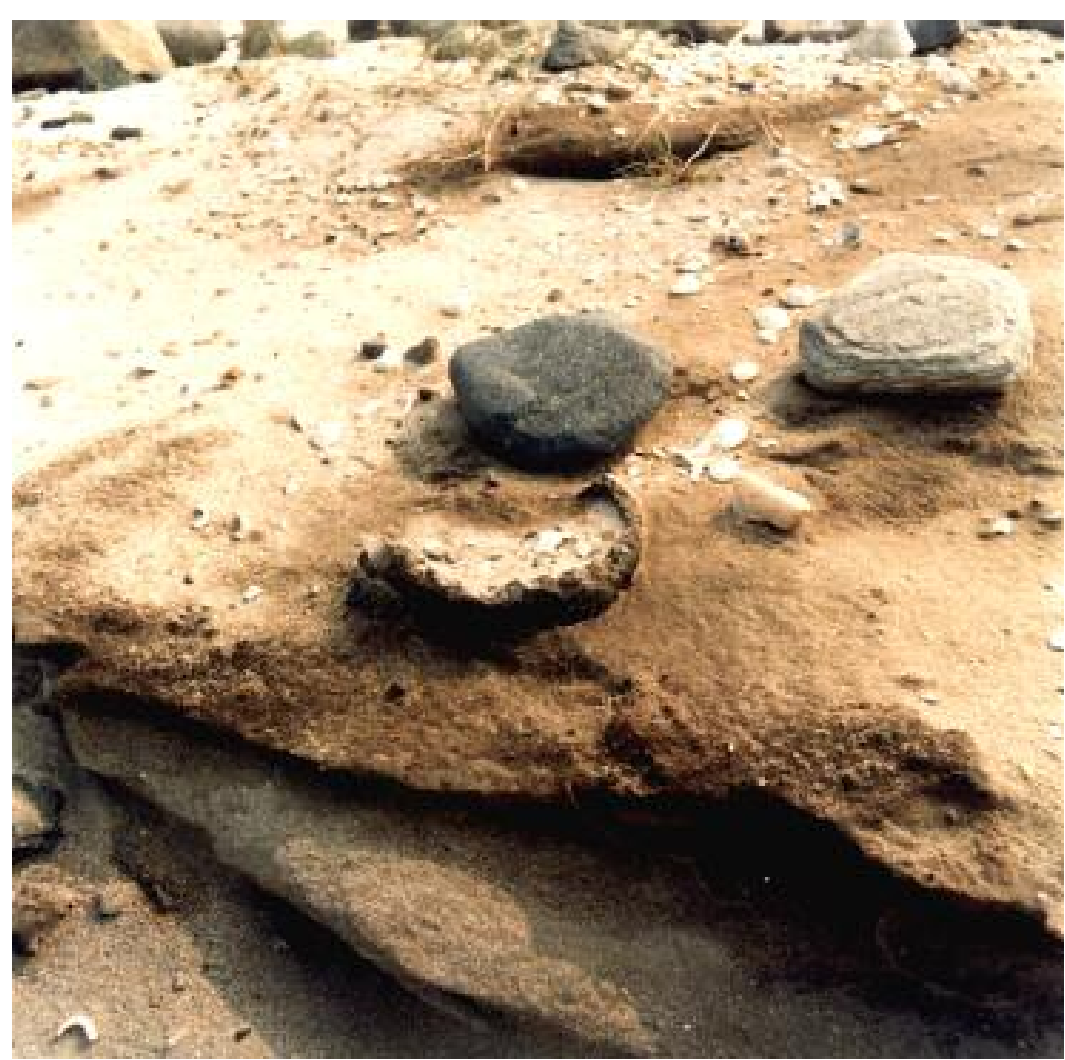

Plate 1. Ceramic vessel in the foreground and other archaeological material of Dark Age date on the island of Ensay, Sound of Harris

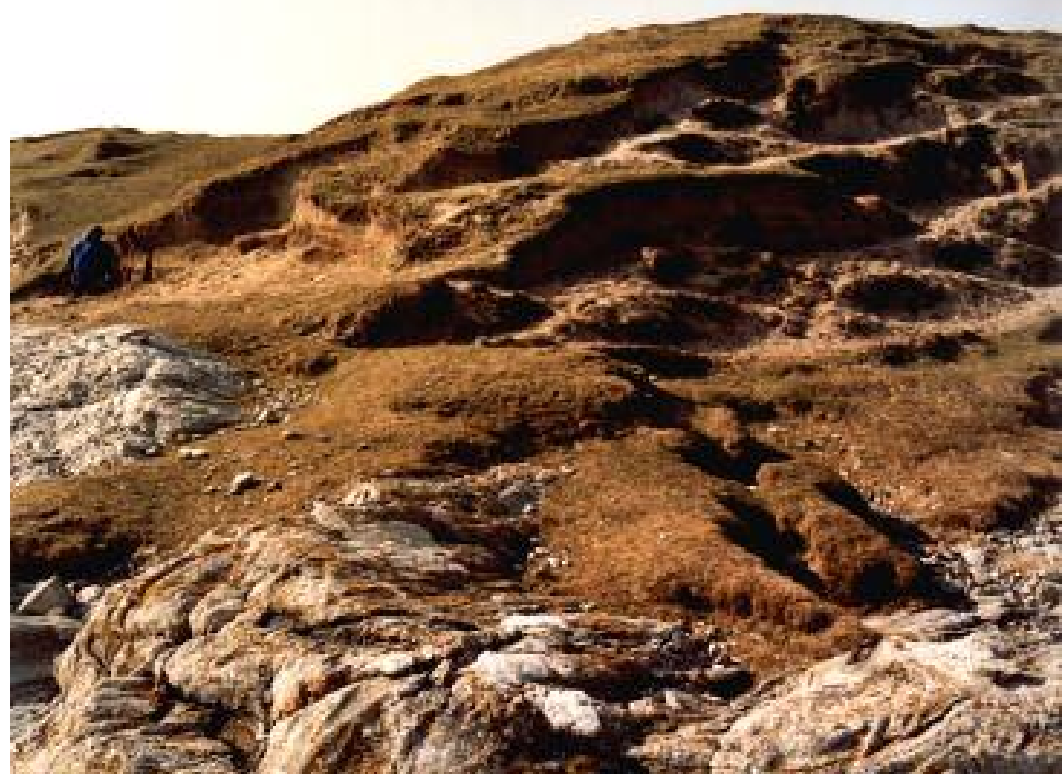

Plate 2. Site of Paible, North Uist. Figure to left is examining Beaker period midden deposit at the base of the dune. Coring showed that the Beaker deposits drop steeply inshore of the exposure so that parts of it lie at 10-15 m below the current land surface 


\section{CHAPTER I: BACKGROUND TO THE WESTERN ISLES PROJECT}

\section{I.I INTRODUCTION}

Hebridean sites of the coastal sand cliffs and associated machair, or sandy plain have been known for many years. Artefacts and ecofacts of various types have long been collected from archaeological sites in the eroding sand-cliffs of the machairs of the Outer Hebrides (Plate 1, and see Beveridge 1911, 227-39, for example). The then Office of Works commissioned the excavation of a series of machair sites, on South Uist, in 1965, in advance of the establishment there of the rocket range. Later, in 1978, HBM commissioned a survey of the coastal sites (Shepherd \& Shepherd 1978) and a list of over 100 was compiled. This survey was complemented by Cowie's survey of the coastal sites of Harris and Lewis (pers comm) to provide a database of sites at risk from coastal erosion, in the Outer Hebrides. More recently, Historic Scotland has commissioned surveys of the coastal strip $50 \mathrm{~m}$ deep in several areas while the work of SEARCH, the Sheffield University archaeological programme in the Hebrides has added many more sites.

Early in 1983, personnel of the then Central Excavation Unit (CEU) of Historic Scotland's predecessor (SDD Ancient Monuments) revisited very nearly all of the coastal sites then known in the Long Isle, with the specific task of identifying those at immediate threat from coastal erosion and of assessing the feasibility of their excavation or preservation. Some thirty-two sites were seen to be undergoing active erosion. About one third of these could not be excavated cost-efficiently because they were overlain by high dunes, in some cases the overburden being as high as $15 \mathrm{~m}$ (Plate 2). A further third were not available for examination because the owners' consents were not forthcoming. In virtually all such cases the owners were engaged in attempts to stabilise the calcareous shell sand deposits in which the sites lay. Since this meant that the sites were also in the process of being stabilised, their preservation seemed likely, at least in the short term, and they could be removed from the 'sites at immediate risk' category.

Nine sites remained which were being actively eroded but preservation was not being pursued, and where excavation was feasible. These sites were of two morphotypes; sites exposed in roughly vertical sand-cliffs (Plate 3 ) and sites exposed over relatively large horizontal areas of sand deflation (Plate 4). The problems of erosion and its prevention were clearly greatest in deflation sites, and these arguably merited immediate attention. However, the vertical exposures offered sections through the sand-cliff sites which could be examined without increasing the area of the site exposed to further erosion. It was, therefore, decided to examine one sand-cliff site along its exposed face to;

i) record and sample its deposits and retrieve primary archaeological information

ii) to examine its relationships with the machair deposits in which it sat, and most importantly,

iii) to gain experience in the excavation of such sites before contemplating a larger-scale exercise.
The site selected for this preliminary examination was that at Balelone in North Uist (Figure 1) which was investigated in 1983. The writer was invalided for the year in which this site was excavated and the project was managed for CEU by $\mathrm{Mr}$ $\mathrm{M}$ Brooks and the site supervised by Mr P Strong. The archaeological information retrieved at Balelone is presented in Chapter 4.

Investigations conducted in parallel with the excavation revealed that the site did not extend inland from its exposure in the sand-cliff for more than about $10 \mathrm{~m}$ (Figure 9). Furthermore, the level of its uppermost layers dropped from about $1 \mathrm{~m}$ to more than $5 \mathrm{~m}$ below the current ground surface, over that distance. At Balelone, the site has largely been removed by the sea and excavation of the surviving segment is unlikely to repay the considerable costs involved, despite the real wealth of artefactual and settlement evidence revealed in the site's eroding face.

The Balelone excavation was designed to explore the problems associated with the excavation of deep midden sites with complex stratigraphy and the not inconsiderable problems of excavation in sand. Although the latter are commonly lamented in print (Crawford 1978) suggestions for their resolution seem rarely to have been published. The trial excavation concentrated on the erosion face, which was cleaned, recorded and sampled. Two squares, $2 \mathrm{~m}$ by $2 \mathrm{~m}$, were excavated behind the face to provide larger samples.

Balelone demonstrated that the length and apparent wealth of the exposed faces were not reliable indicators of the surviving areal extents of the sites. Furthermore, the sampling strategy proved inadequate and simple dressing of the erosion face did not reveal, until a late stage in the project, that large pieces of the face had become detached from the main deposit and slipped downwards. Clearly, a new approach was called for. A structured approach was decided upon, aimed firstly at establishing the three-dimensional extent of each of the sites to be examined. On the basis of the information thus gained, it was proposed that sampling excavations be conducted on a small number of sites; four sites were in fact sampled (Figure 1). The information then available would, it was felt, facilitate a realistic appraisal of the likely archaeological benefits to be gained, and an equally realistic estimate of the likely costs involved in larger-scale excavations at these sites. These factors could then guide the final selection of one site - or of a small number of sites - for fuller excavation. It was also felt that if these sampling excavations were carried out within a rigorously defined research framework, they could also be used to establish and refine relevant research questions and thereby guide research design for any subsequent excavation.

\section{I.I.I The coring programme}

The importance of establishing the three-dimensional extents of the sites has been noted above. To facilitate this process, a $10 \mathrm{~m}$ grid was imposed on each site over an area of $100 \times$ $100 \mathrm{~m}$ with the midpoint of one face of the grid aligned on the centre of the exposed midden deposits (Figures 18, 37, $67 \& 72$ ). The south-west corner of each grid square was treated as the origin from which the grid squares were numbered. Each of the grid intersections was levelled with respect 

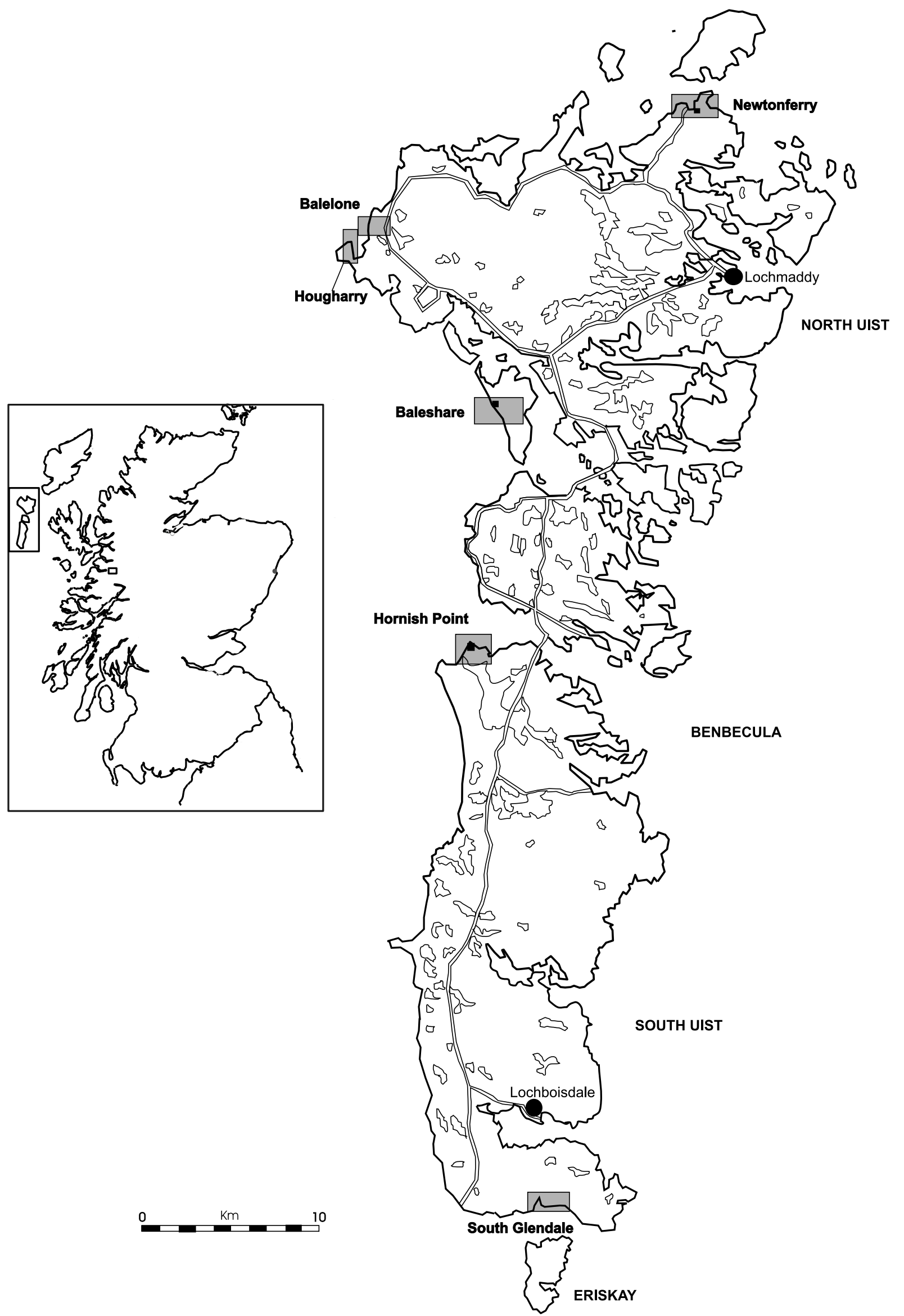

Figure 1. Location map 


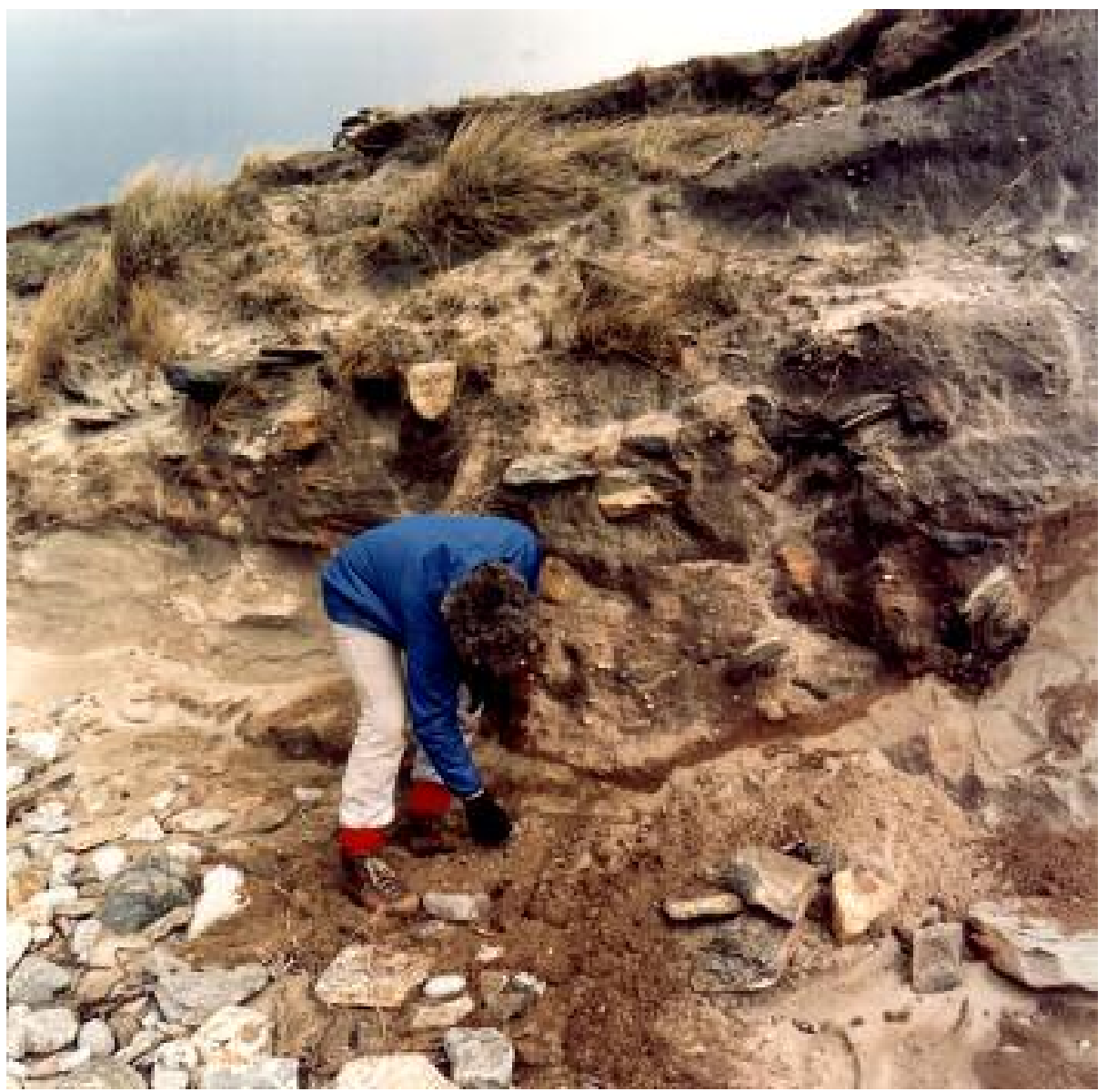

Plate 3. Sandcliffs at Baleshare, prior to excavation

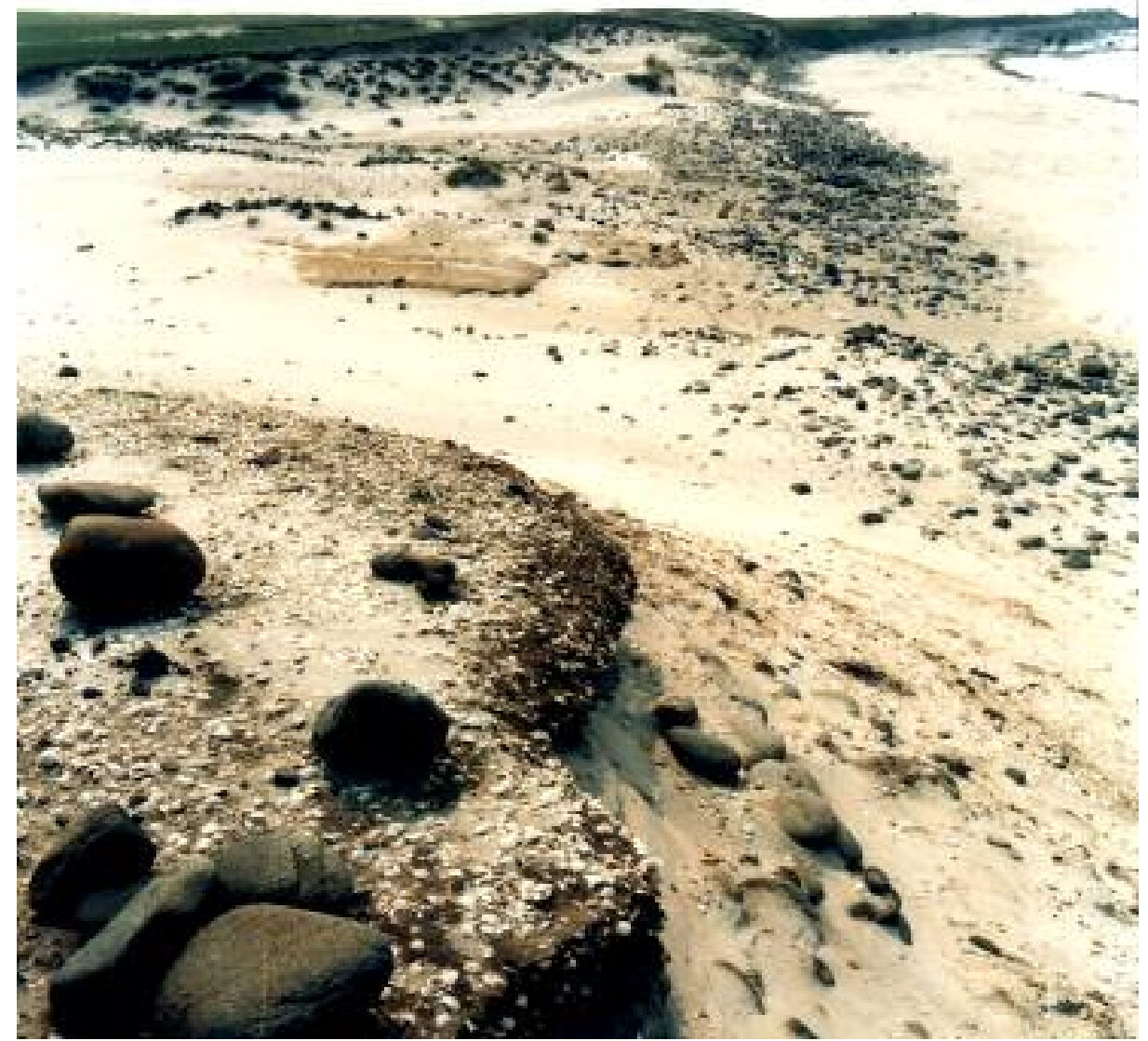

Plate 4. Deflation surfaces on Ensay, Sound of Harris 


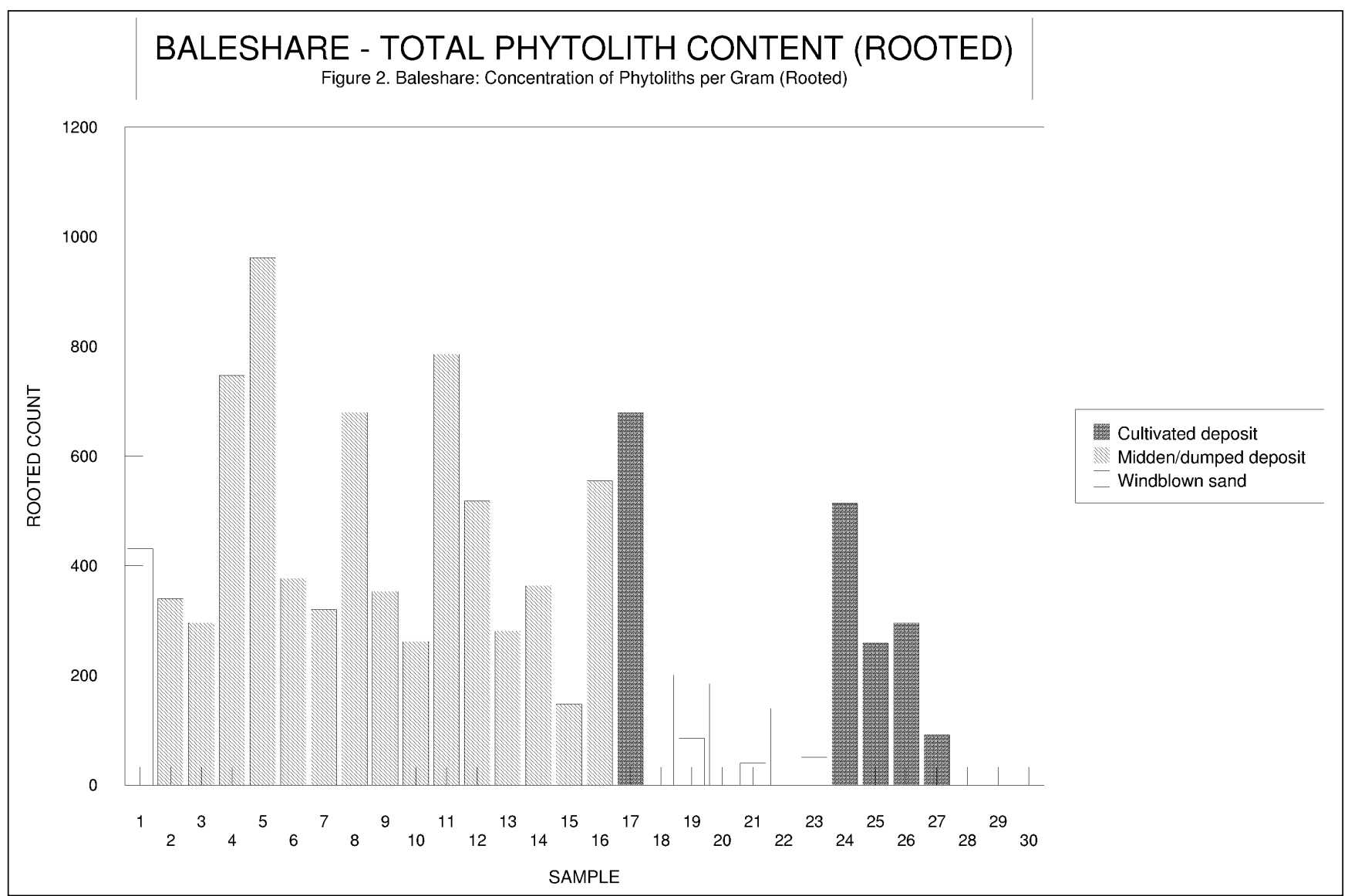

Figure 2. Results of the coring exercise at Baleshare indicating the location of structures at the south-west end of the midden

to a local temporary datum. Topographical surveys of the gridded areas were then undertaken.

Bucket augers were used to core the sites at the grid intersections (Plate 5). Two sizes of auger-head were used, 110 $\mathrm{mm}$ and $150 \mathrm{~mm}$, and both proved very successful in retrieving material without collapsing the sides of the core hole, even when this descended for up to $6.5 \mathrm{~m}$ through loose sand. (The writer is most grateful to Professor W Ritchie for recommending their use and for advice on this problem.) The water table defined the lowest depth that could be cored successfully because wet sand was not retained in the bucket-heads. Although unsuitable for applications requiring fine resolution because of the disturbance to the retrieved material, the bucket augers revealed the levels of the top and the bottom of the midden deposits without ambiguity. This was achieved with minimal disturbance to the deposits, with roughly one part in six thousand of their volume being disturbed. The coring began at the grid intersections immediately behind the exposed face and was extended, thence, back into the grid until at least two successive intersections along a grid line were cored without revealing midden material. The grid was enlarged as necessary for those sites which extended beyond the initial grid.

At Baleshare (Figure 18) however, the size of the site was such that coring outwith the surveyed grid was concentrated along two axes projected from the grid. Material retrieved from the coring was recorded, although it was virtually unstratified, because it was hoped that its horizontal distribution might reveal something of the location of activity areas within the midden. The results of this coring operation are discussed by site below.

\section{Baleshare Upper and Lower}

The site at Baleshare, on the island of the same name, off the west coast of North Uist, proved the most extensive of the cored sites (Figure 18). Coring suggested that it consists of two midden deposits, separated by relatively clean sand. The upper midden, visible along an $80 \mathrm{~m}$ stretch of the eroding sand cliff, extended inland for $30 \mathrm{~m}$, in a rough semi-circle. The lower midden lay at the foot of the eroding sand cliff. It extended $320 \mathrm{~m}$ along the coast and $110 \mathrm{~m}$ back from it. These correspond to the Iron Age (upper) and later Bronze Age (lower) middens, revealed by tapestry excavation, while the relatively clean sand between them is a cultivated, windblown sand (Figure 19).

The augers retrieved anthropic materials including shell, bone, pottery, slag and stone. The distribution of these materials gave an indication of the spatial organisation of the sites, including the location of structures within them. At Baleshare, for example, there seems to be a settlement nucleus at the south-west end of the lower midden which yielded relatively large quantities of bone, shell and pottery (Figure 2). Stones prevented coring in some parts of the area. These are likely to have been structural stone, because isolated stones tend to be moved aside by the auger, or to deflect the auger but do not usually stop its progress. 
Hougharry location map

\begin{tabular}{|c|c|}
\hline 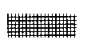 & midden \\
\hline$F+1$ & midden exposed by coring \\
\hline 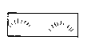 & grass \\
\hline 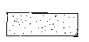 & sand \\
\hline S & sand \& grass \\
\hline $0: 0^{\circ} \circ$ & stones \\
\hline$\infty$ & structural stone \\
\hline 2. & exposed bedrock \\
\hline 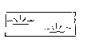 & marsh \\
\hline 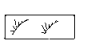 & slumped turf \\
\hline
\end{tabular}

Hougharry 1
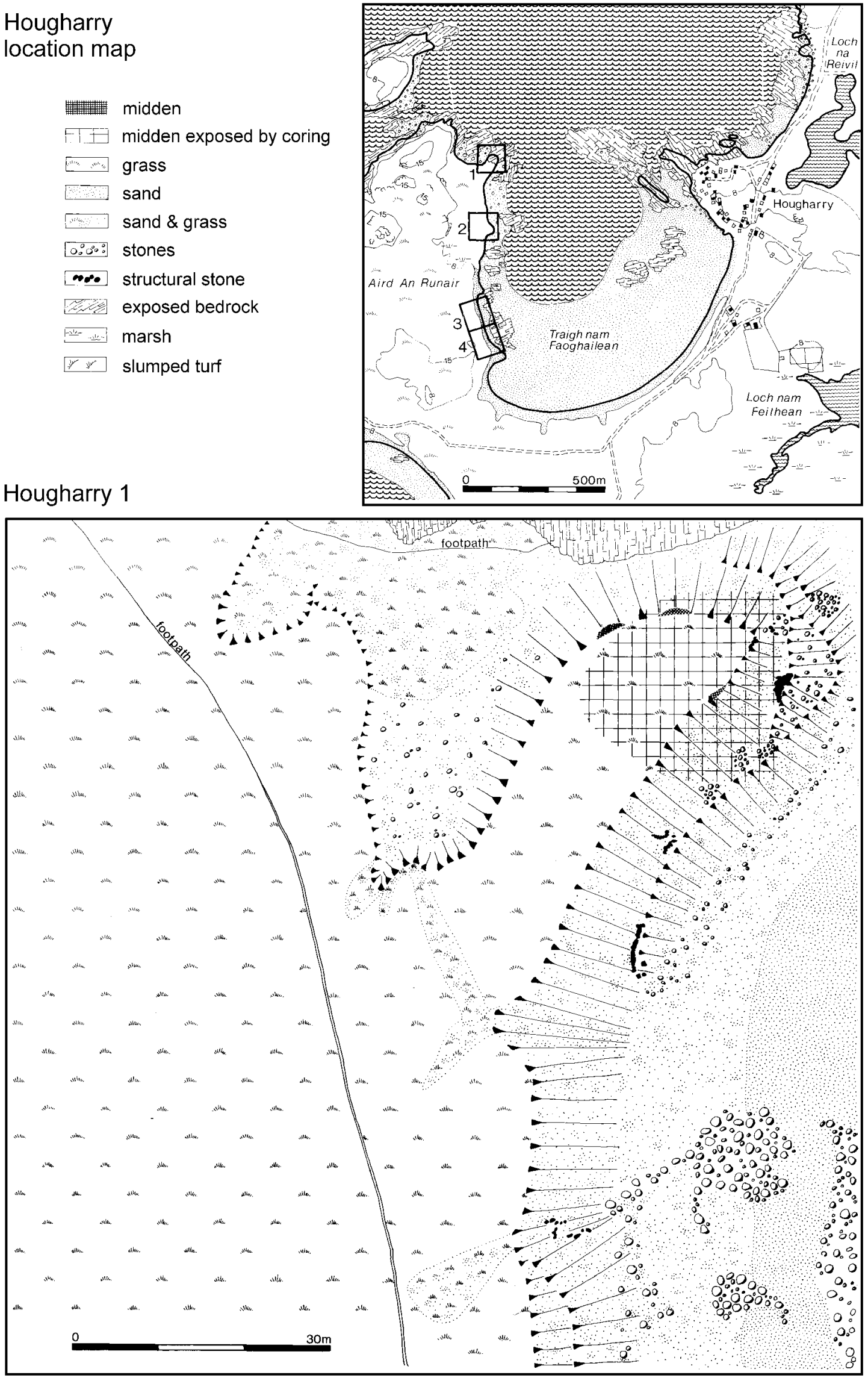

Figure 3. Hougharry: location map and plan of Site 1 


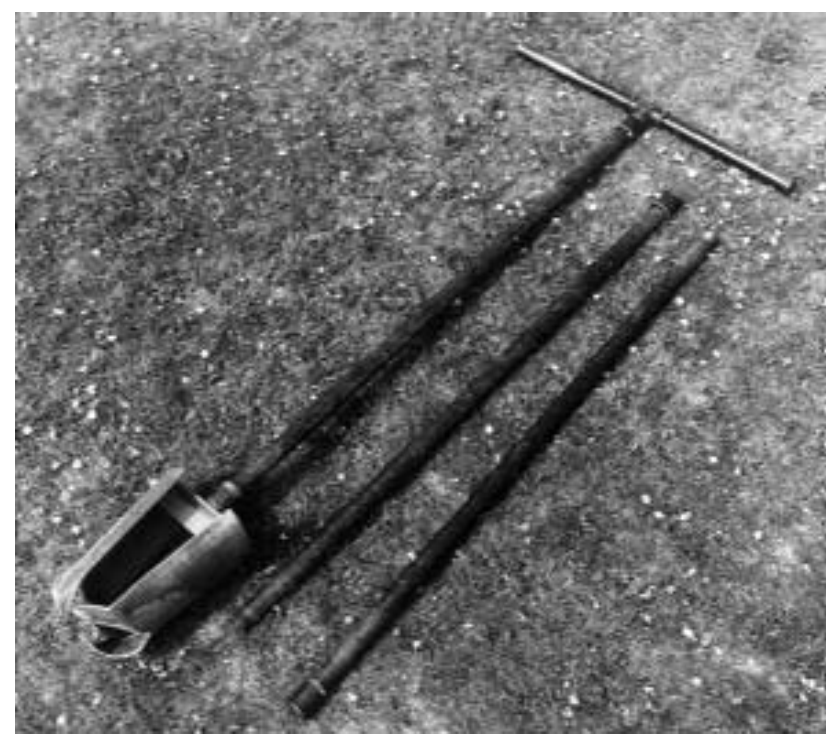

Plate 5. Bucket augers

\section{Hornish Point}

The surviving deposits at the site of Hornish Point, on the north-west of South Uist, covered a roughly rectangular area, $60 \mathrm{~m}$ along the coast by $30 \mathrm{~m}$ inland (Figures $37 \& 38$ ). Coring indicated that a nucleus of structures existed in, and immediately behind, the central and northern parts of the erosion face. Subsequent excavation confirmed this, at least in the area of the erosion face. The retrieved materials and the observable fragments of structures suggested that this was an Iron Age site.

\section{South Glendale}

The deflation site of South Glendale (Figure 67) lies on the north-west side of an isolated bay on the south coast of South Uist. Deposits were found within an area measuring $50 \mathrm{~m}$ by $30 \mathrm{~m}$ but had been badly fragmented in antiquity and extensively deflated in the recent past. They now survive as a very small margin of in situ deposits, on the west, with a large spread grading eastwards from deflated deposits to simple spreads of anthropic materials.

Coring did not reveal any evidence of structures. Clearly, very little of this set of deposits survives. The Shepherds (1978) record this as a Beaker Period site and a single sherd of Beaker pottery was collected from the site during this phase of the survey.

\section{Newtonferry}

The site of Newtonferry (Figures $72 \& 73$ ) lies on the north coast of North Uist, on the east shore of the head of Port Nan Long. It is a deflation site with deposits exposed over large areas. In some areas, especially on its northern side, the deposits seem to have been completely removed by aeolian erosion leaving spreads of shell, potsherds, slag and other anthropogenic materials. The coast is very fragmented in this area with an isolated talard, a grass covered, vertical-sided, sand hillock, still standing within an area of general deflation. From this area tongues of erosion lead south and east into the machair. Anthropic materials are visible over most of the deflation surface and coring has extended and unified the area of archaeologically significant deposits. These cover an area of $130 \mathrm{~m}$ by $50 \mathrm{~m}$ and are truncated by the modern beach along their irregular northern margin. Apparent structural elements which may have been hearths or kelp burning stances or cists were noted, albeit no longer in situ. A larger, apparently rectangular structure was contained within the talard and may have contributed to the latters' survival. The latter seemed clearly post-medieval but the Shepherds identified this site as a Beaker Period site, or rather, as a site containing Beaker Period deposits.

\section{Hougharry Sites I to 4}

Four sites are located opposite the modern village of Hougharry, along the western sand-cliff margin of Aird An Runair, North Uist (Figures $3 \& 4$ ).

Site 1 lies at the outermost point of the western arm of the bay and consists of two separate elements, a very small part of a structure, possibly a wheelhouse, high in the dune-face at the north-east corner of the site, and south of this some elements of structural stone at a lower level. Both are associated with a small, roughly circular area of midden deposits, about $30 \mathrm{~m}$ in diameter. It is probable that these deposits are merely the surviving rump of a site which, if the observable structure was roughly central, may have measured $80 \mathrm{~m}$ by $50 \mathrm{~m}$, or more.

Site 2 was visible as a ledge of organic deposits containing anthropic materials near the foot of a steep sand-cliff some 5 $\mathrm{m}$ to $6 \mathrm{~m}$ high (Figure 4 ). This was a relatively extensive series of deposits measuring roughly $120 \mathrm{~m}$ by $80 \mathrm{~m}$.

Sites 3 and 4 could only be examined in the vertical exposures at the foot of the sand-cliff (Figure 4). A combination of deep deposits of overlying sand and a high water table, perched on the archaeological deposits, defeated attempts at coring these sites.

The materials retrieved from Sites 1 and 2 at Hougharry were not inconsistent with an Iron Age date for these deposits.

\section{I.I.2 The 'tapestry' excavations}

The results of the coring exercise are summarised in Table 1. It was clear that the sites at South Glendale and Hougharry 1 were heavily truncated. Hougharry 2, 3 and 4 are buried, in part, under very deep sand deposits and their excavation is likely to prove wholly uneconomical.

Baleshare and Hornish Point are extensive, both horizontally and vertically, while Newtonferry extends over a large area, but is relatively shallow. It was decided to examine four of these sites, representative of the span of the erosional gradient. Two sand-cliff sites were selected, Baleshare and Hornish Point, and two deflation sites, Newtonferry and South Glendale. Tapestry excavations were proposed for the sand-cliff sites, and in a modified form, for Newtonferry, while a traditional, open-area excavation was decided upon for South Glendale.

Tapestry excavation, the excavation of a strip of deposits along an exposed face, was the preferred method of investigation because, as noted previously, it did not expose any more of the site to erosion than had previously been exposed. Tapestry excavation evolved in Switzerland, in the excavation of highly stratified deposits on lake-dwelling sites. In essence, tapestry excavation is the recording of a vertical strip through the site's deposits. 


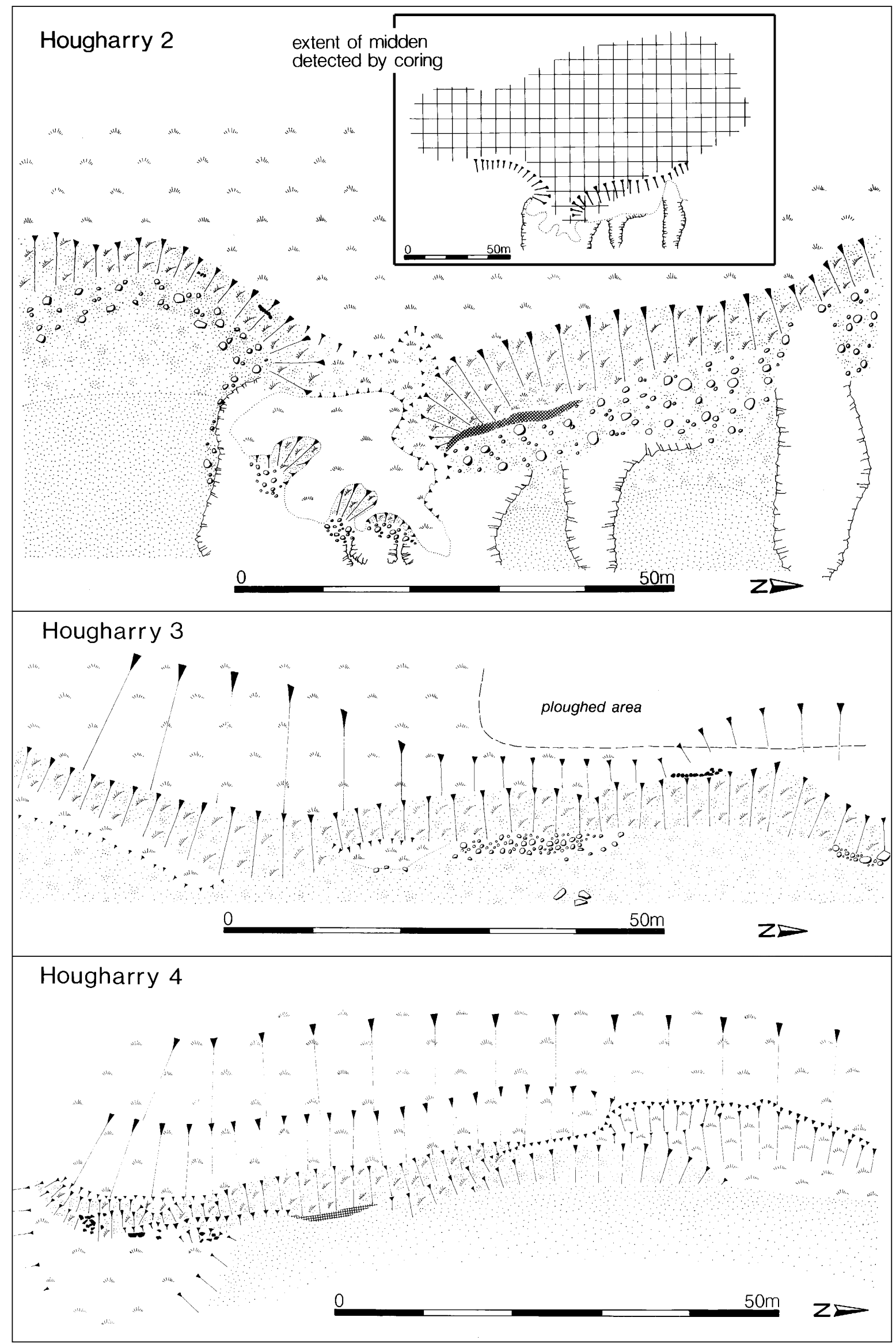

Figure 4. Hougharry: plans of Sites 2-4 


$\begin{array}{lrrrr}\text { Baleshare (upper) } & 80 & 30 & 3.0 & 0.2-4.4 \\ \text { Baleshare (lower) } & 320 & 110 & 1.0 & \\ \text { Hornish Point } & 60 & 30 & 1.5 & 0.3-3.6 \\ \text { Newtonferry } & 130 & 50 & 2.0 & 0.2-1.8 \\ \text { South Glendale } & 50 & 30 & 0.3 & 0.1-1.3 \\ \text { Hougharry I } & 30 & 30 & 1.3 & 0.4-2.2 \\ \text { Hougharry 2 } & 120 & 80 & 1.0 & 0.4-4.3 \\ \text { Hougharry 3 \& 4 } & & & & >4.0 \\ \text { Balelone } & & 10 & 1.0 & 0.9-5.1\end{array}$

Table 1. The maximum extents of the cored sites (measurements in m). The depth of deposits at Hornish Point is not the maximum depth because the cores were blocked by the palimpsest of structures in the deepest area of the site

The advantages of tapestry excavation include the following:

i) Excavated materials are never more than $0.25 \mathrm{~m}$ from a recorded face.

ii) The area of site exposed to further erosion is not increased.

iii) The section offers the opportunity to examine the full, or nearly full, history of the site along the section line.

In practice, the following procedure was observed;

i) Debris and loose material was cleared away from the face of the deposits and the lower boundary located by digging down to the foot of the deposits.

ii) To prevent collapse of the final sections, a stepped face with risers of no more than $1 \mathrm{~m}$ high and treads significantly wider than $1 \mathrm{~m}$ was created. Thus, even if one face collapsed it should not cause the collapse of the face beneath it (the angle of repose of the sand was measured at roughly $45 \%)$.

iii) The treads were cut along the tops of individual layers, ie they were not horizontal along the face of the sites, only at right-angles to it. This simplified recording and facilitated the merging of the separately recorded faces.

iv) The material removed this far was simply shovelled away. Recovered artefacts and ecofacts were treated as 'unstratified'.

$v$ ) The vertical faces were now recorded.

vi) A strip $0.50 \mathrm{~m}$ wide was excavated layer by layer, down each face; all artefacts and ecofacts were recovered and all deposits were extensively sampled.

vii) Finally, the resulting sections were recorded again.

viii) The site was backfilled to something close to its original shape.

\section{I.2 EXCAVATION METHOD}

\section{I.2. I Stratigraphic recording}

The sites at Baleshare, Hornish Point and Newtonferry were investigated by tapestry excavation. South Glendale was excavated horizontally, but its recording and sampling were conducted in the same way as those of the other three sites. At the sand-cliff sites, the exposed faces were first made vertical, with as many steps as safety and the stability of the deposits required. The vertical sections were first drawn by the site supervisors and then checked by the stratigraphic assistant, after which they were again checked by the project director. The stratigraphic record compiled on site was computer 'washed' using a Basic program, drafted by the writer. Errors and omissions were listed, and the record was amended on site.

\section{I.2.2 Soil description and sampling}

Each deposit was described by one of the team of soil-science students (undergraduates and graduates) using the methods and nomenclature of the Soil Survey Handbook (Hodgson 1976). This group were also responsible for taking the Routine Soil Sample (RSS), a sample of approximately $2 \mathrm{~kg}$ (min, $500 \mathrm{~g}$ ), which was sub-sampled for $\mathrm{pH}$, loss on ignition and qualitative phosphates; tests undertaken by the processing crew in the field. A further sub-sample, of approximately 50 $\mathrm{g}$ was heat sealed for future use in pollen analysis, should the need arise. The remainder of the sample was dried and stored, as a voucher sample.

A second sample, the 'standard bulk sample', of approximately $20 \mathrm{~kg}$ was collected from every context which had sufficient material. This was coarse sieved, through $5 \mathrm{~mm}$ mesh, into a Cambridge froth flotation tank. The flot from this was captured in $1 \mathrm{~mm}$ and 300 micron meshes, and dried and stored. The retent of the coarse sieve was sorted and the materials added to the finds inventory for the sampled context.

Samples were also collected for specific purposes, ie purposive samples. These included samples for radiocarbon dating, soil thin-sectioning, etc.

\section{I.2.3 Excavation}

A tapestry, a slice $50 \mathrm{~cm}$ wide, was removed down the prepared face. The deposits in the slice were removed in stratigraphic order, and all sieved through a $5 \mathrm{~mm}$ mesh. The retained materials were sorted by category into pot, bone, stone, macroplant, slag, sea shell, snail shell and other. This sorting was undertaken, off-site, but in the field, by the processing crew.

The documentation of the sampling, sorting of the finds from the coarse sieving and the processing of the Standard Bulk Samples, together with all the related recording were undertaken by the processing crew, under the control of Ms D Lehane. This freed the excavating teams from all work except the actual recording of the sections and excavation of the tapestries. This proved, in practice, a most cost-effective measure. The sorting of finds, etc was undertaken by volunteers and fell somewhat short of perfection. Each specialist 
subsequently found other materials included with that specific to their interests and some late arrival of material was inevitable. Although frustrating to the specialists this did save them the tedium of sorting through everything themselves, and was considerably cheaper than either having specialists, or technicians sort the material.

\section{I.2.4 Data management}

The various sets of records relating to each site were finally brought together in a database. It had been intended that this stage be reached in the field, but this was not possible and it was completed on our return to Edinburgh.

\section{I.3 OBSERVATION AND INTERPRETATION}

\section{I.3.I Interpreting the record}

The excavation methods outlined above concern the recording of observations made in the field. That these entail some low-order interpretations is obvious, but not of demonstrable relevance. An attempt has been made throughout this project to separate that which is principally observation from that which is principally interpretation. As a first step in this process a distinction has been drawn between units of record and units of interpretation.

\section{I.3.2 Units of record}

The transition from units of record (recorded observations) to units of interpretation took place in the field. The strata, units of record, were organised into groups, on the basis that their appearance and contents suggested a common mechanism of sedimentation. Each group, called a Block, consisted of a sequence of interrelated deposits whose interpretation implied a similar depositional mechanism and history, ie a similar taphonomy. These blocks are the basic units of interpretation. The descriptions and analyses of the sites and their contents are described in terms of these blocks. They are based mainly on the colour and texture of the soil matrices and thin microscopic inclusions.

\section{I.3.3 Units of interpretation: the field interpretation}

An interpretation was offered on site for each Block, or where time prohibited, this interpretation was written at the start of the post-excavation process, but at a time when the information available to the site supervisor was still restricted to his own field observations; the results of the work of the processing crew were not known to him. These interpretations, termed 'field interpretations' are listed with the Block descriptions. They are based mainly on the colour and texture of the soil matrices and their macroscopic inclusions.

$\begin{array}{lccc}\text { Material } & \begin{array}{c}\text { No. of } \\ \text { samples }\end{array} & \text { Mean pH } & \begin{array}{c}\text { Standard } \\ \text { deviation }\end{array} \\ \text { Windblown sand } & 12 & 7.09 & 0.12 \\ \text { Cultivated soil } & 16 & 7.19 & 0.2 \\ \text { Sheep dung (machair) } & 17 & 7.61 & 0.39 \\ \text { Cattle dung (machair) } & 10 & 7.65 & 0.35 \\ \text { Sheep dung (moorland) } & 6 & 7.19 & 0.29\end{array}$

Table 2. Acidity $(\mathrm{pH})$ of a range of modern deposits from the Long Isle. The animal dung was collected from machair-grazed and moorland-grazed animals

\section{I.3.4 Testing interpretations}

The first test of the field interpretation is that afforded by an analysis of the anthropogenic component of the deposits in the Block, together with some consideration of the nature of the soil matrix in which they lay.

\section{Depositional diversity index}

The anthropic component consists of all artefacts and of those ecofacts whose deposition was determined by the actions of man. Some nine categories of material were considered under this heading; bone, pot, seashell, snail, macroplant, stone, slag, burnt stone and pumice. These occurred in various combinations of varying amounts in each context. It was decided to calculate a single index, a diversity index, to represent the range and variety of anthropogenic materials, taking into account their value as indicators of human activity and their presence per unit volume of the context, ie their deposition rates. This quantity was termed the 'Index of Human Interference' and its definition and use are described below.

\section{Soil: colour and texture}

The natural soil matrix of the area was wind blown sand. Deposits displaying characteristics other than those of wind blown sand provide evidence of additions of material. In the absence of evidence for natural agencies of deposition, it is assumed that all, or very nearly all, the additional material was brought to site, deliberately or inadvertently, by human activities. The most readily observable differences were in colour and texture. In general brown coloration was interpreted as indicative of the addition of organic matter to the soils, the darker the colour the greater the addition. Similarly, enhancement of the finest fraction of particle size was interpreted as the addition of material, notably peat ash or decayed organic matter, possibly including peat. These factors were further assessed, in the field, by measuring the $\mathrm{pH}$, relative phosphate level and the loss on ignition (LoI) of sub samples of each of the routine samples (see above).

\section{Soil: $\mathrm{pH}$, phosphates and Lol, modern analogues}

Measurements of the $\mathrm{pH}$, phosphate level, loss-on-ignition and particle size distribution of some 61 modern samples were undertaken to provide data on natural sources of input to the machair soil, as well as baseline measurements of these variables in wind blown sands. The results, for $\mathrm{pH}$ are listed in Table 2 and show that windblown sand alone, has a mean 
$\mathrm{pH}$ of $7.09 \pm 0.12$, while modern cultivated soils display a mean of $7.19 \pm 0.20$; the latter information is from published sources. Phosphate values for these materials were uniformly high.

The $\mathrm{pH}$, phosphate level and LoI were routinely assayed for every context. Values, for $\mathrm{pH}$ lower than that evidenced in the windblown sand were interpreted as indicative of the addition of acidic material, eg peat. Low phosphate levels were interpreted as indicative of dilution of the naturally high concentrations, by the addition of material by man, while high loss on ignition values are indicative of the introduction of soil organic matter, possibly as peat or as animal dung or faeces.

\section{Units of interpretation: the archaeological interpretation}

When the full inventory of materials retrieved and the results of the routine soils analyses became available, they provided a first test of the field interpretation. The refined interpretation is recorded, as the 'archaeological interpretation' in the Block descriptions (Chapters 5-9).

\section{Units of interpretation: the conclusion}

Work undertaken by the specialists refined our perceptions of the materials from the various contexts and this information was incorporated into a final set of Block interpretations which are recorded as 'Conclusions', in Chapters 4-8 and form the basis from which the sites are interpreted.

\subsubsection{Presentation of the observations, interpretation and conclusions}

The volume of information returned from these tapestry excavations has necessitated the use of a number of information synthesising techniques, like the diversity index (the IHI below). It has also required an approach to presentation of the data and their interpretation which differs slightly from normal practice. The traditional 'structures' report has been eschewed in favour of a simple presentation of site data (Chapters 4-8) with their interpretations specifically identified and, where possible, tested. Where interpretations have changed, after testing or the integration of further information, the 'new' interpretations have been presented and the reasons for the changes are noted. This approach has allowed for a more highly synthesised form of reporting than is possible with conventional structures reports.

Emphasis on the transition from units of record (the features and contexts) to units of interpretation has also been formalised by the use of Blocks, ie there is a hierarchy of interpretative units. The simultaneous emergence of what is essentially this same mechanism in several English units provided the basis for a conference held in November 1992 (Barber 1993). In the editorial of that publication, this writer identified the common approaches to the interpretation of complex, deeply stratified sites (ibid, 1-2) and nothing further need be added here.

\section{I.3.6 The calculation of the diversity index (IHI)}

A diversity index, the index of human interference or IHI, was formulated to encapsulate the range, quantity and depositional rate of anthropic materials in individual deposits. To begin with, the weights of the materials were first recorded and these were converted to volumetric equivalents by dividing them by the density of the material of which they are composed. The densities were calculated by experiment, by measuring the displacement of industrial methylated spirit by known weights of the individual materials. The resultant values, although approximate, are adequate to the present need. In the case of pottery sherds, the weight was not recorded, rather the number of sherds was used in the calculation and the weighting factor adjusted accordingly.

Weighting factors were used in an attempt to allow for the relative values of the various materials as indicators of human activity. Thus the number of potsherds was multiplied by 16 , while the volume of stone present was multiplied by 1 . The probability of survival of the material was also considered, and carbonised macroplant material, for example was heavily weighted, because field observation showed that it is quickly removed by the wind, and thus probably greatly under represented in the sites' deposits. Thus, macroplant remains were given the highest weighting, $\times 90$; slag, $\times 10$; animal bone, $\times 9$ and sea-shell, $\times 4$. Stone is included with anthropic materials because it cannot have been incorporated into the machair deposits other than by human activities.

The IHI for each context $\mathrm{IHI}_{\mathrm{f}}$ is the sum $(\Sigma)$ of the volume of the material, $\mathrm{VOL}_{\mathrm{m}}$, divided by the volume of the context, $\mathrm{VOL}_{\mathrm{f}}$, and the result multiplied by the weighting factor for that material $\mathrm{W}_{\mathrm{m}}$, thus:

$$
\mathrm{IHI}_{\mathrm{f}}=\Sigma\left(\mathrm{VOL}_{\mathrm{m}} / \mathrm{VOL}_{\mathrm{f}}\right) \times \mathrm{W}_{\mathrm{m}}
$$

This quantity was calculated for every context, of known volume, which contained anthropogenic material.

The stratigraphic blocks, as defined by the excavator, are interpreted as coherent sets of strata of similar origin and depositional mechanics. If this is correct the IHI's for each Block ought to be relatively similar, ie their deviation from the mean IHI for the Block ought to be small (less than $2 \times$ $\sigma$ ), and greater variance should be observed in the range of the Block mean IHI's. In somewhat simpler language what is implied here is that the variability of the finds from within any single Block ought to be relatively small and certainly smaller that the variability of the site as a whole, if our interpretation of the blocks as indicative of particular phases of human activity is correct.

To examine this hypothesis the IHI's for every context in each Block of the Baleshare site, were first calculated. Then the mean and standard deviation of the IHI's for each Block and for the whole site were also calculated. These data are available in the archive, and summarised in Table 3. Some six Blocks, 1,12, 21, 22, 25 and 28 have only one IHI value each and these are excluded from further analysis. Of the remainder, in practice, only six Blocks, 7, 10, 18, 20, 26 and 27 could be accepted as coherent. With the exception of Block 27 , for which $10 \mathrm{IHI}$ values could be calculated, all of these have three or two values. Thus their coherence may be attributed, in some degree, to the smallness of the sample size.

Each Block was then examined to try to evaluate the source of the high standard deviation and in a majority of cases this was found to be due to one or two extreme values, some of which could be dismissed on archaeological grounds. One such sample is [146] in Block 15 at Baleshare. This was 


$\begin{array}{lrrr}\text { Block } & \begin{array}{r}\text { Standard } \\ \text { deviation }\end{array} & \text { Mean } & \text { Index } \\ 2 & 20121.36 & 20306.94 & 19.82 \\ 3 & 8928.23 & 20305.53 & 8.80 \\ 5 & 27022.55 & 15581.06 & 26.62 \\ 6 & 13958.67 & 10870.77 & 13.75 \\ 7 & 27856.07 & 27856.07 & 27.45 \\ 8 & 6714.44 & 5231.50 & 6.62 \\ 10 & 1019.77 & 3642.66 & 1.00 \\ 11 & 147951.10 & 87171.70 & 145.77 \\ 14 & 10528.06 & 12374.27 & 10.37 \\ 15 & 87550.76 & 44170.04 & 86.26 \\ 16 & 38714.69 & 28926.61 & 38.14 \\ 17 & 28748.39 & 35535.34 & 28.32 \\ 18 & 21310.70 & 28067.38 & 21.00 \\ 19 & 13662.76 & 15592.92 & 13.46 \\ 20 & 2959.51 & 12891.45 & 2.92 \\ 22 & 12364.61 & 16005.30 & 12.18 \\ 23 & 5429.93 & 6761.66 & 5.35 \\ 24 & 299985.22 & 110479.96 & 295.56 \\ 26 & 17379.15 & 23566.39 & 17.12 \\ 27 & 10546.71 & 15142.51 & 10.39 \\ & & & \\ \text { Population } & 101497.76 & 34867.10 & \end{array}$

Table 3. The IHI values from the Baleshare Blocks a localised concentration of macroplant remains which was given a separate context number in the field to highlight the non-random nature of the sample. Thus the volume of soil from which it came is virtually the same as the volume of the remains and the calculation of the IHI is consequently heavily biased. When these extreme values are deleted, the coherence of the IHI values for contexts within individual blocks is relatively well demonstrated.

\section{I.3.7 Harris matrices}

The strata within each Block are described in terms of the Harris matrix (Harris 1979). The numbers, in bold, represent the context numbers and are correlated with the tabulated data of results from each context. The vertical axis in the normal Harris matrix is not scaled. It merely represents the shortest branching display of the stratigraphic relationships for a given body of strata. Thus for example, if the matrix shows [10] under [8] this need not mean that [8] physically overlies [10] because [8] could overlie some other context which in turn overlies [10]. The position of the numbers in the table reflects the most efficient demonstration of their gross chronological relationships. For each site a matrix of its Blocks is also presented. 


\section{CHAPTER 2: THE PHYSICAL BACKGROUND}

\section{I GEOLOGY}

\section{G Collins (1986)}

(The following is based on a report by the late Geoff Collins. It is offered here in memory of a good friend. Ar dheis Dé go raibh a anm)

The Outer Hebrides (Figure 5) are composed almost entirely of Pre-Cambrian basement rocks, known collectively as Lewisian (Smith \& Fettes 1979; Fettes et al 1992). These rocks mostly comprise a series of monotonous grey gneisses, often with hornblendic streaks and patches, which are cut by dykes and sills of altered basic igneous rocks to form amphibolites and metadolerites. In south-west Lewis and Harris, extensive granite veins are to be found. Bodies of anorthosite occur in south Harris and east of the Butt of Lewis. Altered sedimentary rocks comprising biotitic, graphitic and calcareous gneisses, quartzites and rare marbles are locally important but form only a small part of the assemblage. In south Harris the metasediments are associated with large bodies of metamorphosed intermediate and igneous rocks. Black, glassy pseudotachylite, found in many localities in the islands, is especially common along the Outer Hebrides Thrust Zone, which extends along the length of the Long Island, generally near the east coast. East of the Outer Hebrides Thrust Zone in South Uist, the eastern gneisses include granulitic facies of gneisses, mylonites and intensely crushed rocks. The Lewisian rocks are cut by a variety of Permo-Carboniferous and Tertiary basic igneous dykes.

\section{I.I Quaternary geology}

The Quaternary geology of the Outer Hebrides is the subject of a report by J D Peacock (1984) of the British Geological Survey. According to this, the earliest feature of probable Pleistocene age was the formation of a raised platform and cliff of marine erosion, remnants of which are found only in the extreme north of Lewis and the Eye peninsula. Their absence elsewhere in the Outer Hebrides may result from glacial erosion, a protective cover of glacier ice, or a tilt below sea-level. Raised beach gravels are found in patches on these platforms and also on the north-west coast of Barra, where they are overlain by till. The clasts of the gravels are mostly of Lewisian gneiss (Plate 6), but red sandstone and arkose, probably Torridonian, and possibly Cambrian quartzites, similar to those of the north-west Highlands, may be found. Micaceous psammites of Moine type are found in the gravels of Barra. Thus, there is evidence for the suggestion that the formation of the raised platforms took place before, or early in, the Ice Age during which ice from the Scottish mainland crossed the extreme north of Lewis and probably over the more southerly islands. Tills formed during this phase were probably reworked by the sea in warmer times to form the raised beaches.

A period of intense glaciation followed in which the whole of the Outer Hebrides except possibly the extreme north of Lewis) was heavily glaciated. Peacock divides this phase into the 'Hebridean Ice-sheet phase', and a later 'valley glacier phase'. From observations of numerous features of ice-movement such as roches moutonnees, striations and plucked surfaces, Peacock suggests that the ice flowed from at least two, possibly three, centres. The first, and most spectacular, was on the high ground of south Lewis and north Harris, from which the ice flowed radially. The second was an elongated dome of ice close to the west coast of Barra and extending northwards off the west coast of South Uist and Benbecula into the western part of North Uist. The axis of the dome was roughly north/south, the ice flowing off to the east across the Uists. The direction of ice-movement near the west coast of the Uists is obscure, indicating that the ice-shed was very close to the present day coastline. The possible third centre was a shallow dome over north Lewis.

The 'valley glacier phase' was confined to south Lewis and north Harris. Peacock describes many features of this phase, including morainic drift, meltwater deposits and landforms. Included in this phase is the magnificent Glen Valtos meltwater channel of south-west Lewis.

Much of Lewis, north of Stornoway, is overlain by a peat-covered sheet of till. To the south the sheet is discontinuous; the till occurring on the distal side of rock knobs. Moundy till is found extensively in North Uist between Lochmaddy and Carinish. Brown sandy till, several metres thick, has been recorded in North Uist at Hoglan Bay and north-east of Newtonferry, brown sandy till, up to $2 \mathrm{~m}$ thick, forms part of Hornish Point in South Uist.

The presence of erratics foreign to the Uists and the islands to the south, has long been known (Jehu \& Craig 1923a; 1923b; 1926). As well as the Torridonian and Cambrian rocks mentioned above, pebbles of hard chalk and flint have been found in Vatersay. Boulders of hornblende-porphyry are common along the western seaboard of North Uist and Benbecula and are found in the Monach Islands. These erratics are probably the remnants of the redistribution of the raised beaches in Barra and the southern islands by the Hebridean ice-sheet phase.

With the coming of warmer times and the disappearance of the ice-sheets, a period of slight submergence of the islands followed. In north-west Lewis, a number of lochs have been impounded by storm beaches. There are many records of archaeological sites and of peat deposits between tidemarks (Ritchie 1979).

Dunes and extensive flat or gently sloping stretches of blown sand characterise the hinterland backing sandy beaches. The blown sand, known as machair, is only a few metres above sea-level. It is usually siliceous, but may contain up to $80 \%$ calcium carbonate, in the form of comminuted marine shell fragments (Ritchie 1971, and below). Small areas are present in Lewis and north Harris on the north-west and west coasts, the largest (circa $1.5 \mathrm{sq} \mathrm{km}$ ) being west of Barvas. In south Harris, the dunes and machair are associated with the huge sandy beaches of Northton and Traigh Luskentyre, on the west coast. The machair reaches its greatest development on the islands in the Sound of Harris, through North Uist, Benbecula and on to the southern end of South Uist. It has been estimated that dunes and machair occupy $10 \%$ of the land surface in these areas (Peacock 1984). Further south in Barra its development is slight. 


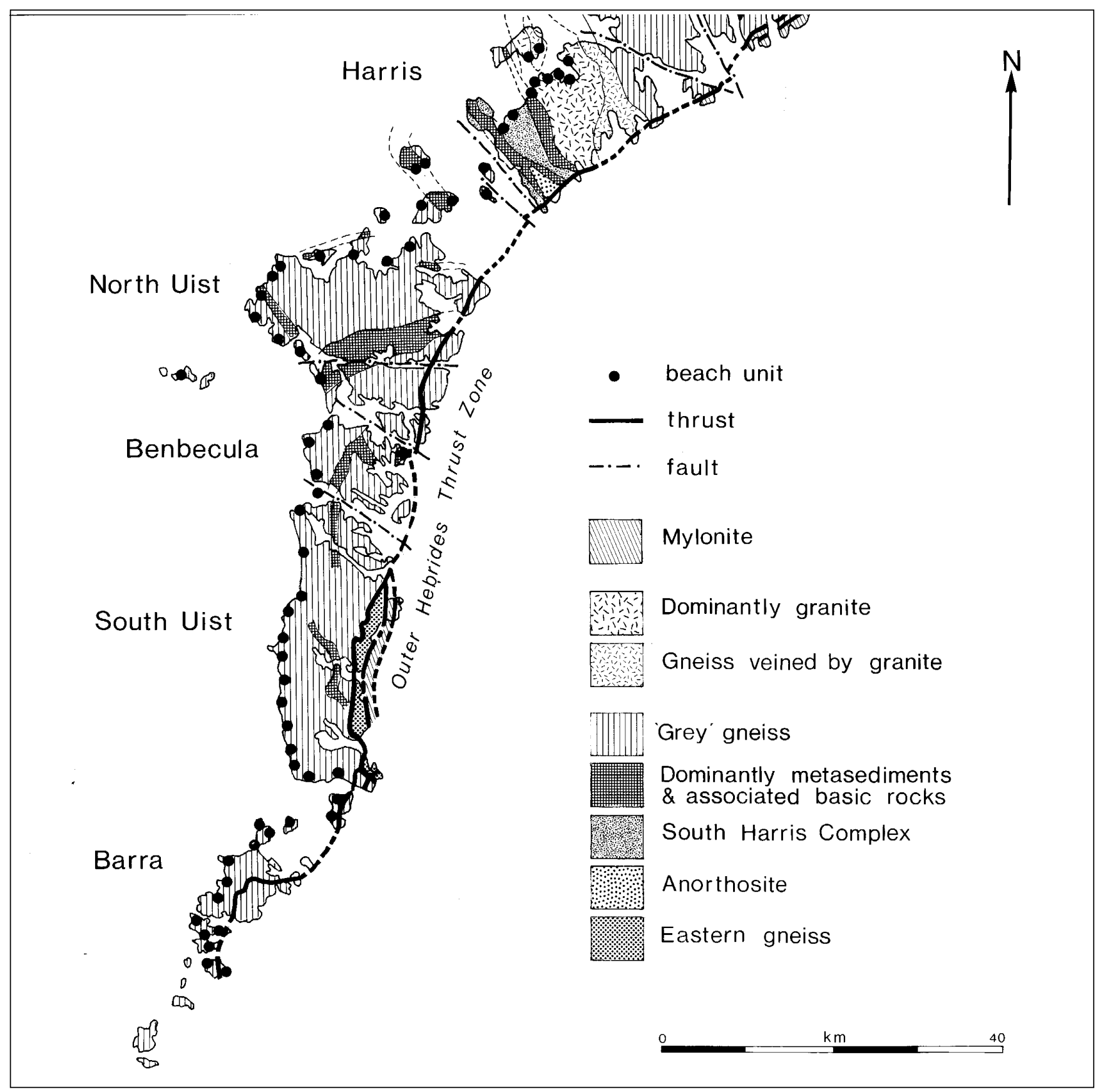

Figure 5. The solid geology of the Western Isles with machair beach units indicated

\subsection{MACHAIR GEOMORPHOLOGY IN THE WESTERN ISLES}

\section{W Ritchie (1986)}

From Sanday in the south to the northern tip of Lewis, most of the Atlantic coast is characterised by a series of blown sand landforms, collectively known as machair. The most extensive areas occur in Barra and the Uists and it is only in Lewis, north of the Eye Peninsula that machair occurs on the Minch coast. Figure 5 shows the distribution of these beach and machair units but the figure is misleading since each dot represents the centre of an area and in most areas the distribution is continuous, as for example in South Uist where the entire west coast is machair land (Plate 7).
Machair land varies considerably in form and extent. Of the 98 units of the Western Isles, 38\% have little or no true dune ridges; the coastal edge consists of a narrow ridge of accreting sand with long dune grasses better described as edge accumulation rather, than as coastal dunes. Size also varies although most machair areas are relatively extensive. Small bayhead units are infrequent and largely confined to Harris and Lewis. One distinctive characteristic of machair in the Western Isles is the high shell content of the sand. In general, the shell sand content of Hebridean beaches, dunes and machair is the highest in Britain, but there are areas with little or no shell content. The actual distribution is described in Table 4.

Other characteristics of machair relate to relief and morphology, viz where there are dunes they have a mean height 


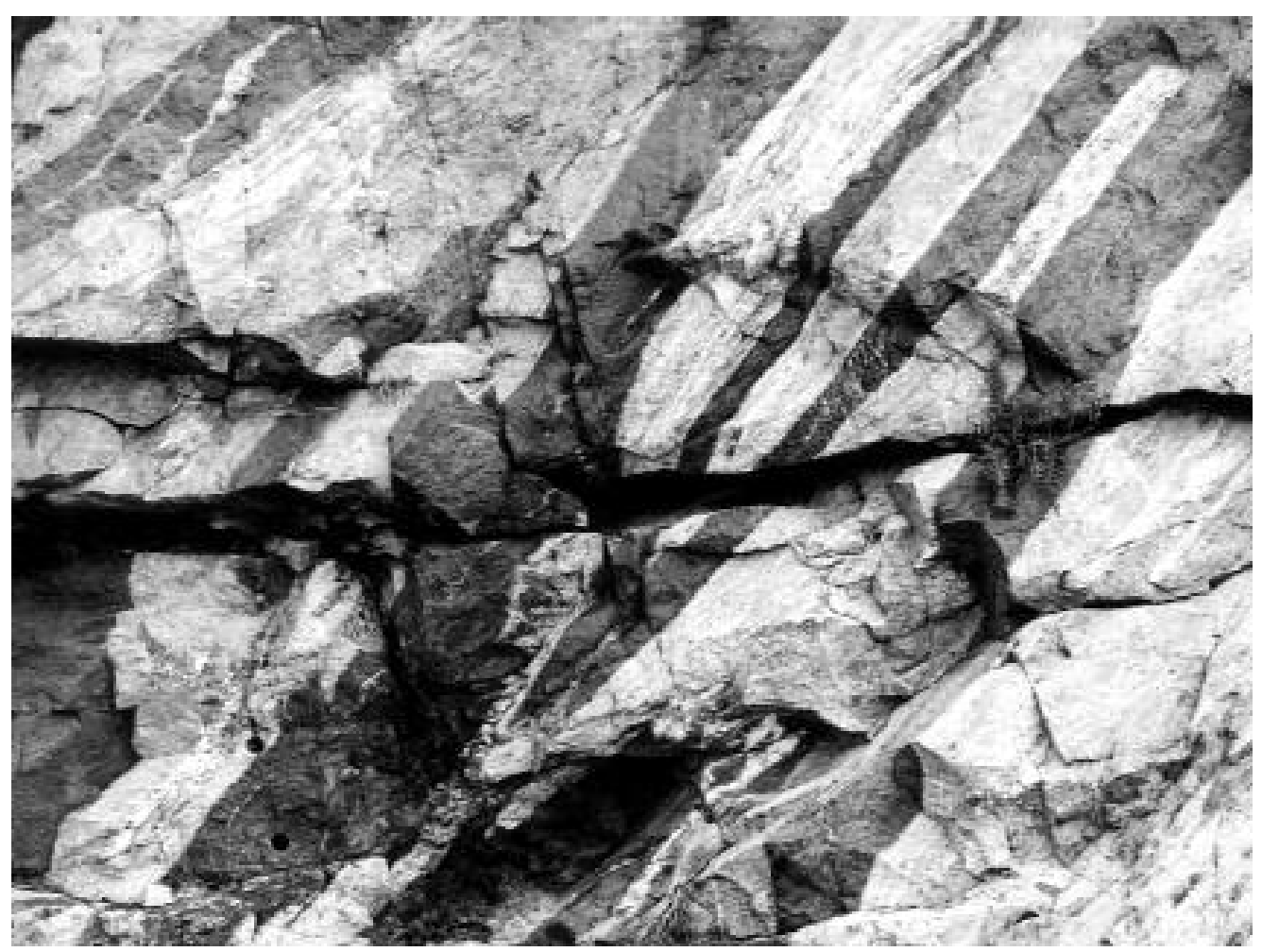

Plate 6. Lewissian gneiss

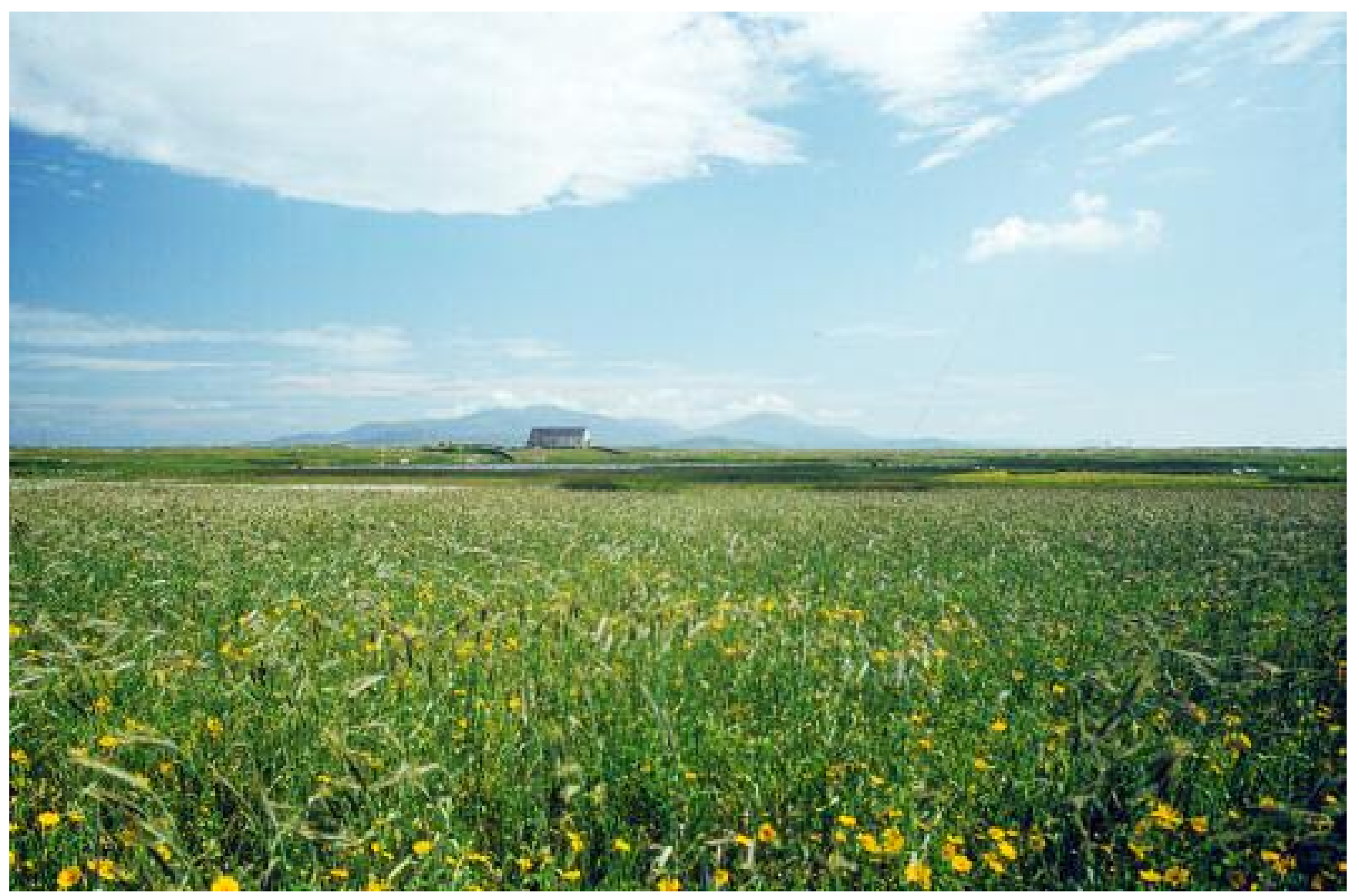

Plate 7. Machair plain at Ardkenneth, South Uist 
No. of beach units
$\mathrm{CaCO}_{3}$ content
$10 \%$

2

\section{II-40\% $\quad 4 \mid-70 \%$}

16
$>70 \%$

27
Table 4. $\mathrm{CaCO}_{3}$ content of beach units

of $9.9 \mathrm{~m}$ in Barra, $10.1 \mathrm{~m}$ in Uists, $14.1 \mathrm{~m}$ in Harris and $10.1 \mathrm{~m}$ in Lewis; the Scottish average being less than $7 \mathrm{~m}$. Equally striking is the altitude to which machair can extend uphill; $42 \mathrm{~m}$ in Barra, more than twice the range of most other areas in Scotland.

Considering machair per se, $31 \%$ of the total area is plain, 28\% hilly, 5\% hillocky, 31\% undulating and $4 \%$ other. Thus the physical characteristics of machair vary considerably, partly as a result of the underlying surface upon which these distinctive landforms have developed. Machair usually rests on part of the ice-scoured Lewisian platform that occupies most of the low ground of the Outer Hebrides. This surface, as described above, tends to consist of a series of gentle basins and ridges with a variable cover of glacial till. Notwithstanding such subsurface control, the evolution of machair from a hypothetical origin as an extensive series of coastal sand dunes is long and complex. Sea-level changes (coastal submergence probably of the order of 3-5 $\mathrm{m}$ since circa 5164 BP; Ritchie 1985), substantial coastal erosion (Ritchie 1979) and numerous episodes of aeolian erosional and redepositional cycles have all pushed machair landforms eastward at the expense of adjacent lochs, marshes and peat-covered 'black land'. Erosion may take the form of discrete hollows, ie blowouts, or more extensive surface lowering and linear escarpment retreat, ie deflation. It is not known if these periods of wind erosion were in direct response to short term climatic changes or triggered by grazing or cultivation of machair land. Although this is a complex and only partly understood series of physiographic processes, an attempt is made in Figure 6 to illustrate possible models of machair evolution. These idealised profiles also give some indication of typical Uist-type machair land. This model does not take account of submergence which would alter water table levels and therefore, the base level of wind erosion, nor does it include coastline retreat. Figure 7 attempts to include the coastline erosion factor and the concept of escarpment retreat to account for the surface morphology and stratigraphy of some machair areas. The archaeological surfaces are tentative and included in order to illustrate the time-scales involved in machair evolution; a time span of probably around 6000 years.

The essence of machair geomorphology can be summarised under two headings: form and process.

\subsection{Form}

Most machair takes the form of low coastal plains with a variety of superficial features such as coastal dune ridges, redepositional hillock zones near the coast, some 'fields' of sand hills, localised bare sand blowouts which can occur on most higher surfaces, inner escarpments, usually stabilised and facing seawards with remnants of older higher sand plateaux sloping gently inland either to marshes, lochs or sloping 'black land'.

\subsubsection{Process}

Continuing coastline erosion is more severe in some areas than in others and this could be due to a combination of submergence and coastal sand deficiency. Wind erosion in this high-energy Atlantic seaboard can be severe if, for any reason, surface vegetation is disturbed. Blowouts and more general deflation carry sand landwards to be redeposited, sometimes at high altitudes, on adjacent hill sides. Very strong winds are most frequent from the north west, but the general resultant direction is south to north or south-west to north-east. Sand tends to encroach into adjacent lochs converting them to freshwater marshes. A significant process factor is grazing pressure, either natural such as rabbits, or husbanded such as sheep and cattle.

\subsection{SOILS AND AGRICULTURE}

\section{D Mate (1987)}

'I never saw fields covered with a greater load of herbage than their cornfields are, but when you examine them hardly one tenth part is corn, the rest is all wild carrot, mustard, etc. The poor creatures do not know which way to clear their fields of weeds and think of nothing but to pluck up corn as their ancestors did which leaves the seeds of the weeds time to ripen.' (Forbes of Culloden 1737)

The Devensian period is believed to have been just one of a number of warm and cold interstadials and stadials, but it was, in the main, a glacial period (Lowe \& Walker 1984, 315 ) with a glacial maximum at or shortly after 18,000 bp (ibid, 326). The proposed ice limits, in the area of the Western Isles, are unreliable. Boulton et al (1977, Figure 2.11 in Lowe \& Walker 1984, 38), suggest that the British ice sheet was an extensive ice-cap stretching seaward to the edge of the continental shelf. This model contradicts field evidence which suggests a rather more limited Devensian ice distribution (Synge 1977; Sissons 1981).

The theory that Scottish mainland ice overrode the Western Isles was originally propounded by Geikie (1878 in Sissons 1983, 166), but evidence now suggests that the Western Isles had their own ice-cap (von Weymarn 1974, 1979; Coward 1977; Flinn 1978; 1980). It is possible that the Western Isles were overrun by mainland ice in earlier glacial periods, but not during the Devensian (Flinn 1978, 1980; von Weymarn 1979, 97; Davies et al 1984, 61; Sutherland et al 1984, 261-72).

On reconsidered evidence, Flinn $(1978,196)$ depicts the position of the Western Isles ice-shed; it ran from the mountains of Harris southward, along the western seaboard of south Harris and the Uists, though it cut across the western part of North Uist.

Ice is less erosive at an ice-shed since horizontal movement is minimal (Sissons 1977, 83). In areas of minimal erosion, or unglaciated areas, pockets of deeply weathered profiles would be expected (Peacock \& Ross 1984, 262); indeed fifteen such sites have been found in the Outer Hebrides (Glentworth 1979, 126). Another such site was discovered during excavations at Balelone. Its presence implies that local 
$1 \mathrm{~A} \& \mathrm{~B}$
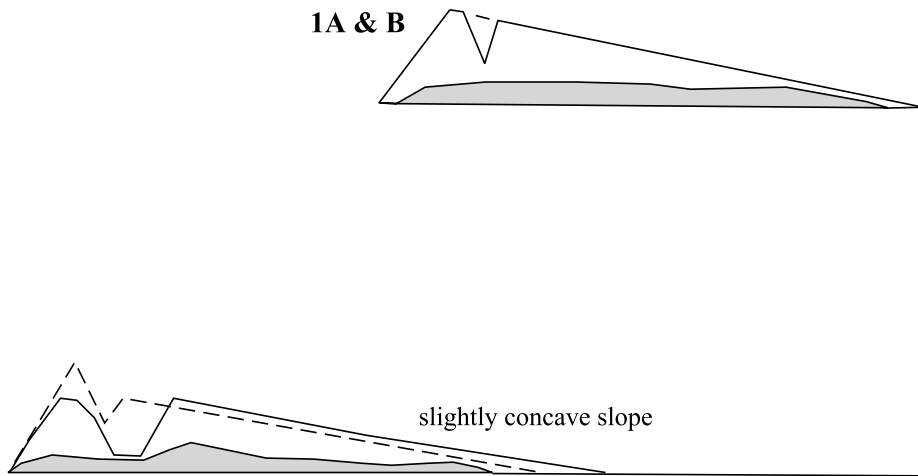

2A

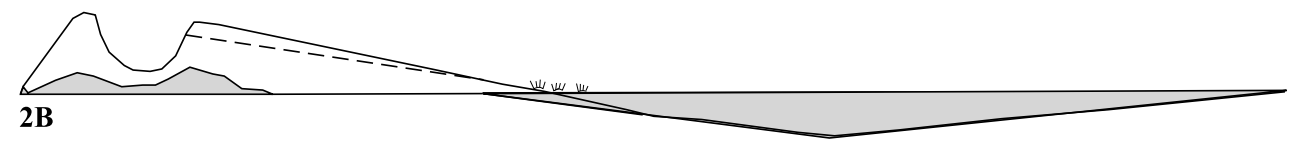

loch draining by seepage
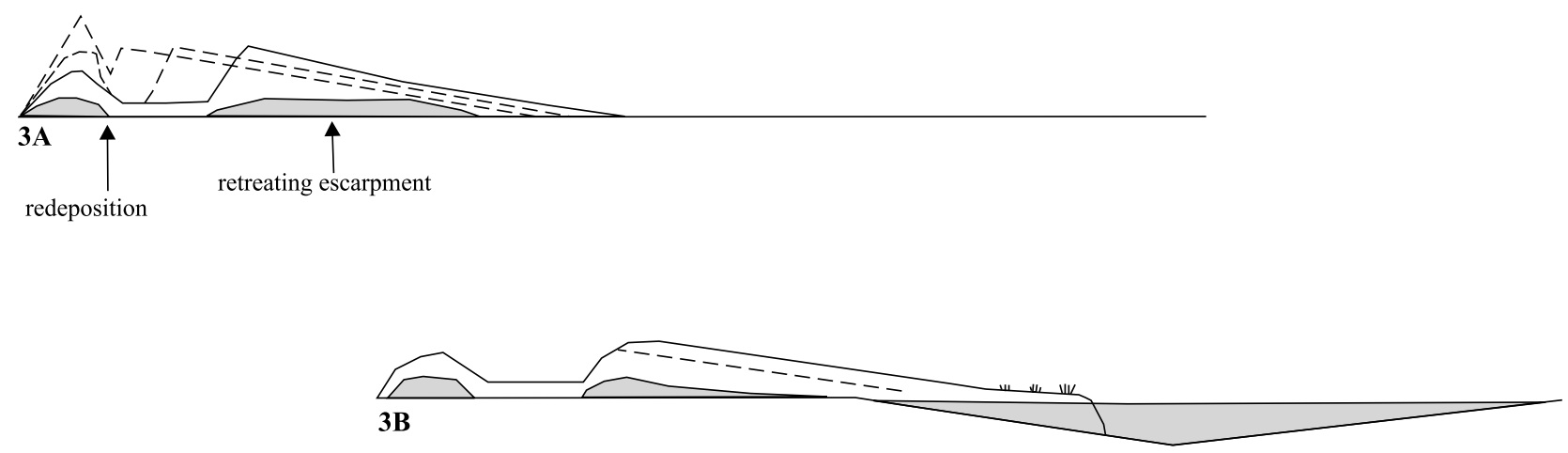

flat machair slow growth over marsh

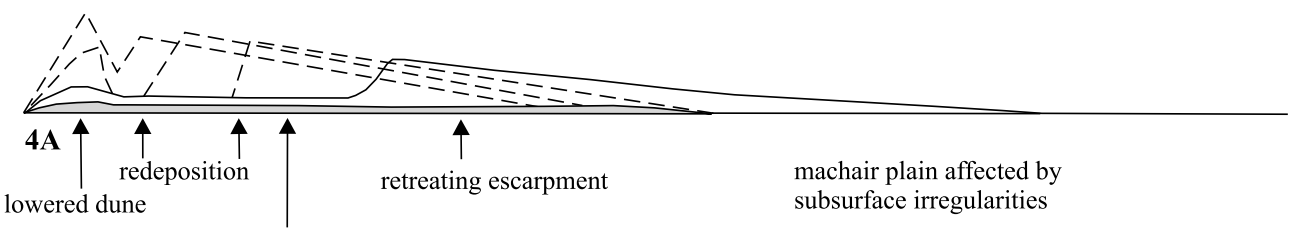

flat machair plain

with slight seaward slope

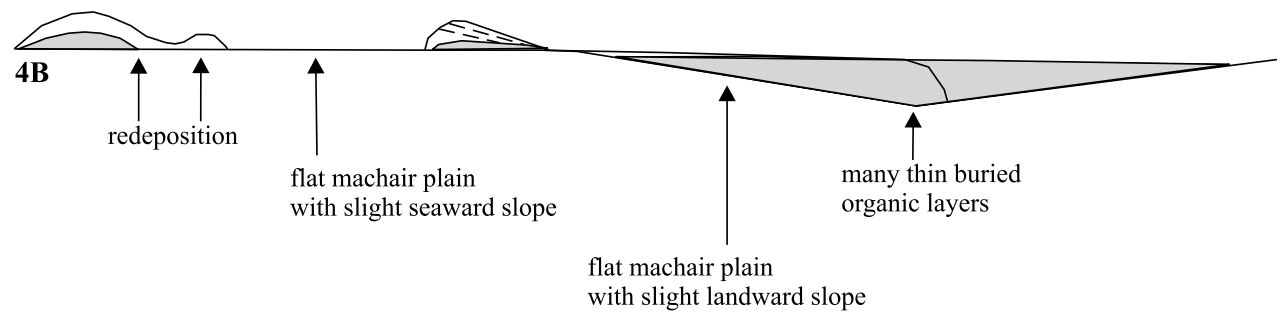

Figure 6. Models of machair evolution 


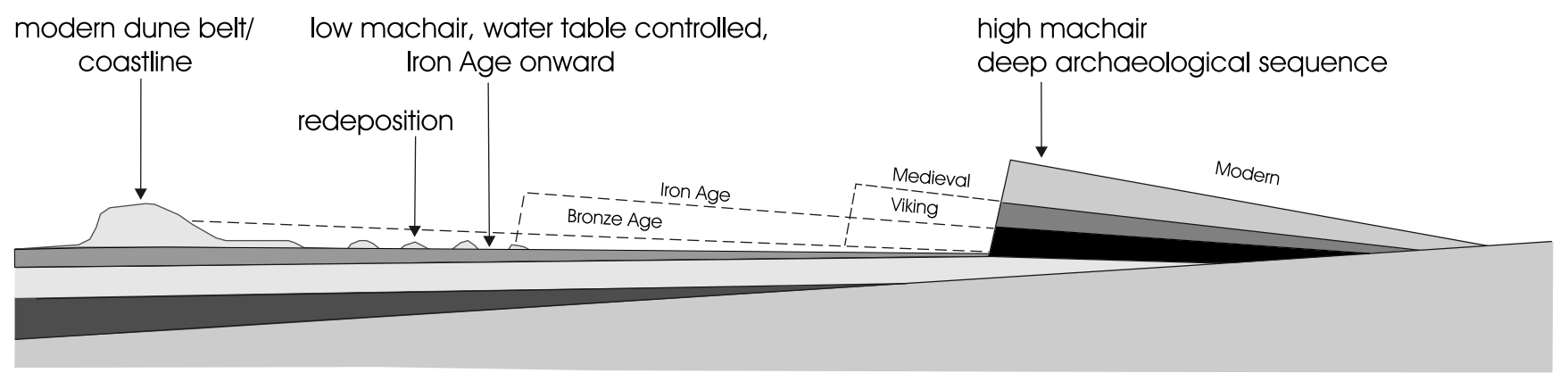

full machair system often with least coastline retreat

truncated system often with low machair coastal edge

truncated system, with severe coastal retreat back to high machair

Figure 7. Machair morphology and archaeological deposits

soils, developed on till, may contain a considerable proportion of material from a previously weathered regolith.

\subsection{The agricultural capability of the machair units}

In the following discussion Ritchie's nomenclature (1979, 120, Figure 6) is adhered to. His machair landscape units, low machair and high machair plains, together with dunes or dune systems, also form significant land-use capability units.

\subsubsection{Low machair plain}

\section{Constraints}

The low machair plain can be taken to include the backlands. The position and level surface of the low machair plain is determined by the ground-water table (GWT), itself determined by the level of the lowest outlet from underlying, rock-carved basins which elsewhere give rise to a lake-dominated terrain (Waterston \& Lister 1979, 329-51). In summer, it may be estimated theoretically that the water table generally lies less than $1 \mathrm{~m}$ below the land surface. Since wet sand is more erosion resistant, the sand level must be set at that which remains relatively wet even through the summer. Water entering a soil system will drain rapidly from larger pores but be stored in the smaller pores where the forces of surface tension are stronger than gravity. The coarse-textured nature of the sand leads to a predominance of large pores and, thus, in turn, to relatively small field (water) capacity (Marshall \& Holmes 1979, 12); though capillary rise can be rapid, the pore size distribution means that the maximum rise is about $0.5 \mathrm{~m}$ (Brady 1974, 181, Figure 7:13). Thus the water table must lie about 0.5 $\mathrm{m}$ below the soil surface. It is probably slightly higher since it rains on most days in the Outer Hebrides.

In some areas the backlands can seem to form part of the low machair plain, with no apparent break in slope between them, as at Balelone Farm in North Uist (see Chapter 4). These are sometimes on a slight rise of slope, away from the level coastal plain. In both cases, the backlands form an area influenced by processes of peat formation and till soils with calcareous sand additions.
Soils

The soils of the low machair plain are a complex mixture, determined by sand supply, organic matter growth and water table levels. They therefore include peats, calcareous humic-sandy gley soils, typical sand-pararendzinas and typical brown calcareous sands.

The larger parts of the low machair plain at Balelone were typical sand-pararendzinas which graded inland to typical brown calcareous sands. The reported chemical characteristics of machair soils, largely of sand-pararendzinas, are, as expected, anywhere between 0-80\% $\mathrm{CaCO}_{3}$ (Ritchie 1971); $\mathrm{pH}$ of 8.0 to 7.2 (Randall 1976), and soil organic matter content of usually less than $10 \%$ though occasionally less than $2 \%$ (Dickinson 1977), with a rapid fall off from the A-, to B-horizons (eg 2.2\% organic carbon in the A-horizon as opposed to $0.7 \%$ in the B-horizon (Roberts et al 1959, 223)). Similar results have been reported from Ireland (Bassett $\&$ Curtis 1985, 1-20). Soils with A-, and B-horizons developed to $60 \mathrm{~cm}$ have been reported in freely drained situations (Glentworth 1979, 133), but these are rare.

The presence of brown calcareous sands need not indicate a longer period of pedogenesis; rather, they may result from an equilibrium between the soil forming factors of sand supply, peat growth, and peaty waters with fluvial additions of mineral matter. Such soils grade into peats and humic-sandy, gley soils and may better be regarded as members of a complex of humic-sandy gley soils, though their cultivation will have emphasised the distinctions and improved the structure of the more freely-drained, brown, calcareous sands. At Balelone, these soils lay at the back of the machair plain. Soil characteristics have not been reported and are likely to be variable but may have organic matter content of $10-40 \%, \mathrm{pH} 6-7.5$ and $\mathrm{CaCO}_{3}$ content of $0-30 \%$. Field capacity is probably adequate, but these soils commonly lie on a slope where natural drainage controls the GWT, ameliorating problems of winter flooding, root zone depth and adequacy of summer water supply.

\section{Agriculture}

Low machair suffers from flooding in winter. Since the flooding is due to a rise in the regional GWT, amelioration of the condition by drainage is generally ineffective, though large-scale open ditch systems can sometimes help. Flooding 
may cause problems with seed germination and emergence and result in heavy crop losses (Cannell et al 1980). It also restricts the rooting zone. Despite these problems, the soil can be excessively dry in summer because of its low field water capacity and low water conductivity, properties associated with its pore size distribution and low organic matter content. Erosion of the substrate, en masse, is unlikely to be a problem, but erosion of the seed bed may be. At Balelone all freely-drained soils on the low machair plain which had been subjected to cultivation had very thin $(<20 \mathrm{~cm})$ A-horizons indicating probable loss from the soil surface. Weed competition on the machair plain is severe, but ploughing, which reduces the competition, also increases the risk of loss of A-horizon material. Ideally, cultivation produces a system of very shallow furrows into which seed is sown and then covered by harrowing. Rolling is also recommended, but weed competition remains severe.

\subsubsection{High machair plain}

\section{Constraints}

The position of the high machair is determined by a number of factors, some of which have already been discussed. The high machair lies to the leeward of the dune system, its height above the GWT determined by the height of the dunes. Its stability is due to high rainfall and lack of a soilwater deficit (ie rainfall more than compensates for water lost by evapo-transpiration, except in June) which enables vegetation to survive and a protective sward to develop on what is an excessively-drained parent-material. No differences in vegetation are discernible between the low machair plain and the high machair plain, only between stable areas and areas being actively supplied with sand (Dickinson $\&$ Randall 1979, 275).

\section{Soils}

Mapping of the machair system soils at Balelone (below) showed that the dune soils were raw sand, grading to typical sand-pararendzinas (Avery 1980), with no recognisable B-horizons and A-horizons less than $0.2 \mathrm{~m}$ thick. On the remnants of the high-machair plain and on stable dune back slopes, sand-pararendzinas dominated, often with A-, and very poorly developed B-horizons which together totalled but rarely exceeded, approximately $0.2 \mathrm{~m}$. There appeared to be little significant increase in clay content or in other characteristics which would hold the soil, other than an increase in thickness of the Ah-, organic-horizon. The soils could not be described as brown calcareous sand; the next step in pedogenetic development. The increased depth and organic matter of the A-horizon is associated with a better field water capacity, noted by Dickinson and Randall $(1979,273)$ as rising to $18 \%$ in such soils.

\section{Agriculture}

The high machair escapes the problems of flooding but suffers those of excessive drainage, the soils being extremely 'droughty'. It has been suggested that the presence of a stable high machair surface is due to the low evapotranspiration rate and the high frequency of and high total rainfall. Plants growing on this surface must be aphreatophytes, that is, not groundwater dependent. To sur- vive the environment, native plants must develop special strategies, such as extensive shallow rooting systems to collect as much rain as possible or deep tap roots. Once the surface horizon is broken, these high machair soils are extremely susceptible to erosion, the entire substrate being available for transport.

\subsubsection{Dune systems}

Dune systems form at sites of active erosion or abundant sand supply.

Soils

On dune soils initial processes tend to decrease the calcium carbonate content and increase organic matter in the surface horizons. Continuing sand supply counteracts both of these pedological processes. Ammophila sp (Marram grass) is the characteristic dune vegetation in the islands (Dickinson \& Randall 1979, 268). It can tolerate accretion rates of up to 1 $\mathrm{m}$ per year and indeed has more vigorous growth where accretion is taking place. Also, it readily regenerates from rhizome fragments, often found in eroded dunes, and thus quickly re-colonises breaks once erosion has halted. It has been found that only about $10 \%$ of the organic matter of the standing crop of Ammophila sp is living and it is thought that the transfer of the dead plants organic matter back to the soil is a key factor in the development of dune grasslands (Boorman 1977, 165).

Estimates of field water capacity of young dunes are about 5\% (Dickinson \& Randall 1979, 273; Salisbury 1952); 'good soils' typically have values above 15\% (Hall et al 1977, 57-60), those of soil organic matter are about $0.4 \%$ (Boerboom 1963); while carbonate values are generally higher than on the machair surfaces, eg $70 \%$ as opposed to 50\% (Randall 1972).

\section{Agriculture}

The dune soils have little or no agricultural significance.

\subsubsection{General comments}

\section{The backlands}

The backland soils of the machair plain are sometimes very good soils. Their land-use capability class may be ' 3 ', ie land with moderately severe limitations on crop growth, range of profitable crops restricted; suitable for some arable crops and grassland (Glentworth 1979, 131), with the chief limitation being climatic rather than edaphic. They are probably as good as any soils found in the islands and West Highlands. They can have a good structure, are stone free, have moderate $\mathrm{pH}$ values with a good nutrient supply and capacity. The high organic matter content ensures that erosion is slight. The current settlement pattern in the Western Isles is noticeably coincident with the back edge of the machair where these soils lie, rather than with the machair itself (cf Boyd 1979, 10).

\section{Nutritional deficiencies}

However, high soil $\mathrm{pH}$ reduces the availability of nutrients to plants. At $\mathrm{pH}$ values greater than 7 , iron, magnesium, zinc, 
copper, cobalt and phosphorus all become less readily plant-available (Brady 1974, 388, fig 14.8) and sheep grazed on machair alone would suffer from cobalt deficiency (pining). Due to soil conditions there are also serious deficiencies in potassium (Darling 1955, 190; Glentworth \& Muir 1963, 259) and nitrogen (Grant 1979, 530). The lack of nutrients can be overcome with fertilisers, but machair soils have a very low retention capacity. Dressings of some minerals can be made at critical times during plant growth and are economically justified (Roberts et al 1959, 224). Before the advent of modern fertilisers, only seaweed and animal manures would have been available.

\subsection{CLIMATE}

The unsettled cool-maritime climate of the Western Isles is, to quote Professor Manley, '....an extreme modification of that of the British Isles generally...' (Manley 1979, 47). It is markedly windy, often wet and usually humid and cool. The influence of the sea does much to ameliorate the worst effects of the islands' latitude and the islands enjoy the advantages of a maritime climate, viz small annual variation in temperature, high wind speeds and high rainfall, evenly spread throughout the year.

On the western, machair lowlands the average total annual rainfall is relatively small, ranging from about $1000 \mathrm{~mm}$, in the south to $1200 \mathrm{~mm}$, in North Uist. This latter, is just under that level of rainfall which facilitates the formation of peat, and considerably less that the annual rainfall of the adjacent mainland. It is also significantly less than the rainfall on the higher, peat-covered, eastern side of the islands (1400 $\mathrm{mm}$ to $1600 \mathrm{~mm}$ ).

However, even on the lowland of the west coast area the influence of the low rainfall is considerably increased by its persistence. Throughout the year, there is measurable (ie $>2$ $\mathrm{mm}$ ) rainfall on three out of every four days. Allied to persistence, the high humidity (annual average 85\%) inhibits evaporation with the unhappy consequences for agriculture noted by Mate.

Almost one third of the recorded winds at the Butt of Lewis are 'strong to gale force', ie in excess of 21 knots, making this the most storm prone station in the British Isles. Further south the situation is rather better, with only fifty 'storm-days' a year, on average at Stornoway, for example. However the average annual wind speeds are extraordinarily high with mean winter speeds of $10 \mathrm{~m}$ per second and mean summer speeds of $5 \mathrm{~m}$ per second, they are amongst the highest recorded in the world (Hudson et al 1982, 15). Exposure to such persistent, damp, chilling winds is a major constraint, not only on agriculture, but on all spheres of human activity in the isles. Manley $(1979,48)$ has commented on the exhausting demands made on the human body by working in areas with exposure to wet chilling winds at temperatures below 13 degrees centigrade.

The average of the mean daily temperature for Stornoway is 8.3 degrees centigrade, in a range of 11 degrees to 5.6 degrees centigrade (mean daily maximum to mean daily minimum). The impact of these low temperatures on the growing season are, however, ameliorated by the number of daylight hours during that season, so that an annual average of 1244 hours of sunshine are recorded at Stornoway; 1383 at
Benbecula. Further, the isles are almost free of frost. The number of days on which the air temperature drops below $0{ }^{\circ} \mathrm{C}$, at Stornoway, is 47; at Benbecula, 33; at Tiree, 17. These values compare with values of 65 to 70, for the Scottish Lowlands and up to 130 for the Highland straths (Manley 1979, 51).

In analysis of the differences between climatic records from different stations, Manley has noted the benefits to be gained from the provision of local shelter. In general he estimates that the daily temperature over the growing season would be increased, on average, by $0.5^{\circ} \mathrm{C}$ in sheltered areas. With growing seasons ranging in duration from 225 days in Lewis, to 250 days in the south of the region, this increase in temperature adds over 100 day-degrees centigrade to the accumulated temperature of a location. This could be sufficient to convert a 'cool' area to a 'warm' area (sensu Hudson et al 1982, 10-15), and make the difference between success and failure for crop husbandry at given locations. This observation implies that 'invisible' micro-environments may have existed in the past, which would have influenced the siting of settlements and cultivated areas.

Manley has also noted that the impact of climatic change on the islands would have been moderated by the preponderating influence of the sea. Thus, for example, the climate during the summer of 1968, the sunniest on record and the hottest for over 100 years, was largely determined by conditions in the Atlantic (Manley 1979, 53; Murray \& Ratcliffe 1969). In general Manley notes that cooler Hebridean seas would occasion later Springs while warmer seas would probably occasion greater rainfall, especially in the Autumn.

Parry $(1978,81)$ has determined the absolute climatic limits to cultivation for areas in Scotland, mainly in the Southern Uplands. He estimates that the limits for oats lie close to an accumulated temperature of 1050 day-degrees centigrade above a base of 4.4 degrees, a Potential Water Surplus (PWS) of $60 \mathrm{~mm}$ and maximum exposure at 6.3 metres per second. In the case of barley he records limits of 1200 day-degrees centigrade, PWS of $20 \mathrm{~mm}$ and 5.0 metres per second average wind speed. It can readily be seen, from the mean annual values cited above, that conditions on the machair approach these marginal values in most years. Thus, the machair is currently a marginal zone for cereal cultivation. It thus necessarily follows that the settlement potential of the machair varies considerably in response to relatively minor climatic variation.

The general pattern of post-glacial climatic development in the British Isles has seen a progressive improvement in climate up to about $5500 \mathrm{BC}$, the Atlantic/Boreal transition. Thereafter the rate of change diminished and the climatic optimum was reached in the Atlantic Zone, between 4000 and 3500 BC. After 3000 BC, ie from the Sub-Boreal Zone onwards, the climate has been marked by great and sometimes abrupt fluctuations, imposed on a generally deteriorating trend. The period from 1300 to $900 \mathrm{BC}$ witnessed a reduction in mean annual temperature, of about 2 degrees centigrade. The following period was, for the west coast of Britain, a period of unprecedented wetness, and Tregaron $\mathrm{Bog}$, in west Wales, put on a full metre of peat in the period 800 to 400 BC (Turner 1965). The deposition of the next metre of peat took a further two millennia. After $400 \mathrm{BC}$, the climate seems to have improved and the period from $400 \mathrm{BC}$ to AD 500 was significantly warmer and drier than the preceding period. 

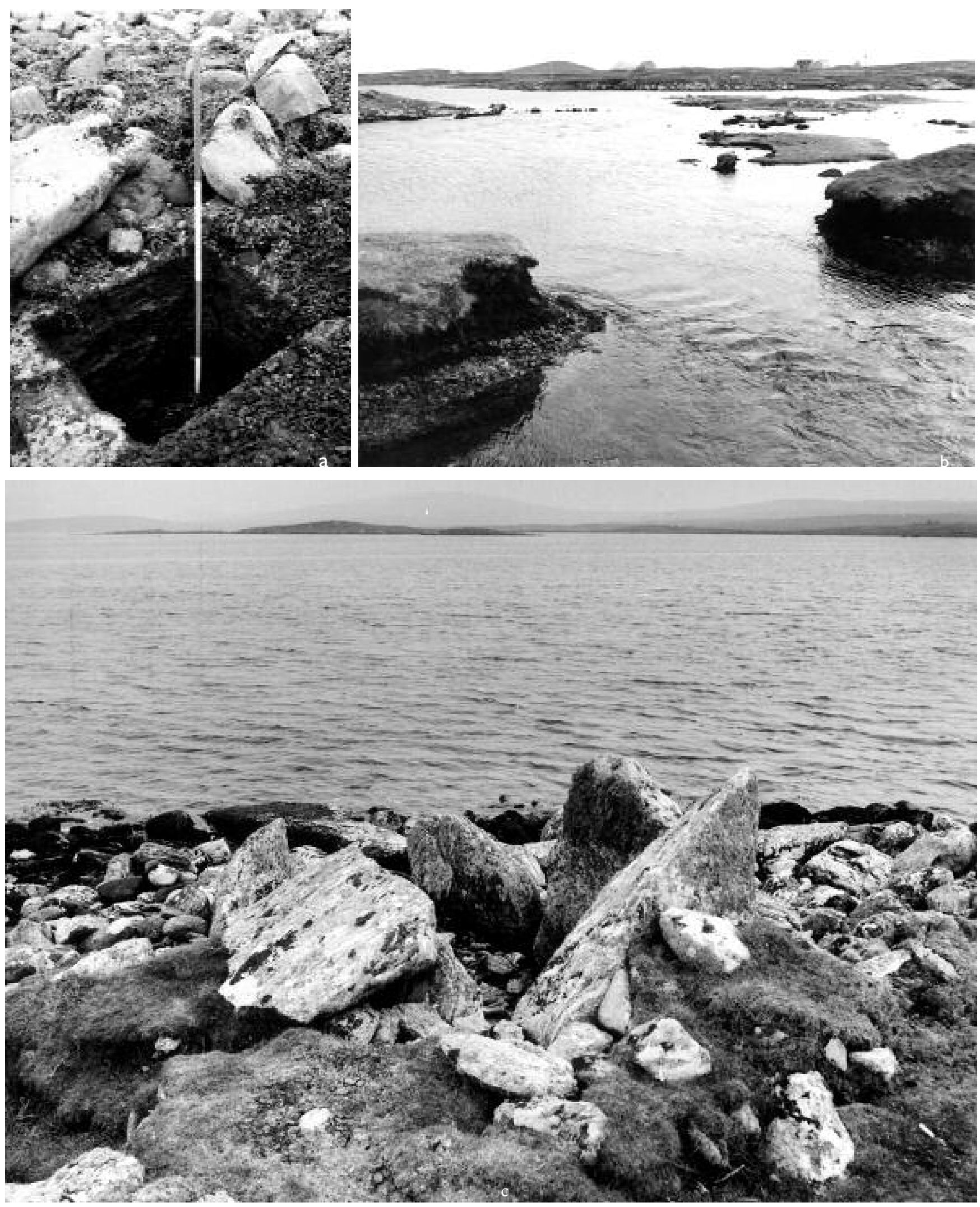

Plate 8. Evidence for progressive drowning of the landscape: a) Inter-tidal peats at Baleshar e b) Surface peats now being eroded by the sea at Benbecula c) The Neolithic chambered cairn at Geirisclett now partly submerged at high tide 


\subsection{THE PHYSICAL LANDSCAPE AS A SETTLEMENT RESOURCE}

\subsection{Geological deposits}

The Lewisian Gneiss bedrock of the islands is a particularly poor building stone: it does not produce regular slabs or blocks, is friable and disintegrates when heated. Its ubiquity is in marked contrast with the virtual absence of stones useful to early settlers. The islands are all but devoid of readily available, good quality rock suitable for chipping, like Arran's pitchstone (Thorpe \& Thorpe 1984) or the bloodstone deposits of Rhum (Wickham-Jones 1990). Flint is not readily available either (Wickham-Jones \& Collins 1978). However, mylonite was occasionally worked. This poverty of raw materials continues into later epochs as the islands are also devoid of useful mineral deposits or metal-ores. Clay deposits suitable for pottery manufacture are similarly rare and localised; a consequence of the heavy and extensive glacial scouring of the gneiss shield. In general, the geological deposits of the Outer Hebrides were resource-poor for the prehistoric settler.

\subsubsection{Landscape formation}

It is generally assumed that eustatic sea rise has outpaced isostatic uplift of the land in the Hebrides throughout the post-glacial period (Sissons 1977, 131). Ritchie's radiocarbon dates (1985) from now sub-marine peats range from $9000 \mathrm{bc}$ to $2400 \mathrm{bc}$ and indicate that, in freshwater lochs on the western margin of the islands, peat development continued, free of substantial sand inundation, into the late Neolithic Period.

\subsubsection{The chronology of machair formation}

The absence of machair sand from deposits underlying earlier sites has also been noted. At Northton, Harris, the earliest Neolithic deposits rest on brown earths formed on tills as do the earlier Neolithic settlements at the Udal (Evans 1971, 52-62). The earliest archaeological deposits overlying shell sand at Northton have been radiocarbon dated to $2461 \pm 79$ bc (BM 705) (Evans, ibid; Simpson 1976, 222). The corresponding deposits at the Udal seem to date to the same period. At Paible, a date of $2110 \pm 270$ bc (GU-1088) has been returned for the lower levels of a thin cultural deposit which yielded AOC Beaker material and which overlies a thin deposit of shell sand (I Shepherd pers comm). The Beaker period deposits at Rosinish, similarly overly shell sand (Shepherd 1976) and earliest dates from this site are contemporaneous with the latest of the sub-marine peat dates. This latter implies that in the Late Neolithic period deposition of shell sand had begun, at least on the seaward margin of its current distribution, and that this deposition continued into the Early Bronze Age, but that some areas remained sand-free, even at this time. Taking this archaeological evidence together with Ritchie's evidence for progressive drowning of the landscape, one interpretation is indicated; that the machair soil has been progressively moving eastwards as the west coast is progressively inundated by the rising sea (Plate 8 ). The eastern edge of the machair reached what is now the islands' west coast in late Neolithic/early
Bronze Age times but had not become fully established in the current coastal zone in the early Bronze Age.

Bronze Age sites, later than those of Beaker period date are almost unknown in the machair while sites of the Iron Age are found in large numbers, in and on machair deposits. It may therefore be assumed that the machair plain continued to develop throughout the Later Bronze Age. Examination of the Iron Age midden sites exposed by coastal erosion reveals that they now exist as rounded to hemispherical knolls with no stratified links into the surrounding shell sand deposits of the machair (Plate 9). This implies that, at some time after their formation, the surrounding machair was completely deflated, at least in the immediate areas of the sites. It is possible that more than one such period of destabilisation of the machair occurred but documentary records exist of the most recent. In his description of his tours in the Hebrides made in 1774, Pennant noted that the machair plain appeared as a strip of bare sand with little or no vegetation cover. This may reflect the response of the local ecosystem to the Little Ice Age of, approximately 1550 to 1850 AD (Lamb 1982, 31).

\subsubsection{Peat formation}

The formation of peat in confined mires or raised bogs can have begun very early in the post-glacial period. A radiocarbon date of $7190 \pm 140$ uncal BP has been returned for basal peat in the Little Loch Roag area (Birks \& Madsen 1979) and, earlier deposits very probably exist in the Isles. I have discussed elsewhere a model for pedogenesis and peat formation on Scotland's West coast (Barber \& Brown 1984, 169). From the beginning of the Post-Glacial period, soils will have improved, until Brown earths developed on the glacial tills. Following the Post-Glacial climatic optimum (circa 3500 BC) conditions over wide areas in the isles were such as to facilitate the emergence of blanket, or climatic peat. While they remained available, the soils developed on tills would have been more fertile, and more easily cultivated that were the machair soils.

The period during which the climatic peat developed is not known, for the Western Isles, but some indications are available from the archaeological record. All of the Neolithic sites which have been excavated rest on soils developed on tills. This is true of both settlement and funerary sites. We have already noted that at both Udal and Northton (Evans 1971, 52-56; Simpson 1976, 222) the earliest Neolithic deposits lie on till soils. Scott (1951, 1-3) observed that the pottery rich deposits at Eilean an Tighe also lay on till soils. Scott also noted that the tombs of Clettraval and Unival, although in peat, are not on peat (ibid, 2), an observation reiterated by Henshall $(1972,115)$. Inland, but still relatively close to the coast, Neolithic sites have been found on boulder clay. At Bharpa Carinish, North Uist, pottery and hearth deposits dating to 4300 to $4400 \pm 100$ uncal BP have been interpreted as the remains of Neolithic houses (Crone 1993, 364). The initial Neolithic land-use at Callanish, Lewis is interpreted as rig-and-furrow cultivation, apparently on mineral soils (Ashmore 1995, 30), albeit that this must await radiocarbon dates for confirmation. It is clear that, although many peat deposits had begun to form in the Neolithic period, soils developed on tills covered the greater part of the present area of the islands and climatic peat had not yet begun to spread. 


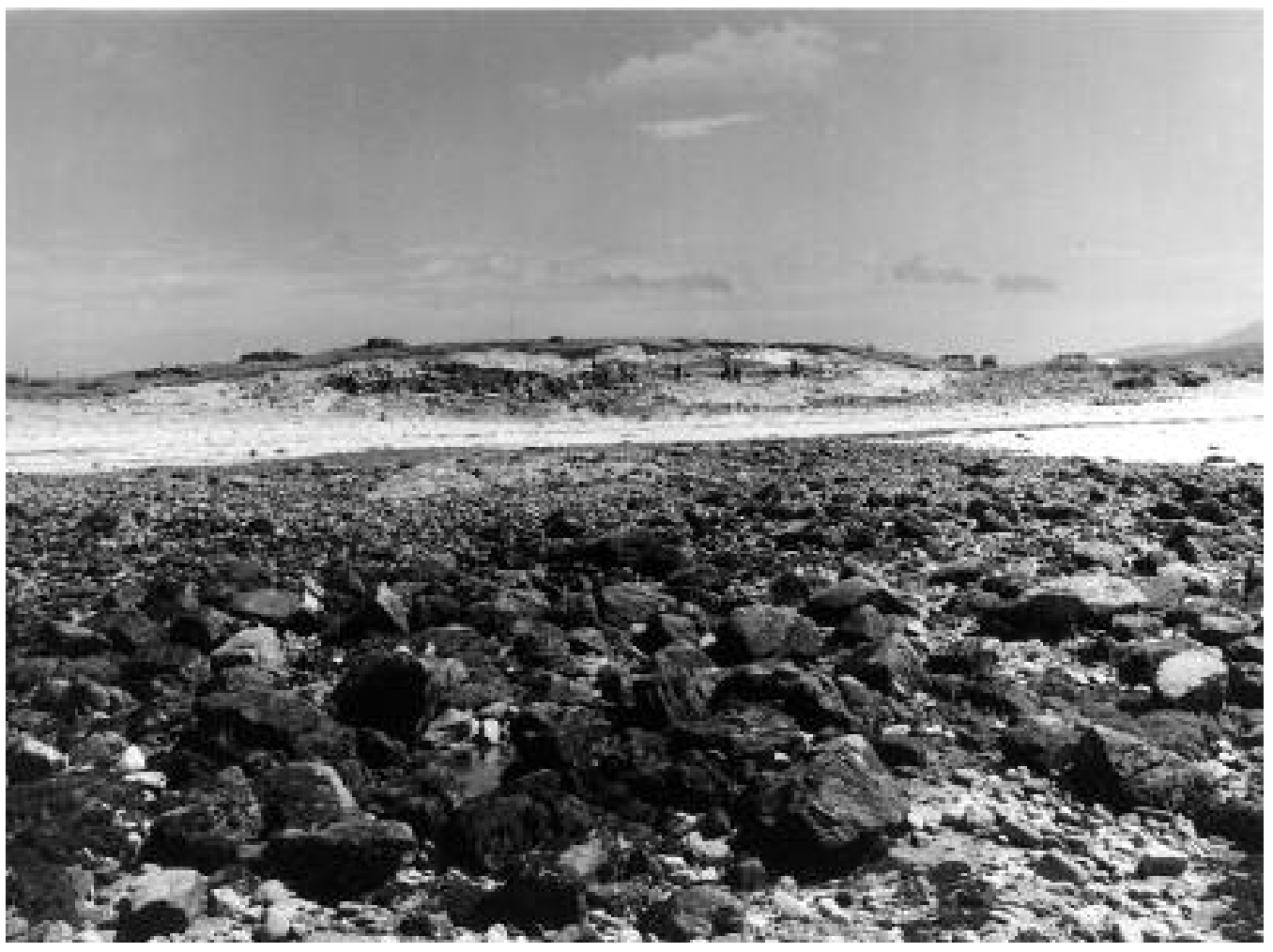

Plate 9. The domed structure of Baleshare midden viewed from the seaward side

The picture for the Bronze Age is less clear. The hut circles and field fences now emerging in peat cuttings at North Dell, Lewis, are directly comparable, at least in their gross morphologies, with Inner Hebridean sites such as those on Islay (Barber \& Brown 1984, 173-78; RCAHMS 1984) and on Jura (Stevenson 1984, 127-160) and elsewhere on the Scottish west coast (Barber 1997). In part these are probably later Bronze Age in date, and they lie on mineral soils under peat. Throughout mainland Scotland, the LrBA was a period of large scale expansion into marginal areas and it is highly improbable that this should not also have happened in the Outer Hebrides, especially as it is so clearly evidenced in the Inner Hebrides (RCAHMS 1980; 1984). The apparent absence of visible remains of the Later Bronze Age expansion in the Outer Isles may be accounted for by the fact that peat now covers the LrBA landscape. Recent archaeological and environmental work has revealed later Bronze Age remains in and under peat, in apparent confirmation of this view. At Sheshader, on the Eye Peninsula, Newell (1989) investigated a wall lying on peat, the latter dated to $2900 \pm$ 100 uncal BP (GU-1665). At Loch Portain, Mills et al (1994) investigated a similar phenomenon, dated to $2630 \pm 110$ uncal BP (GU-2452). The walls in peat at Tob Nan Leobag, near Callanish, have been dated to roughly half way between $3320 \pm 65 \mathrm{BP}$ and $2355 \pm 65$ BP (Bohncke 1988; Bohncke \& Cowie forthcoming). Similarly, peat-covered walls form an enclosure abutting a Neolithic Chambered cairn at Carinish, North Uist, and these have been dated to $2750 \pm 50 \mathrm{BP}$ (GU-2457) and $3100 \pm 80 \mathrm{BP}$ (GU-2689) (Crone 1993). These sites are variously associated with arable or pastoral land use, or both, but essentially confirm that the Outer Hebrides were sufficiently extensively occupied during the Later Bronze Age to have some settlement pushed out onto the peatlands.

The known distribution of Iron Age sites is consistent with the idea that peat cover in the Isles had reached its present extent by the beginning of that period. The settlements primarily associated with tillage are concentrated in the machair, while the domestic economy of the duns and brochs of the peatlands seems to have been based, primarily, on animal husbandry. On balance, then, it seems likely that climatic peat began to spread over the till soils during the Bronze Age period, and that it may have reached its present horizontal extent by the Iron Age.

To the total of useable land lost beneath peat must be added the significant areas lost to the sea. The average slope of the seabed west of the Hebrides is 1:250. If Ritchie's estimates are correct and the sea has been gaining on the land at an average rate of $1 \mathrm{~m}$ per millennium, a strip of land, $250 \mathrm{~m}$ wide, is being lost to the sea, per millennium. If, then, the Uists extended some $1.25 \mathrm{~km}$ further west than the current shoreline during the Neolithic Period, the implications for settlement during that, and subsequent periods are considerable.

Unlike the geological deposits, the landscape of the Isles was a considerable settlement resource at almost every period in the past. During the earlier periods, the brown earths on the tills were readily cultivable. When these were lost beneath peat the machair, for all of its constraints, was still the best agricultural land in the region; cultivable, albeit with some effort, and providing grazing over the greater part of the year. 


\section{CHAPTER 3: THE NATURAL HISTORY AND ARCHAEOLOGY}

\section{I INTRODUCTION}

It may seem a little strange to include an account of the islands' natural history in an archaeological report but just as the physical environment sets limits on the possibilities for settlement through time so also do the natural resources for flesh, fish, fowl and vegetation have an economic significance for early settlers. Between them, the physical background and the natural resources of an area define an envelope of potential for settlement which expands and contracts with the varying fortunes of time. Social organisation forms part of the definition of this envelope and by appropriate strategic adaptation facilitates or hinders settlement potential also. In this Chapter then the framework of this envelope is explored.

\subsection{NATURAL HISTORY}

The Western Isles can be divided into six general ecological zones which also constitute economic resource zones (Figure 8 ). Ranged west to east they form a series of parallel linear units consisting of open water, shore, machair lands, backlands, skinned lands and peatlands, before returning to shore and sea on the east side of the island.

Two of these zones are artificial, or at least partly so. Skinned lands consist of former peatlands that have been stripped down to a thin layer of peat which, when dug into the underlying mineral material, can form a useful agricultural soil. The backlands occur where calcareous sands from the machair combine with peats, a process which can produce the richest agricultural soils of the Western Isles. This can occur naturally when wind-transported machair-sand falls onto the peatlands. They are also artificially created or extended by the deliberate addition of sand, seaweed or other manures and by cultivation, grazing and trampling of livestock, ultimately to produce the rich plaggen soils known as Lewisian Black Earths (Whittow 1977, 285-6). The flora and fauna of these six zones are grouped below, into two ecosystems; the marine ecosystem, consisting of the sea and shore, and the terrestrial ecosystem, consisting of the other four zones.

\subsection{The marine ecosystem}

The marine ecosystem consists, for our purposes, of the open sea, the inshore waters and sea lochs and the extensive and varied shoreline of the Outer Hebrides. Both open sea and inshore waters are rich in a wide variety of fish. In the Mesolithic levels of the Oronsay shell middens, saithe (coalfish) constitute over $90 \%$ of the fish bone material and are in many contexts the only species present (Mellars \& Wilkinson 1980; Mellars 1987). This species is probably the easiest to catch from the shore. Data from later period sites on the Western Isles is scarce but an Iron age midden on Lewis produced mostly cod as well as ling, pollock and saithe (Baden-Powell \& Elton 1937, 359). This increase in the range of fish caught through time has been more clearly demonstrated on the Orkney Islands where ten species were noted on a Neolithic/Bronze Age site, thirteen on an Iron
Age site and twenty-three species on a Late Viking site (Colley 1983, 159). Crustaceans, especially crabs, seem to have been caught for food from earliest times.

The shoreline of the Western Isles varies greatly ranging from large expanses of sandy beaches to rocky shores and cliffs and each of these provides habitats ranging from open water to cliff top and including the upper shore and the intertidal zone. This variety encompasses a wide range of vegetational and faunal resources and was of vital importance in early as well as more recent times.

At the highest levels of the shore can be found growths of channel and flat wrack. The bladderless form of wrack is the main vegetation of the intertidal zone. Also present in certain conditions are Lithothamnion, Alaria esculent (tangleweed) and various algae (Darling \& Boyd 1964, 182). The shores of the sea lochs are dominated by fucoid weeds including knotted and flat wrack. These wracks can be used a fertiliser and as food for sheep and cattle. At low tide carragheen and dulse, both valuable foods for humans, could be gathered. Most importantly, however, the coastal zone contained the richest fauna of any of the islands' zones, including mollusca, mammals, fish and birdlife.

The marine mammals are, and probably were in prehistory, a much more important resource than their terrestrial counterparts. The grey seal population of the Western Isles is one of the largest in the world and the common seal is also plentiful in the area. Archaeological data provides ample evidence for their early exploitation. Indeed by the Early Christian Period, some rookeries were regarded as the private property of individual settlements (Anderson \& Anderson 1961, 295-6; McCormick 1981, 317). Cetaceans, either deliberately hunted or accidentally stranded were an occasional resource available to the inhabitants of the area and their exploitation by early man has been demonstrated by excavation (Clarke 1960, 169).

The varied coastline of the Isles is rich in mollusca with a greater diversity of species in sheltered areas than on the more exposed and rocky shores (Smith 1979, 179). Excavations suggest that shellfish were collected at all periods. The mollusca of rocky shorelines, such as winkle and limpet, were relatively heavily exploited while the more valuable food species, like cockle or oyster, of the sandy shores, although present, are rare. Shellfish are also used as fish-bait and the apparent preference for less edible species may be explained by their use for fishing rather than their routine inclusion in the human diet. However, their use as 'famine food', ie as a resource to be exploited in times of food shortage may account for their occasionally abundant presence on the sites considered here.

\subsubsection{The terrestrial ecosystem (including rivers and inland lakes)}

\section{Peatland}

Peat now covers most of the surface of the Western Isles, ranging from the eastern seaboard to the western machair lands. The peatlands, especially of the Uists, are interspersed with fresh-water lakes (Plate 10), most of which drain to the sea and are colonised by migratory fish. While the fauna of the peatlands extend into the agriculturally rich black-, and skinned-lands, the flora of these zones is largely artificial and varies with their current agricultural use. 


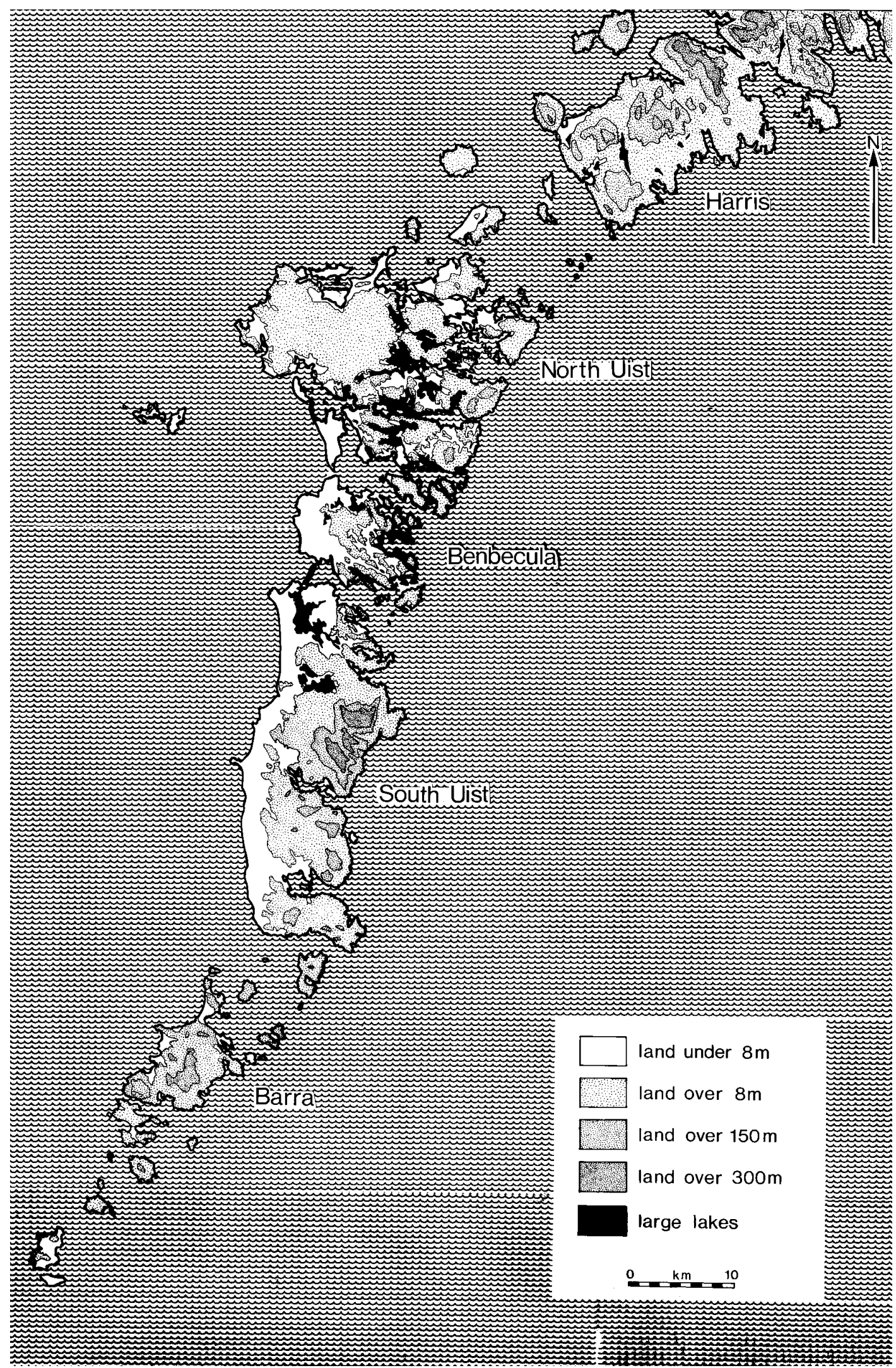

Figure 8. Ecological units on the Western Isles. The physical relief of the Outer Hebrides contributes to their zonation in north/south strips. Land under $8 \mathrm{~m}$ is concentrated in a strip of machair plains along the west coast. Small seasonal lochs (not illustrated on this scale) and extensive shallow permanent lakes lie between the machair and the high ground. The latter is peat covered and stretches north south along the east coast. The west coast descends into the sea in a shallow slope (averaging 1 in 250), while the east coast is steep-to and the sea plunges steeply to depths of $300 \mathrm{~m}$ or more. 


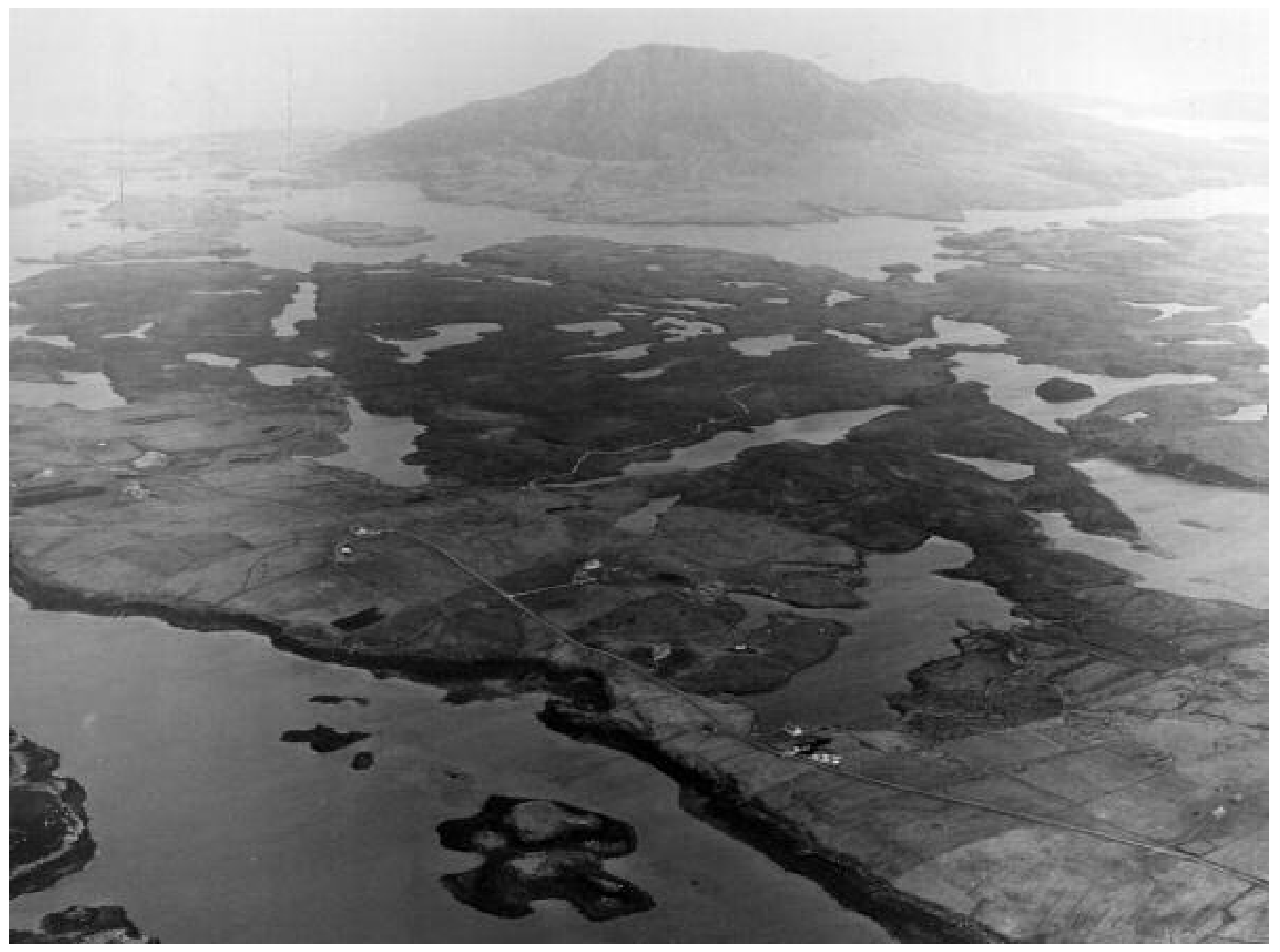

Plate 10. Knock-and-lochan, or hill and loch, in North Uist

The peatlands today support a typical heathland vegetation dominated by Erica tetralix interspersed with mosses such as Racomitrium lanuginosum. On better drained slopes Calluna dominates the vegetation while deeper peat carries more Molinia, due to the high acidity of the drainage water. Less acidic peats carry a high proportion of Eriophorum (Darling 1955, 161). In the past, peatlands provided rough grazing and peat was used as fuel, animal bedding, roofing and as a fertiliser for machair soils. Peat is still extensively used as fuel but its other uses, evidenced in these excavations, have been largely usurped by modern materials.

\section{Machair}

The high $\mathrm{pH}$ of its calcareous sands is responsible for the machair's distinctive grassland vegetation now dominated by Festuca rubra, both on the low machair and the stabilised high machair. The agricultural potential and limitations of machair lands are discussed above (Chapter 1); they provide moderate to poor grazing which is susceptible to damage by overgrazing. Cultivation can only be sustained when accompanied by constant manuring and a generous rotation cycle.

\section{The vegetational history of the terrestrial system.}

Erdtman's pollen analysis (1924, 486 et seq) of material from some twenty sites in Lewis is the earliest pollen work to have been undertaken in the Isles, although it is now of little more than historical interest. Blackburn studied samples from Calvay Island and Stoneybridge, South Uist (Blackburn 1946; Heslop-Harrison \& Blackburn 1946), but seems to have assumed that the sampled peat began to form about $6000 \mathrm{BC}$, an assumption which may have been unwarranted. In general her diagrams indicate that non-arboreal pollen predominated throughout prehistory. Analyses of now intertidal peats, undertaken as part of Ritchie's geomorphological researches (1966), are somewhat schematic and the results reflect conditions in the immediate environs of the freshwater lakes in which the peat deposits originally formed.

Pollen analysis was undertaken on a sediment sequence from Little Loch Roag, West Lewis, covering the period from $9140 \pm 140$ uncal BP (Q-1531) to date (Birks \& Madsen $1979,825)$. This reaffirms the general lack of woodland development, a factor the authors attribute to exposure. At its most developed, the vegetation cover seems to have consisted of a mosaic of grassland, heath and tall-herb communities with occasional birch and hazel scrub. The earliest evidence for human influence in this deposit was detectable at levels dating to approximately 1900-2000 BC (Birks \& Birks 1980).

Peat deposits from Tob nan Leobag, near Callanish, were investigated by Bohncke (1988), as part of an investigation of sub-peat field fences in that area. The sequence runs from about $6000 \mathrm{BC}$ to date. Bohncke suggests that, until roughly 2000 BC, the landscape supported pockets of birchwood. 
Following some early, possibly Mesolithic clearances, a large-scale clearance took place in the period 2250 to 2000 $\mathrm{BC}$, which effectively rendered the area treeless, in which state it has apparently remained ever since.

Palynological work at the Beaker site of Rosinish, North Uist and Killin, on Grimsay (Whittington \& Ritchie 1988) and on peat deposits from Sheshader in the Eye Peninsula, Lewis (Newell 1989), also suggest that the arboreal component of the local vegetation was slight and variable. Newell's work further reveals the importance of 'muirburn' for tillage after peat formation. The deposits from Killin indicate phases of landuse in the area during the Neolithic Period (5340 BP), the earlier Bronze Age (3900 BP), and the Iron Age, together with Medieval and later settlement (Whittington \& Ritchie 1988, 8-11).

The emphasis on the presence or absence of woodland, or even of trees, in the palynological literature, takes no cognisance of the other evidence for the existence of trees in the Western Isles in prehistory. Wood, tree-stumps and roots have been noted in peat at Garry Tigharry and Loch Eport (Beveridge 1911, 5), at the head of Loch Erisort (Martin 1703, 10) and at Vigdale, Loch Seaforth and other sites (Wilkins 1984). Intertidal peats with similar deposits have been noted at Sithean, Benbecula, Dik Mor and Hornish Point, South Uist and Vallay, North Uist and Ritchie (1966, 79-86) has radiocarbon-dated wood from submarine peats from Borve, Benbecula to $3750 \pm 170 \mathrm{cal} \mathrm{BC}$ (I-1543).

Trees are still to be found in the Isles, albeit in small groups and isolated stands where local topography gives shelter from the wind and protection from overgrazing by sheep. The occurrence of bluebells and wood sorrel in the birch wood on the slopes of Allt Volagir, South Uist (Darling \& Boyd 1964, 50) suggests that, in at least a few areas trees may never have been truly absent from the Isles, regardless of the contra indications from palynology! Both macroplant remains from excavated sites and the remains of woodland denizens like wildcat and blackbird from Galston, South Lewis (Baden-Powell \& Elton 1936) support this view.

\subsubsection{Fauna}

In common with many islands, the fauna of the Uists and Benbecula is a sub-set of that of the adjacent mainland, at least, at the specific level. In comparison with the thirty-eight species of land vertebrates and 152 species of breeding birds of the Central Highlands, North Uist has only fifteen and 114 such species, respectively, Benbecula seven and sixty-three and South Uist nine and eighty-one. Amongst the vertebrates, only the seal and, on North Uist, the red deer, would have provided a useful protein resource for man. However, other species, such as the otter, may have been exploited for their fur.

It has been argued that the fauna of the islands necessarily arrived via a land bridge, which survived into the early part of the Post-glacial Period. However, Berry $(1979,34)$, has argued that only the pygmy shrew and the red deer can be said to have arrived in the Isles without the intervention of man. Even this estimate may be optimistic, since he includes red deer on the basis of the occurrence of their bones and antlers on prehistoric sites or in peat deposits. However, the finds of complete deer skeletons in midden deposits at Links of
Noltland raises the possibility that they may have been, in effect, domesticated during the Neolithic period (Clarke \& Sharples 1985,77$)$.

Berry (1979) suggests that all the other non-domesticated vertebrates must have arrived along with man and he suggests that their genetic similarities with Scandinavian vertebrates make a strong case for their introduction by Viking or Norse settlers. However, it is clear from excavated assemblages that most, perhaps all, were present in the Hebrides in prehistory. Perhaps those genetic traits examined in this study were, in the islands, swamped by the genetic contributions of the animals re-introduced by and with the Vikings. However, the possibility that links with Scandinavia also existed during earlier periods should not be forgotten.

The many lakes of the Western Isles, especially the Uists, contain salmon, trout of the migratory (sea) and non-migratory (brown) type and eel. Charr have a more restricted distribution but are presently found in several lakes in north Uist (Campbell \& Williamson 1979, 389). There is no evidence to suggest that any of these fish were deliberately introduced.

The Western Isles is now rich in birdlife and it seems reasonable to assume that this was also the case in the past. Islands can contain a wider range of birds, per unit area, than mainland sites of the same area because they, the islands, contain a greater variety of ecological habitats. At present some 286 species are recorded in the Outer Hebrides, just over 150 of which are known to breed in the area (Cunningham 1979, 207). These consist of terrestrial birds, birds of prey (raptors), waders, seabirds and waterfowl. Birds can be found in all habitats but the coast and inland lakes are the richest in those birds which may be most readily considered as a food resource. The machair lands, which are the main concern of this report, also contain many breeding types. The machair wetlands presently contain many waterfowl including Mute Swan, Little Grebe, Shelduck, Gadwell, Shoveller, Tufted Duck, Wigeon, Pintail, Pochard, Scaup, Water Rail, Spotted Crake and Moorhen (Hopkins \& Coxon 1979, 346-7) most of which are known to have been exploited as food. Waders commonly found nesting in the machair drylands include Oystercatchers, Ringed Plovers and Lapwings (Fuller et al 1979, 425).

\subsection{THE ARCHAEOLOGY OF THE WESTERN ISLES}

\subsection{The Mesolithic period}

Mesolithic sites are apparently absent from the Uists and Benbecula. In contrast, there is an abundance of Mesolithic sites in the Inner Hebrides (Mellars 1987; Mercer 1979; 1980; Wickham-Jones 1991; Mithen 1989), on the adjacent mainland Scottish coast to the East (Lacaille 1954, 109; Bonsall 1989, 134) and on the Northern Irish coast (Movius 1942; Woodman 1978) to the south. The drowning of the coastline of the Outer Hebrides (Chapter 1) has removed the evidence for coastal sites of the period, while sand inundation and peat formation have covered inland sites. Given the abundance of Mesolithic remains in the region it must be concluded that the Outer Hebrides were also settled during the period and that Mesolithic sites will emerge in due course. In this context, the early, possibly Mesolithic episodes of deforestation noted by Bohncke (1988) in the pollen anal- 
ysis of peat from Tob nan Leobag, and by Brayshay \& Edwards (1996) at Loch an-t'Sil should be noted.

\subsubsection{The Neolithic period}

\section{Funerary monuments}

Henshall (1972) has identified thirty-four megaliths on the Western Isles most of which are located on North Uist. The majority are passage graves; round cairns which, where the internal features are visible, cover a short passage leading to a round chamber. The passage often opens out into small funnel-shaped forecourt. Three tombs of the Clyde type, with segmented rectangular chambers and cairns defined by peristyliths, also occur. Nine possible long cairns have been noted.

Inter-visibility between cairns characterises this group of sites, most of which are set in conspicuous locations. In North Uist cairns are frequently located on hill slopes and occur in juxtaposition with other monuments such as standing stones (eg Craonaval, Maari, South Clettraval and Marrogh). Nine possible stone circles are listed for the islands

(RCAHMS 1928). The largest circles (Pobull Fhin; $27.5 \times$ $28.0 \mathrm{~m}$ : Loch an Phobaill; $42.5 \times 35.1 \mathrm{~m}$ : Carinish $41.5 \times$ $39.0 \mathrm{~m}$ ) are all located near large chambered cairns and Burl $(1976,147)$ suggests that these are, possibly, Neolithic.

There has been only one recent excavation of a Hebridean cairn, at Geirisclett, North Uist (Dunwell et al forthcoming). Little is known of the mode of burial in the tombs. Beveridge (1911) notes the presence of burnt bone in all the tombs he investigated and cremated human bone was also noted at Clettraval, North Uist (Scott 1935, 499). Acidification of the soils, widespread in the non-machair areas of the Hebrides after the Neolithic period, would have removed evidence for the deposition of unburnt bone. At Unival, North Uist, Scott $(1948,14)$ describes a badly preserved inhumation displaying evidence of partial burning.

\section{Occupation sites}

Seven Neolithic settlement sites are known in the Outer Hebrides. Two of these, Udal, North Uist (Crawford 1981; 1996) and Northton, Harris, (Simpson 1976, 221) are coastal sites now covered by shell-sand deposits. At Udal two rather insubstantial, circular stone settings with diameters of $4 \mathrm{~m}$ and 5 $\mathrm{m}$, have been interpreted as buildings. They have been radiocarbon dated to $3650 \pm 40$ uncal BP $(\mathrm{Q}-3054)$ and $3710 \pm 50$ uncal BP (Q-3055) (Crawford 1980; 1981) and these dates seem rather late to be Neolithic but, until these excavations are published we cannot know their true significance. At Northton, the earliest of the two Neolithic phases is represented by a scatter of settlement debris on boulder clay. The second Neolithic phase did not have structures either. Shell-sand material from this phase has been dated to $4411 \pm 70$ uncal BP (BM-705; Simpson 1976, 222) so that the attribution of these deposits to the Neolithic period seems reliable.

Eilean an Tighe, an island site in Loch nan Geireann, North Uist, consisted of a series of much disturbed structures associated with a rich assemblage of Neolithic pottery. The site was originally interpreted as a kiln site (Scott 1951) but Simpson (1976) suggests that the site is domestic rather than industrial, because no wasters were found amongst the 4,000 sherds of pottery retrieved. The site produced a wide range of decorated styles including Unstan ware. A limited exami- nation of the gritting in the pottery indicated that it was of local origin (ibid, 34). Neolithic settlement on lake islands was revealed again, recently, in the excavation of what had been thought to be an Iron Age dun on a small island in Loch Olabhat. This site produced a mixture of Hebridean and Unstan wares and plain bowls (Armit pers comm).

Excavations to examine pre-peat walls exposed in peat-cuttings just north-east of Caravat Barp, revealed a series of hearths in the mineral soil. These have been radiocarbon dated to the Neolithic period (Crone 1993). It is not improbable that much more of the islands' Neolithic settlement is similarly concealed beneath deep peat, or, perhaps, beneath Iron Age duns on islands within the freshwater lakes. As noted in Chapter 1, Neolithic sites have not been found lying on machair sands and it is improbable that the machair existed at this time, at least in the area it now covers.

A group of sites have been investigated at Allt Christal, Barra (Branigan \& Foster 1995, 49) that have been radiocarbon dated to the Neolithic period. The group comprises areas of domestic activity, small shelters or storehouses, flint working areas and a large ring cairn. The excavators argue that these are probably all components of a single farmstead housing probably no more than a single extended family group (ibid, 51). Many of the structures are extremely small and it is unlikely that they could have offered anything more than temporary, or short-term shelter (Barber \& Crone forthcoming). Given Crone's observations (1993) perhaps we should envisage these as the surviving stone-built elements of structures largely built of turves. While it is not impossible that some of the Neolithic associations at Allt Christal are based on little more than the presence of residual material they nonetheless attest to an area in which there was extensive Neolithic activity.

Other traces of Neolithic occupation were found on North Uist during excavations in advance of the causeway linking Berneray to North Uist (Downes \& Badcock 1998).

\subsubsection{The Bronze Age}

The evidence for Early Bronze Age settlement on the Long Isle is rather limited. Beaker period material has been retrieved from excavations at Udal, North Uist (Crawford \& Switsur 1977, 128; 1996), and Rosinish, Benbecula (Shepherd 1976, 209-16). Beaker pottery has been retrieved from a number of middens, notably from a deposit at Paible, radiocarbon dated to $4060 \pm 135$ uncal BP (GU-1088), and in smaller amounts from beneath later settlement deposits at Newtonferry, North Uist, and South Glendale, South Uist.

Excavations at Rosinish (Shepherd 1976) also revealed an area of ard marks cutting through the primary midden layer. The area was bisected by a ditch which was interpreted as a boundary separating two fields. Shell from midden material overlying the ard marks produced a date of $3850 \pm 75$ uncal BP (GU-1064) and a date of $3920 \pm 60$ uncal BP (GU-1065) was returned for the old ground surface. Carbonised remains of six-row barley with smaller quantities of emmer were also retrieved (ibid, 112-113).

Food vessel pottery was retrieved from deposits at the Udal which were overlain by a machair and shingle level, over which, in turn, was a triple kerb-cairn complex. A crouched inhumation from one of these provided a radiocar- 
bon date of $3430 \pm 85$ uncal BP (Q-1458) (Crawford \& Switsur 1977).

Little is known of Later Bronze Age settlement in the Long Isle except on South Uist where fourteen settlement mounds of the Late Bronze Age/Early Iron Age period are known. Field walls under or in peat, dating to the late second or early first millennium BC have been noted above. Palynological studies suggest that these were associated with arable and/or pastoral cultivation (see Mills et al 1994 for discussion). It seems reasonable to assume that these enclosures are associated with settlement sites but we have yet to locate the settlements. Excavations at Carinish have revealed field walls dating to $3180 \pm 50$ uncal BP (GU-2454) and $2750 \pm 50$ uncal BP (GU-2457), beneath $1 \mathrm{~m}$ to $1.5 \mathrm{~m}$ of peat (Crone 1993). Crone (ibid, 380) and Newell $(1988,81)$ have traced parts of wall systems in peat but neither survey was sufficiently extensive to locate the putative settlements.

Armit identifies the period following the Beaker settlement period at Udal and Northton as a 'settlement break' for the Hebrides as a whole or at least as a break in the evidence currently available. He has also suggested $(1996,108)$ that the settlers of the Beaker Early Bronze Age showed affinities with their predecessors of Late Neolithic date while those of the Later Bronze Age had more in common with their Iron Age successors. This view has much to commend it and implies that some substantial cultural change evolved or was imposed in the intervening period. Armit's identification of a settlement break may simply reflect this more significant change.

\subsubsection{The Iron Age}

\section{Terminology}

The concepts of 'the Mesolithic of Scotland' or indeed of 'the Neolithic of Scotland' are still tenable, albeit that even in these remote periods some elements of regionalism can be distinguished. In this context, regionalism is defined as the emergence of significant differentiation between the relevant material cultures in separate regions throughout Britain and Ireland. Sampling theory predicts that some regionally distinctive elements will necessarily appear in regionally collected data sets. Such regional variations do not constitute regionalism, in the sense meant here. As a working hypothesis the writer suggests that significant regionalism begins to be detectable in the archaeological record during the Bronze Age. By the Iron Age, clear regional differences are in evidence even within Scotland. While it remained unrecognised regionalism encumbered archaeological debate with a fruitless pursuit of continental prototypes and sources. However, over-emphasised, regionalism has introduced a probably unhelpful degree of parochialism to Scottish archaeology. Carter et al (1995) considered only the Iron Age in Shetland in their concluding discussion on broch sites. Armit, in his publications on the Atlantic Iron Age makes only passing reference to their larger national and international context (albeit that his more recent work is beginning to address this deficit). The inclusion of papers on Scottish Iron Age sites in corpora of British Iron Age studies (see for example, Gwilt $\&$ Haselgrove 1997; Bevan 1999) is encouraging but in the absence of synthesis, does little to redress the situation.

Limiting the study area contributes to more highly targeted research and perhaps to better and faster reporting but it is beginning to facilitate a fragmented view of the Iron Age in Scotland that lacks coherence. This is not the place to attempt to redress this balance. This monograph deals with some Iron Age sites in the southern part of the Outer Hebrides but their interpretation will be incomplete without some reference to the larger social and geographical landscapes in which they functioned (below).

The term 'Highland Iron Age' describes Iron Age remains in the, now defunct, administrative areas of Highland Region, the Western Isles Island Area, the Orkney and Shetland Islands Areas, and the western part of Strathclyde Region. This division roughly parallels the upland part of Fox's upland/lowland division, but also takes cognisance of latitude and oceanicity which may modify local conditions to make altitudinal highlands ecological lowlands, and vice versa.

Much discussion of the Highland Iron Age has centred on the origins of Childe's 'castle complex' (1935), the group of monuments which includes brochs, duns and wheelhouses and their several variants (see, for examples, Mackie 1965a; 1965b; Caulfield 1978). The relationships between these sites and sites of the Iron Age in lowland Scotland, has been but little debated (Mackie 1972) while the relationships of both with sites and cultures of the English, Irish and continental European Iron Age remain largely unexplored. The differences in regional archaeologies are exacerbated by the differences in significant cultural stimuli operating in each area during the later prehistoric and early historic periods. The highlands, for example, seems to have been largely unaffected by the arrival of the Romans, while the lowlands did not experience the Dalriadic migration.

The term 'Atlantic Iron Age' has been popularised by Armit and others (see Armit 1996 for bibliography) and means the subset of the Highland Iron Age concentrated in the Western and Northern Isles and on the adjacent mainland. It is a useful term because it highlights the role and significance of the sea and seafaring along the Atlantic sea coast throughout this period and part of that role must, necessarily have been to facilitate some expression of cultural contiguity throughout the Atlantic province. In rehearsing above the opposition of regional to extra-regional interpretational frameworks for the Iron Age this writer is merely revisiting a major theme of the 1969 CBA Conference on The Iron Age in the Irish Sea Province. Alcock's summary paper therein remains as readable and relevant now as when he published it $(1972,106-8)$.

\section{The sites}

The many recent publications on the Iron Age structures of the Hebrides and of the Atlantic Iron Age in general, obviate the need for much by way of descriptive text here and the reader will find in Armit 1996, a bibliography that provides access to the relevant literature. The following is a brief review of the relevant trends in discussion of the nature and interrelationships of the various forms identified.

Armit decried the 'typological morass' that included broch towers, galleried duns, semi-brochs, island duns and an assortment of other variants, into which the sites of Childe's castle complex had been classified. He proposes instead a broad class of Atlantic Roundhouses which subsumes the whole panoply of variations $(1996,114-5)$. That said, the terms broch, dun, wheelhouse, etc continue in use as descriptors; perhaps their general usefulness has not been altogether lost. In his BAR report (1992), based on the work 
undertaken for his PhD thesis, this re- or possibly, de-classification, is allied to an analysis of the landscape, using Thiessen polygons (ibid, Chapter 12) and their functional interpretation based on some elements of geographical locational analysis. The terminology of his description of the chronologies of these sites is Darwinian: '...recent work is beginning to point to a gradual development of complexity from early simple versions to the elaborate broch towers... ' albeit that he acknowledges that simple forms can also occur in the later period. In general, and despite many closely argued criticisms of the 'established view' Armit has not moved very far from an essentially typological and distributional paradigm for his interpretation of these sites; Plus ca change plus c'est le meme chose.

Harding (1997) also uses the older class definitions adding, after Mann, the class of dun-house or roofed dun. Unlike Armit, however, he considers the interaction of these sites in their social landscapes (ibid, 139-40) and explores the possibility that some form of social ranking may explain part of the bewildering diversity of Hebridean and west coast Iron Age sites. Only wheelhouses were discovered in the excavations reported upon here and, on the basis of the evidence from excavations and from surveys, the latter undertaken before and after these excavations, the wheelhouse is virtually the type-site of the machair plains.

\section{Wheelhouses}

Wheelhouses are circular, drystone-walled structures characterised by the radial subdivision of their interiors into a number of bays by means of short piers, leaving a clear central area. The bays are occasionally divided from the central area with small upright stones, as at A Cheardach Mhor, (Young \& Richardson 1960, Figure 2). The bays were converted to cells by the addition of corbelled domes whose upper surfaces were probably built up into a single, annular roof, leaving a relatively small central area to be roofed by other means. At floor level, the clear central space usually contained a hearth and postholes found in that area are interpreted as supporting the inner roof structure whose outer rim rests on the annular stone roof.

Wheelhouses have been subdivided into several groups on structural and morphological grounds. The term 'earth-house' was formerly used to describe wheelhouse-type structures dug into the soil, the walls of which are often non-load bearing, lining walls, one stone thick, eg Foshigarry, North Uist. Entrance is sometimes effected through a passageway as at Bac Mhic Connain, or directly through the outer wall.

Aisled roundhouses are a sub-group of the wheelhouses, characterised by a gap, between 0.20 to $0.80 \mathrm{~m}$ wide, which lies between the inner edge of the piers and the inner face of the outer wall. Examples of this type were found at Allasdale and A Cheradach Bheag. At Jarlshof, Shetland, however, this space was in some cases filled by rough stonework. In other cases the piers were tied to the outer walls by means of pairs of lintels; at Machair Lathan, for example, the lintels were set some $1.2 \mathrm{~m}$ above floor level.

The Hebridean wheelhouses are found as isolated monuments or in small groups of two or three, usually of varying dimensions as at A Cheardach Bheag, and in complexes of wheelhouse structures as at Foshigarry. At Allasdale and Clettraval, the wheelhouses were set in 'yards' and are said to be accompanied by subsidiary structures, interpreted as barns or byres.

The distribution of the different wheelhouse types reflects the adaptation of the basic architectural concept to local conditions. They are 'dug-in', ie of wheelhouse type, wherever they occur on, or in, machair sand, eg A Cheardach Mhor, A Cheardach Bheag, and Kilpheder. On the east, where the landscape is more hilly and the soils shallower, the wheelhouses are free-standing and commonly located on hillocks, as at Usinish. It is possible that the known distribution of such sites in the machair may not represent their 'original' distribution because virtually all of the known examples were sand-covered in the recent past and only revealed by the accidents of erosion.

Although they are generally built on a more modest scale, wheelhouses have very many features in common with brochs. Where the monuments are found together, excavators have argued for occupational continuity between the two. Thus, at Clickhimin and Jarlshof in Shetland, wheelhouse structures were interpreted as secondary components, inserted within and around the walls of the brochs in the second or early third century AD (Hamilton 1956; 1968). This seems to suggest that the origins of the wheelhouses must be sought in the brochs. The apparent replacement, on the same site, of the highly defensive broch by the wheelhouse, which is common on the Northern Isles, does not seem to have occurred in the Western Isles, where, in general the wheelhouses are located some distance from the brochs. Nonetheless, Hamilton's view has become, in default of other views, the 'established view' and suggests that wheelhouses are later from and in some way devolved from the brochs.

At the excavation of the broch site of East Shore, in Shetland, the writer's field observation could detect no physical evidence to suggest that the construction of the radial piers within the broch post-dated the construction of the broch wall by anything more than the necessary interval required in construction. Carter et al $(1995,462)$, in writing up the site have described the piers as 'Later Broch Features' but acknowledge that the interval between the construction of the broch wall and that of the piers is difficult to assess. Similarly, Hedges and Bell $(1980,88)$ have argued that radial segmentation is a primary feature of the brochs. Perhaps, therefore, we should consider radial segmentation another common architectural feature of all the sites of the 'Castle Complex', albeit that the case has yet to be fully made for the other site types.

At the Udal a radiocarbon date of $340 \pm 120$ ad (Q-1131) marks a terminus ante quem for the end of the wheelhouse occupation (Crawford \& Switsur 1977, 129). Armit's attribution of wheelhouses to a period earlier than the first century BC $(1992,68-9)$ is based largely on the results of the excavations reported on here. Previously wheelhouse sites have been dated, principally by the pottery which, in the Western Isles, must be regarded as a particularly unreliable method, or on Roman inclusions which seem to place them in the second century AD. However, Campbell (1991), on the basis of radiocarbon dates, Roman inclusions and comparanda, suggests that the sites at Sollas also probably date to the second century $\mathrm{AD}$. 


\subsubsection{Discussion}

The architecture of HIA structures is remarkably consistent along the Atlantic coast. The structure of entrances and the entrance 'furniture' of almost all the known structure types are virtually standard features. The hollow-wall construction of brochs, semi-brochs, duns, forts, promontory forts and blockhouses indicates a consistency of approach which, in prehistory, is only paralleled in the megaliths. As has been argued above, a shared emphasis on the radial segmentation of the outer annulus of the enclosed areas may be a another part of their common architectural inheritance.

\section{Material culture}

The greater part of the evidence for the material culture of the Iron Age inhabitants of the Western Isles is based on the large collections of uncontexted finds made during the last two centuries, mostly from eroding sand faces. A much smaller group of material has been retrieved from archaeological excavations. This consists mainly of pottery, of which thousands of sherds are recovered from the Hebridean sites, and bone and antler objects which are similarly numerous but less chronologically diagnostic, at this time.

\section{Pottery}

The wheelhouse sites of A Cheardach Mhor, A Cheardach Bheag, Kilphedir, Allasdale and Foshigarry, have all produced pottery, as have the nearest excavated brochs, Dun Mor Vaul (Tiree), Dun an Iardhard (Skye), Dun Carloway (Lewis) and Dun Vulan (South Uist), and the excavated dun site at Dun Cuier (Barra). The assemblages have generally been categorised on the basis of form and decoration.

Young $(1956,48)$ suggests that the sequence of Iron Age pottery begins with the incised- and pin-stamped decoration on S-shaped vessels with inverted rims (ibid, Fig 4, 2). Some also have raised bosses or an applied cordon under the rim. These are found on most wheelhouse sites. The shouldered pins, used for the decoration, have been dated at Dun Mor Vaul, to between 700 and 250 BC (Clarke 1971, 30) while Young (1966) places their dates earlier than 200 BC. Inverted-rim vessels continued in use throughout the period, even after the appearance of other forms.

The second type consists of globular vessels with everted rims, either undecorated or with an applied, fluted, zig-zag, decoration around the 'shoulder'. Some sherds have an arcaded finger channel decoration between the shoulder fillet and the rim. This type is referred to as 'Clettraval-ware' from the type site (Scott 1935). Young suggested a date of the 1st or 2 nd century AD for the everted rim ware, based on the dating of the annular yellow glass beads found in association with it. However, these are now dated to the period $300 \mathrm{BC}$ to AD 200 (Guido 1978). Guido's date range is based on her perception of the date range of the broch complex and so some element of circularity is involved here, but the existence of a number of supporting radiocarbon dates from sites in southern England suggest that the proposed range may not be entirely misleading (Ritchie \& Lane 1980, 219-20).

In a final Iron Age phase Young identified a coarse plain ware from the upper levels of wheelhouse and dun sites. This she saw as intrusive, possibly following the Dalriadic settlement of the Western Isles which she dates to about AD 500. However, Ritchie and Lane $(1980,220)$ suggest that the Udal provides a terminus ante quem date for undecorated bucket-shaped wares of circa 400 AD. Crawford and Switsur $(1977,129)$ suggest that the change occurs somewhere in the range $\mathrm{AD} 200$ to $\mathrm{AD} 400$.

At Dun Mor Vaul, Mackie found a ware with two form types - inverted and S-shaped (his 'Vaul ware') from the pre-broch levels (Mackie 1974a), radiocarbon dated about 500 uncal BC, and from all the subsequent phases. The everted rim ware of characteristic Hebridean type was found in all phases of the broch from its construction onwards. Campbell $(1991,168)$ suggested 'with some diffidence' that the introduction of the everted rim wares may be contemporaneous with the construction of the wheelhouses. Armit, while accepting this possibility $(1996,152)$ suggests that the absence of everted rim ware from the earlier features on this site may simply reflect functional differences between the earlier and later structures, eg the earlier could be byres and the later houses.

An additional type, termed 'Dunagoil ware' (Marshall 1964) was found in small quantities in the pre-broch levels at Dun Mor Vaul. Mackie describes this as thick, gravelly and plain, and possibly related to the wares of the vitrified forts of the Scottish mainland. The final phases at Vaul include a 'degenerate' Clettraval style which Mackie likened to that from Dun Cuier, and which, he suggests, was of Dark Age date.

A few Roman sherds have been found in the Western Isles. Samian sherds of the second century AD, have been found on Bac Mhic Connain (Beveridge 1931, 61), Berie (Lewis), Dun Ardtreck, and Dun Mor Vaul (Robertson 1970). Dun Mor Vaul also produced a spindle whorl made from a sherd of Roman coarse ware (Mackie 1974a, 155), also of second century date. Most recently, the excavations at Dun Vulan have produced a radiocarbon-dated sequence Iron Age ceramic styles between circa $400 \mathrm{BC}$ and circa AD 700 (Parker-Pearson \& Sharples 1999).

\section{Metalworking}

The date of the inception of the Iron Age in Scotland in general, and in the Highland Zone in particular, is simply not known. The sites of the 'Castle Complex' all contain some evidence of metalworking, in iron and bronze, and in some instances this is abundant. A furnace, constructed of stone slabs and associated with some $17 \mathrm{lb}$ (circa $8 \mathrm{~kg}$ ) of iron slag has been found in the cave site of Rudh 'an Dunain, Skye, dated to the 1st century BC (Scott 1934). On the wheelhouse site of Bac Mhic Connain, Vallay, North Uist, an almost square, stone built hearth was identified as a furnace because of its association with bronze slag and crucibles (Beveridge $\&$ Callander 1932). Iron slag, iron rivets and a fragment of haematite were also found on this site (ibid, 48). However, the metal-working debris was probably associated with a furnace which had been dug into the secondary deposits infilling the wheelhouse. The debris therefore post-dates the wheelhouse, the latter being dated to the Roman or post-Roman Iron Age on the evidence of the Samian sherd from the site.

At A Cheardach Mhor, South Uist, Hearth 3, in the Phase I wheelhouse, was encrusted with peat ash and contained two pieces of slag while other fragments of slag were found in the subsequent phases (Young \& Richardson 1960, 142 \& 172, Figure 2). Iron slag was found on other wheelhouse sites including Garry Iochdrach, Vallay Strand (Beveridge \& Callander 1932) and Foshigarry (Beveridge \& Callander 
1931), Allasdale (Young 1953), on the dun site of Dun Cuier, and the broch at Dun Mor Vaul, and on the midden at Galston (Baden-Powell \& Elton 1937). At Sollas, a mould for a projecting ring headed pin was found together with a triangular-cross-section crucible that had contained bronze and an iron ring. Apart from these '...there were a few iron fragments...' (Campbell 1991, 164). Of note also is Campbell's identification of crushed haematite ore used as a filler in pottery fabric, given that there are no sources of haematite in the Hebrides (ibid, 150).

Metalworking was carried out at wheelhouse sites, mostly evidenced by finds of slag, but the smallness of the individual pieces and the low total weight of slag from any one site, suggest that smithying rather than smelting was being practised. This is confirmed by the admittedly negative evidence of the absence of furnace parts, furnace bottoms (ie molten wasters), and the paucity of iron objects. The wheelhouse at Garry Iochdrach produced twenty-two fragments of much corroded ironwork, including rivets, pieces of knife blades, '... an instrument 5 " long with two prongs...', a pin and the slag noted above (Beveridge \& Callander 1932, 41). A plough share from A Cheardach Bheag has been identified as possibly of Romano-British date (Fenton 1963, Fig.4:8).

Tylecote $(1986,124)$ notes that no part of the British Isles is completely devoid of iron ore of some form. However, the Western Isles has no local source of the carbonate, limonite or haematite ores (see above). These may have been imported from mainland Scotland or the north-east coast of Ireland.

The evidence for bronze working comes from broch, wheelhouse and dun sites in the form of crucibles, clay moulds, tongs and bronze slag, and bronze objects found on excavated sites consist of small personal ornaments, rings and pins. A trumpet brooch of Roman origin was found on the wheelhouse site of Kilpheder (Robertson 1970, 207). Warner (1983, 165 et seq) has noted, from the Western Isles, cast-bronze, ring-headed pins and waisted, cast-bronze 'spear-butts', together with mould fragments for the latter, all of which have clear affinities with Irish material of the same period, which he terms 'Early Iron Age'. There are no known deposits of copper ore in the Western Isles and no known sources of tin in Scotland. The presence of bronze-working slags, suggests that ore, as well as finished products was traded and Warner (ibid) has argued quite convincingly that a large part of this trade was with Northern Ireland. The existence of inbound trade goods implies the existence of tradeable commodities, perhaps food surpluses and other organic materials, in the Hebrides. In turn this implies a level of social organisation consistent with the accumulation of those surpluses.

The metal objects from the Hebridean Iron Age sites are not, in general, indicative of a high level of acculturation. They compare very poorly with the quality of the Late Bronze Age assemblages like those of the Adabrock hoard, Lewis, circa seventh century BC; (Coles 1960, 48-50) or the seventh century BC leaf shaped swords of Minch type (ibid, 45), etc.

Trade played an important role in the economy of the island settlements. Long distance trade connections can be inferred from developments in the Dark Ages and later, but Mackie $(1971,50)$ postulates a link with the south of England, on the basis of the occurrence of spiral finger rings in both areas. He suggests that the influx of the Belgae into south-east England displaced the native populations, some of whom travelled thence, by sea, to the Western Isles (ibid, 25). Clarke (1971) has highlighted the dangers inherent in using exotic objects for the definition of chronological events or cultural connections. In particular he refutes Mackie's arguments mainly on the basis of the chronological insensitivity of spiral finger rings.

\subsubsection{Conclusion}

While in general, it may be fairly claimed that the physical structures of the Hebridean Iron Age are well documented and their architecture relatively well understood, our ignorance of their chronology and their social and economic organisation, both within and between sites, has been until very recently, almost complete. The domestic products of the period seem singularly undiagnostic and lacking in chronological significance while the exotic imports may have done more to mislead us than to clarify the situation (Clarke 1971). 


\section{CHAPTER 4: EXCAVATIONS AT BALELONE}

H F James \& P Strong

\section{I INTRODUCTION}

The site lies to the west of Balelone Farm on North Uist, at NF 719740 (Figure 9). It was revealed by coastal erosion, in a steep, cliff face cut into machair sand. To the landward side, the undulating machair consists of a series of gentle ridges and hollows. The sand cover is thick and has been deposited against, and partly over, the till covered rocky peninsula of Varlish. To the south, there is a stream in the bed of which, approximately $300-400 \mathrm{~m}$ east of the site, peat-like bands outcrop. These indicate shallow lacustrine or wet marsh environments in the area, before the deposition of the machair sands. Ritchie has suggested that these layers provide evidence for the existence of a loch in a large part of the inter-ridge basin of Balelone Varlish (Ritchie 1985). This loch was subsequently infilled with windblown sand. Inter-tidal organic layers with windblown sand were also found, 70-100 $\mathrm{m}$ south-west of the site, at approximately mid-tidal level.

Before excavation, the site was discernible as a $2 \mathrm{~m}$ high, elongated, grass-covered mound, the seaward side of which was cut by marine erosion. It was $35 \mathrm{~m}$ long. The lower face was obscured by a loose mass of tumbled material forming a slope of $45^{\circ}$, which extended onto the beach. The slope was colonised by clumps of marram grass. At the south end of the site the mound sloped down into the gully of the stream. To the north the site terminated in a steep grass slope. Large, round, waterworn beach boulders and course gritty sand from the upper beach lay against the base of the site.

\section{I.I Archaeological features}

A stone structure was noted near the centre of the exposed face. It consisted of four courses of rough, angular stones forming a corner or niche. Above this and slightly to one side, a number of flat rectangular stones formed an ashlar face parallel to the shore line. A tallard of midden layers, which had not collapsed, jutted out above the stone structure.

\subsubsection{Site history}

Beveridge states that the name Balelone means 'township of the marsh' but that this name does not appear in early documents, probably because it formed part of the township of Scolpaig. Balelone appears to have been mentioned in the Judicial Rental of 1718 and the Balranald Rental of 1764 (Crawford 1983). Reid's map (1799) showed planned improvements of the land then owned by Alexander, Lord Mac-
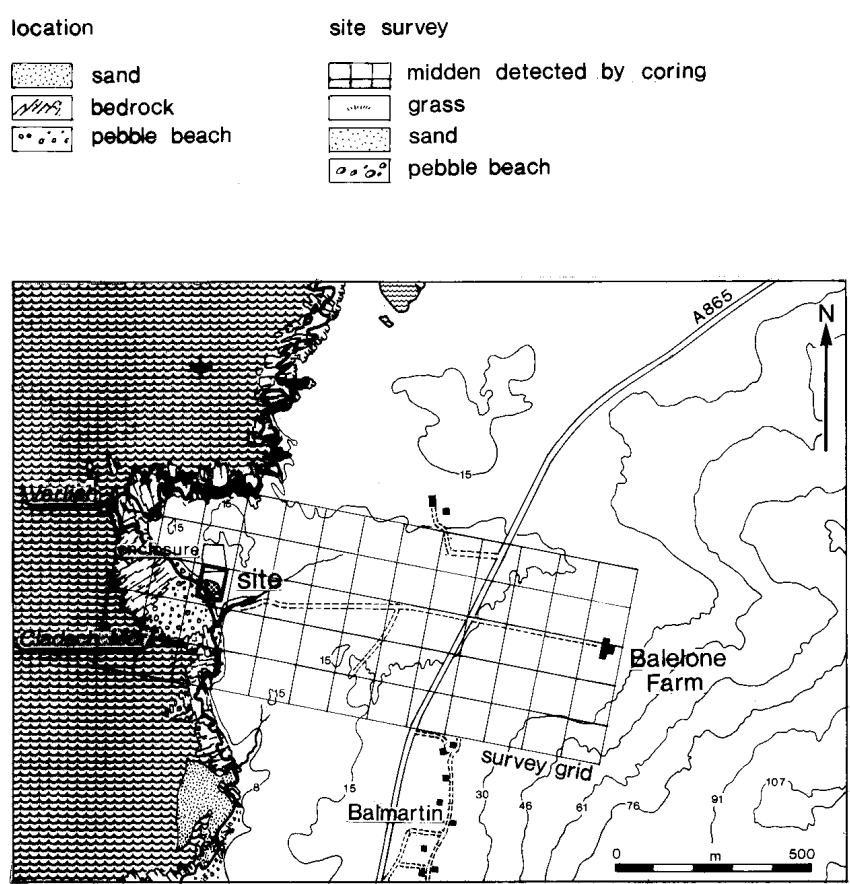

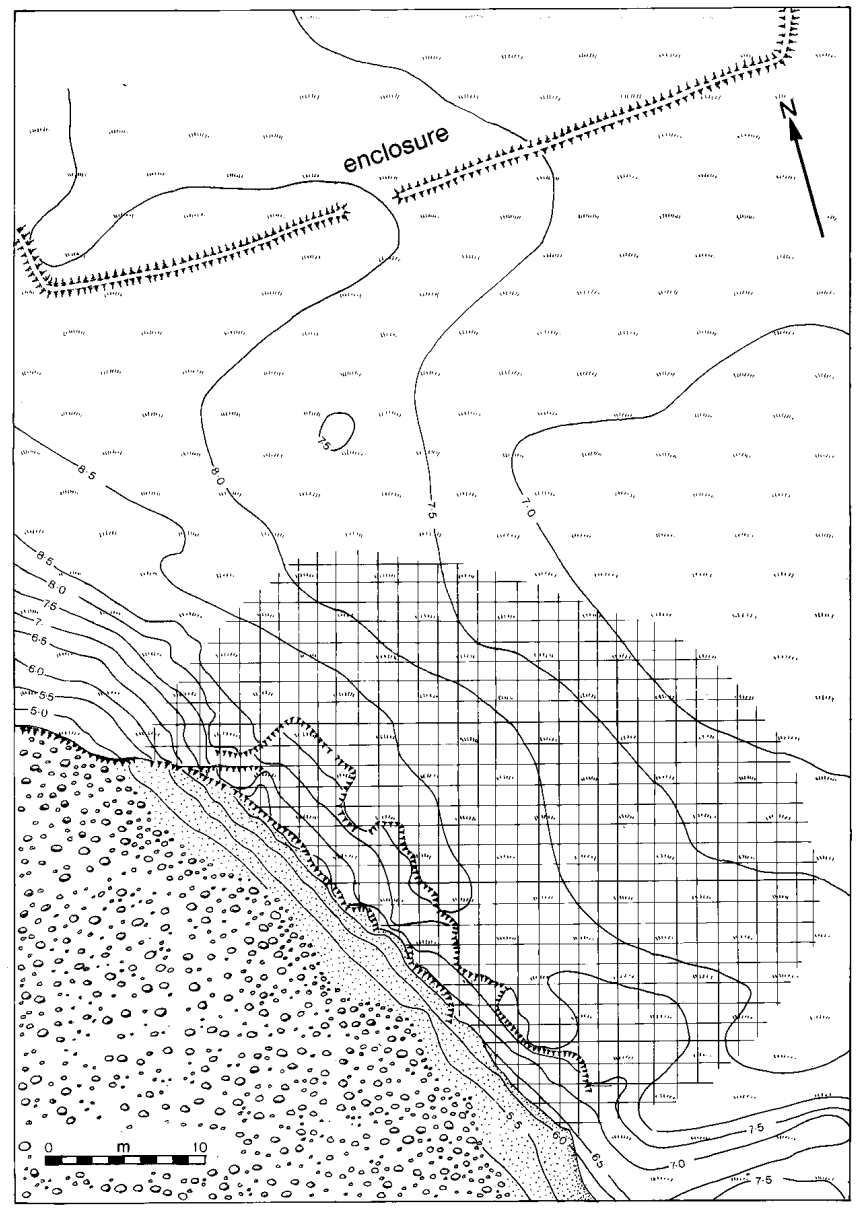

Figure 9. Balelone: site location and survey 


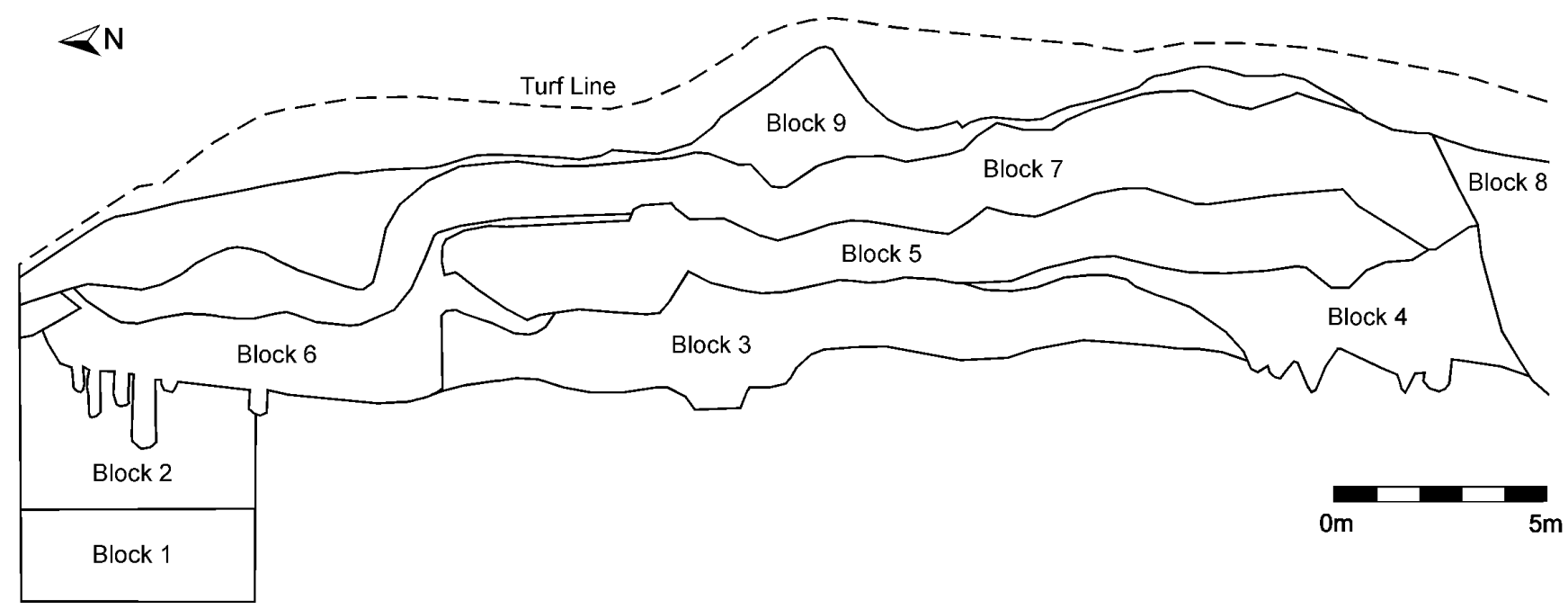

Figure 10. Balelone: main section showing Blocks

Donald. The plans for lotting of the land were superimposed over the medieval runrig system. Moisley (1961) noted that 'lots are shown on Balelone and Baleloch which were probably never lotted, being cleared for farms in $1815^{\prime}$.

The 6-inch OS map of 1904 marks the site of the excavation as the position of 'Erd Houses'. Beveridge records that here, thin layers of kitchen midden were exposed in the eroding face of the machair. In the upper portion of this sandy knoll there were traces of a 'slight' wall which curved in a northerly direction for several yards and seemed to represent part of the underground lining of one of the 'earth houses'. He also lists several finds from the site, including hammer-stones, pottery with both incised and applied decoration, iron slag, butchered bone, a re-used quern and a small hollowed oval stone. The Society of Antiquaries of Scotland received a 'fragment of a large hand-made Vessel with a notched fillet encircling it, and chevron ornament, from a kitchen midden at the seashore west of and opposite Balelone .... adjacent to a buried earth house', (PSAS 1916, 12). A fragment of an oval pebble with deep rounded indentation on both faces was also donated (PSAS 1922, 16). The Shepherds' report (1978) describes the site as a substantial midden deposit $35 \mathrm{~m}$ long and $2 \mathrm{~m}$ deep, enclosing the remains of a structure.

\section{I.3 Local sites}

Immediately behind the house at Kilphedir lay a broken monolith, one part standing to $1.5 \mathrm{~m}$ and the other part circa $1.5 \mathrm{~m}$ long lying close beside it (Beveridge 1911, 263). At Varlish Point, the name of which is probably of Norse derivation (ibid, 100) an earth house is said to have existed (ibid, 116). However this site was not located by the RCAHMS in 1965.

\section{I.4 Method of excavation}

Unlike Baleshare and Hornish Point, the site at Balelone was not conceived of as a tapestry excavation, and it was dug in separate sections. The seaward face of the site was divided into five equal areas separated by $1 \mathrm{~m}$ wide baulks and then cleaned of loose sand. In each area a trench was dug leaving a vertical section face at right angles to the slope to establish the limit of the undisturbed midden layers below the slip and the extent of damage by erosion. The baulk sections were drawn, to establish a relationship with the beach material. The section face was cut with a series of steps, to prevent its collapse. At the north end a small horizontal area was opened to examine the lower shell sand strata, down to the underlying bedrock (Figure 10). At the south end, a soil pit sondage was cut to ascertain the full depth of the midden deposit.

Towards the end of the excavation an attempt was made to join up the separate sections and reduce the repetition of context numbers. However, several stratigraphic problems remained unresolved. Samples were only collected systematically within the two test squares. Therefore, it is not possible to compare the material retrieved from the layers to the extent that was done on the later sites. In general the levels of interpretation and description attained at Balelone are not as detailed as those achieved at the other sites. Balelone was the first erosion face excavated in the current project and its main value to the project lies in the lesson it taught and the experience it provided. In consequence of the differences in approach to this site, the organisation of this report differs from the others. The Blocks described here are in fact groups of Blocks, as defined for the other sites. The Blocks are stratigraphically ordered from the lowest, Block 1 , to the topmost, Block 9 (Figure 10).

\section{Note on Sampling}

Every layer which was sieved produced some material. Therefore, when no material is listed for a given context, below, it means that this layer was not sampled and sieved. Bone and pot are recorded as numbers of pieces, while seashell, macroplant, stone, and slag are recorded by weight in 

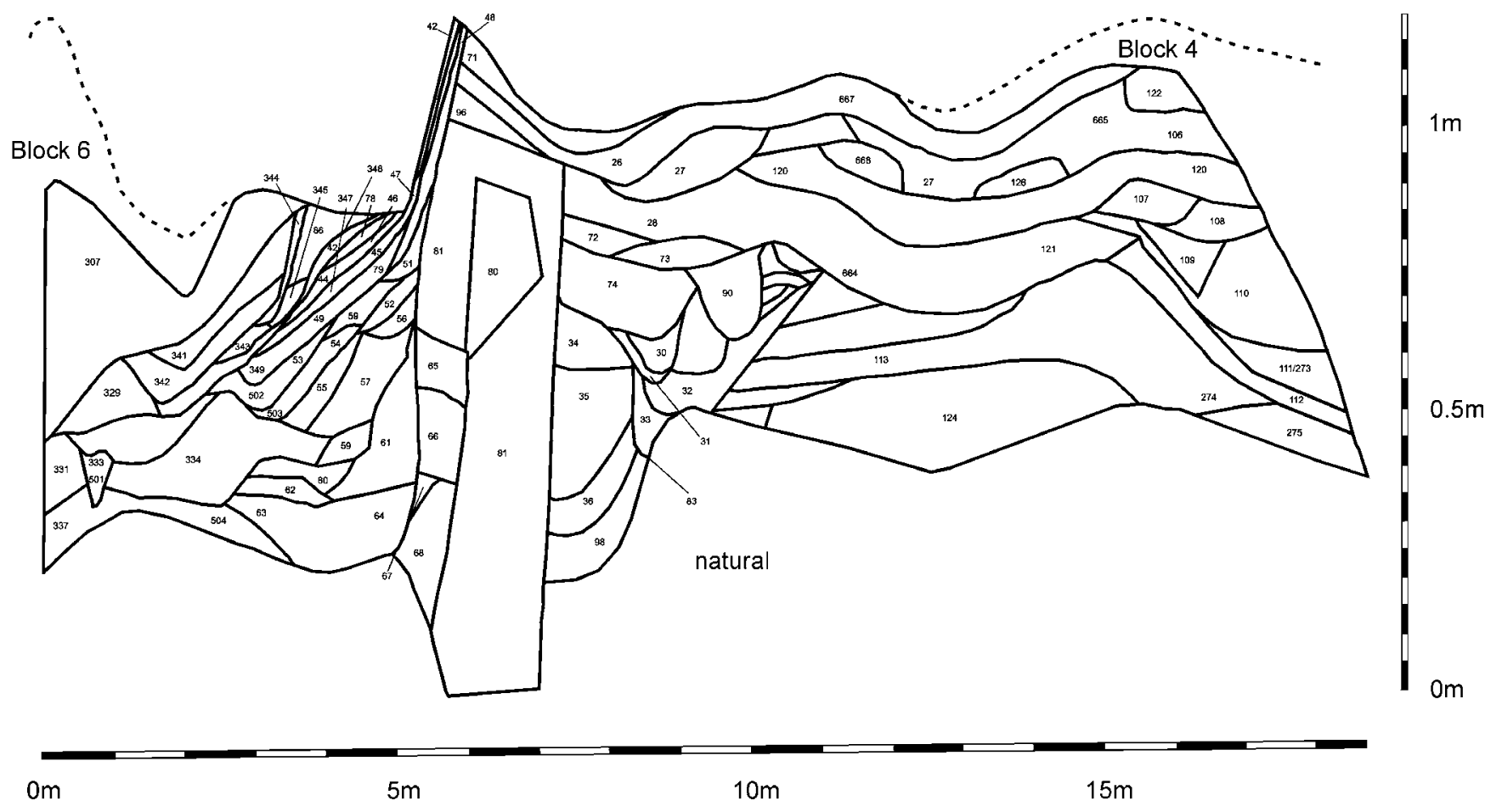

Figure 11. Block 3

grams. Due to the heavily truncated nature of site and the absence of structures to which they could be related, the animal bone and macroplant material were not studied further. Eoin Halpin identified the animal bone recovered by hand on site and his identifications are summarised at the end of each Block report. The much larger number of fragments recovered by wet-seiving and flotation are listed in the tables accompanying each Block report. None of this material was included in the faunal study undertaken by Halstead (Chapter 11.2).

\subsubsection{Summary of Blocks}

$\begin{array}{ll}\text { Block No. } & \text { Final interpretation } \\ 1 . & \text { Cultivated deposits } \\ 2 . & \text { Windblown sand and cultivated deposits } \\ 3 . & \begin{array}{l}\text { Midden-site deposits with windblown sand, } \\ \text { intermittently cultivated }\end{array} \\ 4 . & \text { Midden-site deposits } \\ 5 . & \text { Drystone structure and midden-site deposits } \\ 6 . & \text { Pits, post-holes and associated deposits } \\ 7 . & \text { Midden-site deposits, intermittently cultivated } \\ 8 . & \text { Windblown sand } \\ 9 . & \text { Windblown sand }\end{array}$

\subsection{BLOCK I - CULTIVATED DEPOSITS}

\section{See Table p. 273}

Block 1 lay at the north end of the site, at the base of the test trench (Figure 10). Its deposits were exposed over a distance of $6.5 \mathrm{~m}$ and were circa $1 \mathrm{~m}$ in depth, lying directly on bedrock. There were five layers within this Block which ranged from orange to dark grey black in colour and from humic sand to sand in texture. Cultivation marks were cut into the surface of layers [9] and [203]. These were filled with light coloured sand which in both cases differed from the overlying layers. The $\mathrm{pH}$ values recorded for [8] and [10] were 7.6 and 7.3 respectively.

\section{Archaeological interpretation}

The loamy texture of some of the layers in this Block and the presence of ard marks indicates that cultivation took place during the accumulation of its deposits. The scale of cultivation is unknown as the full horizontal extent of this Block was not revealed.

\section{Specialist contribution}

A total of fifteen unidentifiable bone fragments were recovered. Two teeth were present, one of pig (M3) and one of cow (M1/M2).

\subsection{BLOCK 2 - WINDBLOWN SAND AND CULTIVATED DEPOSITS}

\section{See table p. 273}

Block 2 was revealed to a depth of $1.1 \mathrm{~m}$ only at the north end of the site (Figure 10), but sufficient was exposed to show that it covered the whole site above Block 1 and beneath Block 3. It consisted of numerous interdigitated soil layers which could only be differentiated stratigraphically with enormous effort. They ranged from very pale brown to 

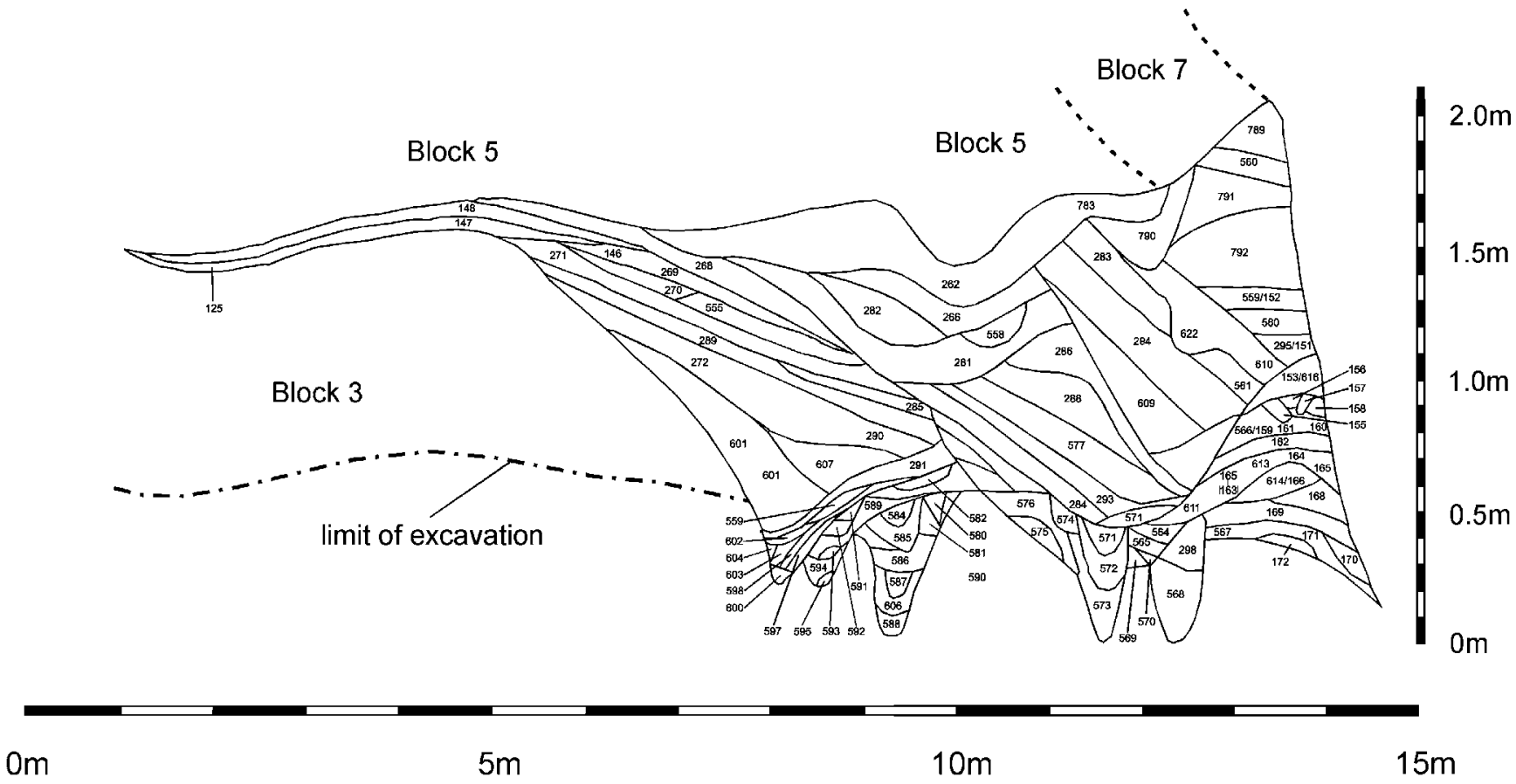

Figure 12. Block 4

brown in colour and all were sand. The boundaries were predominantly diffuse and irregular. One layer, [511], had ard marks cut into its surface, filled with a slightly greyer sand than that above and below.

\section{Archaeological interpretation}

The light colour of the sand within this Block indicates that its organic matter content was low. This implies that the bulk of the deposit is windblown sand. However, the presence of ard marks in the upper layers indicated that these layers, at least, were cultivated.

\subsection{BLOCK 3 - MIDDEN-SITE DEPOSITS WITH WINDBLOWN SAND, INTERMITTENTLY CULTIVATED}

See table p. 274

$*{ }^{14} \mathrm{C}$ date $2330 \pm 70 \mathrm{bp}$ (GU-1801) from layer [113] (Seashell)

Block 3 lay in the middle of the site beneath Blocks 4 and 5 (Figure 10). At its north end it abutted the masonry of Block 6 and in the south it was cut by Block 4. It extended for $18.5 \mathrm{~m}$ along the section and its maximum depth was 1.2 $\mathrm{m}$. It consisted of seventy-two soil layers and a single masonry context (Figure 11). The masonry, [81], was constructed of large stone blocks which in plan formed two arms. In the section the masonry measured $1.3 \mathrm{~m}$ wide and 1 $\mathrm{m}$ high. It had been cut into the layer beneath Block 3 and the deposits of Block 3 either abutted or overlay it. South of the masonry, the layers were generally extensive. To the north the lower layers were extensive while the upper ones consisted of thin layers and lenses that rose up over the masonry. The soil colours throughout the Block varied from very pale brown to dark grey-brown. However, the sloping layers were more consistently dark in colour than the rest of the Block. The soil boundaries were predominantly wavy. Cultivation marks were noted at the boundary of the basal layer, [124], and the Block beneath (Plate 11). The $\mathrm{pH}$ values recorded for this Block ranged between 7.1-7.6.

\section{Archaeological interpretation}

The Block contained the remains of a drystone structure set into the deposits of Block 2. Against this to the north and south, deposits of windblown sand and midden-site deposits had built up. These latter deposits were identified as such because of their dark colour and loamy texture. The presence of ard marks in the base of this Block indicated that the basal deposit to the south of the masonry had been cultivated and the wavy soil boundaries further up the section in this area suggest that further, intermittent, cultivation may have taken place. To the north of the walling deposits rich in soil organic matter appeared to have accumulated.

\section{Specialist contribution}

A total of 211 bone fragments were recovered. Identifiable fragments comprised a possible sheep horncore and dog mandible fragments from [331] \& [28]. Unidentified bird bones were retrieved from [331]. Sheep bones and a cattle tooth (P4) were recovered from [667] and sheep teeth (M1 and M2) from [113]). Fish bone fragments were also recovered from the latter. Sheep and cattle fragments were recovered from [106], including unidentified fragments with cut marks from [665]. A deer phalanx was found in [120]. 


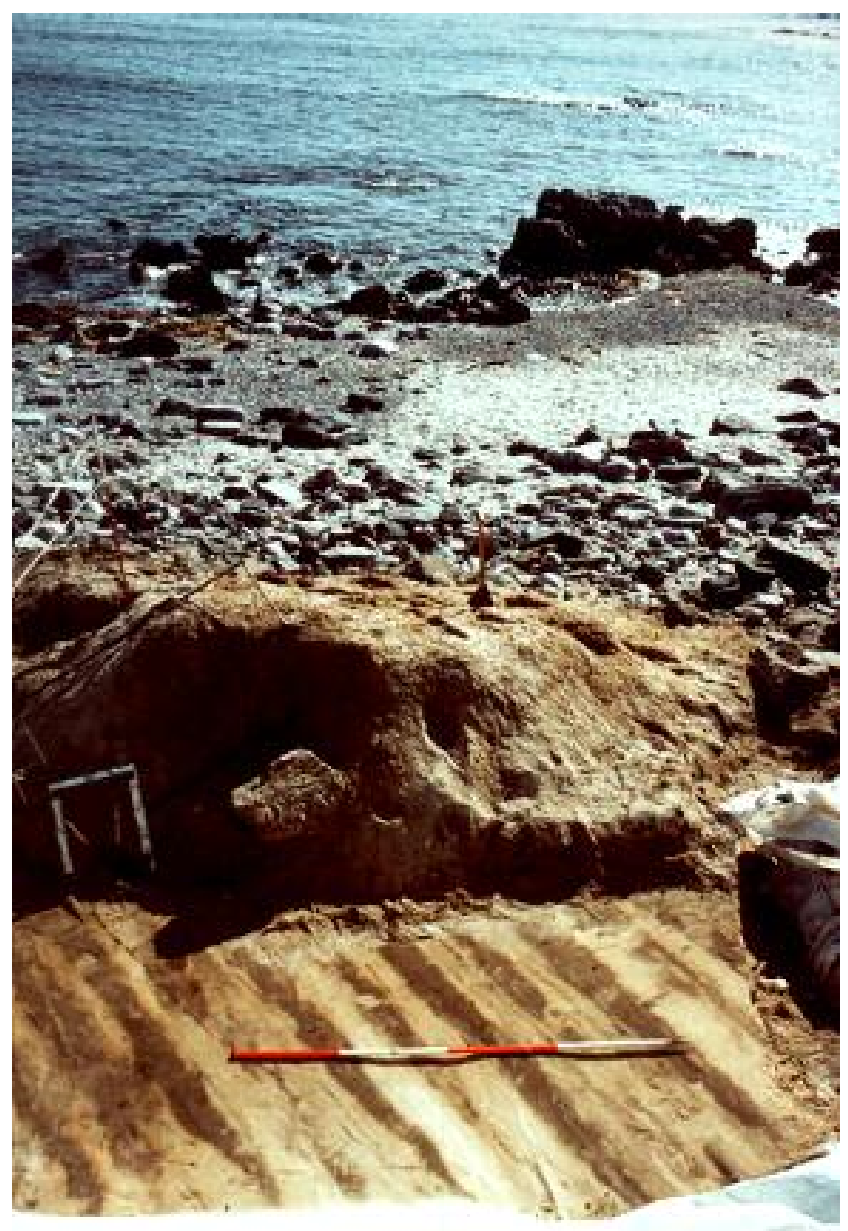

Plate 11. Cultivation marks at the base of the Balelone midden

\subsection{BLOCK 4 - MIDDEN-SITE DEPOSITS}

See table p. 275

$*{ }^{14} \mathrm{C}$ date $2440 \pm 80 \mathrm{bp}$ (GU-1803) from [166] (Seashell). Block 4 lay at the south end of the site (Figure 10). It overlay Block 3 and its southern margin had been cut by Block 8. It extended for $11.6 \mathrm{~m}$ in the section with a maximum depth of $1.3 \mathrm{~m}$. There were ninety-six contexts within this Block, including eight pits. The complex stratigraphy within the Block (Figure 12) is the result of the repeated cutting and refilling of these sediments. Generally, the sand layers sloped down from the north. They consisted of layers which range in depth from less than $0.01 \mathrm{~m}-0.2 \mathrm{~m}$ and in extent from $6 \mathrm{~m}$ down to small lenses. These layers range in colour from very pale brown to dark grey-brown and in texture from sand to sandy loam. A pocket of winkle shells was noted in the section, [266], and many other layers contained large numbers of seashells. The soil boundaries were generally wavy and abrupt. Eight round bottomed pits which ranged in depth from $0.2 \mathrm{~m}-0.4 \mathrm{~m}$ were seen at the base of the Block. The fills of the pits, where recorded, were described as brown sands. The $\mathrm{pH}$ values for this Block ranged from 7.2-7.6.

\section{Archaeological interpretation}

The layers were interpreted as midden site deposits because of the variability of soil colour and texture. These deposits have been periodically dug away, probably for use as manure. The pits could not be interpreted from the information available.

\section{Specialist contribution}

A total of 157 bone fragments were recoverd from this Block. Identified bones include a left sheep mandible [780] and various sheep and cattle fragments from [288] and [284]. A sheep illium from [289] had cut marks.

\subsection{BLOCK 5 - DRYSTONE STRUCTURE AND MIDDEN-SITE DEPOSITS}

See table p. 276

Block 5 lay near the centre of the site, above Blocks 3 and 4 (Figure 10). It extended for $22.8 \mathrm{~m}$ and its maximum depth was $0.7 \mathrm{~m}$. It consisted of three segments of masonry, three post-holes and twenty-six layers and lenses (Figure 13). Masonry [37] measured $1.5 \mathrm{~m}$ long and $0.6 \mathrm{~m}$ high, and was seen towards the north end of the section (Plate 12). It was built of large rectangular boulders, roughly faced to the south and it was up to three courses high. This masonry had been constructed directly on top of a layer of dark reddish brown sand, [21], and was abutted by the layers above. Towards the south end of the Block, some walling, [654], curved out from section face for a distance of $4 \mathrm{~m}$ (Plate 13). It consisted of two faces; the north face was constructed of a single course of large rectangular stones while the south face was formed of more than one course of smaller rounded boulders. Smaller stones and flat slabs were set into the space between the faces. Further masonry, [779], was seen in the section consisting of four stones extending for $0.6 \mathrm{~m}$ along the section. The layers within this Block were generally extensive and gently undulating. They were up to $0.3 \mathrm{~m}$ in depth and were described as ranging in colour from very pale brown to black and in texture from peat through sandy loam to sand. The lowest layers in this Block were the most extensive, stretching from the stones [779] for a distance of circa $20 \mathrm{~m}$ to the north. Their depths ranged between a few centimetres to $0.3 \mathrm{~m}$ and they were well compacted layers of red-brown clay sands or sandy clays (fig 00, Block 10). The three post-holes, [803], [804] and [805], had been dug from the top of layer [340], to the north of the masonry, [37]. They were all circular and measured $0.23 \mathrm{~m}-0.30 \mathrm{~m}$ in diameter and between $0.12 \mathrm{~m}$ and $0.21 \mathrm{~m}$ in depth. They were sealed by a layer of black sandy peat, [39]. The $\mathrm{pH}$ values recorded from this Block ranged from 7.2-7.5. 


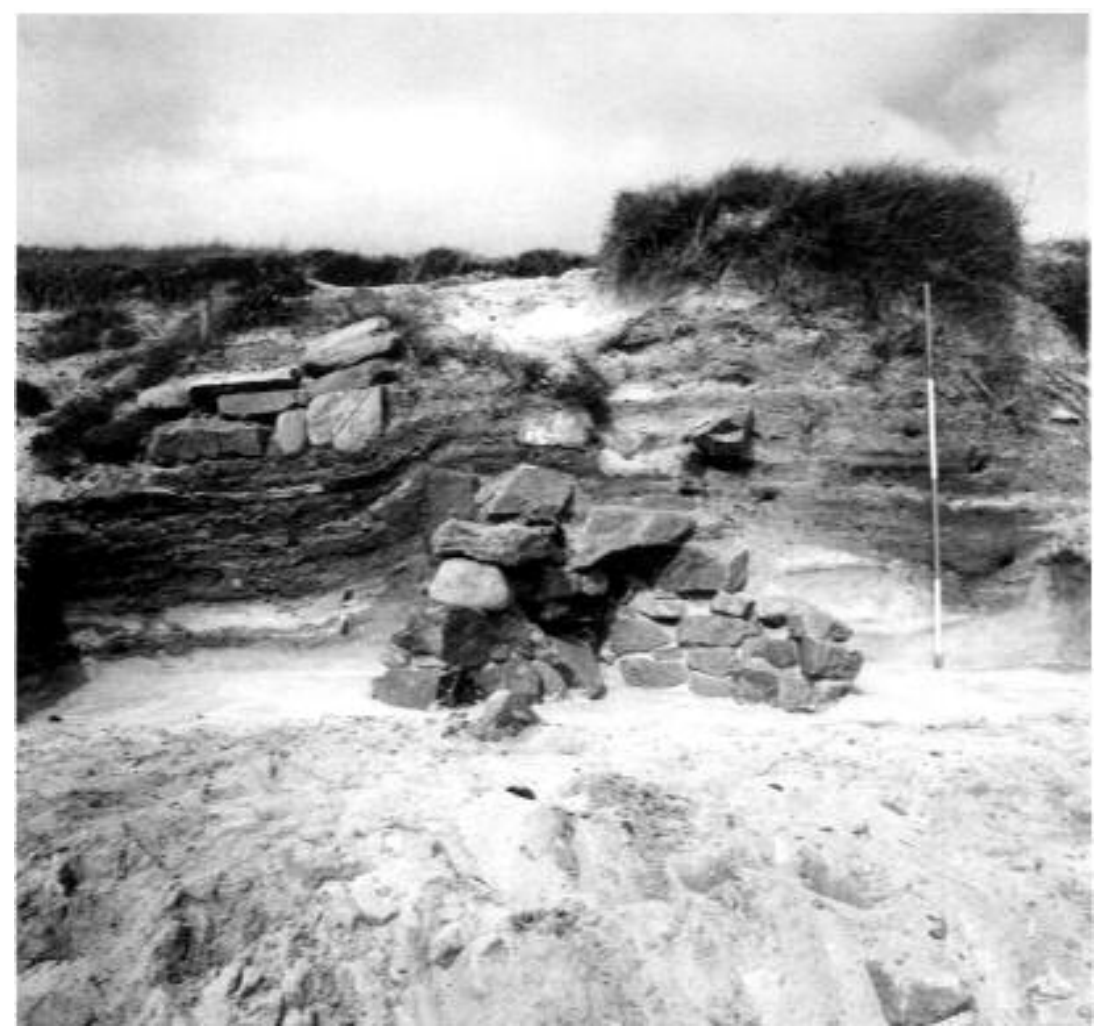

Plate 12. Balelone. Masonry [37] in Block 5

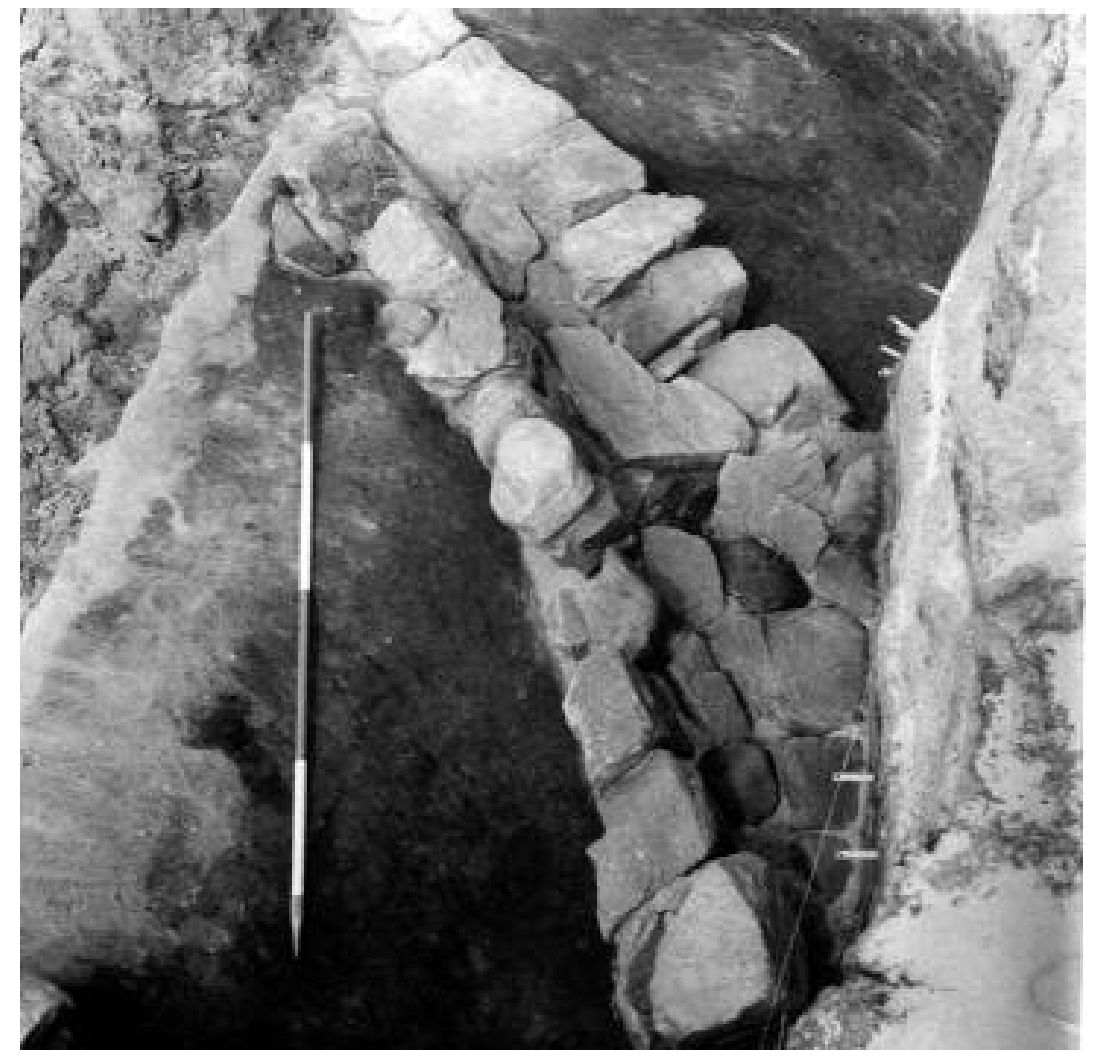

Plate 13. Balelone. Masonry [654] in Block 5 


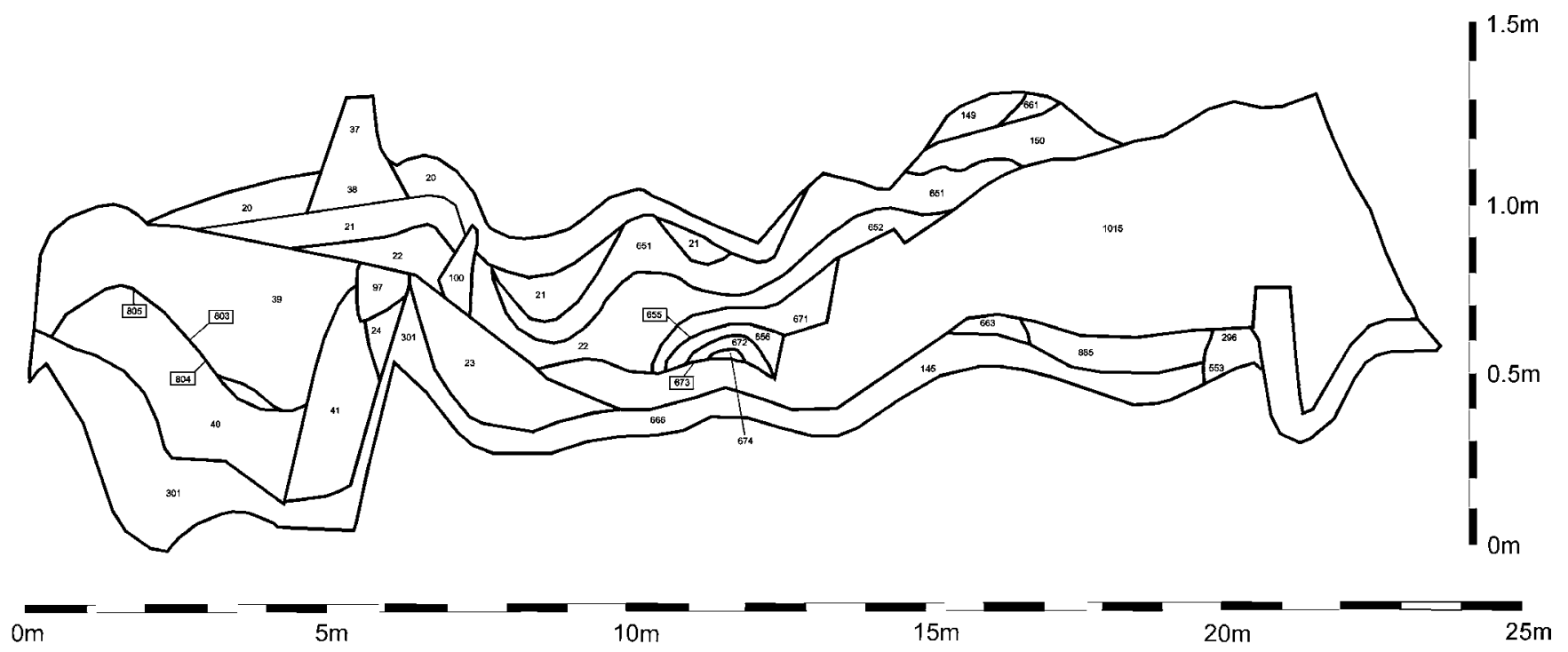

Figure 13. Block 5

\section{Archaeological interpretation}

The layers within this Block were interpreted as midden-site deposits because of their variability in texture, colour and their extent. The lower layers appeared to contain substantial amounts of burnt peat. Subsumed within this deposit were remains of drystone walling. The walling [654] was thick and slightly curving, suggestive of the enclosing wall of a wheelhouse, but no other architectural features, eg radial walls, were found. It is stratigraphically later than the masonry, [37], which like the stones [779], could not be interpreted from the visible remains. The post-holes could not be interpreted further from the information available; however, it was clear that they were sealed by sand layers before the masonry was constructed.

\section{Specialist contribution}

A total of 1807 bone fragments were recovered. Butchery marks were present on a cattle scapula from [301] and a sheep vertebra from [20] and [1023]. Sheep fragments with cut marks were also identified in [22] and [1023]. Radii of sheep and cattle were retrieved from [662] and [88] respectively, while sheep teeth (M2, M3 and P4) were found in [39] and [1017]). A pig jaw and red deer antler antler were found in [20] and a possible otter humerus was found in [1023].

\subsection{BLOCK 6 - PITS, POST-HOLES AND ASSOCIATED DEPOSITS}

\section{See table p.277}

Block 6 lay at the north end of the site above Blocks 2 and 5 and beneath Block 7 (Figure 10). It extended for $13 \mathrm{~m}$ along the section and had a maximum depth of circa $1 \mathrm{~m}$. The earliest features in this Block were ten, circular, round-bottomed post-holes (Plate 14). Six of these, [711], [713], [715], [717], [719], and [721], were cut by the section line; these cut into the layers of Block 2 (Figure 14). They ranged in diameter from $0.23 \mathrm{~m}-0.5 \mathrm{~m}$ and in depth from $0.1-0.7 \mathrm{~m}$. Their fills were described as dark grey, yellow and white sand, all with a significant charcoal content. Post-pipes were visible within all of the post-hole fills. The $2 \mathrm{~m}$ square box, cut back into the section at this point, revealed four more pits, [521], [530], [532] and [535]. These were also circular and had similar fills to those noted above. They were also cut into the layers of Block 2. These pits had been truncated before the layers of the overlying Block 6 were deposited. At the south end of Block 6 was a drystone wall, [317], constructed of stones of varying sizes, all irregular in shape. In the section this masonry stood $1.1 \mathrm{~m}$ high, with five courses still in situ, and was circa $0.3 \mathrm{~m}$ wide. The walling was constructed against a vertical face cut into the layers of Block 3. A further pit, [336], was noted at the foot of the wall. The layers and lenses which had built up against wall [317] stretched to the edge of the excavated area. The lower layers were generally pale brown sand except for layer [710] which consisted of laminated layers of pale sand and black peat. Above this was a thick deposit of layers and lenses which ranged from black to orange brown in colour and from peaty sand to loamy sand, in texture. Several layers produced large amounts of seashells. The uppermost layer, [309], was of peat ash and this sealed the walling [317] and the layers of Block 5. The $\mathrm{pH}$ values recorded for the pit fills ranged from 7.2-7.5, the modal value was 7.3. The $\mathrm{pH}$ values for the layers ranged from 7.3-7.5, the modal value being 7.4 .

\section{Archaeological interpretation}

All above-ground remains of this structure had been scooped away before the layers forming the rest of the Block were deposited. The pits were interpreted as post-holes because of the presence in them of post-pipes. They had been cut from a level now lost and, while their contemporaneity is probable, it is not certain. Pit [722] was cut by [720] so at least two phases of posts are indicated. There is no clear chronological relationship between the destruction of the post structure and the construction of the walling, [317]. Wall [317] was interpreted as a boundary, possibly constructed to check the 


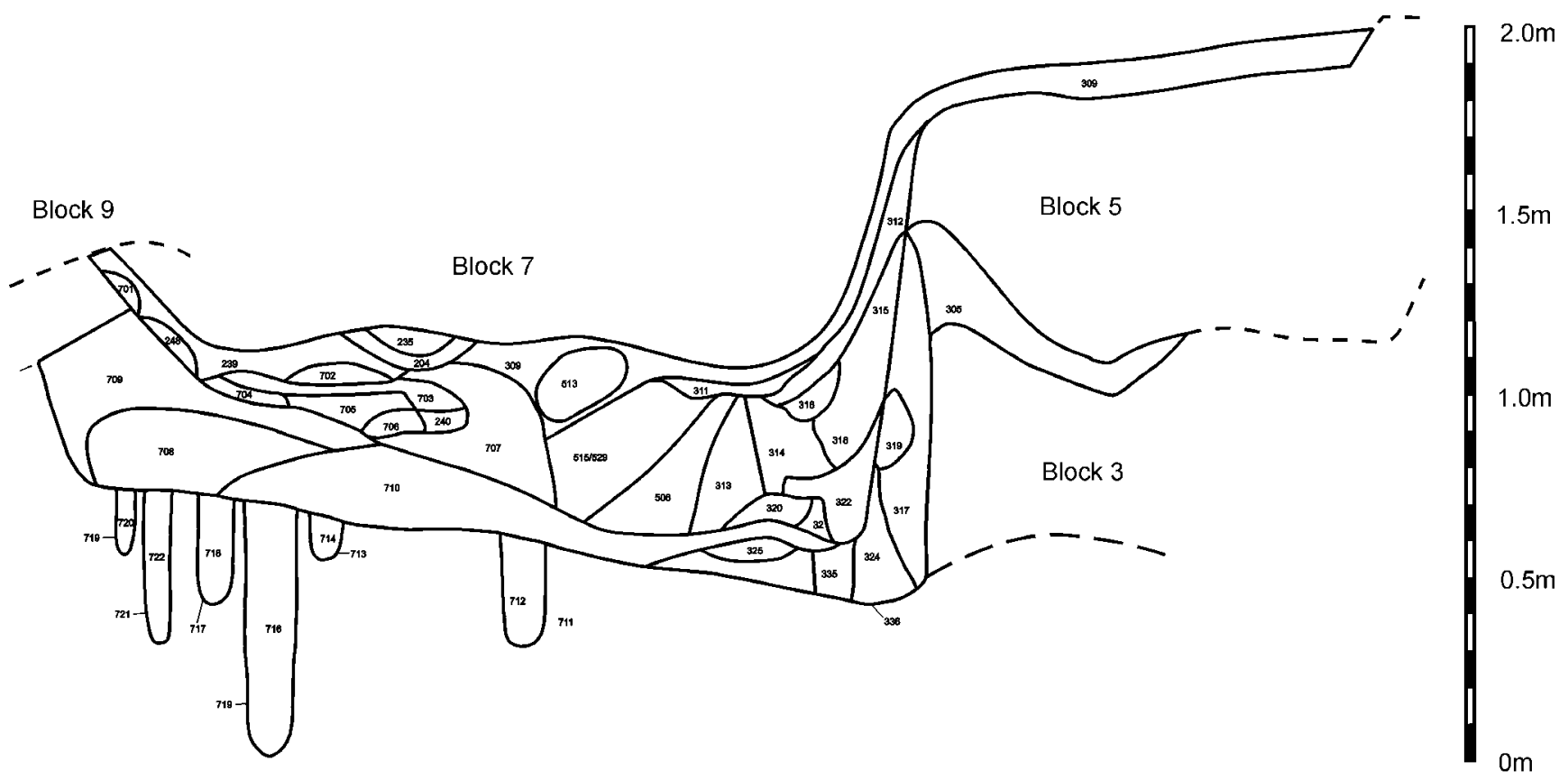

$0 \mathrm{~m}$

$5 \mathrm{~m}$

$10 \mathrm{~m}$

$15 \mathrm{~m}$

Figure 14. Block 6

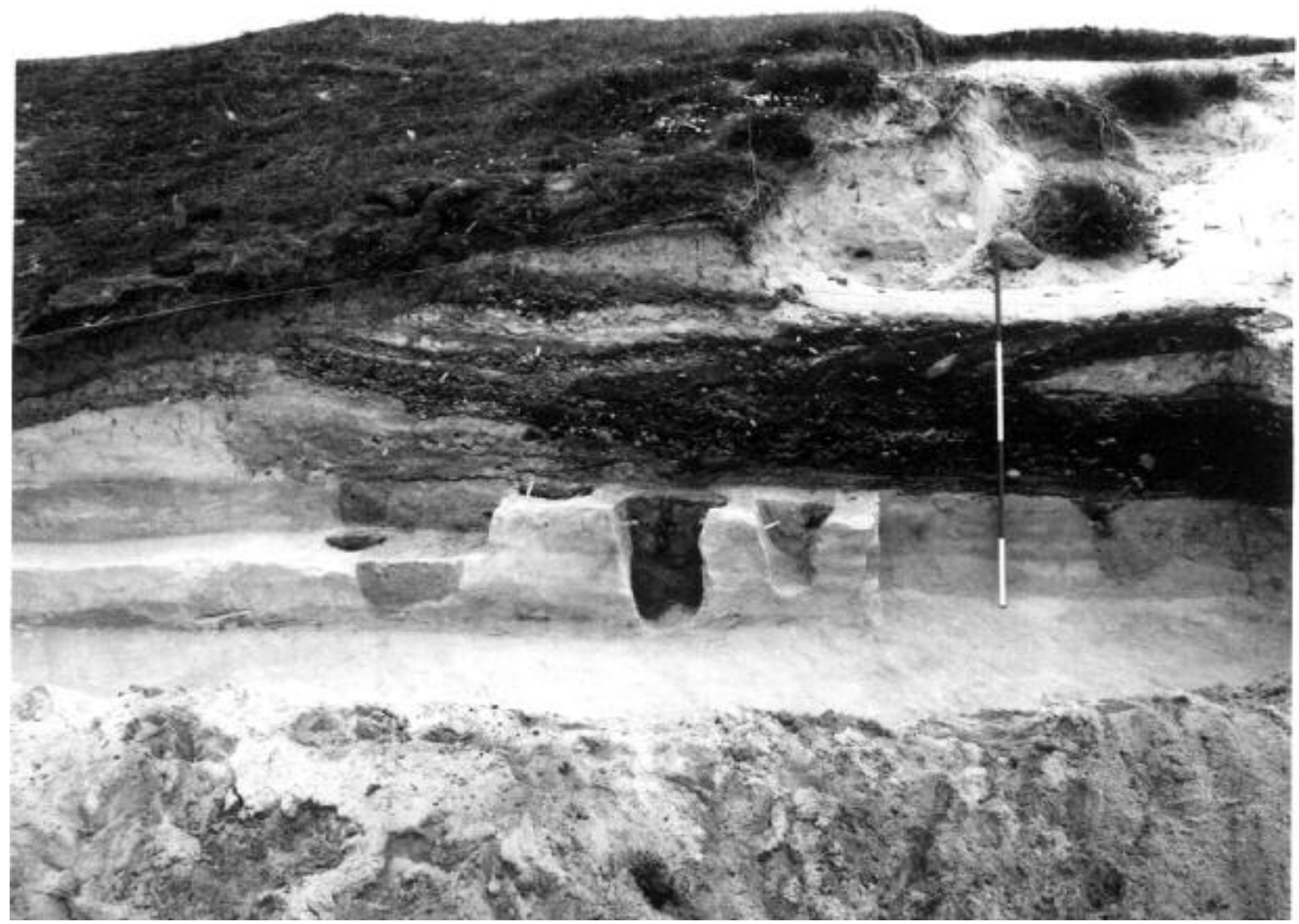

Plate 14. Balelone. Pits and postholes in Block 6 


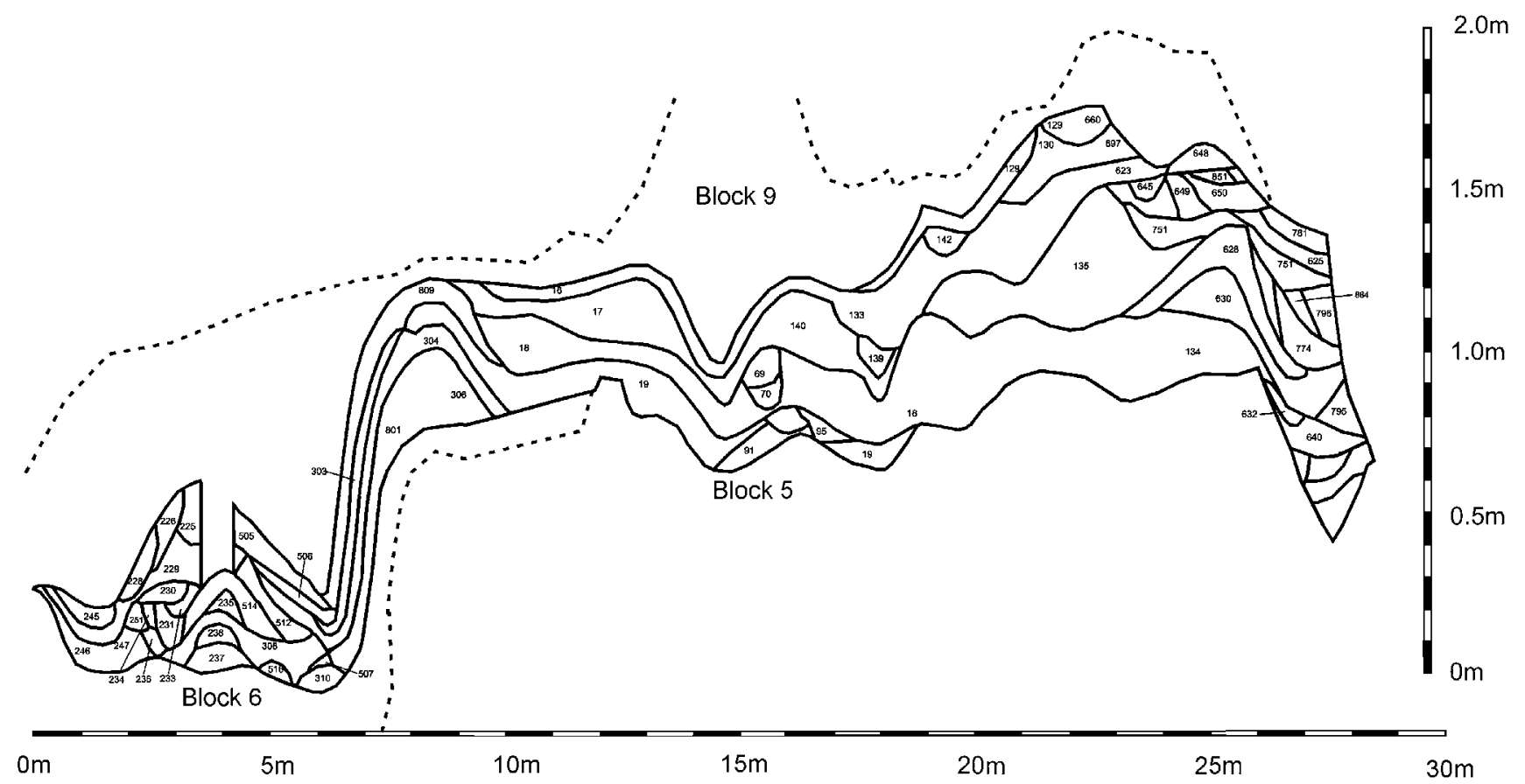

Figure 15. Block 7

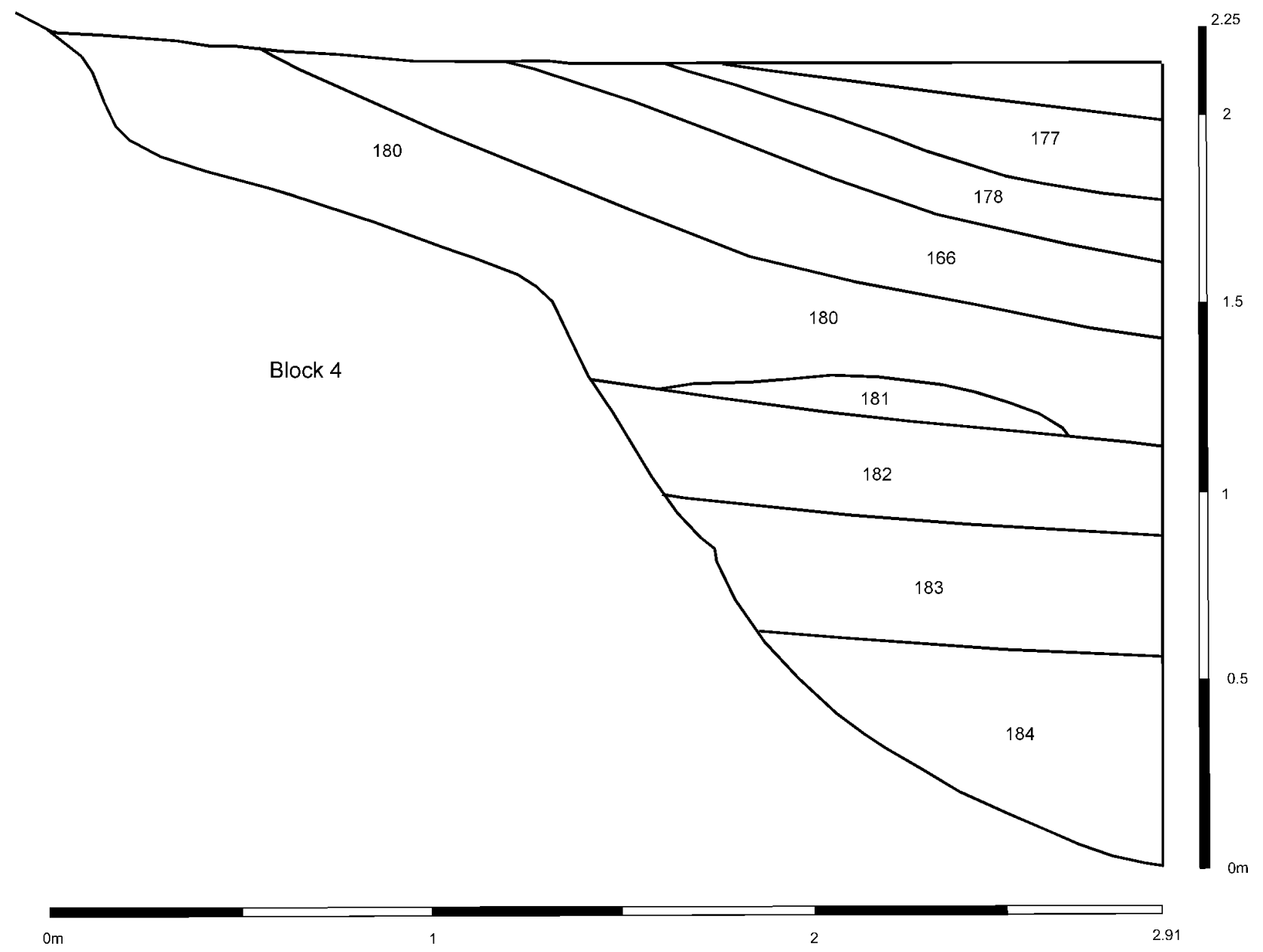

Figure 16. Block 8 


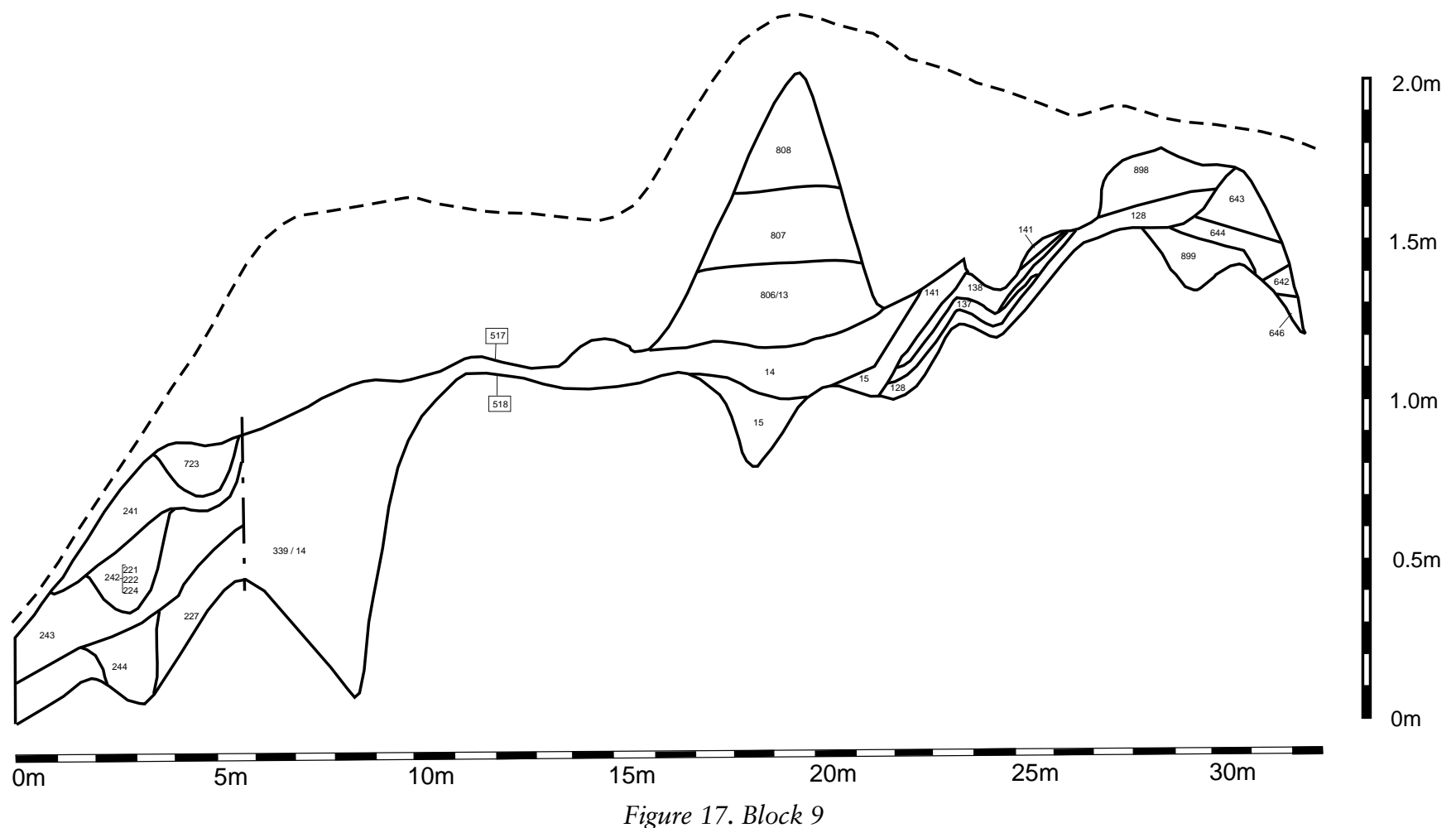

spread of the midden-site deposits of Blocks 3 and 5. To the north of the wall, firstly windblown sand and then material with an extremely high organic and anthropogenic content had accumulated. These latter deposits, have been interpreted as dumped deposits.

\section{Specialist contribution}

A total of 1827 bone fragments were recovered. These comprised the 3rd phalanx of a sheep, sheep mandible fragments, teeth and worked pieces of horncore, together with cattle teeth, all from [524] and [1022]. Crab claws were also present.

\subsection{BLOCK 7 - MIDDEN-SITE DEPOSITS, INTERMITTENTLY CULTIVATED}

See table p. 278

Block 7 extended over the greater part of the revealed site, for a distance of $35 \mathrm{~m}$ and to a maximum depth of $1.6 \mathrm{~m}$ (Figure 10). It consisted of extensive layers, $0.02 \mathrm{~m}-0.05 \mathrm{~m}$ deep, and numerous lenses (Figure 15). The soil colours range from very pale brown to very dark brown and the soil textures, from sand to sandy loam. The uppermost layers were predominantly pale brown sands, while the lower layers consisted of bands of extremely variable colour and texture. There were two small pits [94] within this Block and another with two fills, [70] and [69].

\section{Archaeological interpretation}

This Block was interpreted as midden-site deposits that had been intermittently cultivated. The reasons for this interpretation were the predominance of extensive layers mixed with small lenses of presumably dumped material and the presence of wavy soil boundaries, although sufficient time must have elapsed to allow the posts to rot in situ as there is no evidence for their removal. The $\mathrm{pH}$ values recorded for this Block ranged from 6.9-7.7.

\section{Specialist contribution}

A total of 1982 bone fragments were recovered. Cattle were represented by a tooth from [244] and fragments with cut marks in [19] and [1019]. Fragments of sheep bone with cutmarks and a sheep humerus were found in [522]. A pig tooth was recovered in each of [17] and [306] and a dog jaw fragment was found in [631]. Unidentified bird and fish bones were also recovered from [640] and [522] respectively, together with six crab claws.

\subsection{BLOCK 8 - WINDBLOWN SAND}

See table p.279

Block 8 lay at the extreme south end of the site (Figure 10). It extended from where Blocks 7 and 4 had been cut away to the limit of the excavation, a distance of $4.3 \mathrm{~m}$, and had a maximum depth of $0.55 \mathrm{~m}$. It consisted of layers which 
sloped down towards the south (Figure 16). They were predominantly pale brown sands except for the basal layer, [184], which was a dark brown loamy sand. The boundaries were either clear or broken.

\section{Archaeological interpretation}

This Block was interpreted as windblown sand because of its light colour, sandy texture and the small amounts of anthropogenic material which it contained. The organic matter in the basal layer and the bone and pot in layers [166] and [181] probably derive from the eroding deposits of Blocks 4 and 7.

\section{Specialist contribution}

Two sheep mandible fragments were recovered from this Block.

\section{I0 BLOCK 9 - WINDBLOWN SAND}

$*{ }^{14} \mathrm{C}$ date $2290 \pm 60 \mathrm{bp}$ (GU-1802) from [339] (Shellfish) Block 9 extended over the whole length of the site (Figure 10). It consisted mainly of modern layers of windblown sand and cultivated deposits, which varied in depth from 0.2 m-1.2 m (Figure 17). However, the lower contexts in the block, while disturbed, contained archaeological materials. Thus, one pot sherd was recovered from context [252] and the radiocarbon date was returned from context [399]. 


\section{CHAPTER 5: EXCAVATIONS AT BALESHARE}

H F James \& A Duffy

\section{I INTRODUCTION}

The tidal island of Baleshare lies $0.5 \mathrm{~km}$ west of the coast of North Uist, to which it is connected by a modern causeway. At low tide it is still possible to walk to Baleshare across the sand.

The site, at NF 776 615, is known locally as Ceardach Ruadh, meaning the 'Red Smithy' (Figure 18). It lies on the exposed west coast of Baleshare at the boundary of the townships of Baleshare and Illeray. The bedrock rises to the surface at Ceardach Ruadh forming a slight promontory; the coastline is otherwise gently curving. The machair plain stretches eastwards for $1.5 \mathrm{~km}$, all of it below the $8 \mathrm{~m}$ contour. Small inland lochs, pasture and occasional fields are found in this area. Beyond this, on the east side of Baleshare the undulating landscape has very thin soils and many rocky outcrops. To the south are the sand dunes of Eachkamish and to the north, the sand spit of Lang Gorm.

Ceardach Ruadh is a sand mound which stands about $8 \mathrm{~m}$ above the surrounding machair and measures about $45 \mathrm{~m}$ along the coast extending $26 \mathrm{~m}$ back from the sea. Two large deflation hollows have been formed to either side of the mound and these stretch about 120 metres inland. A modern navigation cairn, $2 \mathrm{~m}$ high, is situated just to the north of these, $3 \mathrm{~m}$ from the dune face ( $n b$ : this cairn was lost to coastal erosion by 1997). The exposed face measures up to 3.5 $\mathrm{m}$ high with slumped sand and beach pebble material beneath.

\section{I.I Archaeological features}

The exposed midden stretched for a distance of $48 \mathrm{~m}$ along the coast, covered by $1.3 \mathrm{~m}$ of clean sand. Pottery and bones were found, prior to excavation, in the midden face and around its base. No stone protruded from the eroded face.

\section{I.2 Site history}

The name 'Baleshare' means 'East Village' according to the Rev Earnest Beveridge. 'Illeray', which now refers to the northern township, he interpreted as the Norse for 'bad island', and may once have been the name for the whole island (Beveridge 1911, 48, 78). He also states that there was once a west village that has become engulfed by the sea. Local legend records that the walls of ruined cottages may still be seen underwater off the western shore. He points to a 'devastation' about the year 1540 when lands worth two to three marks per annum were deducted from the rental and he believed this may refer to the events which also drowned the village of Baleshare (ibid, vii). In 1859 a high tide with south-westerly gale washed away soil from the island and new channels were formed (ibid, 48). The Admiralty Chart of 1909 shows the shallow water below 4 fathoms, off the west coast with a submerged headland off the coast from Ceardach Ruadh to the rocks of Sgeir na Galtun.

The OS Name Book entry refers to the site as a place where kelp is made. The lines of stones used for kelp drying still exist on the summit of the sand mound (Figure 18) and these have been used within living memory. The area inland is known by locals to have contained burials and at least one was found within a stone slab coffin. These are now covered in sand.

\section{I.3 Earlier excavations}

Ernest Beveridge recorded finds of slag, ashes, antler, a few hammerstones, flints, fragments of crude pottery and pins of bone and brass from the site which were donated to the NMS (PSAS 1922, 16). He also states that '...here cists and bones are sometimes disclosed ....and pins of bone and brass have been found' (Beveridge 1911, 229). Subsequently, Fairhurst and Ritchie excavated an area of the site in 1963. They found there the remains of what they interpreted as a wheelhouse, exposed by coastal erosion, revealing two distinct floors (Fairhurst \& Ritchie 1963). Below this was a deposit of stained sand containing thick sherds. About 40 sherds of thinner undecorated 'wheelhouse' pottery was found at the base of the cliff and apparently from this structure. The excavation consisted of a trench cut along the face of the cliff at the top of the beach. They discovered that the stained sand continued about $2 \mathrm{~m}$ below the wheelhouse floor onto pure machair sand which was circa $0.3 \mathrm{~m}$ above the High Water Mark. Professor Ritchie confirms that the site reported upon below is probably that which was examined in 1984 .

A skeleton which had become exposed in the eroding face of the site was excavated in September 1964 by Dr T Robberstad. It was about $1 \mathrm{~m}$ below the grass surface and circa $5 \mathrm{~m}$ south of where a stone wall jutted out from the edge of the dune at the same depth. The legs were fully extended and the skeleton had an east-west orientation. Coal was found within the fill of the burial, (Crawford 1964; and letter, Robberstad 1964).

Most recently, severe storms and high tides in early 1993 exposed another cist in the dune face (Armit 1993). The cist, of which only half survived, contained an extended inhumation and two animal teeth which were found in the area of the neck and shoulders of the skeleton. The cist appears to have been cut into the top of midden layers and is, therefore, probably later than the sediments excavated by the CEU.

\section{I.4 Adjacent sites}

\section{Sloc Sabhaidh (NF 7823 6085)}

About $1 \mathrm{~km}$ south of Ceardach Ruadh and about $200 \mathrm{~m}$ from the coast is the site of Sloc Sabhaidh, which means 'saw pit' (Figure 18). It is not mentioned in the Ordnance Survey Name Book (OSNB) and it does not appear on the OS 1st-edition maps. Beveridge records this site as a sand hill containing middens, ashes, shells, bones, hammerstones, quartz, pottery and possibly a Viking bronze ring (Beveridge 1911, 228). Beveridge also mentions a bone pin recovered from this general area as well as burials found in the southern portion of the site. He further records a circle of small stones enclosing an area of circa $1 \mathrm{~m}$ in diameter associated with flint flakes, pottery and charred bones (ibid, 266). The finds are in the National Museum of Scotland (PSAS 1912, 330; PSAS 1922, 16). 
Baieshare

location \& site survey
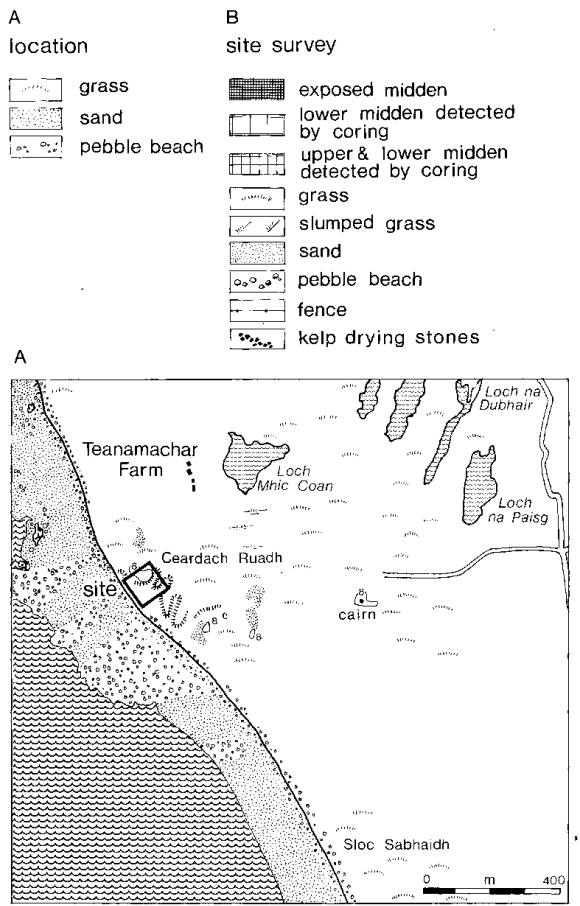

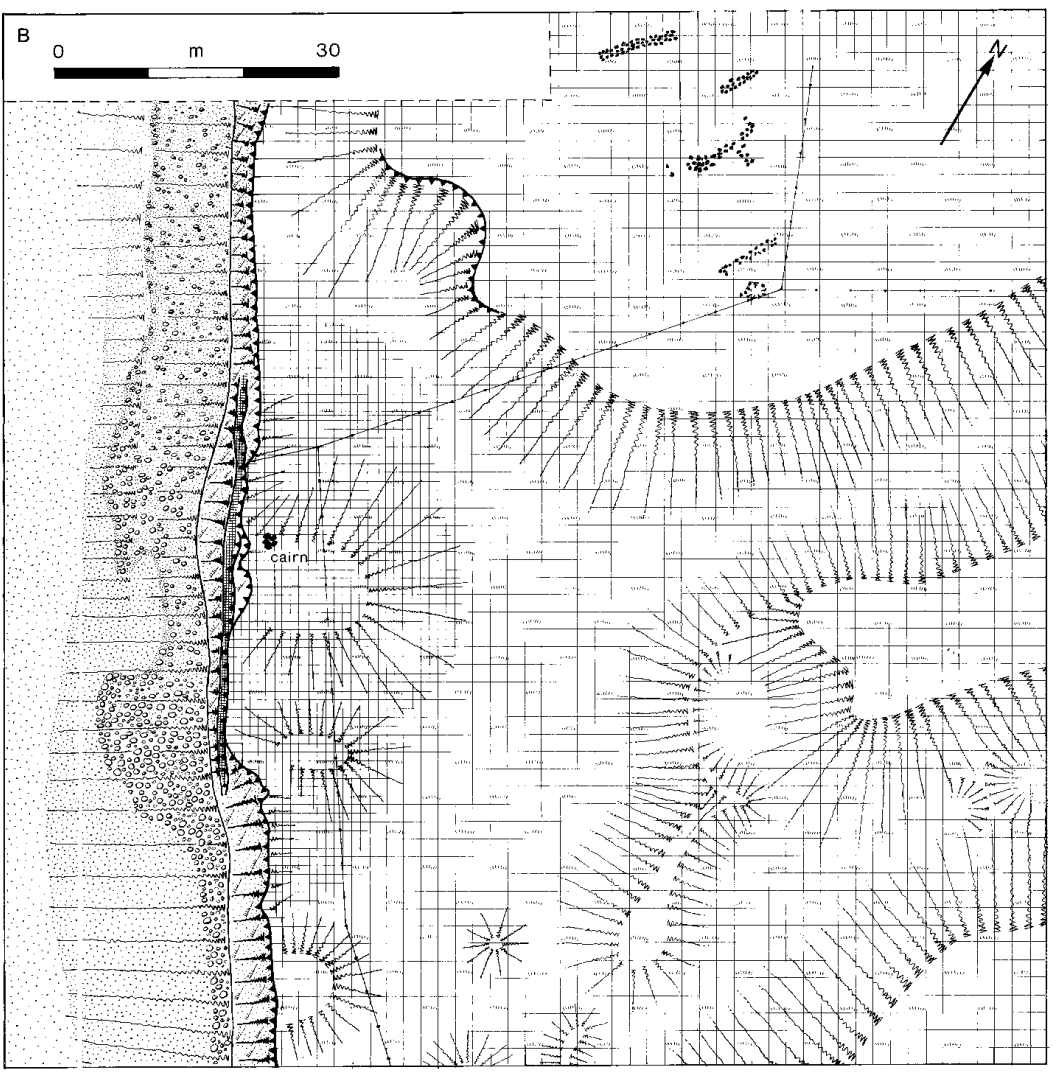

Figure 18. Baleshare: site location and survey
In 1912 Wedderspoon recorded the presence of a mound ' 200 yards in circumference and $25 \mathrm{ft}$ high ...on the west side of Baleshare island...broken up into a number of semi-detached knolls.... One of these contains, in addition to a number of quite modern grave-mounds, a network of stone-lined enclosures varying in size but with the general appearance of a group of cists with the covers removed. The stones, set on edge, project a few inches above the turf.' (Wedderspoon 1912). The OS Field Inspector thought this referred to the site of Sloc Sabhaidh, which he visited in 1965 and noted shells, bones and ash in rabbit holes in the mound. In 1987 CEU staff revisited this site and recorded the series of mounds thought to be the sites of wheelhouses. Coring in the area indicated sub-surface midden material (Barber 1987).

\section{Other sites}

There are several duns on Baleshare Island. The Royal Commission recorded four island duns in Loch Mor, near the centre of Baleshare island (RCAHMS 1928, 176). Three of these are located on the OS 1:10,000 map. This map also shows a further possible dun in Loch na Paisg accessible by stepping stones. To the south of this loch is the site of Dun na h-Ola (RCAHMS 1928, 312). Lastly, near the shores of the probably shrunken Loch an Duin Mor are the remains of Dun Mor. This type of site is thought to range in date from the Iron age to the post-mediaval period. However the excavations of what was considered an island dun in Loch Olabhat, North Uist, has been shown to be of Neolithic date (Armit 1987; 1988). There is a chambered cairn in the north-east of Baleshare island, Carnan nan Long, located at NF 79076367 (Henshall 1972, 506). The remains of a Medieval church, Teampull Chriosd lie at NF 7835 6133, (RCAHMS 1928, 161).

\subsubsection{Summary of Blocks (see Figure 19)}

$\begin{array}{cl}\text { Block No. } & \text { Final interpretation } \\ 1 & \text { Cultivated deposit } \\ 2 & \text { Midden-site deposit } \\ 3 & \text { Conflation horizon } \\ 4 & \text { Grave pit } \\ 5 & \text { Dumped deposits } \\ 6 & \text { Windblown sand and erosion products } \\ 7 & \text { Dumped deposits } \\ 8 & \text { Structural phase - cut of a ditch, parallel walls } \\ & \text { and infilling } \\ 9 & \text { Ditch fill } \\ 10 & \text { Windblown sand } \\ 12 & \text { Structural phase - circular structure } \\ 13 & \text { Structural phase - revetting walls } \\ 14 & \text { Not used } \\ 15 & \text { Infilling and collapse of circular structure } \\ 16 & \text { Midden-site deposit } \\ 17 & \text { Midden-site deposit } \\ 18 & \text { Dump of burnt material }\end{array}$




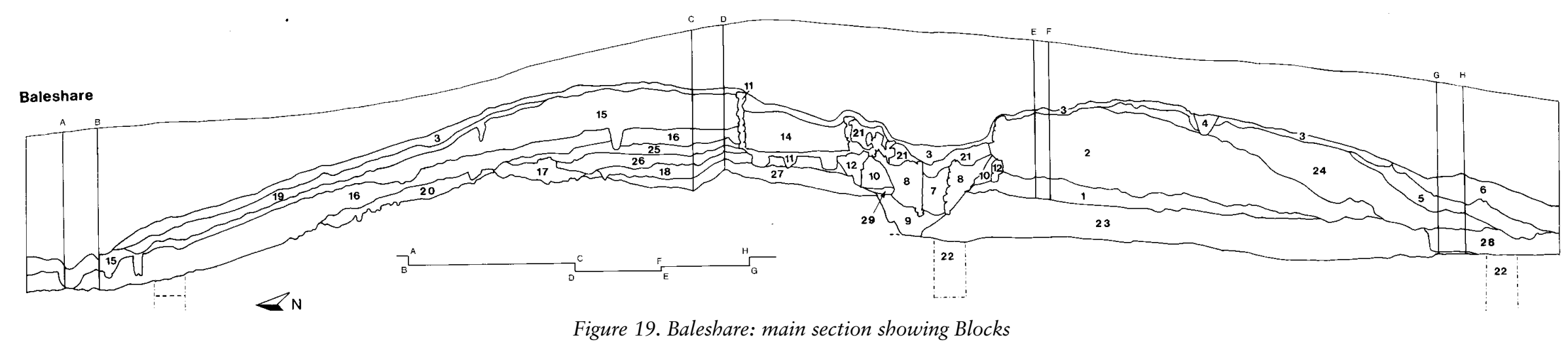




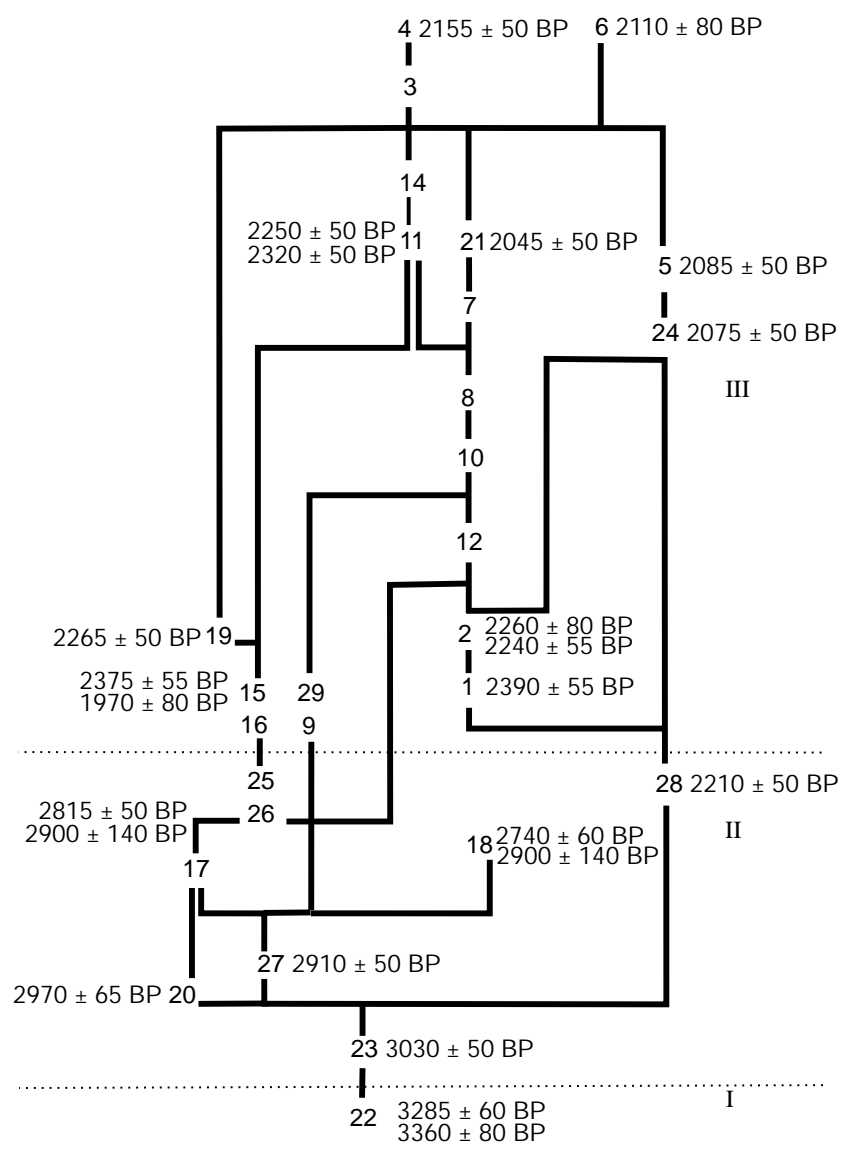

$\begin{array}{ll}19 & \text { Midden-site deposit } \\ 20 & \text { Cultivated deposit } \\ 21 & \text { Windblown sand with erosion products } \\ 22 & \text { Cultivated deposit } \\ 23 & \text { Cultivated windblown sand } \\ 24 & \text { Cultivated midden-site deposits } \\ 25 & \text { Cultivated deposit } \\ 26 & \text { Cultivated deposit } \\ 27 & \text { Possibly cultivated sand } \\ 28 & \text { Cultivated deposit } \\ 29 & \text { Occupation layer }\end{array}$

\subsection{BLOCK I - CULTIVATED DEPOSIT}

See tables p. 280

* ${ }^{14} \mathrm{C}$ date $2390 \pm 55$ bp (GU-1961) from layer [68] (Periwinkle).

Block 1 lay at the base of the south part of the site (Figure 19). It tapered out at its southern end below the midden-site layers of Block 2, and in the north it had been truncated by Block 12. It consisted of a single layer of brown/dark brown, silty, loamy sand, $0.1 \mathrm{~m}$ to $0.3 \mathrm{~m}$ in depth and $10.7 \mathrm{~m}$ in length, with a clear, undefined boundary. Several ard marks were noted at the bottom of layer [68].

\section{Field interpretation}

This Block was thought to be a cultivated deposit because of its extent, colour, texture and the ard marks in its base. The Block mean IHI has been calculated at 5,000, which represents a wide range, but a small number of material finds. Some ten of the thirty-seven potsherds from this Block were examined. These were small to medium in size, in the 2 to 6 range. The soil $\mathrm{pH}$ value was 7.5 and the phosphate value was 3 (on the 0 to 5 scale).

Block 2

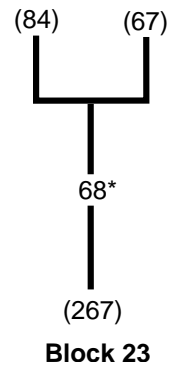

\section{Archaeological interpretation}

The presence of ard marks within the Block make its interpretation unequivocal. The IHI values, general anthropogenic content and the soil characteristics are all consistent with the field interpretation of Block 1 as a cultivated deposit.

\section{Specialist contribution}

Sheep, cattle and red deer were identified as well as bones from cod and hake.

\subsection{BLOCK 2 - MIDDEN-SITE DEPOSIT}

See tables p.281, 282

* ${ }^{14} \mathrm{C}$ date $2240 \pm 55$ bp (GU-1960) from layer [42] (Periwinkle).

* ${ }^{14} \mathrm{C}$ date $2260 \pm 80 \mathrm{bp}$ (GU-2555) from layer [42] (Animal bone).

This Block lay in the south part of the site, abutting wall [192] (Block 12) (Figure 19). It formed a dome extending over $11 \mathrm{~m}$ before tapering away beneath Block 24. It had a maximum depth of $1.4 \mathrm{~m}$ and consisted of several extensive layers up to $0.5 \mathrm{~m}$ in depth, between which were smaller lenses of material 0.05-0.15 m deep (Figure 20). The soil colours ranged from light greyish brown to very dark brown and in texture from silty sandy loam to sand.

\section{Field interpretation}

This Block was interpreted as midden-site deposits because of it's shape, the humus enrichment of the deposits and the relative abundance of their anthropic contents. The Block mean IHI was calculated at 21,000, representing a range of between 


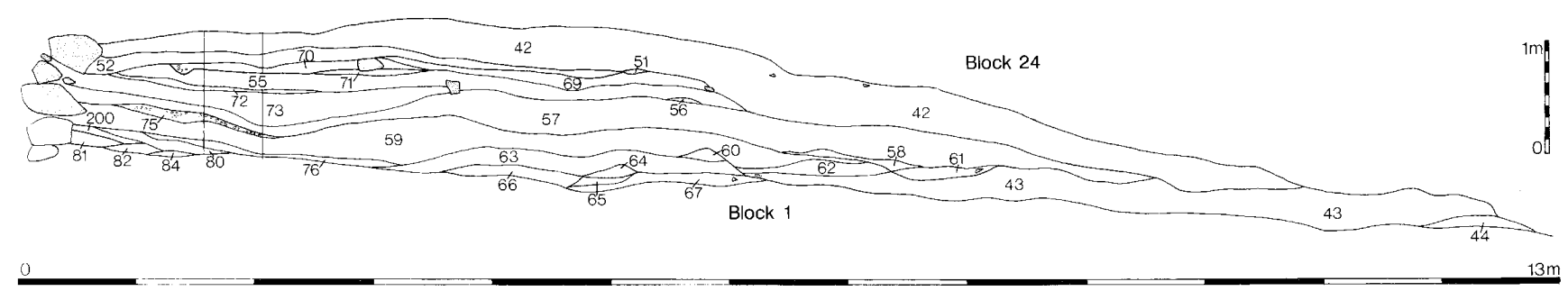

Figure 20. Block 2

2,000 and 80,000 . The extreme values are caused by [61] which has a large amount of sea-shell, bone and stone relative to its volume, and [82] and [81] which produced extremely small amounts of material. The IHI represents a wide range of materials. One piece of carved pumice was retrieved from [73] (Figure 77b) and unmodified fragments were retrieved from [62] and [65]. Of the 495 potsherds in this Block, the sizes of 116 were measured and their distribution is markedly Poisson. They ranged in size-class from 1 to 13 and almost one third of the sherds are above average in size. The $\mathrm{pH}$ values recorded for this Block range from 7.1 to 7.6 with a modal value of 7.3. Phosphate values most commonly ranged from 1 to 5.2. The soil colours were brown, with a wide range of shades. The soil textures ranged through sands, loamy sands and loams and all of the layer boundaries were clear.

\section{Archaeological interpretation}

The IHI supports the field interpretation. Variability of the anthropogenic component throughout the Block is consistent with the idea of uncontrolled, or rather, unlocalised deposition of refuse. The large numbers of smaller potsherds maybe indicative of disturbance by human and animal forces as there is no evidence for the cultivation of these layers and all of the layer boundaries are clear. The soil colours and textures are indicative of the addition of organic material and together with the variability in the phosphate content, all testify to the heterogeneity of the deposits.

\section{Specialist contribution}

Bones from the following species were identified: sheep, cattle, pig, seal and red deer. Bones of puffin, guillimot, great auk and Turdus sp. were also recovered as well as five unidentifiable bird bones.

\subsection{BLOCK 3 - CONFLATION HORIZON}

See tables p.282, 283

Block 3 consisted of a single layer of dark brown, clayey sand, [5], circa $0.1 \mathrm{~m}$ thick, and the fill of a pit, [13] (Figure 19). Layer [5] ran almost the entire length of the site above the domed midden-site deposits and the central stone structure. It lay beneath $1.3 \mathrm{~m}$ of windblown sand. The grave [292] (Block 4) cut into the surface of [5] and the pit fill, [13], appeared on the north side of this feature. Because of its large extent $80 \mathrm{~kg}$ were taken as a bulk sample from four different locations along its length.

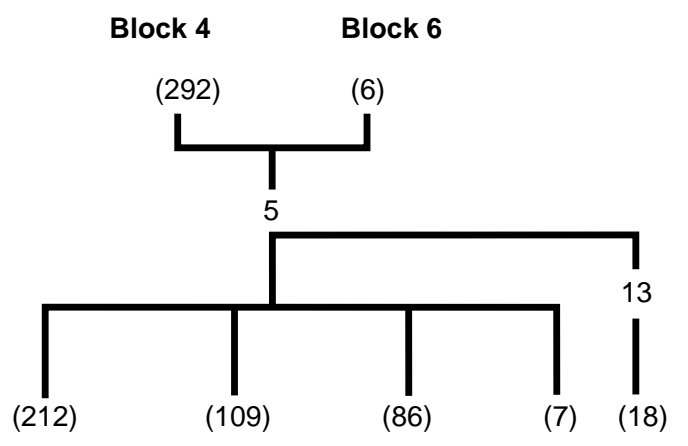

Block 19 Block $14 \quad$ Block 21 Block 5 Block 24 


\section{Field interpretation}

This Block was interpreted as windblown sand with some humic input. This interpretation was based on the extensive nature of layer [5] and its apparent lack of organic matter. The Block mean IHI is 77,000 , but is unrepresentative as it is based on the IHI of 150,000 from the extensive layer and 4,000 from the pit. The high value is based on a total sample of $80 \mathrm{~kg}$, but it reflects the exceptional richness of this Block. Some $25 \%$ of the stone in [5] was burnt and fragments of pumice were retrieved from it. Of the ninety-three potsherds recovered, twenty-five were examined and they range in size-class from 2 to 4 , with twenty sherds in class 2 . The $\mathrm{pH}$ values recorded range from. 7.2 to 7.7. Phosphate values ranged from 2 to 4 .

\section{Archaeological interpretation}

The exceptional quantities of anthropogenic materials retrieved from Block 3 precludes the possibility that this is a windblown sand deposit. This Block consists essentially of a single layer which covers the entire site, lying on deposits of earlier and differing dates. The process of its formation may be hypothesised as follows:

i) The uppermost layers of the site are removed by aeolian erosion and their anthropogenic component deflated onto the surviving surface.

ii) This surface develops as an A Horizon creating an apparent 'deposit' on the surfaces of the surviving, asynchronous deposits.

iii) With the development of the A horizon, increased biological activity facilitates the incorporation of the deflated material into the 'deposit'. This hypothesis is the archaeological interpretation of Block 3. It is proposed to refer to deposits of this apparent formation as conflation horizons.

\section{Specialist contribution}

Identifiable bones of sheep, cattle, pig and red deer were recovered. Three great auk bones and a single pollock vertebrae were also recovered.

\subsection{BLOCK 4 - GRAVE PIT}

\section{See tables p. 283}

* ${ }^{14} \mathrm{C}$ date $2155 \pm 50$ bp (GU-1962) from Grave pit fill [46] (Periwinkle).

This Block consisted of a grave pit, [292], which was dug into the top of layer [5] (Block 3) (Figure 19). It was discovered midway along the south midden and excavated horizontally. It contained a complete articulated skeleton ([220] see Chapter 11.1.1) aligned east-west, with its head to the west (Figure 21). The grave fill was of grey sand, [46], similar to the overlying deposits. A small pit, [290], was cut into the

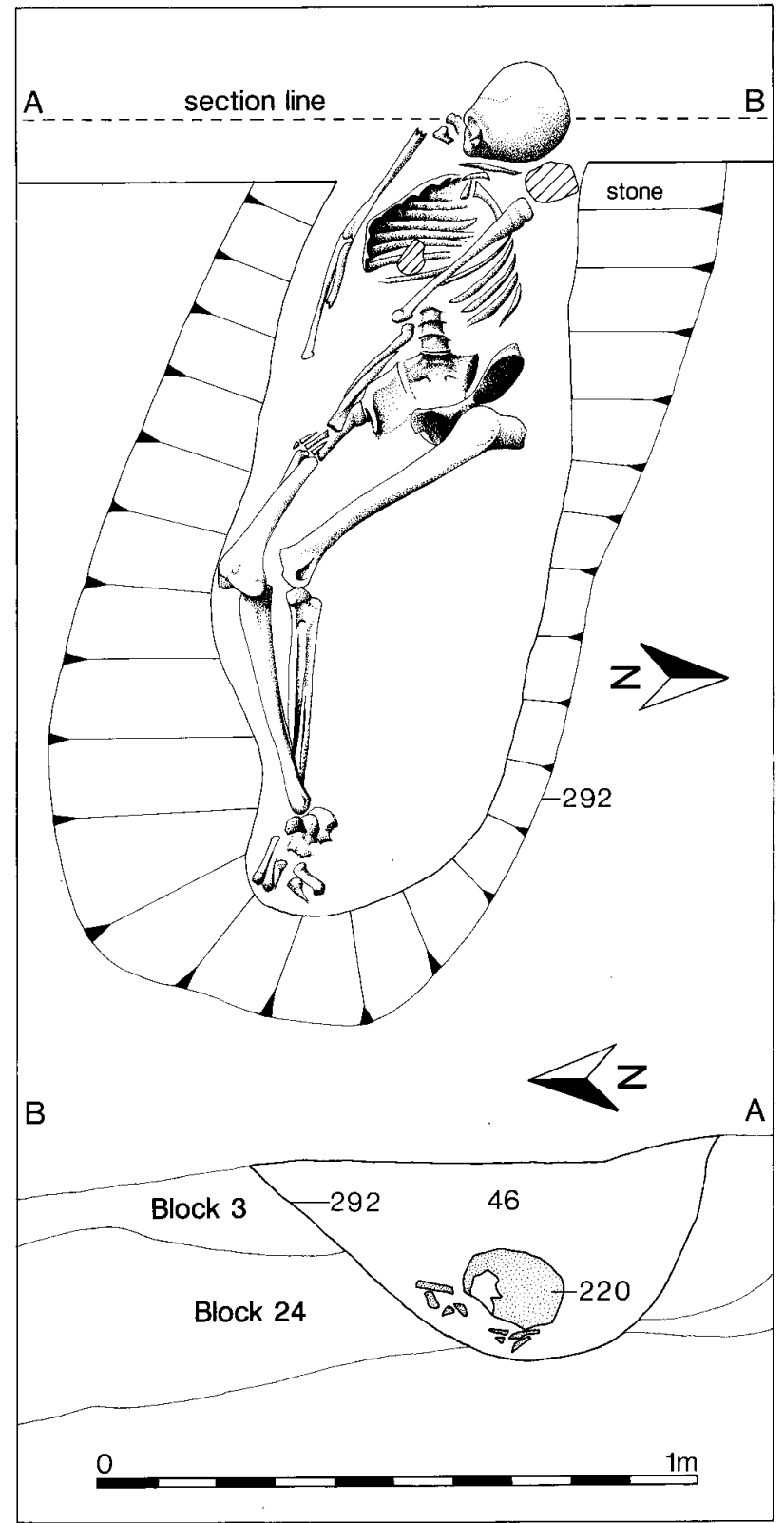

Figure 21. Block 4

top of the grave, and was also filled with grey sand, [47]. There was no evidence of a coffin.

\section{Field interpretation}

This Block consisted of an articulated inhumation within a pit cut into layer [5] from an unknown level. A later pit was cut into the fill of the grave. An IHI value was calculated for the grave fill, at 13,000. This value was based on the presence of bone and sea-shell in moderate quantities. One potsherd was retrieved from layer [47]. This was not examined. The two $\mathrm{pH}$ values recorded for this Block were 6.7 and 7.6. Both phosphate values were 5 . 


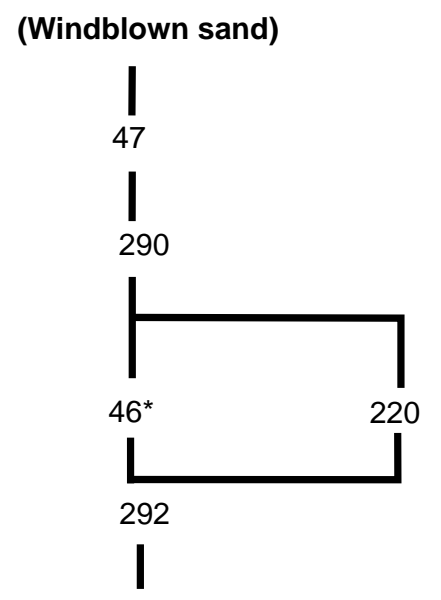

(5)

Block 3

\section{Archaeological interpretation}

The field interpretation is clearly correct. It is interesting to note the high phosphate values from both the grave fill and the later pit. The radiocarbon date from this pit is misleading. It does not date the burial but merely some shell, which in all probability is derived from the layers of Blocks 3 and 24, into which the grave pit was cut. The fill of the grave pit is primarily clean shell sand. This implies that the pit was cut through clean sand from a level above the top of Block 3. The burial is therefore later than the site, but its actual date is unknown.

\section{Specialist contribution}

Identifiable bones of sheep and pig were recovered.

\section{Conclusion}

This is, clearly, a grave-pit.
Block 6

Block 3

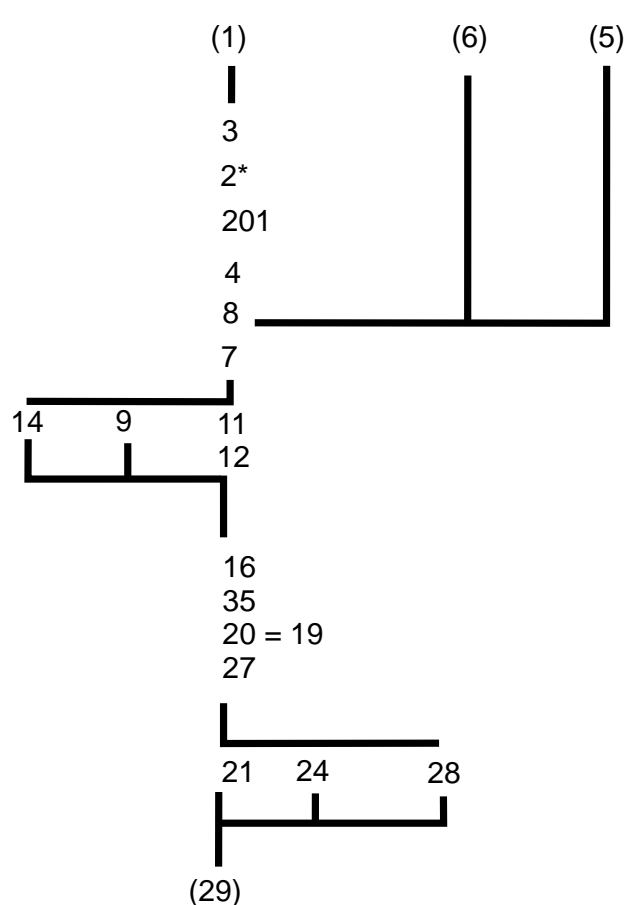

Block 24

\subsection{BLOCK 5 - DUMPED DEPOSITS}

See tables p. 284

* ${ }^{14} \mathrm{C}$ date $2085 \pm 50$ bp (GU-1972) from layer [2] (Periwinkle).

This Block lay at the south end of the site, sloping gently above the layers of Block 24 (Figure 19). It was between $0.1 \mathrm{~m}$ and $0.3 \mathrm{~m}$ in depth and extended for $5.6 \mathrm{~m}$. The layers and lenses which constitute the Block were generally $0.05 \mathrm{~m}$ to 0.2 $\mathrm{m}$ in depth (Figure 22). They were light yellowish brown to very dark greyish brown in colour and ranged in texture from sandy loam to sand. All the deposits contained charcoal.

\section{Field interpretation}

This Block was interpreted as a series of dumped deposits because it consisted of small lenses of markedly different mate-

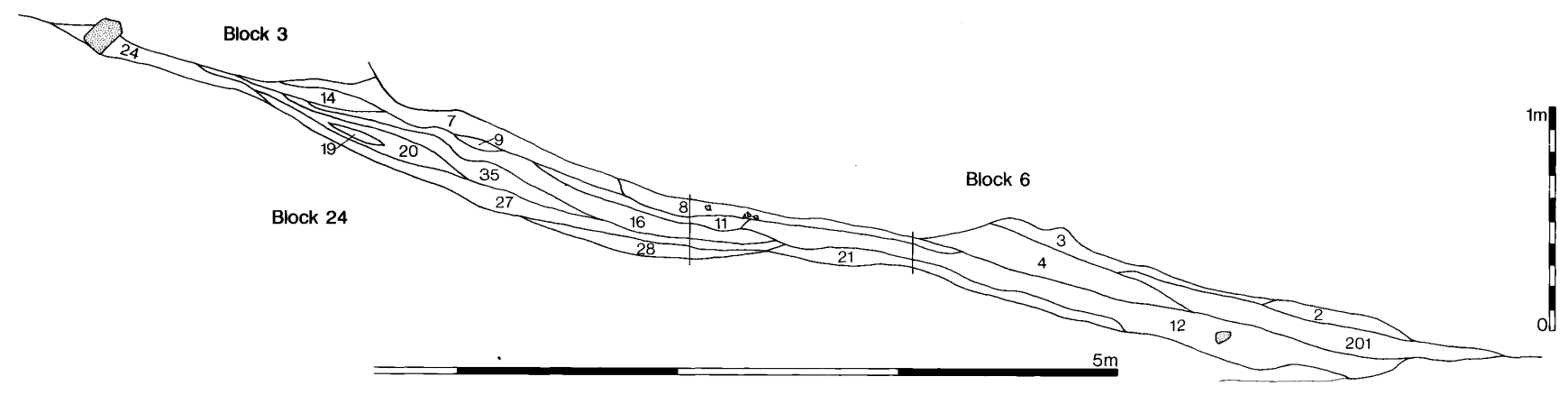

Figure 22. Block 5 
rial which had undergone little disturbance since its formation. The Block mean IHI was calculated at 15,000, representing a range of between 800 and 98,000. The extreme values are caused by [8] (IHI of 800) which has very low quantities of material, [24] (IHI of 98,000) which has large amounts of bone relative to its volume, and [2] $(76,000)$ which produced large quantities of sea-shell. This variability is consistent with the interpretation of these strata as individual dumps of refuse with relatively little sand material.

The IHI represents a restricted range of materials present in moderate amounts. Less than 5\% of the stone from layer [12] was burnt. Of the thirteen potsherds from this Block, three were examined and all were small, ranging in size-class from 2 to 4 . It is difficult to assess the meaning of this distribution, partly because of the small sample size, but also because, as a dumped deposit, the original sources of the materials are unknown.

The $\mathrm{pH}$ values recorded for this Block range from 7.1 to 7.8 with a modal value of 7.5 . Phosphate values ranged from 2 to 5 with 3 being the most common value. Layer boundaries were predominantly clear, two of them being wavy.

\section{Archaeological interpretation}

The small but variable sizes of the individual deposits, together with the marked heterogeneity of their anthropogenic components lend strong support to the field interpretation of this Block as being a group of dumped deposits.

\section{Specialist contribution}

Sheep, cattle, pig and starling bones were identified. Fish species represented were hake, ballan wrasse and plaice.

\section{Conclusion}

The radiocarbon dates from this Block and from Block 24 suggest an inversion of the Block's strata. On balance it seems from the chronological evidence, that this Block consists of upcast from some adjacent excavation. Thus the chronology is reversed.

\subsection{BLOCK 6 - WINDBLOWN SAND AND EROSION PRODUCTS}

See tables p.285, 285

$*{ }^{14} \mathrm{C}$ date $2110 \pm 80 \mathrm{bp}$ (GU-1964) from layer [1] (Periwinkle)

This Block lay in the extreme south end of the site (Figure 19). It extended for $5.6 \mathrm{~m}$ from the south edge of the excavation, tapering away over Block 5. It had a maximum depth of $0.5 \mathrm{~m}$. It consisted mainly of layer [1], the upper part of which is brown in colour. The lower part had several patches of colour and fragments of charcoal similar to the layers of Block 5. With the exception of layer [6], a small

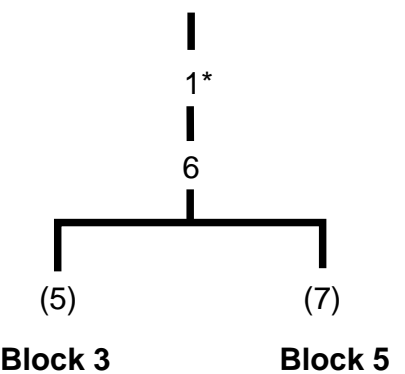

lens of dark brown sandy loam, no differentiation could be confidently made to subdivide this deposit.

\section{Field interpretation}

This Block was interpreted as windblown sand that has incorporated within it humic material and products from a settlement. Those finds noted were presumed to derive from the higher parts of the site, probably to the north. The lower part of the Block appears to be transitional between the brown sand of layer [1] and the coloured lenses of Block 5. The Block mean IHI was not a useful indicator in this case as [1] returned a value of 20,500 while [6] was calculated at 1,000. A wide range of material including much charcoal was returned from the dated context [1] and the materials were present in large quantities. The opposite is true of [6] which was almost devoid of anthropogenic material. Of the ninety-seven potsherds recovered from this Block, twenty-two were examined and they range in size-class from 2 to 8 . This distribution is largely composed of very small sherds with eighteen of the twenty-two examined being smaller than the site average. The $\mathrm{pH}$ values recorded for the two contexts of this Block are 7.6 and 7.8. The phosphate values were 2 and 3 . The soil colours are recorded as dark brown with many mottles and the soil textures as loamy sand and sandy loam. Layer boundaries were clear.

\section{Archaeological interpretation}

It is probable that Block 6 is similar in nature to Block 3 and, is also best interpreted as a conflation horizon (see Block 3, for details).

\section{Specialist contribution}

Bones of sheep, cow, seal, hake, pollock, mackerel and plaice were identified together with bird bone of the Turdinae family.

\section{Conclusion}

This Block is essentially, windblown sand. The field interpretation envisaged the inclusion of material eroded from elsewhere on the site. It is not impossible that this is a conflation horizon. 


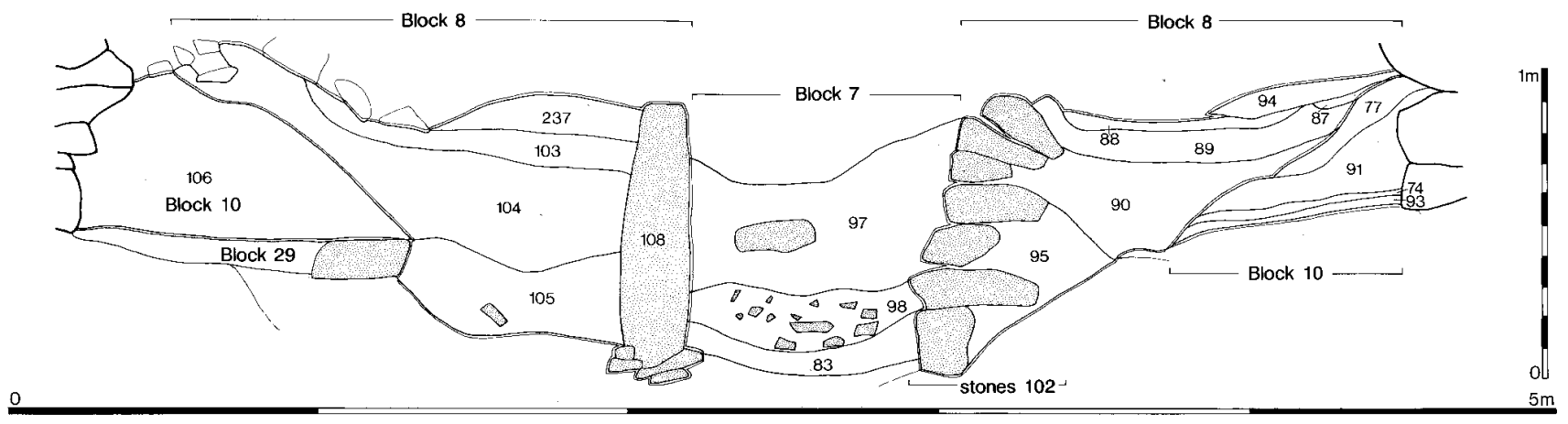

Figure 23. Blocks 7, 8 \& 10

\subsection{BLOCK 7 - DUMPED DEPOSITS}

See tables p.286, 286

This Block lay in the centre of the site between the stone walls of Block 8 (Figure 19). The deposits were $0.6 \mathrm{~m}$ to 0.9 $\mathrm{m}$ in depth forming a meniscal surface between the walls (Figure 23). Layer [97] was described as a brown/dark brown loamy sand and layer [98] as a brown loamy sand, while layer [83] was undescribed. The boundaries between the layers were indistinct. A large number of potsherds were found within layers [83] and [98]. These included an almost complete pot, sherds of which were found in all three contexts (a total of 208 sherds, not included in the table below). Part of another pot was found lying on its side on the surface of layer [98] (sherds also not quantified in the table below).

\section{Field interpretation}

The initial two fills between the walls contained large amounts of conjoining pottery (including the reconstructed vessel illustrated in Plate 15 and Figure $75 \mathrm{~d}$ ) and was interpreted as accumulations of settlement debris between the walls of a disused passageway. The third and deepest fill was probably backfilled during consolidation work prior to the construction of the masonry in Block 11, (see Chapter 10.1.3). The Block mean IHI was calculated at 47,000, representing a range of from 15,500 to 69,000 . The IHI represents a wide range of materials present in large quantities, with [98] being particularly rich. Less than $5 \%$ of the stone from this context was burnt. Some seventeen of the seventy-two potsherds were examined, size-classes range from 2 to 8 and are generally smaller than the site average. The

\section{Block 21}

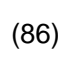

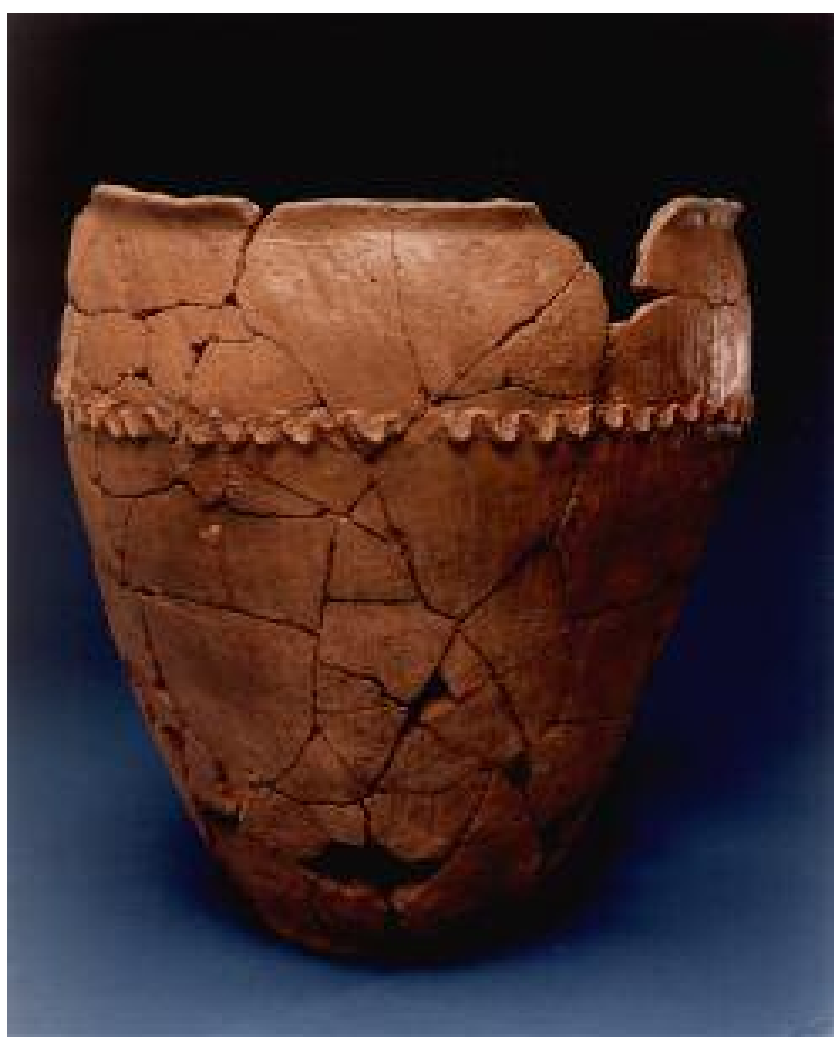

Plate 15. Baleshare. Vessel 81/98 from Block 7

sherds from almost complete vessels were not considered in this analysis. The $\mathrm{pH}$ values recorded for this Block range from 6.5 to 7.3 with a modal value of 6.9. Phosphate values range from 2 to 4 . Layer boundaries from diffuse to clean and wavy were recorded.

\section{Archaeological interpretation}

In general the archaeological interpretation agrees with the site interpretation. The situation seems to be one where the lowest context, [83], accumulated between the walls, probably during the final period of use of the passageway. Upon its upper surface the materials comprising [98] were dumped, possibly accidentally but the use of the abandoned passageway for deliberate dumping cannot be rejected. At any rate, the status of the context as a primary dump cannot be disputed as this is 


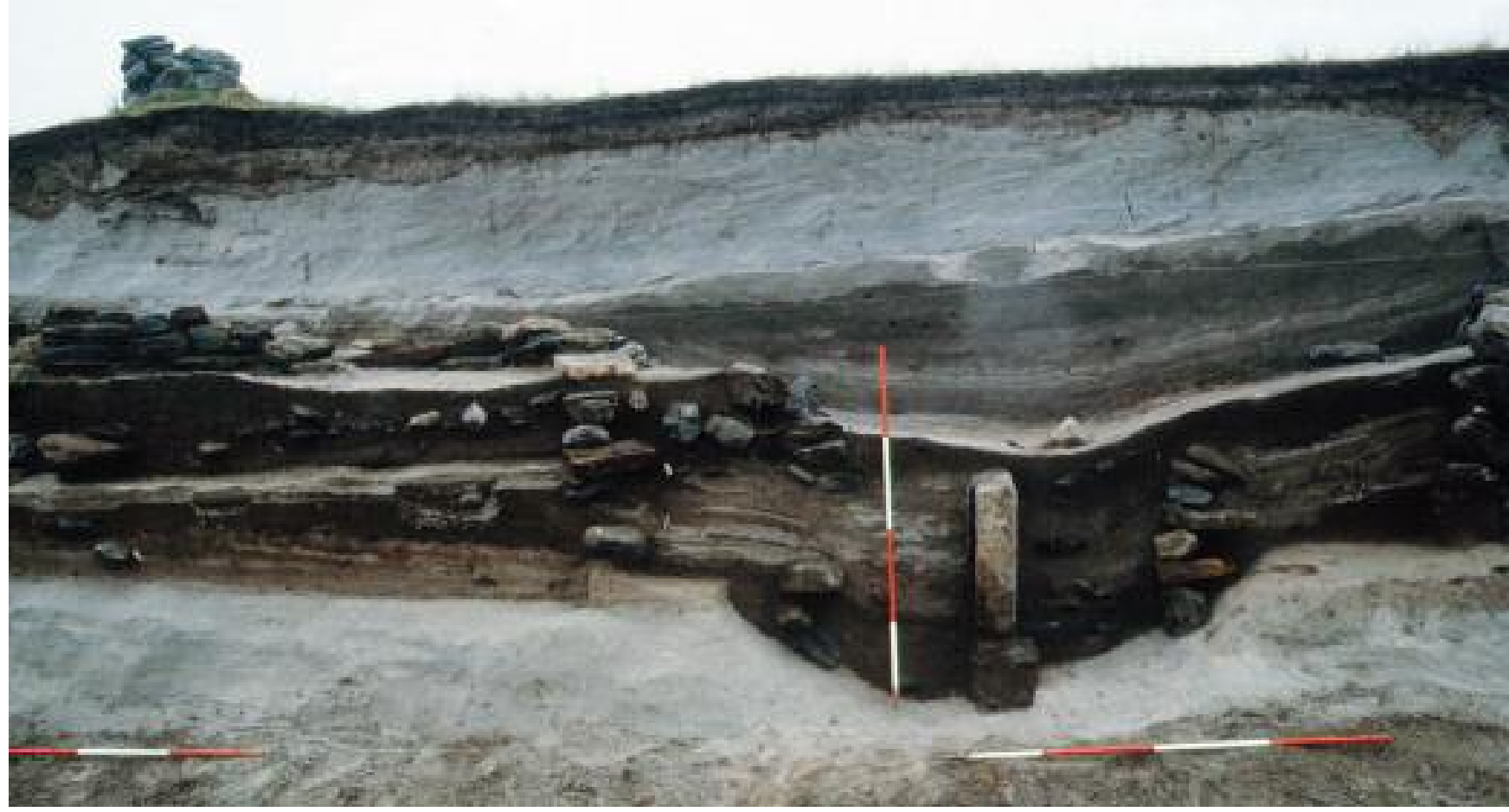

Plate 16. The entrance feature, Block 8 , consisting of parallel walls running into unexcavated sediments, sits in the basal sediments of a broad, shallow ditch. The revetment walls, Block 12, associated with this feature are visible at the higher level to the left and right

clearly demonstrated by the presence of the large vessel fragments. Finally the passageway seems to have been infilled with the material which constitutes context [97].

\section{Specialist contributions}

The animal bones from [98] merit some comment. Apart from an assortment of fragments representing parts of at least three juvenile-adult cattle, one juvenile pig and one neo-natal lamb, most of the bones in this feature were apparently derived from one neo-natal calf (Chapter 9.3.3). The following body parts were represented:

Head: including both mandibles,

Trunk: axis, atlas, 5 other cervical, 3 thoracic, 1 sacral and 3 caudal vertebrae, 12 ribs.

Left forelimb: including scapula, humerus, radius and ulna. Right forelimb: including radius and metacarpal; Left hindlimb: including tibia and calceneus. Right hindlimb: including femur and tibia.

There are no indications that the carcass was butchered in any way before being discarded, or subsequently gnawed by carnivores or rodents, so the calf was presumably buried soon after death.

Substantial parts of the skeleton of a fulmar were also found in this deposit (Chapter 11.4.1) and sheep, pig and seal bones were also retrieved from contexts in this Block.

\section{Conclusion}

The middle and upper layers of this Block contain substantial quantities of dumped debris including broken vessels and a dead calf. All the evidence indicates that the Block is a primary dump.

\subsection{BLOCK 8 - STRUCTURAL PHASE - CUT OF A DITCH, PARALLEL WALLS AND INFILLING}

See tables p.287, 287

This Block lay in the centre of the site to the south of the circular structure (Block 11) (Figure 19). It consisted of the cut of a ditch, the insertion of two stone walls, [108] and [102] and the infilling behind the walls (Figure 23). The ditch was cut from the top of Block 10. It was a wide, flat-bottomed feature, with gently sloping sides measuring circa $4 \mathrm{~m}$ in width at the top and $1 \mathrm{~m}$ deep. Into this had been inserted two walls $0.7 \mathrm{~m}$ apart and aligned east-west (Plate 16). The

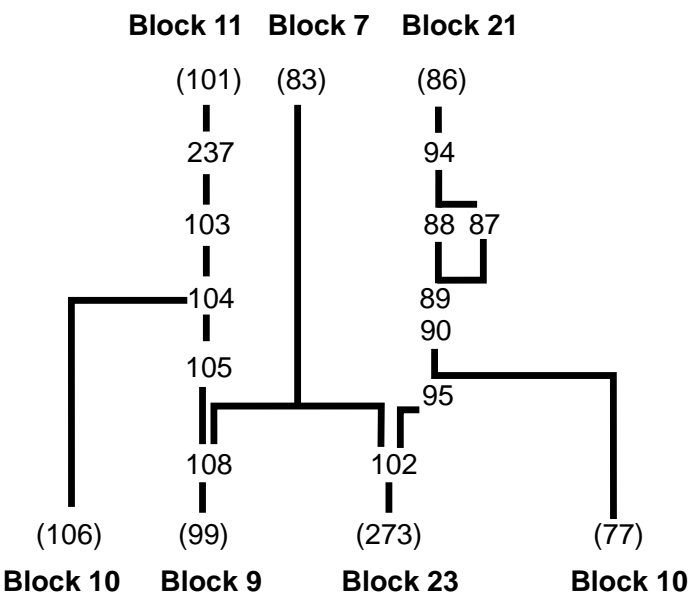




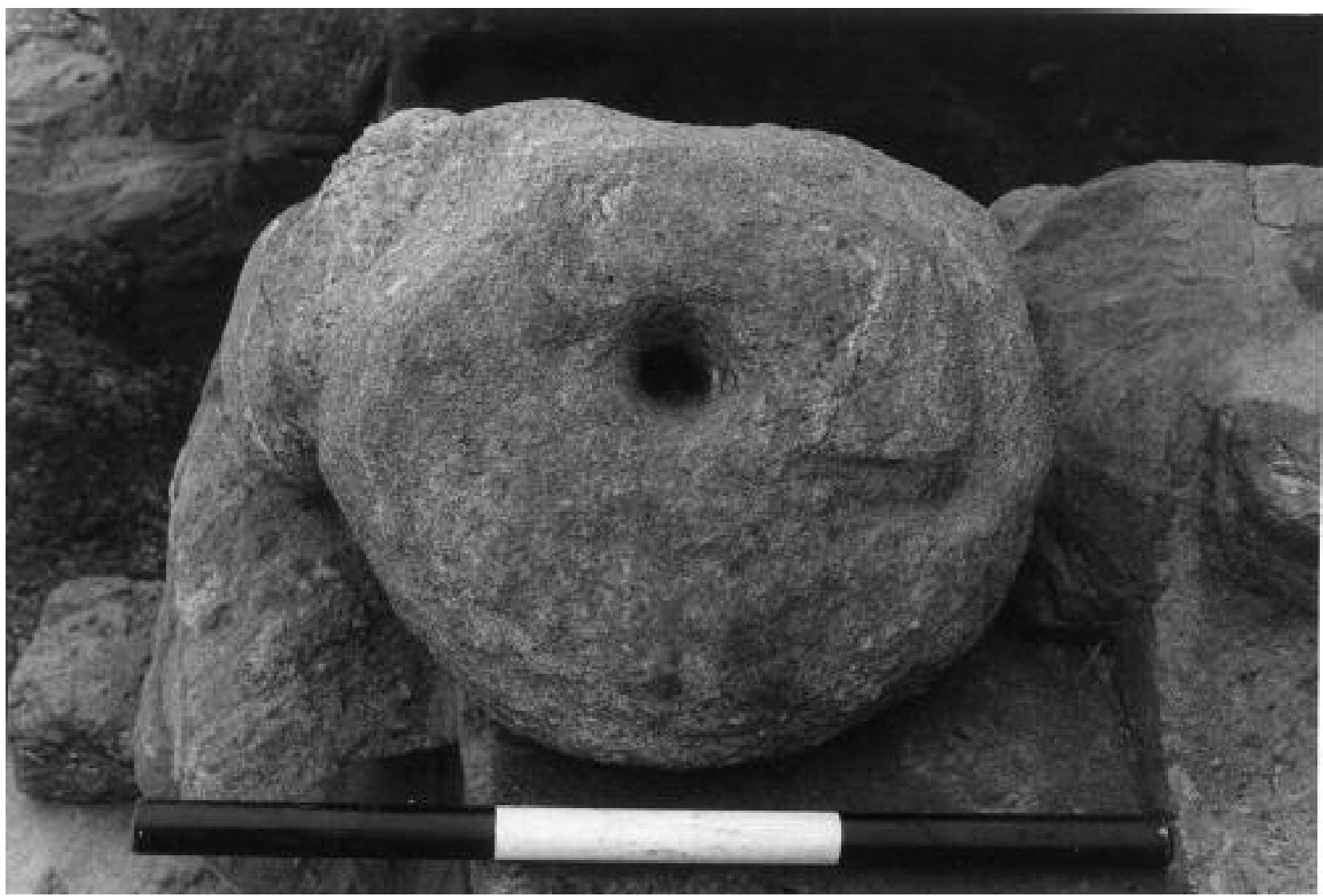

Plate 17. The quern, Block 8

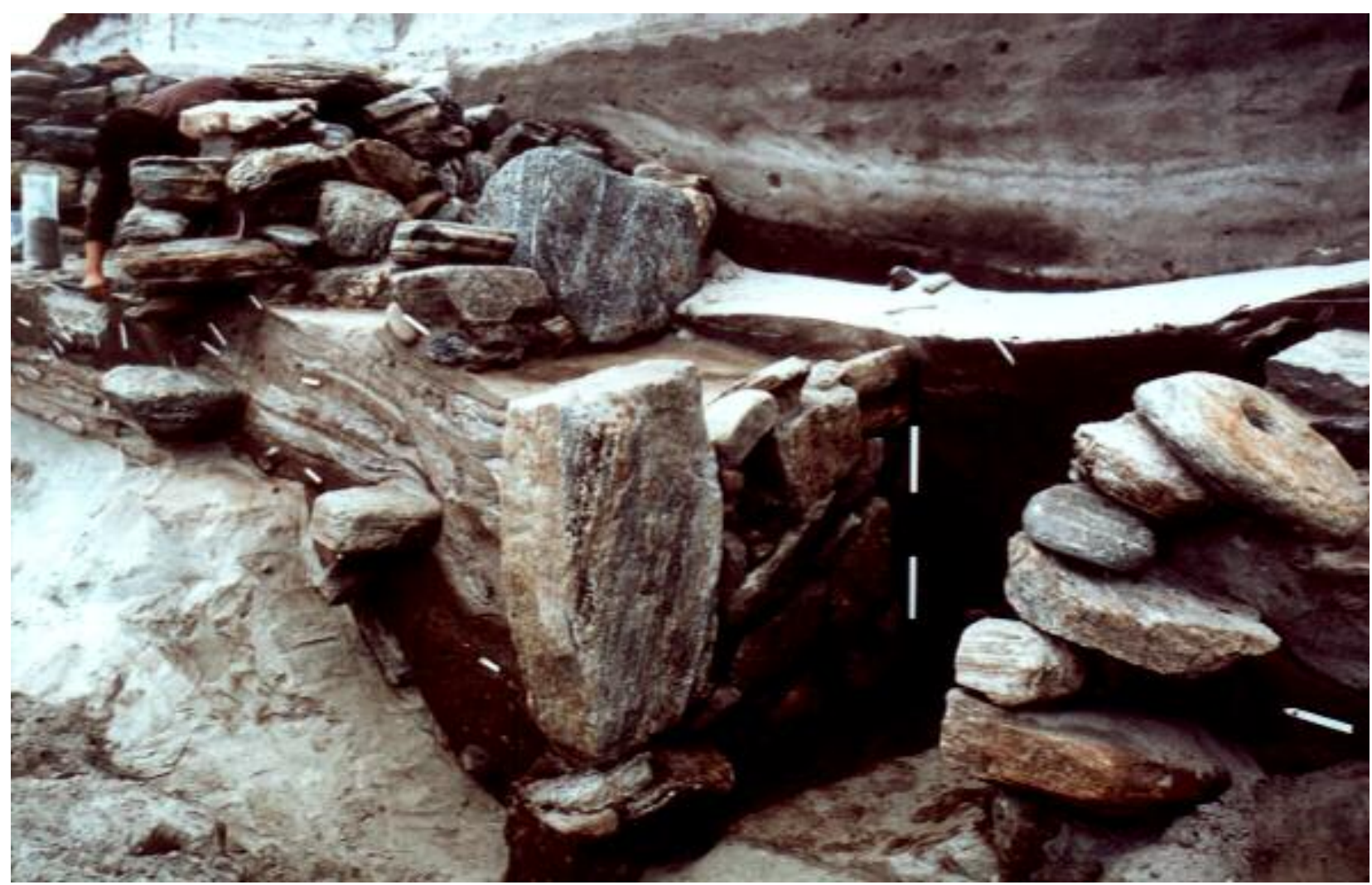

Plate 18. Baleshare (Block 8). Entrance passageway running into unexcavated sediments. Note the pillar stone demarcating the end of the left-hand wall, the dark sediments rich in anthropic materials between the walls and the worn, and now badly decayed, rotary quernstone used in the construction of the right-hand wall. The tip lines in the infilling behind the left wall are clearly visible 


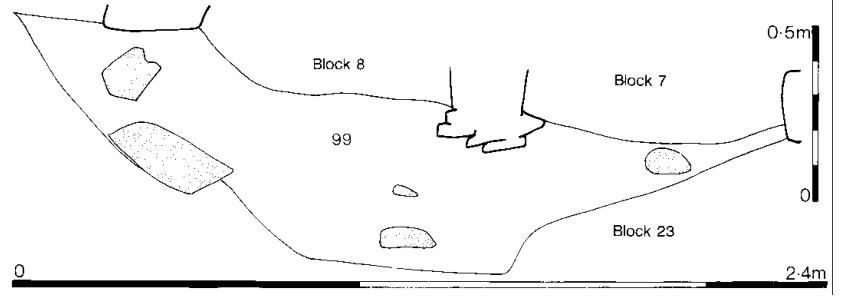

Figure 24. Block 9

south wall, [102], was $0.95 \mathrm{~m}$ high, constructed of seven courses of alternately large slabs and smaller rounded boulders, forming a tusking effect. It included a quern stone in its uppermost course (Plates $17 \& 18$ ). The front, seaward end of this wall was almost vertical and set back about $0.2 \mathrm{~m}$ from the front face of wall [108] which stood to the north. Wall [108] was constructed of more angular stones fronted by a relatively massive orthostat (Plate 18). This orthostat was sitting within a foundation slot cut into layer [99] (Block 9) and was packed with small stones. The sand layers on either side of these walls were a mass of lenses and irregular layers in which several tip lines could be observed. These were divided for convenience into a few contexts, [87], [88], [89], [90], [94] and [95] in the south and [103], [104], [105] and [237] in the north. These were described as light brown and grey sand or loamy sand layers.

\section{Field interpretation}

This Block was interpreted as a structural phase in which a ditch was cut through the layers of Block 10 immediately after which two parallel drystone walls were inserted. The vertical end of wall [102] suggests that there was once a second orthostat fronting this stone wall, as with wall [108]. The space to either side of the walls was then backfilled with sand, possibly derived from Block 10, to act as support for the walls while the central area was left open. This may have acted as a passageway or entrance for a structure. The Block mean IHI was calculated at 5,000, representing a range of between 200 and 18,000. The extremes are [89] (200) having only a small amount of macroplant material, and [105] $(18,000)$ which contains a large quantity of bone and a moderate quantities of other material relative to its volume. The IHI represents a wide range of materials present in small quantities. Only one of the six potsherds was examined and this was attributed to size class 2 . The $\mathrm{pH}$ values recorded for this Block range from 6.6 to 7.2 with a modal value of 6.8 . Phosphate values ranged from 1 to 4 . The layer boundaries were abrupt to diffuse.

\section{Archaeological interpretation}

The archaeological interpretation is consistent with the field interpretation. The IHI values do not rule out the possibility that the backfilling material was derived from Block 10. This structural phase is interpreted as an entrance passageway leading to a structure which may lie beneath the unexcavated midden-site or may have been on the seaward side of the section and therefore already destroyed by erosion.

\section{Specialist contribution}

Bones of sheep, cattle, pig and unidentifiable bird bones were recovered.

\section{Conclusion}

This is a structural phase that includes redeposited material chronologically unrelated to either the construction or use of the stone-walled passage.

\section{I0 BLOCK 9 - DITCH FILL}

See tables p. 287

This Block consisted of a ditch cut and its fill. The ditch lay in the middle of the site and was cut into the layers of Blocks 27 and 1 (Figure 19). It was $2.2 \mathrm{~m}$ wide and $0.7 \mathrm{~m}$ deep, with gently sloping sides and a flat bottom. The fill was an homogeneous dark brown, loamy sand, [99], with large stones lying on the northern slope of the ditch cut (Figure 24).

\section{Field interpretation}

This Block was interpreted as a ditch possibly contemporaneous with the walling at the base of Block 12. The ditch may have been a boundary or drainage ditch dug between the revetted midden deposits to either side. The homogenous fill indicated that it was deliberately backfilled, incorporating some tumbled stones from the wall to the north. The uppermost levels filled naturally with windblown sand (Block 10). The Block mean IHI was calculated at 1,000 , representing a single value. The IHI represents a narrow range of materials present in small quantities. Some $10 \%$ of the stone present was burnt. Of the twenty-five potsherds from this Block only two were examined and both were in size-class 2 . The $\mathrm{pH}$ value was 6.7, the phosphate value 3 .

\section{Archaeological interpretation}

The field interpretation is not contradicted by the post-excavation analysis. The low IHI value suggests that this deposit is almost sterile. The soil colour indicates the presence of some soil organic matter but the texture indicates that this is limited.

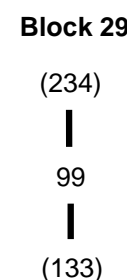

Block 18 


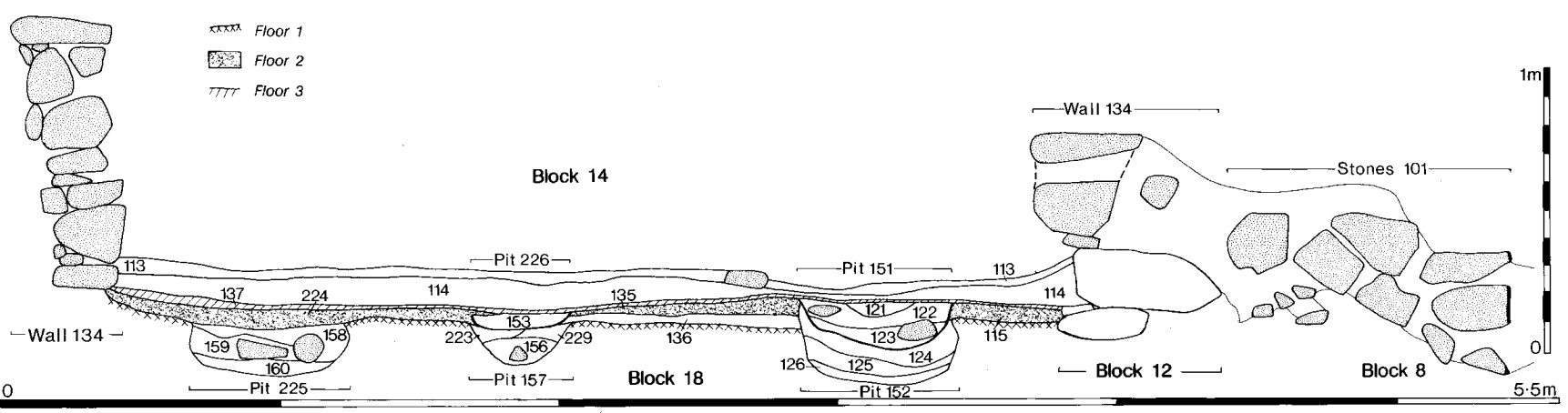

Figure 25. Block 11: section

\section{Specialist contribution}

Bones of sheep, cattle, pig, seal and gannet were identified as well as hake, cod and saithe.

\section{Conclusion}

The material within this ditch appears to have been deliberately introduced as backfill. The secondary derivative nature of the material in this Block prohibits its further meaningful interpretation.

\section{II BLOCK 10 - WINDBLOWN SAND}

\section{See table p.287, 288}

This Block lay in the centre of the site and consisted of two parts, one on either side of Block 8 (Figures $19 \& 23$ ). On the south, the layers [93], [74], [91] and [77] lay against wall [92] to a maximum depth of $0.4 \mathrm{~m}$ and extended $0.7 \mathrm{~m}$ from the wall base. On the north several minor, brown-coloured layers could not be conveniently differentiated and so were grouped as the single context, [106]. These lay against the basal stones of the northern wall (Block 12) to a maximum depth of $0.5 \mathrm{~m}$ and extended $1.1 \mathrm{~m}$ from the wall base, over layer [68] of Block 1. Where described, these layers were light brownish-grey to brown/ dark-brown loamy sands.

\section{Field interpretation}

These windblown sand deposits had accumulated in the space between the two walls of Block 12 some time after the main

Block 8

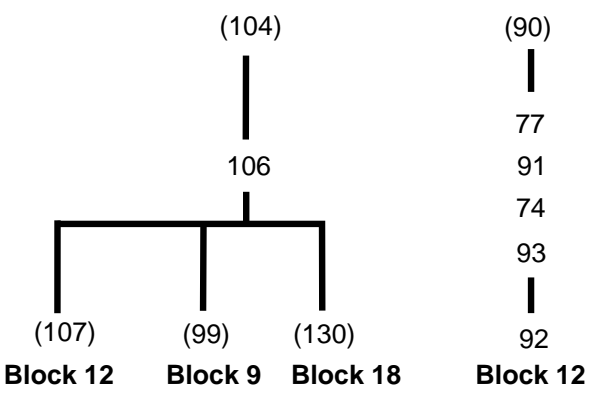

part of the ditch had been backfilled (Block 9). They probably once extended right across the ditch but have been cut in two by the insertion of the structure in Block 8 . The Block mean IHI was calculated at 3,500, based on data from only two contexts. The IHI represents a wide range of infrequently occurring materials. Of the four potsherds recovered, only one was examined and it was of average size for the site, falling into size-group 3 . The $\mathrm{pH}$ values recorded for this Block range from 6.3 to 7.8 which is the greatest range for any Block on the site. The modal value was 6.7. Phosphate values ranged from 2 to 5,2 being the commonest value. The layer boundaries were predominantly clear and sharp.

\section{Archaeological interpretation}

There is no conflict between the archaeological and the field interpretations. What is worthy of comment, however, is that though these are windblown sands they are not 'sterile' in the accepted archaeological sense. Slag is the only material found on this site which was not found in these sand layers.

\section{Specialist contribution}

Bones of sheep, cow and pig were retrieved.

\section{Conclusion}

These are, essentially, windblown sands which incorporate small amounts of site debris, accidentally included rather than deliberately dumped.

\section{I 2 BLOCK II - STRUCTURAL PHASE - CIRCULAR STRUCTURE}

See tables p.288, 289, 290

* ${ }^{14} \mathrm{C}$ date $2320 \pm 50$ bp (GU-2165) from [113] (Periwinkle).

* ${ }^{14} \mathrm{C}$ date $2250 \pm 50$ bp (GU-2166) from [265] (Periwinkle).

The wall and floor levels of a small circular structure in the centre of the site were included in this Block ((Figure 19 $\&$ Plate 19). The drystone wall, [134], was constructed of up 


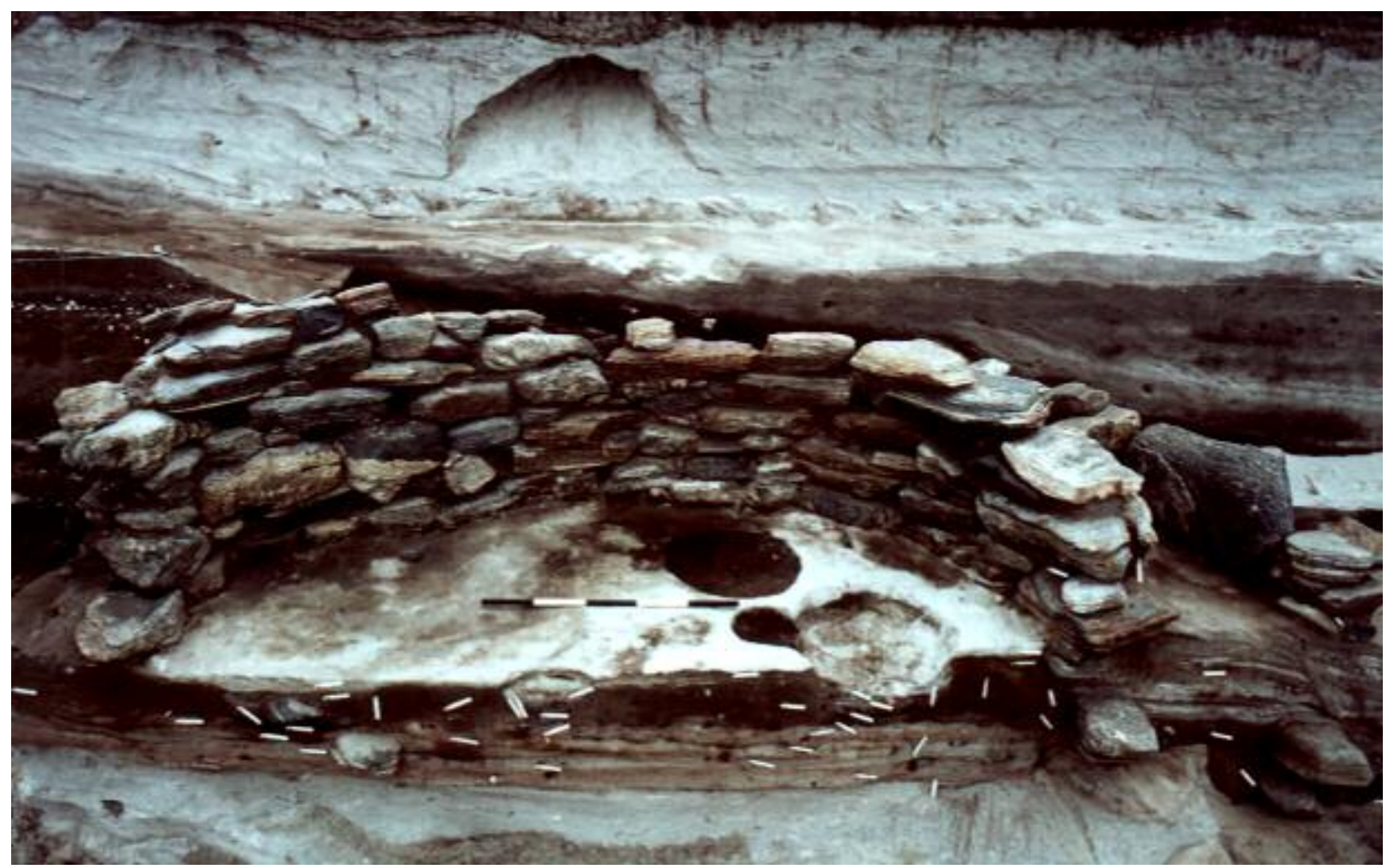

Plate 19. Baleshare. Circular structure, Block 11, excavated to Floor Level 2. The revetment wall, Block 12, is visible to the right of the structure

to eight courses of irregularly sized stones (Figure 25). It measured $1 \mathrm{~m}$ high in the north but decreased in height to the south. The feature formed a third of the circumference of

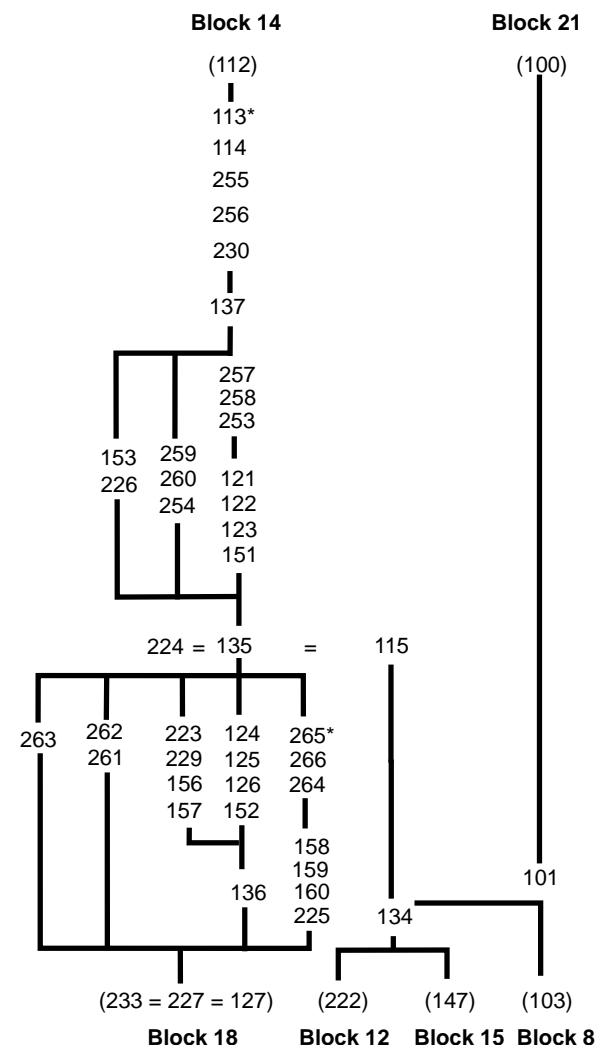

a circular structure which measured $3.3 \mathrm{~m}$ along the section line but would have formed a building with, if circular, an internal diameter of circa $4 \mathrm{~m}$. The wall on the north side was one to two stones in thickness and abutted the deep midden layers of Block 15 and 16. There was no visible cut line through the midden deposit. On the south side, the internal face of the wall was constructed on top of the earlier wall in Block 12. Uncoursed masonry, [101], emerged from the profile to the south of wall [134]. This was faced on its south side and had an east-west alignment. It was parallel to wall [108] (Block 8) and would seem to have originally converged with wall [134]. The masonry was $1 \mathrm{~m}$ wide and infilled with sand ([100], Block 21).

\section{Floor Level I (Figures 25 \& 26)}

The earliest surface was formed of the layer represented by the feature numbers [223], [227] and [127] which made up Block 18. A thin layer of white sand, [136], appeared in the section immediately above the floor level but did not extend back more than $0.3 \mathrm{~m}$ from the exposed face. Cutting these layers were three large circular pits, one small pit and three spreads of burnt material. Pit [264] had cut the top fill of pit [225].

There were two thin spreads of burnt material, [262] and [261], in irregular patches immediately to the south of the pit [264], and one spread of burnt material, [263], against the inside face of the wall. The latter layer extended a distance of $2 \mathrm{~m}$. 


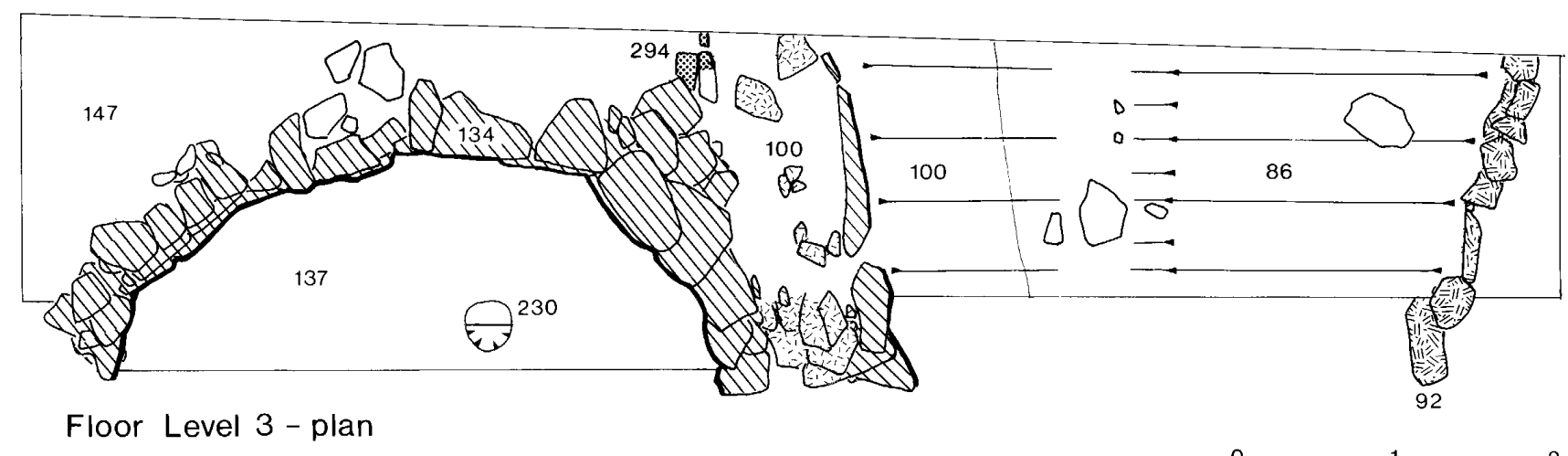

Floor Level 3 - plan
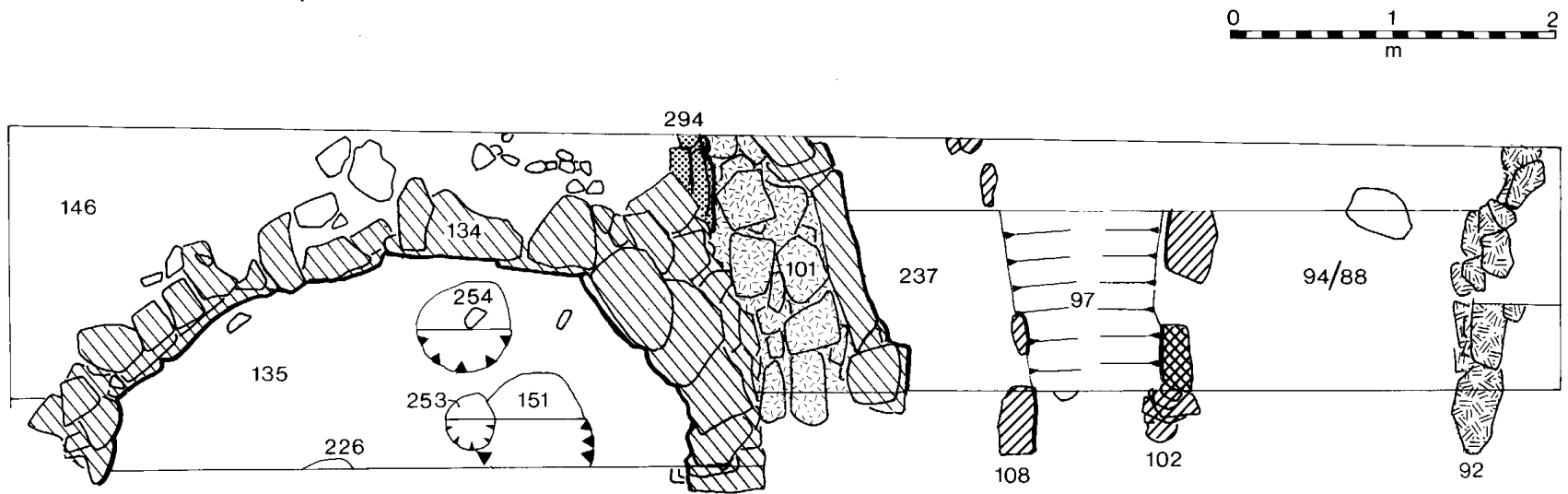

Floor Level 2

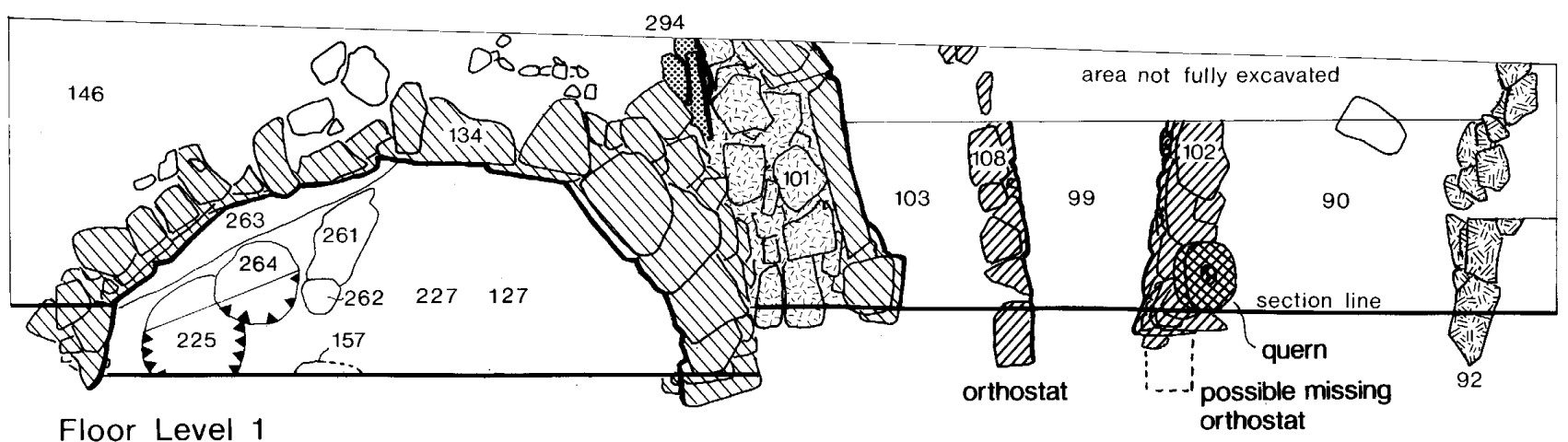

Figure 26. Block 11: plans of Floor Levels 1, 2 and 3

\section{Floor Level 2 (Figures 25 \& 26)}

The second floor level was of white sand, [224], [135] and [115]. It measured up to $0.06 \mathrm{~m}$ thick and extended across the whole structure. Two large circular pits and two smaller pits were cut into the floor from this level. Pit [151] had been cut almost directly above the earlier pit, [152] and feature [226] lay directly above pit [157].

\section{Floor Level 3 (Figures 25 \& 26)}

The third floor level consisted of layer [137], a white sand which had a maximum depth of $0.3 \mathrm{~m}$. Cut into this was a small pit, [230]. These layers and features were sealed by the layers of Block 14.

\section{Floor Level 4 (Figure 25)}

This consisted of a layer of white sand, [114], which extended across the whole width of the structure to a depth of between $0.04-0.15 \mathrm{~m}$. This layer was not sampled so no finds were recorded. Above this was layer [113], a dark brown sand. 


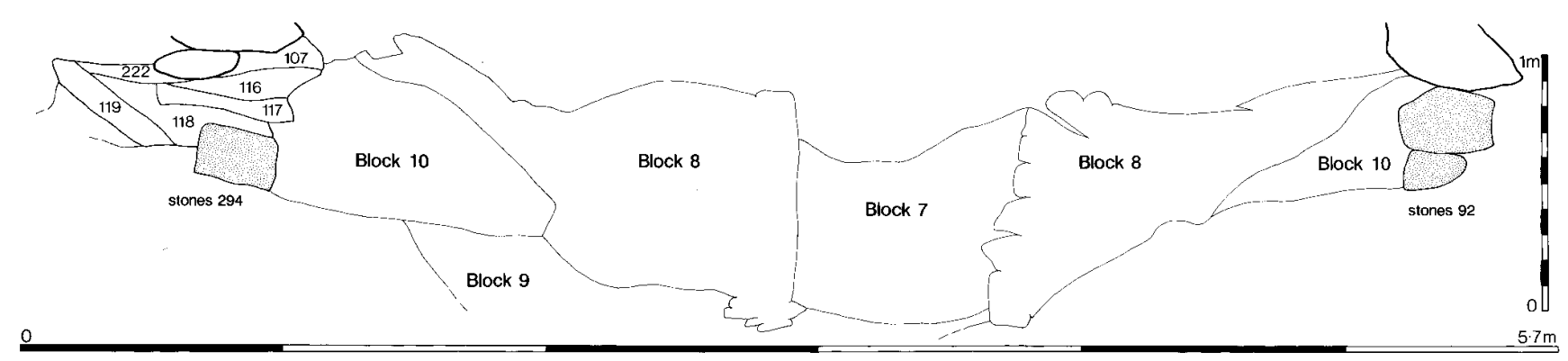

Figure 27. Block 12

\section{Field interpretation}

This Block consisted of the remains of a circular drystone structure with an internal diameter of circa $4 \mathrm{~m}$. It's north and east sides had been set into midden-site layers presumably for support as this wall could not have been freestanding. No cut line resulting from its insertion was visible within the midden material, but this may have been destroyed by the thrusting of stones into a vertically cut face. In the south, where the midden was absent, the masonry, [100] and [101], may have provided the necessary support for the circular walling. The fact that the masonry, [101], continued into the section suggested that it served a further function, which only further excavation could reveal. A small quantity of rubble was found within Block 14 which suggests that the walls did not stand much higher than their present level.

The large pits, [151], [152], [225], [264] and [254], within the structure were all cleanly cut and formed almost perfect circles. They contained large quantities of charcoal, especially in their primary fills.

The Block mean IHI was calculated at 87,000 , representing a range of from 5,500 to 486,000 . The higher values for [258], [260] and [160], are produced by contexts within pits which are both rich in materials and restricted in volume. The IHI represents a wide but variable range of materials present in variable, but generally significant quantities. Burnt stone was found in some six contexts, with values ranging from $<10 \%$ to $20 \%$ The $\mathrm{pH}$ values recorded for this Block range from 6.1 to 7.7 with a modal value of 6.9. Phosphate values ranged from 1 to 5 , the most common value being 2 .

\section{Archaeological interpretation}

The field interpretation remains unchanged after the post-excavation analysis.

\section{Specialist contributions}

The animal bones from [126], the lowest fill of pit [152], floor 1 merit some comment in that they consisted of numerous neo-natal lamb bones (Chapter 9.3.3). The following body parts were represented:

Head: including 1 pair of maxillae and 1 pair of mandibulae. Trunk: 19 cervical, thoracic and lumbar vertebrae, 1 sacrum, a caudal vertebra, 23 ribs.

Left forelimb: including humerus, radius, ulna and metacarpal - all matching pairs with right forelimb (also 1 distal metacarpal of indeterminate side, representing a second individual).

Right forelimb: including scapula, humerus, radius, ulna and metacarpal.

Left hindlimb: including 2 pelves, 2 femora, 2 tibiae, 1 calcaneus, 1 astragalus and 1 metatarsal.

Right hindlimb: including 2 pelves, 1 femure, 1 tibia, 1 calcaneus, 1 astragalus and 1 metatarsal - all matching pairs with left hindlimb.

Toes: 7 first, 8 second and 4 third phalanges.

The jaws, trunk, forelimbs (except the metacarpal of indeterminate side) and toes could all be derived from a single carcass. In the case of the hindlimbs, particularly the left hindlimb, at least two (and probably only two) individuals are represented. There are no indications that the carcass was butchered in any way before its deposition. There was no evidence for gnawing by carnivores or rodents.

Bones of pig, red deer and hake were also identified from this Block together with unidentifiable bird bones.

\section{Conclusion}

That Block 11 constitutes a building with associated strata is beyond doubt. The function of the building, however, remains unclear. The superimposition of succeeding pits suggests that some specific function was undertaken in the structure and that it, or rather, its physical manifestations, remained constant throughout several episodes of 'reflooring'. It is not impossible that it was a domestic structure, albeit lacking both the central hearth and the radial segmentation of the wheelhouse, and while the former may have disap-

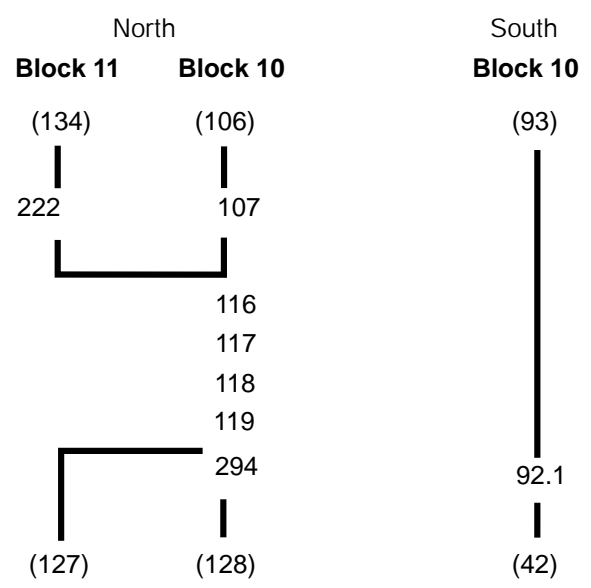

Block 18 Block $27 \quad$ Block 2 


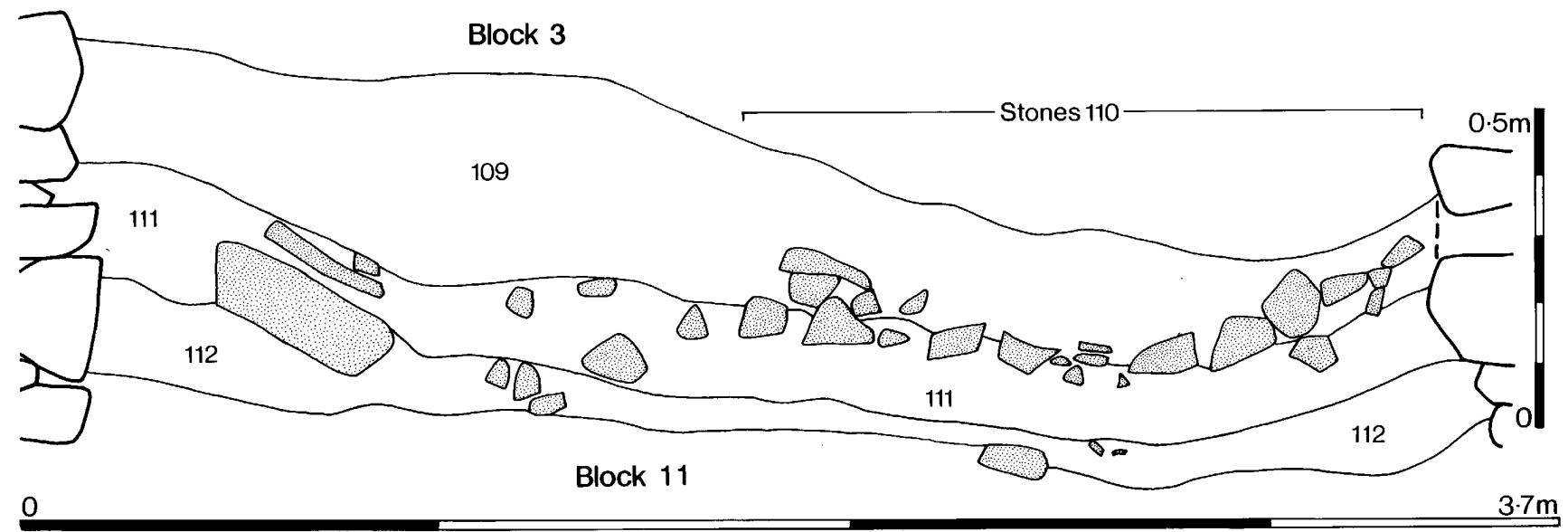

Figure 28. Block 14

peared due to erosion it is very unlikely that evidence for the latter could have completely disappeared. The presence of the neo-natal remains of two lambs prompts the speculation that it may have been an unroofed lambing pen.

\section{I3 BLOCK 12 - STRUCTURAL PHASE - REVETTING WALLS}

This Block consisted of two drystone walls lying in the centre of the site (Figure 19; Plates $16 \& 19$ ). As both walls were abutted by the windblown sand of Block 10, they were included in the same Block. In the north a single stone in the section, [294], represented the basal stone of a wall (Figure 27). After the section was drawn, further stones were observed above [294], up to the base of wall [134] (Block 11), a height of at least $0.5 \mathrm{~m}$. When the stones [101] were removed from behind wall [134], a section of walling thought to be a continuation of [294], was seen emerging from beneath [134] with an east-west alignment (fig 00). This could not be excavated because it was too close to the edge of the sampled area. Layers [107], [116], [117], [118] and [119] infilled the wall stones. Only layer [119] was described and this was a brown loamy sand. In the south the two basal stones of [92] were included in this Block (subsequently named [92.1]). These were $0.4 \mathrm{~m}$ high, set into layer [68] of Block 1 and faced to the south. The lowest layers of Block 2 abutted this wall on its south side. The distance between the two walls was $4.3 \mathrm{~m}$. A berm of $0.5 \mathrm{~m}$ lay between each wall and the cut of the ditch.

\section{Field interpretation}

This Block was interpreted as two drystone walls which revetted midden-site deposits to either side. Their construction may have been contemporaneous with the digging of the ditch in Block 9. One context provided an IHI value of 12,000 . It represents a wide range of infrequently occurring materials. Fragments of pumice were retrieved from [119]. Only three potsherds were recovered, none of which were examined. Both of the $\mathrm{pH}$ values were 6.5. The two available phosphate values were 4 .

\section{Archaeological interpretation}

The field interpretation of this structural Block takes precedence over the archaeological interpretation. The layers lying north of wall [294] may have been cut for the insertion of this wall, but the balance of the probabilities lies with their accumulation against the standing wall. Layer [119] may be a remnant of a more extensive layer cut for the insertion of the wall. Layers [118], [117] and [116] were seen between the stones above [294], which collapsed before the section was drawn, and seem to have accumulated after the wall's construction.

\section{Specialist contribution}

Bones of sheep, cattle and pig were identified.

\section{Conclusion}

This Block consists of two structural elements with which only redeposited material, apparently used in their construction, seem to be associated. Only horizontal excavation could reveal if these walls are the single wall of a dug-in house like that in Block 11. As revealed in section their function appears to be that of revetting the deposits of Blocks 1 and 2, on the south and, possibly, the southern extensions of Blocks 18, 26 and 25, subsequently removed by the insertion of Block 11. Both walls in Block 12 were later used as foundations for Block 11 on the north and the revetment of Block 2 on the south.

\section{I4 BLOCK I4 - INFILLING AND COLLAPSE OF CIRCULAR STRUCTURE}

See tables p. 291

Block 14 lay in the centre of the site within the drystone circular structure, Block 11 (Figure 19). It consisted of several layers which spread across the entire width of the structure, a distance of $3.3 \mathrm{~m}$ in section (Figure 28). They varied from $0.3-0.7 \mathrm{~m}$ in depth. These layers consisted of light to grey 


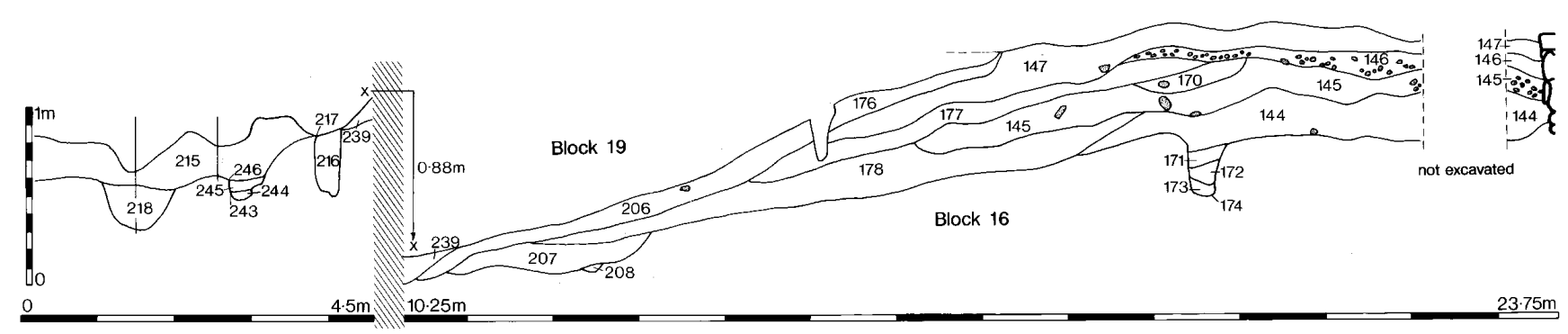

Figure 29. Block 15

Block 3

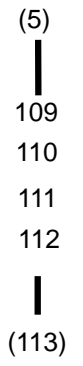

Block 11

brown sands and a layer of stones, [110], which extended from the south wall. Towards the north side a large stone, $0.45 \mathrm{~m}$ long in section, lay with its base embedded into the top of layer [112].

\section{Field interpretation}

This Block was interpreted as the post-abandonment fills of the circular structure in Block 11, the south wall collapsing to form the layer of stones [110]. The slightly dished nature of the fills suggested that they were the result of silting rather than backfilling. The colour of the sand layers indicates a moderate humic content which would suggest that this material incorporated some deposits from midden-site layers in the vicinity. The Block mean IHI was calculated at 7,000, representing a range of from 4,500 to 10,000 . The IHI represents a wide range of materials present in moderate quantities. Of the fifty-six potsherds from this Block eleven were examined and they range in size-class from 1 to 7 , three sherds being larger than average. The $\mathrm{pH}$ values recorded for this Block range from 7.2 to 7.4 with a modal value of 7.3. Phosphate values ranged from 3 to 4 , the most common value being 4 . The soil ranged in colour from light to dark brown and their textures were all sand.

\section{Archaeological interpretation}

The deposits are similar in appearance, have low IHI values and contain increasingly more sea-shell up the profile. The archaeological interpretation is that these deposits constitute the infilling and collapse of the structure. The layers [113] and [114] were initially included in this Block but have been re-interpreted as floor layers associated with Block 11.

\section{Specialist contribution}

Bones of sheep, cow, pig and thrush were recovered, together with single bones of flatfish and a gadoid.

\section{Conclusion}

The post-excavation analyses concur in seeing these deposits as the slow infilling of a deserted structure.

\section{I5 BLOCK I5 - MIDDEN-SITE DEPOSIT}

See tables p.293, 292, 293

* ${ }^{14} \mathrm{C}$ date $2375 \pm 55$ bp (GU-1963) from layer [239] (Periwinkle)

* ${ }^{14} \mathrm{C}$ date $1970 \pm 80 \mathrm{bp}$ (GU-2554) from layer [146]

(carbonised seed)

Block 15 formed a dome-shaped mass to the north of the circular structure, extending to the north end of the excavation, a distance of $18.8 \mathrm{~m}$ (Figure 19). Its depth varied from $0.65 \mathrm{~m}$ at the south to about $0.01 \mathrm{~m}$ at the north. Its south end had been cut by the insertion of the central structure. To the east of the section face, the layers of this Block were seen

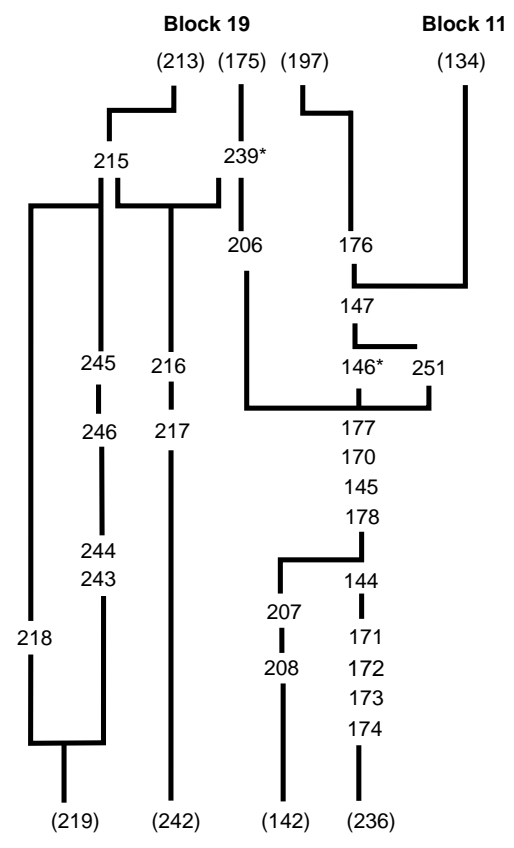

Block 16 


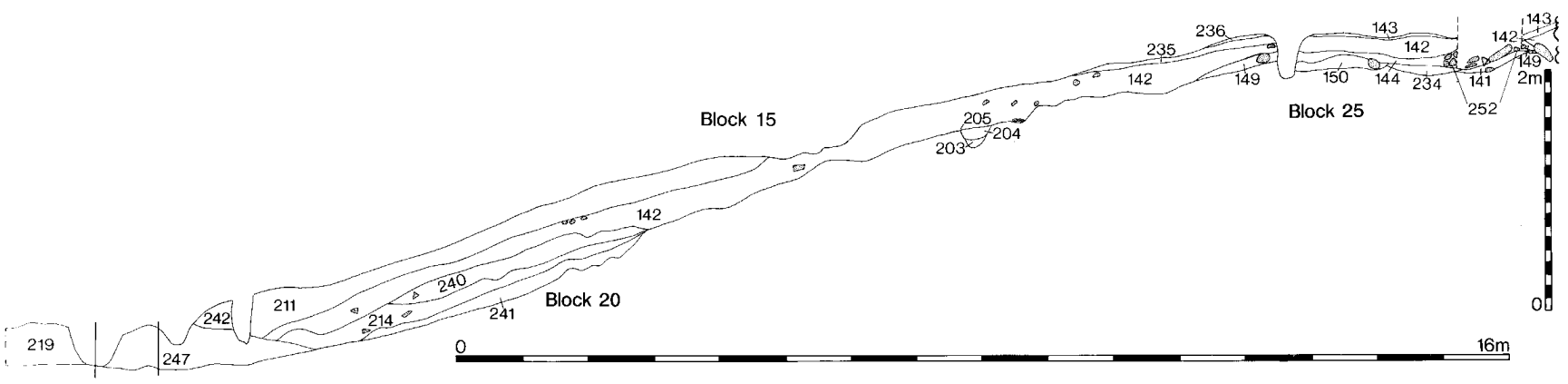

Figure 30. Block 16

to continue south and to abut the wall in Block 12 (see layers [146] and [147], Figure 28). Block 15 consisted of fourteen layers, none of which extended the full length of the Block (Figure 29). Most were concentrated in the south where the Block was deepest. They ranged in colour from very dark greyish brown to brown and in texture from silty sandy loam to a loamy sand. The boundaries were generally smooth and clear. Layer [146] had an especially high concentration of shell and carbonised seeds. Layer [215], a black loamy sand, was revealed during the sampling process and was stratigraphically level with layer [146]. Five ditch features were seen in section within this Block. Before sampling, the ditch [174] was thought to have been cut from the top of layer [144]. After $0.5 \mathrm{~m}$ was removed, evidence suggested that this ditch was much larger and cut from within the body of Block 15. The others were cut from the top of layers [247] and [211] (Block 16).

\section{Field interpretation}

This Block was interpreted as a midden-site deposit in an area of habitation. This was because of it's morphology, horizontal extent, colour and anthropogenic inclusions. The Block mean IHI has been calculated at 44,000. If however the ditch deposits are removed from the calculation this value rises to 55,000, which is more representative of the midden-site deposits, while a value of 19,500 represents the ditch fills. The value, 55,000, is representative of a wide range of materials present in large amounts. Burnt stone is present in twelve contexts and pumice in three ([176], [177] and [216]). Of the 345 potsherds from this Block, seventy-nine were examined and while the majority of these were small a number of larger sherds also survived. Soil $\mathrm{pH}$ values range from 6.4 to 7.8 with a modal value of 7.3 , and they cover the full range exhibited in the entire site. Phosphate values are similarly variable, $1-4$ on the $0-5$ scale. The soils were brown to very dark brown and the textures were mainly loamy sands although three were sandy loams. They had smooth to diffuse boundaries, all of them clear.

\section{Archaeological interpretation}

The heterogeneity of the deposits and the variability of almost every recorded characteristic over the separate layers within the Block, together with the absence of ard, or other cultivation marks, suggest that this Block consists of an accu- mulation of midden-site deposits. The presence of a number of ditches and gullies also supports this interpretation since, in general one would expect a greater number of discrete archaeological features to occur nearer to a settlement than one might expect at some distance from it, as for example in the middle of a cultivated area.

\section{Specialist contribution}

Bones of sheep, cattle, pig, red deer, dog were recovered. Bird species identified were whooper swan, gull and possibly wigeon. Fish species identified were tope, cod and flatfish.

\section{Conclusion}

The post-excavation analyses support the original site interpretation of this Block as comprising midden-site deposits.

\subsection{BLOCK 16 - MIDDEN-SITE DEPOSIT}

See tables p.294

Block 16 lay in the north part of the site beneath Block 15 (Figure 19). It stretched from the circular structure, to the north edge of the excavation, a distance of $21 \mathrm{~m}$. The Block was generally deeper towards the north and measured between $0.3-0.6 \mathrm{~m}$ in depth. It consisted of fourteen layers

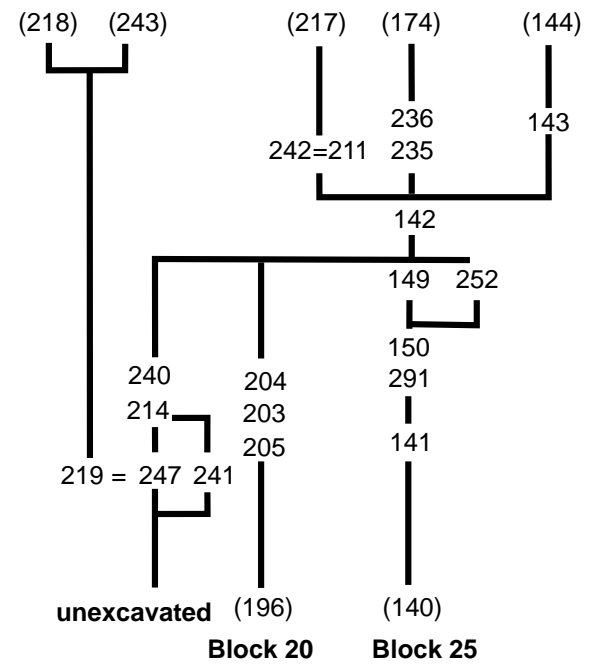




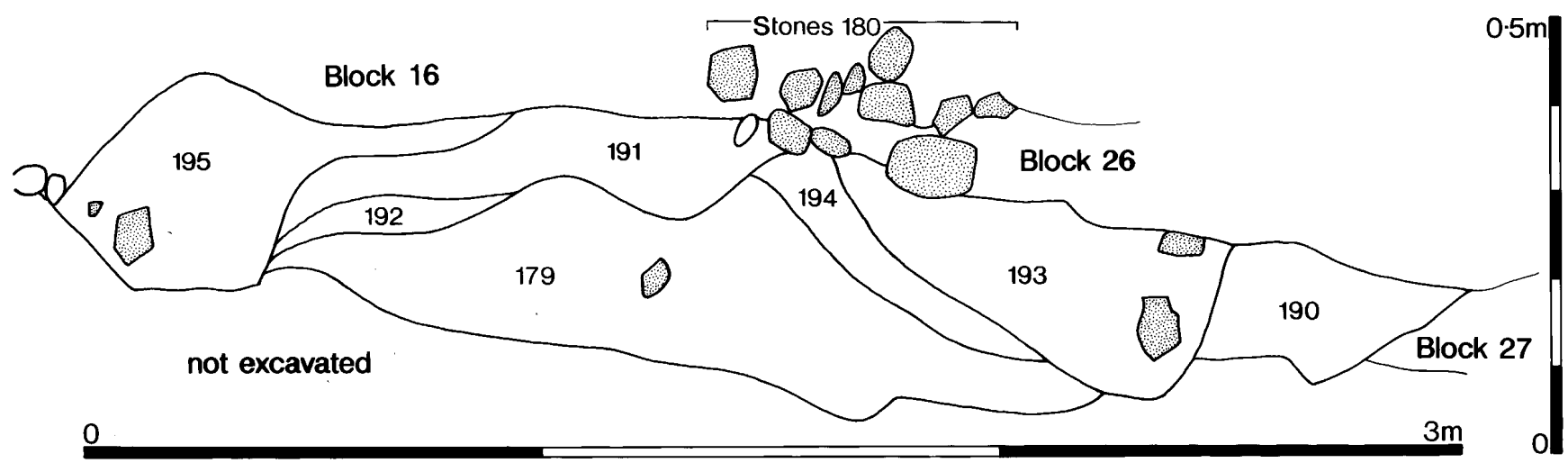

Figure 31. Block 17

which ranged in colour from very dark, grey-brown to pale brown and in texture from silty, sandy loam to pure sand (Figure 30). [252] consisted of a spread of plate-like stones 0.1-0.35 m long. The bases of layers [142], [143], [149] and [140] were described as wavy but no ard marks were observed. [205] is a shallow feature, $0.14 \mathrm{~m}$ deep and $0.04 \mathrm{~m}$ wide, cut from the top of layer [196] (Block 20). It was filled with [203] and [204].

\section{Field interpretation}

This Block was interpreted as a series of midden-site layers because of their dark colour, loamy texture and abundance of finds, especially carbonised seed. The stones [252] which lay on top of layer [291] may indicate the previous existence of a structure, removed by the insertion of Block 11 . The presence of the wavy boundaries may indicate cultivation of the layers to the north of the structure. This Block consists of eighteen contexts and was interpreted in the field as a set of midden-site deposits. The Block mean IHI was 29,000 and this high value represents a full range of material types and an abundance of almost every type. Pumice was retrieved from six contexts and one piece, from [150], was carved (Figure 77a). Almost every context contained burnt stone in quantities ranging from $10 \%$ to $70 \%$ of the stone present. Of the 901 potsherds from this Block, 211 were examined and their distribution is markedly Poisson. Sherds up to size class 12 were recorded and almost one third of the sherds were above average in size. The $\mathrm{pH}$ values ranged from 6.8 to 7.4 , with a modal value of 7.2. These are low to average values for the site. The phosphate values vary greatly between contexts, ranging from 1 to 4 . The soils are pale to very dark brown sands to sandy loams with clear to wavy boundaries. One context, [252], consists largely of a spread of stone which may be derived from the construction phase of a building which does not appear in the profile.

\section{Archaeological interpretation}

The archaeological interpretation does not refute the field interpretation of these layers as midden-site deposits, although the south end of their distribution, now truncated by the insertion of the circular building of Block 11, contains layers like [252] which may, themselves have related to an adjacent building or buildings. Block 16 may have been created as midden-site deposits with the wavy layer boundaries suggesting perhaps that they were subsequently cultivated.

\section{Specialist contribution}

Bones of sheep, cattle, pig, red deer and seal were recovered. Bird species include greylag goose, manx shearwater and possibly redshank. Fish species identified were tope, hake, ling and cod.

\section{Conclusion}

The post-excavation analyses indicate that these deposits were heterogeneous, may have been intermittently and briefly cultivated, contained refuse (albeit not necessarily rich in decaying organic matter), exhibit variable depositional rates, were laid down near upstanding structures and may have been, intermittently, grazed. This confirms their identification as midden-site deposits.

\section{I7 BLOCK 17 - DUMP OF BURNT MATERIAL}

See tables p. 294

Block 17 lay in the north part of the site, within a slight hollow in the surface of the cultivated deposits of Blocks 18 and 20 (Figure 19). It extended for a total of $3 \mathrm{~m}$ and was up to $0.3 \mathrm{~m}$ deep (Figure 31). The seven layers in this Block contained a high proportion of burnt material. Layer [195] was a dark brown, silty, sandy loam.

\section{Field interpretation}

This group of layers is a dump of burnt deposits probably from a hearth, although no associated hearth structure was observed. The Block mean IHI was calculated at 36,500. All contexts, save [193], returned a wide range of anthropogenic materials in large, but variable, quantities. Burnt stone was common in all contexts, for the most part consisting of between $10 \%$ and $50 \%$ of the stone present. Some $90 \%$ of the stone in [193] were burnt. This context 


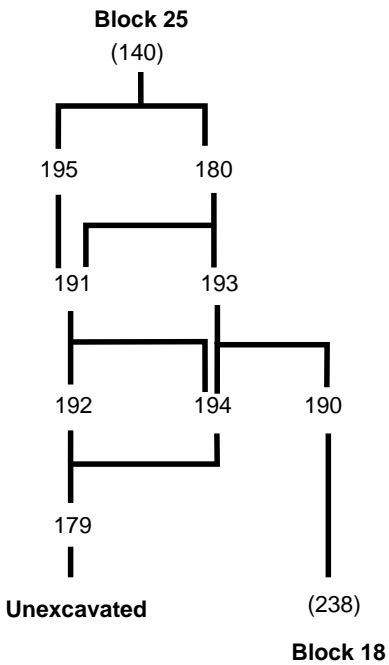

consisted of a single deposition of burnt material. Of the 110 potsherds from this Block, sixteen were examined and while the majority was small a few large sherds were recorded. Phosphate levels were variable, between 1 and 4 and most at level 2 . The $\mathrm{pH}$ values were average to high for the site, at 6.1 to 7.7. with a modal value of 7.4. Only one of the soil layers, [195], was adequately described and this was a dark brown silty sandy loam.

\section{Archaeological interpretation}

The wide range and variability in the materials present along with variability in the potsherd size ranges, the presence of large quantities of burnt stone and the variable soil characteristics, are all factors consistent with the field interpretation of a dump of burnt material.

\section{Specialist contribution}

Bones of sheep, cattle, pig, red deer and possibly greenshank were recovered, together with unidentifiable bird bones and flatfish.

\section{Conclusion}

The anthropogenic component and the other examined characteristics confirm the field observation that this is a primary dump of hearth refuse from within a nearby structure.

\section{I8 BLOCK 18 - CULTIVATED DEPOSIT}

See tables p.295, 295

* ${ }^{14} \mathrm{C}$ date $2740 \pm 60$ bp (GU-1965) from layer [127] (Periwinkle \& Limpet).

* ${ }^{14} \mathrm{C}$ date $2900 \pm 140$ bp (GU-2558) from layers [233], [227] (this Block) and layer [139] (Block 26) (Animal bone). Block 18 extended for $7.6 \mathrm{~m}$ in the middle of the site, and was $0.25 \mathrm{~m}$ deep. It consisted of one layer divided in the section into three components by the pits cut from within the

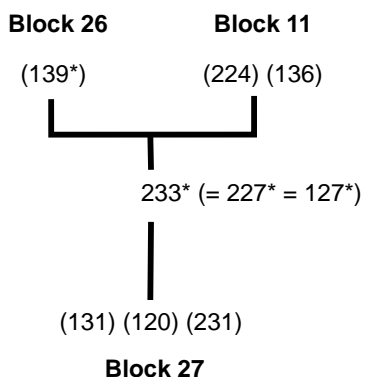

circular structure (Figure 19). The soil textures ranged from loamy sand to sandy loam and the colour from dark brown to brown/dark brown. There were ard marks at the top of the Block, immediately beneath Block 27.

\section{Field interpretation}

This Block was interpreted as a cultivated deposit because of its dark colour, its extent and its level nature. The presence of ard marks within the block and in its surface suggests that the Block above was cultivated, albeit that the latter refer to cultivation from a higher level. The Block mean IHI is 28,000 and this is derived from a wide range of anthropogenic materials present in reasonably large quantities. Two of the three contexts contained burnt stone, present in amounts less than $5 \%$ of the total stone component, and layer [233] contained pumice. Some fourteen of the eighty-eight potsherds were examined and these are all small in size, class 3 or smaller. Phosphate values are low at 2 and the soil $\mathrm{pH}$ is also somewhat low for the site at 6.5 . The soils are loamy sands or sandy loams, with clear boundaries which are irregular (where ard marks occur) to smooth. The deposit is dark brown in colour.

\section{Archaeological interpretation}

The archaeological interpretation is consistent with the field interpretation. The range and quantity of anthropogenic inclusions and the comminution of the potsherds, are all consistent with the manuring of this soil with material from a farmyard midden. The dark soil colour, medium levels of phosphate and low $\mathrm{pH}$ are consistent with this hypothesis.

\section{Specialist contribution}

Bones of sheep, cattle, pig, red deer, thrush, ling, tope and cod were recovered.

\section{Conclusion}

The full range of post-excavation analyses support the field and archaeological interpretation of this deposit as a cultivated deposit. 


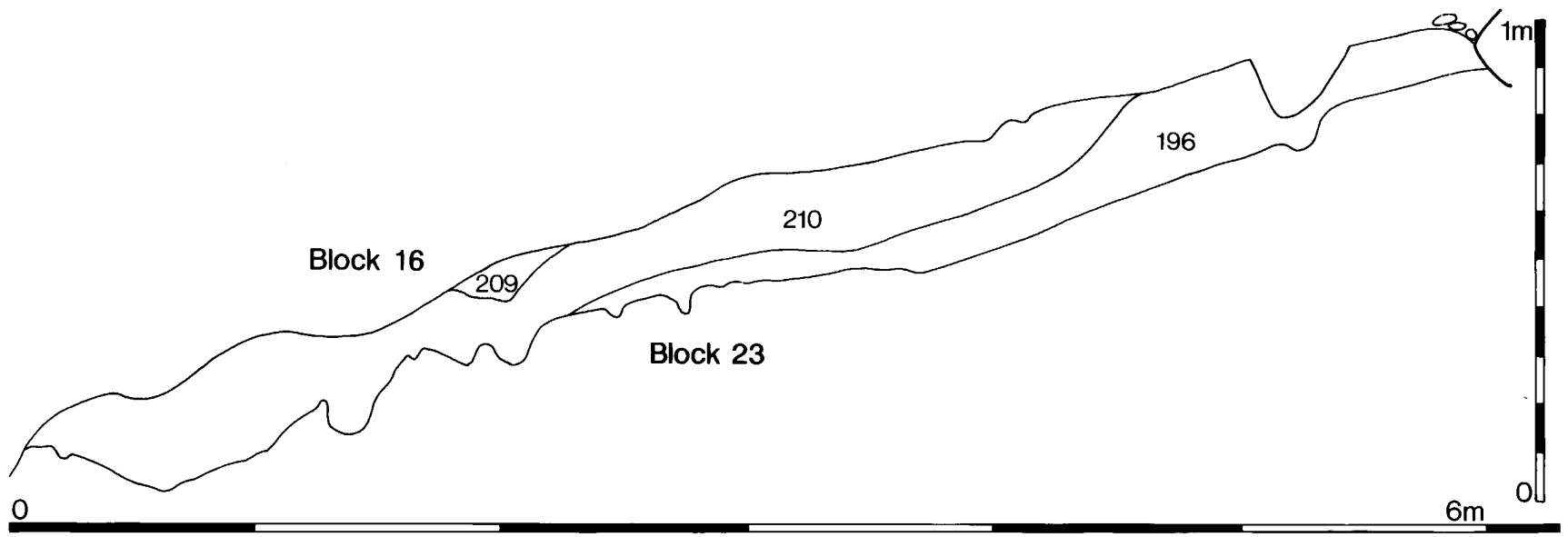

Figure 32. Block 20

\subsection{BLOCK 19 - MIDDEN-SITE DEPOSIT}

See tables p. 295

* ${ }^{14} \mathrm{C}$ date $2265 \pm 50$ bp (GU-1970) from layer [212] (Periwinkle).

This Block lay at the top of the north midden-site deposits (Figure 19). It was about $0.1-0.2 \mathrm{~m}$ in depth, extended for $13.5 \mathrm{~m}$ and the constituent layers ranged from a dark brown, silty, sandy loam to a very dark, grey-brown, loamy sand.

The boundary with the layers of Block 15 was not distinct. A V-shaped slot, [297], $0.25 \mathrm{~m}$ deep and $0.25 \mathrm{~m}$ wide, had cut into the top of layers [176] and [206] of Block 15. It had a north-west to south-east alignment.

\section{Field interpretation}

This Block was interpreted as a midden-site deposit because of its humic content and considerable extent. A drainage gully was cut into the midden-site layers of the Block below and was filled before further midden-site deposits of this Block accumulated. In practice, this Block is a continuation of Block 15 and is divided off from the latter only because the gully indicated that some specific activity, other than the gradual accumulation of deposits, was occurring in this area. The Block mean IHI was calculated at 15,500, representing a

Block 3

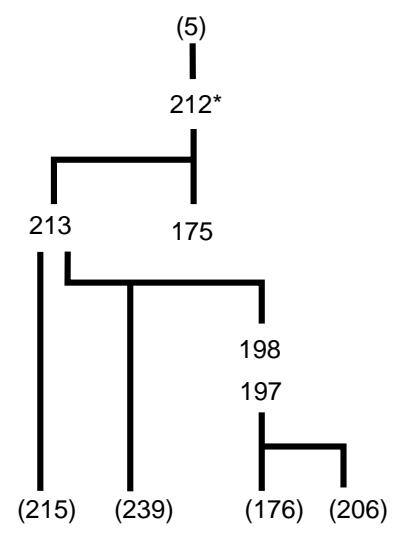

Block 15 range of from 6,000 to 36,000 . The extremes of the range are products of very large and very small volumes, respectively, with little significant difference between the retrieved assemblages. The IHI represents a wide range of materials present in large quantities. The proportions of burnt stone ranged from $<5 \%$ to $15 \%$ of the stone content. Ten of the forty-eight potsherds recovered were examined and they were all small. The $\mathrm{pH}$ values range from 6.7 to 7.5 with a modal value of 6.8. Phosphate values ranged from 1 to 5 , the most common being 3 . The soil colours are browns, ranging from dark to very dark, and the soil textures are silty sandy loams to loamy sands. Layer boundaries were all clear and undefined.

\section{Archaeological interpretation}

The high anthropogenic component, the soils rich in organic matter and high in phosphates and all of the other indicators suggest that this Block is composed of midden-site deposits, as the field interpretation suggests.

\section{Specialist contribution}

Sheep, cattle, pig and unidentifiable bird bones were recovered.

\section{Conclusion}

All of the post-excavation studies tend to confirm that these are midden-site deposits.

\subsection{BLOCK 20 - CULTIVATED DEPOSIT}

See tables p. 296

* ${ }^{14} \mathrm{C}$ date $2970 \pm 65$ bp (GU-1967) from layer [196] (Periwinkle \& Limpet)

This Block lay at the bottom of the north part of the site, between Blocks 16 and 23 (Figure 19). It extended over a distance of $5.8 \mathrm{~m}$ and had a depth of $0.25 \mathrm{~m}$. [196] was yel- 


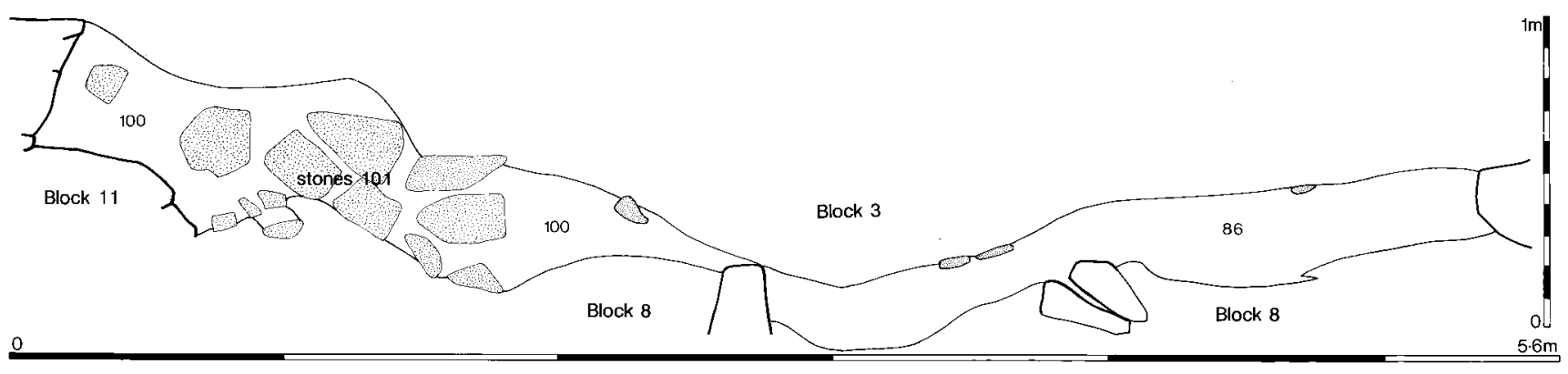

Figure 33. Block 21

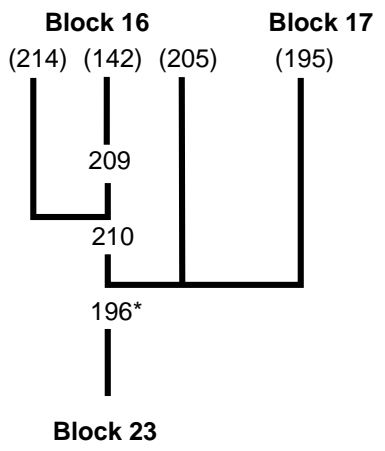

lowish brown silty loamy sand while [210] was a brown/dark brown, loamy sand. The boundary with the light sand below (Block 23) had several undulations, $0.05-0.2 \mathrm{~m}$ wide and 0.05-0.1 m deep, spaced irregularly in the section, interpreted as spade marks (Figure 32).

\section{Field interpretation}

This Block was interpreted as a cultivated deposit because of its extent, colour, loamy texture and the presence of furrows or spade-cultivation marks cut into the layer beneath. The Block mean IHI was calculated at 13,000 and represents a moderate range of materials. Stone was retrieved from all contexts and the burnt component varied from $<5 \%$ to $50 \%$. Thirteen of the sixty-five potsherds from the Block were examined and all were small in size, classes 1 and 2. The phosphate levels were 2 , indicative of low to moderate presence of soil phosphates, while the soil $\mathrm{pH}$ values of 6.4 to 6.8 are relatively low. The soils are loamy sands, yellow brown to dark brown in colour.

\section{Archaeological interpretation}

On balance the archaeological interpretation gives clear support to the field interpretation. The range of anthropogenic inclusions and the comminution of the potsherds are consistent with manuring the soil from a farmyard midden with subsequent degradation caused by ploughing. The soil colour and texture both indicate the addition of finer, organic matter to the shell sand, which consequently has slightly depressed the soil $\mathrm{pH}$ value.

\section{Specialist contributions}

The bones of sheep, cattle, pig and cod were recovered, together with gadoid and a shark vertebra.

\section{Conclusion}

The post-excavation analyses suggest that Blocks 20, 23, and 27 were initially windblown sands which were then cultivated. To these a restricted range and quantity of materials were introduced during manuring.

\subsection{BLOCK 21 - WINDBLOWN SAND WITH EROSION PRODUCTS}

See tables p.296

* ${ }^{14} \mathrm{C}$ date $2045 \pm 50$ bp (GU-1968) from layer [100] (Periwinkle)

Block 21 lay in the centre of the site above Blocks 7 and 8 (Figure 19). It comprised contexts [86] and [100], which had slumped over the backfilled layers between the drystone walls, [102] and [208] (Block 8), and infilled the masonry of [101] (Block 11) (Figure 33). They consisted of a band of dark greyish brown, silty, loamy sand, circa $0.2 \mathrm{~m}$ to $0.3 \mathrm{~m}$ deep.

\section{Field interpretation}

This Block was interpreted as windblown sand that had incorporated within it material eroding from the midden-site to the north. The Block mean IHI was calculated at 5,000, and represents a wide range of materials present in small quantities. The three potsherds from this Block were not examined. The $\mathrm{pH}$ of the contexts were 7.4 and 7.5 while the phosphate levels were recorded at 2 and 4 . The soil was a dark grey brown silty loamy sand with clear boundaries.

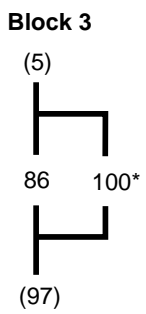

Block 7 

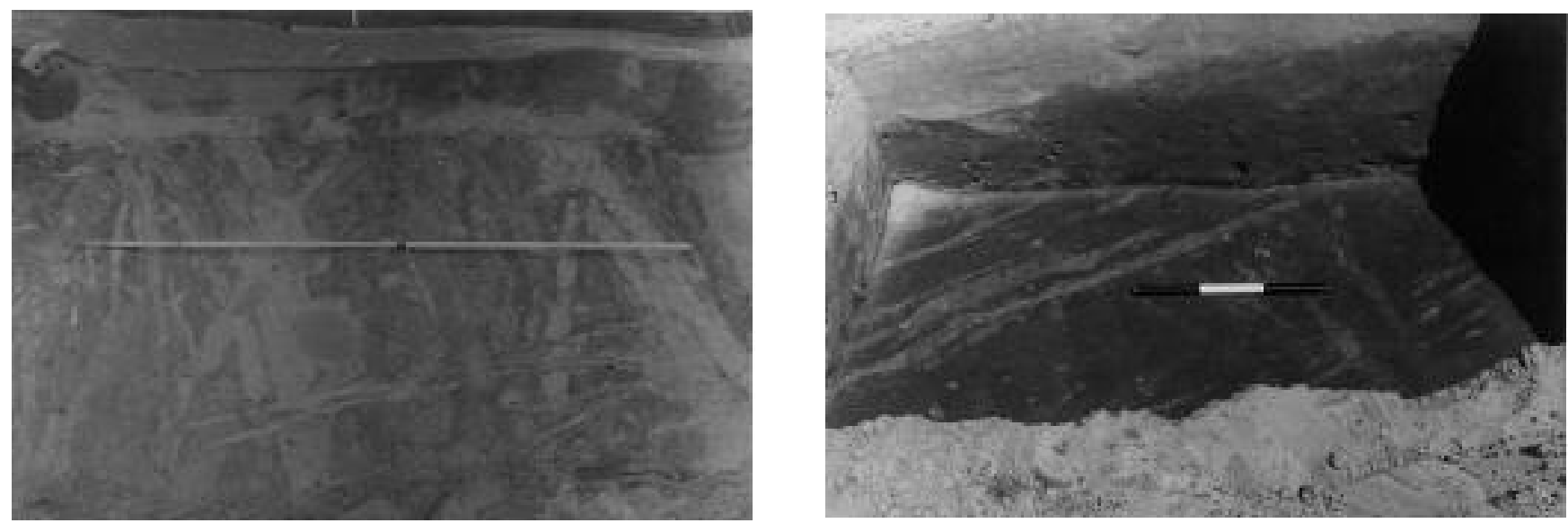

Plate 20. Baleshare. a) \& b) ardmarks exposed at different levels within Block 22. In a) later cultivation episodes are visible in the profile

\section{Archaeological interpretation}

The archaeological interpretation agrees with the field interpretation and suggests that this deposit accumulated naturally, mainly from windblown sands trapped in a hollow. Small quantities of anthropogenic materials were introduced and these may derive from the midden-site deposits to the north. The soil colour and texture indicate some admixture of soil organic material, possibly from the same source. Alternatively, it could constitute a natural deepening humus which developed over a long period of time.

\section{Specialist contribution}

The bones of sheep, cattle, pig and red deer were recovered.

\section{Conclusion}

The field interpretation is partially substantiated by the post-excavation analyses. These deposits are essentially windblown sands. The molluscan evidence suggests that the materials may be derived from incidental dumping rather than from the erosion of midden-site deposits, as originally suggested.

\subsection{BLOCK 22 - CULTIVATED DEPOSIT}

See tables p.297, 297

* ${ }^{14} \mathrm{C}$ date $3285 \pm 60 \mathrm{bp}$ (GU-1966) from layer [280] (Periwinkles, limpet \& cockle).

* ${ }^{14} \mathrm{C}$ date $3360 \pm 80$ bp (GU-2556) from layers [277], [278], [279], [280] (Animal bone).

This was the lowest exposed Block (Figure 19). Its presence was first indicated by coring, which suggested that it extended for approximately $300 \mathrm{~m}$ by $100 \mathrm{~m}$. Its depth beneath the surface caused safety problems during excavation. Therefore, unlike the rest of the site, it was sampled in three separate locations in $1 \mathrm{~m}^{2}$ pits on the south, middle and north of the excavated face. Although it consisted of a single deposit, aver-

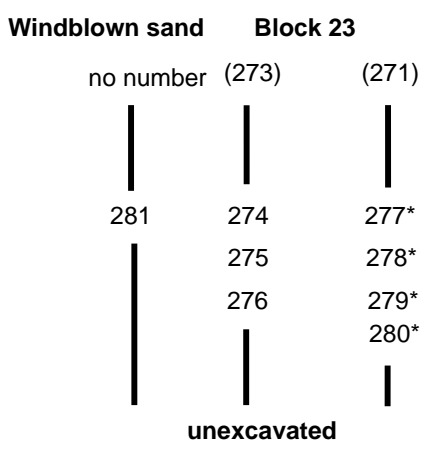

aging $1 \mathrm{~m}$ in thickness, it was sampled and recorded using a total of eight separate context numbers. These are essentially identical. The feature numbers were as follows; [277], [278], [279], and [280] in the extreme south, [274], [275] and [276] further north beneath wall [102], and [281] at the north end. Upon excavation numerous ard marks were exposed on the surface of the lower midden. Further ard marks were observed within the deposits of this Block (Plate 20).

\section{Field interpretation}

This was interpreted as a cultivated deposit because of its dark colour, extensive horizontal uniformity and the presence of ard marks, at least some of which were contemporary with this deposit. The mean IHI for the Block was 16,000 and it can be suggested that midden material was introduced during manuring and spread by ploughing. Of the 498 potsherds recovered ninety-seven were examined and the size distribution is also consistent with this interpretation, being markedly skewed, almost Poisson in form. The $\mathrm{pH}$ values ranged from 6.6 to 7.7 with a modal value of 7.5. Analysis of the soils reveals moderate to high phosphate levels, between 2 and 4 . However the soil organic matter content, as revealed by loss on ignition, is low, ranging from $1 \%$ to $2.2 \%$. It may be that the levels of introduced humus were never high. 


\section{Archaeological interpretation}

On balance the archaeological interpretation agrees with the field interpretation as identifying this as an area of cultivated shell-sand deepened by repeated manuring with midden material. The latter both stabilised and deepened the cultivated horizon and introduced into it a range of anthropogenic materials which, in turn, at least in the case of the pottery, was progressively degraded by the continuing disturbance of the deposit by ploughing.

\section{Specialist contribution}

Sheep, cattle, pig, red deer, dog, cormorant and angel shark were the species identified.

\section{Conclusion}

The field observation of ard marks contemporaneous with the deposit indicates that it was a cultivated deposit, probably a deepened A-horizon. The post-excavation analyses support this interpretation.

\subsection{BLOCK 23 - CULTIVATED WINDBLOWN SAND}

See tables p.297

* ${ }^{14} \mathrm{C}$ date $3030 \pm 50 \mathrm{bp}(\mathrm{GU}-1969)$ from layer [272] (Periwinkle).

This Block lay beneath the cultivated deposits of Block 1 and 28 in the south and Block 27 in the north (Figure 19). Because of its great depth below the surface it was only excavated in the south part of the site for a distance of circa 20 $\mathrm{m}$. The seven layers in this Block had a total depth of about 1 $\mathrm{m}$ but in the south they tapered to $0.1 \mathrm{~m}$. There were no professional soil-descriptions for these layers, but they were noted by the excavator as light brown-yellow sands and apparently contained little material, although this was subsequently contradicted by the results of the sieving.

\section{Field interpretation}

This Block was interpreted as a windblown sand deposit because of its texture, light colour and apparent absence of

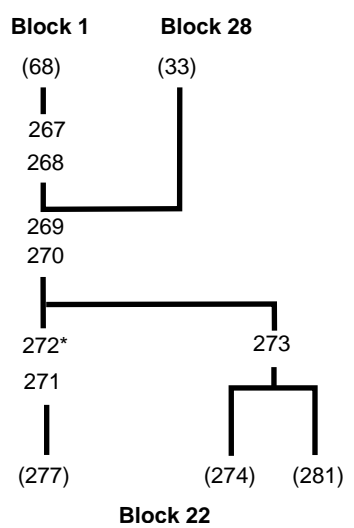

finds. It consisted of seven separate layers which were differentiated from each other on the basis of colour, though the differences were slight. This absence of strong coloration, together with the apparent absence of anthropic materials suggested in the field that these deposits were formed of windblown sand, possibly separated from each other by transitory regeneration horizons (Chapter 6 for details). The mean IHI for the Block is 7,000 which is low for the site. The highest quantities of material are bone, stone and sea-shell. Five contexts contained stone, of which $<5 \%$ to $10 \%$ was burnt. One piece of pumice was retrieved from [270]. Nine of the forty-one potsherds were examined. All of these were small, size-class 2 . The soil organic matter content revealed by LOI is low, ranging from $0.8 \%$ to $1.2 \%$. Its phosphate levels are a moderate 2 to 3 . Soil $\mathrm{pH}$ values range from 6.4 to 7.1 . None of these are anthipathetical to the hypothesis that these are windblown sands.

\section{Archaeological interpretation}

Despite the presence of some anthropic materials, on balance the archaeological interpretation agrees with the field interpretation.

\section{Specialist contribution}

Sheep, cattle, seal, otter and cod were identified.

\section{Conclusion}

Only in exceptional circumstances can windblown sand contain particles as large as $1 \mathrm{~mm}$, yet this deposit contains significant amounts of pot-sherds, stone, etc. The homogeneity of the contents of individual contexts and the plurality of contexts rules out deflation as a likely means by which this material can have become incorporated in the deposits. The snail evidence tends to suggest that these deposits represent accumulations of windblown sand, sometimes stable or slowly accreting and sometimes accumulating rapidly. They were cultivated for short periods and occasionally grazed. The anthropic inclusions represent, therefore, sporadic episodes of manuring, the material being subsequently dispersed. This Block should therefore be interpreted as cultivated windblown sand.

\subsection{BLOCK 24 - CULTIVATED MIDDEN-SITE DEPOSITS}

See tables p. 298

* ${ }^{14} \mathrm{C}$ date $2057 \pm 50$ bp (GU-1975) from layer [29] (Periwinkle).

This Block lay in the south part of the site with a total length of $12 \mathrm{~m}$ and a maximum depth of $0.9 \mathrm{~m}$ (Figure 19). It tapered away at both ends, to the north over layer [42] of Block 2 and to the south beneath Block 5. This Block was separated from the midden-site deposits of Block 2 by two initial dumps of material, one consisting of [40], [38] and [39], and the other of [34] and [45] (Figure 34). These ranged from 


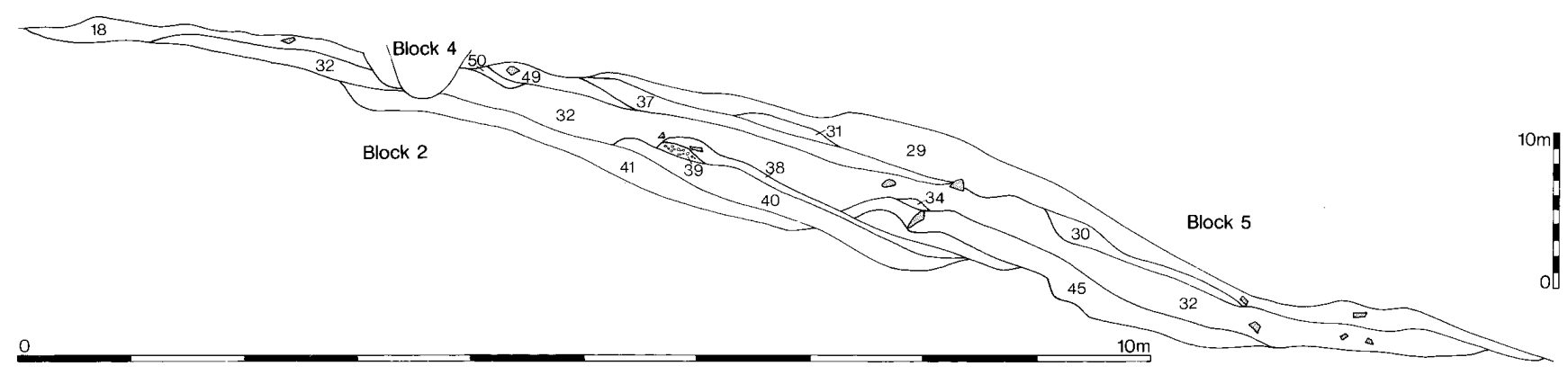

Figure 34. Block 24

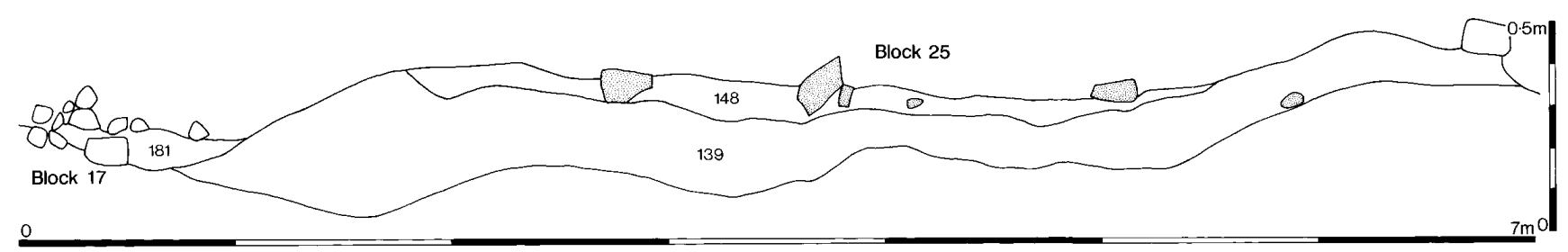

Figure 35. Block 26

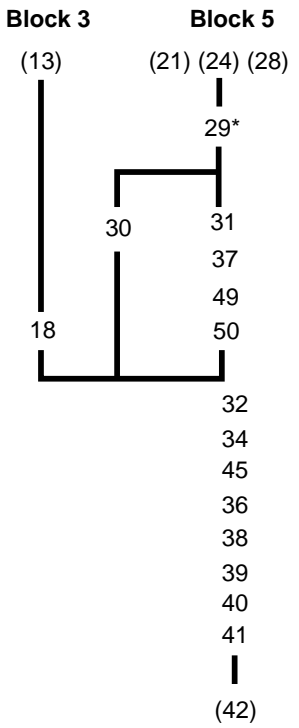

Block 2

brown /dark brown silty, sandy loam to dark brown loamy sands. These were then covered with more extensive deposits of brown loamy sands or sandy loams. There were wavy boundaries at the base of layers [49], [37] and [29].

\section{Field interpretation}

This Block was interpreted as dumped deposits with midden-site layers above. The wavy boundaries at the base of three of the upper layers suggested the presence of a cultivation horizon within the Block. The Block mean IHI was calculated at 110,500, representing a range of from 5,000 to $1,150,000$. The extreme values 5,000 for [49], is caused by very small amounts of all types of material while the value $1,150,000$, from context [39], is caused by a large amount of sea-shell relative to its volume. The IHI represents a wide range of materials present in large but very variable quantities. Burnt stone was found in quantities ranging from $<5 \%$ to $25 \%$ in six contexts. Sixty-two potsherds out of 244 were examined and they range in size-class from 1 to 12 . About one quarter of the sherds were larger than the site average. The $\mathrm{pH}$ values range from 7.1 to 7.7 with a modal value of 7.4. Phosphate values ranged from 2 to 5 , the most common value being 2 . The soil colours are all recorded as shades of brown and the soil textures are mainly loams with some loamy sands. Layer boundaries were predominantly clear, some being sharp and wavy.

\section{Archaeological interpretation}

The archaeological interpretation is in agreement with the field interpretation. The very high IHI values and survival of large potsherds both attest to the dumped nature of the deposits while soil colours and textures indicate that significant quantities of soil organic matter was included.

\section{Specialist contribution}

The bones of sheep, cattle, pig, dog and cod and plaice were recovered, together with bones of mallard and great auk, the latter with butchery marks (Chapter 11.4.1).

\section{Conclusion}

The evidence from the snail analysis suggests a five-fold subdivision of this Block. The ranges and quantities of material from the re-grouped contexts may suggest that $24 \mathrm{~A}, \mathrm{C}$ and D were midden-site deposits and $24 \mathrm{~B}$ and $\mathrm{E}$ cultivated deposits. It must be accepted that the field and archaeological interpretation were incorrect and that this Block consisted of a series of midden-site deposits with intermittent cultivation. 


\subsection{BLOCK 25 - CULTIVATED DEPOSIT}

See tables p.298, 299

This Block consisted of a single layer, [140], in the north part of the site situated between the Blocks 16 and 26 (Figure 19). It abutted the bottom stone of the circular structure (Block

11) and extended circa $6.1 \mathrm{~m}$ to the north. It was a brown/dark grey loamy sand with a depth of $0.1-0.2 \mathrm{~m}$.

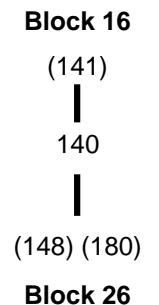

\section{Field interpretation}

This layer was interpreted as a cultivated deposit because of its texture, colour and extent. The Block IHI is high, at 23,500 , and this represents a wide range and large quantity of anthropogenic material. Some $30 \%$ of the stone from the Block is burnt. Of the 135 potsherds recovered, thirty-five were examined and of these the size range is very wide (classes 1 to 17, at the extremes), with almost a quarter of the sherds longer than size class 3 . The soil $\mathrm{pH}$ was estimated at 7.1 and the phosphate value was medium, at 2 . The soil was a dark grey loamy sand, with clear boundaries.

\section{Archaeological interpretation}

The archaeological interpretation is consistent with the field interpretation of this Block, ie as a cultivated deposit. The amounts and range of types of materials and the soil characteristics in general are consistent with this interpretation.

\section{Specialist contribution}

The bones of sheep, cattle, pig, gannet, hake, cod, gadoid and possibly a long rough dab, were recovered.

\section{Conclusion}

The evidence supports the field interpretation of this deposit as a cultivated deposit. The materials included within it suggest that it was originally a midden or midden-site deposit and that it was only briefly cultivated.

\subsection{BLOCK 26 - CULTIVATED DEPOSIT}

See tables p.299

* ${ }^{14} \mathrm{C}$ date $2815 \pm 50$ bp (GU-1971) from layer [148] (Periwinkle).
* ${ }^{14} \mathrm{C}$ date $2900 \pm 140$ bp (GU-2558) from layers [139], this Block, [227] and [233], Block 18 (Animal bone).

This Block lay near the bottom of the north part of the site (Figure 19). It extended $5 \mathrm{~m}$ from beneath the wall, [134], to where layer [181] had infilled the burnt stones, [180] (Block 17) (Figure 35). It was generally $0.1 \mathrm{~m}$ to 0.35 $\mathrm{m}$ in depth. The layers ranged from dark brown to dark greyish brown sandy loam. Layer [181] was merely a thin lens to the south of the stones [180]. The boundary at the base of layer [148] was wavy, although this is not apparent in the section drawing.

\section{Field interpretation}

This Block was interpreted as a cultivated deposit because of its horizontal extent and loamy texture. The IHI for Block 26 has been calculated at 23,500 and this high value reflects the occurrence of a wide range of materials, present in large quantities. This is clearly consistent with the field interpretation. Between $50 \%$ and $70 \%$ of the stone present was burnt and seven pieces of pumice were recovered. Of the 227 potsherds, forty-nine were examined and these varied in size from 2-9. The soil phosphate content was low, with a value of 2 and the soil $\mathrm{pH}$ was also low, ranging between 6.2 and 6.9. The deposits were dark brown loams. The lower boundary of [148] was described as wavy.

\section{Archaeological interpretation}

The archaeological interpretation is clearly consistent with the field interpretation. The large range and quantity of anthropogenic materials, the Poisson distribution of the potsherd sizes the low soil $\mathrm{pH}$ and dark soil-colour all support the hypothesis that this is a cultivated deposit continually manured from a 'farmyard' midden.

\section{Specialist contribution}

The bones of sheep, cattle, pig, red deer, dog, common scouter, tope and hake were recovered.

\section{Conclusion}

The apparent conflict between the snail evidence and the field interpretation can be resolved if we envisage that Block

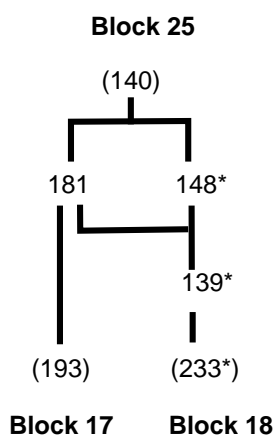




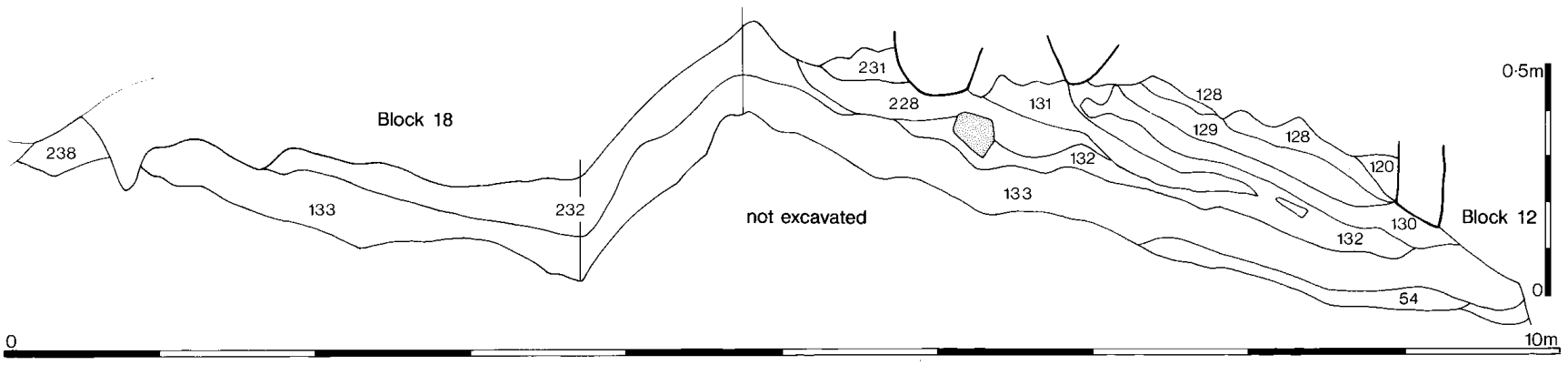

Figure 36. Block 27

26 is a cultivated midden-site deposit, with the periods of cultivation being very limited.

\subsection{BLOCK 27 - POSSIBLY CULTIVATED SAND}

See tables p. 300

* ${ }^{14} \mathrm{C}$ date $2910 \pm 50$ bp (GU-1973) from layer [132] (Periwinkle).

This Block lay in the centre of the site, beneath Block 18 (Figure 19). The layers which constitute this Block can be considered as two separate groups. The stratigraphically lower layers, [54], [133] and [232] were generally more extensive than those above (Figure 36). Layer [54] was $0.04 \mathrm{~m}$ deep and $2.5 \mathrm{~m}$ in length. Layer [133] was circa $0.1 \mathrm{~m}$ deep and extended for $7.8 \mathrm{~m}$ from the edge of the ditch in Block 9 beneath the circular structure (Block 11). Layer [232] was circa $0.1 \mathrm{~m}$ deep and extended for $2.7 \mathrm{~m}$ in the section but only to the north of the circular structure. Layer [133] was a brown silty loamy sand and [232] was a light yellow brown sand. The group of layers above these, [132] to [120], have a total depth of $0.25 \mathrm{~m}$ and individually are circa $0.05 \mathrm{~m}$ in thickness. They ranged from light brownish grey to dark brown in colour and from silty sandy loam to sand in texture. When freshly exposed this upper group of layers appeared to have reddish patches and lenses of white sand within them. When seen in plan the surface of these layers was marked with ard marks and the upper boundaries of layers [131], [129] and [128] were irregular.

Block 18

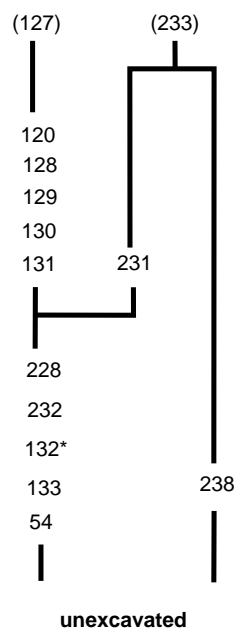

\section{Field interpretation}

The lower group of layers in this Block were thought to consist of windblown sand because of their light colour and texture. At the time of the excavation the upper group was included with the windblown sand even though they differed in extent and coloration. The ard marks in the surface at the uppermost level were caused by cultivation of the overlying Block. This Block consists of twelve contexts, ten of which were sampled for anthropogenic materials. The field interpretation of these deposits was very tentative. They were interpreted as windblown sands, which encapsulated reddened deposits such as [128]. Whether these were fire reddened, or the result of secondary redeposition of iron salts from higher up the profile could not be determined in the field, though the latter was felt to be an improbable occurrence in calcareous sands. It is more likely that the red colour is derived from burnt peat. The top of the Block contained ard marks, which were clearly attributable to the cultivation of the overlying Block (Block 18). The Block mean IHI was 15,000, which seems rather high for a windblown sand, particularly since the range and quantities of materials involved were large. Furthermore, the context IHI values make a distinction between the longer, more homogeneous, layers at the bottom and north end of the Block and the interdigitated layers which overlie them. [232] contained a piece of carved pumice (Figure 77c) while [231] yielded an unmodified piece. Thirteen of the sixty-seven potsherds from the site were examined and these were all in the small size groups 1 and 2 . Ten $\mathrm{pH}$ estimates range from 6.5 to 7.6 , with a modal value of 6.7. Phosphate values range from 1 to 5 , six of the ten values being high, ie 4 to 5 .

\section{Archaeological interpretation}

On balance the archaeological interpretation casts doubt on the field interpretation. These deposits seem to constitute an old ground surface. On the north end of this a series of sand deposits were dumped followed by possible cultivation, or at least disturbance due to the cultivation of the overlying layers.

\section{Specialist contribution}

The bones of sheep, cattle, pig and dulin were recovered. 


\subsection{BLOCK 28 - CULTIVATED DEPOSIT}

See table p.300

* ${ }^{14} \mathrm{C}$ date $2210 \pm 50$ bp (GU-1974) from layer [33] (Periwinkle).

This Block lay at the south end of the site (Figure 19). It consisted of a brown sandy loam, [33], which filled a distinctive hollow in the windblown sand of Block 23. It was $0.4 \mathrm{~m}$ deep and extended beyond the south limit of the excavation.

\section{Field interpretation}

This Block was interpreted as a cultivated deposit because of its colour, texture and homogeneity. The Block IHI was calculated at 6,000, and this represents a narrow range of materials present in small quantities. Four of the sixteen potsherds were examined and they range in size-class from 2 to 4 . The soil colour was brown and the soil texture a sandy loam.

\section{Archaeological interpretation}

The soil colour and texture and the presence of the, admittedly small, anthropogenic component all support the field interpretation. The depth and homogeneity of the deposit, together with its soil characteristics are consistent with its interpretation as a cultivated deposit.

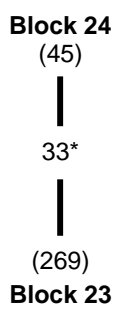

\section{Specialist contribution}

Sheep and pig bones were recovered.

\subsection{BLOCK 29 - OCCUPATION LAYER}

See tables p.300, 301

Block 29 consists of the single layer, [234], which lay beneath the windblown sand of Block 10 and overlay the fill of the ditch in Block 9 (Figure 19). It was a dark brown loamy sand.

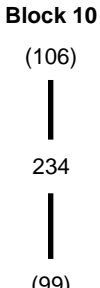

Block 9

\section{Field interpretation}

It is not impossible that this deposit represents a surface associated with the walls of Block 12. However, the extent revealed in section is insufficient to confirm this and horizontal excavation would be required to elucidate its nature. 


\section{CHAPTER 6: EXCAVATIONS AT HORNISH POINT}

\section{H F James \& R P J McCullagh}

\section{I INTRODUCTION}

Hornish Point lies on the north-west of South Uist at NF 758 472 (Figure 37). The site lies on a low rocky headland at the north-east end of North Bay, which has Ardivacher Point at its south-west end. To the east of Hornish Point is Bagh nam Faoilean, the shallow stretch of water which divides South Uist from Benbecula. A sand bar (Gualan) has accumulated across this opening, leaving a narrow water channel at its north end. Behind Hornish Point the machair landscape is gently undulating below the $8 \mathrm{~m}$ contour. There are two lochs within $300 \mathrm{~m}$ of the site, Loch an Duin Bhig to the south-east and Loch an Duin Mhoir to the south. The extensive Loch Bee lies circa $1 \mathrm{~km}$ to the south-west.

The site of the excavation is a sand hill on the west side of Hornish Point, grid reference NF 758 470, called Cnoc Mor which means 'big hillock'. Its undulating surface extends up to $3 \mathrm{~m}$ above the surrounding machair surface. It extends north-south for $70 \mathrm{~m}$ and $65 \mathrm{~m}$ back from the coast. Its west side had been eroded to a vertical face $1 \mathrm{~m}$ high with gentler slopes of collapsed sand and grass beneath. At the foot of the slope lies the narrow storm beach of large pebbles and stones and beyond this is the sandy beach.

The machair sand on Hornish Point is generally grass covered except for the reeds along the borders of the lochs.

\section{I.I Archaeological features}

The midden in the exposed west face of Cnoc Mor extended for $50 \mathrm{~m}$ north/south, was $0.5 \mathrm{~m}$ deep and was covered by up to $2 \mathrm{~m}$ of clean sand. In two areas the sand covering has been removed for a distance of 3 and $5 \mathrm{~m}$, leaving the midden exposed on the surface. On the top of the hill a circular depression with a radius of circa $7 \mathrm{~m}$ was noted.

\section{I.2 Site history}

In the early nineteenth century Hornish Point was part of the Balgarva estate belonging to MacDonald Clanranald. On the map of the estates, dated 1805 , the point is called $\mathrm{Ru}$ Cuinafenagh. The small lochs behind the site appear to be more extensive than at present. The first edition OS map of 1882 shows a structure and enclosing wall to the north-east of the Cnoc Mor summit and also a trackway running east-west from Balgarva to the coast. The Admiralty chart of 1909 records Ru Hornish and shows an extensive tapering area of shallow water extending westwards from the point.

In 1980 an Iron Age midden was recorded at NF7583 4720 about $170 \mathrm{~m}$ north of the summit of Cnoc Mor. This included a substantial deposit of midden exposed in the sand dunes at the edge of the beach. Finds included Iron Age sherds, a bone fish gorge, animal bone (mainly teeth), shells and a small decorated sherd.
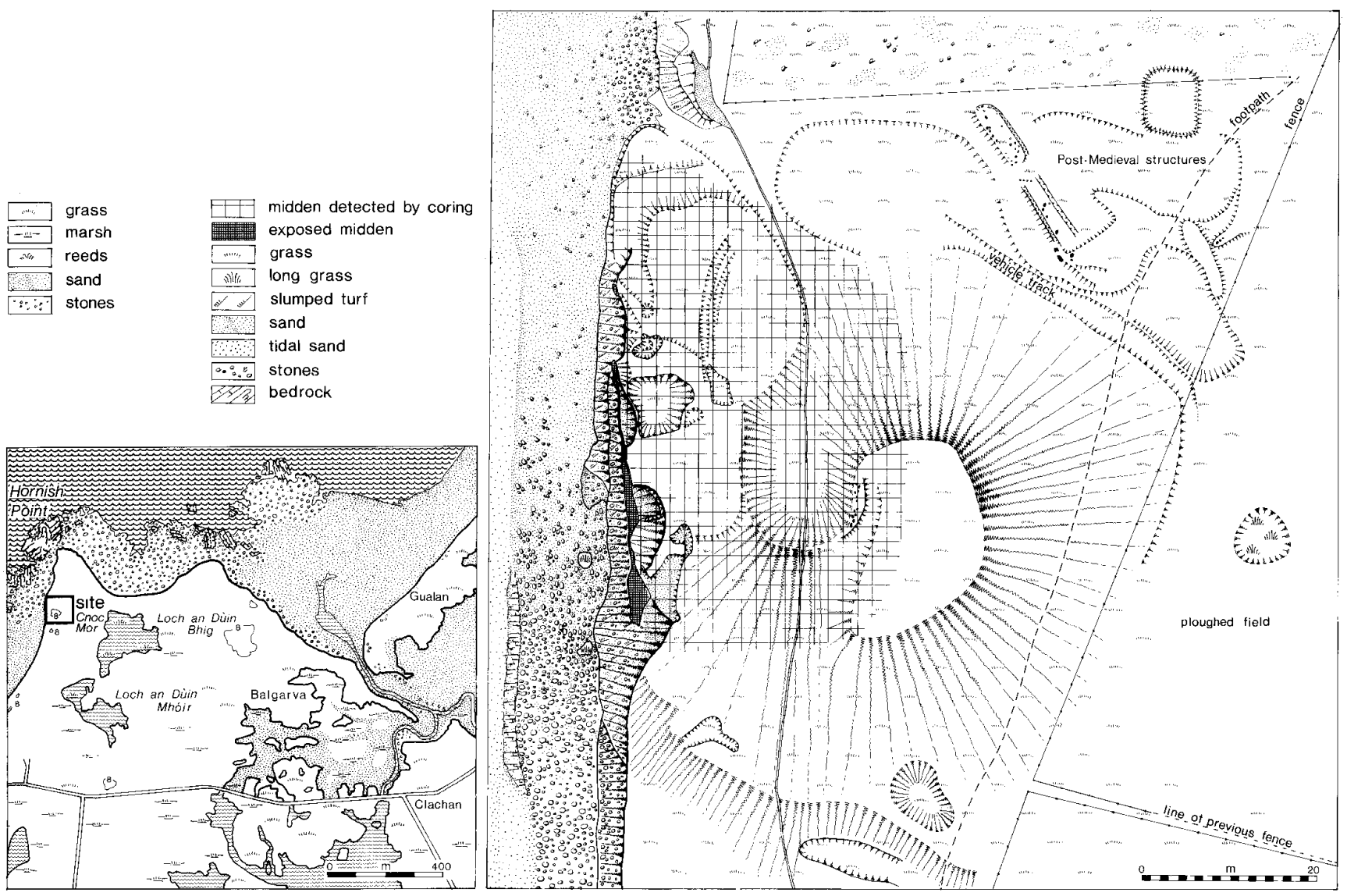

Figure 37. Hornish Pt: site location and survey 


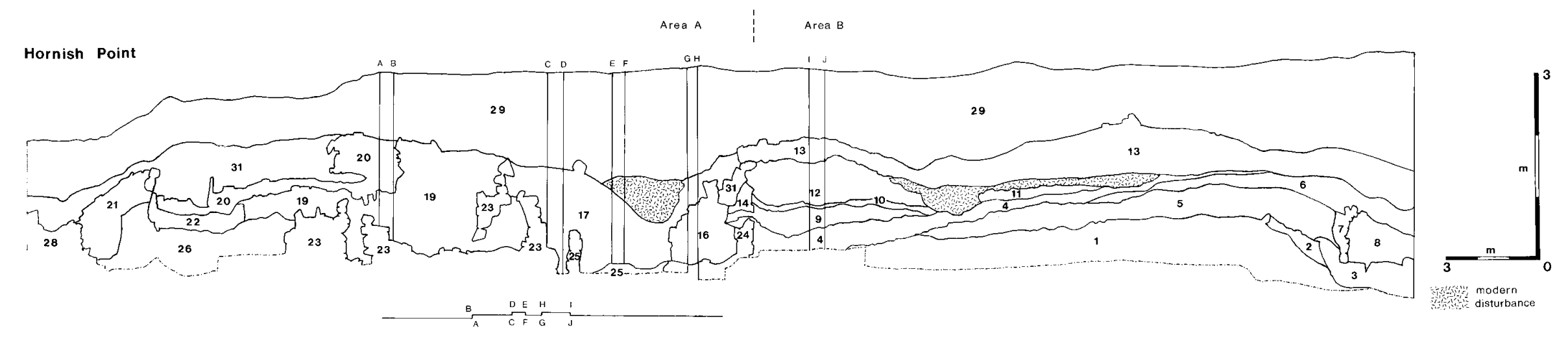

Figure 38. Hornish Pt: main section showing Blocks 


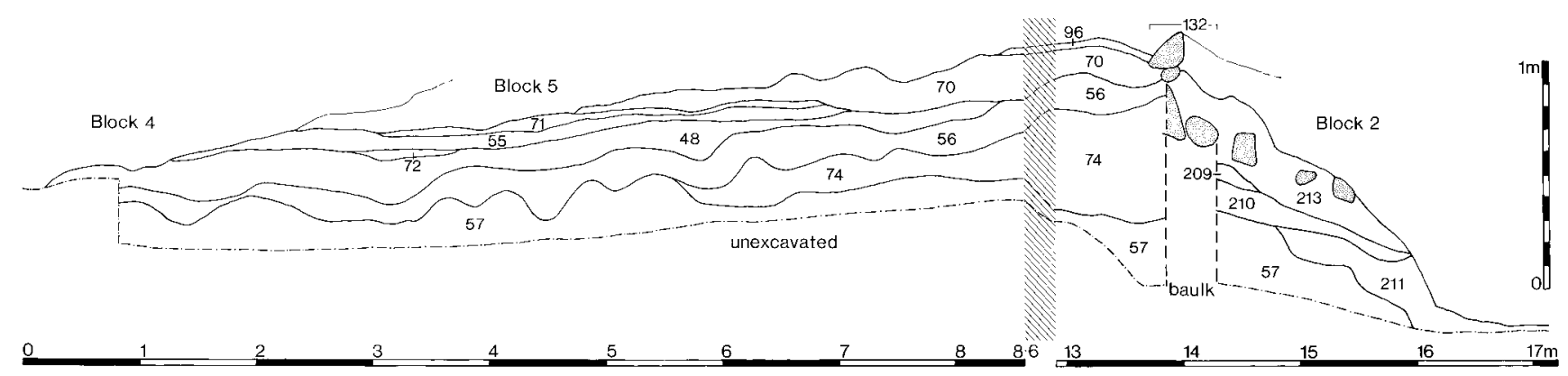

Figure 39. Block 1

\section{I.3 Local sites}

Only $350 \mathrm{~m}$ to the south of Hornish, there is the site of a dun in Loch an Duin Mhor. Further east at Eocher lies a probable broch, Dun Buidhe (RCAHMS 1928, 373), and a cairn. Along the west coast of South Uist, lying in the machair, there are several wheelhouses or aisled house sites, some of which were excavated in the 1950's by the then Ministry of Works in advance of the construction of the Ministry of Defence guided missile range.

There is a possible Viking settlement at the north end of Hornish Point, consisting of roughly rectangular wall foundations appearing through the grass cover (Godden \& Godden 1980).

\subsubsection{Summary of Blocks (see Figure 38)}

$\begin{array}{cl}\text { Block No } & \text { Final interpretation } \\ 1 & \text { Cultivated deposit } \\ 2 & \text { Cultivated deposit } \\ 3 & \text { Windblown sand } \\ 4 & \text { Cultivated deposit } \\ 5 & \text { Midden-site deposit } \\ 6 & \text { Cultivated soil and midden deposits } \\ 7 & \text { Revetment wall } \\ 8 & \text { Midden-site deposit } \\ 9 & \text { Midden-site deposit } \\ 10 & \text { Cultivated deposit } \\ 11 & \text { Midden-site deposit } \\ 12 & \text { Midden-site deposit } \\ 13 & \text { Midden-site deposit } \\ 14 & \text { Masonry } \\ 15 & \text { Structure 5 - partially preserved structure } \\ 16 & \text { Structural debris } \\ 17 & \text { Rubble and midden-site deposits } \\ 18 & \text { Structure 5 - wall arc with radial piers and } \\ & \text { post pits } \\ 19 & \text { Dumped deposits } \\ 20 & \text { Structure 7 - post-medieval black house } \\ 21 & \text { Dumped deposits } \\ 22 & \text { Structure 6 - fragment } \\ 23 & \text { Structure 1 - wheelhouse } \\ 24 & \text { Structure 3 - fragment } \\ 25 & \text { Structure 4 - fragment } \\ 26 & \text { Cultivated deposit } \\ 27 & \text { Structure 2 - masonry and floor deposits } \\ 28-31 & \text { Uninterpretable } \\ & \end{array}$

The site was divided into two elements; the southern half of the excavated section (Area A) consisted of deep stratified layers while the northern half (Area B) was characterised by masonry structures.

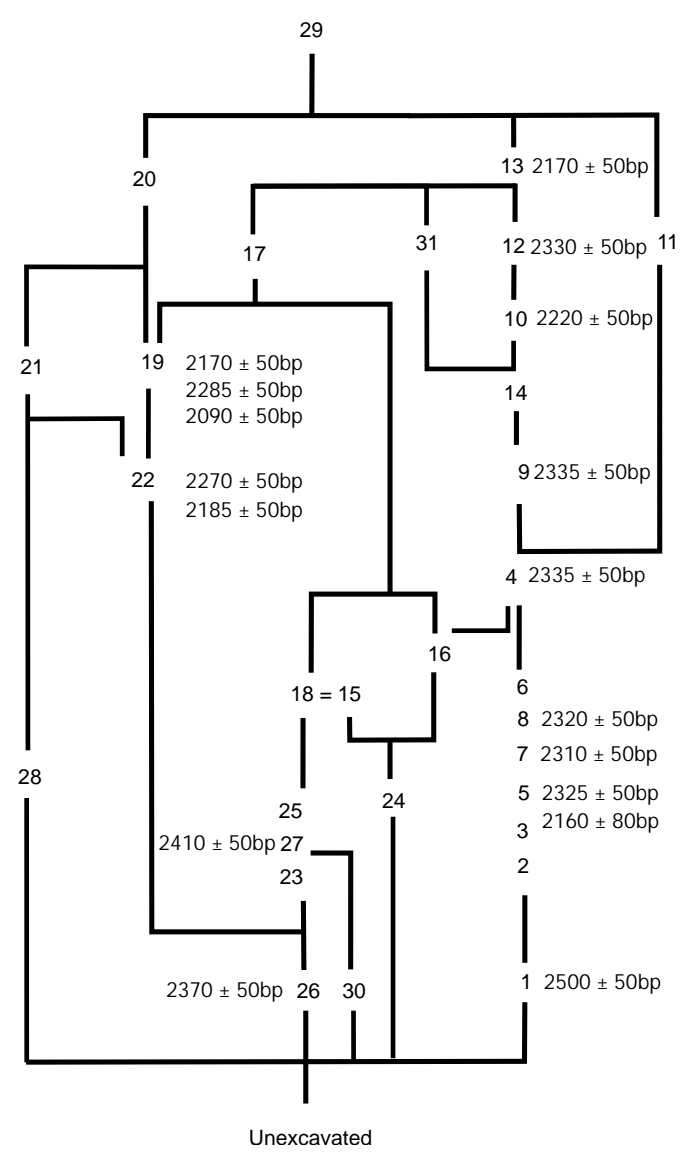

\subsection{BLOCK I - CULTIVATED DEPOSIT}

See tables p.302, 302

* ${ }^{14} \mathrm{C}$ date $2500 \pm 50$ bp (GU-2020) from layer [74] (Periwinkle).

Block 1 lay near the base of Area A beneath Blocks 2, 4 and 5 (Figure 38). The base of the Block was not reached so the maximum depth recorded at its southern limit was $1 \mathrm{~m}$. The depth gradually decreased northwards to $0.20 \mathrm{~m}$. It was exposed over a length of $14 \mathrm{~m}$, but its northern limit was not 


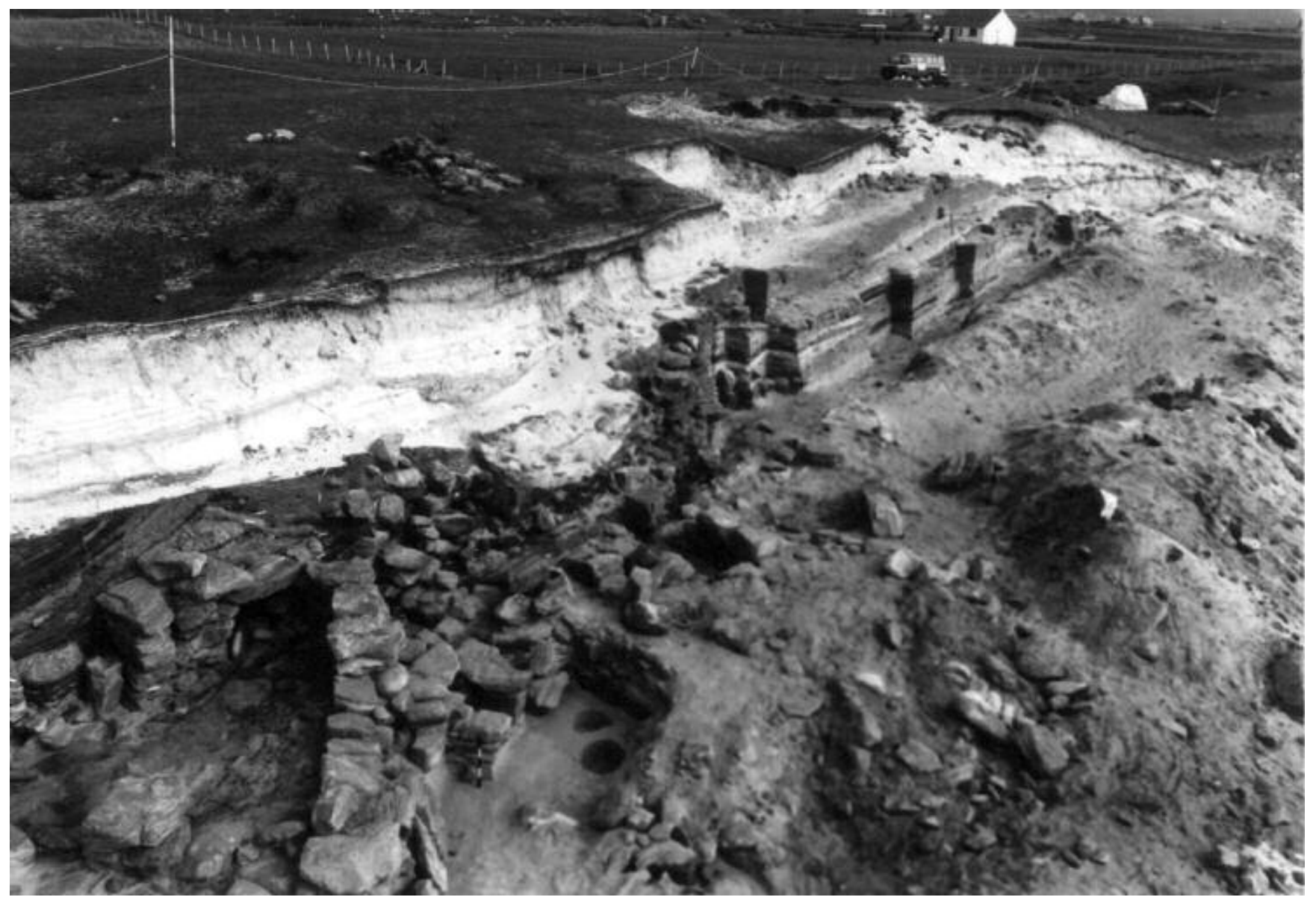

Plate 21. A general view of excavation in progress at Hornish Point shows how the site divided into complex masonry remains at the north end and deep, finely stratified cultivated deposits, Blocks 2-13, at the south end

revealed. It consisted of thirteen layers and a revetment of stones (Figure 39). Only four of these layers, [57], [56], [70] and [74], were extensive. The other contexts in the Block consisted of thin layers and lenses. In general the contexts became shallower and more undulating towards the north They ranged in colour from light grey to dark brown and in texture from sand to sandy loam. [74] contained a discrete lens of seashells. Towards the southern end of Block 1 several of the layers were revetted by a stone wall, [132], which consisted of a course of upright slabs overlain by sub-angular stones (see fig. 00). It is possible that originally only [74] was cut through and revetted by upright slabs. The overlying stones may have been added as the other contexts of Block 1, ie [56] and [70], accumulated. In plan the revetment was seen to curve southwards. Abutting this revetment to the south were further layers which sloped gently to the south for a maximum of $2 \mathrm{~m}$ at which point they were truncated by another revetment (Block 3).

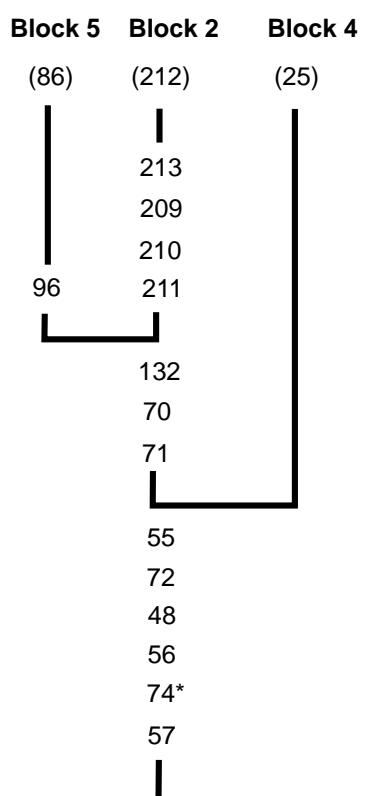

Unexcavated 

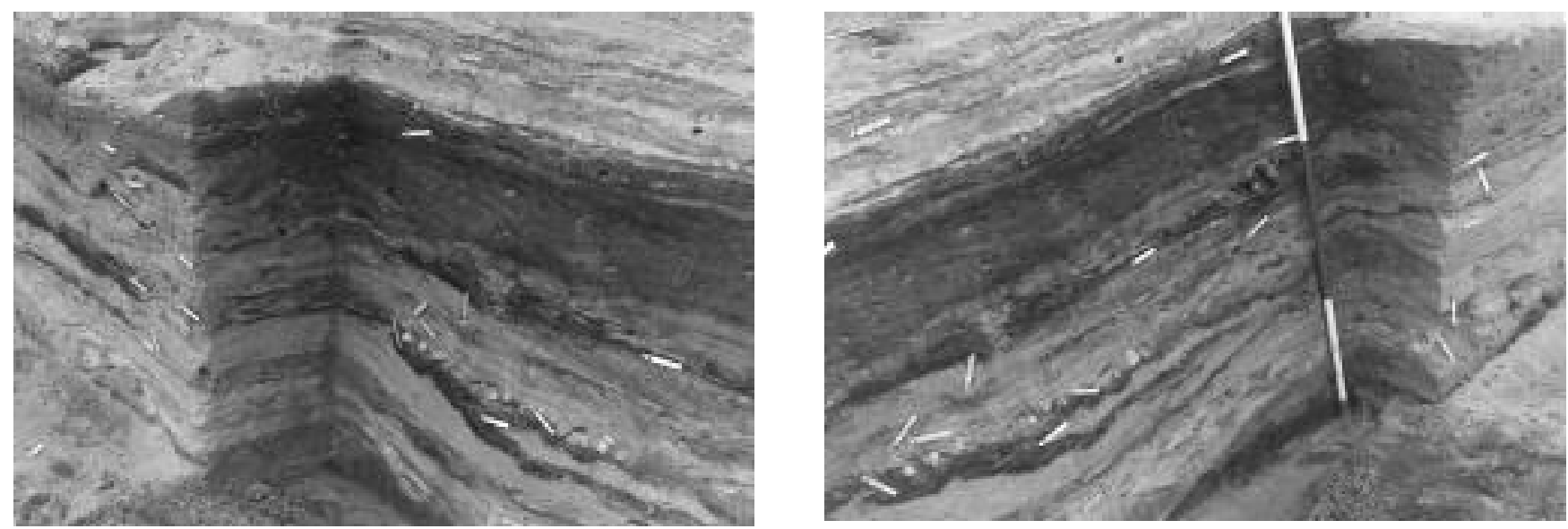

Plate 22. Hornish Point. Section through the finely stratified deposits of Blocks $2-13$

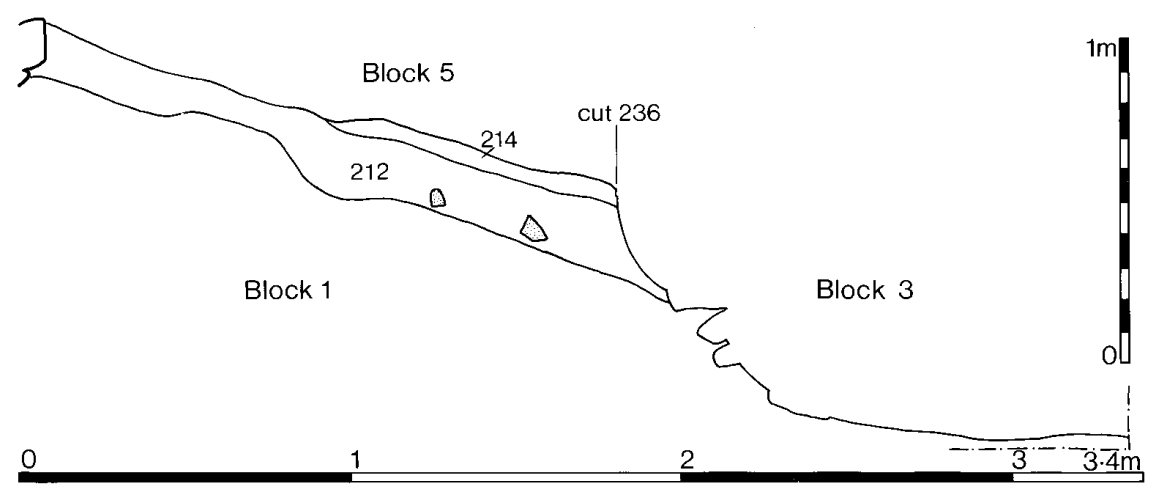

Figure 40. Block 2

\section{Field interpretation}

This Block was interpreted as a deepened cultivated deposit because of its extent, the presence of wavy boundaries and the dark colour of some of the constituent layers. The wall, especially its upper courses, may have been heightened intermittently as the Block deepened. The Block mean IHI was calculated at 17,500, representing a range of from 350 to 119,000 . The upper limit is due to the very small volume of [71]. The lower values are caused by low retrieval rates from relatively large contexts (eg [70]). The IHI represents a relatively wide range of materials present in small quantities. Between $<5 \%$ and $30 \%$ of the stone in a total of four contexts was burnt. Of the forty-five potsherds in the Block, 31 were examined and these range in size-class from 1 to 3 , all but four of them being smaller than the site mean. The $\mathrm{pH}$ values recorded for this Block range from 7.0 to 7.5 with a modal value of 7.4. Phosphate values ranged from 3 to 5,3 being the most common value. The soil colours are recorded as ranging from light grey to dark brown and the soil textures from sands to sandy loams. Layer boundaries were predominantly clear, with irregularities of form ranging from wavy to broken.

\section{Archaeological interpretation}

The extensive layers of this Block certainly seem to have been cultivated but the smaller, thin strata could not have survived ploughing. The heterogeneity of the anthropogenic component of these strata also militates against their interpretation as a cultivated deposit. On balance it seems that these layers were cultivated deposits with some input of midden-site material. Cultivation was probably intermittent.

\section{Specialist contribution}

Bones of sheep, cattle, pig and fish bones of hake, cod and pollock were identified.

\section{Conclusions}

This Block formed during a period of shell-sand accretion with varying quantities of anthropogenic material added intermittently. The deposits were cultivated from time to time.

\subsection{BLOCKS 2 TO 12}

See table p.303

This group of blocks consists of the deposits at the southern end of the site above Block 1 and beneath Block 13 (Figure 38; Plates $21 \& 22$ ). They are grouped together because, despite their disparate sedimentary mechanisms, they were continuously cultivated over a relatively short period of time. 


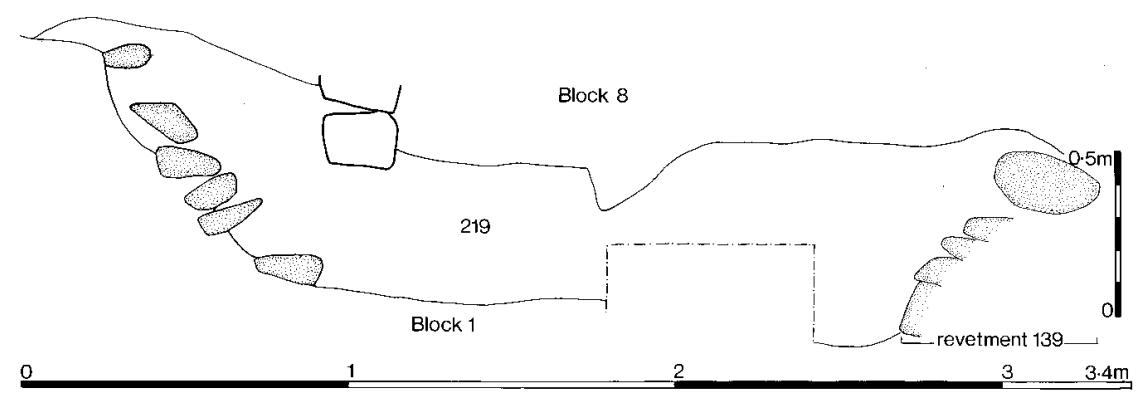

Figure 41. Block 3

The stratigraphy and field interpretation of the different blocks in this group are discussed separately below while the finds, archaeological interpretation and conclusions are presented below for the group as a whole.

\subsection{BLOCK 2 - CULTIVATED DEPOSITS}

\section{See table p. 305}

Block 2 lay at the southern end of Area A, near to the base of the section face. It was $2.5 \mathrm{~m}$ in length and up to $0.30 \mathrm{~m}$ deep and consisted of two layers the surfaces of which sloped to the south (Figure 40). These layers were cut through on the southern side, and the exposed face revetted by the stones of a wall of Block 3. The layers ranged in colour from dark greyish brown to dark brown and in texture from silty, loamy sand to sandy loam.

\section{Field interpretation}

This Block was interpreted as a cultivated deposit because of the texture and colour of its layers. The southerly slope of the contexts in this Block suggests that it did not extend much further in that direction. However their truncation and the insertion of the stone wall makes it impossible to estimate their original extent.

\section{Specialist contribution}

Bones of sheep, cattle and pig. Hake bones and a crab chela were also identified.

\subsection{BLOCK 3 - WINDBLOWN SAND}

See table p.305

Block 3 lay at the southern end of Area A (Figure 38) and consisted of a single infilling layer, lying between a revetment, [134], on the north and a second revetment, [139], on the south (Figure 41). Its maximum length was $3.2 \mathrm{~m}$ and its depth was $0.80 \mathrm{~m}$. It overlay the two lowest layers of Block 1 and was under Blocks 5, 7 and 8.The infilling layer consisted of an homogeneous light grey sand, [219]. This material overlay the uppermost stones of the north revetment. The deposits beyond the south revetment, [139], were not investigated.

\section{Block 5

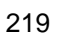 \\ 139 \\ 134 \\ 236 \\ (211)}

Block 1

\section{Field interpretation}

Block 3 is interpreted as the result of infilling by windblown sand of a revetted space cut into the deposits of Block 2.

\section{Specialist contribution}

Block 3

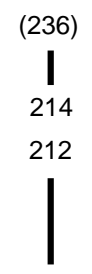

(213)

Block 1
Sheep, cattle and pig bones were recovered.

\subsection{BLOCK 4 - CULTIVATED DEPOSIT}

See table p.305

* ${ }^{14} \mathrm{C}$ date $2335 \pm$ bp (GU-2017) from layer [24] (Periwinkle). 


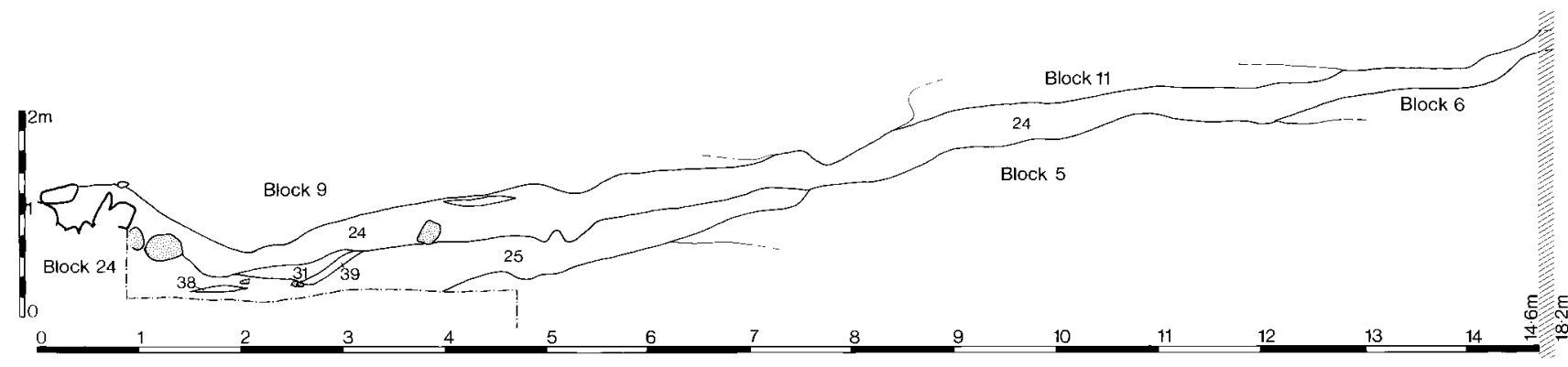

Figure 42. Block 4

Block 4 extended for a distance of $19.3 \mathrm{~m}$ in Area A (Figure 38). It lay over Blocks 1, 5, 6, and 24 and lay beneath Blocks 9 and 11. At its southern end the Block consisted of a shallow deposit which sloped downward to the north and deepened to a maximum of $0.5 \mathrm{~m}$ (Figure 42). It consisted of two extensive layers, [24] and [25], and four lenses, [31], [38], [39] and [46]. The deposits range in colour from a yellowish brown to pale brown and in texture from loamy sand to sand. At the northern end of the Block, layer [25] abutted a drystone wall ([195], Block 24) which was then sealed by layer [24].

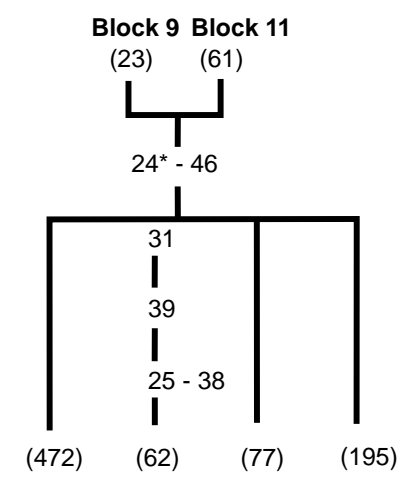

Block 16 Block 5 Block 6 Block 24

\section{Field interpretation}

This Block was interpreted as a cultivated deposit because of its extent, homogeneous texture and colour. The dark lenses were interpreted as remnants of some form of organic input.

\section{Specialist contribution}

Sheep, cattle and pig bones were recovered.

\subsection{BLOCK 5 - MIDDEN-SITE DEPOSIT}

See table p.306

* ${ }^{14} \mathrm{C}$ date $2325 \pm 50 \mathrm{bp}(\mathrm{GU}-2021)$ from layer [87] (Limpet).

* ${ }^{14} \mathrm{C}$ date $2160 \pm 80$ bp (GU-2550) from Contexts [79], [87], [90], [203], [217], [204], [69], [64], [207], [63], [68], [208] \& [65] (carbonised seed).

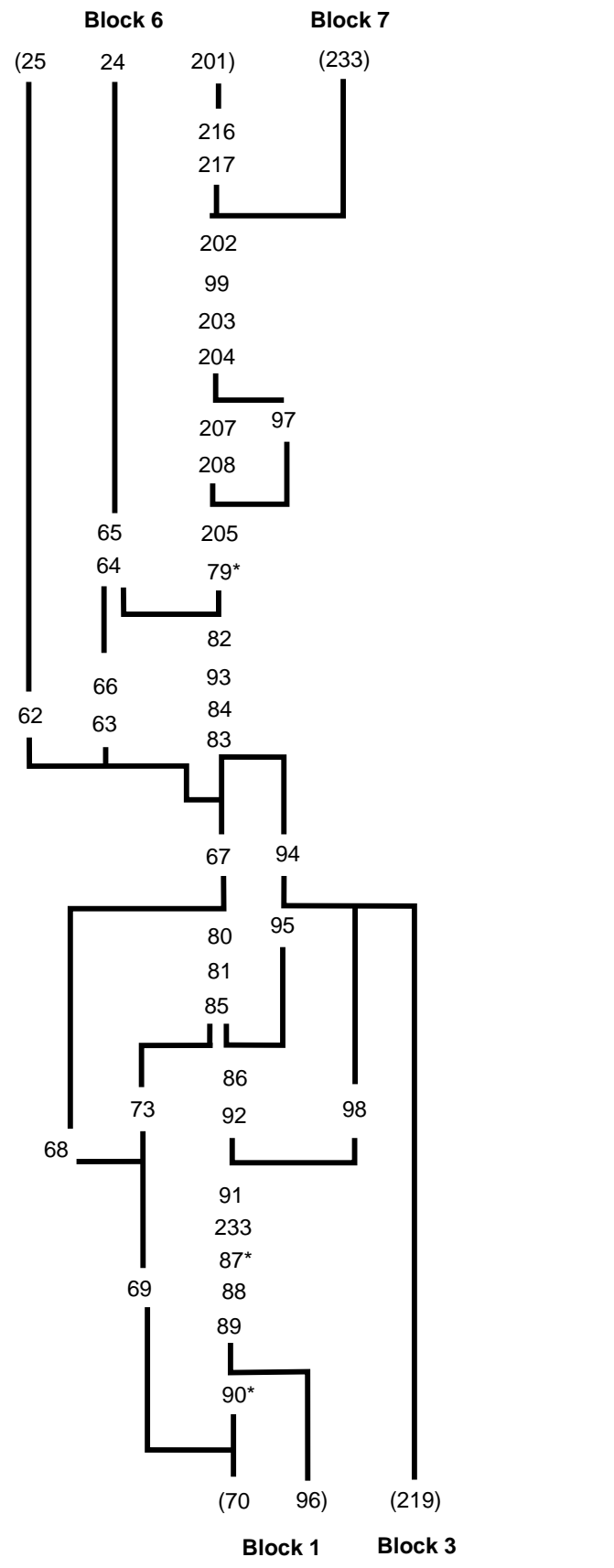

Block 5 lay in Area A above Blocks 1, 2 and 3 (Figure 38). It lay beneath Blocks 4,6 and 7 . It was $14 \mathrm{~m}$ long and formed as light dome with a maximum depth of $0.6 \mathrm{~m}$ in the south, tapering to the north. This Block consisted of thirty-eight contexts which included both extensive layers 


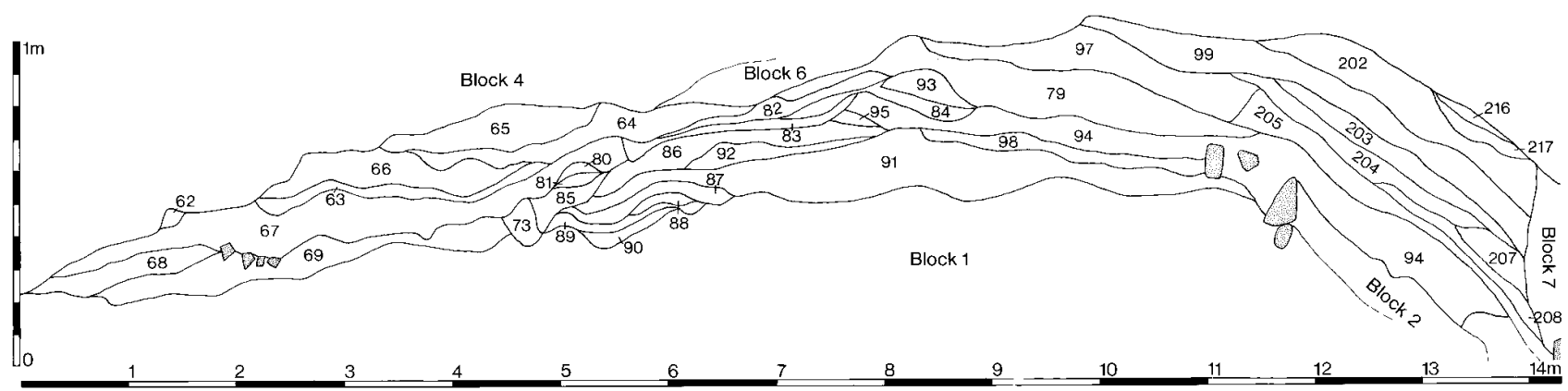

Figure 43. Block 5

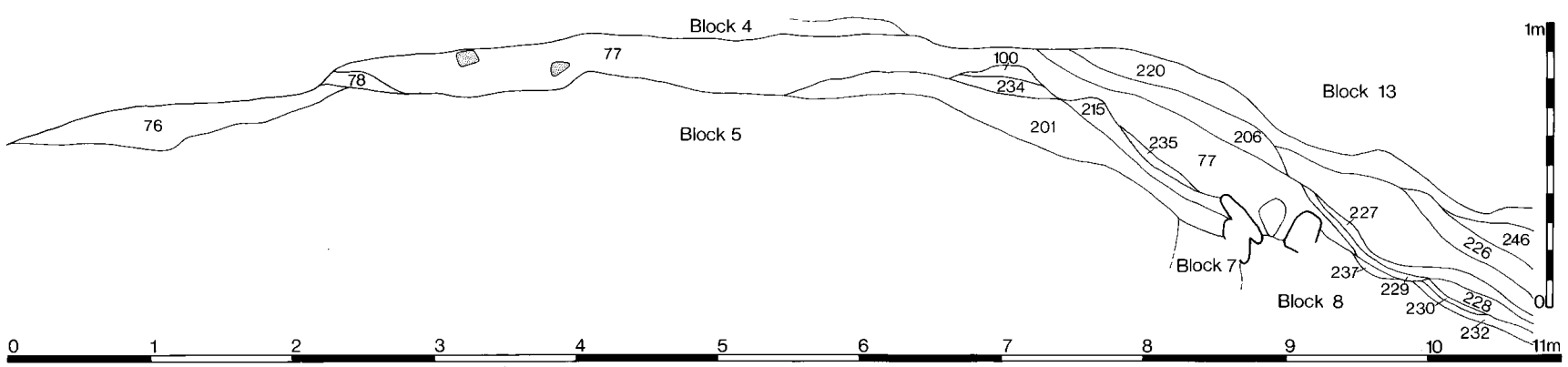

Figure 44. Block 6

and small lenses (Figure 43). Many of the uppermost layers in the Block appear to have been truncated. The contexts ranged in colour from white to very dark greyish brown and in texture from sand to silty sandy loams. Many of the dark coloured lenses occurred in discrete clusters. The Block is truncated at its southern end by the insertion of a revetment (Block 7).

\section{Field interpretation}

This Block was interpreted as midden-site deposits because of the variability of its constituent contexts. The nature of the upper surface of the Block suggests that it had been truncated.

\section{Specialist contribution}

Bones of sheep, cattle, pig, red deer and raven were identified. Saithe and unidentifiable fish bones were also recovered from this Block.

\subsection{BLOCK 6 - CULTIVATED SOILS AND MIDDEN DEPOSITS}

See table p.307

Block 6 lay in the southern part of Area A (Figure 38). It extended from the south end of the excavated section for a distance of $10.7 \mathrm{~m}$ with a maximum depth of $0.5 \mathrm{~m}$. It lay over Blocks 5, 7 and 8 and beneath Blocks 4 and 13. It was slightly domed. It consisted of nineteen contexts including both extensive layers and small lenses (Figure 44). These contexts ranged in colour from light grey to very dark brown, and in texture from sand to silty sandy loam. [77] ran almost the entire length of the Block and contained a discrete lens of razor shells. The lowest two layers, [201] and [215] abutted the upper courses of a revetment (Block 7).

\section{Field interpretation}

This Block appeared to have been formed by two separate but successive processes. The extensive layers were inter-

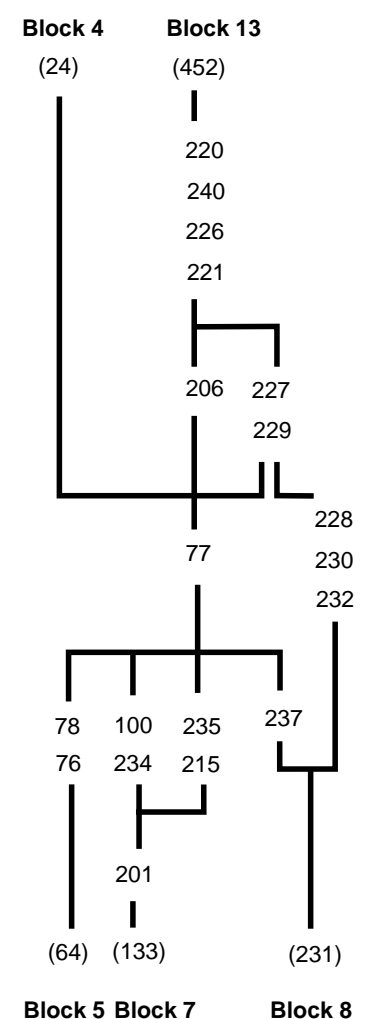




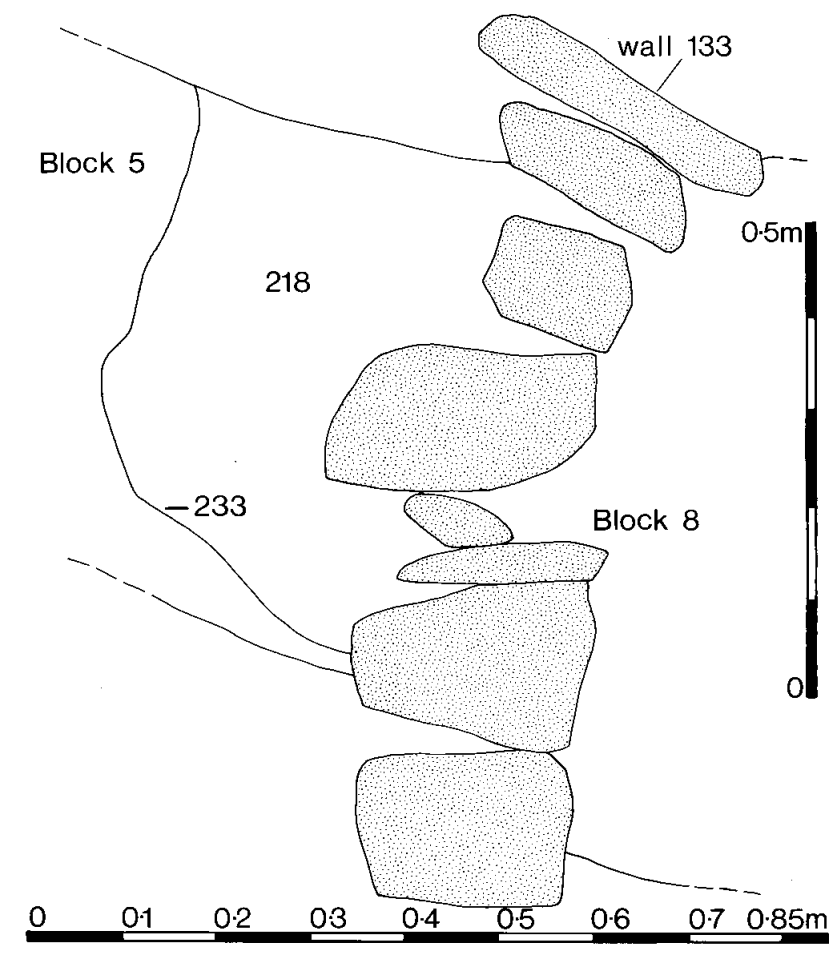

Figure 45. Block 7

preted in the field as cultivated deposits because of the extent of the dark layers and their loamy content. The presence of the lenses, however, indicated the presence of dumped midden deposits at the southern edge of the cultivated area.

\section{Specialist contribution}

Bones of sheep, cattle, pig, cod, pollock, ling were recovered together with other unidentifiable fish and bird bones.

\subsection{BLOCK 7 - REVETMENT WALL}

\section{See table p.307}

* ${ }^{14} \mathrm{C}$ date $2310 \pm 50 \mathrm{bp}$ (GU-2022) from layer [218] (Limpet). Block 7 lay at the southern end of Area A (Figure 38). It consisted of a revetment wall, [133], of tabular stones of varied sizes and backfill, [218], within the cut [233] (Figure 45). The wall was eight courses high and measured up to $0.98 \mathrm{~m}$.

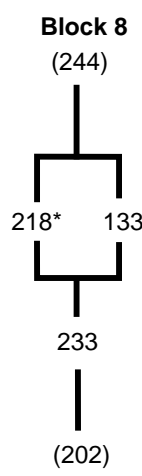

Block 5
Three stones seen in section within Block 6 and 8 appear to have collapsed forward from the wall line. The backfill consisted of grey deposits with darker lenses.

\section{Field interpretation}

Block 7 was a revetment wall constructed to face Block 5 and to restrict deposition in the area subsequently occupied by Block 8 . The presence of the darker, organic lenses within [218] suggests that the wall may have been built of stone and turves.

\section{Specialist contribution}

Cattle and pig bones were identified from this Block.

\section{I0 BLOCK 8 - MIDDEN-SITE DEPOSITS}

See table p.308

* ${ }^{14} \mathrm{C}$ date $2320 \pm 50 \mathrm{bp}$ (GU-2023) from [231] (Periwinkle). Block 8 lay at the southern edge of Area A (Figure 38). It had accumulated against the revetment wall in Block 7, lay above Block 3 and was sealed by Block 6 . It extended to the edge of the excavated area, a distance of only $2 \mathrm{~m}$. Its maximum depth was $0.8 \mathrm{~m}$ and its nine layers ranged in colour from white to dark greyish brown and in texture from sand to loamy sand (Figure 46). There were several large sub-angular stones within these layers, the uppermost two of which represent collapse of wall [133] (Block 7). A V-shaped feature cut through the basal layer [244] into the underlying Block. [225] consisted of the fill of a depression, although it was not certain if the feature was man-made.
Block 6
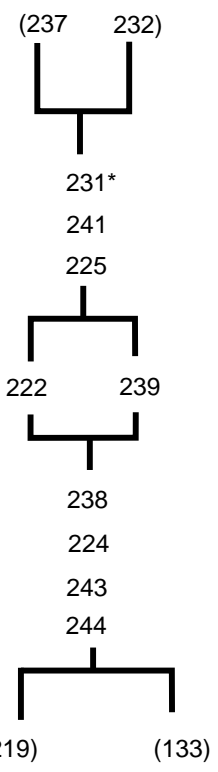

Block 3
Block 7 


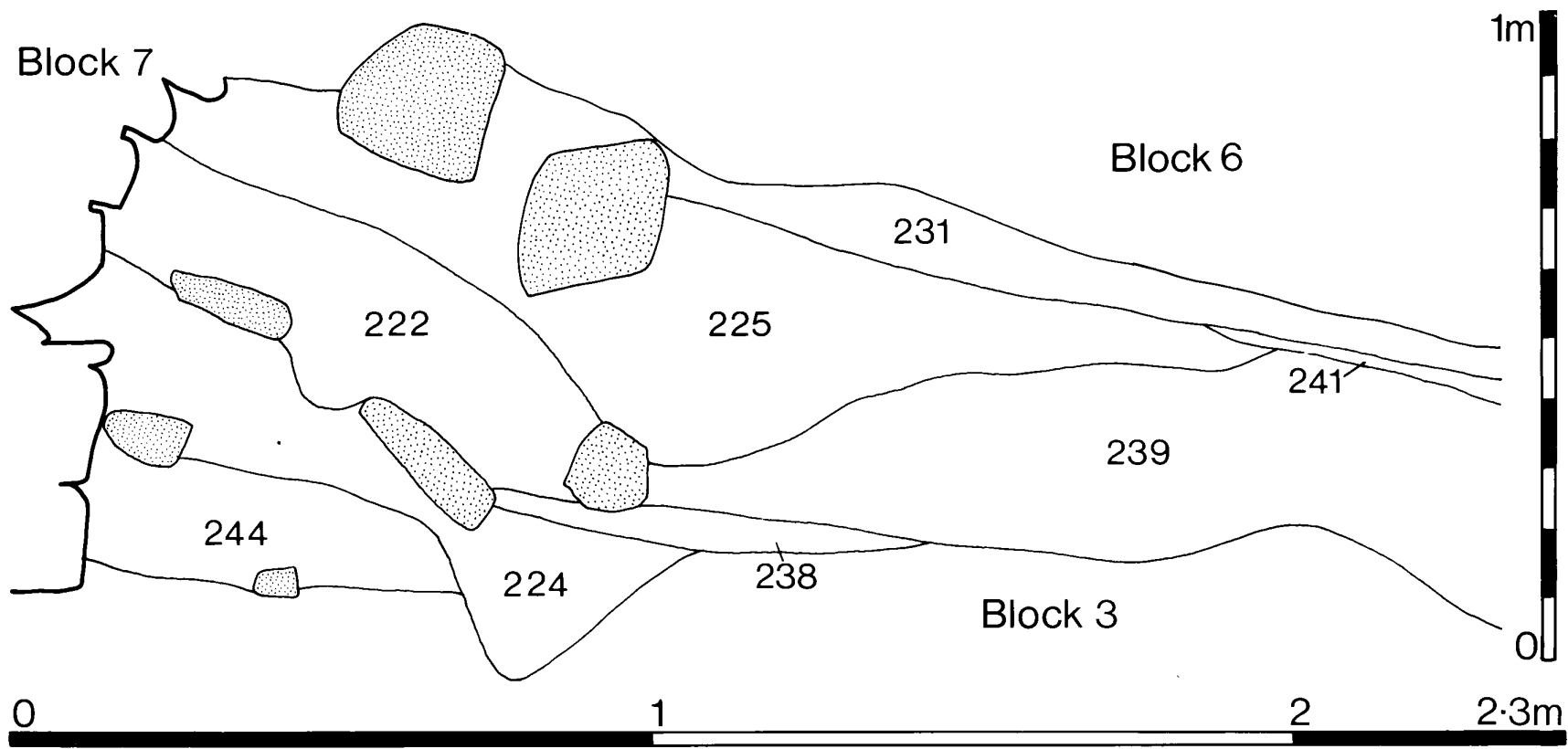

Figure 46. Block 8

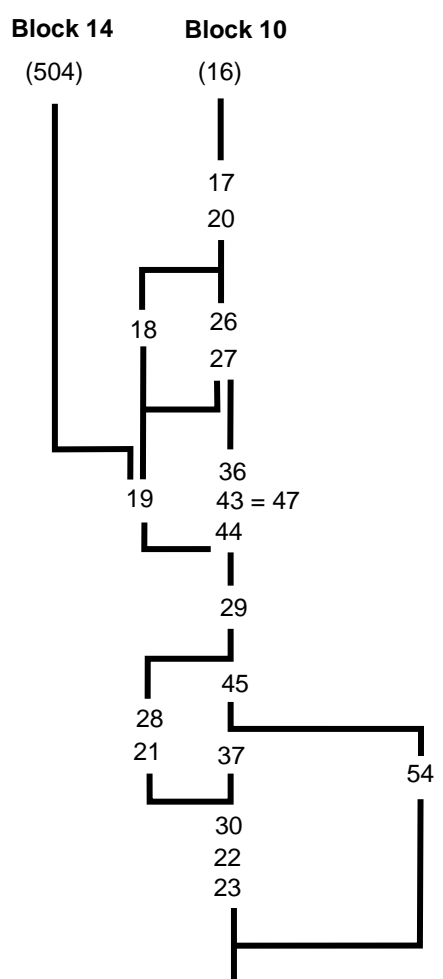

(24)

Block 4

\section{Field interpretation}

The contexts of Block 8 were interpreted as cultivated deposits because of their dark colour, despite their generally sandy texture. This material had accumulated to the south of the revetment wall of Block 7 .

\section{Specialist contribution}

Sheep and cattle bones were identified from this Block.

\section{II BLOCK 9 - MIDDEN-SITE DEPOSITS}

See table p.308

* ${ }^{14} \mathrm{C}$ date $2345 \pm 50 \mathrm{bp}$ (GU-2019) from [37] (Periwinkle). Block 9 lay in the northern part of Area A, over the sloping surface of Block 4 and below Blocks 10 and 14 (Figure 38 ). It extended for $14 \mathrm{~m}$ and had a maximum depth of 0.45 $\mathrm{m}$. Layer [19] underlay Block 14, while two other layers, [17] and [18], abutted the basal stone of the masonry [505] in Block 14 (Figure 47). At the junction of these layers and the masonry of Block 14, a vertical zone of discoloration, $0.05 \mathrm{~m}$ wide, was noted. The nineteen contexts within Block 9 were thin layers and lenses, $0.02-0.11 \mathrm{~m}$ deep. They varied in colour from very pale brown to brown dark brown and in texture from sand to loamy sand.

\section{Field interpretation}

This Block was interpreted as a midden-site deposit because the constituent layers were shallow while the variations in colour and texture were distinct. It seems probable that the masonry of Block 14 was cut into Block 9.

\section{Specialist contribution}

Sheep, pig and the bones of a manx shearwater were identified. 


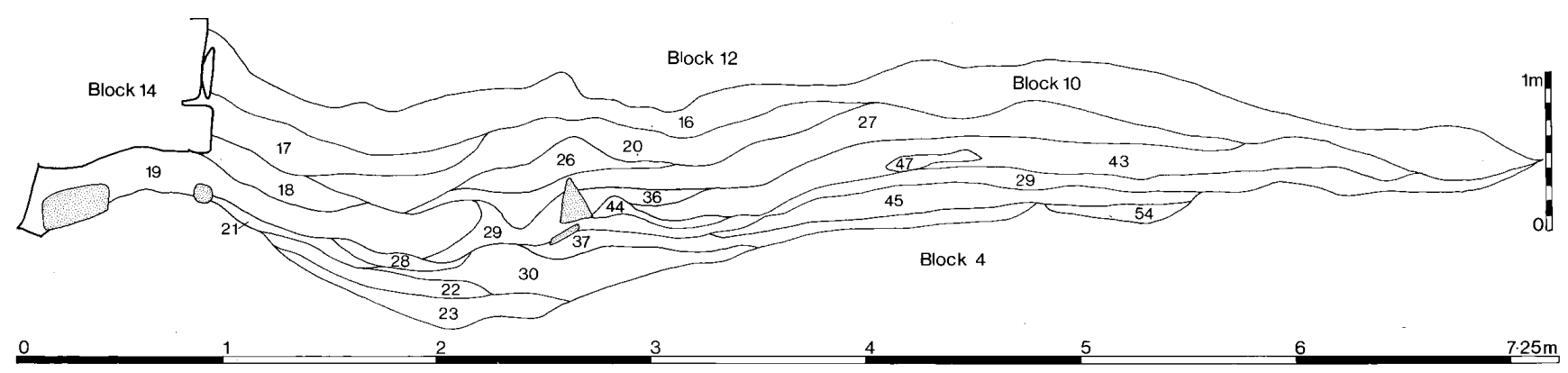

Figure 47. Block 9

\section{I2 BLOCK 10 - CULTIVATED DEPOSIT}

See table p.309

* ${ }^{14} \mathrm{C}$ date $2220 \pm 50 \mathrm{bp}$ (GU-2016) from [16] (Periwinkle).

This Block lay in the northern part of Area A (Figure 38). It consisted of a single extensive layer, [16]. It overlay Block 9, abutted Block 14 and underlay Blocks 12 and 29. Its maximum depth was $0.1 \mathrm{~m}$ and it extended for $6 \mathrm{~m}$. A vertical zone of discoloration, similar to that noted in Block 9, was observed at the junction of [16] and Block 14. [16] was a uniform, dark yellow-brown, sandy loam.

\section{Block 12}

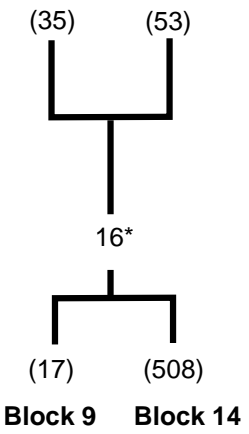

\section{Field interpretation}

This Block was interpreted as a cultivated deposit because of its loamy texture, its extent and homogeneity.

\section{Specialist contribution}

Sheep and cattle bones were identified.

\section{I3 BLOCK I I - MIDDEN-SITE DEPOSIT}

See table p.309

This Block lay in the southern part of Area A, above Block 4 and beneath the site overburden (Figure 38). The Block was $4.1 \mathrm{~m}$ long with a maximum thickness of $0.18 \mathrm{~m}$ and consisted of four layers (Figure 48). They ranged in colour from dark yellowish brown to dark brown and were loamy sand in texture.

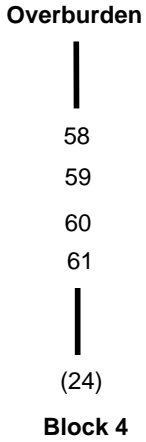

Field interpretation

The contexts in this Block were interpreted as midden-site deposits because of their high organic content and their heterogeneous nature. They resembled the deposits of Block 12 which was separated from the present Block by a modern erosion hollow.

\section{Specialist contribution}

Sheep and pig bones were identified.

\section{I4 BLOCK 12 - MIDDEN-SITE DEPOSIT}

See table p. 310

$*{ }^{14} \mathrm{C}$ date $2330 \pm 50 \mathrm{bp}$ from layer [33] (Periwinkle).

This Block lay in the northern part of Area A (Figure 38). It lay above Block 10, abutted Block 14 and lay beneath Blocks 13 and 29. It extended for $6 \mathrm{~m}$ to the south of Block 14 with a maximum depth of $0.8 \mathrm{~m}$. It consisted of thirty-one contexts which were generally extensive but shallow layers and also contained a few lenses (Figure 49). They ranged in colour from white to very dark brown and in texture from sand to sandy loam.

\section{Field interpretation}

The extent and general heterogeneous nature of the contexts, coupled with their loamy texture and generally high organic content, suggests that the Block was a midden-site deposit. 


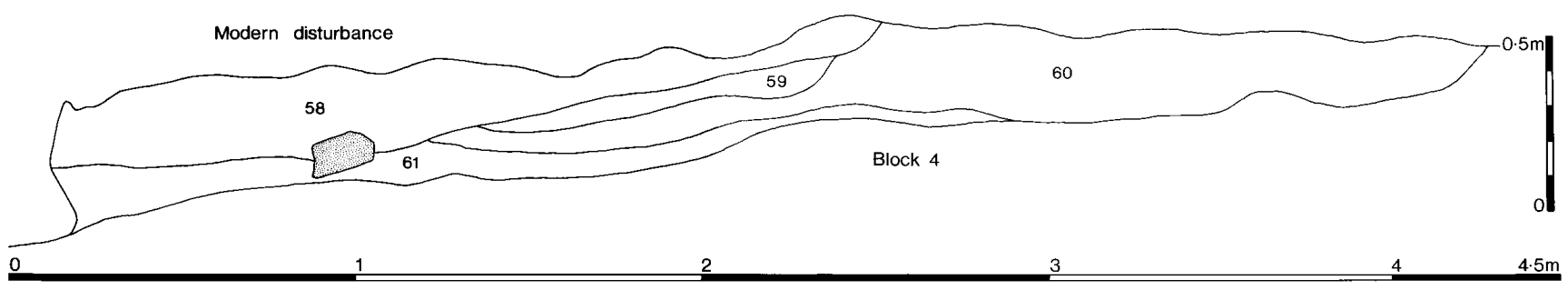

Figure 48. Block 11

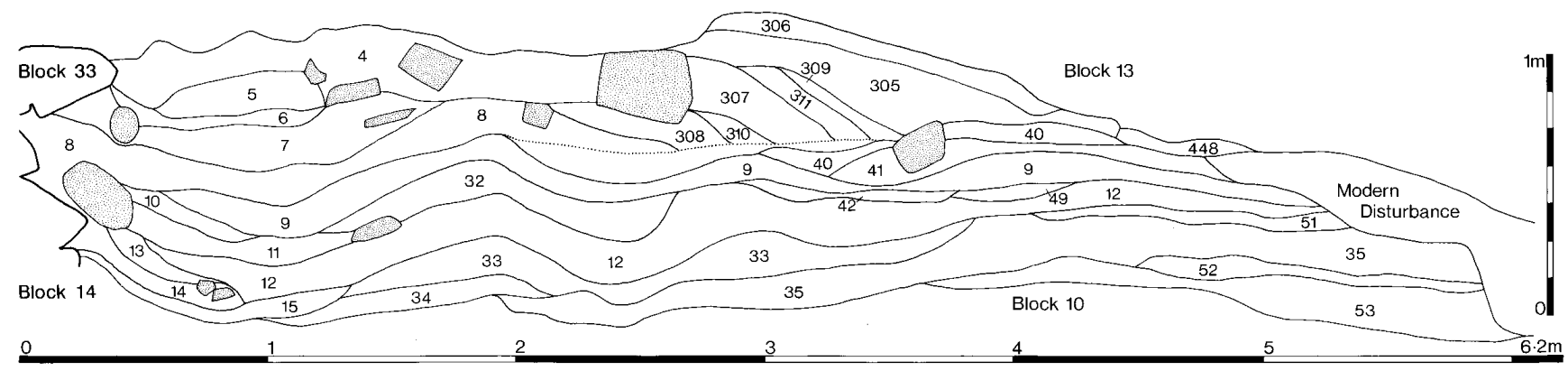

Figure 49. Block 12

\section{Specialist contribution}

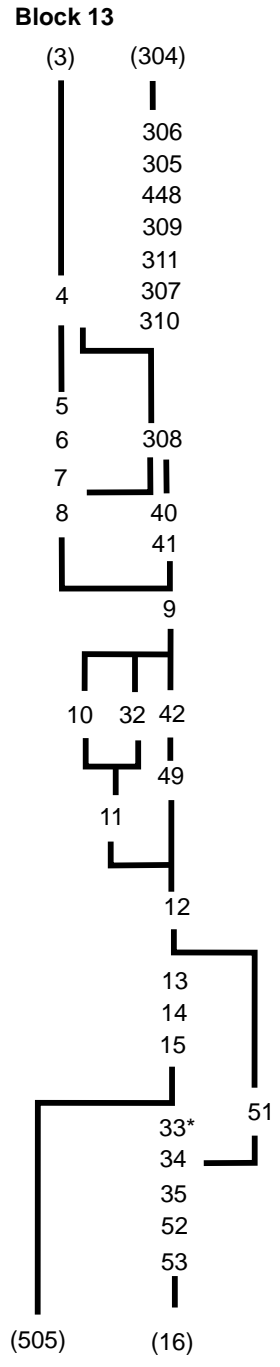

Sheep, cattle and pig bones were identified. Hake bones and those of the great auk were also recovered, the latter with butchery marks (Chapter 11.4.2).

\section{I5 BLOCKS 2 TO 12 - POST-EXCAVATION ANALYSES}

There are 136 contexts in this group of blocks, the field interpretations of which included wind blown sand (Block 3), cultivated deposits (Blocks 2, $4 \& 10$ ), midden-site deposits (Blocks 5, 8, 9, $11 \& 12$ ) and a revetment wall (Block 7). Block 6 was interpreted as cultivated and midden-site deposits. The cultivated deposits were identified on the basis of the presence of ard marks, wavy boundaries and evidence of organic input, ie manuring. The midden-site deposits had variable soil characteristics, were less extensive than the cultivated deposits and appeared to be high in anthropic material. The mean IHI for the group was based on seventy contexts. It was calculated as 8,500 with values ranging from 4 ([86]) to 70,000 ([37]). This represents a wide range of material present in variable quantities. Burnt stone was present in forty-five contexts in quantities ranging from $<5$ to $80 \%$ (the latter being [99] in Block 5). Of the 223 potsherds recovered from this Block, 207 were examined and they range from 1 to 9 in class size, with those in classes 1 to 3 predominating. The $\mathrm{pH}$ values ranged from 6.8 to 8.2 with a modal value of 7.4. Phosphate values ranged from 1 to 5 , with 3 being the most common. The soil colours ranged from very pale brown to very dark brown and in texture ranged from silty sandy loam to sand. The layer boundaries were predominantly clear and smooth or wavy.

Block 14 Block 10 


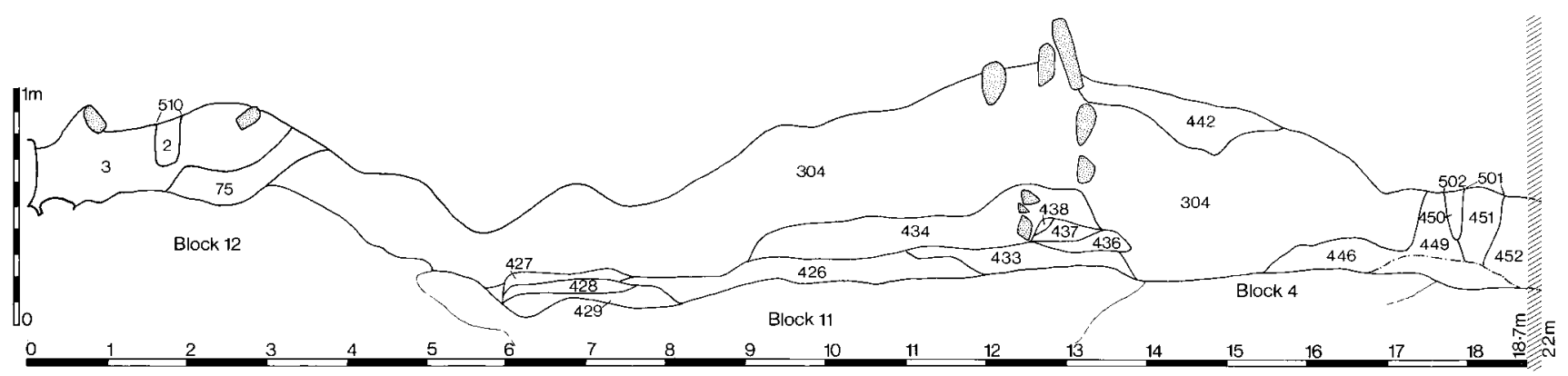

Figure 50. Block 13

\section{Archaeological interpretation}

Block 3 was interpreted as a revetted space infilled with wind-blown sand. The soil characteristics support this field interpretation, but the presence of bone, snail and sea shell, macroplant debris and stone suggests a more complex accumulation process. Block 7 was interpreted as a revetment wall and the backfill behind it. The materials contained in the latter are redeposited and most probably derived from the deposits of Block 5. Consequently the radiocarbon date may not date the context. Blocks 2, 4, 10 and part of Block 6 were interpreted as cultivated deposits. The evidence presented above is consistent with the field interpretations. The survival of discrete lenses within Block 4 seems anomalous and suggests that, like Block 2, this Block may have originated as midden-site, or even dumped deposits, which were subsequently and intermittently cultivated. Blocks 5, 8, 9, 11 , and 12 were interpreted in the field as midden-site deposits. The extreme heterogeneity of the deposits in Block 5 fully supports the field interpretation. However, it is possible that the variability of the deposits is, to a certain extent, due to the grouping together of deposits which could probably be legitimately sub-divided. Along with Block 6, these deposits may be midden-site deposits, intermittently cultivated. Both the high IHI values and the variability of the soil characteristics in Block 8, support the field interpretation that these are midden-site deposits. The soil textures, however, are mainly sands and this to some extent contradicts this interpretation. On balance, it seems likely that these deposits were formed by an overspill of material from Block 5 with the addition of some windblown sand. interpretation of the Block as 'derived' midden-site deposits would explain the apparent contradictory evidence. The variety, range of colours and loamy textures implying the presence of organic matter clearly indicate that Blocks 9, 11 and 12 are groups of midden-site deposits.

\section{Conclusions}

The field interpretation of these blocks identify them variously, as midden-site deposits or cultivated deposits. Subsequently the snail evidence suggests that these deposits vary only in their rates of accumulation and the degree to which they include fresh organic material. While the snail evidence may be somewhat overworked here, it is nonetheless clear that the terminology used in the interpretations is inadequate. This problem is considered at some length in Chapter 14. It must be concluded that these deposits formed in condi- tions of continuous, if variable, accretion of sand with intermittent inclusion of anthropogenic materials and occasional inclusion of fresh organic material. Where the rate of deposition of anthropogenic and organic material exceeds that of sand accumulation the layers appear to be midden-site deposits; where these materials are attenuated, by an increase in the rate of sand deposition, the layers appear to have been cultivated. The inclusion of discrete clods of organic material also points to the physical re-working of the deposits. In conclusion then it seems that these blocks are midden-site deposits, diluted in places by an increase in (natural) sand accumulation and altered, in places by cultivation. Blocks 5 to 9 have produced five radiocarbon dates which are not significantly different from each other, suggesting that the rates of deposition were, indeed, high.

\subsection{BLOCK I3 - MIDDEN-SITE DEPOSIT}

See tables p. 310

* ${ }^{14} \mathrm{C}$ date $2170 \pm 50$ bp (GU-2015) from layer [3] (Periwinkle).

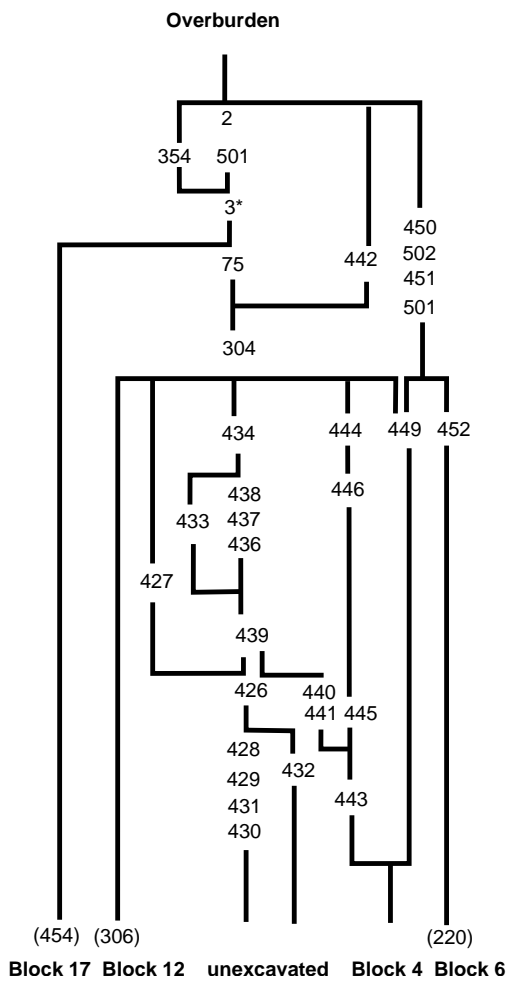


Block 13 spanned the entire length of Area A where it lay above the group of Blocks 2-12, 14 and 16, and extended into Area B where it lay over Block 17 (Figure 38). It was sealed only by the site's overburden of windblown sand, Block 29. The lowest layers of the Block do not appear in the drawn section because of the stepped nature of the section at this level. The Block extended for a distance of $24 \mathrm{~m}$ and varied in depth from $0.25 \mathrm{~m}$ to $1 \mathrm{~m}$. It consisted of three deep and extensive layers, [3], [304] and [452], three small pits or gulleys, [510], [501] and [502], and numerous shallow layers (Figure 50). The layers ranged in colour from white to dark greyish brown and in texture from sand to sandy loam. The three pits or gulley features penetrated the Block from its upper surface, their fills barely distinguishable from the layers into which they intruded. Many of the lower, shallow layers were truncated. Midway along the Block a concentration of sub-angular and rounded stones were observed. These lay in [304] over an apparent line of truncation of six underlying layers, [434], [438], [437], [436], [433] and [426] (see fig. 50).

\section{Field interpretation}

Block 13 was interpreted as a deepened, cultivated deposit because of the colour and texture of the extensive layers. The lower layers were more variable in colour and texture and represented eroded midden-site deposits. The coincidence of the alignment of stones, near the centre of the Block and the underlying plane of truncation suggests that a wall may have existed at this point.

The Block mean IHI, based on only two values, was calculated at 4,500, representing a range from 1,500 to 7,500. The lower value represents a moderate amount of material produced from a relatively large volume and the higher value represents a moderate quantity of material from a somewhat smaller volume. The IHI represents a restricted range of materials present in moderate amounts. $20 \%$ of the stone from [75] was burnt. Thirty-three of the thirty-five potsherds recovered from this Block were examined and they range in size-class from 1 to 3 . The $\mathrm{pH}$ values recorded for this Block range from 7.0 to 8.2 with a modal value of 7.5 . Phosphate values ranged from 1 to 4 . The soil colours are pale to dark greyish brown and the soil textures from sand to sandy loams. Layer boundaries were predominantly abrupt to sharp and irregular to wavy.

\section{Archaeological interpretation}

Like many of the Blocks in Area A, Block 13 seems to have consisted of midden-site deposits which were subsequently cultivated.

\section{Specialist contribution}

Sheep, cattle, pig and great auk, as well as unidentifiable bird and fish bones were recovered.

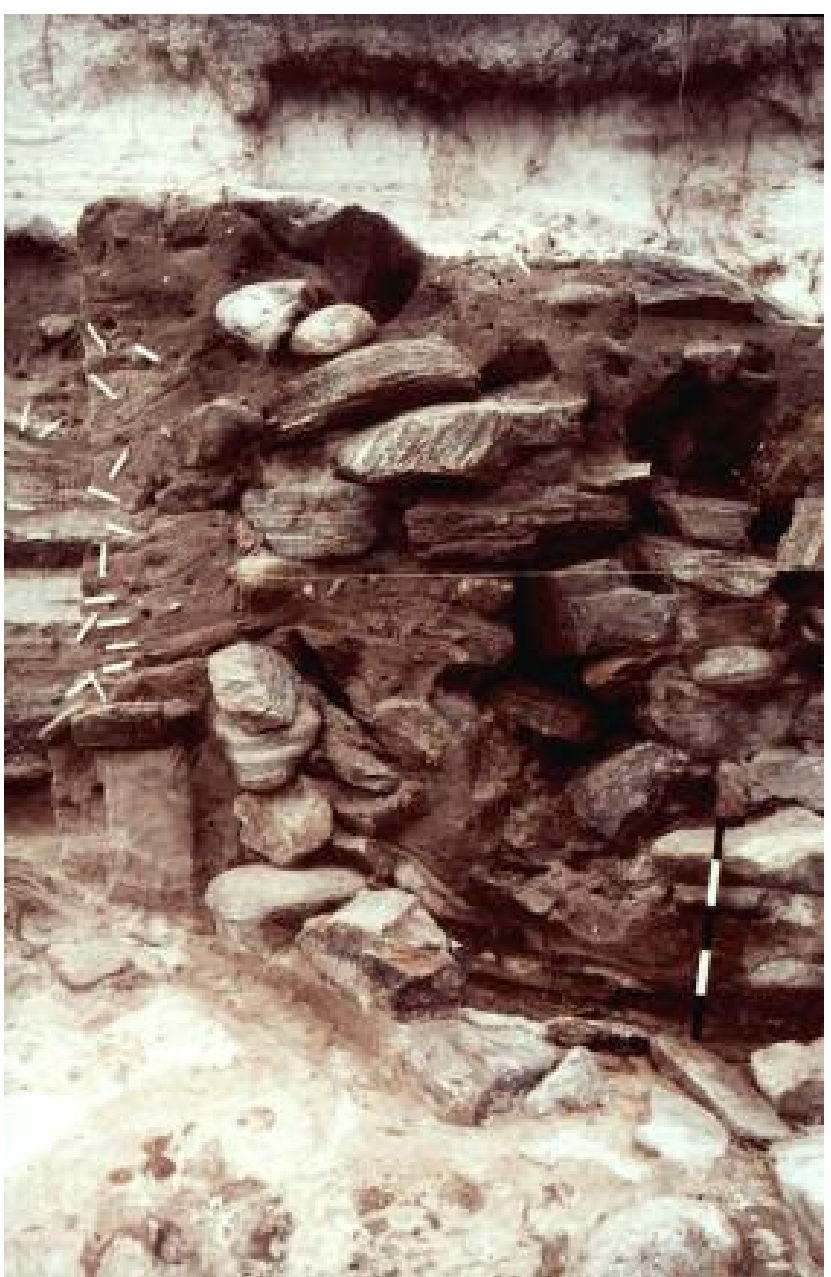

Plate 23. Hornish Point. The interface between the masonry to the north and the sediments to the south consists of Block 24 at the bottom of the profile separated from Block 14 at the top by the sediment layers of Block 9

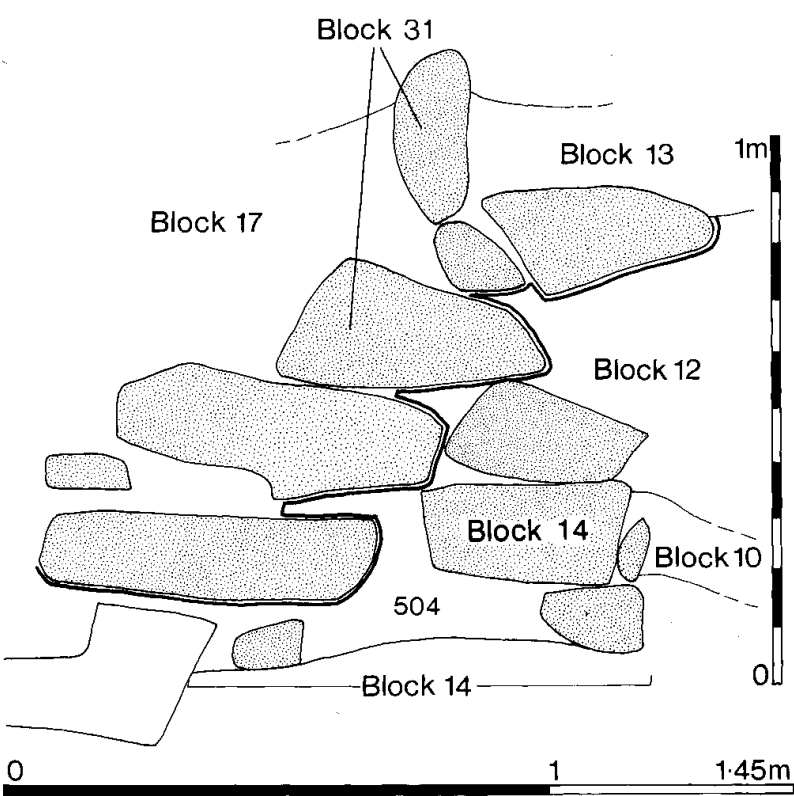

Figure 51. Block 14 


\section{Conclusion}

While it is probable that the deposits of this Block are midden-site deposits, subsequently cultivated, it is not impossible that this is, in part, a conflation horizon marking an hiatus in the site's occupation and that it represents pedogenic rather than anthropogenic developments.

\section{I7 BLOCK I4 - MASONRY}

This Block lay at the north end of Area B (Figure 38 \& Plate 23). It consisted, in section, of four vertically set, angular stones and a single deposit of sand beneath and to the north of them (Figure 51). The Block was cut into, and overlay Block 9 through Block 10 and through the lower layers of Block 12. The upper part of Block 12 seemed to have accumulated after the wall was built (see Block 12). Block 14 was subsequently overlain by the masonry of Block 33 . The masonry of Block 14 measured $0.40 \mathrm{~m}$ high and a maximum of $0.40 \mathrm{~m}$ wide. Observed in plan it was revealed as a drystone wall with a north-west/south-east alignment. The soil within the wall consisted of a light brown sand, [504].

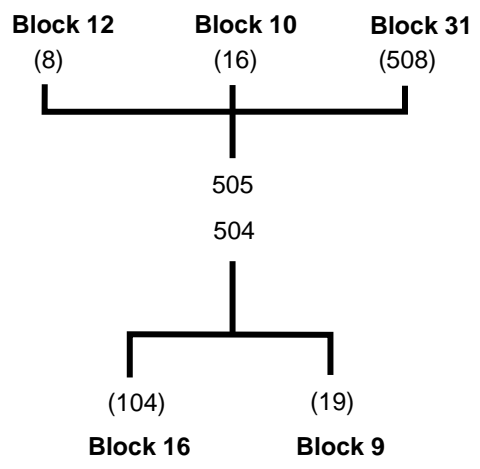

\section{Field and Archaeological interpretation}

This Block was interpreted as a wall, faced to the south.

\section{Specialist contribution}

Sheep, cattle and pig were identified.

\section{Conclusion}

This revetment wall seems to have been built against the truncated face of Blocks 9, 10 and the lower layers of Block 12. A light brown sand deposit had accumulated against its face but this was largely removed by the insertion of Block 33. Its function can only be revealed by further excavation.

\section{I8 BLOCK I5 - STRUCTURE 5 - PARTIALLY PRESERVED STRUCTURE}

See table p.312

This Block does not appear in the section drawing. It was located to the west of the section face at the southern end of Area B and was excavated horizontally. As the features did not extend as far eastwards as the section face the stratigraphical relationships between the two were not always clear. The structure survived as a horse-shoe shaped setting, corbelled to a height of almost $2 \mathrm{~m}$ at the rear (Figure $54 \&$ Plate 24). It probably includes earlier masonry, especially at the rear, and its northern arc was re-used in Block 18. Across the front of the horse-shoe a low, rectilinear wall, [154], had been built. Uncoursed rounded stones [103] lay behind Structure 5 , in the space between it and the recorded section face. The space enclosed within the cell had infilled with a series of deposits. Beneath the corbelling, these had survived to a height of $1.2 \mathrm{~m}$ while in the rest of the enclosed area only the lowest layers survived. The lowest layers, [192], [191] and [190], lay beneath the front wall. Features [192] and [191] were sandy layers and [190] was a layer of peat ash. Dark sand layers [166] and [149] abutted the wall [102] and were covered with a layer of clean sand, [148]. These layers were cut by an oval pit, [485], which measured $1.6 \mathrm{~m}$ by $1.2 \mathrm{~m}$ and had gently sloping sides. Its full depth could not be excavated, for reasons of safety, but its upper fill was a pale grey sand, [168]. A further dark sand layer covered the pit and fill, [147]. This was penetrated by a stake hole [486] which measured $0.1 \mathrm{~m}$ in diameter and was filled with grey brown sand. This, in turn, was sealed by a layer of orange peat ash [155]

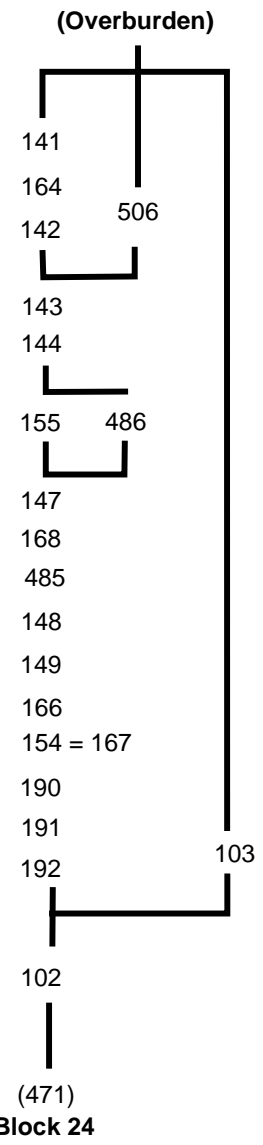




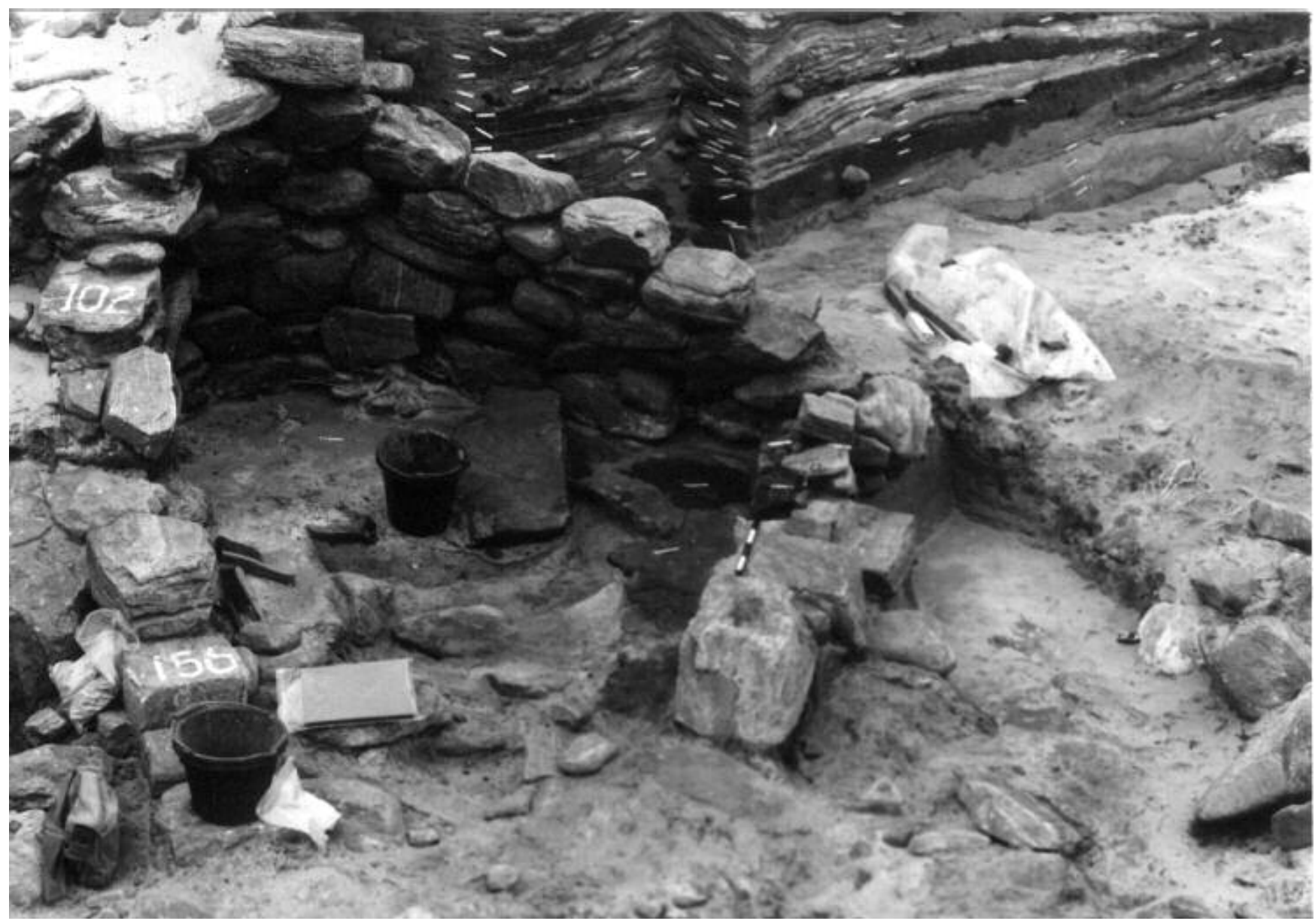

Plate 24. Hornish Point. The horse-shoe shaped setting and the sediments it contained comprises Block 15. The curving wall on the north side (left in the photograph) may have been part of an earlier structure and its upper parts were rebuilt as part of Block 18. The tabular blocks along the front may similarly have been re-used in Block 18 (qv)

and a layer of dark mottled sand [144] which survived over almost the whole of the enclosed area. Above the mottled sand lay a pile of rubble, [506], which seems to constitute the first post-abandonment deposit within the structure. Further layers survived beneath the corbelled rear of the structure. These consisted of sand and sea-shell deposits, [143], [142], [164] and [141].

\section{Field interpretation}

This Block was interpreted as a fragment of a circular drystone, partially corbelled structure. The southern arc of walling was probably the outer wall and the front and northern element of wall [102] were internal partitions. Within the surviving structure, shallow organic layers may have represented successive occupation deposits. Subsequently a large pit and a posthole had been cut into these deposits. After its abandonment, some masonry, [508], collapsed and shell-rich sand layers accumulated within the cell to the height of the surviving corbelling.

[155], a layer of peat ash, contained stone, of which some $5 \%$ was burnt. Some nine of the ten potsherds recovered were examined and range in size-class from 2 to 6 . These were all from the lower, probable occupation layers. The $\mathrm{pH}$ values recorded for this Block range from 7.1 to 7.5 with a modal value of 7.3. Phosphate values ranged from 2 to 5,2 being the commonest value. The soil colours are recorded as dark to pale grey and in texture were sand, they also included two layers of peat ash.

\section{Archaeological interpretation}

The field interpretation that this Block, along with Block 18, formed part of a wheelhouse cannot be tested by the post-excavation analyses.

\section{Specialist contribution}

Sheep, cattle, pig, unidentifiable fish bones and bones of a mallard were recovered.

\section{Conclusion}

This Block forms part of a wheelhouse with associated deposits. The evidence of the snail shells suggests that the lower deposits (up to and including [155]) were associated with settlement in the wheelhouse; the central deposits ([144] to [142] inclusive) indicate a period of use of the abandoned 


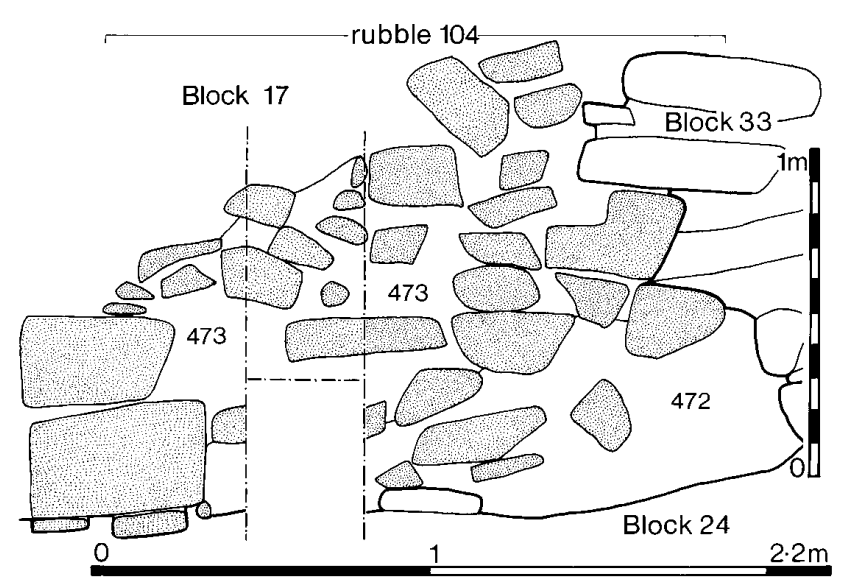

Figure 52. Block 16

structures as dumps; the upper deposits are largely windblown sand and possibly post-date the abandonment of the site.

\subsection{BLOCK 16 - STRUCTURAL DEBRIS}

Block 16 lay at the southern end of Area A (Figure 38). It overlay Block 24 and was beneath Blocks 4, 31 and 17. It extended for $2 \mathrm{~m}$ in length, and was $1.3 \mathrm{~m}$ high and consisted of numerous large angular stones and slabs, [104], within a matrix of dark brown sandy loam, [473], and a stub of walling, [152] (Figure 52). It overlay a deposit of brown sandy loam, [472]. The rubble of Block 16 , revealed immediately to

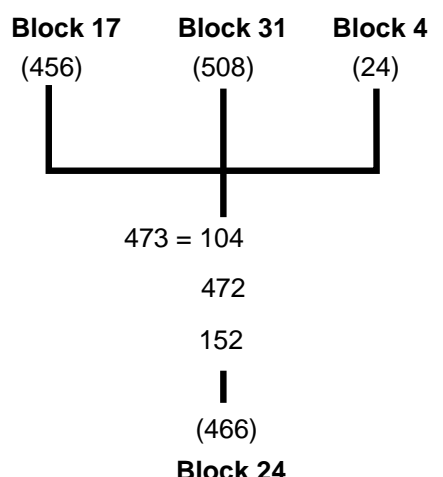

the east of Block 15, appeared to be a continuation of the stones observed behind the corbelled end of Block 15 .

\section{Field and archaeological interpretation}

It is probable that it represents structural debris probably from a house lying behind the excavated profile.

\section{Specialist contribution}

Sheep, cattle and pig bones were recovered.

\subsection{BLOCK I7 - RUBBLE AND MIDDEN-SITE DEPOSITS}

See table p.312

This Block lay at the southern end of Area A (Figure 38). It consisted of a series of deposits between Blocks 23 (Structure 1), 24 (Structure 3) and 16. These deposits contained numerous large angular stones and slabs, [484] and [194], which were concentrated in the centre of the Block (Figure 53). The

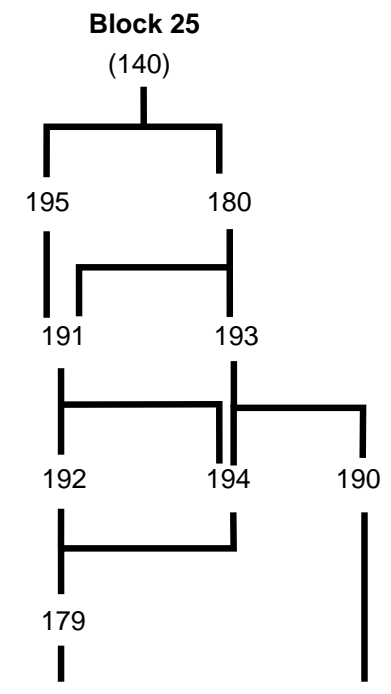

Unexcavated

Block 18

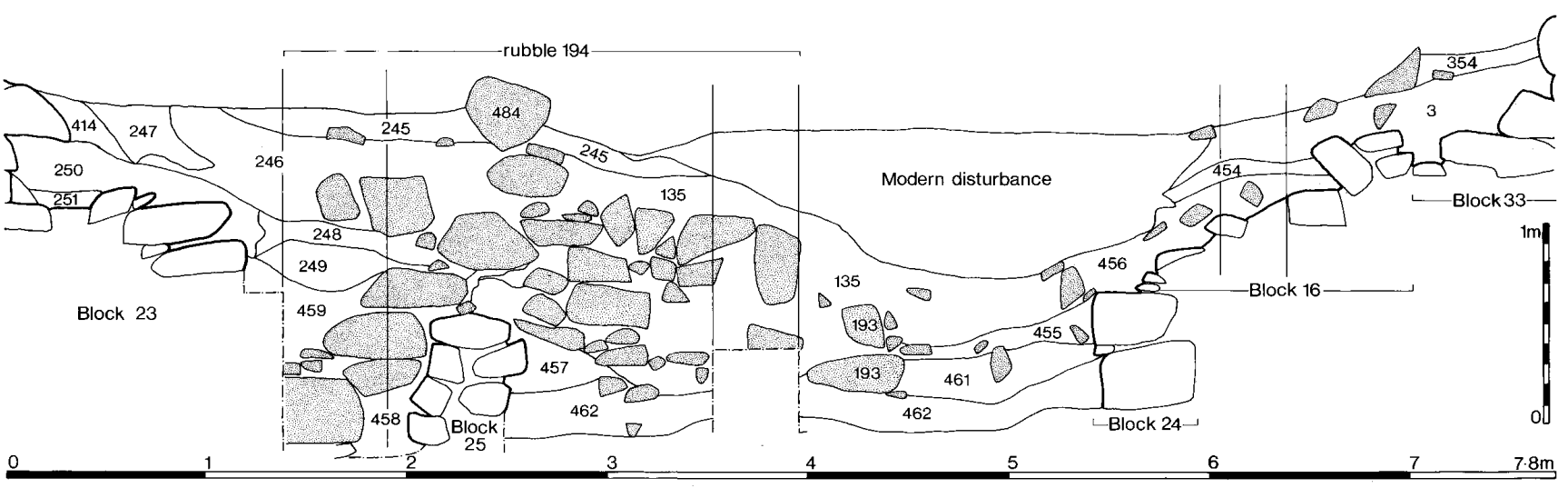

Figure 53. Block 17 


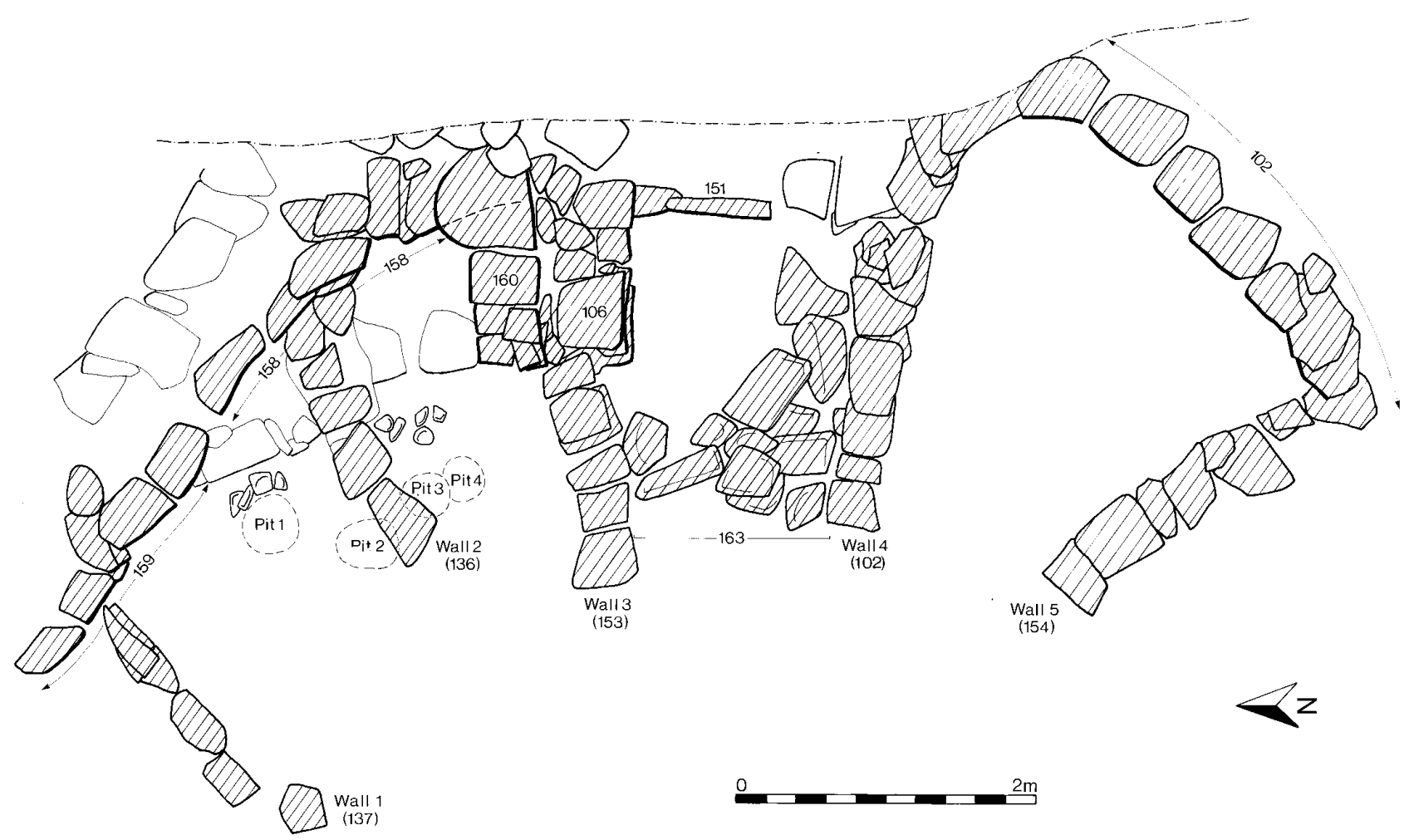

Figure 54. Blocks 15 \& 18

sand layers ranged in colour from pale brown to dark brown and in texture from loamy sand to sandy loam and they sloped down from the north.

\section{Field interpretation}

The field interpretation was that this Block consisted of midden-site deposits and rubble. This interpretation was based upon the colour and texture of the layers. Although finds were retrieved from the layers in this Block, no IHI has been calculated because the volumes of soil excavated were not recorded. A moderate range of finds were present in variable quantities. Burnt stone was found in quantities ranging from $5 \%$ to $30 \%$ in 4 contexts. Of the ninety-five potsherds recovered from this Block eighty-two were examined and they range in size-class from 1 to 8 . The distribution is markedly skewed to the lower end and is almost Poisson in form. The $\mathrm{pH}$ values recorded for this Block range from 7.6 to 8.2 with a modal value of 7.6. Phosphate values ranged from 2 to 4,3 being the most common value. The soil colours are recorded as ranging from pale brown to dark brown and the soil textures range from loamy sand to sandy loam. Layer boundaries were predominantly either clear or sharp and wavy.

\section{Archaeological interpretation}

The variability of the deposits, in both their soil characteristics and anthropogenic components support the view that these are midden-site deposits. The regularity of the layers militates against their interpretation as dumped deposits infilling the structures over which they lie. This, and the smooth, clear to sharp, boundaries also suggest that the sedi- mentation rate was relatively high. On balance, the archaeological interpretation is that these are midden-site deposits, but the source of the rubble which they contain could not be discerned from the recorded profile.

\section{Specialist contribution}

Sheep, cattle and pig and the bones of a saithe and a rook/crow were recovered.

\section{Conclusion}

This Block consists of midden-site deposits which accumulated rapidly in the vicinity of occupied houses. They may not, on the evidence of the snail study, have developed a sward at any time and the rubble deposits may derive from abandonment of the related houses.

\subsection{BLOCK I8 - STRUCTURE 5 - WALL ARC WITH RADIAL PIERS AND POST PITS}

See table p.313

This Block does not appear in the section drawing because it lay to the west of the main section line. It consisted of the northern part of Structure 5 (the rest of which comprises Block 15), an arc of drystone wall and three radial buttresses (Figure 54). The Block also contained four large pits (Figure 54) and numerous layers. 


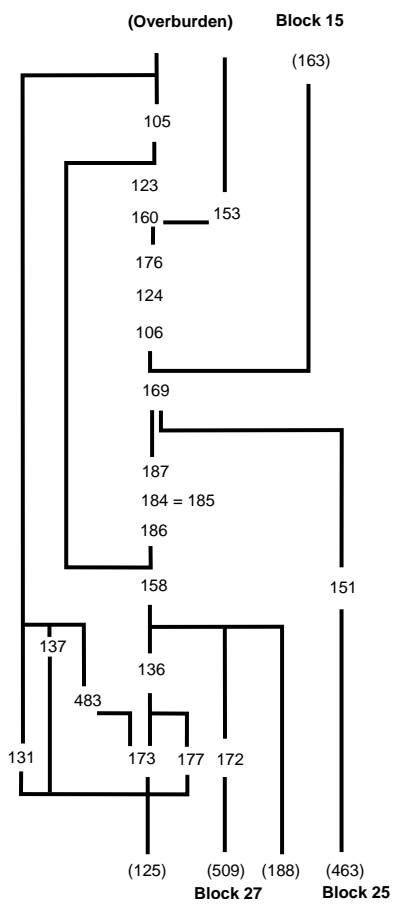

Pits

At the base of this Block four circular pits were noted. They averaged $0.4 \mathrm{~m}$ in diameter and $0.8 \mathrm{~m}$ deep. The pit fills were all similar, consisting in their lowest levels of about 0.5 $\mathrm{m}$ of light brown sand, covered by a layer of shattered and compacted bones. Pit 1 also contained four vertically set stones on its east side at this level. The uppermost fills were of dark sand. Their sections revealed evidence of recutting. These pits contained a divided human burial, discussed below and reported upon elsewhere (Barber et al 1989; and see Chapter 11.1.2). At least three further pits were noted about $3 \mathrm{~m}$ to the north, clustered around radial Wall 3 (see below) but they were not recorded.

\section{Masonry}

A west facing arc of dry stone wall, [158], and radial Wall 2, were constructed after the pits were filled. The arc of wall consisted of a maximum of six courses of large angular stones with small stones within the joints. The face of this wall was slightly corbelled and measured $5.2 \mathrm{~m}$ long. Some of the stones of the wallface, [158], appeared to be keyed into those of [107] (Block 23). Radial Wall 1, [137], consisted of a line of large slabs which abutted the wall face, [158]. Radial Wall 2 , [136], consisted of thin slabs of which only the lower two courses survived. This line of stones was $1.8 \mathrm{~m}$ long and 0.4 $\mathrm{m}$ wide. The slabs at its east end were keyed in to the drain, [171], of Block 23. At the west end of this wall the stones were large and tabular. Radial Wall 3, from the excavated evidence, appears to have been stratigraphically later than the other two walls. It consisted of three masonry elements, [106], [160] and [153]. [106] consisted of four courses of a freestanding drystone wall constructed of large slabs and blocks. Its northwards thickening, [160], was also constructed of large slabs. [106] was separated stratigraphically from [160] by the layers [124] and [176] which underlay
[106] and abutted [160]. A line of slabs two courses thick, [153], extended the alignment of [106] from its west end. The total length of the composite Radial Wall 3 was $2.3 \mathrm{~m}$. Within the upper three courses of the arcing wall, mid-way between the Radial Walls 1 and 2, was a gap which measured circa $0.5 \mathrm{~m}$ wide and $0.35 \mathrm{~m}$ deep, set into the back of the wall [107]. This was filled with layers collectively called [170] and included dished deposits of white, orange and dark brown sand.

\section{Layers}

The lower layers included in this Block were laminated light and dark grey-brown sands, except for a black sand, [187] and a deposit of bright orange peat-ash, [184]. The uppermost layers in this Block included loose, soft-textured brown loam, [123], and rubble, [105], which lay over the arcing wallface, [158], from the back of the wall [107] as far as the radial wall 3 .

\section{Field interpretation}

The field interpretation of the Block, like Block 15, was that it comprised the remains of a circular structure with some residual floor deposits. This structure overlay four pits filled with human and animal bone.

Burnt stone was found in quantities of less than $5 \%$ in one context. Of the seventy-five potsherds recovered from this Block fifty-nine were examined and they range in size-class from 1 to 5 . The distribution is Poisson in form. Human bones consisting of the remains of a single individual, were retrieved from the four pits (Chapter 11.1.2). The $\mathrm{pH}$ values recorded for this Block range from 7.1 to 7.8 with a modal value of 7.6. Phosphate values ranged from 2 to 4 . The soil colours, excluding those of the pit fills, are recorded as ranging from pale brown to very dark grey brown and in texture from sand to loamy sand. Layer boundaries were clear and wavy. The pit fills were light to dark brown in colour and sandy in texture.

\section{Archaeological interpretation}

The masonry which constitutes the main part of this Block seems to be part of a wheelhouse. Inside this wheelhouse were a series of deposits including some located within the stones of the walls.

\section{Specialist contribution}

Three of the four pits containing the remains of a juvenile human also contained animal bones. Pit 1 held substantial parts of the skeleton of a juvenile bovid (circa 18-30 months old, sex unknown). Pit 2 produced substantial parts of two female sheep (>3years and circa 18-30 months old at death). Pit 4 contained much of a second juvenile bovid (slightly older, with sex again unknown). These three pits offer an interesting example of 'structured deposition', because the four carcasses had been thoroughly processed before burial. Both 
cattle bear cut marks indicative of skinning, dismembering and filleting, while their long bones were deliberately broken for marrow extraction. One bone had been heavily chewed by a dog. Both sheep show signs of dismembering and filleting. The fact that the two cattle in Pits 1 and 4 have apparently not been mixed, either with each other or with the sheep in Pit 2, may simply be because the pits were dug and filled at different times. Nonetheless, the fact that these bones, including some quite small splinters, were collected and buried, rather than being combined with other domestic refuse is unusual. Taken in conjunction with the physical anthropological and stratigraphic evidence, it suggests the remains of feasts associated with extended funerary rites. The importance attached to these feasts is further underlined by the particular choice of animals for slaughter. Both the two cattle and the younger sheep were, unusually for prehistoric Hornish Point and Baleshare, killed in their second or third year, ie at an age when they offered plentiful meat. As the pits were not preserved in their entirety, no significance should be attached to the absence of particular body parts.

\section{Pit I}

Body parts represented are;

Head: included both maxillae and both mandibles

Trunk: included axis, 1 other cervical and 3 thoracic vertebrae, fragments of ribs

Left forelimb: included radius, ulna and metacarpal

Left hindlimb: included pelvis, tibia, astragalus, calcaneum, navicular-cuboid and metatarsal

Right hindlimb: included pelvis and femur

Toes: 5 first, 3 second and 4 third phalanges representing both fore and hind feet.

All these elements were apparently derived from one carcass, the maxillae and mandibles are perfect pairs, the left distal tibia, astragalus, navicular-cuboid and proximal metatarsal articulate correctly and the states of fusion of first and second phalanges are uniform.

This carcass had been subject to the following processes;

Skinning; transverse knife marks on left metatarsal (posterior face of distal shaft - cf Binford 1981, 140 Table 4.04 'MTd-2'), on 4 first phalanges (on plantar face of 3, on plantar, lateral and volar faces of 4th) and 2 second phalanges (planter face of proximal articulation - cf Binford 1981, 103; von den Driesch \& Boessneck 1975, 20; Parkin,

Rowley-Conwy \& Serjeantson 1986).

Dismembering; knife marks on right mandible (lateral face of ramus - cf Binford 1981, 136 Table 4.04 'M-2'; von den Driesch \& Boessneck 1975, 7 fig. 1), left astragalus (cf Binford 1981, 120 Fig.4.27 'TA-1' and 'TA-2'), right pelvis (cf Binford 1981, 113 fig. 4.22 'Ps-8' and 'Ps-9'; also acetabulum chopped at junction of ilium and ischium), right femur (cf Binford 1981, 117 fig. 4.25 'Fp-1'), cervical vertebra (posterior articular process) and ? also 1 thoracic vertebra (dorsal spine - cf Binford 1981, 111 - 'segmentation of the spinal column').

Filleting (?); knife marks on 1 thoracic vertebra (cf Binford 1981, 112 Fig. 4.21 'TV-2'), right femur (cf Binford 1981,

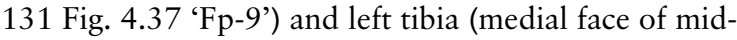
shaft).

Marrow extraction; characteristic impact scars and splintering of shaft of all represented long bones ( $v i z$ left radius, left metacarpal, left tibia, left metatarsal and right femur - cf Binford 1981, 155, fig. 4.48 and 160 Fig. 4.53).

Gnawing; probably by dog, of left calcaneum.

Age at death: mandibular M2s have wear on both cusps, mandibular M3s are visible incrypt/beginning to erupt - circa 18-30 months. Maxillary M3s are visible in crypt. Second phalanges are in the process of fusing.

\section{Pit 2}

Body parts represented are;

Head: a few cranial fragments

Trunk: 2 atlas (1 larger, 1 smaller), 2 axis (1 larger with fused and one smaller with unfused epiphysis), 9 other cervical vertebrae (4 large with fused/fusing epiphyses, 5 small with unfused epiphyses), 21 thoracic vertebrae (10 large with fused epiphyses, 11 smaller with unfused epiphyses), 14 lumbar vertebrae (5 fused, 5 fusing and 4 unfused epiphyses), 1 sacrum (with fused epiphyses), 13 ribs

Left forelimb: scapula (fused), proximal humerus (fused), radius (proximal and distal fused) and matching ulna (proximal fused)

Right forelimb: humerus (proximal unfused, distal fused and articulates well with proximal radius and ulna), radius (proximal fused, distal unfused, shorter than left radius) and matching ulna (proximal unfused)

Left hindlimb: pelvis (acetabulum fused, female), femur (proximal and distal unfused), tibia (proximal unfused, distal just fused), calcaneum (tuber unfused)

Right hindlimb: pelvis (acetabulum fused, female, smaller than left pelvis), tibia (probable pair with left tibia), calcaneum (pair with left calcaneum)

On the evidence of state of fusion, size, matching pairs and quality of articulation between adjacent elements, at least two (and probably no more than two) individuals are indicated. The first, a larger, older individual was represented by most of the vertebral column, most of the left forelimb (scapula, proximal humerus, radius, ulna) and part of the left hindlimb (pelvis); a smaller, younger individual was represented by most of the vertebral column. The second individual, was represented by most of the right forelimb (humerus, radius, ulna) and parts of both hindlimbs (right pelvis, left femur, left and right tibiae, left and right calcanea).

The carcass of the older individual had been subject to the following processes:

Dismembering; chop marks on atlas (cf Binford 1981, 111 Fig. 4.20 'CV-1'); dorsal articular processes chopped off between fifth and sixth cervical vertebrae (cf Binford 1981, 110); dorsal spines of 3 lumbar vertebrae chopped or cut (cf Binford 1981, 112 Fig. 4.21); transverse knife marks on scapula (cranial margin of neck - cf Binford 1981, 122 Fig. 4.29 'S-2'), left radius (cf. Binford 1981, 125 Fig. 4.32 'RCp-5'), left pelvis (cf. Binford 1981, 113 Fig. 4.22 'PS-7' and 'PS-8'). 
Filleting; knife marks across transverse processes of 2 lumbar vertebrae (cf Binford 1981, 113).

The carcass of the younger individual had been subject to the same processes:

Dismembering; dorsal spines of 2 lumbar vertebrae chopped or cut (cf Binford 1981, 112 Fig. 4.21); transverse knife marks on right humerus (cf Binford 1981, 123 Fig. 4.30 'Hd-2'), right radius (cf Binford 1981, 125 Fig. 4.32 'RCp-5'), right pelvis (cf Binford 1981, 113 Fig. 4.22 'PS-7'), left femur (cf Binford 1981, 117 Fig. 4.25 'Fp-1', 'Fp-2' and 'Fd-1') and right calcaneum (cf Binford 1981, 120 Fig. 4.27 'TC-3').

Filleting; knife marks into dorsal spine of 1 and across transverse processes of another lumbar vertebra (cf Binford 1981, 113); transverse or diagonal knife marks on right humerus (posterior and medial faces of mid-shaft), right pelvis (cf Binford 1981, 130 Fig. 4.36 'PS-6') left femur (posterior face of mid-shaft, medial face of distal shaft), left tibia (cf Binford 1981, 132 Fig. 4.38 'Td-4' and medial face of mid-shaft) and right tibia (cf Binford 1981, 131 Fig. 4.37 'Tp-4' and lateral face of mid-shaft).

Age at death. On the basis of the state of epiphyseal fusion, the older female was $>3$ years old (proximal humerus and distal radius fused), while the younger female died in her late second/early third year (distal tibiae just fused, proximal ulna unfused).

\section{Pit 4}

Body parts represented are;

Head: included 1 loose maxillary tooth

Trunk: atlas, axis, 3 other cervical vertebrae, fragments of ribs

Left forelimb: humerus and metacarpal

Right forelimb: metacarpal

Left hindlimb: femur, distal tibia and astragalus

Right hindlimb: pelvis, distal femur, calcaneum, navicular-cuboid and metatarsal

Toes: 5 first, 3 second and 2 third phalanges representing both fore and hind feet.

All these elements were apparently derived from one carcass, the left distal tibia articulates well with astragalus, as does the right navicular-cuboid with proximal metatarsal. The states of fusion of first and second phalanges are uniform.

This carcass had been subject to the following processes: Skinning; transverse knife marks on 3 first phalanges (plantar face).

Dismembering; knife marks on right calcaneum (cf Binford 1981, 120 Fig. 4.27 'TC-1'), right navicular-cuboid (cf Binford 1981, 122 Fig. 4.28 'TNC-1') and (?) right metatarsal (longitudinal on distal articulation).

Marrow extraction; characteristic impact scars and splintering of shaft of all represented long bones (viz. left humerus, left metacarpal, right metacarpal, left femur, left tibia, right metatarsal and perhaps right femur - cf Binford 1981, 155 Fig. 4.48 and 160 Fig. 4.53). Transverse knife marks on posterior face of left metacarpal (proximal and distal shaft) and right metacarpal (distal shaft), suggestive of filleting, may reflect cleaning of bone prior to marrow cracking (Binford 1981, 134).
Age at death: loose left maxillary M3 just coming into wear and second phalanges in process of fusing suggest slightly older than bovine in pit 1 - circa $>30$ months.

Red deer, dog bones and cod bones were also identified from this Block.

\section{Conclusion}

While it is clear that Blocks 15 and 18 functioned together as a single wheelhouse it is equally clear that they are not of one build. Indeed, Block 18 almost certainly includes some earlier elements in its masonry (notably walls [158] and [151]) while Pier 3 is of at least two and probably three separate builds. Similarly, the four pits containing human and animal bone clearly predate Pier 2 and may predate the entire structure. Marine erosion had reduced the internal deposits in this structure and effectively removed any chance of relating them to the period(s) of occupation and use. The evidence from the snail-shell assemblages suggests that these deposits may have consisted largely of windblown sand but small amounts of stone, bone, pottery and macroplant remains indicate some anthropic contribution to the deposits formation. Whether this was as 'primary' in situ debris or 'secondary' dumping cannot now be ascertained.

\subsection{BLOCK 19 - DUMPED DEPOSITS}

See tables p.315, 318

* ${ }^{14} \mathrm{C}$ date $2170 \pm 50$ bp (GU-2024) from layer [257] (Periwinkle).

* ${ }^{14} \mathrm{C}$ date $2285 \pm 50$ bp (GU-2025) from layer [272] (Periwinkle).

* ${ }^{14} \mathrm{C}$ date $2090 \pm 50 \mathrm{bp}$ (GU-2549) from layers [260], [259], [264], [265], [267], [268], [295], [269], [270], [373], [300], [299], [252], [253], [254], [255], [272], [273], [274], [372] and [356] (Carbonised seeds).

Block 19 lay in Area B, above Structure 5 (Block 23) and Block 26, and below Blocks 20 and 17 (Figure 38). It extended for $9 \mathrm{~m}$ and was up to $1.9 \mathrm{~m}$ in depth. It consisted of numerous layers which infilled Structure 5, and continued over the wall of Structure 5 as far as the stone slabs of Structure 7, Block 22 (Figure 55). The layers within this Block were generally shallow, ranging from $0.05 \mathrm{~m}$ to $0.15 \mathrm{~m}$ in depth and sloped steeply to the north. Beneath the lintel stone of Structure 5 deposits were generally deeper, up to $0.5 \mathrm{~m}$ in depth. The layers within this Block ranged from light brownish grey to very dark greyish brown in colour and from sand to sandy loam. In particular, [265] contained carbonised peat and peat ash. [372] and [268] were rich in seeds and [264] contained many shells. Part of a cetacean vertebra was found in [301].

\section{Field interpretation}

This Block was interpreted as dumped layers deposited from the south into the space within the inner facade of Structure 


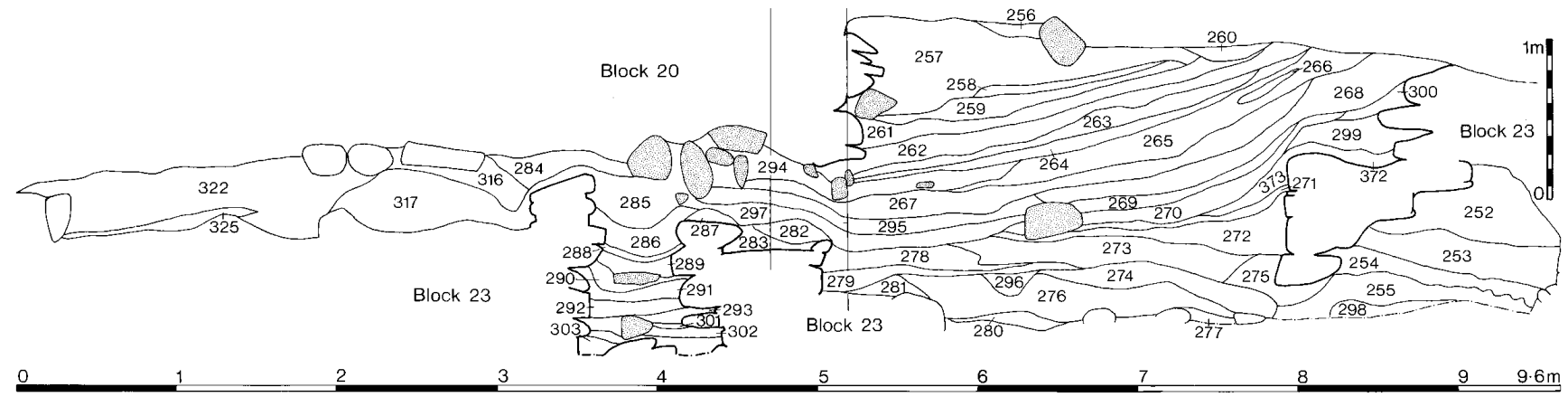

Figure 55. Block 19

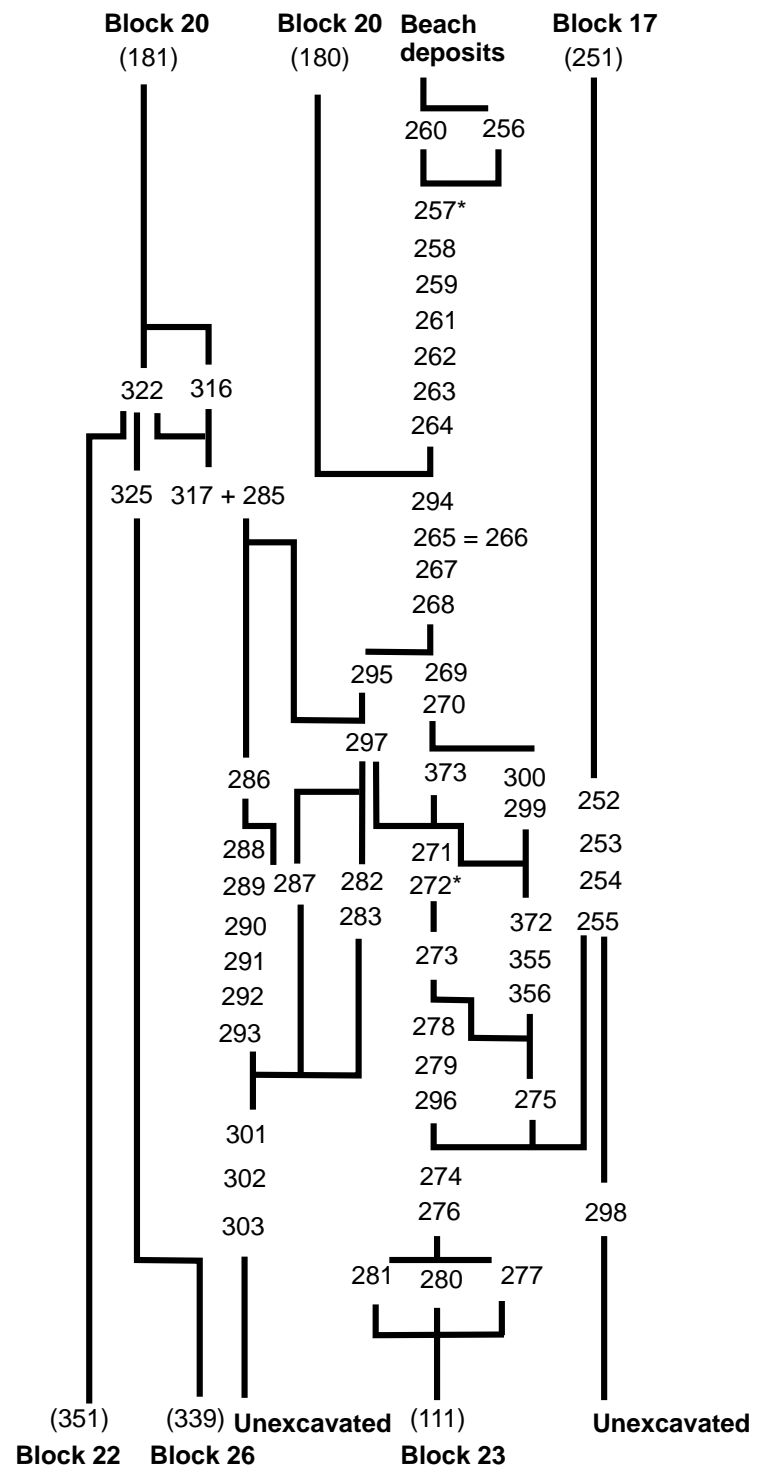

1, Block 23. The lack of windblown sand within the dump suggests that deposition was rapid.

Burnt stone was found in quantities ranging from $<5 \%$ to $10 \%$ in twelve contexts. Of the ninety potsherds recovered from this Block seventy-two were examined and they range in size-class from 1 to 6 . The distribution is markedly skewed to the smaller end. The $\mathrm{pH}$ values recorded for this Block range from 7.5 to 8.1 with a modal value of 7.7. Phosphate values ranged from 1 to 5,2 being the commonest value. The soil colours are recorded as ranging from light brownish grey to very dark grey brown and the soil textures ranged from sand to sandy loam. Layer boundaries were predominantly abrupt to clear, and smooth to wavy.

\section{Archaeological interpretation}

The variability of these deposits, the clarity of their boundaries and the variability of their anthropogenic component suggest that these may be midden-site deposits. The size and regularity of the individual layers militate against their interpretation as primary refuse deposits.

\section{Specialist contribution}

Sheep, cattle, pig, red deer and dog bones were identified, as were bones from a number of fish species including saithe, cod and ling. Bones of great auk were also recovered.

\section{Conclusion}

Identified in the field as dumped deposits and subsequently as midden-site deposits these deposits have something of the character of both types. Within the abandoned structure of Block 23 windblown sand was trapped and domestic refuse was dumped to create a series of heterogeneous layers which, on the snail-shell evidence, accumulated at varying rates in varying degrees of dryness and with varying amounts of fresh organic matter. It is clear from the radiocarbon dates that the entire Block was deposited quite rapidly (Chapter 18.8.6). Perhaps the deposits with greatest anthropic inclusions were formed of reworked dumped deposits, in which case, their identification as such remains literally true.

\subsection{BLOCK 20 - STRUCTURE 7}

See tables p.316, 317

Block 20 lay in the northern part of the site over Blocks 19 and 22 (Figure 38). It consisted of a drystone structure (Figures $56 \& 57)$. The section was drawn in two parts because the upper part, ie the east section of masonry, [121], was in reality set back circa $1 \mathrm{~m}$ from the underlying drawn layers, hence the lack of clarity of the boundaries. The masonry 


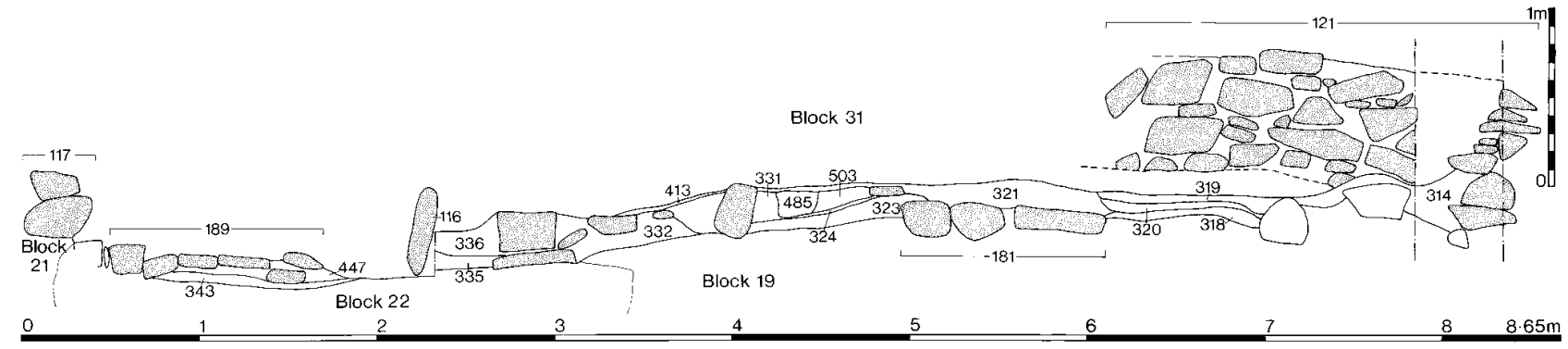

Figure 56. Block 20: section

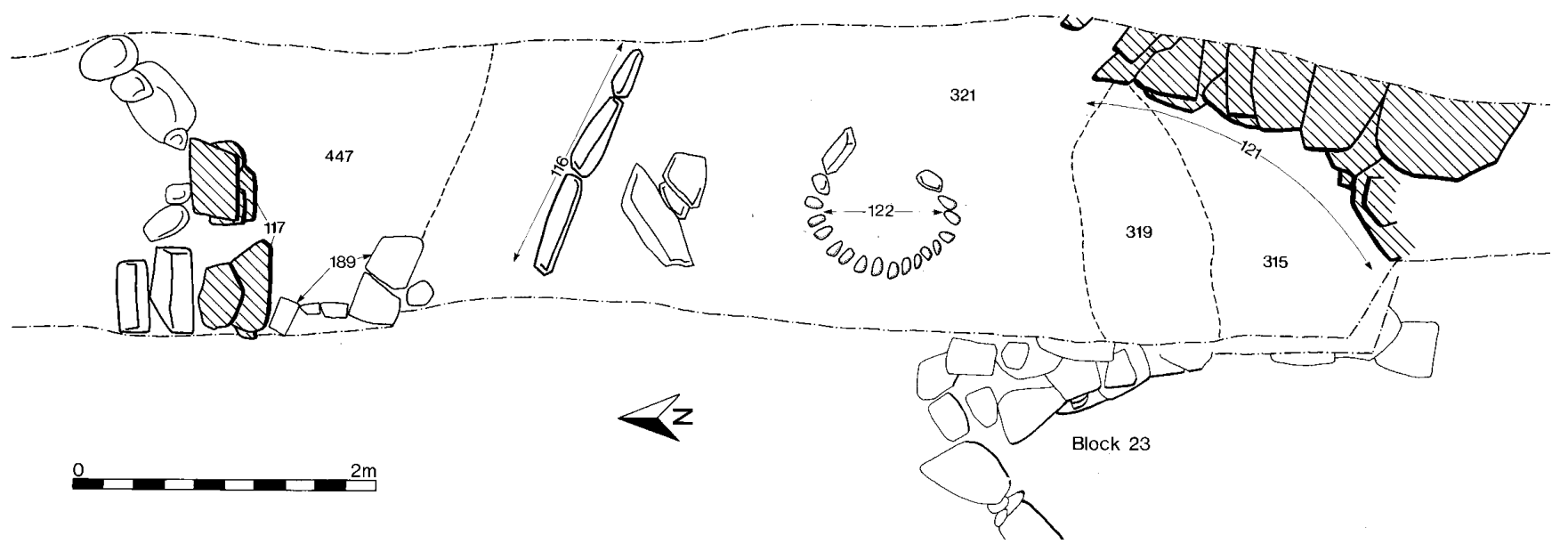

Figure 57. Block 20: plan

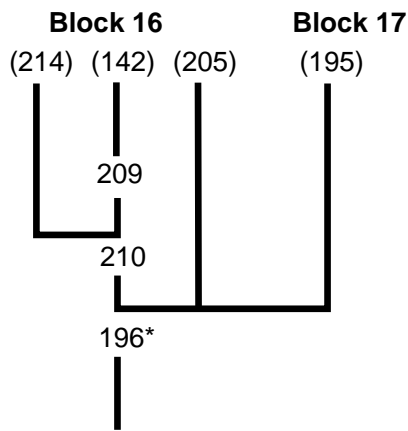

Block 23

formed a rounded corner set into the midden layers of Block 19. It was constructed of large irregularly shaped, uncoursed boulders with smaller stones between and faced on its inner side. This wall was up to $0.9 \mathrm{~m}$ high. The eastern arm was revealed for a distance of about $2.5 \mathrm{~m}$ before it disappeared into the section. At a distance of $6 \mathrm{~m}$ to the north of [121] lay three vertically set slabs, [116] (Figure 57). These were on an alignment perpendicular to the line of the east wall of [121]. Some $2 \mathrm{~m}$ to the north of these was a revetment of large blocks, [117] which was faced to the south. This lay on an alignment which diverged from that of the slabs [116]. Contained within the structure were a number of layers, within the uppermost surface of which was a circle of burnt cobbles, [122] (Figure 57). This was about $3.5 \mathrm{~m}$ to the north of the south section of [121]. On the east side these were of irregular shaped slabs set vertically into the ground. The rest of the circuit constituted rounded pebbles each about $0.1 \mathrm{~m}$ long and set radially to the circuit. This feature measured 0.8 $m$ in diameter externally. Lying between the masonry, [117] and [116], were five slabs, [189]. The northernmost slab abutted the wall [120] (Block 22). The slabs extended for $1.2 \mathrm{~m}$ from [120] but did not quite reach [116]. Further south, set into layer [322] (Block 19) were three flat topped boulders, [181]. These extended for $1.1 \mathrm{~m}$ midway between [116] and [121]. More irregularly shaped boulders, [180], appeared in the section just to the north of the wall [121] and were set into layer [294]. The layers within this Block were generally thin and not very extensive. They ranged widely in colour and texture from white sand ([323] \& [343]) to a black silty loam ([413]) while the rest were light to dark brown grey sands. Just to the north of the stones [181] was a U-shaped cut $0.15 \mathrm{~m}$ deep, [503], which was filled with carbonised peat, [435].

\section{Field interpretation}

This Block was interpreted as the remains of a roughly rectangular, drystone built structure divided into two parts by a line of slabs. The southern part was the larger and contained a circular hearth. The northern part was slightly sunken and has been interpreted as a byre. The skewed alignment of the northern end was thought to be evidence of the sites' collapse. Very little displaced stone was found within the structure suggesting that it had been de-roofed prior to it infilling with deep shell sand deposits (Block 29).

Less than $5 \%$ of the stone from one context was burnt. Of the twenty potsherds recovered from this Block sixteen were examined and they range in size-class from 1 to 9 , with 


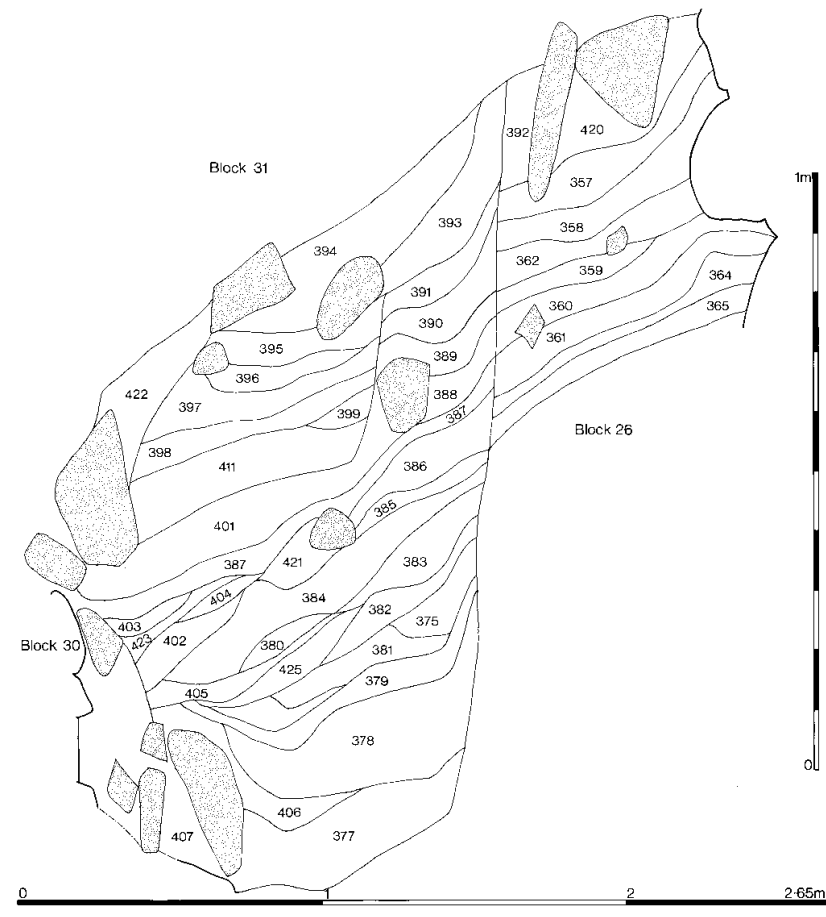

Figure 58. Block 21

14 sherds smaller than the site average. The $\mathrm{pH}$ values recorded for this Block range from 7.4 to 7.8 with a modal value of 7.6. Phosphate values ranged from 2 to 4,3 being the most common value. The soil colours were pale brown to very dark brown and the textures varied from sand to silty sandy loam. Layer boundaries were predominantly clear to abrupt and smooth to wavy.

\section{Archaeological interpretation}

The field interpretation of the structure takes primacy over any observations based on the information presented here. This seems to have been a relatively recent 'black house' and the hearth structure and division of the floor, into residence and byre, are typical of such structures.

\section{Specialist contribution}

Two contexts contained faunal material of particular note. [314]; This context contained the remains of at least two (and probably only two) neo-natal lambs, represented by the following body parts:

Left forelimb: 1 humerus, 1 radius and one metacarpal.

Left hindlimb: 1 pelvis, 1 femur, 1 tibia and 2 metatarsals right hindlimb: 1 pelvis, 2 tibiae, and 1 metatarsal.

Toes: 4 first, 4 second and 4 third phalanges.

A probable single sheep was represented by a complete cranium and parts of all four feet, ie left metacarpal, left and right metatarsal, 8 first, 3 second and 2 third phalanges. This combination of body parts is suggestive of primary butchery waste. Cut marks on the occipital condoyles of the cranium could have been caused when the head was severed from the body (cf Binford 1981, 102 Fig. 4.11b 'S-1'). Both the post-cranial evidence, all epiphyses fused and dental evi- dence, all permanent maxillary teeth in wear, indicates that this sheep was fully adult. With the exception of a right metatarsal, representing a second sheep, none of the animal bone in this context had been gnawed by carnivores.

[413]; In addition to a few fragmentary specimens, this context contained the following complete bones; right metatarsal, left metatarsal (distal epiphysis only), 3 first, 2 second and 3 third phalanges. These bones could all be derived from the hind feet of one individual, a juvenile of less than 2 years age, on the evidence of epiphyseal fusion, and again may represent primary butchery waste. Gnawing was only evident on two further right metatarsals, representing two additional individuals.

A wing of a mallard with cut marks was also recovered (Chapter 11.4.2).

\section{Conclusion}

This structure represents a post-medieval 'Blackhouse' which at sometime, possibly after its abandonment, was used for butchering sheep and lambs.

\subsection{BLOCK 21 - DUMPED DEPOSITS}

See table p.318

This Block lay in the extreme northern end of the site (Figure 38 ). It was up to $1.1 \mathrm{~m}$ deep and $2.5 \mathrm{~m}$ long. It consisted of several thin layers which have suffered at least two periods of slumping (Figure 58). The displaced layers were not considered further. The eleven layers that remain slope gently up to the south, for a distance of $0.9 \mathrm{~m}$ with a maximum depth of $0.6 \mathrm{~m}$. The layers are generally thin, between $0.03 \mathrm{~m}$ and $0.15 \mathrm{~m}$, and have distinct boundaries. They

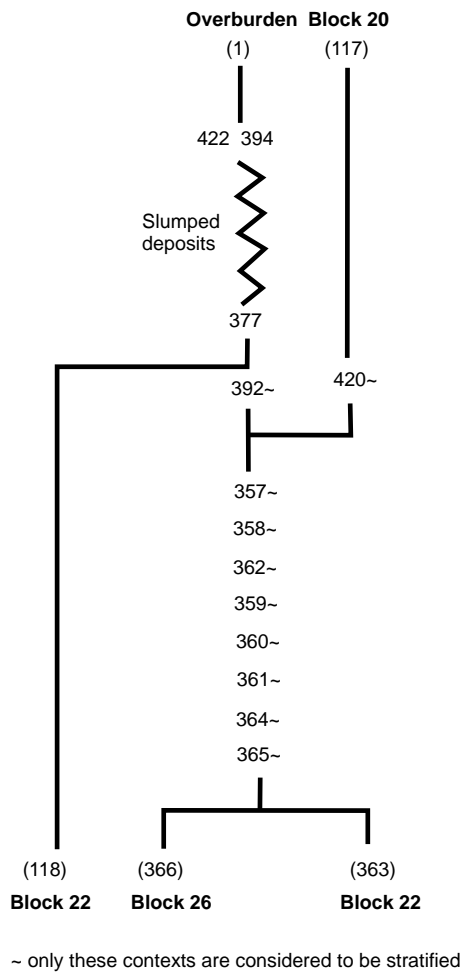




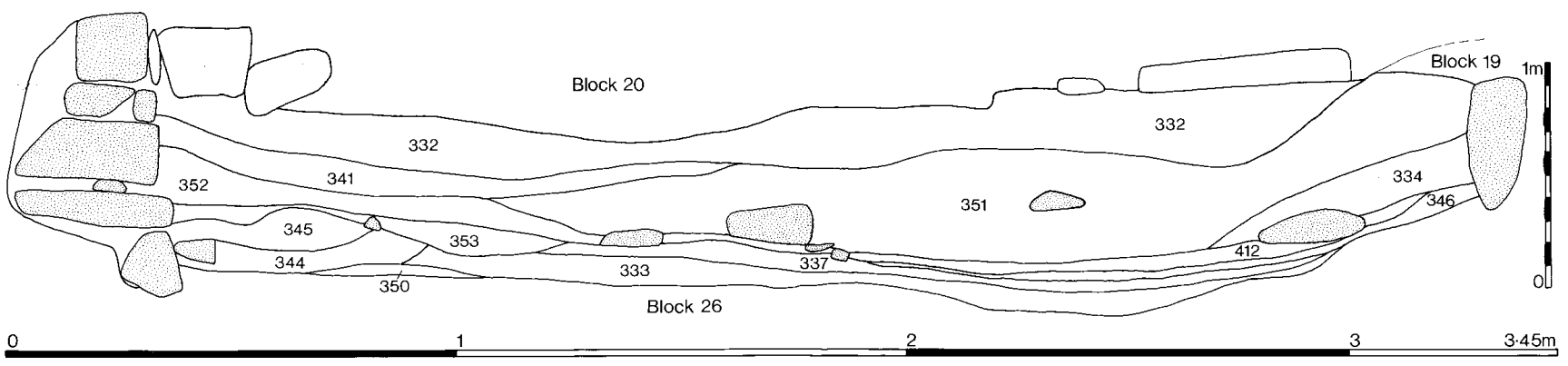

Figure 59. Block 22

range in texture from sand to a silty sandy loam and in colour from very pale brown to very dark greyish brown. Some of the displaced layers to the north could be visually matched with those described above. They also include layers which have presumably slumped from a higher level than [392]. These include two layers, [393] and [397], which were particularly rich in shells.

\section{Field interpretation}

This Block was interpreted as a series of deposits dumped over the masonry of Block 28. They have suffered the effects of storm damage at the north end of the site. The structure in Block 20 was cut into these deposits on their southern side.

All four bodysherds returned from this Block were examined, and they range in size-class from 2 to 3 . The $\mathrm{pH}$ values recorded for this Block range from 7.2 to 7.8 with a modal value of 7.6. Phosphate values ranged from 1 to 5,3 being the most common value. The soil colours range from pale brown to very dark greyish brown and the soil textures from sand to silty sandy loam. Layer boundaries were predominantly sharp and wavy.

\section{Archaeological interpretation}

The variability of the soil characteristics and the anthropogenic component of these deposits together with the clarity of the layer boundaries all support the field interpretation of this Block as a set of dumped deposits. The slumped deposits to the north suggest that the continuation of the site in that direction is largely destructured and also that the midden, at least at this northern end, was considerably higher in the past.

\section{Specialist contribution}

Sheep, cattle and pig were identified.

\section{Conclusion}

The deposits of this Block are dumped deposits derived from settlement structures which, on the snail-shell evidence, lay in the immediate vicinity.

\subsection{BLOCK 22 - STRUCTURE 6 - FRAGMENT}

See table p.319

* ${ }^{14} \mathrm{C}$ date $2270 \pm 50$ bp (GU-2028) from layer [351] (Periwinkle).

* ${ }^{14} \mathrm{C}$ date $2185 \pm 50$ bp (GU-2026) from layer [332] (Periwinkle).

Block 22 lay at the northern end of Area B, beneath Structure 7, Block 20 (Figure 38). It extended over $3.3 \mathrm{~m}$ and had a maximum depth of $0.6 \mathrm{~m}$ (Figure 59 ). On the north side the masonry, [120], had five courses of stone blocks and was faced to the south. It had been cut into the material of Block 26 and the space behind the masonry filled with a dark brown loamy sand, [363]. The second course of stone was reddened in colour where it was in contact with layer [345] (see below). In plan this masonry continued out from the section face with an upright slab and disturbed stones seen within the beach sand; these curved slightly towards the south. At a distance of $2.85 \mathrm{~m}$ from the face of [120] a single slab, [129], appeared in the section. Its base was at the same level as that of [121] and it measured $0.3 \mathrm{~m}$ high. Abutting this masonry were several layers and lenses with a maximum depth of $0.50 \mathrm{~m}$. The layers that abutted [120] were each up to $0.1 \mathrm{~m}$ deep. They included a domed layer of orange peat ash, [345], which, along with the black, sandy silty loam beneath, [344], was bordered by an arc of vertically set stones. To the south were thin layers which were slightly sunken below the base of the slab [129]. These were $0.02 \mathrm{~m}$ to $0.05 \mathrm{~m}$ deep and were either dark or very dark grey brown in colour

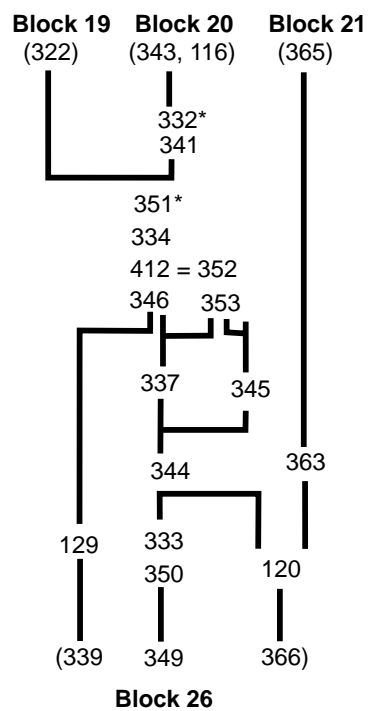




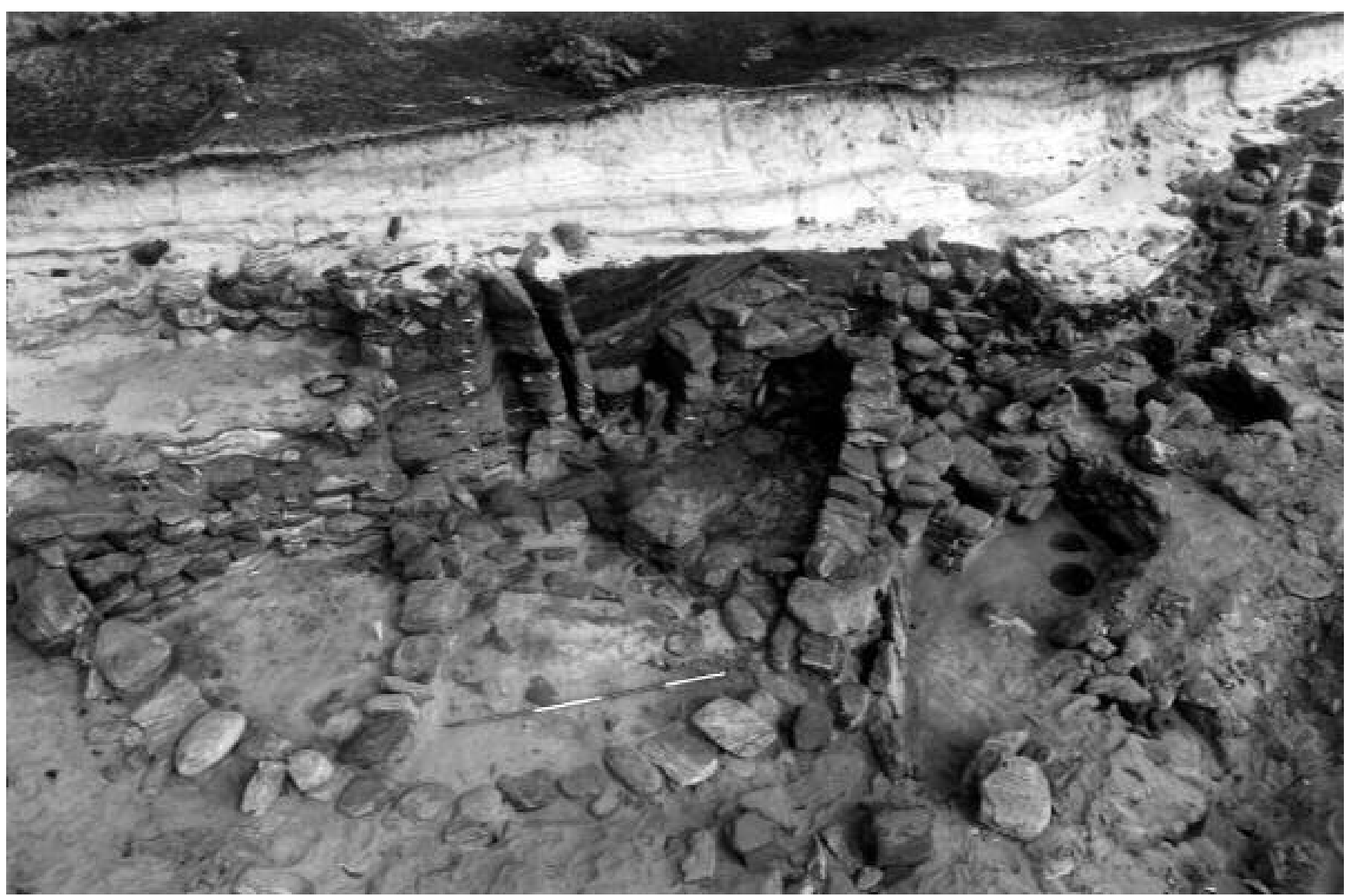

Plate 25. Hornish Point. Structure 1 - fragment of wheelhouse. The aisled space between the pier and the outer wall is just visible. Abutting it to the right, and keyed into its outer wall, is Structure 2, the drain through which can be seen

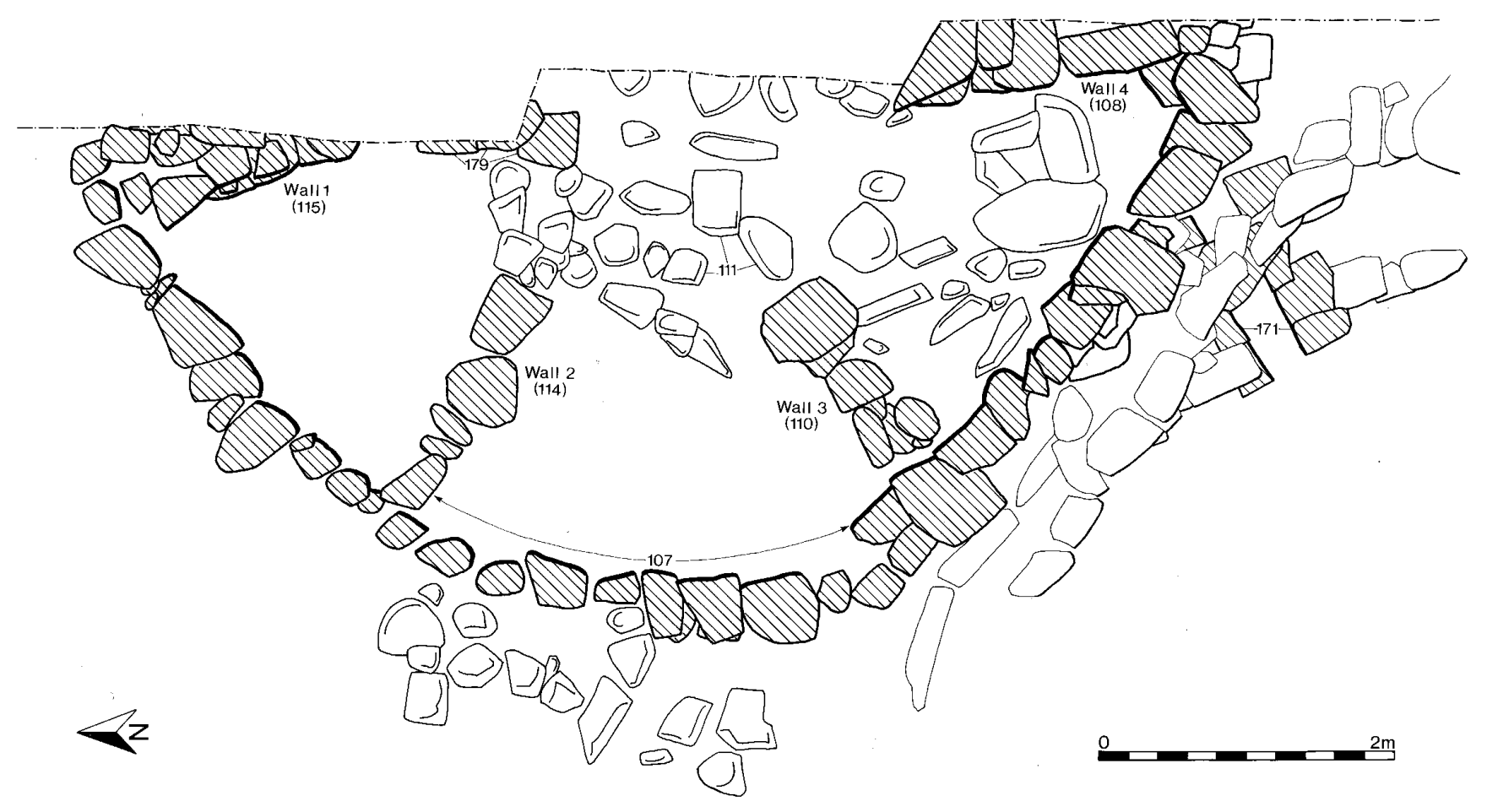

Figure 60. Block 23: plan 


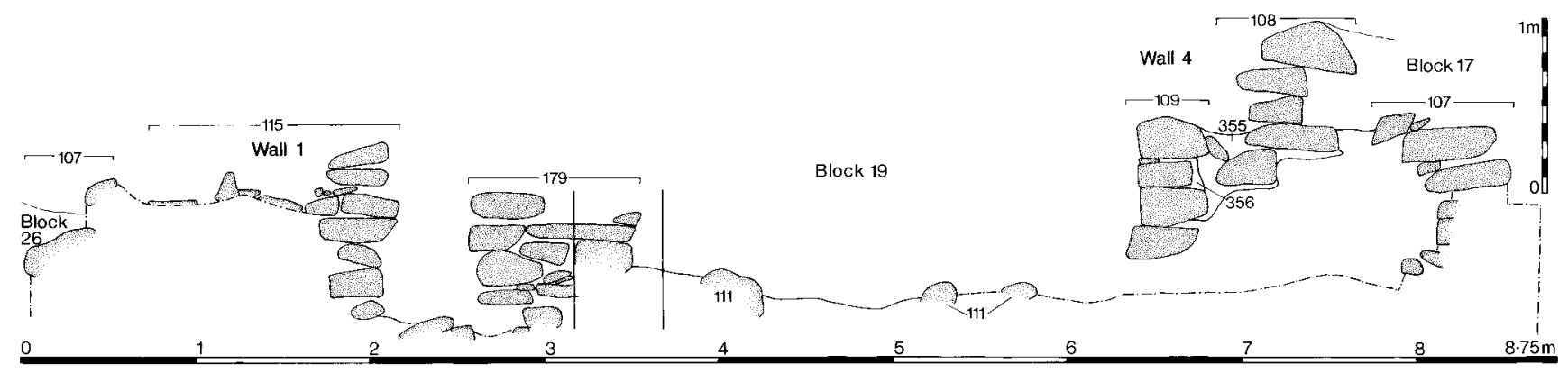

Figure 61. Block 23: section

but included carbonised peat, [337], loamy sand or sandy loam. These layers were sealed by deeper layers of dark brown sandy loam, [351] and [341], and a dark grey-brown loamy sand, [332].

\section{Field interpretation}

Block 22 was interpreted the remains of a circular structure. It contained a possible hearth and layers rich in organic matter. Its internal diameter would have been over $3 \mathrm{~m}$.

Some $5 \%$ of the stone found in one context was burnt. Some thirty-nine of the forty potsherds in the Block were examined and they range in size-class from 1 to 7 . The $\mathrm{pH}$ values recorded for this Block range from 7.3 to 8.2 with a modal value of 7.6. Phosphate values ranged from 2 to 4,7 being the most common value. The soil colours range from very pale brown to black and the soil textures from sand to sandy silty loam. Layer boundaries were predominantly sharp and smooth to wavy.

\section{Archaeological interpretation}

The interpretation of the structural elements of this Block must remain that based on the field observations. The deposits contained within it are not inconsistent with this interpretation, but would not be inconsistent with their interpretation as midden-site deposits either.

\section{Specialist contribution}

Sheep, cattle, pig and cod bones were identified.

\section{Conclusion}

This apparently simple structure seems to contain a series of post-abandonment deposits of rapidly accumulated windblown sand.

\subsection{BLOCK 23 - STRUCTURE I - WHEELHOUSE}

See table p.319

Block 23 lay in Area B, beneath Block 19 (Figure 38). It consisted of a semi-circular arc of masonry with four internal ra- dial piers (Figures $60 \& 61$ ). It measured $8.5 \mathrm{~m}$ in length and in plan it extended approximately $4 \mathrm{~m}$ out from the section face. The outer wall, [107], was one stone thick, faced on the inside. In the section face it measured up to $1 \mathrm{~m}$ in height in the south and $0.5 \mathrm{~m}$ in the north. It was constructed of large slabs which were slightly corbelled, and a few rounded stones. The wall had been reduced in height out from the section to a single course at its outermost. Within this arc were four radial walls; Walls 1, 2 and 3 abutted the inner face of [107] and the fourth was of the aisled type. Wall 1, [115], in the north of the wheelhouse, measured $1 \mathrm{~m}$ high and $1.4 \mathrm{~m}$ long. Wall 2, [114] was $1.7 \mathrm{~m}$ long and was revealed as a single line of stones. However, a sondage subsequently revealed the presence of several underlying courses. Wall 3, [110], was $1.3 \mathrm{~m}$ long and consisted of a single course of slabs except at the end where the slab was surmounted by a large boulder. Further masonry within the wheelhouse was bisected by the section. The masonry, [179], lay about $0.5 \mathrm{~m}$ to the south of Wall 1 towards the centre of the wheelhouse. It measured 0.8 $\mathrm{m}$ high and $1 \mathrm{~m}$ long. About the same distance north of the outer wall in the south was the masonry, [108] and [109]. This was revealed to be two faces of a masonry Block which had tilted westwards intruding through the deposits of Block 19. Together they measured $1.4 \mathrm{~m}$ high and $1.2 \mathrm{~m}$ in width. After the section was drawn this masonry was found to be joined to the outer wall, [107], with a lintel stone. A drain feature, [171], was revealed outside the wall line, [107], beneath the structure formed by Block 18 . It consisted of two facing lines of wall at a distance of $0.35 \mathrm{~m}$ apart. The inner edge of this feature was not revealed as the layers within the wheelhouse, known to exist from a sondage, were not investigated.

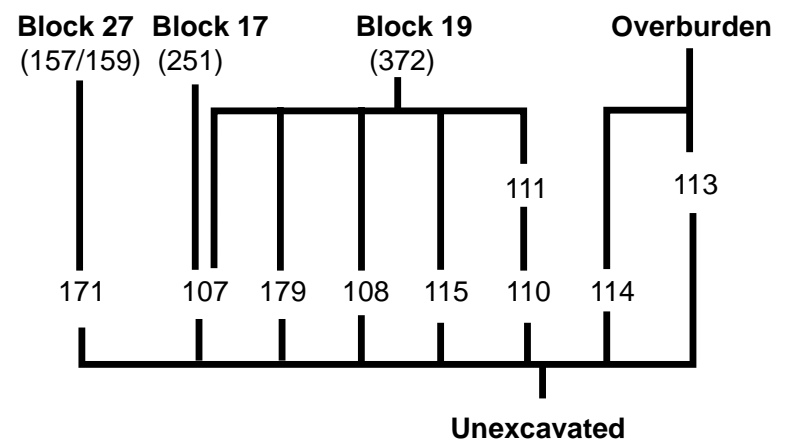




\section{Field interpretation}

This Block was interpreted as the remains of a wheelhouse (Plate 25). Its internal diameter was about $7.5 \mathrm{~m}$. It had three radial walls which abutted the outer wall face and the fourth was aisled. The inner ends of these radial walls were more massive than those used in their general construction. The single aisled wall was separated from the outer wall at its base but connected to it with a lintel stone at a higher level. Three bays of slightly different sizes were formed by the radial walls, with a clear area left at the centre of the house, except for some rubble seen at the level of the section base. The floor surfaces associated with the occupation of the wheelhouse were shown to exist beneath the windblown sand but were not excavated.

\section{Archaeological interpretation}

The archaeological interpretation of this Block must be that based on the field observations, ie that this is a remnant of a wheelhouse. There was no post-excavation analysis undertaken due to the lack of material. The conclusion, therefore, does not differ from the Archaeological interpretation.

\section{Specialist contribution}

Sheep, cattle and pig bones and two unidentifiable bird bones were identified.

\subsection{BLOCK 24 - STRUCTURE 3}

This Block lay at the south end of Area A, at the base of the section (Figure 38). It consisted of the masonry, [195], and several soil layers (Figure 62). [195] only became visible after Block 15 had been removed. It was constructed of large stone blocks and measured $0.65 \mathrm{~m}$ high and was about $0.6 \mathrm{~m}$ wide. Its north face was continued out from the section by a line of slabs, [467]. These were $0.25 \mathrm{~m}$ to $0.4 \mathrm{~m}$ in length. They curved northwards back into the section running under the wall, [152] (Block 16). The four layers included in Block 24 lay within the arc of slabs, [467], and abutted the wall, [195]. They were saucer-shaped, up to $0.3 \mathrm{~m}$ in depth, and dipped back into the section. They ranged from very pale brown sand to brown/dark brown loamy sand.

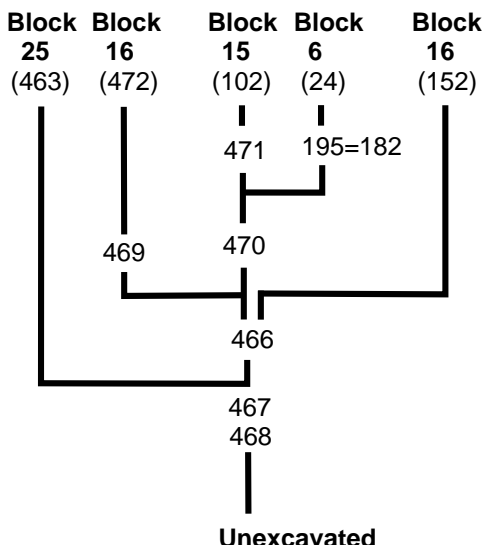

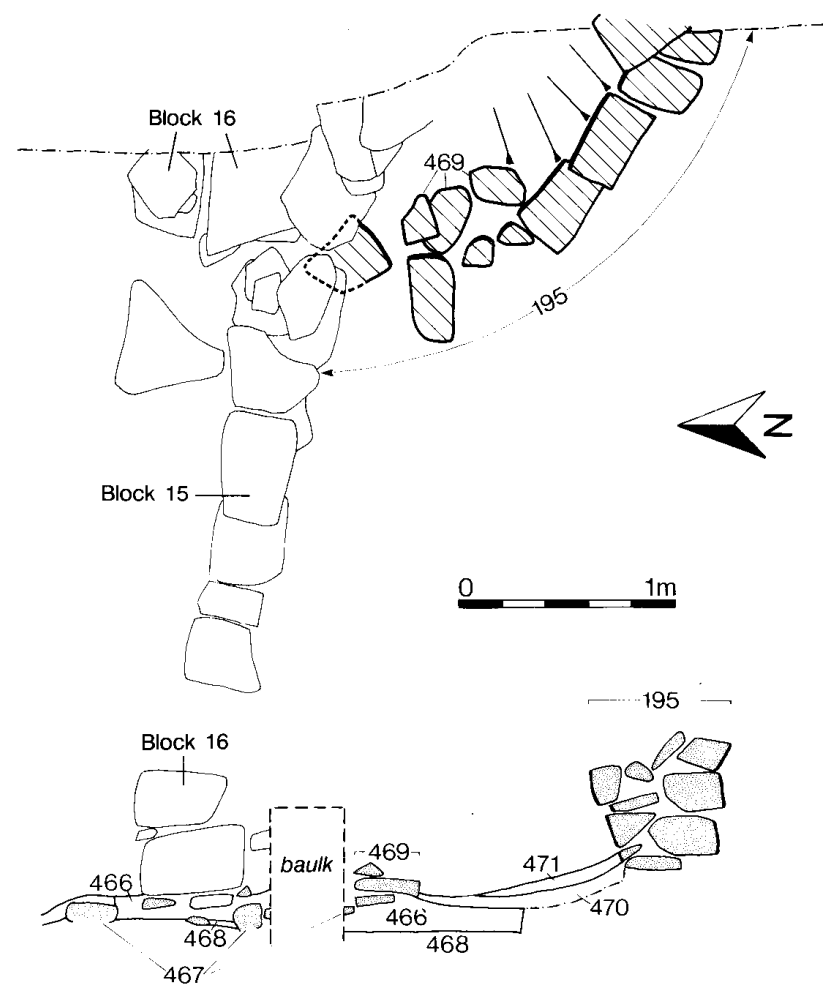

Figure 62. Block 24

\section{Field interpretation}

This Block was interpreted as the surviving fragments of one or more structures of unknown dimensions. It consisted of an arc of slabs, a wall and a series of layers contained within them. These latter lay over a pale brown sand which was not excavated.

The two $\mathrm{pH}$ values recorded for this Block are 7.6 and 7.7. The soil colours are recorded as very pale brown to brown dark brown and in texture from sand to loamy sand. Layer boundaries were predominantly sharp and wavy.

\section{Specialist contribution}

Sheep, cattle and pig were identified.

\section{Archaeological interpretation}

The archaeological interpretation of these deposits must be based on the field observation and cannot, in this case augment it. It is possible that the soil contexts included here are midden-site deposits, but the absence of any finds militates against this interpretation. Consequently, this Block cannot be interpreted. 


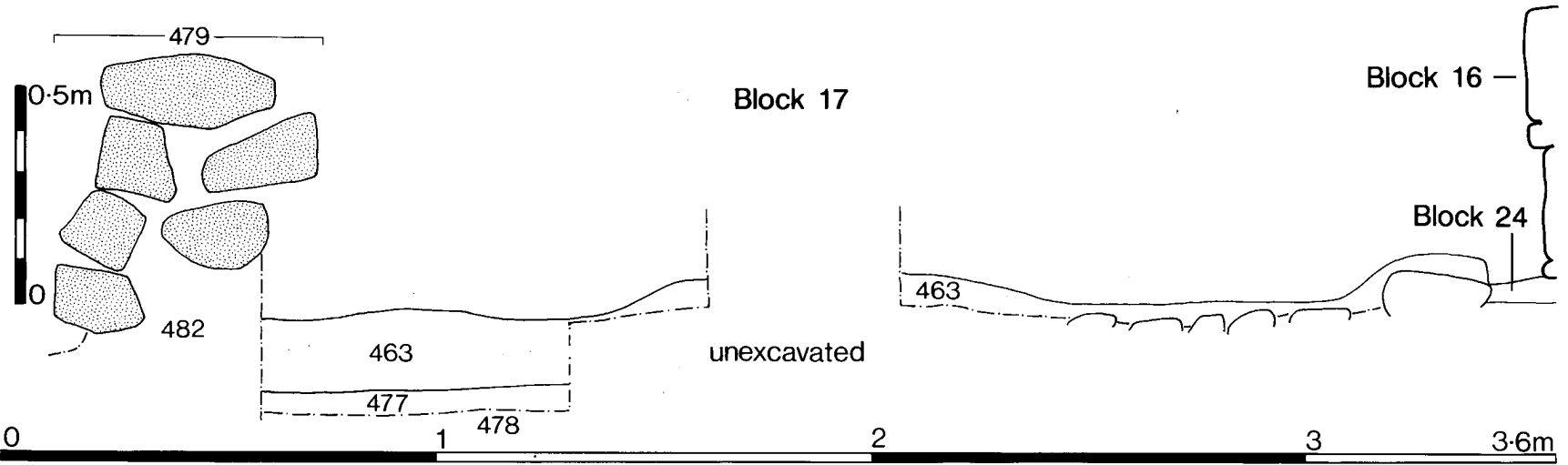

Figure 63. Block 25: section

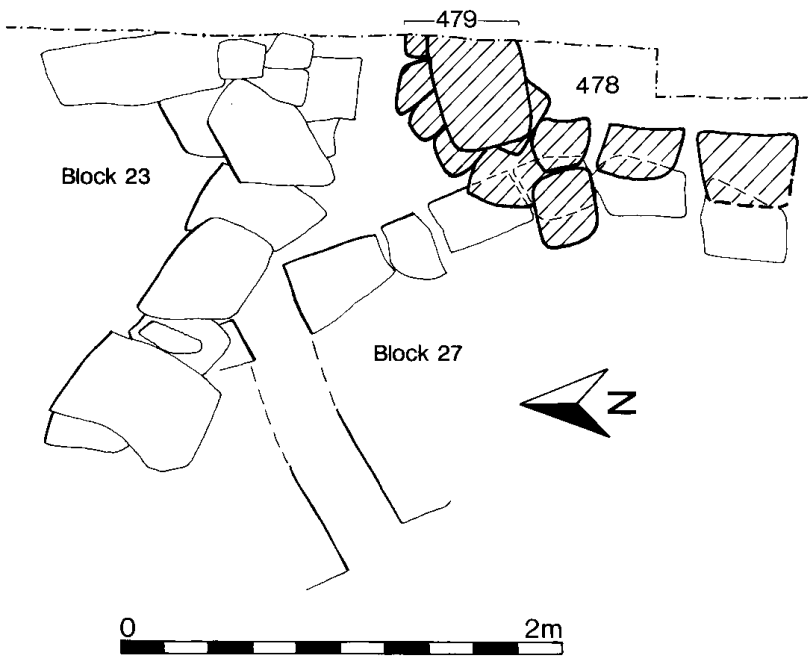

Figure 64. Block 25: plan

\subsection{BLOCK 25 - STRUCTURE 4}

Block 25 lay in the centre of the site at the base of the section under Block 17 (Figure 38). Its full depth and extent were not determined but its layers were revealed in the section for a depth of $0.25 \mathrm{~m}$ and for a distance of $4.5 \mathrm{~m}$ (Figure 63).

This Block included a wall, [479], seen beneath the sloping stones of Block 17. It was $0.6 \mathrm{~m}$ high and $0.5 \mathrm{~m}$ wide and constructed of rounded stones. Excavation revealed that

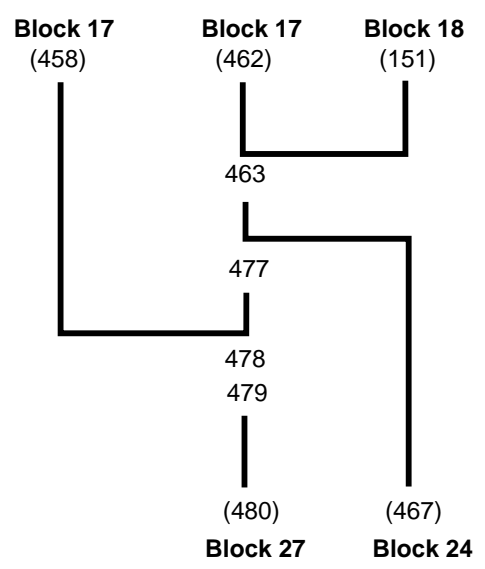

[479] was a wall face, one stone thick, which projected forward from the section face for approximately $0.5 \mathrm{~m}$ before turning south to run parallel with the section for a distance of $1.2 \mathrm{~m}$ (Figure 64). It was not possible to record the layers within this Block for safety reasons. However, the uppermost layer in this Block, [463],was seen to abut the masonry [479], and was of pale brown sand. It was thought that the layers beneath also abutted [479] but this was difficult to establish. Layer [477] was a dark brown sand while the others were all light brown sands.

\section{Field interpretation}

This Block was interpreted as a fragment of a structure represented by a single wall [479] and possible floor surface [477].

\section{Archaeological interpretation}

The associated strata were revealed over too small an area to be interpretable and so the archaeological interpretation must be that this Block consists of a structure of unknown association and function.

\section{Specialist contribution}

Sheep, cattle and pig were identified.

\subsection{BLOCK 26 - CULTIVATED DEPOSIT}

See tables p. 320

* ${ }^{14} \mathrm{C}$ date $2370 \pm 50$ bp (GU-2027) from layer [339] (Periwinkle).

Block 26 lay in the northern part of the site (Figure 38). It abutted Block 23 and extended for $6.2 \mathrm{~m}$ to the north. Its was not excavated to its full depth but was revealed for a total depth of $1 \mathrm{~m}$. It consisted of layers and lenses which sloped downwards to the north (Figure 65). Some layers, notably [338] and [339], appeared to have been truncated at their northern ends, with subsequent redeposition of material, [348] and [349]. The layers ranged in colour from light yellow-brown to dark greyish brown and in texture from 


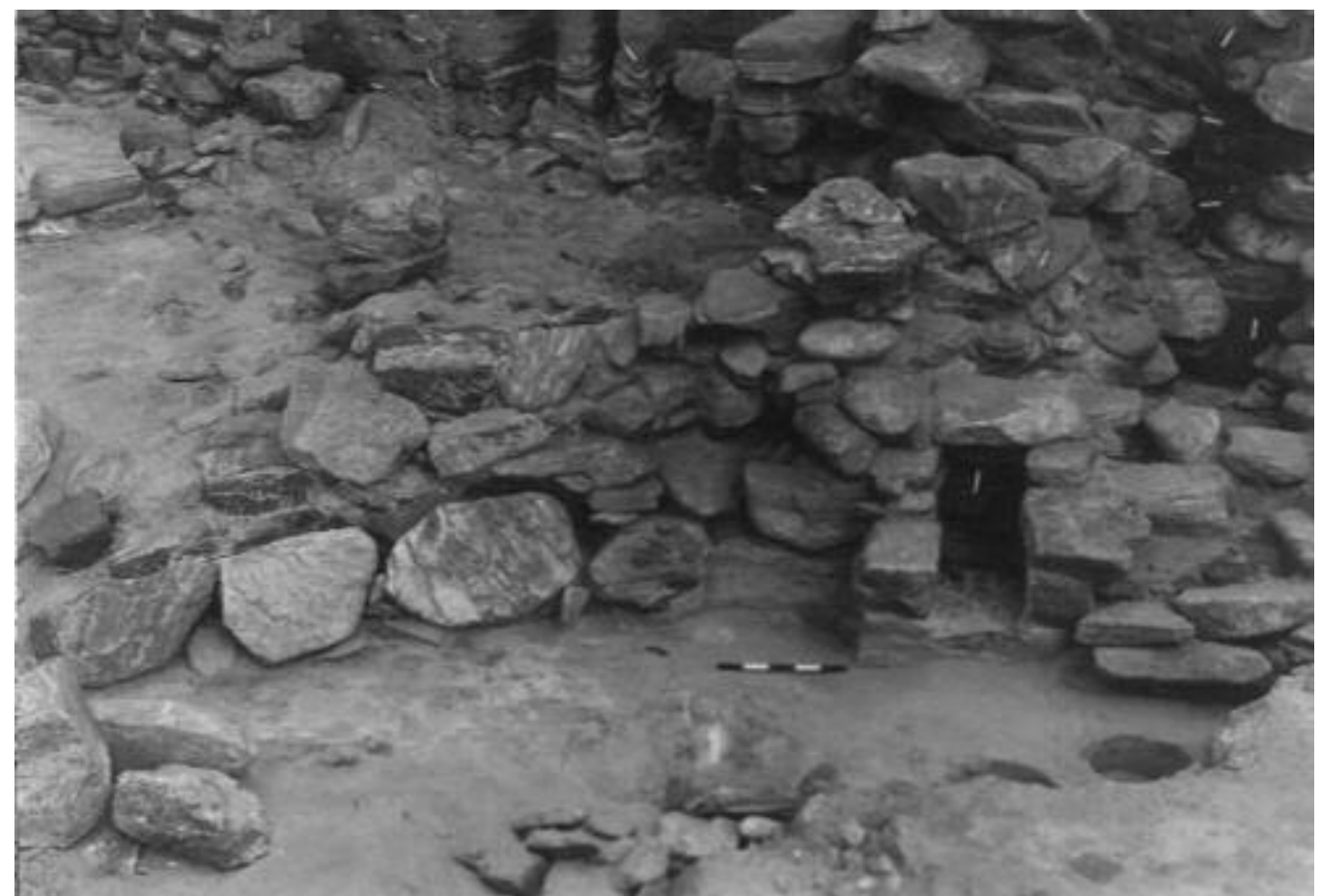

Plate 26. Hornish Point. The masonry wall to the right of the drain [172] has been removed, revealing the side-set slabs [161]

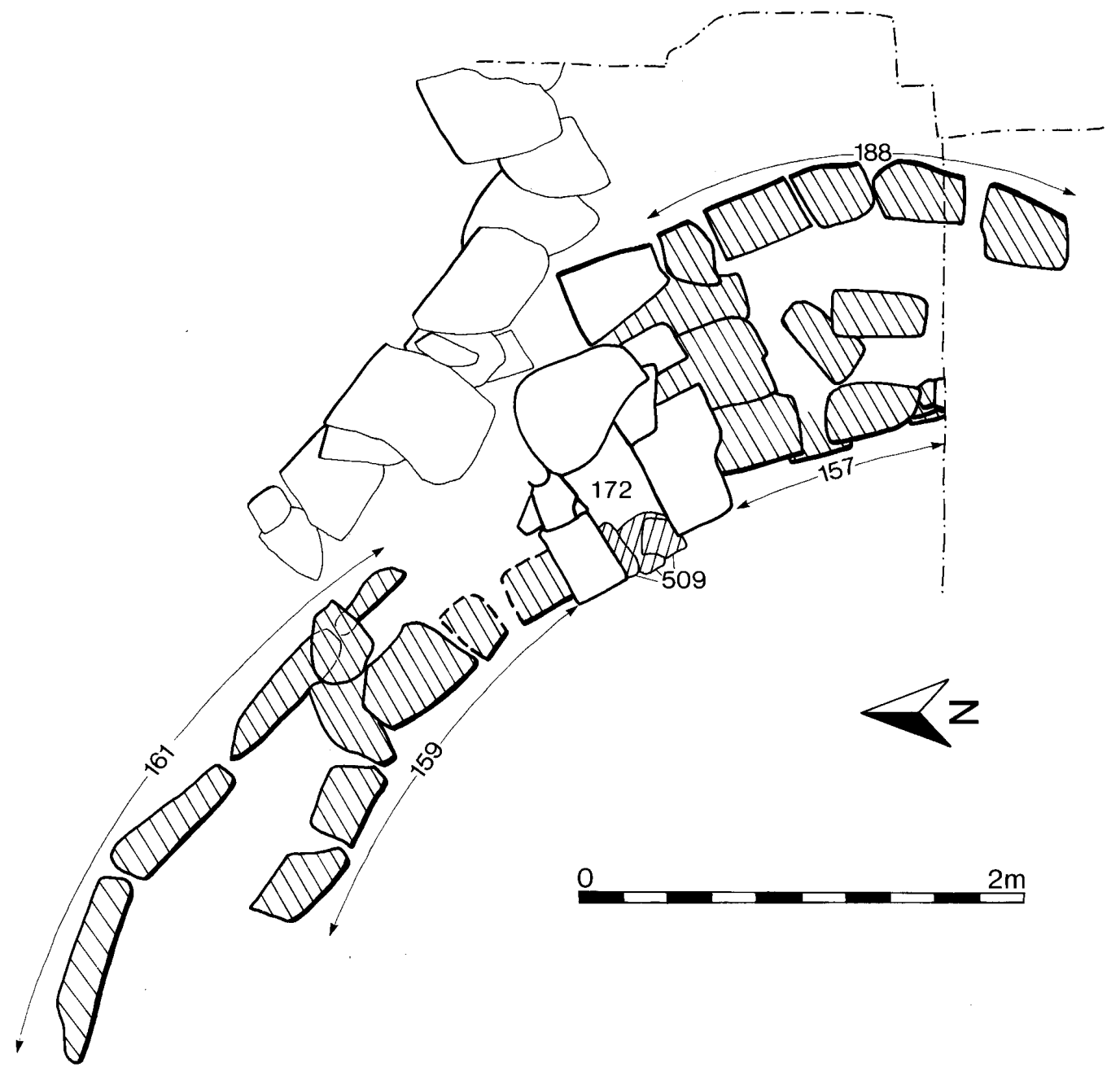

Figure 66. Block 27 


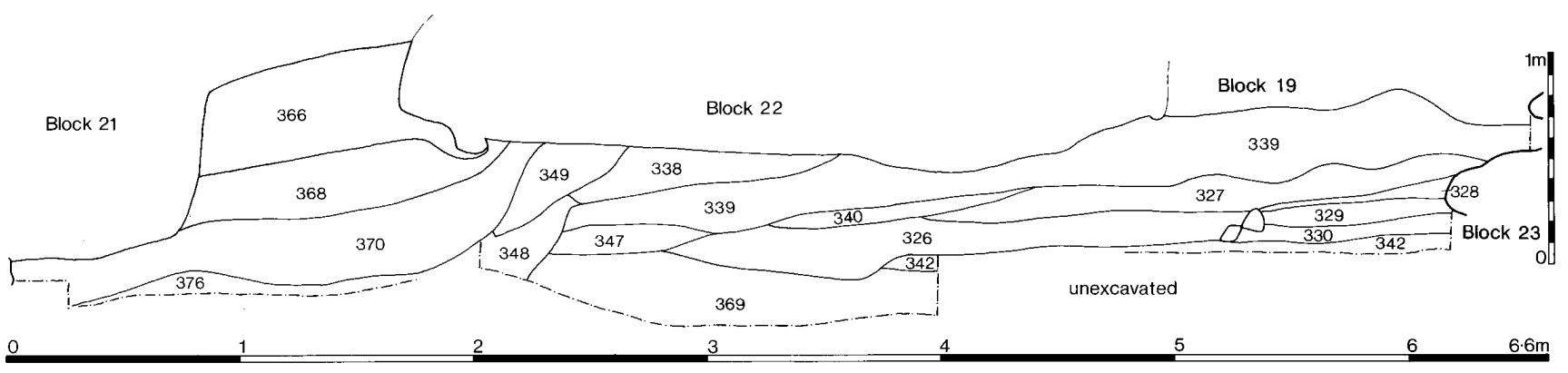

Figure 65. Block 26

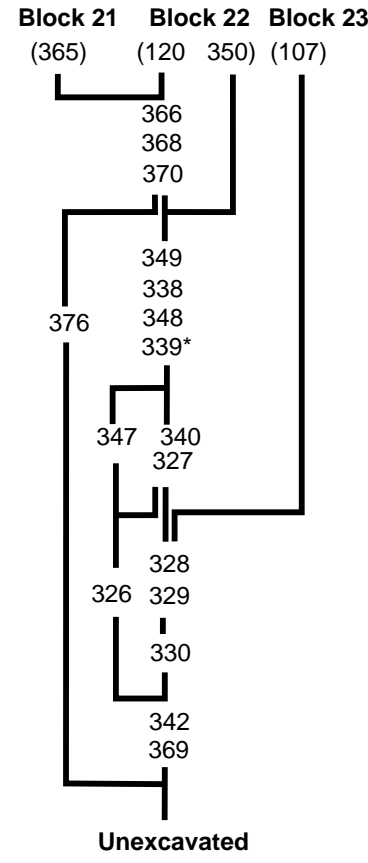

loamy sand to sand. The boundaries were often clear and wavy. Within 2-3 $\mathrm{m}$ of the south end of the Block a trelliswork of fine brown-stained filaments was noted throughout its depth of the Block. These appeared to have been the result of ground-water fluctuations. The Block was truncated by the structure in Block 22 .

\section{Field interpretation}

This Block was interpreted as a cultivated deposit because of its depth, extent and content. Structure 1 (Block 23) had been inserted into this deposit.

No IHI has been calculated for this Block but material from nine contexts was retrieved in variable, but mostly small, amounts representing a restricted range of types. All ten potsherds returned from this Block were examined. They range in size-class from 2 to 5 and are mainly small. The $\mathrm{pH}$ values recorded for this Block range from 7.3 to 8.0 with a modal value of 7.5. Phosphate values ranged from 2 to 4,4 being the most common value. The soil colours are recorded as ranging from light yellow brown to dark greyish brown and in texture from sand to loamy Layer boundaries were predominantly abrupt to clear and wavy to smooth.

\section{Archaeological interpretation}

The information recorded above is consistent with the interpretation of this Block as a set of cultivated deposits. The relative paucity of anthropic materials suggests that the Block was at some distance from the contemporaneous structures or that the cultivation was of short duration. The pot sherd size distribution for the Block tends to support the latter hypothesis.

\section{Specialist contribution}

Sheep, cattle and pig were identified.

\section{Conclusion}

This Block consists of a set of deposits which were, probably, intermittently cultivated.

\subsection{BLOCK 27 - STRUCTURE 2 - MASONRY AND FLOOR SURFACES}

See table p.321

$*{ }^{14} \mathrm{C}$ date $2410 \pm 50 \mathrm{bp}(\mathrm{GU}-2161)$ from layers [79, $464 \&$ 465] (Periwinkle \& limpet).

This Block does not appear in the section drawing as it lay to the west of the section face. It lay beneath Block 18 and to the south-west of Structure 1 (Block 23). Block 27 consisted of a curving drystone wall face built to either side

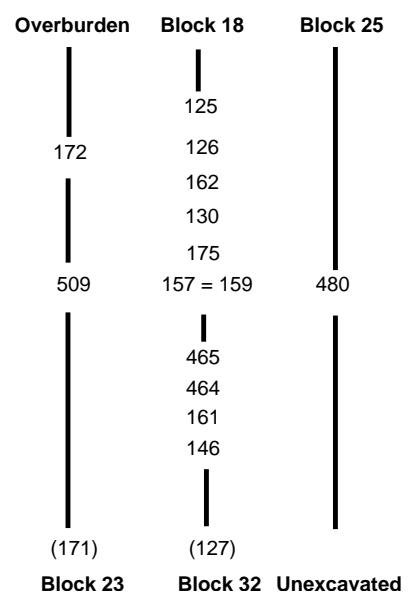


of the drain associated with Structure 1 (Figure $66 \&$ Plate 25 ). The wall face was constructed of up to four courses of large stone slabs and measured $0.6 \mathrm{~m}$ high. It was exposed in plan for a distance of $4 \mathrm{~m}$ (Plate 26). The outer face of this wall was keyed into the rear of the Structure 5 wallface, where the two curves conjoined. The drain feature was filled initially with brown sand layers and then several irregularly shaped stones, [509], had been placed in line with the wall face which effectively blocked it. Behind and above this blocking were a sequence of sand layers, grouped under the context number [172]. These consisted of mainly light coloured sand except for occasional thin layers of dark brown sand. Behind the wall face at its north end, were four vertically set slabs, [161] (Plate 26). These were roughly concentric with the inner wallface, $0.3 \mathrm{~m}$ back from it and stood about $0.6 \mathrm{~m}$ high. Small stones were packed around their bases. Two deposits were seen between these and the inner wallface. These were a laminated sand deposit and a light brown sandy loam, [464] and [465], respectively. Beneath the slabs was a light brown sand. Abutting the wallface were four layers, seen in the area of the pits (Block 18). They consisted of alternately light coloured sand, [130] and [125], and dark coloured sand, [175] and [126]. A group of small slabs, [162], were set vertically into the surface of layer [130] about $0.2 \mathrm{~m}$ to the west of the wall face.

\section{Field interpretation}

This Block was interpreted as a fragment of a curved structure, which was faced on both sides. Part of this construction included the blocking up of an earlier drain, emerging from a wheelhouse, Block 23. The vertical slabs, [161], were thought to be a constructional element of the wallface [157]. The dark coloured sand layers which abut the wallface may have been the floor surfaces of this structure separated by layers of clean sand.

It was not possible to calculate the IHI values for this Block but anthropogenic materials were present in variable quantities in six contexts, representing relatively restricted ranges of material types. Less than $5 \%$ of the stone from one context was burnt. Of the twenty-five potsherds from this Block seventeen were examined and they range in size-class from 1 to 14 . The two $\mathrm{pH}$ values recorded for this Block range were both 7.3. Phosphate values were both 5. The soil colours were light brown to dark brown and the textures were sand to loamy sand. The single recorded layer boundary was abrupt and wavy.

\section{Archaeological interpretation}

The field observation of the masonry structure remains untested by the information listed here. The characteristics of the putative floor levels are consistent with their interpretation as floor levels. The presence of nineteen of the twenty-five potsherds from this Block in an apparently sterile sand layer between the floor deposits is worthy of note.

\section{Specialist contribution}

[465] contained, in addition to a fragmentary metatarsal of indeterminate side, the following complete bones of sheep: 1 left metatarsal, 2 first, 1 second and 2 third phalanges. All these bones could be derived from the left hind foot of a single juvenile sheep (less than 2 years old, on the evidence of epiphyseal fusion) and may well represent primary butchery waste.

Bones of flatfish were also found.

\section{Conclusion}

This Block represents a fragment of an early structure surviving beneath and partly incorporated into Blocks 18 and 15 .

\subsection{BLOCKS 28 TO 31}

See table p.321

Blocks 28, 29 and 31 are shown in Figure 38. Block 30 was exposed in a machine trench to the west of the section face and therefore does not appear in the illustration. Insufficient evidence was available to facilitate interpretation of these Blocks. The overburden of windblown sand (Block 30) was between 1 and $2.5 \mathrm{~m}$ deep over them, making it unsafe to excavate or even to survey them properly. 


\section{CHAPTER 7: EXCAVATIONS AT SOUTH GLENDALE}

H F James \& W Forbes

\section{I INTRODUCTION}

The site (NF 798 143) lies at the south tip of South Uist, about $800 \mathrm{~m}$ to the south-east of the settlement of South Glendale and east of Bagh Mor, a sandy inlet (Figure 67 \& Plate 27). Sand has accumulated against the rocky coastline and, because of the protection of a small headland, has formed a small area of fairly level machair. The site faces south to the Sound of Eriskay and the land behind rises steeply to a hill, known as Cruachan, $177 \mathrm{~m}$ high.

The level area is grass covered and measures $200 \mathrm{~m}$ east-west by $120 \mathrm{~m}$ north-south. Its north and east sides have suffered erosion, the north by a deeply incised stream and the east by deflation (fig 00). Grass topped sand promontories with vertical faces up to $1 \mathrm{~m}$ high and a single large tallard, or island of sand, have been formed on this east side, from which the sand slopes gently away towards the beach to the east. The sand has blown up the slope to the north to a height of $30 \mathrm{~m}$ above sea level, and is mainly grass, bracken and heather covered. Above this the hill is peat covered with heather and rough grass.

\section{I.I Archaeological features}

The surface of the machair was interrupted by low banks and occasional stones broke through the grass cover. These were the remains of small circular structures, probably shielings, which have appeared and been abandoned within living memory.

At the edge of the machair erosion had formed vertical sand faces. The first metre was of clean sand below which lay deposits of dark stained sand containing pottery, shells and bone. Spread around the base of the sand cliffs on the deflation surface of the sand were large quantities of these materials. Large stones emerged from the base of the sand cliffs (see the south-east corner of fig 00 ).

\section{I.2 Site history}

A plan of the property of R G McDonald of Clanranald in 1805, marks the small machair area as 'Gorstan'. This name does not appear on the later OS maps. In 1978 cord-decorated Beaker sherds, quartz, flint tools and pumice were retrieved from a midden circa $30 \mathrm{~m}$ long and up to $0.30 \mathrm{~m}$ deep at NF 804143 (Maclean et al 1978). A CEU team visiting the site in 1983 collected further Beaker pot sherds.

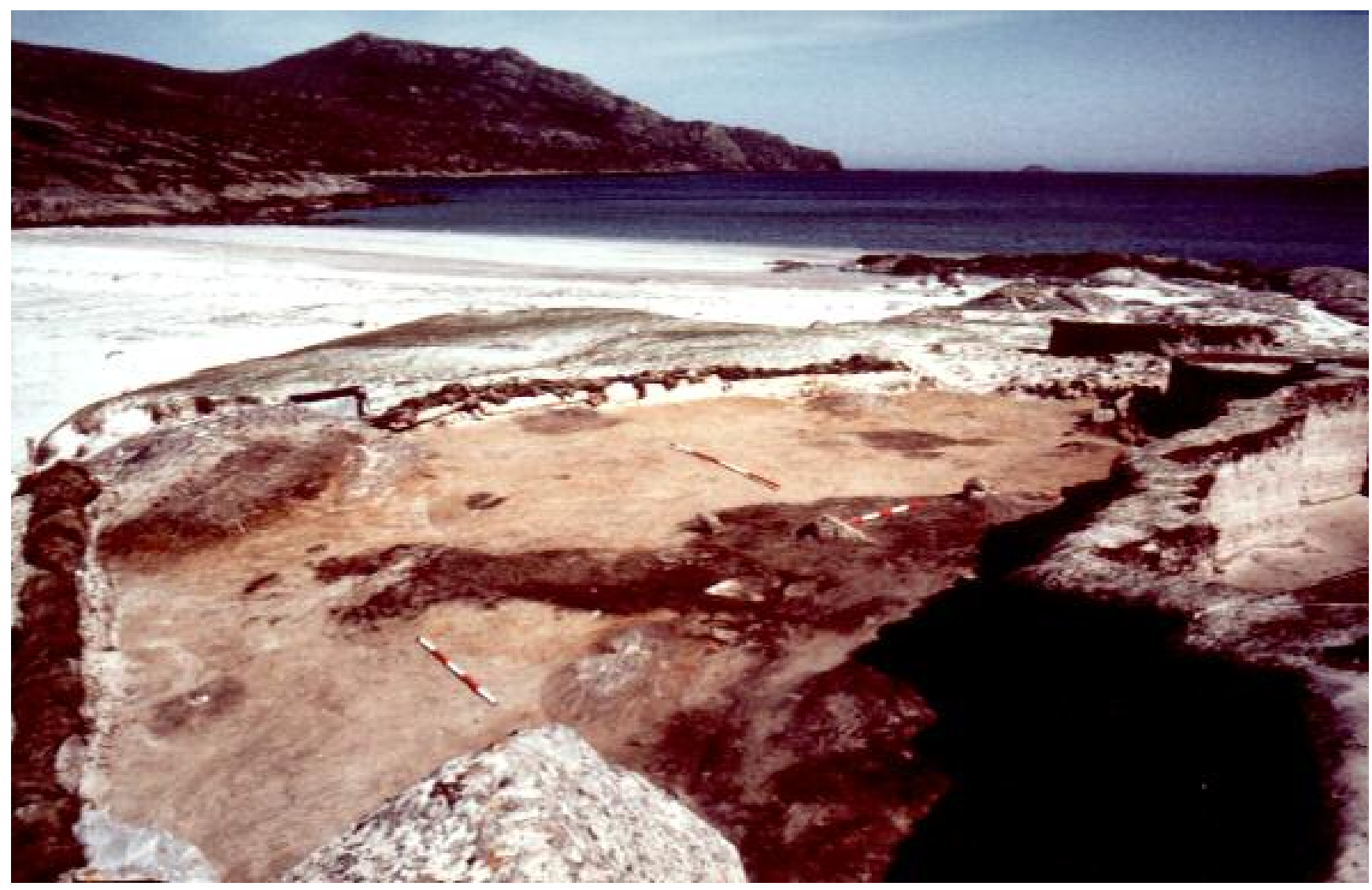

Plate 27. The site at South Glendale 


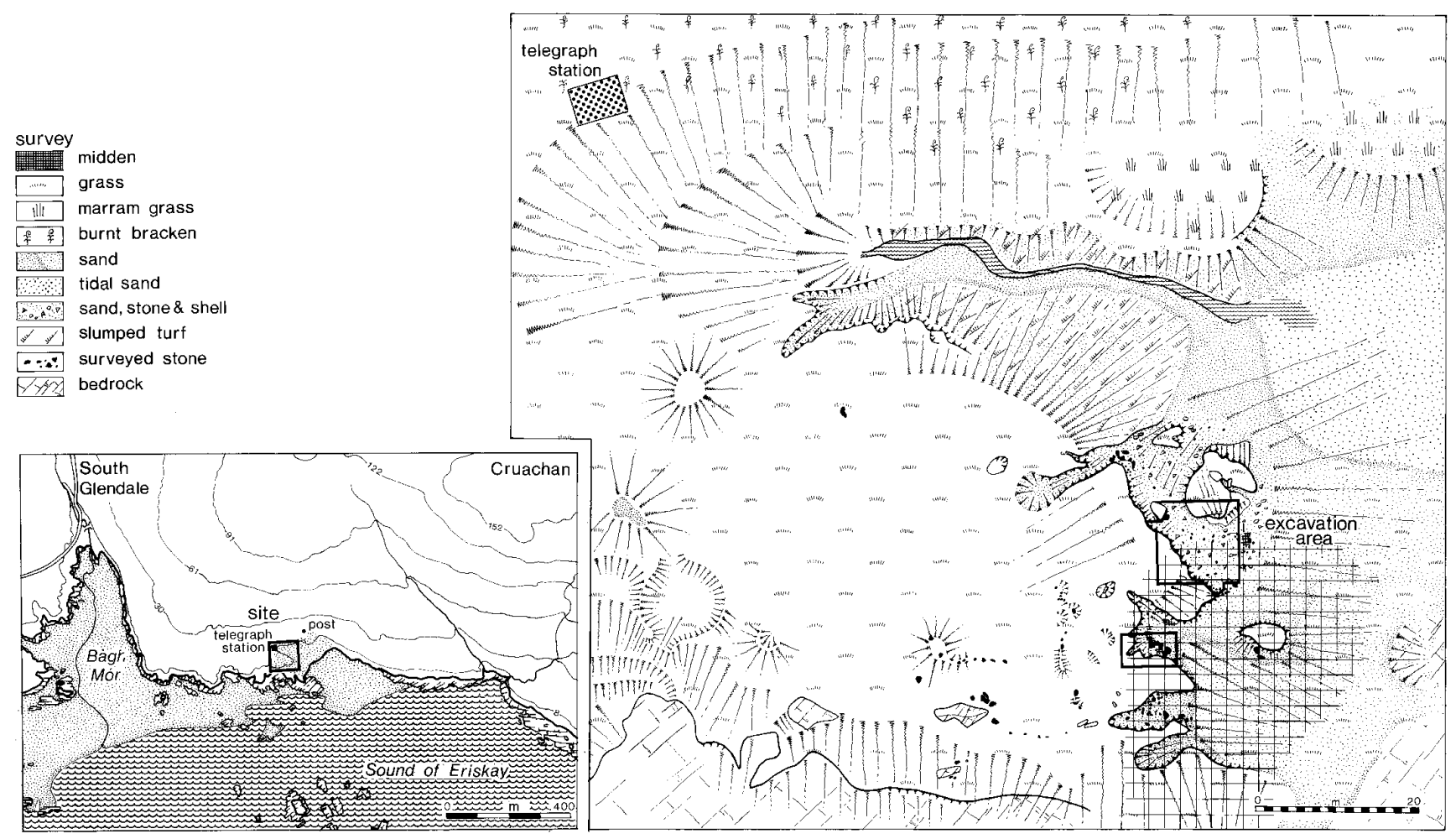

Figure 67. South Glendale: site location and survey

\subsubsection{Local sites}

There is a cairn, possibly chambered, $1.2 \mathrm{~km}$ to the west of the site at NF 81031434 . This has a later, nineteenth century shieling inserted into its north side.

\subsection{AREA I}

Two areas were chosen for excavation at the eroding edge of the machair (Figure 67). The north trench measured $10 \mathrm{~m} \times$ $10 \mathrm{~m}$ (Figure 68). Only 30\% of the grassed surface survived in this square, at a level of $0.80 \mathrm{~m}$ above the eroded surface. A baulk was retained at the edge of the sand face in an attempt to protect the site from further erosion and reduce the danger of windblown sand to the excavators. The loose sand to the east of the baulk, which contained the shells, bone and pot, was cleared away. To the west of the baulk the surface was cut down to the same level through mainly grey sand with very thin layers of humic material. This material did not contain any finds in its upper levels but near the base there were shell and modern artefacts. Two large rocks outcropped within the square, in the north-east and north-west corners. Figure 69 illustrates the main layers of the site, although not all the site's layers are depicted or described in detail. Three Blocks were identified in the section.

\section{Block I - Cultivated deposit}

See table p.322

Block 1 lay immediately beneath loose grey beach sand. It had a maximum depth of $0.40 \mathrm{~m}$ and consisted of numerous layers of sand which ranged in colour from pale yellow to dark brown, the textures being described as sand. There were occasional lenses of charcoal rich sand and ash.

Initially, a deep layer of dark coloured sand, [4], extended across the southern half of the area. It contained lenses of lighter and darker sand and considerable amounts of bone, pot and shell were recorded. Recorded beneath this layer was a probable hearth feature, several pits, stake-holes and ard marks. The possible hearth feature consisted of an oblong shaped area of charred black and red sand, [21], surrounded by set stones, [18], with two possible stake-holes on either side, [306] and [111]. Four flat stones, [308], extended for a distance of $0.40 \mathrm{~m}$ to the north. $\mathrm{Nu}-$ merous intercutting pits were seen at this level ranging from shallow scoops to pits up to $0.40 \mathrm{~m}$ deep, and they varied in shape from round to sub-rectangular. Their fills were generally of dark sand. Several stake-holes were seen mainly in the south of the area. There were nine ard marks recorded within this area, They were all filled with dark material except for [57] which was filled with white sand. Where the ard marks cut the pits the former were seen to be the later features. The excavator also noted the presence of individual spade-marks cut from within the midden material.

\section{Field interpretation and conclusion}

This Block was interpreted as a cultivated deposit because of the presence of spade-marks, ard marks and dark stained sand. The presence of the pits, hearth and paving stones are suggestive of settlement. The pits and stake-holes appeared to be clustered in the south and west of the area but no structures could be identified on the evidence recovered. 


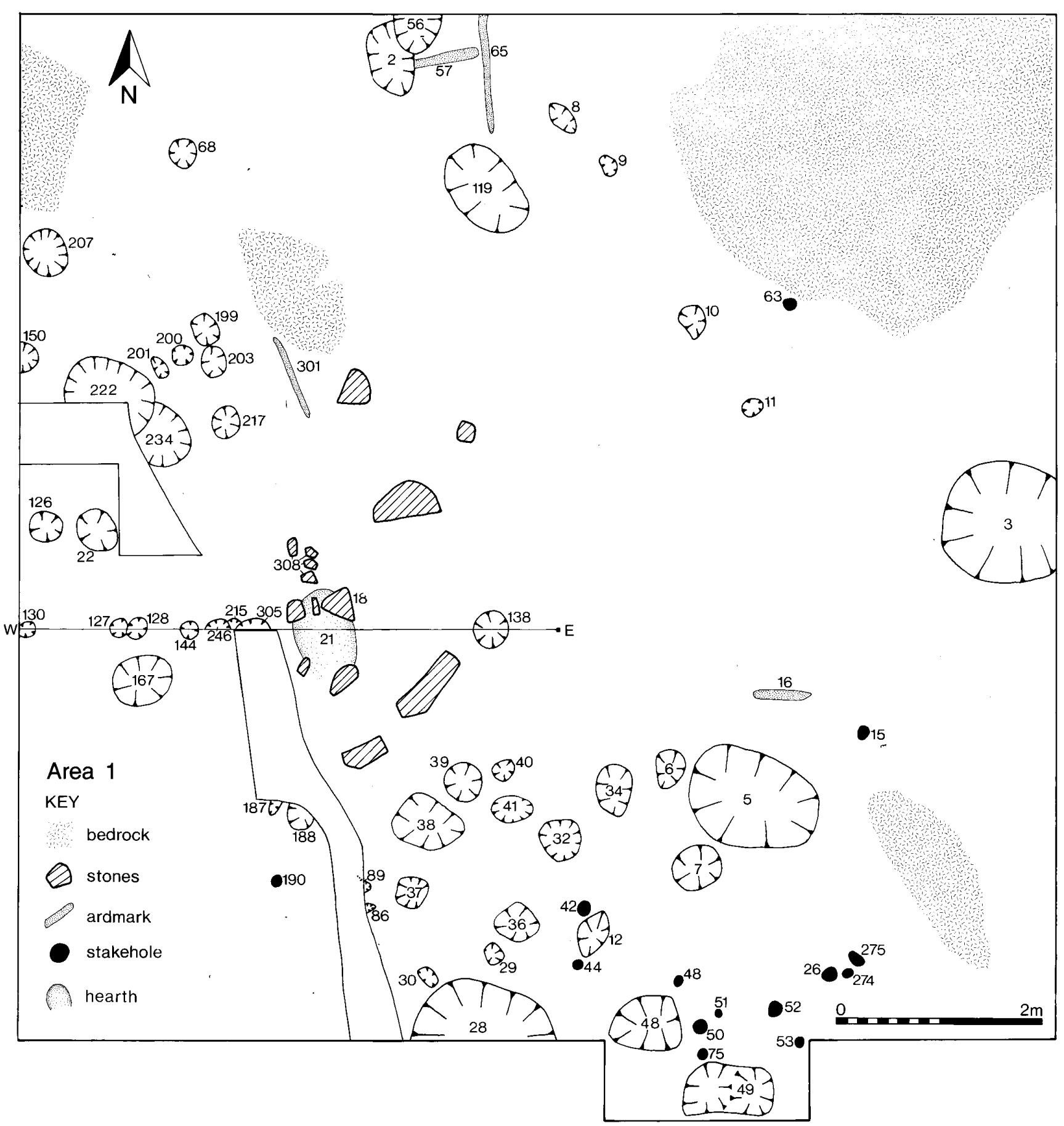

Figure 68. Area 1: plan

\section{Block 2 - Windblown sand}

See table p.322

Block 2 lay beneath Block 1. It consisted of two extensive layers one of grey sand with dark mottles, [92], and a yellow sand, [20], above it. They lay to a depth of between $0.05-0.40 \mathrm{~m}$. Except for a piece of pottery and a stone in one of the mottled patches ([103]) within [92] there were no finds.

\section{Field interpretation and conclusion}

This Block was interpreted as windblown sand because of the general lack of anthropogenic materials and light colour. The single potsherd was of a significantly different type to that found in the midden in Block 1, suggesting that there was a break in the chronology between the two Blocks. 
E

W

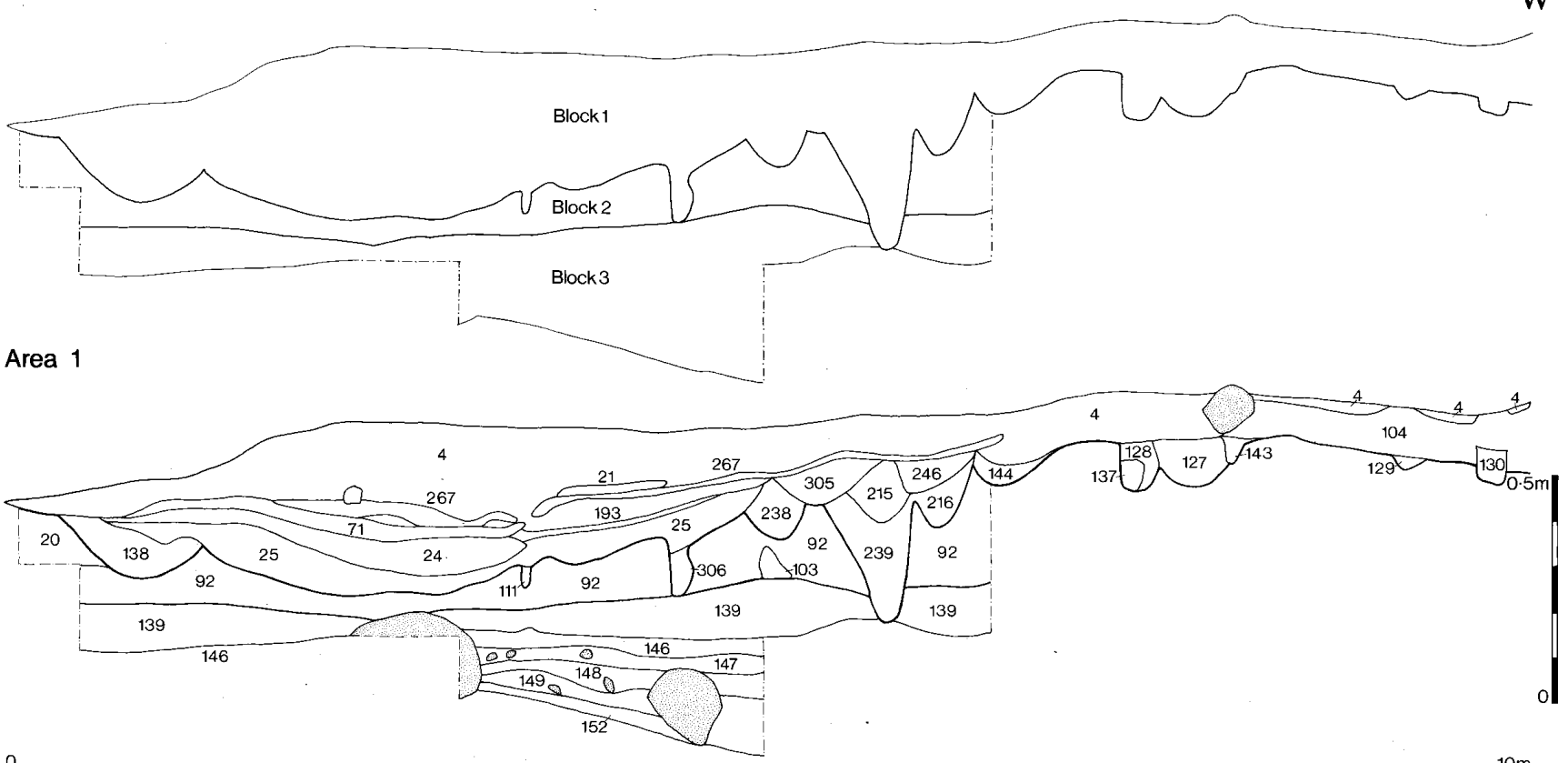

Figure 69. Area 1: section

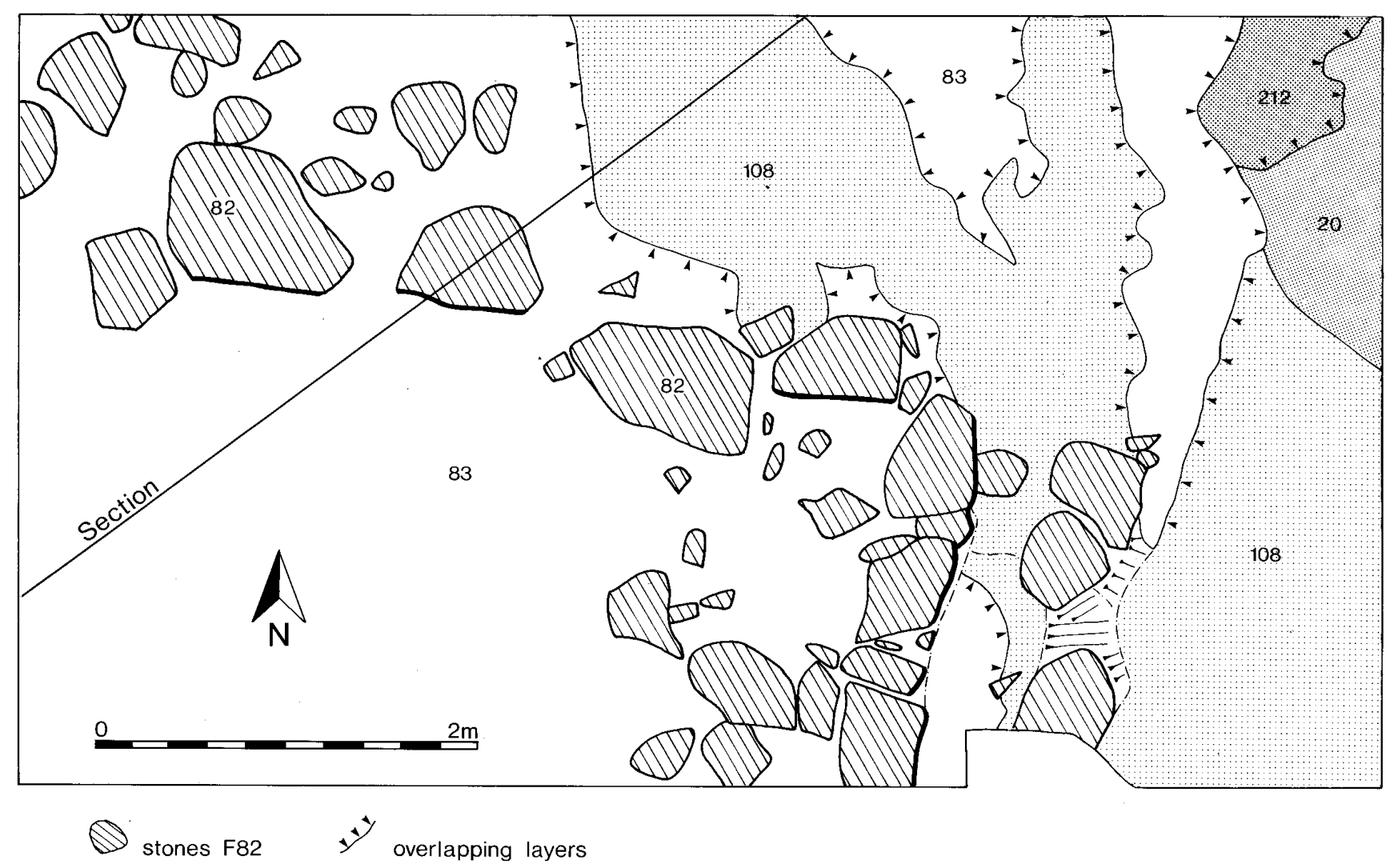

Figure 70. Area 2: plan 


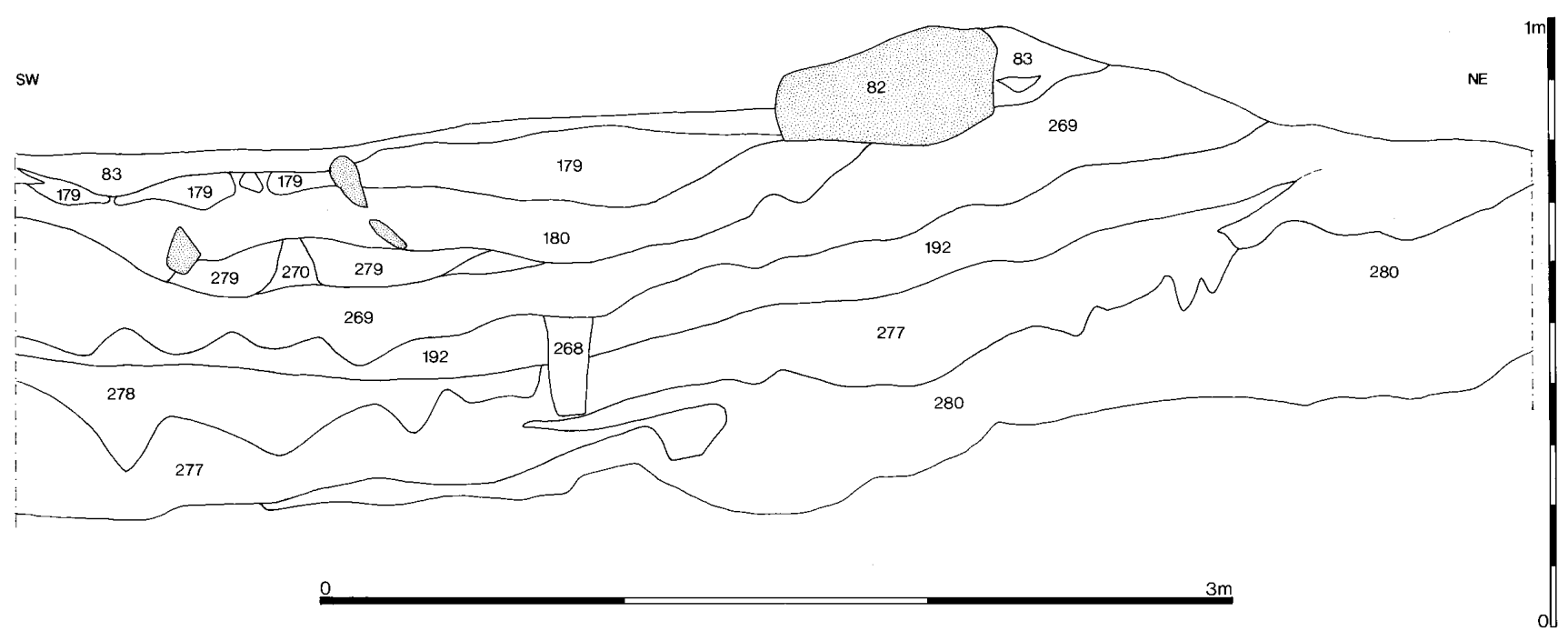

Figure 71. Area 2: section

\section{Block 3 - Natural deposit}

See table p. 323

Block 3 lay beneath Block 2 and above the bedrock. It had a maximum depth of $0.40 \mathrm{~m}$. The layers consisted of dark grey sand [139], below which was a black layer, [146], then a layer of small stones in a gritty soil, [147], a dark brown gritty layer, [148], a light brown sand and clay, [149], and finally a layer of brown clay, [152].

\section{Field interpretation and conclusion}

This Block was interpreted as a natural deposit.

\subsection{AREA 2 - POST-MEDIEVAL BYRE STRUCTURE}

* ${ }^{14} \mathrm{C}$ date $540 \pm 50 \mathrm{bp}(\mathrm{GU}-2159)$ from layer [108] (Limpet $\&$ razor).

$*{ }^{14} \mathrm{C}$ date $550 \pm 50 \mathrm{bp}(\mathrm{GU}-2160)$ from layer [212] (Limpet $\&$ cockle).

The southern trench measured $7 \mathrm{~m} \times 4 \mathrm{~m}$ (Figure 70). It was examined because of the presence of midden material and stones emerging from the base of a low sand cliff.

The midden layers were beneath $0.40 \mathrm{~m}$ of clean sand. A trench was dug through the midden deposits and stonework. These deposits were not divided into Blocks because of the absence of discernible episodes within them (Figure 71).

The aligned stones formed a right-angled corner of a probable rectangular ruined structure. The walls were of rough unmortared stones, [82], a single course high except for small stones beneath part of the east wall. The east wall measured $2.3 \mathrm{~m}$ and the north wall was exposed for $5 \mathrm{~m}$. The walls were double skinned, the outer wall being the more ruined, separated by a space of circa 0.30 m. A black organic layer, [83], covered and surrounded the wall stones.

A black organic layer, [180], was found within and slightly beneath the wall stones. It contained modern artefacts including an iron kettle and a cloth-covered brass button.

The layers beneath the stone structure sloped gently to the south and consist of alternating stained and clean sand layers. Near the base of the section was a layer of brown sand, [277], at the base of which were cultivation ridges. This material also contained an iron object. Below layer [277] was a layer of black organic material. The total depth of the floor levels and stained sand beneath was circa $0.70 \mathrm{~m}$. Beneath this was clean white sand.

\section{Field interpretation}

This area was interpreted as the corner of a medieval or post-medieval rectangular structure, probably a byre from the presence of the black organic deposit found within it. Pre-dating the structure were layers of midden and cultivated deposits.

\section{Archaeological interpretation}

Layer [108], a dark coloured sand, lay outside the structure defined by the wall [82] but beneath the rubble from this structure and beneath layer [83] which covers and surrounds the stones. Layer [212], a brown sand, lay beneath [108], separated from it by a single layer [211]. Both layers overlay yellow sand interpreted in the field as the same layer as [20] in Area 1.

\section{Conclusion}

The excavated remains represent a post-medieval byre, built over midden-site layers, some of which have been cultivated. 


\section{CHAPTER 8: EXCAVATIONS AT NEWTONFERRY}

\author{
H F James \& J S Rideout
}

\section{I INTRODUCTION}

Newtonferry is situated on the north-east coast of North Uist. The coastline in this area is rocky except for the sand filled meandering inlet, Port nan Long, which lies between two low hills, Suenish and Beinna' Chaolais (Figure 72). Beveridge $(1911,91)$ wrote that 'Port nan Long', meaning 'Harbour of the ships', derives from the local tradition that ships of the Spanish Armada were wrecked here and stated that these could still be seen at very low tides in the shallow water between Port nan Long and Berneray.

The road divides just south of the inlet, continuing on to the settlement of Newtonferry and curving round the coast to the pier for the Berneray ferry. Immediately to the south of the inlet is a small loch, Loch an Sticir, and on the east side of the inlet there is a smaller loch called Loch a'Chaolais. To the south the land is low lying for circa $1 \mathrm{~km}$ until it rises gently to the hills of Beinn Mhor and Beinn Bhreac. To the south-west of Newtonferry a wide machair plain runs along the coast for $4.5 \mathrm{~km}$ to Vallaquie strand.

To the east of Port nan Long lies a sandy bay between the rocky outcrop, Cnoc Raineach, and the rocky shore of Rubha na Traghead. At the back of this bay the undulating grassy surface has been broken through by wind and sea erosion to form vertical sand faces up to $1.2 \mathrm{~m}$ high and an isolated tallard or island of sand. Cnoc Raineach and the area of stable sand at the back of the bay are grass covered, while some marram grass has become established on the hummocky sand at the base of the beach to the north of the site. Around the edges of the loch and in the depression to the south of Cnoc Raineach there are clumps of yellow flag. The higher ground to the east and south is covered with only a very thin layer of sand and as a result the grass cover is intermittent.

\section{I.I Archaeological features}

Concentrations of pottery, bones and shells, created by the deflation of overlying sand deposits, have been noted at the back of the sandy bay. Dark stained deposits containing these materials were exposed in some parts of the vertical faces. On the west side of the tallard midden deposits and possible stone foundations could be seen. Further stone alignments lay $10 \mathrm{~m}$ to the south, lying on the surface and forming a right angle. Some $15 \mathrm{~m}$ to the north-east of the tallard were further amorphous stone settings.

\subsubsection{Site history}

In his description of the antiquities of North Uist, Beveridge $(1911,227)$ mentions that from the north-east anti-clockwise, the 'first noticeable sand hill is at Rudha na Traghead, a shelving slope which faces southwards on the east side of Port nan Long.' Here he discovered several cists, deposits of slag and ashes and a large amount of pottery as well as bone pins, bronze/brass brooches and rivets of Viking type (ibid, 227-8). He also found a cist with an inverted urn (ibid, 268).
In 1965, the OS Field Inspector noted an extensive spread of midden material and fragmentary building remains in the area of open dune centred at NF 98827820 . The OS 2.5 inch maps mark this site as a finds spot for 'cists, pottery, bronze brooches'. The MacKenzie Collection, donated to the National Museum in 1972, contained a large collection of antiquities collected between 1880 and 1935 by $\mathrm{H} \mathrm{H}$ Mackenzie, factor of the North Uist Estates, and by Mrs McNeil of Newton House, Lochmaddy. In the catalogue Caolais Newton is mentioned as a find spot for a silver ring and bone artefacts (Close-Brooks \& Maxwell 1974, 287).

In 1983, members of the CEU had visited the site and collected a few sherds of Beaker pottery from the deflated areas.

\section{I.3 Local sites}

Several cist burials have been discovered in this area. These include one found on the west side of the road leading to Port Nan Long in 1848 (ONB 1878, 78). To the west of Newton House three short cists formed of flat slabs and holding human remains were apparently found in 1845 (ONB 1878, 72). In 1955 a further cist was uncovered by the plough at this site and excavated by personnel from Edinburgh University. It contained a crouched female skeleton and two small sherds of pottery, one of which Professor Atkinson thought to be of 'wheelhouse' type (Megaw \& Simpson 1961).

The Iron Age remains include a probable earthhouse at Screvan which was partially excavated in 1887. It apparently lay on the east side of Port Nan Long, in a sandy hillock and included a possible souterrain (Beveridge 1911, 114). This site, however, was not found by the Field Inspector in 1965. The massive remains of Dun an Sticir, a galleried dun or broch, lie to the south of Cnoc Raineach, at NF 89727768 (RCAHMS, 1928, 51-2, no. 171). A rectangular structure built within the ruined dun walls is traditionally associated with Hugh MacDonald, who fled from Skye and lived here temporarily in 1601-2 (Beveridge 1911,138-144).

The north-west shore of the rocky promontory to the north-west of Cnoc Raineach, Rubh' a' Charnain Mhoir, has produced evidence of Viking burials. A cairn, partially excavated by Beveridge, contained a skeleton accompanies by iron rivets, suggesting the presence of an unburnt burial of a 'Norseman' with his boat (ibid, 267). This lay 50 yards to the north of a smaller cairn which the OS 6 inch map of 1904 marked as 'Human Remains found AD 1840' and which Beveridge also believed was Viking from the presence of a similar iron rivet.

Two standing stones, Crois Mhic Jamain, each on the summit of low mounds, are situated on the west of the road to Port Nan Long. In 1862, it is said that a very large skull was discovered here (ibid, 277).

A local tradition that there was a pre-clearance settlement lying beneath the road at the back of the sandy bay, is supported by Beveridge who states that the settlement of 'Balliviconen' was one of three townships - the others being Baile Mhic Phail and Caolas (or Kyles Berneray) - which were cleared in order to make the single large farm of Newton, whence the very modern name of the latter' (ibid, 47). Beveridge considered that Kyles Bernera, meaning 'the sound of Berneray' seemed to have been identical in position with 

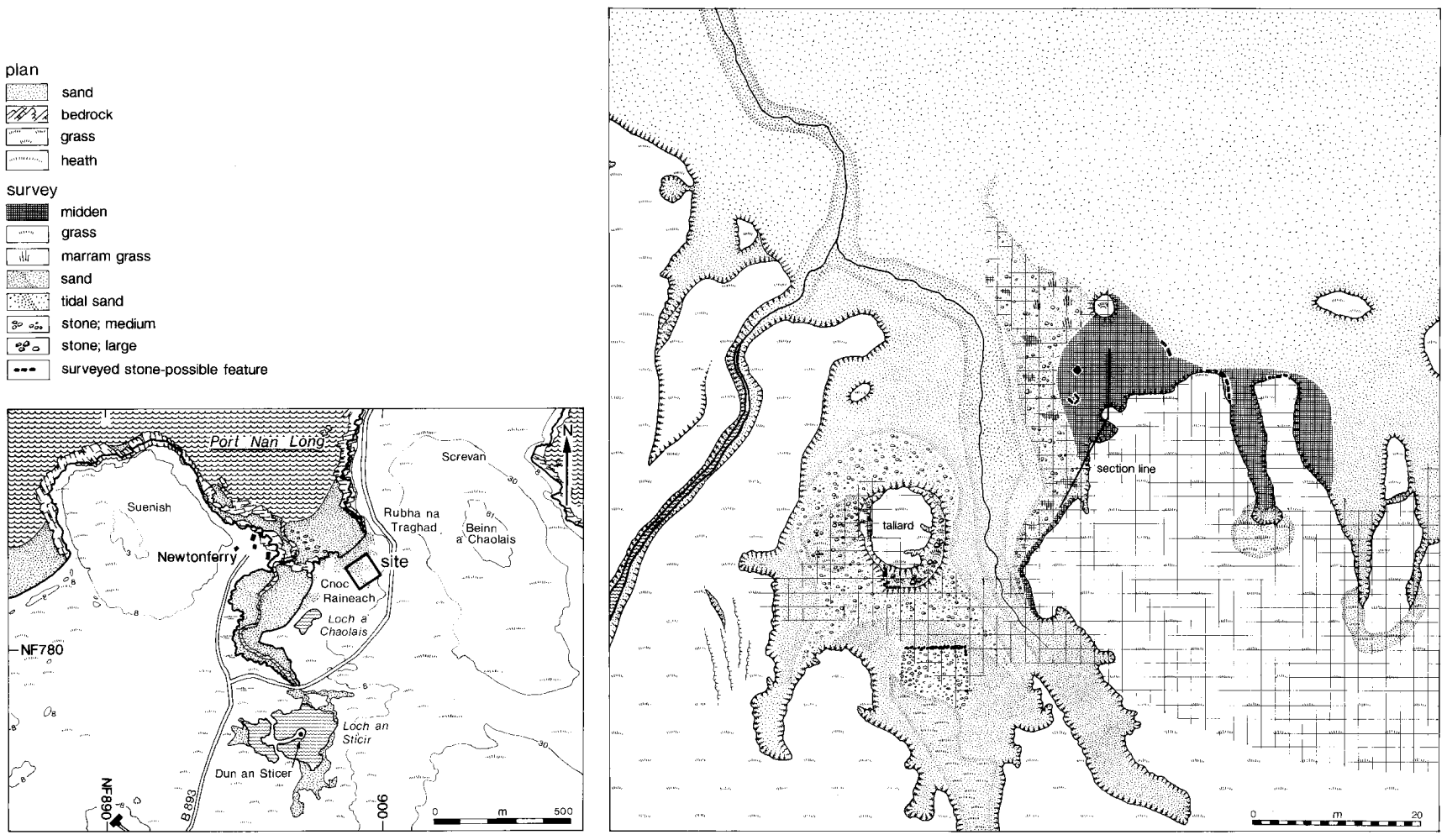

Figure 72. Newtonferry: site location and survey

Port nan Long, a little north of Newton (ibid, 83). This township seems to have been also known as Baile Mhic Cumhais (Crawford 1983). Bleau's map of 1654, while depicting 'Dunamich' (presumably Dun an Sticir) and two sites along the machair coast, does not refer to a site on the east side of the inlet. The first known reference to this placename is in the Judicial Rental of 1718 (MacDonald 1904, vol 3, 662), which includes the entry, 'Kyles, etc. Wm McLeod of Bernera. 200m'. About 50 years later, the Balranald Rental mentions that Donald Roy MacDonald became tacksman of Kyles-Bernera, at the north end of North Uist, shortly before 1764 (MacDonald 1904, vol 3, 537).

The Reid Survey of 1799 is unfortunately damaged in its north-east corner, but locates a group of 'house steads' at the back of the bay on the east side of the inlet. The name survives only as 'Kyli' (Reid Survey 1799). This is enough, however, to confirm the existence of a pre-clearance township which is first recorded in the eighteenth century but may well have its foundations well back in the medieval period.

\subsubsection{Method of excavation}

Two areas were examined in 1984 (Figure 72), one at the base of the tallard where the stonework and midden material was seen (Plate 28), and the other in the shaded area of exposed midden.

The midden deposits on the west side of the tallard were shallow and contained burnt peat and little else. These layers tapered away immediately to the west of a line of walling that protruded from the tallard. Sufficient walling was exposed to show that it formed a straight line and that it sur- vived within the tallard immediately beneath the grass cover. The stability of the tallard, the proximity of the stonework to its surface and the paucity of the midden remains discouraged further examination.

Attention was then concentrated on the area to the east where midden deposits and stone settings were seen on the surface. Loose sand, containing bones, shells and pottery, was cleared from the surface of the exposed midden and from around the extruding stonework. The vertical sand cliff, which also contained midden deposits, was straightened and a trench dug at its base to reveal the depth of the deposits. The section line was in two parts, the first, aligned north/south, measured circa $13 \mathrm{~m}$ along the edge of the sand cliff and the second, aligned north-west/south-east, measured circa $7 \mathrm{~m}$ from the sand face across the surface of the exposed midden. Towards the south end the trench was deepened to circa $1 \mathrm{~m}$ below the lowest stained sand deposit.

As with the other sites of Baleshare and Hornish Point the deposits were grouped into Blocks of contexts (Figure 73). Block 1 was situated to the west of the section line. The main section has been divided into four Blocks, the clean sand that lies beneath the midden (Block 2), the main midden deposit (Block 3), a small midden to the south (Block 4), and the wind blown sand that covers the site (Block 5). 


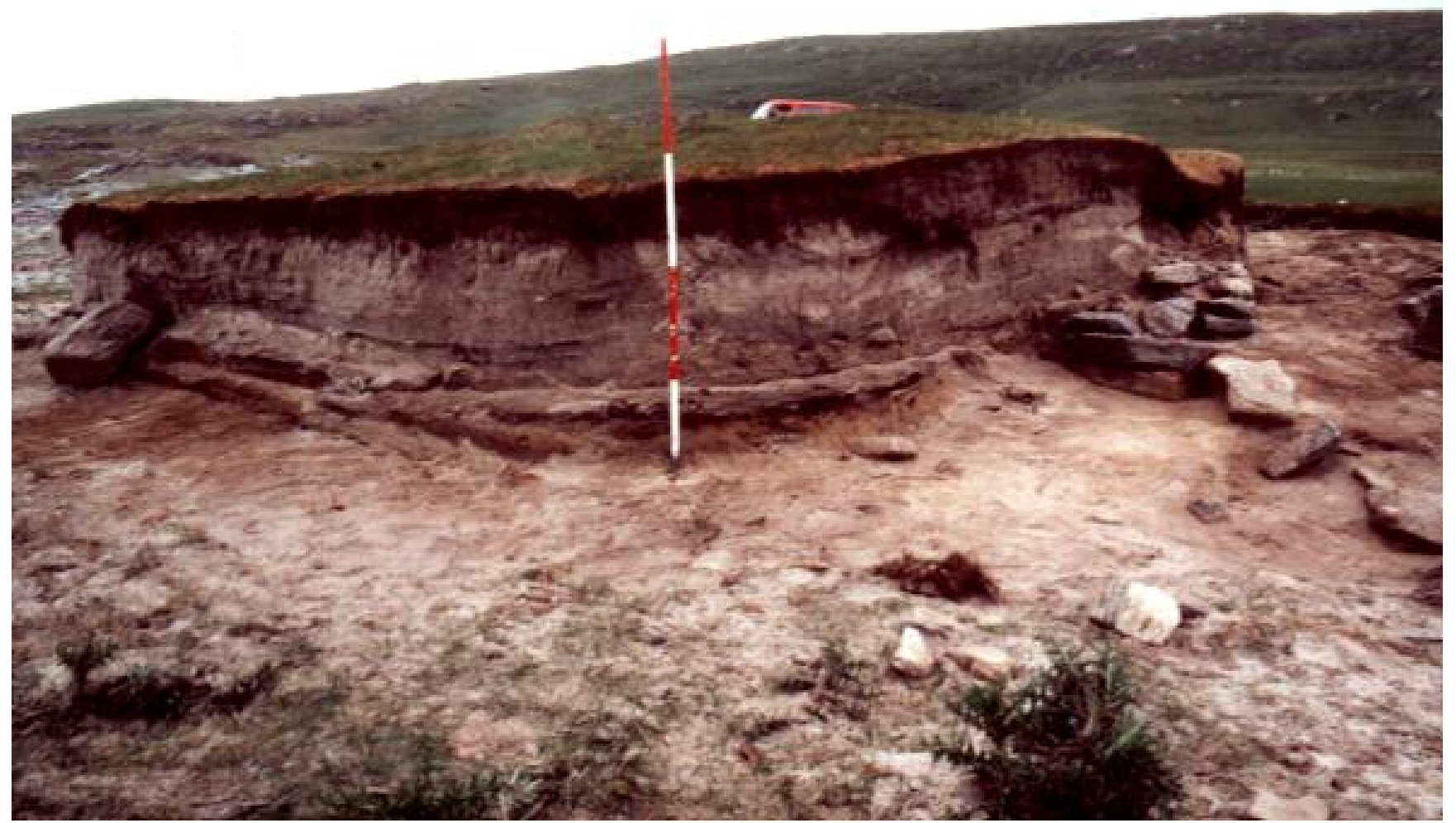

Plate 28. The tallard at Newtonferry after deflation material has been removed from the surrounding surface. Masonry of Block 1 is visible at the base of the tallard

\subsection{BLOCK I - MEDIEVAL OR POST-MEDIEVAL STONE SETTING}

See table p. 324

The features within Block 1 do not appear on the section drawing. They lay to the west of the section line at the edge of the eroding midden (Plate 28). Set within a $0.10 \mathrm{~m}$ deep layer of stained sand, [1], were upright slabs, [2], and flat settings of stones and two cetacean vertebrae, [3]. Beneath [1] lay clean sand [4] which was probably the same layer as [50] (Block 2).

\section{Field and archaeological interpretation and conclusion}

This Block was interpreted as a stone setting probably of post-medieval date.

\subsection{BLOCK 2 - WINDBLOWN SAND}

\section{See table p.324}

Block 2 lay beneath the midden deposits and stone settings of Blocks 1, 3 and 4 (Figure 73). It consisted of a layer of pale brown sand, [4] and [50], which contained within it lenses of slightly darker sand. These became more definite towards the southern end. The trench dug towards the south end of the section revealed this deposit to be of at least $1 \mathrm{~m}$ in depth.

\section{Field and archaeological interpretation and conclusion}

This Block was interpreted as wind blown sand because of its light colour and sandy texture. The increase in organic input towards the south end may be the remains of stable soil horizons within the windblown sand.

\subsection{BLOCK 3 - MIDDEN DEPOSIT}

See table p. 324

* ${ }^{14} \mathrm{C}$ date $700 \pm 50 \mathrm{bp}(\mathrm{GU}-2163)$ from layer [19] (Periwinkle).

* ${ }^{14} \mathrm{C}$ date $710 \pm 50$ bp (GU-2164) from layer [33] (Periwinkle).

* ${ }^{14} \mathrm{C}$ date $1150 \pm 70$ bp (GU-2162) from layer [8] (Periwinkle, limpet \& razor).

Block 3 extended for $14 \mathrm{~m}$ in the section. It had a maximum depth of $1.5 \mathrm{~m}$ and consisted of numerous, generally thin layers which ranged in colour from light to very dark brown and in texture from sand to sandy loam (Figure $73 \&$ Plate 29).

There were four shallow features with round or flat bottoms, unevenly spaced along the section, [14], [25], [34] and [36]. The fill of [34] was a bright orange burnt peat, while the other sand fills were of brown sand and some burnt peat.

At the north end of the section there was a small irregularly shaped stone setting, [9]. Two of these stones, [10], were set on edge and delimited the layer of peat, [11]. 


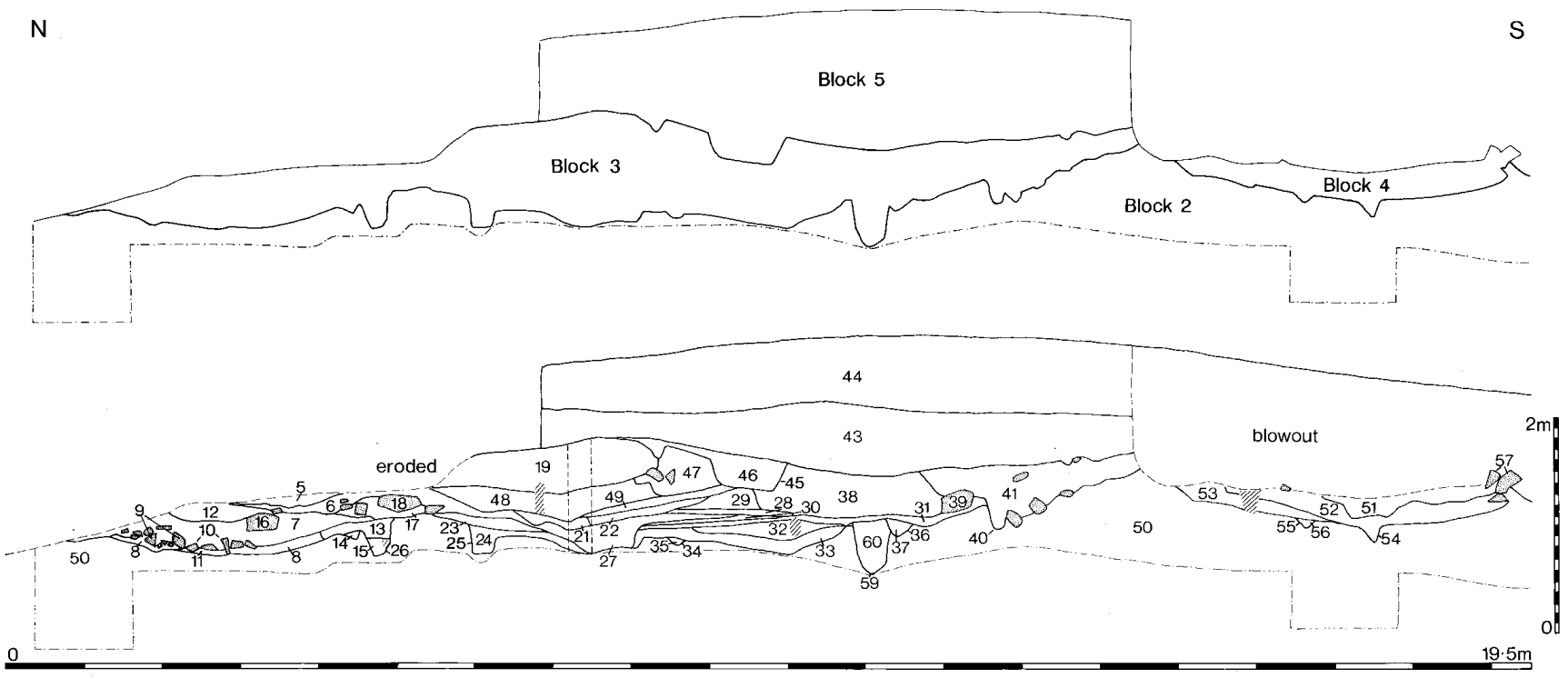

Figure 73. Newtonferry: main section

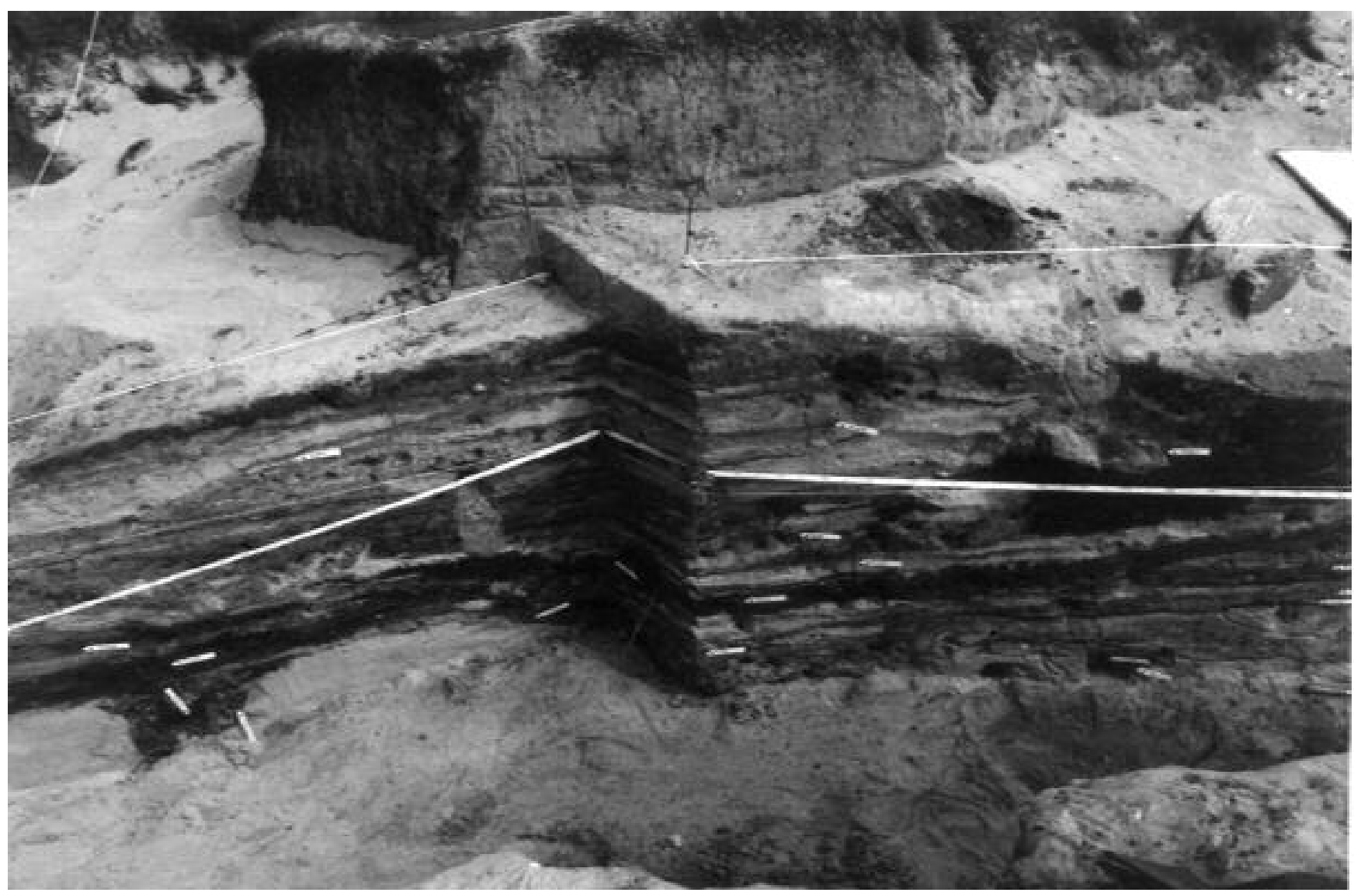

Plate 29. Newtonferry. The midden deposits of Block 3 
Post dating [34] was a large round-bottomed pit, [59]. This measured $0.45 \mathrm{~m}$ deep by $0.45 \mathrm{~m}$ wide. Its fill consisted mainly of white sand though there were thin layers of dark sand, [60], in the centre and around its base. Cut into the south edge of this feature was a small, shallow, round-bottomed feature, [36]. Both [59] and [36] were sealed by a thin, very dark brown, silty sandy loam, [31].

At the south end of the site, there was a round-bottomed feature, [40]. A large stone, [39], lay just to the north of this feature and two smaller stones were set into its base.

\section{Field and archaeological interpretation and conclusion}

This Block was interpreted as midden-site deposit because of the variable colours and textures of the layers. Within this deposit were several features interpreted as probable post-holes, and there was evidence for a stone-built hearth. This Block was largely of Medieval date but a Dark Age date was returned from context [8].

\subsection{BLOCK 4 - MIDDEN}

See table p. 325

Block 4 lay at the south end of the section above Block 2 (Figure 73). The deposits above Block 4 had been removed and so separated it stratigraphically from Block 3. It extended for a distance of $4.4 \mathrm{~m}$ and had a maximum depth of $0.25 \mathrm{~m}$. Two small V-shaped features, [54] and [55], were cut from within this Block. Above these lay a dark brown loamy sand, [53], and a lighter brown loamy sand, [52]. At the extreme south end were three irregularly shaped stones, [57], that appeared to be retaining the midden to its north.

\section{Field and archaeological interpretation}

This Block was interpreted as a midden-site deposit, probably of medieval to post-medieval date. It was probably in part contemporaneous with the midden of Block 3.

\subsection{BLOCK 5 - WINDBLOWN SAND}

See table p.325

All the layers and features above the midden of Block 3 were included in this Block. It survived in section for a distance of $7.7 \mathrm{~m}$ (Figure 73). Its maximum depth was $1.2 \mathrm{~m}$. A flat bottomed feature, [45], filled with light brown grey sand and numerous shells, [46], had been cut from within this Block into the surface of Block 3. Above this were two light coloured sand layers with lenses of humic material, [43] and [44].

\section{Field and archaeological interpretation and conclusion}

This Block was interpreted as wind blown sand with humic lenses marking periods of stability and vegetation growth. These deposits represent the reversion of the area to abandoned landscape after the Medieval period. 


\section{CHAPTER 9: RESEARCH QUESTIONS AND METHODOLOGY}

\section{I RESEARCH QUESTIONS}

In so far as it has proved possible, the so-called 'hypothetico-deductive' method has been followed throughout. This rather grandiose phrase describes the simple process of defining relevant, appropriate questions (the research questions) and determining tests which are ideally necessary and sufficient to provide unambiguous answers to them.

The research questions considered in this project were derived, where possible, from the existing body of relevant literature reviewed in Chapters 2 and 3 above. Strict adherence to this practice would, however, have left many relatively obvious problems untackled. The nature of the deposits on the sites and the mechanisms by which the sites were formed, for example, have not been widely discussed (but see Davidson et al 1983, on comparable Orcadian sites). The research questions relating to matters not formally discussed in the existing literature were formulated by first developing models, based on general principles, which seemed applicable to the particular circumstances of the sites, in the light of our knowledge of them and our recent experiences at Balelone. Research questions were then formulated to test the validity of the models.

The 'relevance' of research questions is in part founded in their derivation from previously published work or from properly formulated models, as outlined above. However, it is also dependant on their relationship with the data, in that only questions which can be answered directly from the available data may be considered relevant. Middle range theories, for example, those relating to the nature of the agricultural economics of Hebridean Iron Age machair sites, are not research questions, because their elucidation relies on inferences drawn from the answers to more basic questions, ie from the answers to relevant research questions. Topics of this type are discussed in the concluding chapters after the research questions have been considered.

Six principal areas of research seemed to present themselves. The nature of the sites themselves, their structures and deposits constitute the first and their chronology, the second. The regional environment in which they functioned, through time, may be considered next, because it sets outer limits to the possibilities for the development of the economies of the sites, the fourth research area. Technology and trade, while aspects of site economy, merit separate consideration and the settlement landscape, the distribution and location of these sites is also of sufficient importance to stand alone, as a research topic. Hereunder are listed, without comment, the questions with which we approached these sites. This is followed by the methods employed to answer to them.

\section{I.I The sites}

i) What processes were involved in the formation of the sites themselves?

ii) What processes of post-depositional change are evidenced in the sites and to what extent do they constrain interpretation?

\subsubsection{Deposits}

i) What is the character of the soil matrix of the deposits? How does it differ from the machair soils? What is the source of the materials in which they differ? What is the depositional mechanism by which they were formed?

ii) What is the anthropic contribution to the deposits and what light does it cast on the process of formation of the deposits?

iii) What natural, non-soil, materials are present in the deposits and what information do they convey about the formation of the deposits?

\subsubsection{Structures}

i) What types of structures, and of what date and duration, are evidenced in the sites?

ii) If structures of the dun/broch/wheelhouse complex are uncovered, do the different structures represent chronological succession or social differentiation?

iii) What was the local environment of the sites like? To what extent did the sites modify the ambient environment?

\subsubsection{Artefacts}

i) What classes of artefacts are present in each site and where the deposits are of sufficient duration, do they provide evidence for the existence of chronosequences or typologies?

ii) Do the artefactual assemblages from each deposit convey meaningful information about the nature or function of the individual deposits?

\subsubsection{Chronology}

i) What is the date of the inception of each site?

ii) What is the duration of each site?

iii) Are there significant breaks in the depositional chronology of the sites, representing phases of abandonment between periods of occupation?

iv) Are there less significant breaks indicative of phases of relative inactivity in the sampled areas during periods of continuing occupation at other foci within the site?

\section{I.6 Regional environment}

i) What is the impact of the post-glacial vegetational succession of the Uists on the natural succession of human settlement, especially during those periods when the excavated sites were occupied? 
ii) By what date was the machair system established in the areas it now occupies?

iii) At what date did the general spread of blanket peat take place?

\subsubsection{Site economies}

This research topic breaks naturally into two parts the first of which concerns the agricultural economy of the site while the second covers the hunting and gathering aspect of the settlements.

\section{Agricultural economy}

i) Were both animal and crop husbandry being practised by the occupants of the sites?

ii) What domesticated animals are represented in the site assemblages, and in what proportions?

iii) Were the animals kept primarily for meat or for secondary products like milk or wool?

iv) Is there any evidence for the use of domesticated animals as draft animals?

$v$ Is there evidence for the existence of non-consumable animals such as pets or commensals?

vi) What implications do the likely herd sizes and structures have for the scale and organisation of the farms?

vii) Is there evidence for cultivation, direct or indirect?

viii) What crops were cultivated?

ix) Is there evidence for crop processing including storage, on the sites?

$x$ Where were the cultivated fields, and what sizes were they?

xi) What was their likely fertility and how was it improved or maintained?

xii) At what level was their agricultural technology practised and what agricultural hardware is evidenced from the sites?

\section{Non-agricultural aspects of site economies}

i) To what extent were the sites truly subsistence economies, ie they consumed all they produced and produced all they consumed? Were animals or plants present which could not have occurred naturally in the islands natural and man-made ecosystems?

ii) To what extent did the marine produce, derived from both flora and fauna, contribute to the site economies? iii) To what extent were undomesticated animals or birds used in the sites economies?

\subsubsection{Technology}

i) What level of technology is evidenced in the artefacts, both finished products and by-products?

ii) What level of technology is evidenced in the architecture of the sites' structures?

iii) What level of technology is evidenced in the food producing activities recorded on the site?

iv) How does the general level of technological achievement evidenced on the sites compare with that of contemporary sites elsewhere in the Isles, on mainland Scotland, in Britain and further afield?

\subsubsection{Trade}

i) Are any of the sites materials necessarily derived from non-local sources and can these sources be identified?

ii) Are there any locally available materials, used on the sites, which might be identified on sites elsewhere?

iii) Does the analysis of the sites economies indicate possible surpluses of potential trade goods, which are not detectable in the archaeological record?

\section{I.10 Site distribution and location}

i) Why are the sites in the positions they now occupy?

ii) How does their distribution relate to the overall distribution of contemporaneous sites of all types?

iii) Why have the sites survived and what is the prognosis for their continued survival?

\subsection{METHODS USED IN ADDRESSING THE RESEARCH QUESTIONS}

It seems useful to present here the methods used to address the research questions outlined above. The specific methodologies employed by the various specialist contributions to this project are provided below.

\subsubsection{Site formation}

The processes of site formation and change are explored on two levels, that of the nature of the deposits which comprise them and that of their gross structure as geomorphological entities. The methods applicable to the former are the characterisation and sourcing of the anthropic contributions to the natural soil matrix of the area. This entailed routine soil 
analyses, site pollen analyses, phytolith analysis and a taphonomic analysis of the artefactual and ecofactual inclusions in the sites together with an assessment of their rates of sedimentation. The conclusions reached in this matter, together with field observations of the unexcavated coastal sites, provided the basis for comment on the sites as geomorphs.

\subsubsection{Structures}

The nature of the structures revealed in excavation would be determined by recording their forms and contents and by using primary contents, where they existed, to assess the function/s of the structures. Their dating forms part of the general problem of site chronology and is discussed below. Their impact on the immediately local environment would be assessed by pollen and phytolith analyses, snail assemblages and the nature of their associated deposits. The social status of the structures relies on an analysis of materials with which they have primary associations, together with a consideration of their relative sizes and elaboration.

\subsubsection{Artefacts}

The artefacts retrieved were subjected to standard archaeological studies. Their range was very restricted and, in practice, only the pottery assemblages proved sufficiently extensive for detailed study. The method favoured was that of attribute analysis. Chronological control was effected by the site chronologies (see below).

As noted above, the range and quantity of artefacts, manuports and some ecofacts provide an insight into the extent to which human activities have altered the natural wind blown sands of the area (see Chapter 1.3.6). Potsherds existed in such quantity that it was decided to explore their size distribution within each context, to assess the extent to which the contexts have undergone gross disturbance, by ploughing, for instance (see Sherd Size Distribution method, below). Both of these indices facilitate the use of artefactual assemblages in the exploration of the nature and function of the sites deposits.

\subsubsection{Chronology}

It was clear from the outset that close chronological control on the depositional sequence provided the only hope of unravelling the tangled skein of deposits which the large sites displayed. It was decided to eschew the traditional archaeological practice of dating specific interesting or important 'events' in the site's evolution and to try instead to date the depositional sequence of the site as a whole, interpolating to date specific events. This would facilitate dating the inception and duration of each site and, hopefully, the date and duration of the separate events represented in the depositional sequences. To that end dates were selected from contexts close to the boundaries of contiguous blocks. Shell was used for dating, because of its ubiquity, and carbonised material was also dated from a number of contexts to assess the marine reservoir effect (see Chapter 18.11).

\subsubsection{Regional environment}

It was decided to explore the regional environment by pollen analysis, diatom analysis, phytolith analysis and by analysis of snail assemblages. The phytolith and snail assemblages were derived from site deposits and the pollen and diatom analyses from peat and lake deposits nearby.

\subsubsection{Site economies}

Analyses of animal bone and macroplant assemblages, and of cultivation marks and cultivated deposits, the latter by pollen and soil analyses, were undertaken to provide some insight into the domestic economies of the sites. Analysis of the fish bone assemblages was undertaken to explore the contribution of the rich marine and peri-marine ecosystems of the domestic economies. Bird bones were also analysed to explore the use of fowling and its contribution to the sites. Carbonised macroplant remains of seaweeds and the remains of seaweed dwelling mollusca indicated the use of seaweed on these sites. While seashells were present in most deposits and abundant in some, no formal analysis was undertaken because the information yield, in the present state of marine molluscan studies, does not justify the costs entailed.

\subsubsection{Technology and trade}

The evidence of the pottery assemblages, of the structural analyses, and of the agricultural activities practised on the sites was used to assess the state of technological sophistication of the sites inhabitants. Evidence of trading was sought in the artefact and other assemblages, by looking for exotica. To this end, the fabrics of the pottery assemblage, the only significant artefact assemblage, were examined for non-local rock and mineral inclusions.

\subsubsection{Site distribution and location}

It is clear that most of the coastal erosion sites of the Long Isle are multi-period sites. Either the locations they occupy are special in some way or the existence of a site provided some advantage over the surrounding machair, such that subsequent settlement was attracted to it. This proposition was examined by a study of the known site distribution, by a separate coring exercise at Baleshare and by an analysis of the results of the study of the site deposits. This latter factor, together with current land-use trends, was explored in an assessment of the reasons for the sites' survival and the likelihood of their continuing survival. 


\subsection{SPECIFIC METHODS}

\subsection{Coarse pottery: analytical methods}

\section{Lehane and L Crone (1986)}

\section{Introduction}

The excavated sites all produced pottery in relatively large amounts as follows; Baleshare 5760 sherds, Balelone 1,500 sherds, Hornish Point 699 sherds and South Glendale 175 sherds. The site at Newtonferry produced 350 sherds all of which were uncontexted and therefore only received a cursory examination. The majority of the pottery came from the sieving of the excavated tapestry strips. However, prior to this any pottery exposed in the section had been recorded and removed.

Traditional pottery reports are based on the examination of a number of features observed on each sherd with a view to producing a typology of culturally significant classes. The features which can be observed are numerous and include colour, hardness, texture, decoration, etc. Those features chosen are not consistently used and are usually selected in response to specific questions posed by the assemblage. It was decided that a set list of features or attributes would be recorded for each sherd. Those attributes were chosen so that the assemblage could be described in terms of type, form, construction, decoration, function and site distribution or provenance. This process mimics the attribute analysis of flint and its strength in pottery analysis lies in the fact that pottery types can be defined easily and unambiguously in terms of any combination of some or all of the recorded attributes.

\section{Attribute recording}

A copy of the attribute list can be found in the site archive; the following supplies brief descriptions of the terms used.

The external curvatures in the horizontal and vertical planes of each sherd were measured using a set of curves with radii ranging from $50 \mathrm{~mm}$ to $210 \mathrm{~mm}$, in $10 \mathrm{~mm}$ steps. The curvature was not always measurable and the smaller the sherd the less reliable the value taken in general. The net result of this may have been to increase somewhat the number of sherds with large radii, but since there is no direct relationship between sherd size and radius it is felt that no significant bias has been introduced.

The minimum and maximum thickness of each sherd was recorded in millimetres and its weight in grams. Colour was recorded for three locations on each sherd external (outer face), internal (inner face), and middle. The colour was defined by the use of the Munsell Colour Chart, (MSCC 1975). The pottery colours, as an index of their firing conditions (Shepard 1956, 107), were noted: fully oxidised (colours clear through cross section of wall), incompletely oxidised (colours clear on surface, grey on wall interior) incompletely or fully oxidised (brown light to dark), unoxidised or reduced (uniform colour).

The gross texture, (in this instance, texture does not refer to the size of the clay particles, but rather to the thickness of the sherd in general), was noted under the following headings: very coarse, coarse, medium, fine and very fine. Their categories were not based on any absolute scale, rather the complete assemblage was examined and relative groups defined.
The base angle, ie the external angle between the side of the pot and the horizontal plane on which the pot stands, was recorded together with the base thickness.

Rim types were defined by simply noting the different forms occurring within the assemblage.

The decoration of the pottery has been recorded under the categories of method and motif. Six different methods were noted: incised, applied, gouged, stabbed, impressed and stamped, along with twenty-four different motifs.

There are a number of attributes which occur so infrequently that a separate attribute space is not required. These include such features as the presence of grass and seed impressions, burnishing, slipping and coil lines or thumb and finger tip impressions associated with manufacture. The presence of adhesions was recorded; adhesion being defined as a deposit which has adhered to the outside or inside of a pot sherd and which is not a post-depositional feature, that is, it does not extend to the broken edges of the sherd.

\section{Analysis}

The analysis of the assemblage records falls into three main sections. Firstly, pot specific information, such as details of type, form, firing, construction and decoration were examined. Secondly, information on functions of individual vessels or vessel type was examined using the evidence from the adhesions, both internal and external. Finally, site specific information based on the nature and use of the sherd size index is discussed elsewhere in this chapter.

Typology has been the traditional requirement of pottery reports, in particular those dealing with material from the Western Isles. However, it is clear from reading the literature that a widespread overlap of types exist. In this project three methods of defining types were considered. It was decided to exclude 'provenance' from the definition of types and to use it as a test of typologies generated, in that it may be assumed that chronologically significant groups would cluster in $\mathrm{mu}-$ tually exclusive or slightly overlapping groups of strata.

i) Attribute analysis: in this report the attributes of colour, firing and gross texture were taken to define type.

ii) Stylistic analysis: a sample of the pottery was sent to a traditional formal and stylistic pottery specialist who produced a typology.

iii) Analysis of fabric.

There are a number of reasons for the occurrence of different pottery types on a site, chronological, functional, social and/or economic. Where the typology had a chronological significance, the defined types should be reflected in the stratigraphy. Therefore, on each site the defined types are tested for stratigraphic significance.

The remaining pot specific analysis details form using the attributes: rim with external horizontal curvature and base with base angle, firing, construction and decoration.

As outlined above, it was proposed to seek evidence for the function or use of the pots by analysing the adhesions which occurred on many sherds. Clearly the possibility exists that these adhesions are a post-depositional phenomenon, but no sherd was observed where the adhesions occurred on the edges of the sherds (on the faces of the breaks) and this 
implies that these adhesions may not be a post-depositional feature. Thus it is argued that the internal adhesion represents the remains of the pot contents and suitable analysis might reveal what these contents had been. If this hypothesis is true, the external adhesions should contain a high carbon content. (The assemblage of sample adhesions forms part of the site archive).

Finally, there are social and economic reasons for the differences observed in pottery types. Working in the Southern Sudan, Braithwaite noted the use of decorated and undecorated wares in the preparing and serving of food and found that woman used only undecorated pots while men used the decorated wares (Braithwaite 1982). A second example comes from the work undertaken by Hodder among the Nuba of Sudan, which revealed that pottery production was geared to their strong sex taboos (Hodder 1982). Unfortunately, social and economic differences are the most difficult to establish archaeologically and are virtually impossible to detect in a limited excavation.

\subsubsection{The calculation of potsherd size distribution}

\section{J Barber}

Common experience suggests that ceramic vessels break into a relatively small number of relatively large sherds when first broken. If at this point the sherds come to rest in a context (in or on a surface) where disturbance takes place, by trample, for example, then further breakage must ensue. If the disturbance of the deposit is prolonged, even if intermittently as it would be, for example in a cultivated deposit, continued breakage must result in the comminution of the sherds. If the forces involved are compressive, the sherds must finally be destroyed completely. If they are tensile, on the other hand, the sherds must be reduced to some minimum size, the dimension of which is related to the tensile strength of the sherd. In both cases the mean sherd size must reduce with time unless the rate of deposition of the sites sediments is sufficiently rapid to bury and thus preserve them. Since different sites produce pottery of different types, vessel size, wall thickness, tensile strength, etc inter-site comparisons are likely to prove difficult or misleading and the hypothesis is therefore restricted to inter- and intra-context comparisons for single sites. Differences in ceramic tradition can also arise through time and on sites of considerable duration, this may need to be taken into account.

The quickest and easiest measure of a sherd's 'size' is to weigh it. However, this is not usually a useful measure because of inter- and intra-vessel variation in wall thickness. The surface area of one face of the sherd is a more useful indicator of size, for our purposes, but this is both awkward and time consuming to measure directly. An index, directly related to this parameter can, however be calculated from the weight and mean thickness of the sherd and as these dimensions are usually recorded in the pottery catalogue, they do not entail any additional work.

To calculate this index it is necessary to assume first that potsherds are approximately tabular solids. The curvature of the sherds contradicts this assumption, but does not introduce significant errors, unless the sherds are small, tightly curved and thick walled. The volume, V, of a tabular body is the product of its thickness, $\mathrm{T}$, with the surface area of one face, $A_{f}$; equation 1 , thus:

$$
\mathrm{V}=\mathrm{T} \times \mathrm{A}_{\mathrm{f}}
$$

The mass (for which, here read weight, W) of a body is related to its volume, $\mathrm{V}$, by its density, $\mathrm{D}$, giving equation 2 thus:

$$
\mathrm{W}=\mathrm{D} \times \mathrm{V}
$$

If we make the reasonable assumption that the density of the pottery from any one site is approximately constant, we can in fact ignore its real value and substitute for this with unity. Thus we can substitute weight, for volume and arrive thereby at an index of sherd size, I, which approximates to the area of the sherd face, $\mathrm{A}_{\mathrm{f}}$ thus;

$$
\mathrm{I}=\mathrm{W} / \mathrm{T}_{\mathrm{m}} \quad \text { (where } \mathrm{T}_{\mathrm{m}}=\text { mean thickness) }
$$

The sherd size index (I) was calculated for all the sherds examined from each site, by dividing the sherd weight by the mean thickness. For each site, the mean and standard deviation of the index was calculated and the range was divided into size classes, each one standard deviation wide, on either side of the mean. The distribution was strongly skewed, the mean occurring in size class 3 of the fourteen size classes, ranging from large (1) to very small (14). However, the size classes are used merely as convenient groupings devoid of any statistical significance and the skewness of the distribution is irrelevant.

\subsubsection{Mammalian fauna: analytical methods}

\section{P Halstead (1987)}

\section{Identification}

Modern comparative specimens were consulted in the collections of the Department of Archaeology at Sheffield University, the Creswell Crags Visitor Centre, that of Dr. Peter Rowley-Conwy and of the author. Distinction between sheep and goat follows Boessneck et al (1964) and Payne (1985); between red and fallow deer follows unpublished notes of $\mathrm{Dr}$ Adrian Lister.

\section{Quantification}

The weaknesses of the traditional alternative systems of quantification (numbers of identified specimens or 'NISP', minimum numbers of individuals or 'MNI') are well documented (eg Klein \& Cruz-Uribe 1984). For most purposes, the basic unit of relevance to archaeozoological analysis is smaller than the individual animal and larger than the (usually fragmentary) individual specimen. For the purposes of this study, therefore, quantification is in terms of the following (Halstead 1985): mandible (cheek tooth row), scapula (articular region), proximal humerus, distal humerus, proximal radius, distal radius, proximal ulna, promixal metacarpal, distal metacarpal, pelvis (acetabular region), proximal femur, distal femur, proximal tibia, distal tibia, astragalus, calcaneum, proximal metatarsal, distal metatarsal, first phalanx, second phalanx, third phalanx; for long bones, the 
proximal and distal units include their respective halves of the shaft. Units from the left-, and right-hand side of the skeleton are counted separately. The phalanges of the fore-, and hind-limb are not distinguished. In calculating the relative abundance of different species, allowance has been made for the greater numbers of foot bones in pig, dog and seal compared with sheep, cow and red deer.

As with MNI, a subjective element with this system of quantification concerns definition of the universe within which actual or notional 'joins' are sought between bone fragments. In the case of Baleshare and Hornish Point, such joins were sought within but not between stratigraphic 'blocks'. A few actual joins between different features within a Block argued against restricting the search to smaller stratigraphic units.

\section{Ageing}

Dental eruption and wear have been recorded for mandibular teeth as follows (codes are recorded in italics in text):

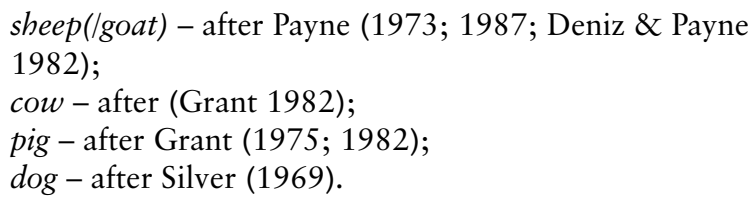

Unfortunately the jaws from Baleshare and Hornish Point are extremely fragmentary and the dental material consists almost exclusively of loose teeth. Detailed consideration of age at death (only attempted for the two commonest species - sheep and cow) concentrates, therefore, on the deciduous mandibular fourth premolar (d4) and the mandibular third molar (M3). For sheep and cow, mandibular $\mathrm{d} 4$ and M3 are very easy to recognise as loose teeth and together they cover the full lifespan of the animal with only a slight overlap (Sheep - Payne 1973, 298 Figure 14; cow - Payne 1984, 79 Figure 11).

Although these $\mathrm{d} 4$ and M3 series could potentially overlap, the virtual absence of heavily worn $\mathrm{d} 4 \mathrm{~s}$ or lightly worn M3s of either sheep or cow argues that the same deaths are not being registered twice. Rather, a bimodal pattern of mortality, separated by the period in which $\mathrm{d} 4$ is shed and M3 erupts, seems apparent for both species. For cattle, the unusual contents of pit [138] are literally the exception that proves the rule: a pair of complete, identically worn mandibles from an individual dying in the interval between the two peaks of mortality confirms advanced wear of $\mathrm{d} 4$ long before M3 comes into wear, viz;

\section{d2 W, d3 W, D4 14L, M1 9A, M2 5A, M3 E/V}

For sheep, a similar conclusion is reached by a more circuitous route: in one mandible each, $\mathrm{d} 4$ at $23 \mathrm{~L}$ and $\mathrm{M} 3$ at $9 \mathrm{~A}$ are associated with $\mathrm{M} 2$ at respectively.

The remaining mandibular teeth are less distinctive than d4 or M3 and provide only a limited check on these data: the early mortality peaks are well represented however, by unworn or lightly worn specimens of $\mathrm{d} 2$ and $\mathrm{d} 3$ (cow) and lightly worn specimens (probably) of M1 (Sheep), while the second mortality peak is well attested for both species by heavily worn specimens of M1 and M2.

For postcranial bones, a 'neonatal' category was recognised, which may include foetal specimens, but largely refers to lambs/calves estimated (by comparison with modern material in the Creswell Crags collection) at 0-4 (-6) weeks old. Bones from [098] (Block 7) and [126] (Block 11) at Baleshare provide a limited amount of internal evidence for the relationship between the neonatal category of postcranial bones and dental development. In [098], the remains of a (large) 'neonatal' calf were associated with a pair of mandibles at the following stage of eruption/wear;

\section{d2 1/2, d3 W, d4 6L, M1 E/V}

In [126], the remains of two neonatal lambs were associated with a pair of mandibles at the following stage of eruption/wear;

$$
\text { d2 E, d3 E, d4 E }
$$

For material older than neonatal, the state of epiphyseal development was recorded as 'unfused', 'fusing' (treated for purposes of analysis as 'unfused'), 'fused' or 'indeterminate'. Ages of epiphyseal fusion are taken from Silver (1969). The two juvenile cattle in pits [138] and [481] provide a limited amount of internal evidence (broadly compatible with Silver) for the rate of epiphyseal fusion;

Pit [138]: proximal radius, axis fused; pelvis (acetabulum), proximal second phalanx fusing; proximal first phalanx, distal metacarpal, distal metatarsal, distal tibia, distal radius, proximal and distal femur, proximal tibia unfused.

Pit [481]: proximal second phalanx fused (just); distal humerus, atlas fusing; proximal first phalanx, distal metacarpal, distal metatarsal, distal tibia, calcaneum, proximal and distal femur unfused.

Note that a distinction between 'neonatal' and 'older' (than neonatal) is possible for all postcranial material. Within the 'older' category, however, a distinction between 'unfused' and 'fused' is possible for only a minority of specimens; also unfused specimens are more vulnerable to attrition than fused and so are more likely to be destroyed or rendered 'indeterminate'. Finally, an unfused specimen indicates an animal which died before the relevant fusion stage but, because each of the fusion stages defined in Table 13 covers a period of several months, the successive episodes of mortality are aged far less accurately than with dental evidence.

\section{Sexing}

There are too few well preserved, mature postcranial elements to determine adult sex ratios on metrical grounds, but a few pelves could be sexed on morphological grounds following Boessneck et al (1964) for sheep and Grigson (1982) for cattle.

\section{Butchery, burning, gnawing and fragmentation}

Cut marks were, where possible, assigned to skinning, dismembering or filleting, following Binford (1981). Evidence of gnawing by dogs and of burning were recorded as 'present' or 'absent'. As regards fragmentation, bones were recorded as 'whole' (including unfused but otherwise complete epiphyses or diaphyses), 'new break' (ie broken during/after excavation) or 'old break'. In two deposits, fragmentation has been attributed to marrow extraction following Binford (1981). 


\subsubsection{Fish bone: methodology and analysis}

\section{A Jones (1987)}

Despite the fragmentary nature of the remains, relatively few of the bones (fifteen from Baleshare, eleven from Hornish Point) were unidentifiable. However, it has not proved possible to assign all the identified remains to species; some were attributed to family, or broader taxonomic group.

All but three of the bones were retrieved by sieving excavated shell-sand deposits on $5 \mathrm{~mm}$ sieves on-site. All bone (mammal, bird and fish) was collected from the sieves and fish bone later sorted from other kinds of bone was submitted to the author for identification and comment. Three small gadid bones were recovered by flotation and provide the main evidence for the exploitation of small fish. The remains were identified by comparing the ancient specimens with specially prepared modern material forming the collection of fish skeletons at the Environmental Archaeology Unit, (EAU), University of York. Mineralized vertebral centra of cartilaginous fishes were identified by using X-ray photographs as well as surface features.

$5 \mathrm{~mm}$ aperture meshes were used in the sieves to recover the bulk of the fish remains, as a result it is very likely that remains of several species of small-boned fishes, which were present in the deposits at the time of excavation, passed through these sieves. These are, of course, retained in the products of the wet-sieving and flotation samples, but were not subjected to analysis.

\subsubsection{Charred plant remains: sampling, recovery and analysis}

G Jones (1987)

Charred plant remains were recovered in three ways:

i) A $0.5 \mathrm{~m}$ strip of each context was sieved using a $5 \mathrm{~mm}$ mesh sieve. These samples have not been studied.

ii) A $20 \mathrm{~kg}$ sample of deposit was collected from each context. This was first sieved as above and the remainder of the sample was processed using a Cambridge froth flotation machine (Jarman et al 1972). The material was retrieved in $1 \mathrm{~mm}$ and 350 micron sieves.

iii) Samples (of unknown volume) were processed as above but without the addition of chemicals. These were subsequently used for radiocarbon dating.

Charred plant material was separated from the rest of the flots from the $1 \mathrm{~mm}$ sieves. Identifiable fragments were then sorted microscopically $($ at $\times 6)$ out of the charred material. The flots from the $350 \mathrm{~mm}$ sieve have not been studied and to do so in their present unsorted state would take a considerable amount of time (even if study was restricted to those samples rich in remains from the coarse sieve). They would provide information on the representation of wild species with seeds smaller than $1 \mathrm{~mm}$ but, given the difficulty of distinguishing weeds of cultivation from wild plants brought in with fuel (Jones, below) such information is of limited value.
Identifications were made by comparison with modern reference material. For the identification of Carex nutlets, descriptions and illustrations provided by Nilsson and Helmqvist (1967) and Berggren (1969) were also used. The nomenclature of species follows Flora Europaea (Tutin et al 1964, 80). Samples from 353 different contexts were examined (176 from Baleshare and 177 from Hornish Point). All but eleven of these (seven from Baleshare and four from Hornish Point) produced some identifiable charred remains.

\subsubsection{Pollen: sampling, preparation and methodology}

\section{A Mannion \& S Moseley (1986)}

\section{Field methods}

In the absence of a boat, a detailed examination of the stratigraphy of Loch Scolpaig was impossible but the well developed hydrosere facilitated access on foot to all but the most central parts of the basin. Little variation in the stratigraphy across the basin was recorded and a core was collected with a Russian sampler (Jowsey 1966) from a position slightly south-west of centre where the sediment sequence was thickest. After extrusion in the field the cores were placed on plastic drainpipe, wrapped in cling film, aluminium foil and polythene and stored in an incubator at $3{ }^{\circ} \mathrm{C}$ on return to the laboratory.

At the Balelone Farm site, the deepest peat section in the area, sampling was carried out by digging a pit and extracting vertical sections of peat in metre-length metal monolith boxes. A wrapping procedure similar to that for the Loch Scolpaig samples was employed due to their bulk; storage at Reading was in a freezer. Prior to freezing samples from 75 $\mathrm{cm}, 150 \mathrm{~cm}, 225 \mathrm{~cm}$ and $300 \mathrm{~cm}$ (the base of the peat) were extracted for radiocarbon dating at SURRC (Chapter 19).

\section{Sub-sampling}

Sub-samples from the Loch Scolpaig core were extracted at approximately $5 \mathrm{~cm}$ intervals and from the Balelone core at approximately $10 \mathrm{~cm}$ intervals for pollen analysis. After cleaning, $1 \mathrm{~cm}^{3}$ was extracted using a displacement method (Bonny 1972). A $5 \mathrm{~cm}^{3}$ measuring cylinder was filled to the 3 $\mathrm{cm}^{3}$ level with distilled water. Crumbs of the sediment were then added until the meniscus reached $4 \mathrm{~cm}^{3}$ after which the sample was washed into a polypropylene centrifuge tube. Three Lycopodium spore tablets were added and allowed to dissolve. The samples were then centrifuged.

\section{Chemical processing}

i) Removal of carbonates: circa $10 \mathrm{ml}$ of $10 \% \mathrm{HCL}$ were added and after the reaction had ceased the samples were centrifuged and washed in distilled water.

ii) Disaggregation and removal of humic acids : circa $10 \mathrm{ml}$ of $10 \% \mathrm{Na} \mathrm{OH}$ were added to each sample and stirred. The samples were then heated at $110-120{ }^{\circ} \mathrm{C}$ for 20 minutes with the occasional addition of distilled water to prevent destruction of pollen grains/spores which may occur if the $\mathrm{NaOH}$ becomes too concentrated. After washing and centrifuging, further washes were carried out until the supernatant liquid was clear. 
iii) Removal of coarse material: The samples were washed through 180 micron sieves into $100 \mathrm{ml}$ beakers and washed with distilled water. They were then retrieved by centrifuging.

iv) Removal of mineral matter: A few drops of distilled water were added to the samples and after re-suspension $10 \mathrm{ml}$ of concentrated HF were added and left for three days. After centrifuging $10 \mathrm{ml}$ of $10 \%$ HCL were added, heated for 5 minutes, centrifuged and washed in distilled water.

v) Removal of cellulose: To each sample $10 \mathrm{ml}$ of glacial acetic acid were added, the sample resuspended, centrifuged and decanted. Some $10 \mathrm{ml}$ of an acetolysis mixture (freshly made 9:1 mixture of acetic anhydride and concentrated sulphuric acid) were added to each sample and heated for 10 minutes. After centrifuging the samples were washed in glacial acetic acid and then in distilled water.

vi) Mounting: A few drops of water and $10 \% \mathrm{NaOH}$ and a drop of safranin stain were added to each sample. After centrifuging any water remaining was evaporated off by gentle heating. A small amount of glycerol jelly was then added to each sample. One drop of the suspension was then placed on a warmed labelled microscope slide and a cover slip placed on top. Two slides were made up for each sample.

vii) Counting: The coverslip of each slide was traversed longitudinally at $1 \mathrm{~mm}$ intervals using a Leitz Laborlux microscope at $\times 400$ magnification or $\times 1000$ for difficult grains. Pollen and spore types were identified using keys and a pollen reference collection. A pollen sum of between 490 and 510 was counted for identifiable grains and indeterminate grains are retained in a separate group outside the pollen sum.

\subsubsection{Snails: methodology}

\section{N Thew (1987)}

\section{Sampling}

Previous studies of mollusca from calcareous coastal sand locations have employed column sampling. Though adequate for essentially natural deposits or for sites with thin, extensive occupation-horizons such as Northton, Harris (Evans 1971; 1972; 1979), column samples are not suitable for stratigrapically complex sites.

Bulk sampling of individual contexts was employed on the sites studied here. Standard bulk samples of approximately $20 \mathrm{~kg}$ were taken from every context which contained sufficient material. Larger samples, taken to collect material for radiocarbon dating occasionally yielded snail shells also. There are a few cases of inconsistencies between faunas from samples from these two sources. It should be noted that snail studies were not envisaged when the sampling strategy was evolved. Thus, as snail assemblages, those retrieved proved at times less than perfect.

\section{Sample processing}

Previous studies from calcareous sands have yielded minimum counts of fifty individuals from 1.5 or $2.0 \mathrm{~kg}$ samples, occasionally reaching maxima of 5,000 or more (Evans 1971; Spencer 1975; Evans \& Spencer 1977; Evans \& Vaughan 1983). In the sites considered here, $20 \mathrm{~kg}$ flotation samples produced between five and 500 specimens. This is largely due to the methods of sample processing employed on these sites.

Comparison with previous studies from coastal, calcareous sand deposits suggests that only $1-10 \%$ of the snail fragments present in a sample will float. Fragile and larger species such as Vitreea, Oxyloma pfeifferi and Vitrina pellucida are more likely to be fragmented and sink. The large land snail Cepaea hortensis is often only recovered as fragments and here was represented only by complete specimens caught in the $5 \mathrm{~mm}$ sieve. Fortunately most of the species recorded from previous studies have relatively small mouths and would probably be able to float even if some of the outer whorls had broken away. It is hoped though, that apart from these biases, that the recovered shells are representative of the original molluscan assemblages of flotation samples.

The restricted number of species from the study sites implies that extreme conditions with low diversity and poverty of habitats prevailed (cf Walden 1981, 370). This seems to have been a consequence of human activity. Comparison with modern studies of faunas on grazed machair in the Orkneys (Evans \& Vaughan 1983) demonstrate their similarity with those from Baleshare, Balelone and Hornish Point.

\section{Taphonomy of snails}

Factors affecting the numbers of molluscs present within a context include original population size, rates of deposition (slower deposition allows more molluscs to accumulate), degree of stability (encourages richer vegetation and molluscan faunas) and preservation. The snails were well preserved throughout though some staining was observed. The mechanics of deposition appear to have been largely through burial by windblown sand, or through incorporation in a deepening turf horizon. Mechanical weathering may therefore reflect attrition by human or animal activity. Thus the majority of numerical variations within molluscan assemblages are attributable to differences in the original populations and the rate of layer accumulation.

Even allowing for the small numbers recovered by flotation the original populations appear to have been restricted both in numbers and species diversity especially in comparison with published sites. Northton, and Buckquoy (Evans \& Spencer 1977) returned twenty-three and twenty non-wet species respectively, and, generally, more than twelve species indicate a high degree of stability and shade. Species counts of fifteen and over often indicate true shade, perhaps rich, long, very stable grassland or perhaps open woodland in the cases of Northton and Buckquoy. In only two instances do the counts of non-wet species equal or exceed twelve, in the present study. At Baleshare, one context produced twelve while at Hornish Point one context returned fourteen species. The assemblages from these two sites, together with those from Newtonferry and Balelone, on the criterion of species frequency, indicate very open environments, with almost no indication of true shade. 


\section{Identification and quantification}

Identification of terrestrial snails was undertaken using the Sheffield University reference collection, guides by Evans (1972) and Kerney \& Cameron (1979), and reference material held by the author. The specimen of Columella edentula was identified using the Columella guide by Paul (1975b). Species identification for Oxychilus, Vertigo and Vitrea were checked by Dr R P Reece.

Hybridization can sometimes take place between the two closely related Cochlicopa species (Paul 1975a), Cochlicopa lubrica and C.lubricella and this seems to have happened at Hornish Point and Baleshare where a continuum between the two species was observed. Samples from Hornish Point were speciated but this was undertaken in few of the Baleshare contexts. Therefore the species counts are under-represented by a value of one at Baleshare. Normally the ratio between the incidences of the two species is used as an environmental indicator, but this was not practicable here given the extensive hybridisation. Banding patters of Cepaea species (Cain et al 1969) were not studied, as their environmental significance is still unclear.

\section{Problems of interpretation}

Interpretation was affected by the low numbers recovered from each sample and the bias against certain species caused by flotation. However, the three species most likely to have been affected, Vitrina, Oxyloma and Cepaea, were only present in small numbers in previously published comparable studies.

The assemblages were characterised by the presence of variable numbers of a few dominant species (mainly, Pupilla muscorum, Cochlicopa spp, and Vallonia spp), and the presence or absence of small numbers of several other species, designated, indicator species. The latter included wet species indicative of flooding. A second indicator group included the Helicelis snails, including Cepaea. The third indicator group included species newly arrived in the area in the later Prehistoric period, such as Helicella itala and Cochlicella acuta. A further indicator group consisted of the Zonited group plus Vitrina pellucida, which being omnivores, can fluctuate independently, together with Lauria cylindraea and Vertigo pygmaea.

The interpretation of the assemblages retrieved from the sites examined here is based on fluctuations in relatively low counts of a restricted number of species. It is possible to generalise and consider that the assemblages as a whole represent open grassy landscape exhibiting variation in stability, dampness and degree of anthropogenically deposited organic refuse. In addition, the fluctuations between the faunas from individual contexts are interpreted as representative of variations in the micro-environments.

Small numbers of wet species have been found in contexts from all four sites, with a few specimens of freshwater aquatic snails. Baleshare, Hornish Point and Newtonferry are located on low-lying flat coastal machair plains liable to episodic winter flooding due to rising water tables (Ritchie 1979). This could account for wet species co-occurring with faunas suggestive of open, relatively dry environments. Consequently the significance of the wet species has been considered separately from the general interpretation of local environment.

Evans $(1972 ; 1979)$ has shown that in periods of surface stability the fossil molluscan fauna represent the immediate local environment while, during periods of surface instability, the molluscs trapped in a sandy layer could represent a much wider catchment area. This problem is reduced, in the present instance, by the large numbers of samples, spatially separated across the sites, which were examined.

Despite the sources of potential bias described above, it is clear from the data that fluctuations among the dominant species seem, in the main, to reflect variations in the natural environment. Variations in certain of the indicator species seems to reflect patterns of human land-use.

The assemblages were classified into faunal associations on the basis of the relative proportions of the dominant species and the presence, or absence, of indicator species. The faunal associations proved adequate for the analysis of material from Baleshare. However, the complexity of the material from Hornish Point and Newtonferry required the construction of a faunal matrix, with variations in the dominant species mapped on one axis and the presence or absence of the indicator species on the other.

Examination of the distribution of the faunal associations indicated a need to sub-divide many of the Blocks of contexts, originally grouped on archaeological grounds. These sub-blocks contained faunal associations which reflected local environmental variations interpretable in terms of degrees of dampness or dryness, degrees of exposure or stability and the extent of middening.

In some cases, however, the archaeological evidence for middening conflicted with the snail evidence. These apparent conflicts may have arisen as a consequence of the nature of organic material added to the soil (fresh or already decomposed), the rapidity of sediment accumulation (fresh waste buried before colonisation) and possibly by discrepancies between samples taken from the base or surface of contexts reflecting not the environment during accumulation of the contexts themselves, so much as the environment before or after a context was formed.

\section{Interpretation}

The interpretation of molluscan fauna from archaeological deposits differs from that fauna from natural sediments in that they are couched in terms of anthropogenic interference, rather than environmental development. Ploughing, animal grazing and penning, and the disposal of different types of domestic rubbish create varying micro-environments superimposed upon the natural environment. Before these can be detected, however, the impact of the natural environment must be identified and discounted. Biological succession, climatic change and the height of the local water table have a significant affect on snail faunas. Aspect, relative to prevailing wind and the degree of isolation of the area, must also be considered, together with the nature of the local bedrock and soils which affect drainage, vegetation and the availability of standing rocks for rupestral snail species. When the variation which can be attributed to these factors has been eliminated, that which remains is due to human activity.

Layers are the products of different processes including, for these sites, the accumulation of wind blown sand, deepening turf horizons incorporating organic material, the deposition of organics matter by grazing animals and the dumping of various types of domestic waste by the inhabitants of the archaeological site. Layer boundaries must therefore represent interruptions to individual depositional processes. 
It is important to remember that most molluscs live on or just below the surface. Therefore, molluscan faunas within layers may indicate that deposition was gradual, allowing the surface fauna to accumulate within the layer. Poor molluscan faunas within layers would, in these circumstances, indicate rapid sedimentation. In natural conditions such deposits would be interpreted in terms of a rapid build up of wind-blown sand with a restricted sparse herbaceous vegetation containing grass species adapted to unstable accumulating conditions. Thus boundaries observed within a deepening turf horizon, could mark interruptions to the depositional process caused by factors such as overgrazing, or a series of severe frosts or droughts. A diffuse change to a sandier layer could merely mark the onset of more rapid sand aggregation. These changes, however, should be detectable by a continuous molluscan record, varying in abundance, and diversity.

The depositional mechanics of dumping and ploughing are somewhat more complicated. If small deposits are regularly dumped, thin spreads will be incorporated into a single layer with a continuous molluscan assemblage reflecting the nature of the surfaces of the spread material. Larger deposits of dumped material form discrete layers with molluscan faunas and herbaceous floras restricted to the surfaces of these layers. In such deposits, few, if any molluscs should occur within the layer. The surface faunas and floras will reflect not only the nature of the dumped material below but also the amount of time that elapses before further dumping occurs or before natural sedimentation begins.

Erosion and redeposition of deposits, whether by human or natural agencies, can cause problems in the interpretation of the molluscan faunas as eroded material can either be lost completely, or redeposited elsewhere on site.

Ploughing is difficult to detect in the molluscan faunas. It mimics natural conditions of instability, and the molluscan faunas reflect the vegetation cover and surface conditions that develop after ploughing. If the fallow period between ploughing episodes is great the molluscan faunas indicate relatively stable grass cover. With shorter intervals between ploughing the fauna indicate greater instability. Ploughing damages and mixes the faunas of all the fallow episodes thus producing an average fauna.

\subsubsection{Phytolith analysis: methodology}

\section{A Powers (1987)}

\section{Processing}

The samples were prepared using the techniques described in Powers and Gilbertson (1987). The technique used simpler, cheaper and less dangerous substances than are commonly used (ibid). In brief, one gram of each sample was disaggregated in hydrochloric acid, centrifuged, desiccated and burnt in alchohol. To the resultant ash a proportion of Lycopodium tracer aliquot was introduced to facilitate 'absolute' phytolith studies in the manner pioneered for palynology by Stockmarr (1971).

\section{Counting}

In general two hundred and fifty phytoliths plus marker grains were counted at a magnification of $\times 1000$ under phase contrast microscopy, after which point new phytolith morphotypes were found to be encountered only rarely (Powers et al 1986). This process took between 1.5 and 16.9 hours per sample. However, the numbers of phytoliths recovered from the modern windblown sands and dune sediments were so very low, that is was necessary to resort to employing 'time-catch' methods to compare the numbers of phytoliths noted per sample, per standard 60 minute search period (see Powers et al 1986; Powers \& Gilbertson 1987).

\section{Identification}

The phytoliths recovered were counted and listed according to their shape. A simple but robust classification of phytolith types was employed (Figure 84) which is based on three criteria (see Powers et al 1989);

i) the overall shape of the phytoliths (eg rods or dumbells)

ii) overall size (small, medium, large)

iii) texture (coarse, fine)

\section{Modern analogues}

The examination and interpretation of prehistoric phytolith assemblages on the basis of the three specific questions outlined above, included several assumptions or expectations which were based on observed fact or logical expectation. Namely, that in respect of the first (and indirectly the second) question posed by the excavator the expectation was that a 'high' concentration of phytoliths per unit of sediment would suggest a stable layer or soil horizon and that a 'low' concentration would suggest an accumulation of blown sand in a locally 'unstable' situation.

The underlying assumptions derive from the oft-observed relationships between sand dune mobility/instability, vegetation abundance and soil development (see Ranwell 1972; Pethick 1983; Salisbury 1952).

The aforementioned sources suggest that per standard unit of sediment, the hypothesised 'stable' layers will contain a higher frequency of phytoliths than non-stabilised layers as a result of;

i) the greater abundance of vegetation and/or

ii) the greater input of plant debris (natural or anthropogenic sequences) which are thought to be associated with the 'stable' situation and/or

iii) the lack of erosion and re-working associated with more stable, well vegetated soils which also ought to lead to higher phytolith frequencies per standard volume of sediment.

To test the basic assumption that high frequencies of phytoliths are equated with stabilised horizons (and the reverse) a series of modern samples were collected by John Barber from the machair of Links of Noltland, Westray, Orkney. Twenty-five samples of free windblown sands were collected, together with twenty-four samples from a transect stretching inland from the dune foreshore and incorporating non-vegetated, marram and herb covered sands (see Powers et al 1986; 1989) 
An unexpected paucity of phytoliths from sediments was found on the sheep grazed, vegetated surface at Noltland (between two and fifteen phytoliths recovered per 60 minute count [see Powers et al 1986; 1989 for full results]). This prompted the acquisition of a second set of modern 'machair-type' samples, this time from the Ainsdale National Nature Reserve on Merseyside (ibid).

It had been conjectured that on Westray the presence of large numbers of grazing ruminants (eg sheep) could have been the reason for the general absence of phytoliths from the vegetated surface sediments. There has been no ruminant grazing or other non-scientific access in the Ainsdale sand dunes for several decades. The effects of non-ruminant (rabbit) grazing on the phytolith suites recovered from machair environments is as yet unknown.

The Ainsdale results however, also indicated a marked absence of phytoliths from modern vegetated dune (between seven and twenty-four phytoliths recovered during a $60 \mathrm{~min}-$ ute count (see Powers et al 1986; 1989 for full results). The sub-surface samples were also practically devoid of phytoliths dismissing any hypothesis that the phytoliths might have been washed down the profile.

The absence of any significant numbers of phytoliths from both the modern analogue sites resulted in abandonment of the anticipated simple equation of 'many phytoliths $=$ stable vegetated horizon' and its corollary 'few phytoliths $=$ unstable poorly vegetated dune surface'. Unfortunately, this meant that it was not possible to address either of the first two questions posed by the excavator other than to answer in the negative. The data produced no clear differences in the total abundance of phytoliths, all samples produced extremely low counts and because of this it was impractical to make any statement about possible differences in phytolith suite composition.

In the event, only the third question posed by the excavator concerning the nature of the organic-rich layers found in the archaeological sites could be addressed. That is not to say however, that other interesting facts did not result from the analyses of the Baleshare and Hornish Point samples.

\subsubsection{Diatom analysis: preparation and methods}

\section{A Mannion \& S Moseley (1987)}

Sub-samples from the core were extracted at approximately $0.30 \mathrm{~m}$ intervals and prepared for diatom counting following the recommendations of Battarbee (1979) and summarised in Mannion (1982) viz for each sample:

i) Approximately $1 \mathrm{cc}$ of sediment was washed through a sieve of $0.5 \mathrm{~mm}$ mesh with distilled water to remove coarse mineral matter.

ii) The residue was then heated gently in dilute hydrochloric acid to remove carbonates and iron compounds.

iii) After washing in distilled water the residue was oxidised by gently heating in 30\% hydrogen peroxide solution and washed again. iv) Since a considerable amount of mineral material remained floatation in zinc bromide solution was carried out at least twice involving centrifugation at 2500-3000 rpm for approximately 5 minutes and the supernatant, containing the diatoms, was collected. The diatoms were recovered from this liquid by diluting with distilled water and centrifuging.

$v$ ) The residue was diluted in $2 \mathrm{mls}$ of distilled water to achieve adequate dilution of diatom frustules

vi) Approximately $0.2 \mathrm{ml}$ of the suspension was dropped onto a coverslip, placed on a slide warming plate and the water allowed to evaporate under gentle heat.

vii) The coverslip was mounted on a microscope slide using commercially available diatom mountant.

viii) Approximately 600 diatom frustules were counted for each sample using oil immersion objectives and magnification of x1000 on a Leitz Ortho-Lux microscope. Identifications were verified using keys such as Hustedt (1930), Patrick and Reimer (1966) and Barber and Haworth (1981). The identification of Fragilaria virescens ver subsalina was kindly undertaken by $\mathrm{Mr}$ Carter.

\subsection{I0 Investigation of lake sediments; methodology}

K Hirons (1986)

\section{Sediment characterisation}

Sub-samples, $1 \mathrm{~cm}$ thick, were collected at $1 \mathrm{~cm}$ intervals using the cut-syringe method (Fletcher \& Chapman 1974), for the determination of fresh density. The following sediment parameters were measured on each centimetre sample; water loss on drying overnight at $105-110^{\circ} \mathrm{C}$; estimated organic content by loss-on-ignition at $550^{\circ} \mathrm{C}$ for 8 hours (LOI); estimated carbonate content by loss-on-ignition at $950{ }^{\circ} \mathrm{C}$ for 8 hours (HT-LOI) (Dean 1974). The $\mathrm{pH}$ of the wet sediment was determined by pressing the electrode bulb directly into the core at $1 \mathrm{~cm}$ intervals (cf Digerfeldt 1972).

\section{Pollen analysis}

Three further sub-samples, $1 \mathrm{~cm}$ thick, were collected for pollen analysis and two tablets of Lycopodium clavatum spores were added to allow the calculation of fossil pollen concentrations (Benninghoff 1962: Stockmarr 1971). The samples were prepared for pollen analysis using $\mathrm{HF}$, acetolysis mixture and $\mathrm{HCl}$. They were then mounted, unstained, in silicone fluid. Preliminary pollen counts of between 100-300 were undertaken on the samples. Outline percentage pollen diagrams were prepared, using a total land-pollen sum. A summary diagram showing tree, shrub (including Coryloid) and herb pollen as percentages of the pollen sum was also prepared. Pollen of aquatics and spores were included in the diagrams, calculated as percentages of total pollen outside the pollen sum. Charcoal fragments encountered in the pollen preparations were also counted and these are represented as a percentage of total pollen. A sum- 
mary pollen concentration diagram of selected taxa was prepared for Askernish.

\section{Sediment chemistry and mineralogy}

Sample digestion for total elemental analysis was by an adaptation of the acid-pressure decomposition method of Bernas (1978). $0.100 \mathrm{gm}$ of dried and ground $(<63)$ sediment was weighted into a $20 \mathrm{ml}$ Teflon 'bomb' with $6 \mathrm{~cm}$ of $\mathrm{HF}$ and 1 $\mathrm{cm}$ of aqua regia (HNO + HCL) and heated to $100{ }^{\circ} \mathrm{C}$ for one hour. Concentrations of NA, K, Mg and CA were determined by atomic absorption spectrophotometry and ex-

pressed as percentages of total sediment (dry weight) and as percentages of the mineral matter fraction (dry weight, cf Mackereth 1966).

Samples for mineralogical investigation were ground to pass a $63 \mathrm{mu}$ sieve, digested in $\mathrm{HO}$ to remove organic matter and then washed and dried at room temperature. For further analysis of the clay fraction, major cations and carbonates were by shaking with ammonium acetate $(\mathrm{pH} 4.4)$ and the $<2$ fraction was obtained by dispersing in water with an ultrasonic probe and settling (Hutchison 1974). The supernatant containing the clay fraction was pipetted off and dried in a microwave oven for investigation by differential thermal analysis (DTA). 


\section{CHAPTER 10: THE ARTEFACT ASSEMBLAGES}

\section{I THE COARSE POTTERY FROM BALELONE, BALESHARE,} HORNISH POINT, SOUTH GLENDALE AND NEWTONFERRY

\author{
A MacSween (1992)
}

(based on contributions from J Barber, E Campbell, G Collins, A Lane \& D Lehane)

\section{I0.I.I Introduction}

\section{J Barber}

When the specialist materials were distributed from these sites, it was decided not to inform the specialists of the phasing, nor indeed the relative chronological position of the several materials. The point of this was simply that of providing an 'objective' test of their conclusions, particularly where those conclusions contained some element of seriation. The test was the simple one of comparing the groups or categories determined by the specialists with the actual site stratification to see whether the defined groups occurred in chronologically coherent blocks of strata.

Attribute analysis was the preferred methodology of lithic analysis at that time and seemed to be achieving much in the way of limiting the operation of preconception in the characterisation and nomenclature of lithic artefacts. It was decided to undertake an attribute analysis of the pottery from the Hebridean sites and Ms D Lehane and Ms L Crone duly carried out this work.

Characterisation of the assemblage was then based on those recorded characteristics which reflect the ceramic technology of the assemblage. This generated groups of sherds, Pottery Types 1 and 8, and the physical distribution of the sherds of these groups throughout the recorded sections were then examined. There was no detectable chronological coherence to their distributions. For example, at Baleshare Type 1 occurs in all but nine of the site's twenty-eight Blocks and is present from the earliest to the latest deposits, a span of some 1300 radiocarbon years. Type 8 , in contrast occurs in only four Blocks, dating to a span of over 800 radiocarbon years and widely separated across the site. Furthermore, it is only represented by body sherds in two of the Blocks and only by rim, base and decorated sherds in the other two.

It seemed so improbable, therefore, that these groups represent a categorisation that had any relevance to the occupants of these sites that a further study was commissioned from Dr A Lane, who has considerable experience of Hebridean pottery studies. Only the Balelone material was available at this time and only the rim, base and decorated sherds were studied. Albeit the chronology of the site at Balelone is a very short one, the proposed types of pottery did not reflect the order of their stratigraphic occurrence.

From this it was concluded that ceramic studies of Hebridean material have not yet reached the stage where the pottery taxonomy is of chronological significance. Indeed, one might venture the opinion that we have yet to achieve a meaningful taxonomy of the ceramics of the Hebrides. The possible reasons for this are discussed further below.

The final pottery report, by Dr A MacSween, was prepared with full access to the stratigraphic and dating evidence and, presumably for this reason, appears a more successful categorisation than either of its two progenitors. However, its success does not in any way weaken the conclusion that we still do not have a successful taxonomy of Hebridean late prehistoric pottery.

\subsubsection{Balelone: summary of the assemblage}

The assemblage from Balelone comprises circa 1500 sherds, sixty-eight of which are decorated, and includes ninety-one rim sherds and fifty-four basal sherds. Apart from two sherds which were identified as coming from Beakers, the assemblage can be attributed to the Iron Age. Where method of manufacture can be determined, the pottery is all coil constructed. Several sherds have a smooth surface which contrasts with the heavily-gritted body. This seems to have been produced by wet-wiping and/or burnishing, rather than by slipping, the process having drawn the plates of mica in the clay to the surface.

\section{Morphology}

Although it was not possible to reconstruct any vessels from Balelone, it appears that all the vessels were flat-based and that some were large, straight-sided bucket forms. Most of the basal sherds are too fragmentary to give much indication of profile, but where the basal angle could be determined, the vessels were apparently steep-walled.

Rims were plain, simple in $70 \%$ of sherds, with everted rims accounting for the remaining 30\%. Where diameter could be measured (67 examples), 55.3\% were under 180 $\mathrm{mm}$ in external diameter and $44.7 \%$ were $180 \mathrm{~mm}$ or over.

\section{Decoration}

The sherds were decorated using a variety of techniques; incised, applied, stabbed, impressed and stamped decoration was represented. Some vessels were decorated with a cordon, either a plain cordon, or one which was decorated with incised oblique or vertical lines, or finger-marking. Applied bosses were also noted. Incised decoration took a variety of forms - random incisions, parallel or single lines, 'ladder decoration', and zig-zagging lines. Stab and stab-and-drag decoration was also used, as well as decoration made by impressing either the finger-tip or a ring. The impressed decoration usually took the form of a row of motifs around the upper part of a vessel.

Often the sherds were too small to determine whether a motif was part of the more complex decoration which usually took the form of a cordon surrounding the shoulder of the vessel, with incised decoration above (Mackie's Balevullin vases [1974b, fig 20]). One vessel (Figure 74a) was decorated with a cordon incised with oblique lines, above which was incised decoration comprising an incised zig-zag line with stabbed dots and ring impressions below. A similarly decorated vessel was recovered from a context in Block 7 (Find $710 / 21$ ), while in the same Block was a vessel decorated with a finger-marked cordon with zig-zagging incised ladder decoration above. This ladder decoration was combined with ring impressions on another vessel (Figure 74b \& Plate 30). 


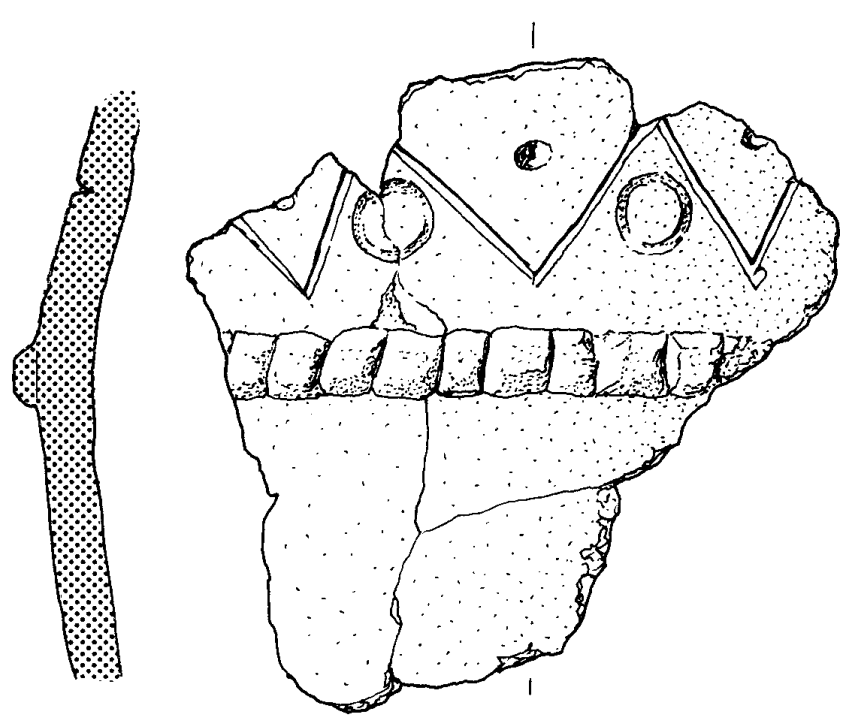

a

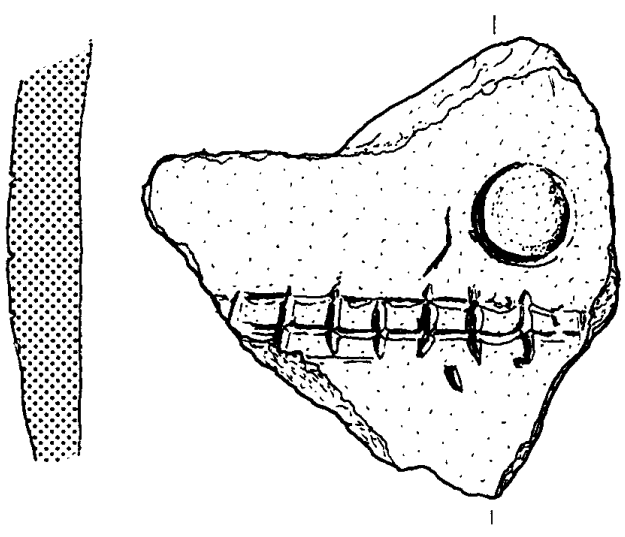

b

Figure 74. Balelone: pottery. a) Find 329/1, Block 3 (Scale 1:1). b) Finds 21/2, Block 5 (Scale 1:1)

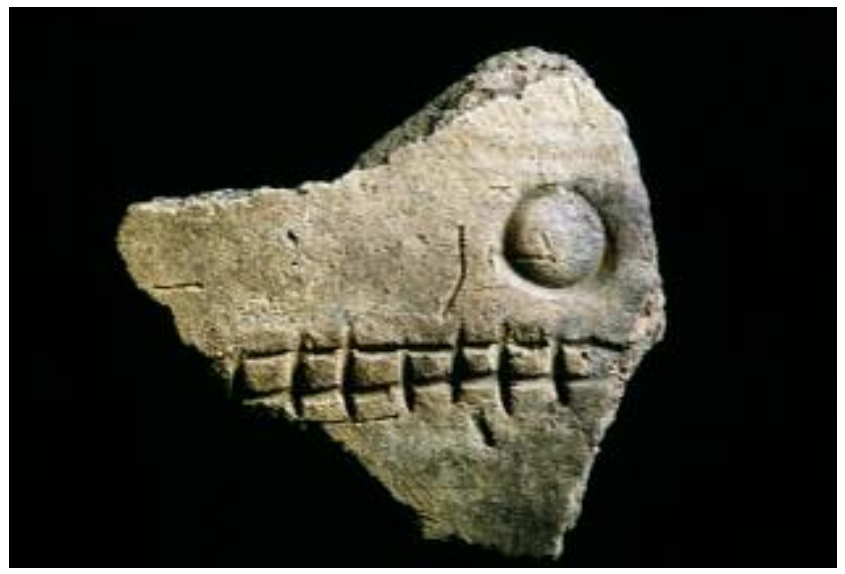

Plate 30. Sherd from Balelone bearing impressed, ring-headed pin decoration
Fabric

Four main fabrics were identified in the Balelone assemblage by examination under a binocular microscope;

Fabric 1: quartz, amphibole \& rock fragments

Fabric 2: quartz, amphibole, rock fragments, organics \& mica

Fabric 3: quartz, amphibole, rock fragments \& mica

Fabric 4: quartz, amphibole, rock fragments $\&$ organics

The grits are angular to sub-angular, but show some evidence of chemical weathering. They are poorly sorted with a size range $1 \mathrm{~mm}$ to $2 \mathrm{~mm}$ and occasionally up to $5 \mathrm{~mm}$. Most of the sherds have a high proportion of inclusions.

The rock fragments identified are of a coarse-grained, quartz-amphibole rock, sometimes including mica. The organic remains are short lengths $(10-20 \mathrm{~mm})$ of plain-sectioned stems of diameter $0.3 \mathrm{~mm}$, identified as moorland grasses such as festuca sp. It is possible that sheep dung was used to temper the pottery. Occasional rounded grains of shell sand are found in all fabrics. The mineralogy is consistent with a local provenance in North Uist, though similar minerals can be found throughout the Outer Hebrides. The local rocks are quartz-amphibole gneisses, in places migmatised and with granitic intrusions (Dearnley 1962). The presence of shell sand argues for production in the machair of the western coasts of the islands. The angularity of the fragments indicates little transport of material subsequent to the breakdown of the rock structure, and suggests a locally-derived glacial or colluvial deposit rather than deliberately crushed rock. This type of deposit would vary in composition over a short distance, making it impossible to be sure if the variation in fabric is due to natural variation or deliberate selection of particular clays.

Certain forms and decoration were seen to relate more to Fabric 1 than to Fabric 2 (there were too few sherds of Fabrics 3 and 4 to make useful comment). The sherds made from Fabric 1 included undecorated bucket-shaped pots, smaller undecorated jar forms and Balevullin vases. The Fabric 1 pottery has the majority of slashed-cordon-decorated sherds in the assemblage, and only six finger-marked cordons. The remainder of the decoration is simple with only a few complex patterns comprising more than one motif.

Fabric 2 has straight-sided vessels, but in this case decorated with fingertip marks on the rim top. The bodysherds are predominantly decorated with fingermarked cordons rather than slashed cordons, and some bases have fingermarking in the interior.

Certain forms of decoration are common to both fabrics. The complex decoration of the fabric 1 Balevullin jar (Figure 74a) with its zigzag incised line, is very similar to the fabric 2 vessel (Figure 74b).

\subsubsection{Baleshare: summary of the assemblage}

The assemblage from Baleshare comprises circa 5760 sherds made, where technique of manufacture could be determined, by the coil-construction method. The pottery, much of which was badly fragmented and abraded, was sorted according to fabric, thickness, decoration and surface finish to determine whether any broad differences could be seen between pottery from the various phases of the site (only presence/absence was recorded). Over 1000 sherds from the assemblage were sub- 


\section{a) thickness \\ Phase}

I

2

3

\section{b) surface finish \\ Phase}

I

2

\section{c) decoration}

\section{Phase}

I

2

3

\section{d) fabric}

Phase

I

3 thin

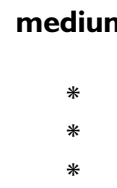

smoothed

grass-wiped

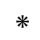

*

incised

finger imp

nail imp

*

*

I

*
2

*

* thick

*

*

*

burnished very thick

Table 5. Baleshare. Pottery attributes

jected to analysis of colour, thickness and firing but no meaningful groups could be identified (Lehane, archive report).

The pottery was categorised as thin $(<5 \mathrm{~mm})$, medium $(6-10 \mathrm{~mm})$, thick $(11-15 \mathrm{~mm})$ or very thick $(>16 \mathrm{~mm})$; the results are presented in Table $5 \mathrm{a}$.

\section{Morphology}

All the vessels seem to have been flat-based, either bucket-shaped or shouldered with more of a barrel-shaped lower portion. A range of rim types is represented; plain, flat, interior bevelled and splayed in Phase 1 , with the addition of rolled, necked and inverted in Phase 2, and everted and tapered in Phase 3. Thirty-two rim sherds have diameters which can be measured. The majority was under $180 \mathrm{~mm}$ in external diameter with the largest proportion measuring $100 \mathrm{~mm}$.

\section{Surface finish and decoration}

The use of a thin slip was noted on sherds from each phase. Smoothing and grass-wiping was present on sherds from Phases 2 and 3, whereas burnishing was restricted to sherds from Phase 3 (Table 5b).

A variety of decorative techniques was recorded (Table 5c). The only decoration on a Phase 1 sherd was a possible incised line. In Phase 2 contexts incised lines, finger tip and finger nail impressions were noted. There was only one example of a cordon in Phase 2, in one of the upper blocks. These techniques were recorded on pottery from Phase 3 contexts with the additional techniques of applied bosses and finger-impressed bases.

These decorative elements were combined in a number of ways (Figure 75). Find 30/3 (Figure 75a) has an applied cor- don decorated with incised zig-zags above which are incised lines forming a chevron, or basket effect. Find 40/43 (Figure $75 \mathrm{~b}$ ) has applied bosses with double incised chevron decoration above. Find 32/96 (Figure 75c) has a slashed cordon with incised decoration above, again possibly forming a woven or basket effect. Find $81 / 98$ (Figure $75 d$ \& Plate 15 ) is a shouldered vessel with a zig-zag cordon around the vessel at the level of the shoulder.

Fabric

The fabrics were categorised as follows - sandy clay (1); coarse sandy clay (2); fine clay (3); sandy clay with rock temper (4); coarse, sandy clay with rock temper (5); and fine clay with rock temper (6) (Table $5 \mathrm{~d}$ ). The presence of organics was noted in examples of each fabric present.

Macroscopic examination of forty-five sherds indicated local production. All contain rock fragments which can be matched with outcrops within $2 \mathrm{~km}$ of the site on North Uist. The majority of the sherds contain fragments, ranging in size from $2 \mathrm{~mm}$ to $12 \mathrm{~mm}$ in diameter, of quartz, granite-gneiss, granite and amphibolite. These fragments are usually rounded, indicating that they derive from a coarse sand, but some are angular, indicating the addition of crushed rock. The smaller grains $(0.5 \mathrm{~mm}$ to $2 \mathrm{~mm})$ usually consist of quartz, hornblende, mica (usually biotite) and, rarely, feldspar. Some $20 \%$ of the 45 sherds examined exhibited elongated cavities from the burning-out of grass or other vegetation. Usually these cavities were infrequent in a sherd, perhaps indicative of vegetation within the clay rather than deliberate addition, but in some cases the cavities are so frequent that deliberate addition is indicated. 

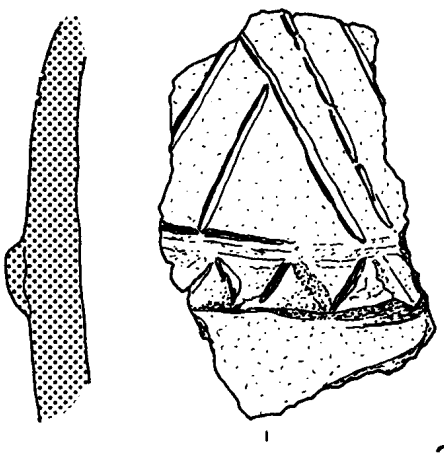

a

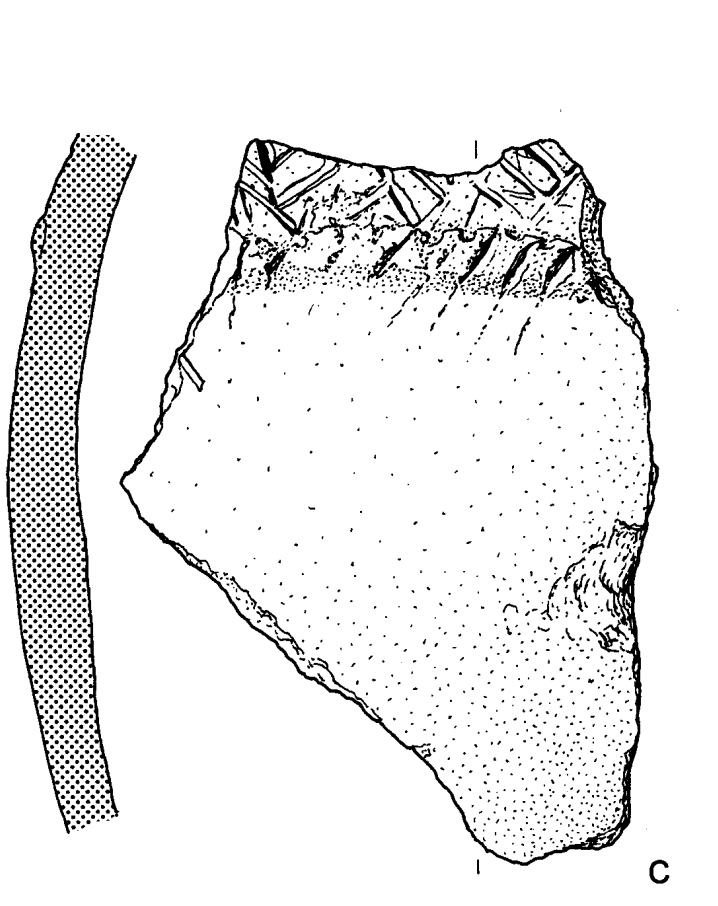

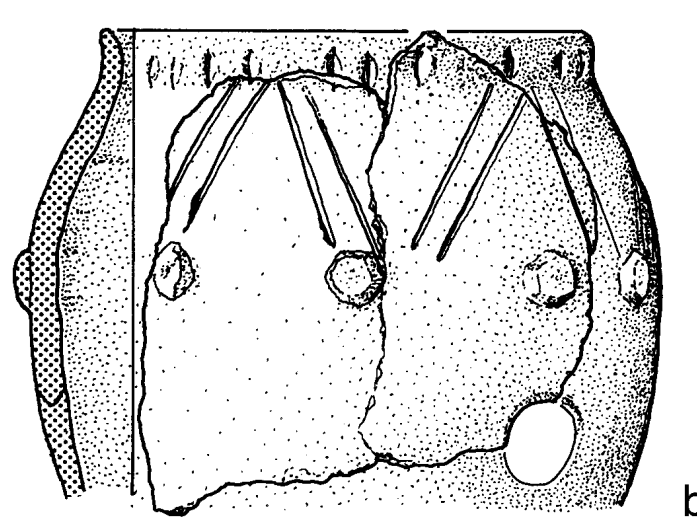

b

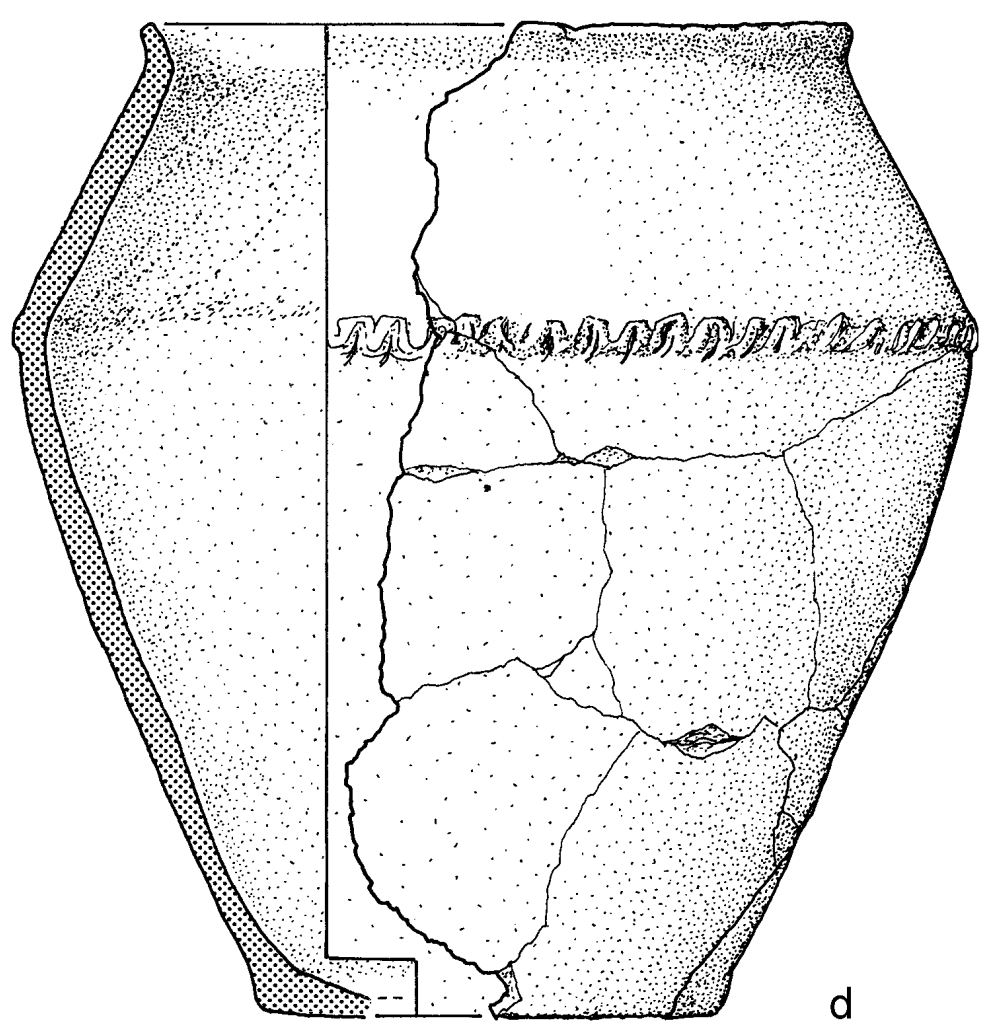

Figure 75. Baleshare: pottery. a) Find 30/3 (Scale 1:1). b) Find 40/43 (Scale 1:2). c) Find 32/96 (Scale 1:1). d) Find 81/98 (Scale 1:2)

The pottery was similar in fabric throughout the assemblage, although there were no thin sherds in Phases 1 and 2. Most of the fabrics were sandy clay or coarse sandy clay, sometimes tempered with rock fragments. Fine clay was only used in Phase 3, although this too was tempered with rock fragments.

\section{Summary of chronology}

Certain differences within the assemblage can perhaps be explained chronologically. The pottery from Phases 1 and 2 does not have any fine sherds and a fine clay was not used. The Phase 1 pottery was undecorated apart from one sherd with possible incised decoration, whereas in Phase 2 incised and impressed decoration predominated, with only one ex- ample of a cordon, and in Phase 3 applied decoration was used in addition to the continued use of incised and impressed decoration. The use of burnishing as a surface finish was only noted in Phase 3. Everted and tapered rims were only noted in Phase 3.

\section{I.4 Hornish Point: summary of the assemblage}

The assemblage of coarse pottery from Hornish Point comprises 699 sherds (581 undecorated body sherds, forty-four rim sherds, twenty-eight basal sherds and forty-six decorated sherds). The vessels were hand-built by the coil-construction method. Over $80 \%$ of the sherds were 


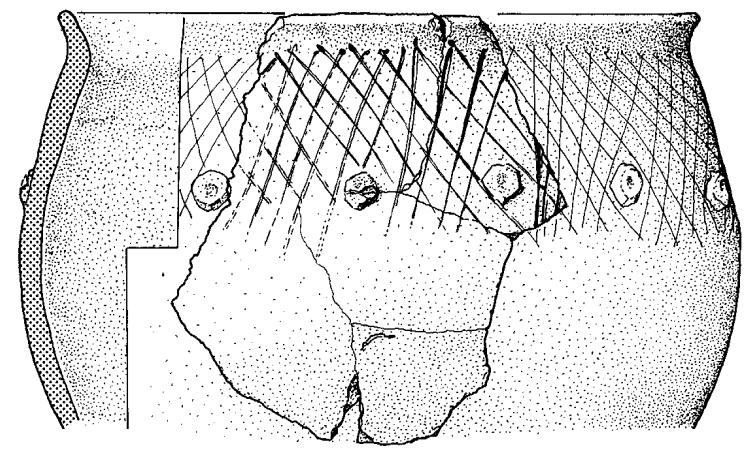

a
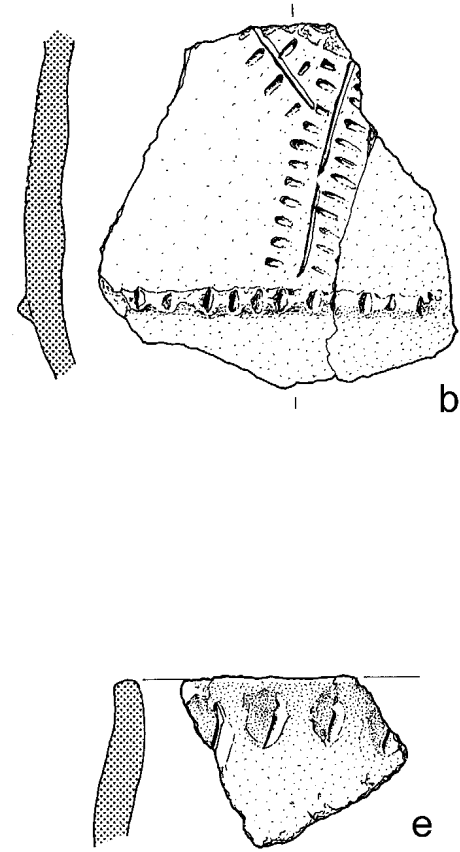

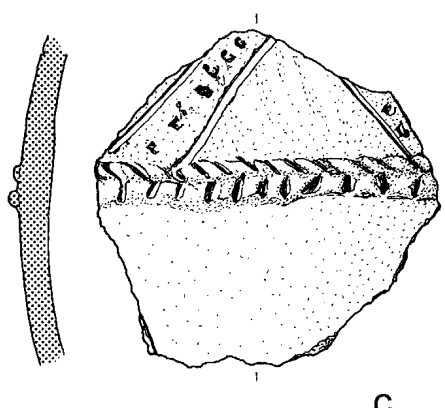

C

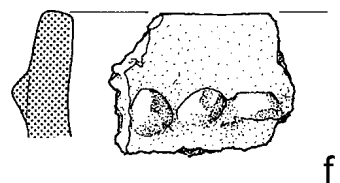

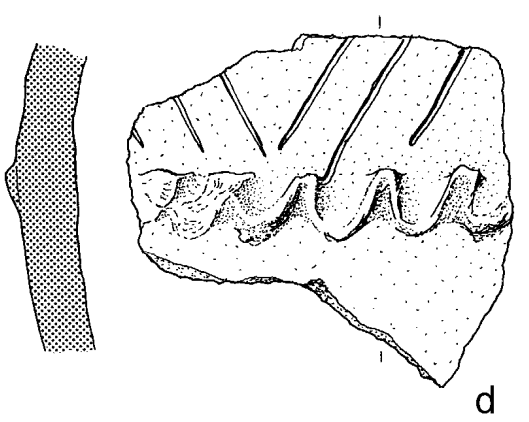

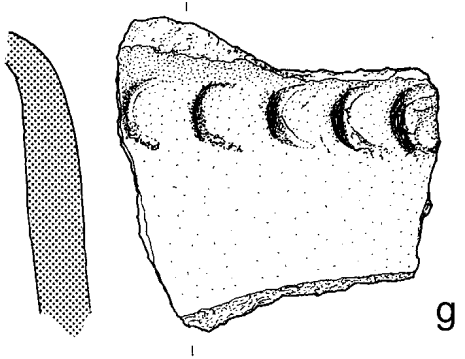

Figure 76. Hornish Point: pottery. a) Find 123/18 (Scale 1:2). b) Find 123/20 (Scale 1:1). c) Find 366/1 (Scale 1:1). d) Find 261/1 (Scale 1:1). e) Find 204/7 (Scale 1:1). f) Find 130/14 (Scale 1:1). g) Find 123/25 (Scale 1:1)

incompletely oxidised. Scraping and smoothing of the surface was sometimes noted, and four of the sherds are grass-marked. When the pottery was subjected to attribute analysis (colour, thickness and firing), eight types were identified (see Lehane, archive report), but none of these were found to have any stratigraphic significance.

\section{Morphology}

The following rim types were noted; everted (29), inverted (1), plain (11) and flat (3). The dominance of the everted rim is consistent with what was noted in the Baleshare assemblage. Only in five cases could rim diameter be measured, and a similar size range to the Baleshare assemblage was indicated. The only basal type recorded was a flat base with angled walls.

\section{Decoration}

Forty-six decorated sherds were recovered with the following methods of decoration represented; incised (35\%), applied (32.6\%), gouged (26\%), stabbed (4.3\%) and stamped (2.1\%).
The range of methods and the motifs is very similar to those noted in the Balelone assemblage.

In general the sherds were too small to obtain a clear impression of the layout of the decoration, but, as at Balelone, a combination of applied and incised motifs appears to have been common (Figure 76). Find 123/18 (Figure 76a) has an incised lattice decoration combined with applied bosses. Find 123/20 (Figure 76b) has an applied cordon with incised slashes with incised 'fringed' chevron decoration above. Find 366/1 (Figure 76c) has an applied cordon decorated with incised chevrons combined with an incised, double chevron, with additional dot decoration above. Find 261/1 (Figure 76d) has an applied wavy cordon with incised, chevron decoration above. In other cases the decoration is confined to a single motif, repeated around the vessel, usually around the neck, eg lentoid decoration on Find 204/7 (Figure 76e), a row of applied bosses on Find 130/14 (Figure 76f), and a row of finger-tip impressions at the point of inflection of the everted rim of Find 123/25 (Figure 76g). 


\section{Fabric}

The fabrics of the vessels are very similar throughout; sandy clay or coarse, sandy clay, with rock tempering only occasionally, and thickness in the range $5 \mathrm{~mm}$ to $15 \mathrm{~mm}$. Thirty-two sherds from the site were examined macroscopically. The larger rock fragments within the sherds were found to be either granite or quartz or a combination. Finer grains (up to $1 \mathrm{~mm}$ diameter) consistently included quartz, hornblende and biotite and, rarely, feldspar. Grass-tempering seems to have been common, noted in around $60 \%$ of the sherds examined.

\subsubsection{Newtonferry: summary of the assemblage}

During the excavations at Newtonferry, circa 350 sherds of pottery were recovered. The majority of sherds were uncontexted but five sherds were retrieved from Block 5 and Block 3. Examples of inverted, necked, plain and everted rims are included in the assemblage. All are uncontexted apart from an inverted rim from (38). There are no basal sherds in the assemblage. Only one sherd from (41) has decoration which consisted of two small incised lines. Most of the pottery is between $5-10 \mathrm{~mm}$ thick. The pottery is morphologically undiagnostic. The fabrics are similar throughout the assemblage, ie sandy clay, occasionally with the addition of organics.

The fabrics of a sample of sherds were analysed in more detail. The results are as follows:

Fabrics 1 and 5: Granite and quartz, mainly up to $2 \mathrm{~mm}$ in diameter, mostly rounded or sub-rounded. Finer black minerals (? hornblende) and biotite, set in a dark grey clay matrix. Many elongated cavities aligned with the walls of the sherd probably from grass tempering. There are occasional grass impressions on both surfaces of the sherds.

Fabrics 2, 3 \& 4: Many angular quartz grits up to $2 \mathrm{~mm}$ in diameter, with smaller quartz and hornblende fragments, less than $1 \mathrm{~mm}$ in diameter. Occasional irregular cavities, some with impressions of vegetation.

Fabric 6: Coarse granite fragments up to $6 \mathrm{~mm}$ in diameter, with finer quartz, feldspar, hornblende and biotite set in a grey clay matrix. Grass impressions on both surfaces.

\section{I.6 South Glendale: summary of the assemblage}

An assemblage of fifty-five contexted sherds and circa 120 uncontexted sherds were recovered during the excavations at South Glendale. In addition, a brown-glazed sherd of post-Medieval date and a possible beaker sherd were recovered during a pre-excavation survey, and Shepherd \& Maclean $(1978,35)$ recovered cord-decorated beaker sherds during earlier fieldwork.

All the contexted pottery apart from one sherd was recovered from the upper Block of midden deposits and pit-digging activity. The pottery is all hand-thrown, by the coil construction method, and the majority of sherds are rock-tempered. From its colour, most was fired in an oxidising atmosphere. Only three sherds are decorated; Find $3 / 3$ which has incised decoration into a slip, Find 4/32 which has an incised line, and Find 103/1 which also has incised decoration. In none of these instances does enough of the decoration survive to indicate a date.
Six rim sherds were noted; an everted rim, a flat rim and an inverted rim with an internal bevel from unstratified deposits and, from Block 1 contexts, a rim with an internal bevel, three flat rims and one from a necked vessel. None of the rim diameters could be measured, but in seventeen cases where the curvature of body sherds could be measured, it appeared that the seven were over $0.36 \mathrm{~m}$ in diameter.

\section{I.7 Discussion}

As the assemblages from Newtonferry and South Glendale are small and undiagnostic, the discussion will focus on the circa 8000 sherds from the other three sites. The ${ }^{14} \mathrm{C}$ dates indicate that the assemblages studied from Baleshare, Balelone and Hornish Point span the period from circa $1350 \mathrm{cal}$ BC to $100 \mathrm{cal} \mathrm{BC}$. The earliest dates were from the Phase 1 assemblage at Baleshare, an undecorated assemblage with medium to thick-walled vessels, often bucket-shaped. The Phase 2 assemblage from Baleshare, dating to circa $1000 \mathrm{cal} \mathrm{BC}$, included rolled and necked vessels. A row of impressed decoration below the rim was most common. The assemblages from Balelone and Hornish Point span similar periods, $550-300 \mathrm{cal} \mathrm{BC}$ in the former case and 550-220 cal BC in the latter. Both have incised and applied decoration and a range of rim forms including everted. The assemblage from Phase 3 at Baleshare is later, circa 200-100 cal BC, but has a similar range of rim forms and decoration.

The largest published assemblage of Iron Age pottery from Uist consists of 19,000 sherds from Dun Vulan (Parker-Pearson \& Sharples 1999). Unfortunately, this report was published too recently for its results to be assimilated or discussed here. Much smaller assemblages were recovered from the wheelhouse sites of A'Cheardach Mhor (Young \& Richardson 1960) and A'Cheardach Beag (Fairhurst 1971) in South Uist, and Sollas in North Uist. Around 1000 sherds were recovered from the wheelhouse at A'Cheardach Beag (ibid). The assemblage had two main components, decorated 'wheelhouse wares' and undecorated 'coarse wares'. In the report it was noted that most of the pottery should be considered as unstratified (ibid, 91), so it is not possible to establish whether the two types of pottery were contemporaneous, perhaps reflecting a functional difference, or whether they represent a chronological division. The 'wheelhouse pottery' has a variety of decorative methods; fingertip decoration, linear and curvilinear incised motifs, stabbing or stab and drag, and wavy or finger-impressed cordons. Fairhurst noted the absence of channelled decoration (also known as 'Clettraval Ware'), ring-headed pin impressions, raised bosses and applied cordon under the rim, which led him to believe, from comparison with other assemblages, that the assemblage was later rather than earlier in the sequence. All of the forms of pottery noted at A'Cheardach Beag were identified in the assemblages from Balelone, Baleshare and Hornish Point.

The pottery from A'Cheardach Mhor was stratified into an earlier and a later group within the wheelhouse (Young $\&$ Richardson 1960). The pottery that Young defines as the earlier group has inverted rims and incised decoration, and came from below the living levels of the bays of the wheelhouse (ibid, 143). Applied cordons and raised bosses were also noted. Everted rims were a distinctive feature of the later stage of Phase 1 , along with various forms of applied decoration. The 
later assemblage, from above the level of the wheelhouse floor, was characterised by vessels with a short neck and was often undecorated. The pottery from the early phase was dated to the second century $\mathrm{AD}$ by association with yellow vitreous beads, while a date within the fifth to seventh centuries AD was suggested for the later assemblage, through comparison with the Dun Cuier, Barra, assemblage (ibid, 154).

The Sollas wheelhouse, which dates to the first century $\mathrm{AD}$, produced an assemblage of around 3000 sherds (Campbell 1991, 148). Shouldered vessels are more common, although bucket shapes were also found. Decoration includes linear incisions forming lattices, chevrons, lozenges, stamped rings, channelled curvilinear designs, cordons on the shoulder and stabs or impressions around the neck. These decorative elements are found in various combinations. While the presence of a cordon and incised decoration did not seem to be chronologically sensitive within the period represented at Sollas, Campbell felt that channelled decoration (shallow grooves forming either arches or asymmetric waves), used by Mackie (1974a, 81) to define 'Clettraval Ware', was late in the sequence, being confined, apart from one example, to pe$\operatorname{riod} \mathrm{B} 2$, the final phase on the site, and that the appearance of everted rim pottery was also sudden, coinciding with the building of the wheelhouse. The lack of channelled decoration in the assemblages at Balelone, Baleshare and Hornish Point would support its later date. However, the presence of everted rims in these assemblages does not support Campbell's theory that they were introduced at the same time as channelled decoration.

From these assemblages from the Uists, and from the assemblages from Balelone, Baleshare and Hornish Point, various observations can be made as to the identification of chronologically sensitive decorative traits. The Baleshare Phase II assemblage indicates that the use of rows of impressed decoration in the early Iron Age in this region is a continuation of a later Bronze Age tradition. Impressed decoration continued to be used solely, or in combination with incised decoration, applied cordons and bosses in the early part of the Iron Age. In the later assemblages, as evidenced at Sollas, channelled decoration is added to the repertoire. The sequence for the area from circa $1000 \mathrm{cal} \mathrm{BC}$ to the first few centuries cal AD appears to involve the addition of new decorative elements rather than the discontinuation of earlier styles as new ones are developed.

In considering how far these observations tie in with other assemblages from the West Coast islands, the discussion will be restricted to published material.

The largest published assemblage is that from Dun Mor Vaul, Tiree. The assemblage was associated with the building, use and abandonment of the broch. Mackie (1974a) was able to identify six phases of pottery beginning with Vaul Ware (vases and barrel-shaped urns sometimes ornamented with geometric incised decoration) which characterised his Phase 1A assemblage (795-255 cal BC [GaK 1098] and 795-180 cal BC [GaK 1092]). The use of this type of pottery continued through the sequence. Clettraval Ware was added in the Phase 2 assemblage (100 cal BC-340 cal AD [GaK 1097]), which represents the construction of the broch, and its use continued throughout the later part of the sequence, the conversion of the broch to a dwelling, circa $160 \mathrm{cal}$ AD.

Other assemblages from the West Coast islands lack dates and have been relatively dated by comparison with Dun Mor
Vaul. An assemblage from Dun Cul Buirg in Iona (Ritchie \& Lane 1980) which included channelled decoration and cordons was interpreted by the excavators as representing one main period of occupation. The occurrence of channelled decoration would indicate a date late in the sequence if compared with Dun Mor Vaul.

A date in the first half of the first century AD was also suggested for the pottery from Tabraham's excavations at Dun Carloway (Tabraham 1977, 156). The most common form of vessel is a necked vessel with a flat or plain rim, or, less often, an everted rim, and the only form of decoration is an applied cordon often giving a wavy effect. The absence of channelled and incised decoration, and the fact that the assemblage appeared to be associated with the secondary use of a broch, led Close-Brooks to suggest that it was perhaps of a similar date to the Phase III middens at A'Cheardach Mhor, South Uist (Young \& Richardson 1960, 154-6, figs 10, 13) and to the assemblage from the fortified house at Dun Cuier, Isle of Barra (Young 1956, figs 7-12). However, Close-Brooks pointed out that the Dun Cuier assemblage could have a longer time span because it included concave rims and bucket shapes not found at Carloway and a small stone mould for the terminal of a penannular brooch, which she felt could extend the date range into the 8th century AD.

There is again little dating evidence for the assemblages from the published Skye sites. The pottery from the brochs Dun Beag (Callander 1921) and Dun Iardhard (MacLeod 1915), is decorated with applied cordons and incised decoration. A date of $172 \mathrm{cal} \mathrm{BC}-\mathrm{cal}$ AD 130 (GU-1662) was obtained for the building of Dun Flodigarry broch, which has a similar assemblage (Martlew 1985). Recent work on establishing a pottery sequence for the Iron Age of the West Coast islands of Scotland has allowed the usefulness of various traits to be evaluated (Lane 1990). Fabric has been discounted as a useful chronological indicator. Where fabrics have been analysed, the conclusion of the analysis is in general that they could have been produced locally to the site. Variations within an assemblage are often in texture rather than materials, and are perhaps a consequence of the size or envisaged function of a vessel. Grass tempering, while appearing to be locally distinctive in certain cases, for example at Sollas, where it was virtually confined to Period A, cannot be used as an chronological indicator over the region, having been noted to occur from Bronze Age to Viking contexts.

The lack of chronologically distinctive fabric types has focused discussion of a sequence on decoration and morphology, of which the appearance of channelled decoration and the introduction of everted rim pottery have had most attention. While Campbell (1991) would see everted rims as a late introduction, Mackie suggested that the presence of an everted rim sherd with a double cordon in his Phase 1 assemblage (795-255 cal BC) at Dun Mor Vaul could argue for earlier origins. Young $(1966,52)$ was also in favour of a late date for the introduction of everted rims with the replacement of incised decoration with channelled decoration at the same time. Campbell $(1991,154)$ disputed the replacement of incised decoration by channelled decoration on the grounds that the four variations of decoration found on everted rim pottery (plain, cordoned, incised and channelled) are all found in the same first/second century AD deposits at Sollas. 


\begin{tabular}{|c|c|c|c|c|c|c|c|c|}
\hline Context & Block & tech & $\mathbf{p} / \mathbf{s} / \mathbf{i}$ & reg & $\mathbf{I}$ & b & th & Notes \\
\hline \multicolumn{9}{|l|}{ Quartz } \\
\hline S476 & 3 & sf & $\mathrm{p}$ & $\mathrm{i}$ & 43 & 22 & 11 & \\
\hline S476 & 3 & $s f$ & $\mathrm{i}$ & i & 25 & 18 & II & \\
\hline 275 & 22 & sf & $\mathrm{i}$ & $\mathrm{i}$ & 35 & 17 & 10 & \\
\hline 275 & 22 & sf & $\mathrm{i}$ & $\mathrm{i}$ & 18 & 15 & 7 & \\
\hline 275 & 22 & sf & $s$ & $\mathrm{i}$ & 22 & 16 & 7 & \\
\hline 139 & 26 & $s f$ & $\mathrm{p}$ & $\mathrm{i}$ & 32 & 29 & 12 & \\
\hline 139 & 26 & sf & $\mathrm{s}$ & $\mathrm{i}$ & 38 & 26 & 17 & \\
\hline 139 & 26 & speb & & & 66 & 43 & 32 & \\
\hline 272 & 23 & sf & s & $\mathrm{i}$ & 36 & 25 & 13 & \\
\hline 276 & 22 & $f$ & s & i & 45 & 46 & 16 & vein quartz \\
\hline 276 & 22 & $s f$ & s & $\mathrm{i}$ & 43 & 25 & 16 & \\
\hline 276 & 22 & sf & $\mathrm{i}$ & $\mathrm{i}$ & 23 & 17 & 6 & \\
\hline 276 & 22 & ch & $\mathrm{i}$ & $\mathrm{i}$ & 32 & 39 & 18 & \\
\hline 279 & 22 & $f$ & $\mathrm{i}$ & $\mathrm{i}$ & 35 & 20 & 10 & bedrock \\
\hline \multicolumn{9}{|l|}{ Flint } \\
\hline 61 & & $f$ & $\mathrm{i}$ & $\mathrm{i}$ & 11 & 9 & 2 & \\
\hline 211 & 16 & $f$ & $s$ & $\mathrm{i}$ & 15 & 17 & 6 & \\
\hline 279 & 22 & $f$ & $s$ & $\mathrm{i}$ & 24 & 13 & 6 & bipolar \\
\hline 279 & 22 & $f$ & s & $\mathrm{i}$ & 20 & 14 & 7 & $\begin{array}{l}\text { retouched } \\
\text { scraper frag }\end{array}$ \\
\hline $\mathrm{u} / \mathrm{s}$ & & $f$ & $\mathrm{p}$ & i & 23 & 18 & 5 & \\
\hline 105 & 8 & $f$ & s & $r$ & 15 & 13 & 5 & bipolar \\
\hline
\end{tabular}

Table 6. Baleshare. Catalogue of lithic finds (measurements in $\mathrm{mm}$ ). All pieces are in a fresh condition and unretouched other than where specified. Key: tech = technology; $p / s / I=$ primary $/$ secondary/inner; $b=$ blade; $f=$ flake; $r=$ regular; $I=$ irregular; speb $=$ split pebble; $s f=$ splintered flake (no conchoidal fracture)

The lack of channelled decoration in the assemblages from the Balelone, Baleshare and Hornish Point add weight to the observation at Dun Mor Vaul and Sollas that channelled decoration is late in the sequence. For the earlier part of the sequence, analysis of the assemblage from Baleshare has led to the suggestion that impressed bands of decoration around the shoulder of the vessel were in use before cordoned/incised decorated pottery. In addition, the information from Balelone and Hornish Point supports Mackie's theory of an early date for everted rims rather than their introduction in the first/second century AD.

\subsubsection{Conclusions}

In spite of the number of West Coast island sites which have been excavated, our ability to define a pottery sequence for the West Coast islands has been hindered by the lack of sites with well-recorded, well-dated stratigraphy. The information obtained from Baleshare, Balelone and Hornish Point has added detail to the earlier part of the sequence for Uist, but many more well-dated assemblages are needed if we are to advance the pottery sequence for the West Coast islands on a local and regional level.

\section{I0.2 LITHIC ASSEMBLAGES}

N Finlay (1992)

\subsection{Introduction}

Flint and quartz are the main materials represented with a single piece of green chert found at South Glendale. Boulders of chalk flint in drift have been reported on Vatersey and Skiport (Wickham-Jones \& Collins 1978, 11-12) but the flint exploited at the sites would appear to be beach pebble in origin. There is a possibility that this material was collected from other islands. The nearest source for the fossil found at Balelone is on the east coast of Skye and is also a flint source (Collins infra). Both vein and pebble quartz was exploited and the use of this poor quality raw material on the islands has been recorded at a number of sites including Valtos, Lewis (Lacaille 1936). The small size of the assemblages recovered and the types of contexts, cultivation deposits and conflation deposits, precludes any detailed discussion of the material.

\subsubsection{Baleshare (Table 6)}

A total of five pieces of flaked flint and fourteen pieces of quartz was recovered from Baleshare. The bipolar technique is represented and the only retouched piece, a secondary flake from Block 22, is a scraper fragment. The quartz from Blocks 23 and 26 has a smooth, waterworn cortex, while that from the other blocks is vein in origin. Some pieces retain part of parent bedrock material. True conchoidal fracture is 


$\begin{array}{lccccccl}\text { Material } & \text { tech } & \text { p/s/i } & \text { reg } & \text { I } & \text { b } & \text { th } & \text { Notes } \\ \text { flint } & \text { f } & \text { s } & \text { r } & 33 & 20 & 8 & \text { hard } \\ & & & & & & & \text { hammer } \\ \text { quartz } & \text { sf } & \text { i } & \text { i } & 29 & 24 & 13 & \\ \text { quartz } & \text { sf } & \text { i } & \text { i } & 23 & 19 & 12 & \\ \text { quartz } & \text { sf } & \text { s } & \text { i } & 28 & 22 & 11 & \\ \begin{array}{l}\text { Top surface } \\ \text { flint }\end{array} & \text { b } & \text { s } & \text { r } & 31 & 13 & 6 & \end{array}$

Table 7. Hornish Point. Flint from [127], Block 30 (measurements in $\mathrm{mm}$ ). All pieces are in a fresh condition and unretouched other than where specified. For key see caption to Table 6

rare in this material, however the pieces are most likely to be the product of a worked assemblage.

\subsubsection{Hornish Point (Table 7)}

A total of five pieces of flint and quartz was recovered, these comprised an unprovenanced surface find of a flint blade, a secondary flint flake and three quartz flakes from Block 30, [127].

\subsubsection{South Glendale (Table 8)}

An assemblage of twenty-four pieces of flint, one chert chunk and circa 100 quartz pieces were recovered from this site. Unfortunately the majority of the material was unprovenanced or from conflation horizons. No pebble quartz was recovered and it would appear that vein quartz was exploited. No retouched pieces were found and the character of the flint assemblage suggests that more than one phase of activity is represented by this material.

\section{I0.3 STONE AND PUMICE SAMPLES}

\section{G Collins (1986)}

\subsection{Balelone}

Of the fifty-five samples examined, the majority were composed of grey-gneiss and hornblende-gneiss of local origin. In addition amphibolite and granite, both probably derived from South Harris, were noted. Some twenty-one of the samples contained burnt stone and two samples from [21/17] and [39] were also rich in ash. An unstratified belemnite, a calcareous fossil, was also found. The nearest in situ occurrence of these fossils is in the Mesozoic outcrops on the east coast of Skye. There may be an association between the fossil and the unworked flint pebble recovered from [515], for flint is also commonly found there.

\subsubsection{Baleshare}

165 samples were examined comprising mostly grey gneiss and granitic or hornblendic gneiss, obtained from the nearby

$\begin{array}{lrrrrrrl}\text { Context } & \text { tech } & \text { p/s/i } & \text { reg } & \text { I } & \text { w } & \text { t } & \text { Notes } \\ 4 & & & & & & & \\ 4 & \text { f } & \text { i } & \text { i } & \text { I3 } & 10 & 3 & \\ 4 & \text { f } & \text { P } & \text { i } & 28 & 17 & 7 & \\ 4 & \text { ch } & \text { i } & & 12 & 16 & 7 & \\ 4 & \text { f } & \text { i } & \text { i } & 15 & 12 & 4 & \text { prox fragment } \\ 5 & \text { f } & \text { i } & \text { i } & \text { I7 } & 10 & 4 & \text { fragment } \\ \text { spall } & \text { f } & \text { i } & \text { i } & & & & \text { chip, knapping } \\ 3 & & & & & & & \\ \text { I3 } & \text { f } & \text { i } & \text { r } & 15 & 13 & 2 & \\ \text { spalls } & \text { f } & \text { s } & \text { i } & 13 & 12 & 3 & \text { burnt, heat } \\ 48 & & & & & & & \\ \text { spalls } & \text { f } & \text { s } & \text { i } & 18 & 15 & 4 & \text { burnt, heat } \\ 59 & \text { ch } & \text { s } & & 13 & 12 & 8 & \\ 59 & \text { f } & \text { s } & \text { r } & 17 & 12 & 3 & \\ \text { I0I } & \text { ch } & \text { s } & & 42 & 23 & 17 & \\ \text { I04 } & \text { f } & \text { P } & \text { i } & 34 & 30 & 9 & \\ \text { I04 } & \text { b } & \text { s } & \text { i } & 27 & 9 & 8 & \\ \text { I } 24 & \text { f } & \text { P } & \text { i } & 23 & 15 & 5 & \\ 207 & \text { f } & \text { s } & \text { i } & 18 & 10 & 5 & \\ 222 & \text { f } & \text { s } & \text { i } & 22 & 16 & 4 & \text { burnt } \\ 224 & \text { f } & \text { s } & \text { i } & 20 & 28 & 6 & \text { hard hammer } \\ \text { u/s } & \text { f } & \text { i } & \text { r } & 27 & 25 & 4 & \text { flat plat, hinge } \\ \text { u/s } & \text { f } & \text { s } & \text { i } & 18 & 23 & 5 & \text { bipolar } \\ \text { u/s } & \text { f } & \text { i } & \text { r } & 21 & 15 & 4 & \text { bipolar } \\ \text { u/s } & \text { f } & \text { i } & \text { i } & 10 & 11 & 3 & \text { prox fl frag } \\ \text { u/s } & \text { b } & \text { i } & \text { r } & 22 & 6 & 2 & \\ \text { u/s } & \text { f } & \text { i } & \text { i } & 20 & 12 & 5 & \text { patinated fl } \\ \text { green chert } & & & & & & & \\ 4 & \text { ch } & \text { i } & & 20 & 11 & 9 & \text { worked chunk }\end{array}$

Table 8. South Glendale. Catalogue of stratified and unstratified lithic finds (measurements in $\mathrm{mm}$ ). All pieces are in a fresh condition and unretouched other than where specified. For key see caption to Table 6

beach and shallow cliffs. Few of the specimens are water rounded. There is a preponderance of heated hornblende-porphyry pebbles from a range of contexts, for example [247], [194] and [233]. Of the 165 samples 102 were found to contain heated rock fragments. It is clear that hornblende was preferentially selected for fire stones over the local grey-gneiss which is prone to disintegration.

Forty-three pieces of pumice were recovered from Baleshare (Table 9), of which three were modified. Only Find 150 is an identifiable object, a perforated pumice float, 55 $\mathrm{mm}$ long (Figure 77a). Find 73 is an oval piece, $64 \mathrm{~mm}$ long, worn flat on one side with indentations on the reverse (Figure $77 \mathrm{~b}$ ) while Find 232 is an amorphous piece, $47 \mathrm{~mm}$ long, with wide grooves worn into it (Figure 77c).

\section{0.3.3 Hornish Point}

170 samples were examined. Hornblende-gneiss and granite-gneiss were represented with rare inclusions of amphibolite and hornblende-porphyry pebbles. Some seventy-six of the samples show signs of burning.

Hornish Point produced a single, unmodified piece of pumice, Find 26, which weighed $0.64 \mathrm{~g}$. 

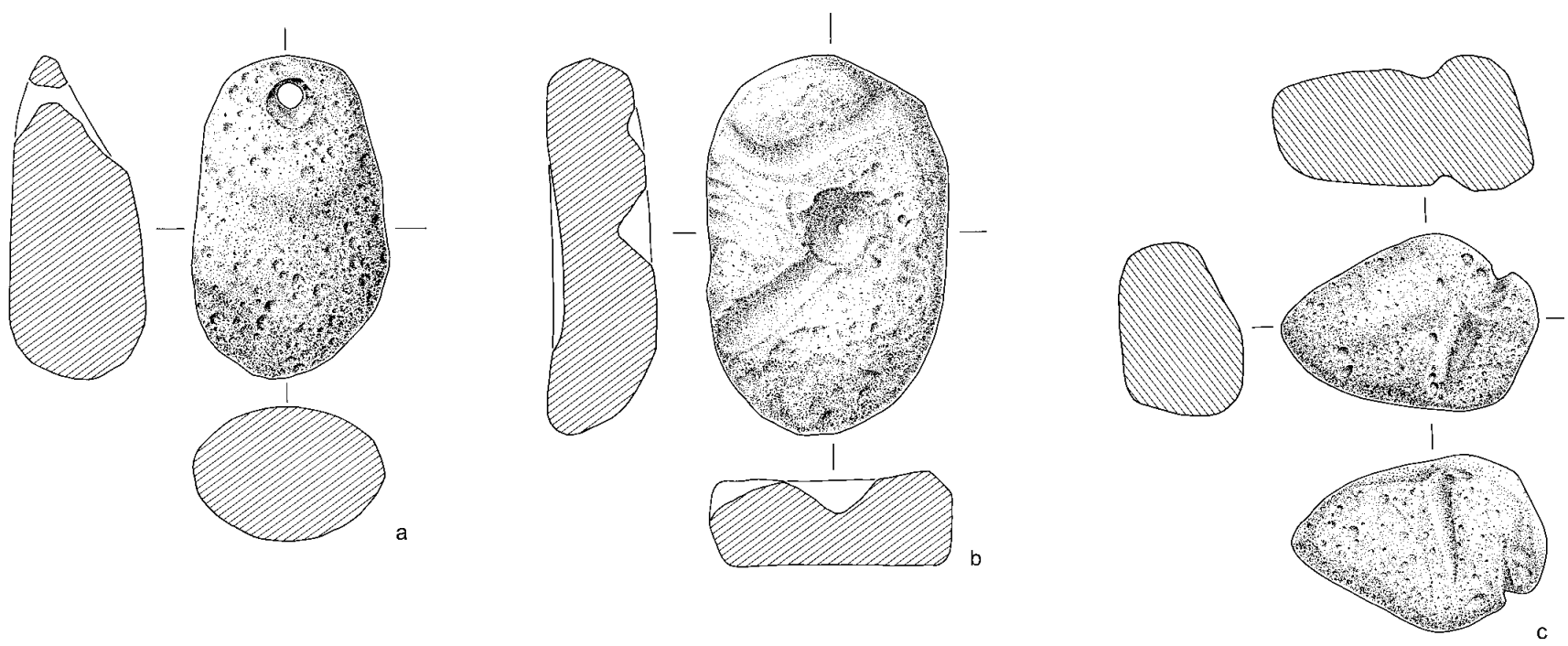

Figure 77. Baleshare: pumice artefacts (Scale 2:1). a) Find 150. b) Find 73. c) Find 232

\subsubsection{Newtonferry}

The majority of the lithic samples recovered from this site are of hornblendic-gneiss and granite. Burnt stone was present in five out of the thirty-seven samples. The lithics are angular with very few rounded surfaces. Lime/shell mortar was also present.

\subsubsection{South Glendale}

Few local gneiss were encountered and the character of the material differs from the other sites in relation to the presence of worked flint and quartz.

$\begin{array}{lrccc}\text { Context } & \text { Block } & \text { No. frags } & \text { Weight } & \text { Date (bc) } \pm \mathbf{5 0} \\ 5 & 3 & 2 & 9.57 & (370-205) \\ 119 * & 12 & 2 & 20.26 & (290-95) \\ 65 & 2 & 1 & 2.18 & 290 \\ 62 & 2 & 2 & 0.96 & 290 \\ 176 & 15 & 1 & 2.4 & 425 \\ 216 & 15 & 1 & 2.87 & 425 \\ 177^{*} & 15 & 2 & 13.46 & 425 \\ 219 * & 16 & 4 & 43.11 & (865-425) \\ 247 & 16 & 4 & 25.75 & (865-425) \\ 149 & 16 & 2 & 10.25 & (865-425) \\ 240 & 16 & 2 & 5.09 & (865-425) \\ 142 & 16 & 1 & 5.08 & (865-425) \\ 140 & 25 & 1 & 10.34 & (865-425) \\ 148 & 26 & 4 & 17.61 & 865 \\ 139 * & 26 & 3 & 19.91 & 865 \\ 233 & 18 & 2 & 11.7 & 790 \\ 231 & 27 & 1 & 10.6 & 960 \\ 270 * & 23 & 3 & 18.73 & 1080 \\ 278 * & 22 & 2 & 12.83 & 1335\end{array}$

Table 9. Baleshare. Unmodified pumice finds. * indicates those contexts from which pumice pieces have been geochemically analysed
South Glendale produced three unmodified pieces of pumice from [108], [4] and [19], weighing, in total, 24.4g.

\section{I0.4 ANALYSIS OF THE PUMICE FROM BALESHARE}

\section{A J Newton \& A J Dugmore (1995)}

\subsection{Introduction and background}

Pumice can be generally defined as 'highly vesicular silicic to mafic glass foam, which commonly floats on water'. The vesicles in the rock are produced by degassing of magma when it reaches the surface. This ability to float means that pumice can be widely distributed by ocean currents if it enters the sea. Pumice can enter the sea either by falling directly into it or being transported by pyroclastic flows or rivers. The geochemical composition of pumice can vary from basic (basaltic) to acidic (rhyolitic).

The archaeological excavations at Ceardach Ruadh, Baleshare produced forty-three pieces of brown and black pumice weighing a total of nearly 300 grams, from blocks throughout the stratigraphic sequence. This pumice is another addition to pumice deposits that are found on raised beaches and archaeological sites throughout the North Atlantic region. A total of nine bulk x-ray fluorescence (XRF) and fifty-one electron probe microanalyses (EPMA) have been carried out on nine pieces of pumice.

The geographical distribution of pumice found throughout the North Atlantic is wide, stretching from Arctic Canada, Greenland, Iceland, Svalbard, Ireland, Scotland to Scandinavia and the Kola Peninsula in Russia. Virtually all of the pumice found in the British Isles and Scandanavia is dacitic, that is it has an $\mathrm{SiO}_{2}$ total of about $65 \%$, and can be either brown or black. The archaeological sites on which this pumice has been found date from the Mesolithic (Jura) to the Late Iron Age (Shetland). This age range reflects the temporal distribution of pumice on the well-developed raised beaches in Norway (Mangerud pers comm; Newton, unpubl). White pumice has also been found in more recent beach deposits 
and sand dunes on Shetland, as well as at an archaeological site on Papa Stour (Newton forthcoming).

The white pumice from Shetland is from the $1362 \mathrm{AD}$ eruption of Oraefajokull, in southern Iceland (Newton forthcoming). The late-glacial white pumice may be associated with the 10,400 BP Vedde tephra which is found in western Norway and the North Atlantic. The Vedde tephra layer was produced form the Grimsvotn Volcanic System in Iceland.

The brown and black dacitic pumice has been correlated with tephra layers from the Katla Volcanic System in southern Iceland. These layers have been dated to between about $6500 \mathrm{BP}$ and $11000 \mathrm{BP}$. The age of this deposit is not as yet known. This work is currently the subject of further research, the aim of which is to date and discover exactly which eruption or eruptions were responsible for the pumice.

The brown pumice, although physically different from the black pumice, which appears to be more glassy, shows no significant geochemical difference to the black pumice. This homogeneity is present in the major and the trace element composition of the pumice and future research will investigate this.

\subsubsection{Pumice finds}

\section{Colour and morphology}

The forty-three pumice pieces were recovered from eleven blocks as shown in Table 9. Only one Block contained black pumice alone, two blocks produced black and brown pumice and the remainder brown only. Whilst 'black' is a fair description of the black pumice, 'brown' pumice may also have a greyish-brown colour. This colour differentiation is noted in other pumice finds in Iceland, Scotland, Ireland and Norway, where mid-Holocene deposits seem to consist of brown and black pumice. Morphological differences between the black and brown pumice are mainly shown by the vesicles which appear far more glassy in the black pumice than the brown. Vesicles in the black pumice also appear to be better developed.

\section{Age of pumice}

Table 9 also gives dates for the blocks containing pumice. These dates are given in uncalibrated radiocarbon years and relative ages are shown in parentheses. Brown pumice is found throughout the chronological range, whilst black pumice is found in only the older samples, primarily Blocks 18, 22,23 , and 26 .

\subsubsection{Geochemical analysis}

Only major element results are presented here, despite trace element results being obtained from the XRF method. Further work on this trace element data is being carried out, including comparisons of the results with recent XRF analyses of other pumice deposits.

\section{$X$-ray fluorescence analysis}

The pumice was prepared for major element XRF analysis by cleaning in an ultrasound bath. This was done to remove any loose sand or dirt from within the vesicles. The pumice was then crushed to a fine powder in a tungsten carbide rock crusher. Finally, the powder was then melted to form glass disks and these were then analysed.

These analyses represent an average composition for each piece of pumice. These results will be discussed with the EPMA results below, but it is worth noting that there is no significant difference between the black pumice of Block 22 and Block 23 and the brown pumice.

\section{Electron probe microanalyses}

EPMA were carried out on the same pieces of pumice as were used for the XRF analyses. The pumice from Blocks 25 and 27 was crushed in the XRF preparation and could not be used for EPMA work. The duplication of the analyses was used to test the reproducibility of the different methods.

The pumice was analysed on a Cambridge Instruments Microscan V electron microprobe. Thin sections of pumice fragments were made so that smooth glass faces could be analysed. The fragments were incorporated in resin on a glass slide, which was ground and polished to a thickness of $75 \mathrm{mi}$ crons and then carbon coated. WDS (Wavelength Dispersive Spectrometer) analyses were carried out using an accelerating voltage of $20 \mathrm{kV}$ and a beam current of $15 \mathrm{nA}$. An andradite standard was analysed regularly during the analyses to provide a clear indication of instrument stability. Only analyses with element totals above $95 \%$ were used for comparative purposes.

Between five and eleven analyses were undertaken on each piece of pumice, enabling the natural geochemical variation of the glass to be studied.

\subsubsection{Discussion}

The mean values for the EPMA analyses do not vary significantly from those obtained by the XRF technique, but differences do occur. For example, the total iron content of Find 247 (Block 16), is greater in the XRF analyses than the EPMA analyses. This is probably due to the presence of a higher concentration of iron bearing minerals such as magnetite. Only glass is analysed in EPMA analyses. As with the XRF analyses there are no significant geochemical variations between the black and brown pumices. This result confirms other analyses carried out on pumice from Iceland to Norway.

Despite the apparent similarity of the XRF and EPMA analyses it is still preferable to use the EPMA results. Although most of the pumice consists of glass, it still contains small phenocrysts. If the piece of pumice analysed has an unusually large number of these, the result will be biased, with over-representation of the elements present in the minerals. During EPMA each point analysed is selected so that only fresh glass is analysed. This leads to better reproducibility between samples. So, only the EPMA results have been used for comparative purposes.

The pumice from Baleshare can be geochemically correlated with dacitic pumice found in Iceland, Ireland, Scotland and Norway. There is a wide range of iron values, often of more than $1 \%$, within a single piece of pumice. This feature would not be shown by XRF analyses where a mean value would have been given. Although there are no major differences between the geochemical composition of the black and brown pumices Find 247 from Block 21 does have slightly 

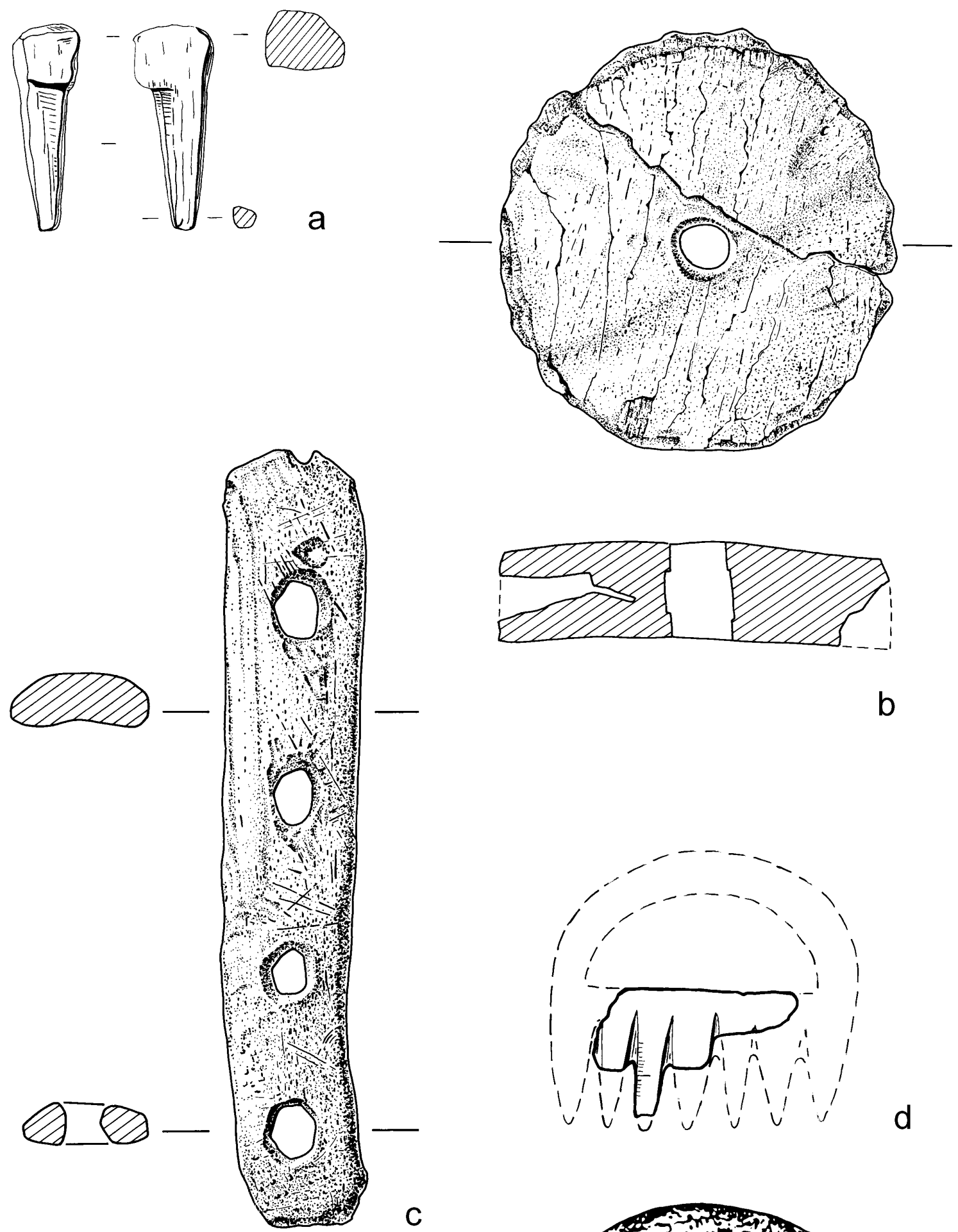

C

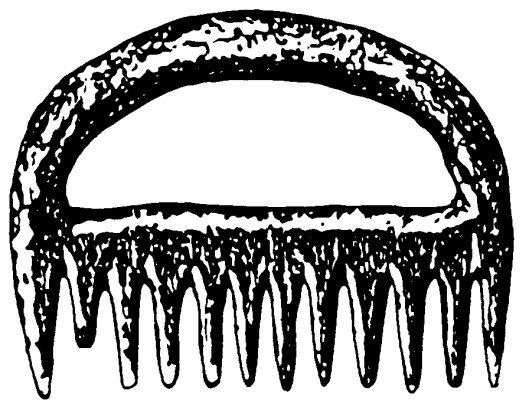

Figure 78. Worked bone and antler artefacts. a) BL3. b) B18. c) H12. d) H13. e) Comb from Bowermadde n, Caithness (after Anderson 1883) 
higher $\mathrm{K}_{2} \mathrm{O}$ than the rest, except for some analyses from Find 139 from Block 26.

\subsubsection{Conclusion}

The pumice would have been collected either from contemporary or raised beach deposit. The Western Isles and Baleshare in particular are excellent sites for the accumulation of flotsam and jetsam. The pumice would have provided an excellent abrasive for all sorts of uses, probably including rubbing of hides and skins and sharpening bone and wooden weapons and tools. Due to its low density fishing floats may have been from the pumice.

The pumice found at Baleshare can be correlated to other dacitic pumice deposits found both in archaeological and natural contexts throughout the eastern North Atlantic region. There are no significant geochemical differences between the black and brown pumice, but the black is only found in the older blocks. XRF and EPMA analyses of pumice both seem to provide similar major element abundances, but it is not possible for XRF analyses to show the natural geochemical variation within a single piece of pumice.

The dating of the pumice is not yet possible. New results from Iceland suggest that there were several eruptions during the mid-Holocene which could have produced the pumice, most probably from the Katla volcanic system. One interesting property of the tephra layers associated with these eruptions is that they are geochemically very similar, a feature shared with pumice deposits. Pumice deposits found at Ben Tangaval, Barra, have similar properties (Newton \& Dugmore 1995).

Future research will investigate the trace element data from the Baleshare pumice and compare this to results from other sites. The recently discovered tephra layers in Iceland provide the best hope of differentiating separate eruptions and of dating the deposits.

\section{I0.5 WORKED BONE AND ANTLER}

\section{A-M Gibson (1988)}

Detailed descriptions of each object can be found in the archive catalogue. The numbers prefixed BL (Balelone), B (Baleshare) and $\mathrm{H}$ (Hornish Point) in the text below refer to the catalogue entries.

\subsection{Balelone}

Only three objects of worked bone were retrieved from Balelone. BL1 (Block 6, [309]) is a smoother/polisher, 144 $\mathrm{mm}$ long, cut from a split cattle metatarsal with rounded end. Polish exists half way along the shaft, where it has been shaped to facilitate hafting. BL2 (Block 7, [18]) is a needle/point fragment, $31 \mathrm{~mm}$ long, with broken hourglass perforation at one end. BL3 is a small peg with a roughly square head (Figure 78a). It may have been a gaming piece.

\subsubsection{Baleshare}

The Baleshare assemblage comprised twenty-one pieces of bone and antler which can be categorised as follows: three complete artefacts $(\mathrm{B} 14,17,18)$; four broken artefacts (B1, B4, B5, B6); two broken points (B3, B12); six off-cuts (B7, $\mathrm{B} 8, \mathrm{~B} 9, \mathrm{~B} 10, \mathrm{~B} 13, \mathrm{~B} 19)$; one utilised piece (B2) and five fragments (B11, B15, B16, B20, B21).

None of the pieces are sufficiently diagnostic to be useful as chronological indicators. The assemblage consists of the types commonly found in later prehistoric collections; examples of finer, well crafted objects which usually accompany these pieces in other assemblages are notably absent.

All the antler in the collection is red deer antler with the exception of one piece (B5) which was possibly made of roe deer antler. However, there is no way of telling from the collection whether the antler used at Baleshare was derived from a local standing population of red deer or was imported. Scarcity of antler cannot be inferred from the small amount recovered from the site as only three pieces of utilised bone were recovered from contexts which produced large amounts of unworked bone. However, two pieces of antler recovered from the site show signs of re-use which suggests that antler was sufficiently scarce to warrant recycling. The strip of antler (B10) has a worn and bevelled outer edge. The piece had been carefully detached, using a groove and splinter technique, from a larger artefact possibly a handle. The strip probably formed part of a small collection of rough outs gleaned from one broken larger piece. The small antler ring (B17) shows excessive and uncharacteristic wear and polish on its outer compact surface. It seems likely that this wear dates from a time when the piece was part of a larger artefact.

Metal awls, drills, saws and choppers were used in the manufacture of the Baleshare assemblage. Iron staining on the inner channel of the Roe deer handle (B5) indicates that this was part of a hafted iron implement. The sharp diamond shaped slits on one side of antler coronet (B8) are the result of hammering a sharp metal awl into the antler. This would have happened during skin and leather working processes, it is also a technique used in fine metal working. The broken needle (B4) and the disc shaped weight (B18; Figure 78b) have both been perforated by the use of a bow drill with a metal bit. Both perforations are too fine and regular to have been produced by a hand drill or awl.

\section{0.5.3 Hornish Point}

A total assemblage of twenty-three pieces of worked bone and antler was recovered during excavation. These can be categorised as follows: three complete artefacts (H7, H12, $\mathrm{H} 23)$; five broken artefacts (H10, H11, H13, H14, H15); six broken points and awls (H1-H4, H6, H8); three off-cuts and roughouts $(\mathrm{H} 9, \mathrm{H} 19, \mathrm{H} 22)$; four fragments $(\mathrm{H} 16, \mathrm{H} 17$, $\mathrm{H} 18, \mathrm{H} 20)$ and two utilised pieces (H5, H21). Only one of the fifteen antler artefacts is made from Roe deer antler (H22), all the rest are made from Red deer antler. One piece (H9), a thin strip of antler exhibits signs of having been cut from a larger artefact. This is similar to the Baleshare example (B10) and again this indicates that broken antler artefacts were re-cycled. 
As at Baleshare, a study of tool marks left on the bone and antler pieces demonstrates the use of a tool kit which does not survive in the archaeological record. There are indications for the use of metal awls or punches, saws, knives and hand drills.

The sharp diamond shaped slits on one side of the whale bone slab (H21) indicates the use of a metal awl or punch during leather or metal working. The other side of the slab displays striations which indicate that the slab had been used to sharpen bone or metal points. Two different saws have been used in the production of the antler comb (H13, Figure $78 \mathrm{~d}$ ) and the off-cut (H19). The interdental notches on the comb were produced by a thin fine saw whereas the saw which detached the off-cut was a thick heavy saw. The perforations on artefacts $\mathrm{H} 12$ (Figure $78 \mathrm{c}$ ) and $\mathrm{H} 14$ have been produced by hand drilling; the perforations are irregular and counter sunk, hand drilling being a less efficient method than bow drilling. The absence of advanced working techniques only indicates selection of appropriate techniques rather than the full range of techniques available. A separate report has been prepared on the comb (see below).

\section{0.5.4 The comb fragment from Hornish Point}

A N Smith (1995)

\section{Description}

This fragment has been derived from a small one-piece, single-sided comb (Figure 77d). The carefully shaped and smoothed back, and the slight curve visible at one end indicate that this comb had probably had an open D-shaped back, and would have looked very much like the complete comb from a broch site at Bowermadden, Caithness (Anderson 1883, 232-3 fig 205; Figure 77e).

The fragment is too small to make a positive identification of the material, but the pattern of cancellous and solid material on the reverse of the piece is more like antler than bone. Unusually for a comb, the teeth are aligned at right angles to the grain of the material, which may have been necessitated by the size and shape of the piece of raw material used in its manufacture. The fragment indicates that a minimum of six teeth were present, with deep $\mathrm{V}$-sectioned cuts continuing towards the upper edge of the comb, a feature also to be seen on the Bowermadden comb. The teeth are markedly tapered, and the longest displays transverse wear grooves on the front surface. One end is blackened and slightly burnt; this is the end which curves up slightly, but the curve is certainly deliberate and there are no signs of heat distortion.

\section{Discussion}

A variety of small, single-sided single-piece combs are known to have been in use in Scotland before the introduction of the composite comb in the fifth century AD. These can be divided into two main groups; combs with rounded backs and incised curvilinear decoration, such as that from Ghegan Rock, East Lothian (NMAS HD78), and Langbank Crannog (NMAS HC105); and small rectangular combs with rectilinear decoration, such as that recently found at Howe (Ballin Smith 1994, 177; illus 90a, 100 SF4907). The Howe comb was found among redeposited midden material infilling the ditch; this infill took place during Phase 7 which is dated from the first to the fourth century AD. Examples of this type have also been found at the broch of Kettleburn, Caithness (NMAS GI37), and from St Boniface, Papa Westray (Wilson 1998, 140). As there is no independent dating for the round-backed examples, it is not yet clear whether this grouping has a chronological or regional basis. Both types are generally provided with suspension holes, and were probably worn round the neck or suspended from a belt.

The openwork back of the Hornish Point and the Bowermadden comb is unusual, and a form which is without parallel in Scotland. On the continent, however, a variety of small one-piece, single-sided combs with pierced and openwork backs have been found (MacGregor 1985, 77; Thomas 1960). Thomas (ibid, 66-71) notes that this type (Type C) has a distribution concentrated predominantly in the Elbe region. The origin and precise dating of these combs is disputed, but it has been suggested that they may be derived from Bronze Age metal prototypes. Thomas (ibid) argues for an early Roman date for the more elaborate examples illustrated, on the grounds of associations with certain fibula types. The comb from Hornish Point is the first of its type from a context which can be independently dated. A date in the early to middle Iron Age for these combs in Scotland would not be at variance with a derivation of the type from Continental Bronze Age metal ancestors.

These combs show clear signs of having been used for combing hair, in the form of transverse wear marks across the teeth, although their small size, all less than $60 \mathrm{~mm}$ long, and relatively short teeth, would seem to make them rather impractical. It is possible, as MacGregor suggested $(1985,78)$ that they were used for combing beards and moustaches. 


\section{CHAPTER I I: THE HUMAN, ANIMAL, BIRD AND FISH BONE ASSEMBLAGES}

\section{I.I HUMAN BONE FROM BALESHARE AND HORNISH POINT}

\section{F Lee (1987)}

Human bones were retrieved from an extended inhumation at Baleshare and from a ritual burial of one individual in four pits, at Hornish Point.

\section{I.I.I Baleshare}

An adult female skeleton aged over 35 years was retrieved during the excavation of the Baleshare midden in 1984. The skeleton was reasonably well preserved and most of the body was retrieved. A low degree of dental hygiene was evident in the presence of four abscesses, three in the upper jaw and one in the lower jaw. Many of the teeth had been lost and periodontal disease resulting in extreme alveolar recession was undoubtedly partially responsible. Degenerative change to the articular surfaces of the bones were noted but are not considered to be unusual considering the age of the individual. Osteoarthritis was present on the apophyseal joints of the vertebral column.

\section{Age}

The individual was found to be older than 35 years. This was estimated from a consideration of the pubic symphyses (Gilbert \& Mckern 1973) in conjunction with the rate of dental attrition (Brothwell 1972).

\section{Stature and physical type}

The stature was estimated from the tibial length to be 167.1 $\pm 3.66 \mathrm{~cm}$ (Trotter \& Gleser 1952). The skull was mesocranic or of average dimensions and the nasal index was also average.

\section{Preservation}

The preservation of the bones ranged from excellent to fair. The more fragile bones, in particular those of the vertebral column and the flat bones were those which had sustained the most damage.

\section{Non-metric variations}

Epigenetic variations and non metric traits are descriptions of minor morphological abnormalities in the skeleton. They are used in human bone studies to establish whether or not there is any degree of genetic proximity between groups. In this instance the following variants were simply noted where present (after Berry \& Berry 1967; Finnegan 1973);

Cranial; Ossicles or wormian bones were present in the left lambdoid suture, at the lambda and at the right asterion. The mandible exhibited a mandibular torus.

Postcranial; Both of the innominate bones have an acetabular crease. The left patella exhibits a small vastus notch. The right tibia has a small squatting facet while both the left and right talus support a corresponding facet on the superior aspect of the bone. Finally the left calcaneum exhibits a double anterior facet.
Dentition

$7654 \mid 4568$

148

The rate of dental wear was more marked on the right side of the jaw. Dental hygiene had clearly been poor. A minimum of ten teeth had been lost before death. Alveolar recession was particularly marked and had resulted in the loosening of the remaining teeth making their loss more likely. The degree of calculus on the crown and roots of the teeth ranged from medium to considerable. The occlusal surface of the upper 3rd right molar had been completely covered by the concretion indicating that the tooth was no longer in use. Calculus may help to initiate periodontal disease, an infection of the alveolar bone and soft tissues of the mouth (Brothwell 1972). Closely associated with periodontal disease are the presence of four dental abscesses. Three of these occur in the extant part of the mandible. The molars and premolars are the teeth affected and although this may indeed be associated with periodontal disease infection by exposure of the dental pulp through increased attrition must also be considered.

\section{Pathology}

Degenerative change to the articular surfaces of the bone were noted. This is considered here to be a feature of the ageing skeleton. Osteoarthritis was visible on the apophyseal joints of the 4th, 5th and 7 th cervical vertebrae. All of the thoracic vertebrae had osteoarthritis of at least one of the apophyseal joints, while in the lumbar vertebrae only the third left inferior facet was affected. Invertebral osteochondrosis, the result of pathological changes in the invertebral disc, was present on the 6th and 7th cervical vertebrae, 1 st and 2 nd thoracic, and 1st, 3rd, 4th and 5th lumbar as well as on the bodies of the three late cervical vertebrae, the 1st, 4th, 5th, 6th and 10th thoracic and all of the lumbar vertebrae.

A complete catalogue of the bones can be found in the site archive.

\section{I.I.2 Hornish Point}

The remains of a single individual were found in four different pits, [138], [174], [178] and [481]. The remains were in a disarticulated state, although the excavator noted that many of the epiphyseal plates were in their correct anatomical positions at the end of the long bone diaphyses.

The age of the individual is estimated from the dentition to be 12 years \pm 30 months and the ages for the appearance and fusion of the epiphyses would support this view. The sexing of juveniles is notoriously unreliable, but the evidence from the pelvis, sacrum and skull suggest, tentatively, that the individual was male.

Non-metric traits are of little value in the study of isolated individuals, they are used predominately to show the variability or genetic distance between groups of individuals. However the following variations were noted; the anterior condylar facets are double and there is a possible ossicle in the right lamboid suture.

There is evidence for Spina Bifida Occulta; this is a much less severe case of spina bifida, detectable in skeletal material as a bony defect and found on average in $2.7 \%$ of British 


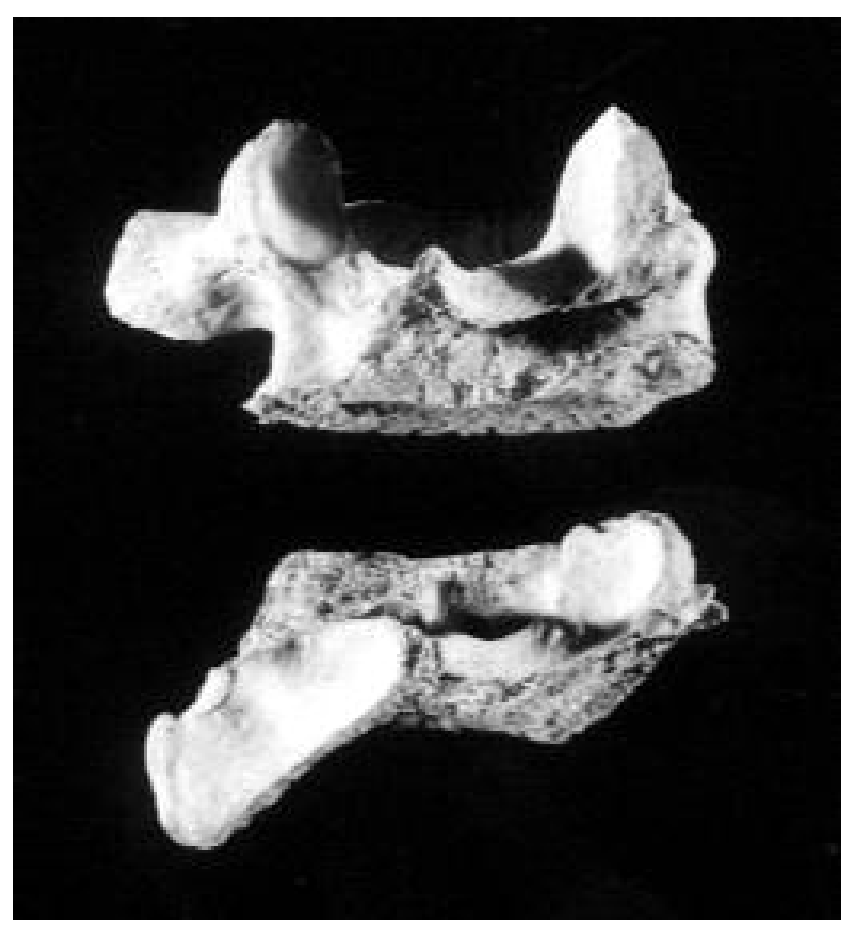

Plate 31. Hornish Point. Human vertebrae from the burial showing evidence of cutting

skeletons (Brothwell \& Powers 1968). The spinal cord is usually normal and lies within its bony canal. The membranes are intact but the spinous processes and laminae of one or more vertebrae are defective, in life these would have been bridged by cartilage or membrane. In this individual the defect occurs in the first three sacral vertebrae. In most cases (and almost certainly here) it would not have given rise to symptoms, although in more severe cases it may be associated with paralytic deformities of the lower limb (Illingworth \& Dick 1979). The dentition is normal and healthy with slight calculus on the labial surfaces.

The fourth and fifth lumbar vertebrae have been subjected to deliberate disarticulation or butchery. The damage suggests two diagonal chops or cuts applied to the back of the individual, slicing through the trunk in the waist to hip region. There is no evidence of damage to the ilium although the unfused iliac crest is absent. One cut has removed both of the inferior articular facets and the right lateral part of the body of L4, and the left superior articular facet and left lateral part of the body of L5. The second cut has removed both of the inferior articular surfaces of L5 and the right lateral part of the inferior body surface. The first of the sacral vertebrae is unaffected (Plate 31). The cleanliness of the cut suggests that it was made with a sharp instrument. It is impossible to ascertain exactly when the 'injury' occurred but it must have been either at death or postmortem. An injury of this kind would have been incompatible with life, nor is there any evidence for healing.

Another possibility is that it was a result of deliberate disarticulation of the individual after death. This could be supported by the evidence for the distribution of the body in it's four contexts. Essentially, [138] contains parts of the body below L5 including the lower right limb and part of the pelvic girdle. [174] contains the upper part of the trunk, upper limbs and skull, all above L4. [178] contains essentially the lower trunk and pelvic girdle, although it also includes a few oddities: the clavicle, two ribs, metacarpal and the lower condyles of the left femur. Finally [481] contains fragments of the left foot. Furthermore, there is evidence to suggest that some degree of excarnation or decomposition had occurred before the bones were placed in the 'post-holes'. [138] contains the left and right pubis and right ischium, while the rest of the pelvic girdle was found in [178]. [174] contains most of the hand and finger bones, but the left second metacarpal and first left proximal phalynx are found in [178]. Finally the left distal epiphysis of the radius in [178] is from the left radial diaphysis in [174]. In most instances however, the epiphyseal plates were noted to be in their correct positions at the ends of the diaphyses, suggesting that while excarnation may have occurred decomposition was not necessarily complete.

\section{I.I.3 Catalogue of human bones from Hornish Point}

The full catalogue is presented here to illustrate the division of bones between the four pits.

\section{Pit [178]}

Pelvis; 3 incomplete fragments. Left pubis, right pubis and ischium (rami fused, acetabulum unfused).

Femur; 5 incomplete fragments. Right-diaphysis \& lower condyles (unfused).

Patella; 1 complete frag, right only.

Tibia; 3 incomplete frags, Right-diaphysis and condyles (unfused).

Unidentified; 5 frags.

Pit [I 74]

Skull; 98 fragments, incomplete. Almost all of the cranium and face is present, but the mandible is absent.

Thoracic; 17 fragments; incomplete. Fragments of 3 neural arches and a minimum of 6 bodies (body epiphysis present but unfused) all are middle to late thoracic.

Lumbar; 2 fragments, incomplete. One upper lumbar vertebra.

Ribs; 52 fragments, incomplete. Minimum no 7 right. Minimum no 8 left

22 fragments side unidentified. (epiph unfused).

Clavicle; 2 fragments, incomplete. Left-medial end and lateral part of shaft.

Scapula; 6 fragments, incomplete. Left: 5 fragments glenoid cavity and coracoid process unfused. Right: coracoid process only.

Humerus; 4 fragments, incomplete. Left humerus diaphysis, head and capitulum unfused.

Radius; 2 fragments, incomplete. Left frags of diaphysis.

6 fragments, incomplete. Right-diaphysis and proximal and distal epiphyseal plates unfused.

Ulna; 2 fragments, incomplete. Left fragments of diaphysis.

4 fragments, incomplete. Right-fragments of diaphysis and distal epiphysis.

Carpels; 8 fragments, incomplete. Left and right lunate and hamate; right capitate, $3 \mathrm{x}$ unidentif.

Metacarpals; 8 fragments, incomplete. Left head of 1st, 4th and 5 th present (distal end unfused). Right-all present (unfused). 
Phalanges; 11 fragments, incomplete. $8 \mathrm{x}$ proximal, $3 \mathrm{x}$ middle.

Sternum; 3 fragments, incomplete; manubrium and 2 segs (unfused) of sternum body.

\section{Pit [138]}

Thoracic; 3 fragments, incomplete. Neural arch of early thoracic vertebrae and $1 \mathrm{x}$ unfused epiphyseal plate for body.

Lumbar; 3 fragments, incomplete. L4 and L5 present and the neural arch of L2 or L3.

Sacrum; 2 fragments, incomplete. 1st-3rd sacral vertebrae, 2nd and 3rd fusing.

Ribs; 2 fragments, incomplete. $2 \mathrm{x}$ right ribs.

Clavicle; 1 fragment, incomplete; 1 Right lateral end.

Radius; 1 fragment, incomplete. Distal epiphyseal plate only.

Metacarpal; 1 fragment, incomplete. Left 2nd M/C, distal end unfused.

Pelvis; 3 fragments, incomplete. Left ilium and ischium (unfused); Right-ilium.

Femur; 1 fragment, incomplete. Left lower condyles unfused.

Phalanges; 1 fragment, incomplete. 1st proximal (hand).

Pit [48I]

Metatarsals; 3 fragments, incomplete; Left 3rd-5th (unfused).

Phalanges; 1 fragment, incomplete; 1st proximal phalanx.

\section{I.2 ANIMAL BONES FROM BALESHARE AND HORNISH POINT}

P Halstead (1987)

\section{I.2.I Introduction}

Mammalian faunal material from the late Bronze/early Iron Age coastal sites of Baleshare and Hornish Point was submitted for analysis. The following questions were posed by the excavator:

i) Are the 'midden' deposits at Baleshare and Hornish Point true farmyard middens or accumulations of domestic refuse?

ii) What are the relative contributions of wild and farmyard animals to the economy? Were deer present on the islands?

iii) Does butchery practice or the selection of particular cuts/species of meat support the idea that Baleshare and Hornish Point lie at the bottom of a social/settlement hierarchy rising via wheel-houses, forts and duns to brochs?

iv) Is the mineral deficiency (eg copper and cobalt) of the machair reflected in the faunal assemblage?

v) Can the nature of local animal husbandry be clarified? vi) On the basis of this pilot study, would a large scale project allow more detailed reconstruction of animal husbandry?

vii) How appropriate were the applied techniques for the recovery of faunal material? Should they be revised for a large scale project?

Questions $i-v$ are concerned with the original animal population of the region and with human selection of particular animals on the basis of species, age and sex, and of particular body parts for different purposes. Faunal evidence for such selective human behaviour is based on the identification of particular carcasses or body parts in the discarded food refuse. The reconstruction of discard practices is also of relevance to question $i$. After faunal material is discarded it may be subject to further selective distortion (cf Clarke 1973) and possible factors may be as follows:

i) during deposition, eg by dogs, weathering,

ii) after deposition, eg by chemical action in the ground,

iii) during retrieval, eg by incomplete recovery,

iv) during analysis, eg by recording of inappropriate variables.

\section{Retrieval bias}

Retrieval bias is the subject of questions $v i$ and $v i i$ and the effects of (post-) depositional distortion should be identified before the data are interpreted in terms of questions $i$ to $v$. In effect, archaeozoological interpretation involves retracing the sequence of distorting filters to which the data have been subject between prehistoric economy and contemporary computer printout.

Prior to addressing the specific questions outlined above, the sequence of filters is considered followed by presentation of certain basic characteristics of the two assemblages relevant to pre-depositional human behaviour.

\section{I.2.2 'Distorting filters'}

\section{Analysis}

The methodology of this study is described in Chapter 9. The mammals identified are sheep (Ovis aries), cattle (Bos taurus), pig (Sus scrofa), red deer (Cervus elaphus), dog (Canis familiaris), seal and otter (Lutra lutra), in descending order of abundance (Tables $10 \& 11$ ). Although the single largest identified group is 'sheep/goat', no specimens were identified to goat (Capra hircus), whereas over 200 specimens from most parts of the skeleton could be assigned to sheep. It can therefore be safely assumed that all the sheep/goat material belongs to sheep. Red deer are represented by numerous fragments of antler while a number of postcranial pieces and one tooth are compatible with red deer in terms of size and morphology. Some of the cervid material is too fragmentary to be definitely assigned to red deer but it is almost certain that the biogeographically less plausible fallow deer Dama dama is not present (cf Berry 1979). On the basis of size, the few bones of seal should probably be assigned to the 


\begin{tabular}{|c|c|c|c|c|c|c|c|c|}
\hline Block & Sheep & Cow & Pig & Dog & Seal & Otter & Red Deer & Total \\
\hline I & 11 & 13 & - & - & - & - & I & 25 \\
\hline 2 & 176 & 85 & 17 & - & 1 & - & I & 280 \\
\hline 3 & 19 & 16 & 3 & - & - & - & 2 & 40 \\
\hline 4 & 1 & - & - & - & - & - & - & 1 \\
\hline 5 & 45 & 2 & 3 & - & - & - & - & 50 \\
\hline 6 & 40 & 12 & 3 & - & 1 & - & - & 56 \\
\hline 7 & 6 & 36 & 3 & - & i & - & - & 46 \\
\hline 8 & 2 & 3 & 2 & - & - & - & - & 7 \\
\hline 9 & 15 & 8 & 2 & - & 1 & - & - & 26 \\
\hline II & 62 & 9 & 2 & - & - & - & 3 & 76 \\
\hline 14 & 19 & 22 & 6 & - & - & - & - & 47 \\
\hline 15 & 107 & 65 & 8 & 1 & - & - & 2 & 183 \\
\hline 16 & 200 & 138 & 18 & - & 1 & - & 3 & 360 \\
\hline 17 & 35 & 17 & 1 & - & - & - & 1 & 54 \\
\hline 18 & 51 & 49 & I & - & - & - & 1 & 102 \\
\hline 19 & 15 & 8 & 2 & - & - & - & - & 25 \\
\hline 20 & 36 & 18 & 7 & - & - & - & - & 61 \\
\hline 21 & 3 & 3 & 1 & - & - & - & - & 7 \\
\hline 22 & 128 & 53 & 5 & I & - & - & 1 & 188 \\
\hline 23 & 22 & 24 & 1 & - & 1 & 1 & 2 & 51 \\
\hline 24 & 69 & 32 & 23 & 4 & - & - & - & 128 \\
\hline 25 & 68 & 27 & 3 & - & - & - & - & 98 \\
\hline 26 & 38 & 46 & 4 & I & - & - & 2 & 91 \\
\hline 27 & 37 & 190 & 3 & - & - & - & - & 50 \\
\hline 28 & 1 & - & I & - & - & - & - & 2 \\
\hline \multirow[t]{2}{*}{ Totals } & 1206 & 696 & 119 & 7 & 6 & 1 & 19 & 2054 \\
\hline & $59 \%$ & $34 \%$ & $6 \%$ & $<1 \%$ & $<1 \%$ & $<1 \%$ & $1 \%$ & \\
\hline
\end{tabular}

Table 10. Baleshare. Minimum numbers of identified anatomical units

common seal (Phoca vitulina). A few eroded pieces of whale bone have not been further identified and could possibly be flotsam collected from the beach. Rabbit (Oryctolagus cuniculus) was represented only by a single specimen from a modern deposit at Hornish Point. Three isolated limb bones from immature rodents (of mouse/vole, rather than rat, size cf Berry 1979, 35, Table 5) in Blocks 2, 17 and 24 at Baleshare could not be precisely identified and could easily be intrusive.

The method of quantification adopted (minimum numbers of selected anatomical units) reduces the risk of repeatedly counting the same fragmented specimen, but also reduces the size of the assemblage. Nonetheless, the size of the assemblages is modest and this prevents systematic comparison of the faunal material from different blocks. Indeed, for many purposes, the assemblages from the two sites are considered together. Overall the number of sexable specimens is very small and the dental evidence for age at death is highly fragmentary.

The patterns of mortality are only discussed for the two commonest species - sheep and cattle. Because so much of the mandibular material consists of loose teeth, analysis of butchery, gnawing, etc is restricted here to postcranial material.

\section{Retrieval}

All the bones were retrieved with a $5 \mathrm{~mm}$ mesh sieve. As a result, recovery of larger mammal remains is excellent with even loose neonatal epiphyses and carpal bones of sheep have regularly been recovered. The method of excavation, out- lined in Chapter 9, resulted in only partial excavation of most features. Caution must be exercised, therefore, in interpreting the absence of particular body parts in deposits which seem to contain substantial parts of individual carcasses.

\section{Post-depositional destruction}

Although the assemblages are highly fragmented and contain a high proportion of very vulnerable neonatal material, there is no sign of serious post-depositional damage to bone surfaces.

A few specimens exhibit surfaces suggesting abrasion by blown sand, but the main source of depositional destruction is gnawing and, to a lesser extent, digestion by carnivores. $11 \%$ of postcranial material at Baleshare, and $20 \%$ in the smaller assemblage from Hornish Point is affected in this way. The primary agents of this destruction are presumably domestic dogs, although actual remains are scarce on the sites (Tables $10 \& 11$ ). The pattern of destruction to be expected of dogs is complex and depends on such factors as the age and hunger of the dog (Payne \& Munson 1985), the age, sex, season of death and the prior treatment by man of the carcass/skeleton in question (Binford \& Bertram 1977). Nonetheless, in the larger assemblage from Baleshare, the frequency of different body parts of sheep is broadly comparable with that reported from two modern Navajo cases where complete sheep were fed to dogs (Binford \& Bertram 1977, $100 \&$ Table 3.5). Both at Baleshare and in the Navajo case (averaging the results from the winter and summer sites), the mandible is the most commonly represented element, 


\begin{tabular}{|c|c|c|c|c|c|c|c|c|}
\hline Block & Sheep & Cow & Pig & Dog & Seal & Otter & Red Deer & Total \\
\hline I & 3 & 14 & - & - & - & - & - & 17 \\
\hline 2 & 7 & I & 2 & - & - & - & - & 10 \\
\hline 5 & 25 & 15 & 3 & - & - & - & 3 & 46 \\
\hline 6 & 30 & 12 & 6 & - & - & - & - & 48 \\
\hline 7 & - & 3 & 2 & - & - & - & - & 5 \\
\hline 8 & 3 & I & - & - & - & - & - & 4 \\
\hline 9 & 2 & - & 1 & - & - & - & - & 3 \\
\hline 10 & 5 & 3 & - & - & - & - & - & 8 \\
\hline 11 & I & - & 2 & - & - & - & - & 3 \\
\hline 12 & 12 & 6 & 9 & - & - & - & - & 27 \\
\hline 13 & 10 & 5 & 4 & - & - & - & - & 19 \\
\hline 15 & 8 & 11 & 1 & - & - & - & - & 20 \\
\hline 17 & 12 & 8 & 5 & - & - & - & - & 25 \\
\hline 18 & 11 & 15 & 5 & 2 & - & - & I & 34 \\
\hline 19 & 30 & 18 & 7 & 1 & - & - & - & 56 \\
\hline 20 & 76 & 3 & 2 & - & - & - & - & 81 \\
\hline 22 & 5 & 3 & 1 & - & - & - & - & 9 \\
\hline 23 & I & I & 2 & - & - & - & - & 4 \\
\hline 26 & 6 & 4 & I & - & - & - & - & 11 \\
\hline 27 & 9 & - & - & - & - & - & - & 9 \\
\hline 28 & 3 & - & - & - & - & - & - & 3 \\
\hline 32 & I & - & - & - & - & - & - & I \\
\hline \multirow[t]{2}{*}{ Totals } & 260 & 123 & 53 & 3 & - & - & 4 & 443 \\
\hline & $59 \%$ & $28 \%$ & $12 \%$ & $1 \%$ & - & - & $1 \%$ & \\
\hline
\end{tabular}

Table 11. Hornish Point. Minimum numbers of identified anatomical units

while the phalanges are particularly scarce. The most common postcranial elements include distal humerus, proximal radius, pelvis and distal tibia in both cases, proximal tibia, proximal and distal metacarpal at Baleshare only, and scapula in the Navajo case only. Much of the variability in the frequency of body parts therefore, at least among the Baleshare sheep, may be attributed to destruction by dogs. The observed differences may simply be a product of small sample size or incompatible methodology.

\section{Discard}

The circumstances surrounding the discarding of bone at Baleshare and Hornish Point can be clarified in a few cases. The most striking case is that of the remains of two cattle and two sheep found in pits [138, $178 \& 481]$ at Hornish Point (see description for Block 18). The carcasses of these animals had been exploited for their skins, meat and marrow, before their dismembered and, in the case of cattle, splintered, bones were collected and buried. Two other forms of apparently deliberate burial are the 'butchery waste' (feet, or heads and feet, of sheep) at Hornish Point in [465] (see description for Block 27), [314] and [413] (see description for Block 20), and the neonatal calf and lambs at Baleshare in [098] (see description for Block 7) and [126] (see description for Block 11) and Hornish Point [314] (Block 20). In each case, two things point to deliberate, or at least rapid, burial. Firstly, several elements apparently derived from the same limb or carcass have remained in association. Secondly, the incidence of gnawing is extremely low, occurring on average in only $3 \%$ of post-cranial material in these deposits compared with $14 \%$ in the remainder of the two assemblages. The incidence of whole bones is also very high with an average of $81 \%$ compared with only $24 \%$ for the remainder of the two assemblages.

One small group of specimens should also be noted. Among the loose deciduous teeth from Baleshare, there are five mandibular $\mathrm{d} 4 \mathrm{~s}$ (three of cow, two of sheep) with roots indicating that they had been shed naturally (Table 12). The cow specimens are from [21] (Block 5), [270] (Block 23) and [40] (Block 24); the sheep specimens are from [52] and (diagnosis uncertain) [57] (Block 2). Blocks 2, 5 and 24 are described as middens or dumps and so these finds perhaps hint that these deposits included stall manure as any deciduous teeth shed in the byre would have become mixed in with manure and bedding material and so could have been incorporated into midden deposits during mucking out. The cattle tooth from Block 23 was found in 'windblown sand' and so could perhaps have been shed in situ by a grazing beast. Alternatively, the anthropogenic items and the loose tooth in this deposit may reflect the admixture of midden material during a brief cultivation episode.

The circumstances of the deposition of the remaining material are less clear. The proportion of the identifiable material bearing unambiguous signs of carnivore gnawing or digestion, 14\% (above) is certainly an underestimate, not least because gnawed bone is much less likely to be identifiable. The proportion of the assemblage, excluding the deposits with deliberately buried material, displaying clear signs of human action in the form of cut marks (5\%) and burning $(16 \%)$ is also low. Burnt bone is less likely to survive and be identifiable than unburnt while cut marks are not always made during butchery and may only be discernible on well preserved bone surfaces. This last point is reinforced by the high frequency of cut marks among the unusually well 


\section{a) Sheep}

d4

0

2A

$5 A$

$8 \mathrm{~L}$

I3L

I4L

$16 \mathrm{~L}$

I7L

$18 \mathrm{~L}$

$20 \mathrm{~L}$

$22 \mathrm{~L}$

$23 \mathrm{~L}$

Total

(35) 33

\section{b) Cattle}

d4

a

b

c

d/e

$\mathrm{f} / \mathrm{g}$

j

k

$>$ n

Total

(I) -

(2) -

(38) 36
Baleshare

Hornish Pt

M3

0

$2 A$

$4 \mathrm{~A}$

$5 A$

$6 \mathrm{G}$

$7 \mathrm{G}$

$8 \mathrm{G}$

$9 \mathrm{G}$

IOG

IIG

I2G

$13 \mathrm{H}$

Baleshare

Hornish Pt

M3
Baleshare

Hornish Pt

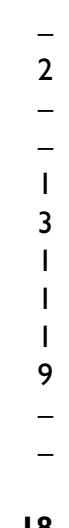

Baleshare

Hornish Pt

3
3
-
-
-
-
$*-$
-
-
-
-

8

$a$
$b$
$c$
$d$
$e$
$f$
$g$
$j$
$k$
$>m$

7
$* * 18$
2
1
3
4
-
-
-
1

Table 12. Baleshare \& Hornish Point. Age at death - wear of mandibular d4 and M3 preserved material in the deliberately buried deposits $(19 \%-$ in spite of the large proportion of unbutchered neonatal remains). There is no reason, therefore, to doubt that most of these two assemblages were initially discarded by man, after the removal of skins, meat and perhaps, to judge from their highly fragmented state, marrow. The major exception to this concerns the large proportion of neonatal bones (cattle 36\%, sheep 9\%), which would not have survived gnawing by dogs and so perhaps represent further (unrecognised or disturbed) deliberate burials.

\section{I.2.3 The assemblages}

\section{Species composition}

In terms of minimum numbers of identified anatomical units, sheep predominate $(59 \%$ at both Baleshare and Hornish Point), followed by cattle ( $34 \%$ and $28 \%$ respectively) and then pigs (6\% and 12\%). The remaining large mammals (dog, red deer, common seal and otter) together constitute less than $2 \%$ of each assemblage (Tables $10 \& 11$ ). Given the small size of the assemblages particularly from Hornish Point, no significance can be attached to the minor differences between the two sites, nor can chronological change within either site be investigated.
Age and sex structure of cattle and sheep

For both cattle and sheep, dental evidence suggests a bimodal pattern of mortality (Table 12). At Baleshare, the first mortality peak of cattle spans the eruption and early wear of mandibular d4: 28 out of 36 unshed teeth are less worn than stage $\mathrm{f} / \mathrm{g}$ and so probably come from calves in just the first few weeks of life (Serjeantson nd). Two of the three heavily worn $\mathrm{d} 4 \mathrm{~s}$ were apparently shed and so probably do not indicate deaths in the period just before P4 erupted (at circa 2.5-3 yrs - Grigson 1982). The second and smaller peak is represented by M3s in an advanced stage of wear. These latter teeth cannot reliably be assigned an age in years, but they represent animals of breeding and/or working age. The smaller sample from Hornish Point is compatible with that from Baleshare, except that a pair of mandibles from the unusual 'funerary feast' deposit in Block 18 context 138 falls between the two main peaks of mortality, (d4s late in wear stage $K)$.

For sheep, the first mortality peak occurs slightly later. Although a few unworn or lightly worn $\mathrm{d} 4 \mathrm{~s}$ attest to neonatal deaths, most $\mathrm{d} 4 \mathrm{~s}$ are in an advanced state of wear: 22 out of 33 unshed specimens from Baleshare fall between wear stages $14 \mathrm{~L}$ and $17 \mathrm{~L}$, and 11 of these fall in stage $16 \mathrm{~L}$. The rate of tooth wear is more variable than the rate of tooth eruption, so the first mortality peak for sheep is more difficult to age in absolute terms than the corresponding peak for cattle. Fortu- 


\begin{tabular}{|c|c|c|c|c|c|}
\hline \multirow{3}{*}{$\begin{array}{l}\text { a) Sheep } \\
\text { age stage }\end{array}$} & \multicolumn{2}{|c|}{ Baleshare } & \multicolumn{2}{|c|}{ Hornish Point } & \multirow[b]{3}{*}{$\%$ dead } \\
\hline & & & & & \\
\hline & neonatal* & older* & neonatal* & older* & \\
\hline \multirow[t]{3}{*}{ new born } & 135 & 816 & 41 & 210 & $15 \%$ \\
\hline & $(90)$ & (77I) & (6) & $(\mathrm{III})$ & $(9 \%)$ \\
\hline & unfused*** & fused** & unfused*** & fused ${ }^{* *}$ & \% dead米米 \\
\hline 6-10 months & 24 & 66 & 4 & 19 & $25(36)$ \\
\hline I3-28 months & 92 & 74 & 24 & 27 & $54(61)$ \\
\hline $30-36$ months & 48 & 22 & 10 & 3 & $70(75)$ \\
\hline $36-42$ months & 58 & 13 & 14 & 7 & $78(81)$ \\
\hline \multicolumn{6}{|l|}{ b) Cattle } \\
\hline age stage & neonatal* & older* & neonatal* & older & $\%$ dead \\
\hline \multirow[t]{3}{*}{ newborn } & 194 & 291 & 41 & 109 & 37 \\
\hline & $(I 78)$ & $(264)$ & $(4 I)$ & $(60)$ & 36 \\
\hline & unfused ${ }^{* *}$ & fused** & unfused ${ }^{* *}$ & fused ${ }^{* *}$ & \% dead米米 \\
\hline $7-10$ months & 2 & 2 & 2 & 2 & \\
\hline $12-18$ months & 27 & 40 & 23 & 10 & $50(69)$ \\
\hline $24-36$ months & 9 & 14 & 7 & 4 & $47(67)$ \\
\hline 36-48 months & 22 & 9 & 7 & 2 & $73(83)$ \\
\hline
\end{tabular}

Table 13. Baleshare \& Hornish Point. Age at death-postcranial evidence. Key: * = minimum numbers of anatomical units - all identified postcranial elements (totals excluding recognised neonatal burial s in parentheses). $* *=$ minimum numbers of anatomical units - sheep: 6-10 months, scapula, dist humerus, prox. radius, pelvis (acetab): 13-28 months, distal tibia, distal metacarpal/tarsal, prox. phalanx 1-2: 30-36 months, prox. ulna, prox. femur, calcaneum: 36-42 months, prox. humerus, distal radius, distal femur, prox. tibia: cow 7-10 months, scapula, pelvis (acetab): 12-18 months, distal humerus, prox. radius, prox phalanx 1-2: 24-36 months, distal tibia, distal metacarpal/tarsal: 36-48 months, prox. humerus, distal radius, prox. ulna, prox. \& dist. femur, prox. tibia, calcaneum. *** excluding neonatal mortality (figures in parentheses adjusted to allow for neonatal mortality of $15 \%$ [sheep] and 37\% [cattle])

nately, four of the $\mathrm{d} 4 \mathrm{~s}$ from stage $16 \mathrm{~L}$ are associated in mandible fragments with M1 (once at wear stage $2 A$ and three times at $7 A$ ) and $\mathrm{M} 2$ (once in the earliest stage of eruption). (A fifth $\mathrm{d} 4$ at the heavily worn stage $23 \mathrm{~L}$ is associated with $\mathrm{M} 1$ at $9 A$ and $\mathrm{M} 2$ at $5 A$ ). In other words, the first peak of sheep mortality falls around the time when M1 is in early wear and M2 is just beginning to erupt, ie probably at a little under one year of age. The second peak of sheep mortality is again represented by M3s in an advanced stage of wear, suggesting animals of breeding age. In fact this peak may be rather clearer than is suggested by Table 12, as several M3s have a distinctive 'flaw' in the enamel which may cause age to be underestimated on the recording system used here. Again, the smaller sample from Hornish Point is compatible with its larger counterpart from Baleshare.

Epiphyseal fusion is a notoriously problematic source of evidence for reconstructing mortality patterns (Chapter 4), but the postcranial material from Baleshare and Hornish Point offers a useful check on the dental evidence (Table 13). The neonatal category accounts for $37 \%$ of cattle and $15 \%$ of sheep postcranial elements, excluding the recognised burial deposits (see descriptions for Baleshare Blocks 7 and 11, Hornish Point Blocks 18, 20 and 27). Thereafter epiphyseal fusion suggests a more or less even division of mortality between the first 1-1.5 years (cattle) or 1-2 years of life (sheep) and 2-4 years or later. The timing of the younger deaths is unclear, but they may well correspond with the early first year mortality of cattle and late first year mortality of sheep indicated by the dental evidence.

The results of the two lines of evidence are fairly clear and mutually consistent. For both sheep and cattle, a small number of animals was kept to an advanced age suitable for breeding or in the case of cattle, traction. Of younger cattle deaths, the majority fell in the first few weeks of life and a minority a little later. The first peak of sheep mortality, on the other hand, fell in the latter part of the first year.

A few sexed pelves with fused acetabulum provide the only evidence for the sex structure of sheep and cattle (Table $14)$. As the reported fusion age for the acetabulum of sheep is 6-10 months, this limited evidence suggests that a majority of the sheep dying in their first year were males, while those surviving to a greater age were mostly females.

\section{Carcass utilisation}

The proportions of the assemblages bearing signs of human intervention, principally cut marks and burning, have already been noted. The frequency of cut marks is the same for cattle and sheep bones (5\%), but sheep bones are more commonly burnt (19\%) than cattle bones (8\%). Large animals tend to be more thoroughly dismembered and filleted before cooking than smaller animals. The burning of the sheep bones could have been caused by the cooking of joints on the bone and probably more likely, by throwing the bones into the hearth after meals. Most of the cut marks observed appear to have

\begin{tabular}{ccccc} 
& \multicolumn{2}{c}{ Baleshare } & \multicolumn{2}{c}{ Hornish Point } \\
& Female & Male & Female & Male \\
Sheep & 15 & 5 & 8 & - \\
Cattle & 2 & 1 & 1 & -
\end{tabular}

Table 14. Baleshare \& Hornish Point. Sex structure of cattle and sheep 
been made with a knife, a few with apparently a heavier cleaver. All marks are compatible with sharp, metal tools.

\section{Metrical data}

Standard measurements were taken, but the small size and fragmented state of these two assemblages prevent useful discussion of the size of the animals represented.

\section{I.2.4 Addressing the research questions}

i) The nature of the midden deposits at Baleshar e and Hornish Point A few deposits appear to be deliberate burials of new born animals, of butchery waste and perhaps in one case, of the remains of a 'funerary feast'. Most deposits contain animal bone, usually including specimens with traces of human activity, eg cut marks, burning and canine, eg gnawing, activity. In other words, most deposits include domestic refuse, much of which has at some stage been discarded in a location accessible to dogs. Unfortunately, domestic refuse partly gnawed by dogs might equally be expected in habitation contexts, in domestic rubbish dumps, in farmyard middens and in 'middened' cultivation horizons. Indeed if occupation sites were quarried for fertiliser or even selected for cultivation in situ, there may be no clear distinction between these different types of midden/site. Deposits classified on archaeological grounds as 'midden', 'cultivation' and 'windblown sand' deposits contain very similar proportions of gnawed, burnt, cut, complete and newborn bones and a very similar ratio of cow to sheep bones. Recognisable 'features' (buildings, pits, etc) are distinguished by more cut and complete bones, more sheep phalanges and fewer burnt bones; all characteristics of the 'burials' which dominate these features. The incidence of complete and recognisable cut bones would probably decrease, however, if these deposits were reworked through middening.

All this is consistent with the archaeological identification of the Baleshare and Hornish Point sites as a mixture of true middens, middened cultivation horizons and occupation deposits subject to reworking or in situ cultivation. The bone component of these deposits would have contributed phosphate to arable land, while horn, hoof and blood would have added nitrogen (FMA 1981). Finally, a few naturally shed deciduous teeth may hint that the middens contained stall manure, the greatest potential contribution of livestock to soil fertility.

\section{ii) The relative importance of wild and farm yard animals}

The mammal bone assemblages are overwhelmingly dominated by domestic sheep, cattle and pigs, and the paucity of remains of wild mammals is most unlikely to be an artefact of taphonomic bias. Red deer specimens include a range of postcranial elements as well as antler, but the sample is far too small to determine whether these represent a red deer population living on the islands or just the occasional skin, joint of meat and antler brought from the mainland or one of the inner islands.

\section{iii) Butchery practice and social hierarchy}

The concentration of cattle mortality in the very young and old age groups - a far from 'gourmet' strategy of husbandry is consistent with, though hardly indicative of low status. At

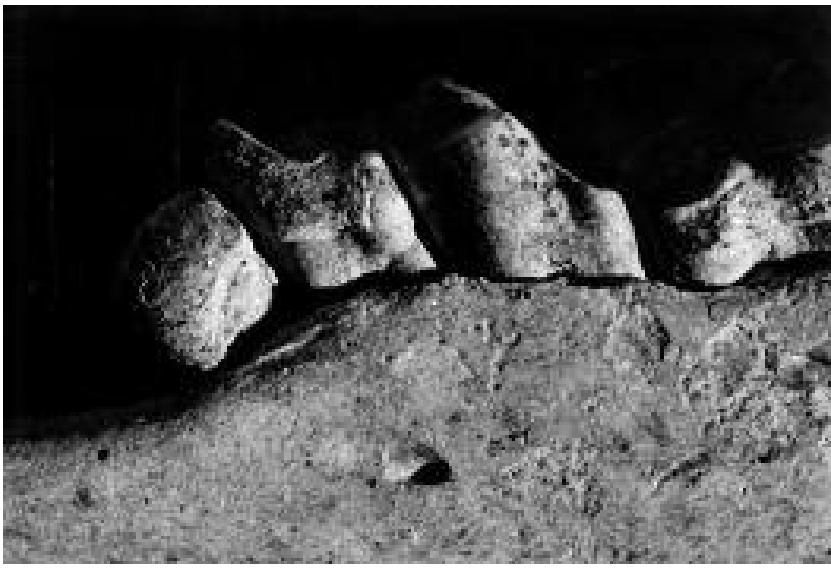

Plate 32. Sheep mandible showing a heavy development of calculus

Hornish Point Block 18, two cattle were, exceptionally, slaughtered at an intermediate, prime meat bearing age and their association with an unusual funerary deposit is both striking and significant. The apparent rarity of either sheep or cattle of breeding age suggests limited demographic potential for producing further animals of prime meat age for export to settlements of higher status. Much of the observed variation in the abundance of different anatomical units is explicable in terms of attrition by dogs. Detailed consideration of selective human usage of particular body parts would require substantially larger assemblages. Above all, investigation of the relationship between social status, on the one hand, and butchery practices and the exchange of animals, on the other, needs comparable assemblages from other levels in the settlement hierarchy.

\section{iv) Mineral deficiency of the machair}

No pathological conditions were observed which can be attributed to the copper or cobalt deficiency of the machair. A possible hint of different dietary problems in the local herbivore populations comes from an adult sheep mandible from Hornish Point Block 1, in which heavy development of calculus has obscured the occlusal surface of P2, while P4 and M1 have been subject to abnormally heavy wear (Plate 32). This condition is common in severe form in modern sheep feeding on seaweed along the shoreline in North Ronaldsay and has tentatively been related to this specialised diet (Baker \& Britt 1984). Seaweed was apparently introduced to the Baleshare and Hornish Point sites, possibly as fodder (Thew infra).

\section{v) The nature of local animal husbandry}

Despite the small size of the samples the type of husbandry practices can clearly be identified. Evaluation of the abundance of neonatal remains is complicated by differences in the treatment of neonatal and older carcasses, with the former perhaps more likely to be preserved by rapid burial. Significantly, however, the abundance of neonatal cattle remains is matched by the scarcity of evidence for juvenile deaths. Conversely, the relative paucity of neonatal sheep remains is offset by abundant evidence of mortality among juvenile sheep. Since the sites of Baleshare and Hornish Point include domestic rubbish dumps and 'middened' cultivation horizons, as well as burials, it seems unlikely that any age group is entirely unrepresented because of discard practices. The abundance of neonatal cattle remains 
is unlikely, therefore, simply to reflect natural infant mortality exaggerated by taphonomic factors.

Such a severe cull of very young calves is characteristic of a specialised dairy economy (Legge 1981; Payne 1973). Young sheep were apparently raised for their meat and killed off towards the end of the first year. Whether this occurred in autumn, to coincide with the end of the summer flush of grazing, or during the course of winter, to compensate for lower or non-existent milk yields from the cattle, cannot as yet be determined. The predominance of females over males suggests that breeding rather than wool production was the principal role of adult sheep. In the later assemblage from the Udal, North Uist, the ratio of sheep to cattle is circa 3:1 to 4:1 (Serjeantson nd), compared with only 2:1 at Baleshare and Hornish Point, which is possibly related to the documented importance of woollen textiles in historical times. Sheep may also have been prized as providers of manure. This same combination of cattle raised under a high input, high output, high risk dairy strategy and of sheep raised under a low input, low output, low risk meat strategy also characterises the later assemblage from the Udal.

Together the young cow and sheep deaths document occupation at Baleshare and Hornish Point at least during spring and during autumn or winter.

\section{vi) The potential for more detailed reconstruction of anima I husbandry}

A broad outline of the animal economy can be provided if the entire assemblages from Baleshare and Hornish Point are pooled. To provide a similar level of information for each site or for individual periods with either site, commensurately larger assemblages would be needed (see Mulville 1999 for Dun Vulan). Even taking the existing assemblages together, the degree of resolution in economic reconstruction is limited. Far larger assemblages would be required for detailed mortality profiles with reliable sex ratios, particularly in the case of cattle. Similarly a useful sample of pathological observations on dietary deficiencies or possibly on the use of cattle for traction, would demand a massive increase in the size of assemblage. Larger assemblages, from a much larger number of contexts of different types, would also allow more detailed reconstruction of bone discard and deposition pathways with advantages both for the reliability of inferences about animal husbandry and for the understanding of middening practices and the use of animal products in maintaining soil fertility in the arable sector. In this latter context, investigation of recent middens could also be very instructive.

As noted earlier with reference to question $i i i$, a major priority is to acquire bone assemblages from other categories of site. Indeed the most profitable strategy, in terms of costs and benefits, may be to extract faunal assemblages, comparable in size and quality to that from Baleshare, from a series of sites of varying date, location and presumed hierarchical status.

\section{vii) The appropriateness of the recovery techniques}

Present recovery techniques are excellent for the larger mammals and indeed the mesh size could be increased somewhat without loss of information if this significantly speeded up recovery. Sample sieving to a finer mesh size would be necessary for recovery of small mammal (and also of fish and bird) bones and might clarify some biogeographical issues concerning the rodent fauna of the Outer Hebrides (Berry 1979).

\section{I.3 FISH REMAINS FROM BALESHARE AND HORNISH} POINT

\section{A K J Jones (1987)}

\section{I.3.I Introduction}

A total of 140 fish bones was recovered, together with the animal bone from deposits excavated at Baleshare, while 111 were recovered from the site at Hornish Point. Most were large bones of fish of a metre or longer in length. Many of the fish remains were broken fragments of robust bones (eg the distal portion the premaxilla and the centra of vertebrae) suggesting that the more fragile elements had not survived the passage of time and the excavation procedures. Despite the fragmentary nature of the remains, relatively few of the bones (fifteen from Baleshare, eleven from Hornish Point) were unidentifiable. However, it has not proved possible to assign all the identified remains to species, some were attributed to family, or broader taxonomic group.

Because $5 \mathrm{~mm}$ aperture meshes were used in the sieves to recover the bulk of the fish remains, it is very likely that remains of several species of small-boned fishes, which were present in the deposits at the time of excavation, passed through the sieves and were lost. Nevertheless, the assemblages are composed of the remains of a great diversity of fishes, ranging from large sharks, large gadoids (the bulk of the remains), wrasse, mackerel and several kinds of flatfishes. (Fish remains from wet-sieving and flotation not analysed but remain available in the archived material).

Table 15 is a summary of the data showing the numbers of identifiable remains for each taxon present in the two assemblages. Catalogues of the fish bones are presented in Tables 16 and 17 .

\section{I l.3.2 Discussion}

All the fish represented in the deposits were marine species and illustrate the diversity of fishes exploited during the period of occupation. Bones of gadoids, (hake, cod, saithe, pollock and ling) comprise $75 \%$ of the identified remains from Baleshare and almost all the identifiable remains from Hornish Point. Other species of gadids were restricted in their distribution. Ling, for example, was present in a single layer at Baleshare, the midden of Block 16.

Hake is a fish which was, and still is, subject to considerable variation in abundance. Hickling $(1935,62)$, reviewing records of the hake fishery reaching back to $1746 \mathrm{AD}$ concludes that '...long before the amount of fishing carried on was enough to matter, there were variations in the abundance of hake, since bad years as well as good years were reported...'. Thus short-time scale variations in the abundance of hake may help to explain why hake were common at one site, but were less abundant at the other. Cod, on the other hand, is less susceptible to fluctuations in abundance.

Remains of sharks were restricted to the lower levels at Baleshare, none being found above Block 16, nor at Hornish Point. External features on the centra suggest that the majority of mineralised vertebral centra were from the tope, Galeorhinus galeus, a determination confirmed by $\mathrm{X}$-radiography. All shark remains were large mineralised 
Latin name

Elasmobranchii

Galeorhinus galeus

Squatina aquatina

Merluccius merluccius

Gadus Morhua

Pollachius pollachius

P.virens

Molva cf molva

Gadoid

Labrus bergylta

Scomber scombrus

Pleuronectidae

Pleuronectidae Platessa

?Hippoglossoides platessoides

Hippoglosoides bothidae
Common name

Baleshare

Hornish Point

Shark

Tope

Angel Shark

Hake

Cod

Pollack

Saithe

Ling

Hake or Gadidae

Ballan wrasse

Mackerel

Flatfish

Plaice

?Long rough dab

Left-eyed flatfish

Unidentified

Total

$\begin{array}{rr}2 & 0 \\ 5 & 0 \\ 1 & 0 \\ 52 & 2 \\ 29 & 72 \\ 4 & 0 \\ 1 & 7 \\ 9 & 1 \\ 10 & 17 \\ 1 & 0 \\ 1 & 0 \\ 4 & 1 \\ 3 & 0 \\ 1 & 0 \\ 2 & 0 \\ 15 & 11 \\ 140 & 111\end{array}$

Table 15. Baleshare \& Hornish Point. Fish species present

\begin{tabular}{|c|c|c|c|c|c|c|c|c|c|c|c|c|c|c|c|c|}
\hline Species* & $I$ & 2 & 3 & 4 & 5 & 6 & 7 & 8 & 9 & 10 & II & 12 & 13 & 14 & 15 & UnID \\
\hline \multicolumn{17}{|l|}{ Block } \\
\hline I & & & & 225,6 & $6,13,2$ & 4,2 & (3) & & & $23,(5), ?$ & ? 14 & & & 3 & & \\
\hline \multicolumn{17}{|l|}{ U (3) } \\
\hline 5 & & & & 21 (2) & & & & & & & & & & & & \\
\hline 6 & & & & 21,22 & & & & & 2 & & I & & 3 & & & U \\
\hline 9 & & & & $21(8)$ & 4,6 & & 22 & & & & & & & & & U \\
\hline II & & & & 22 & & & & & & & & & & & 24 & \\
\hline 14 & & & & & & & & & 25,1 & & & 21 & & & & \\
\hline 15 & & 24 (2) & & & , 22 (2) & & & & 2 & & & 28 & & & & \\
\hline \multirow[t]{2}{*}{16} & & 24 & & $21(28), 2$ & 24 (I2) & 226 & $2 \mid(3), 2$ & $44(8)$ & & & $22(9)$ & 22 & & & & \\
\hline & 17 & & & & & & & & & & & $28(3)$ & & & & \\
\hline 18 & & $24(2)$ & & & 22 & & & 22 & 3 & & & & & & 23 & \\
\hline 20 & 24 & & & & 21 & & & & 15 & & & & & & & \\
\hline 22 & & & 24 & & & & & & & & & & & & & \\
\hline 23 & & & & & 12 & & & & & & & & & & & \\
\hline 24 & & & & & 7,21 & & & & & & & & 18 & & & \\
\hline 25 & & & & 4 & 21 & & & & 14 & & & & & 19 & & U (2) \\
\hline
\end{tabular}

Table 16. Baleshare. Catalogue of fish bones ("for species see Table 16). Key: $1=$ Parasphenoid; 2 = Basioccipital; 3 = Vomer; 4 Dentary; 5 = Articular; 6 = maxilla \& premaxilla; $7=$ Quadrate; 8 = super-cleithrum; 9 = Cleithrum frag;

$10=$ inter-operculum; 11 = Subopercular; 12 = Post-temporal; 13 = Ceratohyal; 14 = Pharynageal; $15=$ Brachial; $16=$ Palatine; $17=$ Squamosal; $18=$ Urohyal; $19=$ Anal pterygihore $; 20=$ First vertebra $; 21=$ Precaudal vertebra; $22=$ Caudal vertebra; $23=$ Vertebral centra $24=$ Vertebrae $; 25=$ Vertebral spine U = unid

vertebral centra of $10 \mathrm{~mm}$ width. One other species of cartilaginous fish was identified, the angel shark, Squatina squatina. Two shark centra could not be assigned to species. Large sharks rarely occur in substantial numbers in British waters. The distribution of shark vertebrae (present at Baleshare but absent at Hornish Point) is difficult to explain, and probably is related to factors which have been obscured by the passage of time. (Of course, it is possible that people at Baleshare liked to catch and eat sharks, while those at Hornish Point did not!) However, scavengers and other natural agents may have influenced the material which has survived at the two sites.
While the bulk of the fish remains were from large individuals, mainly of the cod family or hake, a small number of remains from smaller fish were present. Sieving to $5 \mathrm{~mm}$ produced bones of mackerel, at least one medium sized gadid, and several species of flatfish, while flotation yielded three bones of small (less than $20 \mathrm{~cm}$ total length) gadids, probably saithe, Pollachius virens.

Signs of butchery were restricted to a single cod maxilla from Hornish Point which bore a shallow knife mark on its aboral face.

All the species recovered from the site are found today in the waters around North Uist. While there is no direct evi- 


Species*
Block
I
2
5
6
12
13
15
17
18
19
22
27
28

22

U (I)?

Table 17. Hornish Point. Catalogue of fish bones (" for species see Table 16). Key: 1 = Parasphenoid; 2 = Basioccipital; 3 = Vomer; 4 = Dentary; 5 = Articular; 6 = maxilla \& premaxilla; 7 = Quadrate; 8 = super-cleithrum; $9=$ Cleithrum frag; 10=inter-operculum; $11=$ Subopercular; $12=$ Post-temporal; $13=$ Ceratohyal; $14=$ Pharynageal $; 15=$ Brachial; $16=$ Palatine; $17=$ Squamosal; $18=$ Urohyal; $19=$ Anal pterygihore; $20=$ First vertebra $; 21=$ Precaudal vertebra $; 22=$ Caudal vertebra; $23=$ Vertebral centra; $24=$ Vertebrae; $25=$ Vertebral spine; $U=$ unid

dence for the fishing methods used to capture the fishes all species can be caught using lines bearing baited hooks. Very small saithe can also be caught using hooks of the appropriate size, but it is traditional to catch these small shoaling fish when they come close inshore during the late summer and autumn by using handnets operated from the shore or from boats (Baldwin 1982). Hand-lines and hand-nets were surely available to the sites' inhabitants.

This report shows that remains of a large number of different kinds of fishes occur in the deposits at the two sites. There is good reason to believe that further species will be recovered if sufficient samples of selected deposits (for example, floor deposits, pit fills and midden layers) are sieved on 1 $\mathrm{mm}$ meshes. However, the quantities of fish remains recovered so far may indicate that fish remains are not particularly abundant in the deposits.

Recent experimental work by Payne and Munson (1985), Jones (1986) and others has clearly demonstrated that bones, particularly fish bones, are very vulnerable to taphonomic loss caused by scavengers and other agents. By considering the elements recorded in Tables 16 and 17 it is clear that the bones so far identified from the sites are robust elements of the species present. This evidence suggests that very large numbers of fragile elements have been lost from the deposits. Indeed, it is possible that some species which were exploited by the Late Bronze Age and Early Iron Age populations of North Uist have left no detectable trace.

Thus it is possible that the deposits now contain so few fish remains that archaeologists will never be confident that representative samples of the fish originally deposited at the site are recovered. Consequently detailed questions concerning the nature of fish exploitation at the sites may continue to go unanswered. Nevertheless, the results of this trial work are most encouraging and it is to be hoped that a sampling strategy involving the use of $1 \mathrm{~mm}$ sieving will be executed during future excavations.

\section{I.4 BIRD BONES FROM BALESHARE AND HORNISH POINT D Serjeantson (1987)}

\section{I.4. I Baleshare}

Approximately ninety bird bones were recovered from the excavation at Baleshare, of which sixty-one were identified to species (Table 18). Vertebrae, ribs, phalanges and small undiagnostic fragments were not identified. The identification of some of the incomplete bones is not certain; this is indicated in the table below. The twenty-four bones of the fulmar are from one bird. They were found in the backfill between passage walls (Block 7). Today fulmars use stubs of walls for nesting, so the possibility must be considered that this bird used the site at a time when the settlement was abandoned, and died there. There is no reason however to doubt that most of the other species would have been brought to the site by the inhabitants. There is firm evidence for human activity in the case of the ulna of the great auk found in the midden (Block 24), which has a short butchery cutmark across the olecranon process (Figure 79c). Among the birds present are a number of waterfowl and waders as well as seabirds. Today the waterlogged backswamps of the machair dune system on the west Uist coast are important wetlands, and the waterfowl among the bones indicate that this habitat was present in prehistoric times. The seabirds are (or were) species which bred round the coast in late spring and early summer. Others such as the whooper swan today are winter visitors (Hopkins \& Coxon 1979).

Two extinct birds are represented among the bones recovered, the great auk and a crane. A distal tibia (Plate 33) from the midden (Block 16) is similar to, but larger than, the common crane. It is probably from the north-west palaearctic crane (Milne-Edwards 1856), a large extinct crane which was described by Harrison and Crowles (1977). Other bones of this crane have been found at Glastonbury and in late Bronze Age or early Iron Age levels in the Kings Cave, Jura (Mercer 1978). The great auk is a common find at prehistoric coastal 


\section{Species}

Latin name

Fulmarus glacialis

Puffinus puffinus

Sula bassana

Phalacrocorax carbo

Anser anser

Cygnus cygnus

Anas platyhrhynchos

Anas of penelope

Melanitta nigra

Grus primigenia

Tringa of nebularia

Tringa of totanus

Calidris alpina

Larus sp.

Alca impennis

Uria aalge

Fratercula artica
SC H

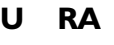

UL CO

FU FE

FE TT CM TM

TM SY AC MN

PH VT Total

Common name
Fulmar
Manx shearwater
Gannet
Cormorant
Greylag goose
Whooper swan
Mallard
?Wigeon
Common scoter
Crane
?Greenshank
?Redshank
Dunlin
Gull ?herring
Great auk
Guillemot
Puffin

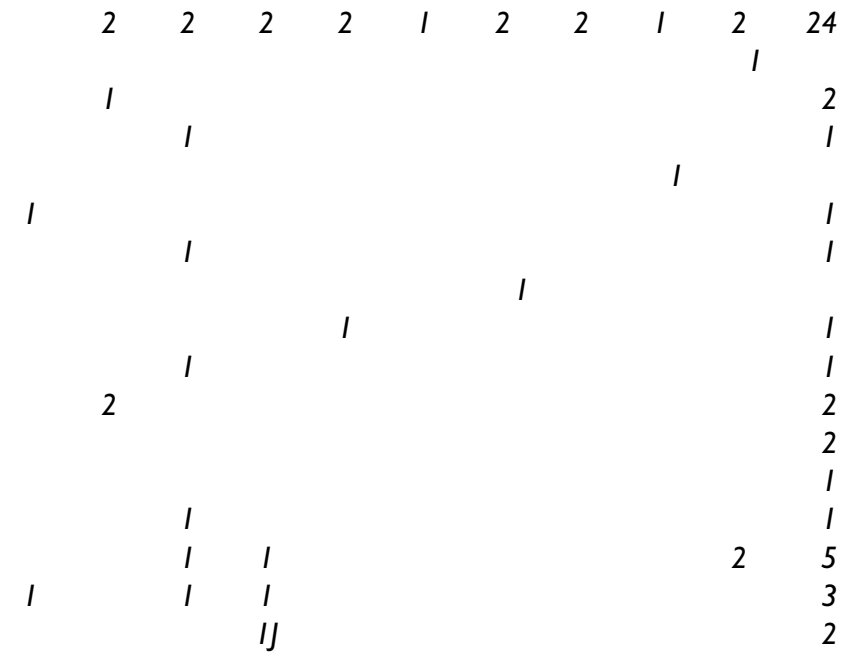

Table 18. Baleshare. Bird species present. Key: $S C=$ Scapula; $T T=$ Tibiotarsus; $H U=H u m e r u s ; C M=$ Carpometacarpus; $R A=$ Radius; $T M=$ Tarsometatarsus; UL = Ulna; SY = Synsacrum; CO = Coracoid $; A C=$ Acetabulum $;$ FU $=$ Furculum; $M N=$ Mandible VT $=$ Vertebra $P H=$ Phalanx $; F E=$ Femur

sites around the north and west of Scotland and the small offshore islands are characteristic of the type of location in which it used to breed.

The number of different species identified (19) is high in relation to the number of bones identified. This is a typical feature of assemblages of bird bones from archaeological sites in the Northern and Western Isles (Serjeantson 1988). It does suggest that wild fowl were a casual rather than a major resource.

\section{I.4.2 Hornish Point}

Twelve bird bones from six species were identified (Table 19). The humerus identified as crow or rook is likely to be from a hooded crow as North Uist today is beyond the range of the rook. Most interesting are two bones of the great auk, both with cut marks. A coracoid from the midden was chopped or heavily cut in two directions above the area of articulation with the sternum, and a further three superficial parallel cuts on the bone show where preliminary attempts were made (Figure 79a). A distal tibia from Block 13 has cuts across the lateral and medial ridges (Figure 79b). Four bones of a mallard found together in the post-medieval structure (Block 20) are from a complete discarded wing. There is a cutmark where the wing was disarticulated on the proximal humerus.

\section{Species}

\section{Latin name}

Puffinus puffinus

Anas platyrhynchos

Alca impennis

Turdus sp

Corvus corax

Corvus sp
HU

RA

\section{Common name}

Manx shearwater

Mallard

Great auk

Thrush/redwing?

Raven

Crow?rook

Unidentified

RA UL

UL

CO

TT

CM

TM

Total

$$
\text { I }
$$

I

II

$\begin{array}{ll}1 & 2 \\ & 1 \\ & 5 \\ & 2 \\ & 1 \\ & 1 \\ & \end{array}$

9

Table 19. Hornish Point. Bird species present. Key: SC = Scapula; TT = Tibiotarsus; $H U=$ Humerus; CM = Carpometacarpus; $R A=$ Radius; $T M=$ Tarsometatarsus; $U L=$ Ulna; SY = Synsacrum; CO = Coracoid AC = Acetabulum; FU = Furculum; MN $=$ Mandible VT $=$ Vertebra PH = Phalanx; FE = Femur 


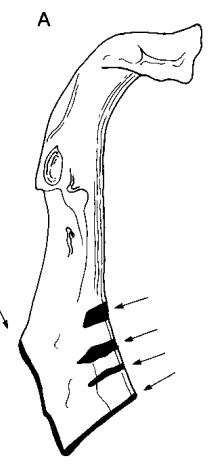

B

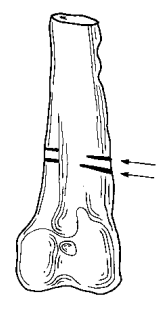

$3 \mathrm{~cm}$

Figure 79. Butchery marks on bird bones from Baleshare and Hornish Point. a) Hornish Point; sternum of great auk. b) Hornish Point; distal tibia of great auk. c) Baleshare; ulna of great auk

C

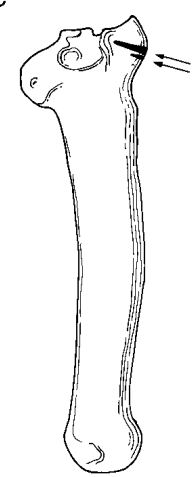

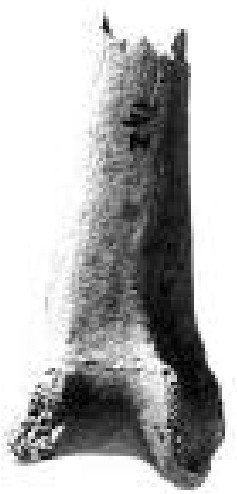

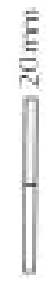

Plate 33. Baleshare. Distal tibia of extinct crane species from Block 16 


\section{CHAPTER I2: THE CHARRED PLANT REMAINS FROM BALESHARE AND HORNISH POINT}

\section{G Jones (1987)}

Samples from 353 different contexts were examined, 176 from Baleshare and 177 from Hornish Point. All but eleven of these (seven from Baleshare and four from Hornish Point) produced some identifiable charred remains (See Tables 20 \& 21).

\section{I AIMS}

This study of the charred plant remains from Baleshare and Hornish Point attempted to answer the following questions:

i) What species are represented, particularly:

a Were cultivated species other than barley present? Was it considered possible and worthwhile to cultivate wheat?

$b \quad$ Which wild species are represented and did these grow locally or were they brought in from further afield?

ii) Does the midden represent accumulations of domestic refuse, true farmyard middens, or are both types of accumulations represented?

iii) Is it possible to distinguish plant material representing food debris from that coming in as fuel and, if so, is it possible to use the wild species introduced by these two routes to indicate the location of cultivated fields and fuel sources?

iv) Are there any differences in the plant remains found at the two sites and, in particular, are differences between sites also apparent when similar deposit types are compared, ie are inter-site differences simply a reflection of the different types of deposit encountered in the excavations?

$v$ Is it possible to distinguish between different types of deposit (eg from features, middens, cultivation layers and windblown sands) on the basis of the quantity and type of charred plant remains, ie can charred plant remains be used as an indicator of human interference?

\section{2.2 SPECIES REPRESENTED}

\subsection{Crops}

By far the most common crop represented was barley which, where determination was possible, was of the hulled variety. No obviously naked grains were found. Twisted grains (and a few identifiable rachis internodes) indicate the presence of the six-row species, Hordeum vulgare. The twisted, lateral grains of six-row barley outnumber the straight, medial grains by two to one while all the grains of two-row barley are medial and, therefore, straight. Straight grains tend to predominate over twisted ones which might suggest the pres- ence also of the two-row species, $H$. distichum. However, most of the grains were indeterminate on the basis of shape and so the apparent predominance of straight grains may simply reflect the difficulty of distinguishing twisting due to natural causes from deformation during charring.

Wheat was represented by very few examples and may have been nothing more than a minor contaminant of barley. All the grains and glume bases which could be further identified were of Triticum diccoccum (emmer wheat).

\subsubsection{Wild species}

The most commonly encountered wild taxa were Carex spp. (sedges), Danthonia decumbens (heath grass), Polygonum aviculare agg (knotgrass) and Brassicao Sinapis (brassicas/charclock). Morphologically, most of the Carex nutlets resembled species in the sections Panicea Carey (C. panicea, C. flacca) or Extensae Fr. (in particular, C. hostiana, C. oederi and C. demissa) though some species from other sections, eg C. rostrata and C. pallescens, could not be excluded. The shapes of a few nutlets at Hornish Point were more typical of C. binervis or C. distans (both in section Extensae Fr.) or even C. lasiocarpa or C. pilulifera.

Fruits of Calluna/Erica (heather ling or heath) were also quite common in some samples. Other frequent taxa included Polygonum cf. persicaria (persicaria), Rumex sp. (dock), Stellaria media (chickweed), Graminaea (grasses) and Cyperaceae/Polygonaceae (sedges/knotgrasses). Chenopodium album (fat hen), atriplex sp. (orache), Bilderdykia convolvulus (bindweed), Medicago sp. (medick), Sherardia arvensis (field madder) and Plantago lanceolata (ribwort) were occasionally present. Vegetative fragments of non-cereal plants, including large numbers of probable rhizomes, were also frequent.

Many of these species could have grown in the machair, eg Carex flacca, C. paniceda, C. hostiana, C. lepidocarpa, C. rostrata and C. pallescens (Currie 1979). Other plants which prefer acidic conditions, eg Calluna/Erica, Danthonia decumbens, Carex binervis and C. pilulifera, (Ratcliffe 1977) would have grown on acidic heath, grasslands or moors. Most of the species mentioned above, except Calluna/Erica but including Danthonia decumbens (Hillman 1981) could also occur as weeds of cultivation and some of them (such as the Polygonum spp, and Stellaria media) are very common weeds. All of the taxa encountered could have grown locally in the Uists (Clapham et al 1962)

A few small fragments of fleshy fruits were found which may have been edible but could not be identified more specifically. Similarly, Brassica spp., if present, could have been cultivated for food but the alternative, Sinapis arvensis, is a common field weed.

\section{2.3 DISCUSSION}

\subsection{Nature of the middens}

With the exception of catastrophic destruction of buildings by fire, plant material at these sites is most likely to have been charred on household fires or in domestic ovens. On balance, the charred plant remains probably represent domestic refuse resulting from accidental losses of food 


Barley Int* Wheat Cereal Str** Root Weeds

\section{Features}

12

II

7

14

9

8

29

Total

\section{Midden}

15

16

5

2

17

19

24

Total
22

253

II

34

18

20

2

39

399

2824

239

88

320

87

491

229

4278

\section{Int}

Cereal

Str**

Root

Weeds

\section{Cultivation layers}

\section{I}

22

26

18

20

25

Total

$\begin{array}{rl}5 & 0 \\ 33 & 0 \\ 121 & 0 \\ 10 & 0 \\ 8 & 0 \\ 125 & 0 \\ 302 & 0\end{array}$

\section{Windblown sand}

3

10

21

23

6

27

Total
28

7

4

7

12

27

85

0
1
0
0
0
0
0
0
1

$\begin{array}{rr}3 & 0 \\ 36 & 0 \\ 3 & 0 \\ 9 & 0 \\ 1 & 0 \\ 1 & 0 \\ 0 & 0 \\ 1 & 0 \\ 54 & 0\end{array}$

1
13
0
0
1
0
0
3
18

$\begin{array}{rrrr}191 & 2 & 15 & 48 \\ 18 & 0 & 8 & 12 \\ 6 & 2 & 8 & 23 \\ 3 & 0 & 26 & 19 \\ 0 & 0 & 3 & 9 \\ 25 & 0 & 3 & 25 \\ 7 & 9 & 23 & 19 \\ 250 & 13 & 86 & 155\end{array}$

\section{SUMMARY}

\section{Features}

Midden

Cultivation layers

Windblown sand Total

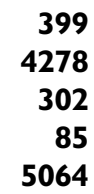

0
1
0
0
0
0
0
1
2

2
0
0
1
0
1
0
4

$\begin{array}{rl}0 & 0 \\ 4 & 0 \\ 20 & 0 \\ 0 & 0 \\ 1 & 0 \\ 0 & 0 \\ 25 & 0\end{array}$

$\begin{array}{rr}0 & 0 \\ 2 & 2 \\ 6 & 1 \\ 1 & 6 \\ 0 & 2 \\ 1 & 1 \\ 10 & 12\end{array}$

$\begin{array}{rrrr}4 & 0 & 5 & 6 \\ 0 & 0 & 0 & 0 \\ 0 & 0 & 0 & 0 \\ 0 & 0 & 0 & 0 \\ 0 & 0 & 1 & 0 \\ 2 & 0 & 3 & 7 \\ 6 & 0 & 9 & 13\end{array}$

54
250
25
6
335

0
13
0
0
13

12
86
10
9
117

18

155

12

13

198

Table 20. Baleshare. Carbonised plant remains. * = barley rachis internodes. "*grass occl nodes

plants and/or material used as fuel. The ability to distinguish true farmyard middens (deliberately accumulated as fertilizer to be spread onto cultivated fields) from ordinary domestic refuse (casually deposited in the vicinity of settlement sites) depends on the extent to which such domestic refuse was added to farmyard middens. This cannot be solely determined on the basis of the plant remains present.

On the islands of Orkney and Shetland surface turves from grassland, heath and moor, as well as underlying peat, were collected for fuel and the resulting ash thrown onto middens (Fenton 1978). Animal dung, sometimes mixed with turves, seaweed or straw from the byre, was also used. If this was common practice in the Western Isles in the Iron Age, it is likely that the two types of midden would be indistinguishable on the basis of charred plant remains. It may nevertheless be possible to distinguish between plant material derived from food debris and that derived from fuel. This could, by an analysis of the species represented, suggest the likely location of cultivated fields and the areas exploited for fuel (see Smith 1999 for results from Dun Vulan). 


\begin{tabular}{|c|c|c|c|c|c|c|c|}
\hline Identifications & Barley & Int* & Wheat & Cereal & Str** & Root & Weeds \\
\hline \multicolumn{8}{|l|}{ Features } \\
\hline 3 & 5 & 0 & 0 & 0 & 0 & 2 & 0 \\
\hline 7 & 44 & 0 & 0 & 8 & 1 & 13 & 21 \\
\hline 15 & 116 & 5 & 0 & 13 & 0 & 18 & 33 \\
\hline 18 & 144 & 2 & 0 & 6 & 0 & 27 & 24 \\
\hline 20 & 16 & 0 & 0 & 0 & 0 & 3 & 6 \\
\hline 22 & 121 & 0 & 0 & 6 & 0 & 4 & 13 \\
\hline 27 & 72 & 0 & 0 & 7 & 0 & 5 & 2 \\
\hline 29 & 12 & 0 & 0 & 0 & 0 & 6 & 3 \\
\hline Total & 530 & 7 & 0 & 40 & 1 & 78 & 102 \\
\hline \multicolumn{8}{|l|}{ Midden } \\
\hline 8 & 256 & 1 & 2 & 9 & 2 & 18 & $4 I$ \\
\hline 9 & 256 & 0 & 0 & 13 & 0 & 19 & 13 \\
\hline 11 & 214 & 0 & 1 & 8 & 0 & 21 & 40 \\
\hline 12 & 206 & 0 & 0 & 9 & 1 & 18 & 23 \\
\hline 13 & 69 & 0 & 0 & 2 & 0 & 5 & 4 \\
\hline 17 & 237 & 0 & 1 & 9 & 0 & 15 & 35 \\
\hline 19 & $14 \mid 4$ & 0 & 9 & 105 & 10 & 238 & 221 \\
\hline 21 & 57 & 0 & 0 & I & 0 & 2 & 13 \\
\hline Total & 2709 & 1 & 13 & 156 & 13 & 336 & 390 \\
\hline \multicolumn{8}{|l|}{ Cultivation layers } \\
\hline 1 & 273 & 1 & 0 & 6 & 0 & 14 & 13 \\
\hline 2 & 155 & 0 & 1 & 9 & 2 & 4 & 22 \\
\hline 5 & $|53|$ & 2 & 6 & 59 & 1 & 122 & 110 \\
\hline 6 & 1380 & 4 & 9 & 83 & 14 & 269 & 414 \\
\hline 10 & 40 & 0 & 0 & I & 0 & 0 & 5 \\
\hline 26 & 180 & 0 & 0 & 19 & 0 & 23 & 29 \\
\hline Total & 3559 & 7 & 16 & 177 & 17 & 432 & 593 \\
\hline \multicolumn{8}{|l|}{ Windblown sand } \\
\hline 4 & 116 & 0 & 0 & 6 & 0 & 17 & 20 \\
\hline Total & 116 & 0 & 0 & 6 & 0 & 17 & 20 \\
\hline \multicolumn{8}{|l|}{ SUMMARY } \\
\hline Features & 530 & 7 & 0 & 40 & $\mathbf{I}$ & 78 & 102 \\
\hline Midden & 2709 & $\mathbf{I}$ & 13 & 156 & 13 & 336 & 390 \\
\hline Cultivation layers & 3559 & 7 & 16 & 177 & 17 & 432 & 593 \\
\hline Windblown sand & 116 & 0 & 0 & 6 & 0 & 17 & 20 \\
\hline Total & 6914 & 15 & 29 & 379 & 31 & 863 & 1105 \\
\hline
\end{tabular}

Table 21. Hornish Point. Carbonised plant remains. ${ }^{*}=$ barley rachis internodes. ${ }^{* *}$ grass occl nodes

\section{2.3.2 Derivation of plant material}

Food plants (eg cereals) may be accidentally charred during preparation and residues from grain cleaning may be discarded onto household fires. The parts of the cereal plant most likely to survive are the grains and denser chaff fragments, together with any associated weed seeds, since these tend to filter down through the fire into the ashes where they remain in a charred state (Hillman 1981). With barley as the predominant cereal, food preparation accidents should be dominated by grains, possibly contaminated by weed seeds and small quantities of chaff (rachis internodes), while grain cleaning residues would result in quantities of weed seeds with relatively few cereal remains (Hillman 1981, 1984; Jones 1984; 1987). Earlier stages of crop pro- cessing would be identified by larger quantities of cereal chaff and straw (culm nodes) and vegetative fragments of weed plants. Cereal culm bases and rhizomes from wild species could also be present in these early processing residues, if the barley was harvested by uprooting. Turf or peat used as fuel, on the other hand, would be composed of plants from the habitat where it was formed. It is doubtful whether much identifiable plant material would survive peat burning as, being rather dense, there would be little opportunity for the heavier fragments to fall into the ashes and be preserved (J Hillman pers comm). The looser turf, however, might provide such an opportunity and vegetative fragments of wild plants (including rhizomes) as well as seeds and fruits could be introduced in this way. Similar species may be introduced with both turf and dung used as fuel 


\begin{tabular}{|c|c|c|c|c|c|c|c|c|}
\hline & & ites & & & & shPo & & \\
\hline & xts & & & & xts & & cks & \\
\hline & 1 & 2 & I & 2 & I & 2 & I & 2 \\
\hline No. cereal grains/litre & 0.8 & - & - & 0.6 & - & 0.9 & - & 0.9 \\
\hline No.vegetative frags./litre & 0.8 & - & - & 0.9 & - & 0.7 & - & 0.9 \\
\hline$\%$ Calluna/Erica & - & - & 0.5 & 0.5 & - & - & - & - \\
\hline \% Polygonum aviculare agg. & - & - & - & - & - & - & 0.7 & - \\
\hline \% Polygonum cf. persicaria & - & - & 0.9 & - & 0.7 & - & - & - \\
\hline \% Rumex sp. & - & - & - & - & - & - & 0.8 & - \\
\hline \% Stellaria media & - & - & - & - & - & - & - & - \\
\hline \% Brassica/ Sinapis & - & - & - & -0.5 & - & - & - & - \\
\hline$\%$ Danthonia decumbens & - & - & - & - & 0.8 & - & 0.5 & - \\
\hline$\%$ indet.Gramineae & - & -0.8 & - & - & & - & - & - \\
\hline$\%$ Carex spp. & - & 0.7 & - & - & -0.6 & - & -0.8 & - \\
\hline \% Cyperaceae/Polygonaceae & - & - & 0.8 & - & - & - & - & - \\
\hline
\end{tabular}

Table 22. Baleshare \& Hornish Point. Principal Components analysis of the carbonised plant remains. 1 and $2=$ first two varimax-rotated Principal Components in each analysis. Loadings of less than 0.5 are not shown

since animals could have grazed the same grassland that would be used for turf cutting.

Since Calluna/Erica cannot grow as a weed of cultivation, the presence of these fruits at Baleshare and Hornish Point indicates that this plant at least was not introduced with cereals and raises the possibility of its introduction with fuel. Moreover, the cereal assemblage is heavily dominated by barley grains with very few rachis internodes, culm nodes or culm bases suggesting that the early stages of barley processing are not represented. It is likely then that the vegetative fragments of wild plants were introduced with fuel or some commodity other than cereal products. (It should however be noted that although rachis and culm fragments may survive charring less well than cereal grain (Boardman 1987) there is no reason why they should be underrepresented in comparison with the, often fragile, vegetative parts of non-cereal plants.)

In order to investigate the origin of other wild plant taxa, Pearson correlation coefficients and principal components were computed (using SPSSx procedures = SPSS Inc. 1983). The aim of these analyses was to see whether any taxa were consistently associated with one another and whether it was possible to identify a group of taxa representing food (perhaps associated with cereal remains) and another group representing fuel (perhaps associated with vegetative remains of wild plants).

Statistics were computed for individual contexts as well as consolidated blocks and sites were treated both together and individually. Only contexts (or blocks) with 30 or more identifiable plant items were used. The variables used were the densities of cereal remains and non-cereal vegetative fragments (number of items per litre) and the proportions of the different wild taxa. Percentages were based on the total number of seeds and fruits of common wild taxa and calculated only when the number of species was ten or more. Statistics involving wild taxa were not calculated for Baleshare as the number of contexts/blocks was too small and only the principal components analyses and correlation coefficients significant at the 0.05 level were interpreted.

There was a consistent and significant correlation between the density of cereal items and the density of vegetative wild plant fragments at Hornish Point, the site which provides the majority of the charred remains. This correlation was also reflected in the principal components analyses where the densities of cereal grain and vegetative fragments consistently load high on the same rotated principal component (Table 22). This could indicate that the vegetative fragments were brought in with the cereal harvest but it is equally likely that their association is due to the fact that they result from the same household fires, the vegetative fragments being introduced with the fuel and the cereal remains as food debris. Given the apparent lack of early cereal processing waste, however, the latter alternative is more likely and may simply indicate that some contexts are richer in charred remains than others.

If cereal remains represent food debris and vegetative non-cereal fragments fuel, then their consistent association will tend to blur any grouping of wild taxa due to their introduction with either food or fuel. This is borne out by a lack of consistently significant correlations or associations amongst the wild taxa. There is a significant correlation between the density of vegetative fragments and Calluna/Erica fruits among contexts from Hornish Point, but this correlation breaks down when consolidated blocks are considered. Similarly a significant correlation between Calluna/Erica fruits and Carex nutlets is apparent for whole blocks at Hornish Point but not for separate contexts. These correlations should, therefore, be treated with caution.

Given the difficulty of distinguishing species brought in with cereals from those introduced with fuel, it is not possible to determine whether cultivation was concentrated on the machair (as it has been recently - Grant 1979) or spread more widely onto acid soils. Nor is it possible to identify areas which may have been used for turf cutting.

\subsubsection{Differences between sites}

Various aspects of the plant assemblages from Baleshare and Hornish Point were compared using Student's t (applying the procedure in SPSSx-SPSS Inc 1983). As before, tests were conducted for separate contexts and for whole blocks and only differences significant at the 0.5 level were interpreted.

The density of both cereal and non-cereal remains (calculated for all contexts and blocks) was consistently and significantly greater at Hornish Point than at Baleshare. 
Conversely, fewer animal bones were recovered from Hornish Point than from Baleshare (Halstead infra) even though the quantity of deposit excavated at the two sites was comparable. There were also high ratios of cereal chaff, non-cereal fruits/seeds and non-cereal vegetative fragments to cereal grain (calculated only for contexts or blocks with 30 or more cereal grains) at Hornish Point though the first was significant only when separate contexts were considered.

To determine whether these differences simply reflect the proportions of different deposit types excavated at the two sites, the tests were repeated comparing similar deposit types (ie features, middens, cultivation layers or windblown sands) from each site. In fact, the differences between the sites were still apparent though, due to the smaller numbers of contexts blocks in each category, they were not always significant.

A possible reason for the differences between sites is the rate of deposition which was faster at Hornish Point (below). This would account for the lower density of animal bones at Hornish Point and could also have resulted in better preservation of charred plant material through rapid burial, giving greater densities of material and better representation of the more fragile remains such as chaff and non-cereal items. However, the most likely reason is chronological, due to changes in crop processing during the first millennium BC, which have been noted at other sites on South Uist (Helen Smith pers comm).

There was no significant difference in the ratio of wheat to barley grains or the ratio of straight to twisted barley grains at the two sites but the percentages of some of the wild taxa were significantly different. Danthonia decumbens (and sometimes Polygonum cf. persicaria) was more common at Baleshare and Carex spp. (and sometimes Polygonum aviculare agg, Calluna/Erica and Brassica/Sinapsis) at Hornish Point. The archaeological significance of this will be easier to assess when information is available from a larger number of sites in a variety of different environments.

\subsubsection{The use of charred plant remains as an indicator of human activity}

The same aspects of the plant assemblage, excluding the proportions of different wild taxa as the number of contexts/blocks was too small, were compared for different types of deposit, viz features, middens, cultivation layers and windblown sands, by analysis of variance (from SPSSx-SRSS Inc 1983). For both sites, the density of both cereal and non-cereal remains was found to be greater in middens and cultivation layers than in features and windblown sands. These results were particularly significant for cereal remains especially when both sites were considered together. The same pattern was observed when each site was considered separately though the results were not always significant, especially for Baleshare, and the differences for non-cereal remains were not significant for blocks.

The only other significant difference was in the proportion of cereal chaff to grain at Hornish Point, where there was more chaff in the features. Given the extremely small number of chaff fragments in total, however, this difference is probably not of archaeological significance.

At first, the apparent lack of charred plant material in features (comparable only with windblown sand) is surprising.
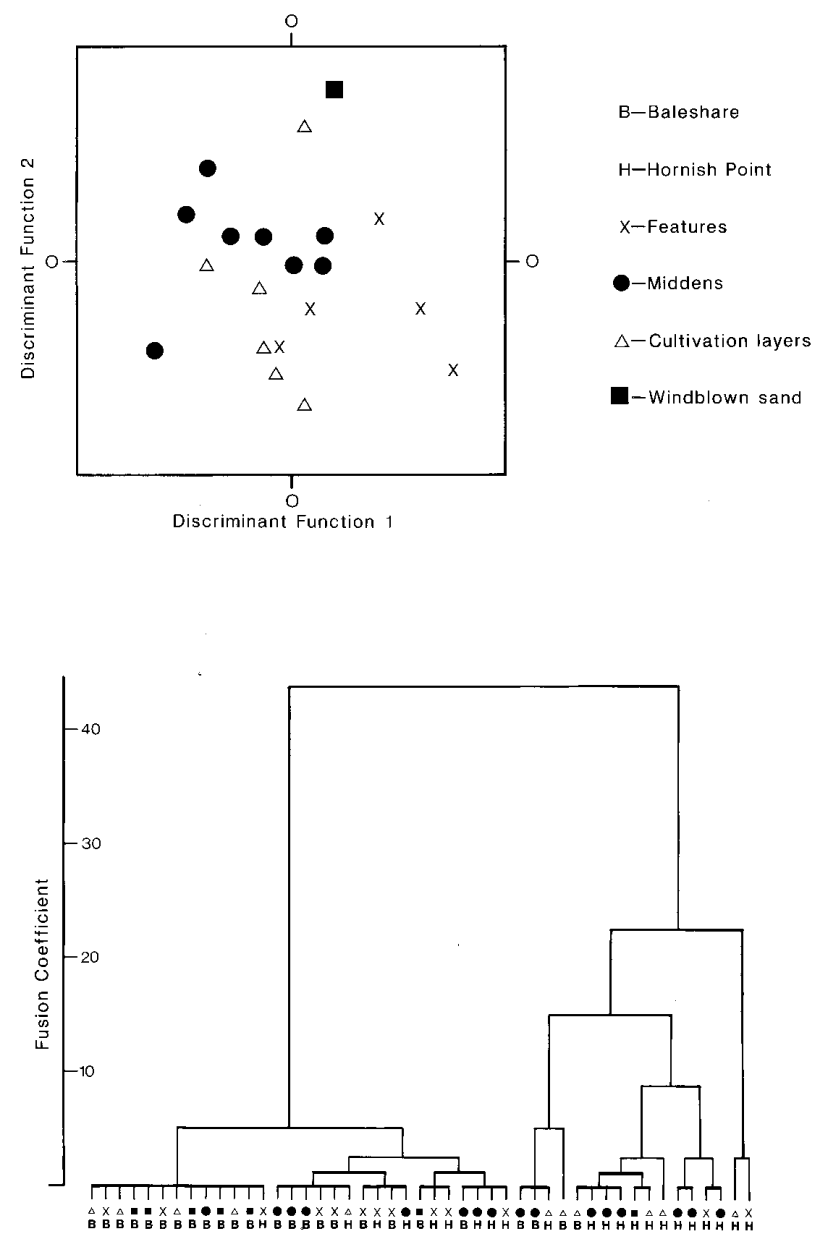

Figure 80. a) Discriminant analysis of Hornish Point Block types using characteristics of the charred plant assemblage b) Cluster analysis of Baleshare and Hornish Point Blocks using densities of charred plant remains

However, little charred material would be expected in masonry while ditches, pits and floors may have been subject to periodic cleaning out. Whatever the reason, it highlights the need to be cautious when using charred remains (or other rubbish eg animal bones) as an indicator of human interference since too much 'interference' may produce a very clean result. The similarity between middens and cultivation layers is interesting however, and may indicate that midden deposits were being used to fertilise the fields. This raises the possibility of using the density (and type) of charred plant material, if not as an indicator of human interference, then at least as an indicator of refuse use.

In order to explore the potential of charred plant material as an indicator of human refuse use, discriminant analyses (using the SPSSx procedure - SPSS Inc. 1983) were performed. The densities of cereal grains and non-cereal vegetative fragments, the ratios of cereal chaff, non-cereal fruits/seeds, and non-cereal vegetative fragments to cereal grain as well as the ratio of wheat to barley were used as discriminating variables and the four major deposit types as the groups to be discriminated. The discriminant analysis reduces the discriminating variables to three composite functions which maximise the statistical separation of the four predefined groups. A useful measure of the discriminating value of 
the functions is given by their ability to reclassify contexts or blocks correctly.

The ability of the variables to discriminate between contexts from deposit types was poor. Even when analysis was restricted to contexts with 30 or more cereal grains, only $69 \%$ of contexts from Baleshare and $43 \%$ from Hornish Point could be correctly reclassified into their original groups on the basis of the discriminant functions extracted. The reclassification of consolidated blocks was better $-85 \%$ of blocks from Baleshare and 75\% from Hornish Point were correctly reclassified when blocks of 30 or more cereal grains only were used (Figure 80a). This suggests that any index based on aspects of the charred plant assemblage should be applied to whole blocks (where the quantities of charred material are sufficiently large) rather than to individual contexts.

The results of the study were promising but it is still necessary to test the ability of these variables to assign blocks to particular deposit types without prior knowledge of the types represented. For this reason, the same variable were used in cluster analyses (using Ward's method of hier- archical clustering from the CLUSTAN package - Wishart 1978). Unfortunately, no clear clusters emerged, regardless of the numbers of blocks (or contexts) used or whether the sites were treated together or separately. Moreover, such clusters as were present bore little relationship to the deposit types as originally defined.

The cluster analyses of blocks were repeated using only the densities of charred grain and non-cereal fragments which the analyses of variance had shown were most significantly different between deposits. This produced rather more interpretable results, the most obvious separation being between sites (Figure $80 \mathrm{~b}$ ). The separation of deposit types was less clear resulting in two major clusters, one composed largely of midden and cultivation deposits from Hornish Point and the other comprising most of the features and windblown sand deposits but also including large numbers of midden and cultivation deposits. This 'mis-classification' of many of the midden and cultivation deposits was also apparent when the sites were considered separately. 
CHAPTER 13: POLLEN ANALYSES OF ORGANIC HORIZONS FROM THE BALELONE MIDDEN

\section{A Mannion (1986)}

\section{I3.I INTRODUCTION}

The extensive midden deposits excavated at Balelone Farm contained a wealth of archaeological remains embedded in a matrix consisting variously of sand, clay and organic horizons. It was considered that the latter horizons in particular might yield information on the nature of the material that produced them and thus augment the results of the archaeological excavation by providing additional information on resource use and subsistence strategies.

A number of possibilities were suggested relating to the derivation of these organic horizons viz that they originated as animal bedding, animal faeces, thatch, peat and/or domestic refuse. Consequently, it was decided that pollen analysis, a palaeoecological technique widely used in the examination of the relationship between people and environment, should be undertaken to determine whether or not such data could elucidate more precisely the nature of the organic material.

Pollen analysis was undertaken on organic horizons contained within monolith boxes and bag samples collected by CEU. This report details the results of these analyses and examines the data in relation to the possible origins of the Balelone midden organic horizons.

\subsection{RESULTS}

The stratigraphy of the two monoliths is given in Table 23 . Six additional bagged samples were also analysed from Balelone, the sediment characteristics of which are also given in Table 23.

It proved necessary to examine at least two slides from each sample to obtain a reasonable total pollen count. In general, however, the total counts were low, usually between 200 and 300 , due to the presence of relatively large numbers of poorly preserved palynomorphs that made identification impossible. The subsamples from $16 \mathrm{~cm}$ and $19 \mathrm{~cm}$ of Monolith 1 contained too few palynomorphs $(<40)$ to give reliable counts. The results from the remaining subsamples are given in Figures 81 and 82 . In both these diagrams the results are expressed as percentages of total pollen although in the following discussion reference is also made to pollen concentrations.

\section{I3.3 DISCUSSION}

Overall, the results show that the pollen spectra are dominated by Gramineae, Cyperaceae and Calluna vulgaris. All of these taxa are abundantly present in peatland and moorland communities which are widespread in North Uist today and, as Mannion and Moseley have shown (passim) by pollen analysis of lake sediments and peat in the immediate vicinity of the Balelone midden, were present in the island from about 7000 years BP, long before the midden came into exis-
a) Monolith I
Level $(\mathbf{c m})$
$0-10$
$10-16$
$16-22$
22-26
$26-42$
$42-50$

\section{Description}
Greenish shell sand matrix with large shell remains
Red clayey matrix. Some fragments of charcoal and shell remains
Light brown clayey matrix with shell and charcoal? remains
Transition between 16-22 cm above and $26-42 \mathrm{~cm}$ below
Light coloured shell sand with some siliceous sand. Small $(2-3 \mathrm{~mm})$ organic horizon at $38 \mathrm{~cm}$ below which sand is iron-stained for $\mathrm{I}-2 \mathrm{~mm}$
Brown horizon with some shell sand, shell fragments and charcoal? fragments

b) Monolith 2
Level (cm)
$0-7$
$7-12$
$12-14.5$
$14.5-20.5$
$20.5-23$
$23-30.5$
$31.5-43$
$43-50$

\title{
Description
}

Red clayey matrix with some shell sand containing shells of limpets and winkles and charcoal? remains

Dark humic layer of hard compacted deposits. Initially dark red-brown in colour but turning black after exposure

Dark brown humic deposits with high water content

Coarse deposits of small shell fragments with weathered chalk, tinged green

Hard black organic horizon

As $20.5-23 \mathrm{~cm}$ but slightly less compacted

Shell sand with slight green tinge. Iron layer at $40 \mathrm{~cm}$

Shell sand

c) Bagged samples
Sample
209
875
204
132
710
714

\author{
Description \\ Brown material matter of small friable particles including shell fragments and charcoal? \\ Brown mineral matter similar to 0209 \\ As above, with charcoal and iron pyrites \\ Red-brown mineral matter with organics, charcoal and iron pyrites \\ As 0132 but with organic matter \\ Very dark brown cohesive mineral matter and a high proportion of organics and a few shell fragments
}

Table 23. Balelone. a) stratigraphy of Monolith 1. b) stratigraphy of Monolith 2. c) description of bagged samples 


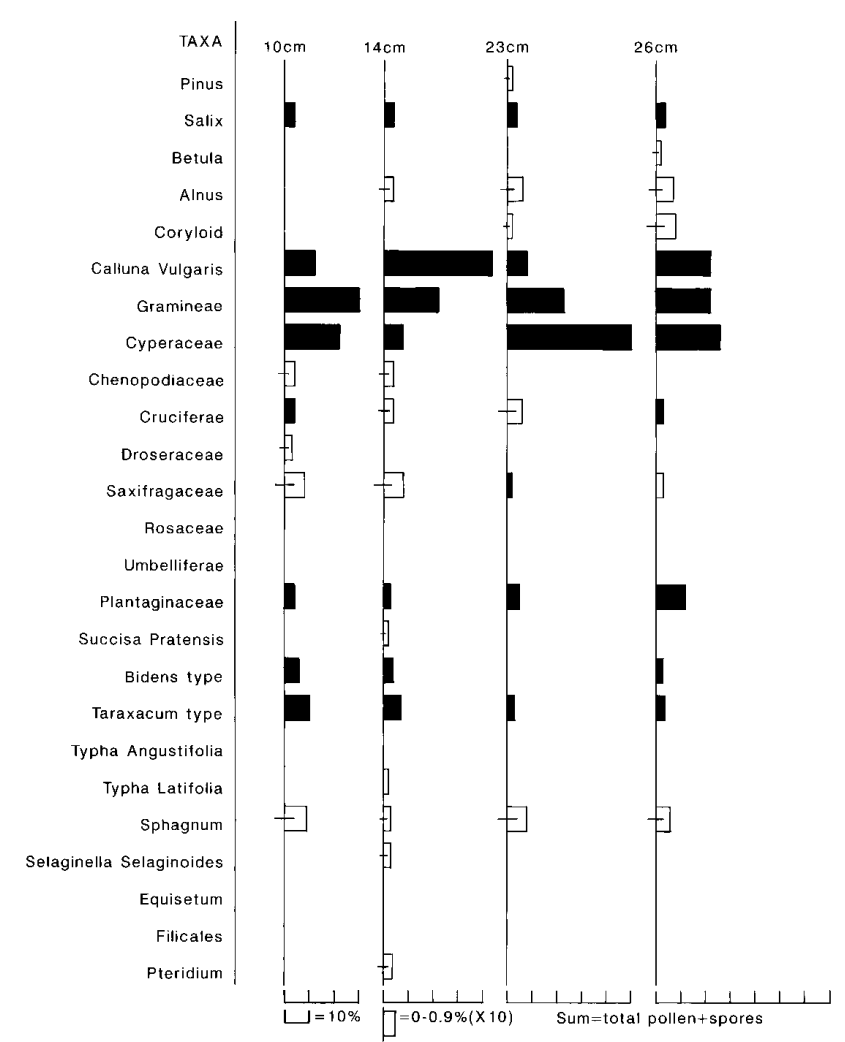

Figure 81. Balelone Farm; percentage pollen histograms for the monolith samples

tence. Thus, there is every likelihood that the midden organic horizons originated, at least in part, as peat which was collected as fuel and/or animal bedding. Moreover, it is also possible that the Gramineae, Cyperaceae and Calluna vulgaris pollen originated from material that was collected for thatch. Dickson and Dickson (1984), for example, suggest that the preponderance of Calluna vulgaris pollen at the Iron Age site of Crosskirk Broch, Caithness, may indicate the use of ling heather as a thatching material. It is also possible that a wider range of vegetation types may have been similarly used, especially grasses and sedges, which could provide very adequate roofing materials. If such practices were common then it is also likely that pteridophytes, such as Polypodium and Pteridium, and bryophytes, such as Sphagnum, were collected and this would account for the significant presence of their spores in the midden organic horizons. There is certainly no pollen analytical evidence from the Balelone midden organic horizons that positively disprove that they originated as peat, animal bedding or thatch.

Moreover, since Mannion and Moseley (infra) have shown that the moorland and peatland vegetation communities of North Uist were well established by the time the midden began to accumulate it is also highly likely that such communities were grazed by domesticated animals. This, therefore, lends some support to the hypothesis that the midden organic horizons originated from animal faeces. There have been very few studies on the relationships between the pollen content of animal faeces and the representation in the modern pollen rain of extant vegetation communities with which to compare the midden pollen data. Moe (1983) has undertaken such a study in Norway and he concludes that there may not be a simple or direct relationship between the

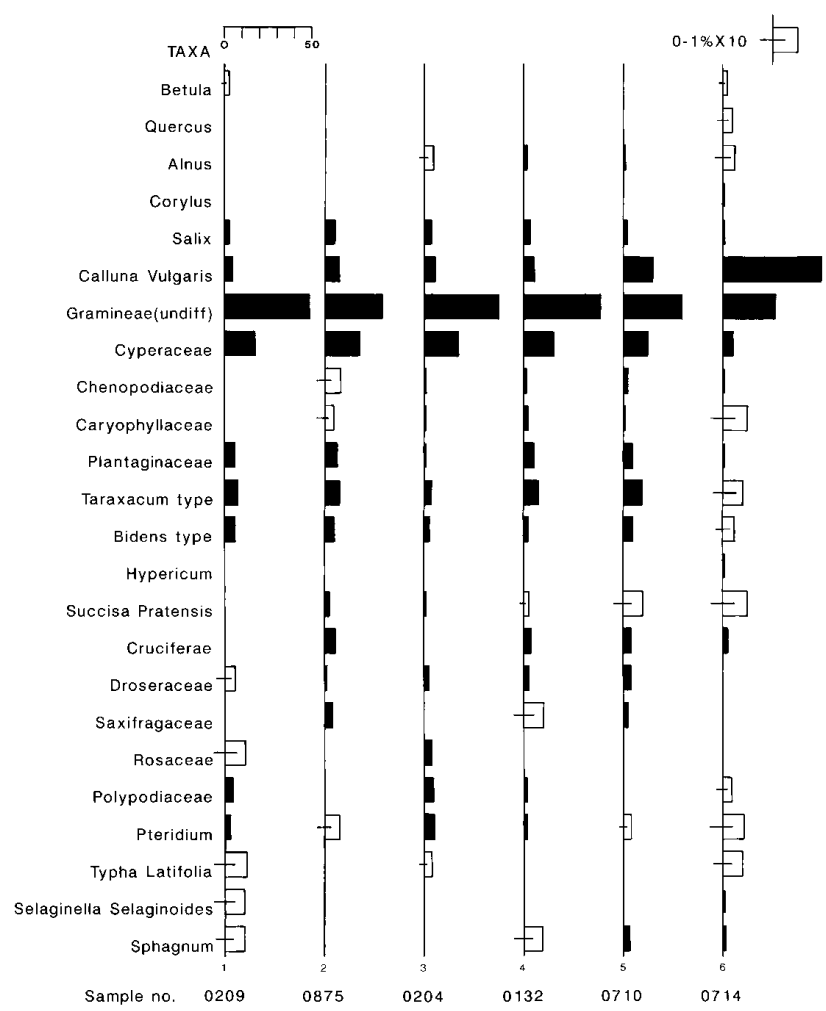

Figure 82. Balelone Farm; percentage pollen histograms for the bagged samples

pollen spectra from the faeces of grazing animals, such as sheep, and the local pollen rain. The pollen analytical data from the Balelone midden organic horizons do not preclude the possibility that the latter were derived from animal faeces but further work is presented below, based on pollen analyses of modern animal faeces, to show that the midden organic horizons cannot be attributed solely to animal faeces.

As Figures 81 and 82 show, the Balelone midden organic horizons contain quite a wide variety of pollen taxa. It is extremely unlikely that such a wide pollen spectrum would have been derived from a single source and any more positive conclusions must consider the exploitation of the varied machair, peatland and moorland vegetation communities as well as the possible inadvertent inclusion of 'weed' plants and the deliberate cultivation of crop plants. Cruciferae pollen, for example, are particularly abundant in the $13 \mathrm{~cm}$ level of Monolith 1. Cultivated brassicas are members of the Cruciferae family and it is quite possible that such taxa were being cultivated and their remains left to rot, in much the same way that compost heaps are presently used. It is also highly likely that many of the Gramineae pollen types identified were Cerealia, although the poor preservation of palynomorph types in general precluded their separation from the Gramineae. If cereals were being cultivated, as is indicated in the pollen analytical data from the Balelone Farm peat profile (Figure 81 ), it is not difficult to envisage a situation where chaff etc. was discarded, along with the remains of other cultivated plants and 'weeds' of cultivation which had been inadvertently collected as part of the harvest. This explanation would account, at least in part, for the relatively wide variety of taxa recorded in the midden or- 

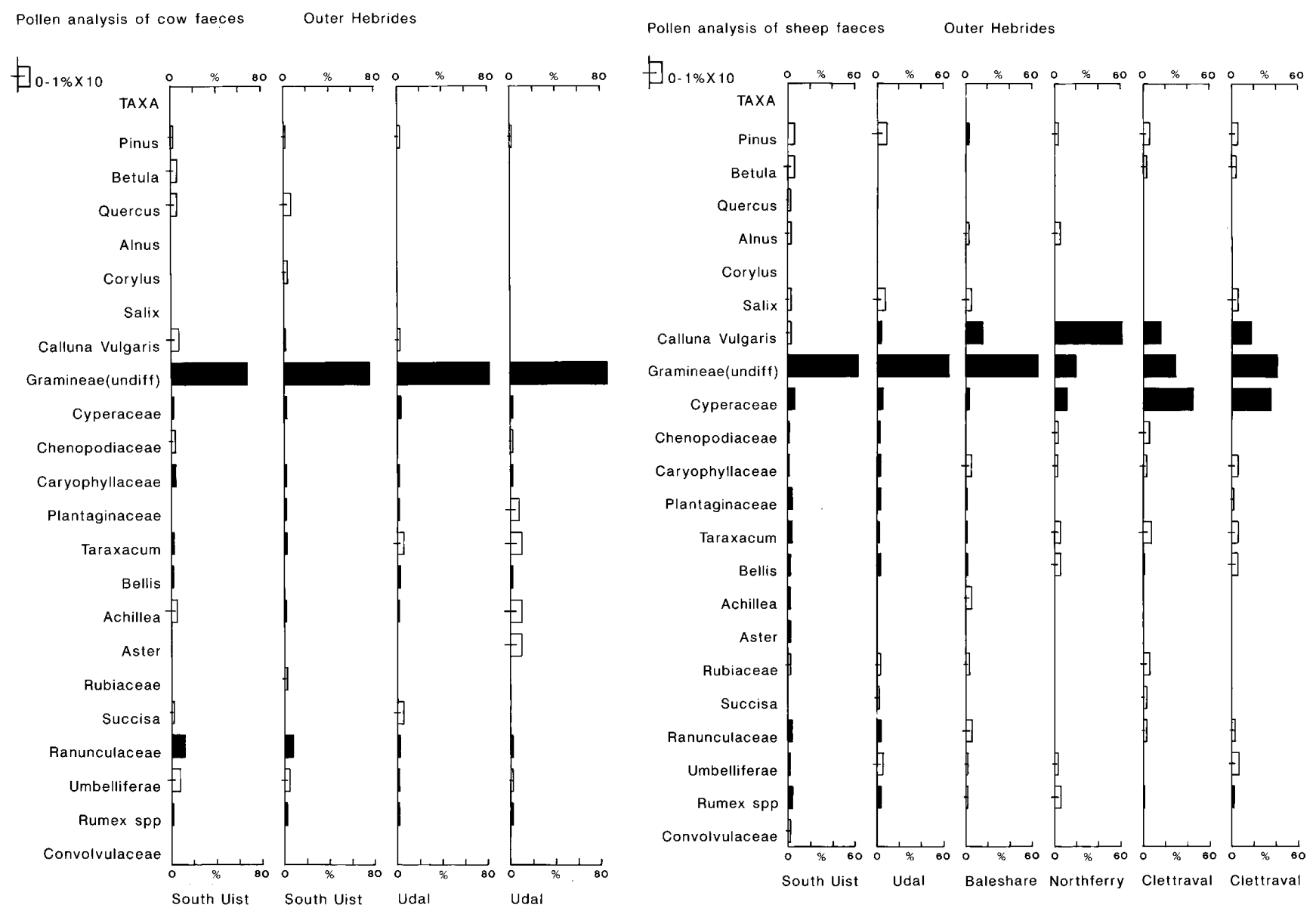

Figure 83. Percentage pollen histograms for animal faeces a) cow faeces b) sheep faeces

ganic horizons and in particular, the significant percentages of Plantaginaceae, Compositae and Cruciferae pollen, all of which may have originated from the machair plain as it was cultivated for cereal production or, alternatively, cropped for hay.

\section{3.4 POLLEN ANALYSES OF SHEEP AND CATTLE FAECES FROM THE OUTER HEBRIDES}

To test the hypothesis that the organic horizons may have derived from animal faeces, modern faeces of sheep and cattle were collected for pollen analysis, the results of which are presented below.

\subsection{Field and laboratory methods}

Samples of sheep and cattle faeces were collected from a number of sites on North and South Uist, ranging from the machair plain at Udal and Baleshare, to moorland sites at Northferry and Clettraval. Ten samples, four from cattle and six from sheep were subjected to the procedures for laboratory preparation of pollen slides (see Chapter 4). Although it was not intended to present the data as pollen concentrations, since in the case of animal faeces this is meaningless, Lycopodium spore tablets (Stockmarr 1971; 1972) were added to each preparation to ensure replicability and to de- termine whether the samples were sufficiently polliniferous to yield reliable counts.

\subsubsection{Results}

All ten samples yielded sufficient pollen for counting, most of which was in identifiable conditions. The results are given in Figure 83 where each taxon or genus is expressed as a percentage, based on a minimum count of 300 pollen grains. Figure 83 has been drawn at the same scale as those for the Balelone midden organic horizons to facilitate direct comparison.

\subsubsection{Discussion}

In common with the midden organic horizons the faeces samples contain a wide variety of pollen types (Figure 83). Of particular note is the absence of bryophyte (moss) and pteridophyte (fern) spores from the faeces. In none of the midden samples are these abundant but the results show that they are consistently present, especially Polypodiaceae and Pteridium. On this basis an origin for the midden organic horizons from animal faeces has to be discounted. This is not surprising as it is very probable that animal faeces were highly prized as manure, particularly for cultivation of the machair in which organic matter is not abundant. The pollen analyses of the animal faeces also provide grounds for some 
further observations. Samples of both sheep and cattle faeces from South Uist and Udal indicate that the animals were grazing on a similar vegetation, probably the machair, since the pollen spectra are dominated by Gramineae and a range of herbaceous taxa. The sheep faeces from Northferry and Clettraval, however, contain abundant Cyperaceae and Calluna vulgaris pollen indicating that these animals grazed moorland and peatland vegetation communities. Moreover, the general range of pollen from herbaceous taxa must represent only those plants which were in flower at the time the animals were browsing. It is highly likely that if faeces samples were collected at different times during the year pollen of different herbaceous plants would be present. A study of this variation would necessitate the tracking of individual animals and the collection of their faeces at regular intervals as Moe (1983) has done in western Norway. It would also be interesting to compare the pollen spectra from the faeces with the pollen rain of the area to evaluate how representative the former is of the latter and how both relate to the present-day vegetation communities. The presence of arboreal pollen in the faeces is also somewhat anomalous as it is unlikely that the animals were grazing on trees such as Pinus. The most plausible explanations for the presence of arboreal pollen, albeit in small numbers, are that it was blown onto the faeces or that it adhered to the vegetation which was subsequently grazed.
It, therefore, seems most unlikely the Balelone midden organic horizons are derived from animal faeces. This conclusion rests on the complete absence of spores, both bryophyte and pteridophyte, from the faeces samples.

\section{I3.5 CONCLUSION}

In conclusion, the specific origin of the midden organic horizons remains an enigma and the pollen analytical data prompt more questions than answers. Of the possible origins for the midden organic horizons given in the introduction only an origin from animal faeces can be discounted. Moreover, the presence of a relatively wide variety of pollen taxa can only be adequately explained by considering the exploitation of the most abundant habitats in North Uist, ie the machair grassland, peatland and moorland communities and possibly the cultivation of specific crops such as cereals. A combination of practices involving the exploitation of all the dominant habitats for thatching and/or animal bedding and/or fuel as well as the cultivation of specific crops would account for the pollen spectra of the Balelone midden organic horizons. It would not be unreasonable to suppose that the producers of the midden were indeed using such a wide variety of natural resources but there is no viable palaeoecological test which suggests itself as the panacea to this enigma. 
CHAPTER I4: THE MOLLUSCAN ASSEMBLAGE

N Thew (1987)

\section{I INTRODUCTION}

A number of studies of snail faunas from calcareous sands from the western coasts of Britain, including the coasts of the Hebrides and Ireland have now been completed by Evans and his co-workers Spencer and Vaughan (see Evans 1979 for bibliography). These, however, have been in the nature of column sampling through cliff sections to investigate environmental change through time, and few have included substantial archaeological layers, such as midden-site deposits, within the sample columns. The sampling of the sites of Baleshare and Hornish Point, and to a lesser extent Newtonferry and Balelone, was designed to investigate variation in archaeological material and environmental indicators through both space and time. For the molluscan analysis this represents a new departure and allows an investigation into the way that molluscan faunas vary with the form and intensity of natural processes of erosion or deposition and the colonisation of surfaces by vegetation as well as anthropic processes like cultivation or the deposition of refuse. The effects of 'intermediate' processes such as sheep and cattle grazing which affect vegetation and surface stability seem to be more difficult to detect in snail faunas. Molluscan analysis therefore, can perhaps progress from being merely a monitor of the environmental changes that have taken place through time, to the position where it is possible to throw some light on the mechanisms of site formation through the balance of natural and anthropogenic processes.

In general, the analysis suggests that mollusca are sensitive to vegetation and moisture, and to the lack of vegetation in areas where wind-blown sand is being deposited. Moreover, certain snail species seem to be sensitive to the deposition of fresh domestic organic waste, ie middening, while intensive ploughing also seems to influence molluscan faunas. Further work on modern snail faunas in analogous local environments needs to be undertaken in order to add more resolution and reliability to these preliminary indications.

Already, it seems that careful investigation of the way in which molluscan faunas vary within complex archaeological deposits might allow an insight into the way that local environments and land use patterns vary across a site and how this variation changes through time. In turn these patterns constitute the site formation processes that result in the archaeological deposits.

The present study covers deposits ranging from later Bronze Age to later Iron Age as well as the post-Medieval period. Unfortunately, the results of the analysis thus far seem to indicate that more work needs to be done on unravelling the imprint of biological succession so that it is possible to compare later faunas with earlier ones.

\section{I4.2 INTERPRETATION OF THE RESULTS}

Interpreting the results of the molluscan counts can only be tentative because of the low numbers recovered from the individual samples and the bias against certain species caused by flotation. The three species most likely to have been affected,
Vitrina, Oxyloma, Cepaea, were usually present only in small numbers in previously published comparable studies.

Most of the samples revealed fluctuations in the relative numbers of a few 'significant' or 'dominant' species (Pupilla muscorum, Cochlicopa spp, and Vallonia spp), and the presence or absence of small numbers of several other species. These included species of wet habitats which, in most contexts, would have arrived in flood waters; the Helicelid snails (including Cepaea); Helicella itala and Cochlicella acuta, species newly arrived in the area and contemporary with the three earlier sites studied here; the Zonited group plus Vitrina pellucida, which being omnivores, can fluctuate independently; and two further species, Lauria cylindraea and Vertigo pygmaea. Fluctuations between small numbers of a restricted number of species are difficult to interpret and it would be possible to generalise and consider almost all contexts together as an 'open landscape, grassy, with greater or lesser stability, with varying dampness and varying amounts of anthropically deposited organic refuse'. It is believed that the fluctuations between context faunas are indicative of variations in the micro environment.

Evans, $(1972 ; 1979)$ has noted the problem, that in periods of surface stability the fossil molluscan fauna will represent the immediate local environment, while during unstable periods the molluscs trapped in a sandy layer could represent a much wider catchment area. A variety of samples spatially separated across a site will reduce the problem.

Helicella itala and Cochlicella acuta appear to have arrived in the Outer Hebrides during Late Bronze times, thus were absent from the earliest levels at Baleshare and appeared only in small numbers during the Late Bronze Age phase of the site. Iron Age Baleshare and Hornish Point have, by contrast, significant numbers of Helicella itala and very few Cochlicella acuta. A post-Medieval context at Hornish Point and post-Medieval Newtonferry however, have faunas dominated by Cochlicella acuta and smaller numbers of Helicella itala. Comparing faunas between sites and between deposits of different ages is difficult. The pattern of arrival of these two species has made it possible to use the number of Helicella itala and Cochlicella acuta present within a sample as a tool for phasing and relative dating of sites. This has been attempted at Baleshare, and the four sites within this study are also compared.

The final problem in interpreting the molluscan faunal assemblages is that species can change their ecological range. Today, Gyraulus laevis, an aquatic snail, and Vertigo angustior, a terrestrial damp species found at Northton, Harris, Outer Hebrides, (Evans 1971) and Ardnave, Islay, Inner Hebrides, (Evans 1983), seem to be declining and forced into small local refuges which may not be representative of habitats which they occupied in the past. This does not apply to any of the species recovered in this study, although Vallonia costata, Columella edentala, Pupilla moscorum, Zonitoides nitidus and Clausilia bidentata would all appear to be declining within the Outer Hebrides. However, the converse can also be true and a species can extend its ecological range. In Orkney, Lauria cylindracea, a species that normally requires shady vegetated or rupestral (walls, rocks, etc) habitats has adapted to dry open fixed-dune pasture and sand-dune habitats. This change seems to have taken place in post-Roman or possibly post-Medieval times. The deposits with dominant Lauria at post-Medieval Newtonferry may indicate that Lauria similarly adapted within the Outer Hebrides. 


\begin{tabular}{|c|c|c|c|c|}
\hline Faunal association & $\mathbf{A}$ & $C / D$ & C & C \\
\hline \multirow[t]{2}{*}{ Faunal groups } & $I P$ & $\| P$ & III & IV \\
\hline & $\begin{array}{c}804 \\
\text { (Burnt) }\end{array}$ & $\begin{array}{c}633,720 \\
805\end{array}$ & $\begin{array}{c}531,533 . \\
803\end{array}$ & 520,534 \\
\hline \multicolumn{5}{|c|}{ IN SITU TERRESTRIAL FAUNAS } \\
\hline Number & $<10$ & $<10$ & $40-50$ & $10-20$ \\
\hline \multicolumn{5}{|l|}{ Dominant species } \\
\hline Cochlicopa & & & SIG & V.SIG \\
\hline Pupilla & & SIG & F.SIG & VF-F \\
\hline Vallonia & & SOME & V.SIG & SOME-F.SIG \\
\hline \multicolumn{5}{|l|}{ Indicator species } \\
\hline Vertigo pygmaea & SOME & & SOME & VF-SOME \\
\hline Lauria cylinracea & SIG & & FEW & VF-SOME \\
\hline \multicolumn{5}{|l|}{ Omniverous species } \\
\hline Oxychilus alliarus & SOME & & VF & VF-F \\
\hline Vitrina pellucida & & & VF & \\
\hline Nesovitrea hammonis & & SOME & & VF-SOME \\
\hline \multicolumn{5}{|l|}{ Helicelid species } \\
\hline \multicolumn{5}{|l|}{ Helicella Itala } \\
\hline Cochlicella acuta & & & VF & VF \\
\hline Cepaea hortensis & SOME & & & \\
\hline \multicolumn{5}{|l|}{ Flood arrivals } \\
\hline \multirow[t]{2}{*}{ Wet species } & & & VF & \\
\hline & & & & Lym.trunculata \\
\hline \multicolumn{5}{|l|}{ Seaweed species } \\
\hline \multirow[t]{3}{*}{ Marine } & VF Rissoa & & VF Rissoa & VF-F Rissoa \\
\hline & Litt. saxatilis & & & VF-SOME \\
\hline & & & & Litt. saxatilis \\
\hline
\end{tabular}

Table 24. Balelone. Faunal groups and faunal associations as defined by species characteristics. Key: SIG = significant; F = few; $\mathrm{VF}=$ very few

Despite these problems, however, an attempt has been made to determine the nature of faunal assemblage variations and then interpret them. It would appear that fluctuations among the major species reflect, predominantly, natural environmental conditions. Variations in certain of the other species, however, seemed to be far more sensitive to patterns of human land-use. The 'faunal groupings' could therefore be clustered into 'faunal associations', two of which seem to reflect the presence of middening, while two other faunal associations indicated more or less stable natural grassland. At Hornish Point and Newtonferry, however, because of the great number of subdivisions required for certain stratigraphic blocks (eg Block 19) indicative of rapid changes in middening or natural deposition, a faunal matrix was constructed with fluctuations of main species along one axis, and fluctuations in the presence or absence of lesser indicator species along the other axis.

Interpretation of these faunal groupings and associations has allowed an assessment of the past local sub-Block environments to be made in terms of natural dampness, dryness, the degree of exposure and stability and middening. In some cases, however, the snail evidence indicating an absence of middening, would appear to conflict with the archaeological and soil evidence in sub-blocks with high organic contents and abundant bone, seed and seashell waste. Explanations to resolve these conflicts have been formulated in terms of the nature of organic material added to the soil (fresh or already decomposed) the rapidity of sediment accumulation (fresh waste buried before colonisation) and possible discrepancies with samples taken from the base or surface of contexts reflecting not the environment during accumulation of the contexts themselves, so much as the environment before or after a context was formed.

\subsection{RESULTS}

The counts for all molluscan species (terrestrial, aquatic and marine) from the floated samples, together with total numbers and the number of species for the terrestrial snails, can be found tabulated by Block within the appropriate sections of Chapters 4-8. Within these tables, samples are listed in stratigraphic order within blocks and in Block order, also for north, south and central portions of the complicated deposits of the midden sites investigated. Investigation of the molluscan assemblages within blocks has led to the stratigraphic blocks being further subdivided into sub-blocks (labelled A, B, C, etc) to allow a more detailed interpretation of the faunas.

For Balelone and Baleshare, sub-blocks have been clustered into faunal groups on the assumption that these groups are characteristic of different microenvironments (Tables 24 and 25). The faunal characteristics of these groups in terms 


\begin{tabular}{|c|c|c|}
\hline \multicolumn{2}{|c|}{$\begin{array}{l}\text { Faunal } \\
\text { association }\end{array}$} & \multirow{2}{*}{$\begin{array}{l}\text { Faunal } \\
\text { groups } \\
\text { 6A, 16A, 16C }\end{array}$} \\
\hline $\mathbf{A}$ & I & \\
\hline & IP & $\begin{array}{l}\text { I, I6A (203, 204, 24I, 240, I49, I50) } \\
\text { I8 G, } 25 \text { *** }\end{array}$ \\
\hline \multirow[t]{11}{*}{ B } & II & 3 (13), 2 IB, 24D [3], 29 [2] \\
\hline & II $H$ & $5 E, I I C, I I D$ \\
\hline & $\| N$ & IIC (259) \\
\hline & III $N$ & B8? (237) [1], II (II3) [2] \\
\hline & IV & $5 \mathrm{D}[2]$ \\
\hline & IV N & $7 \mathrm{~A}$ \\
\hline & $V$ & $7 \mathrm{C}[4], \mathrm{IIA}[\mathrm{I}], 24 \mathrm{~A}[\mathrm{I}]$ \\
\hline & $V N$ & $\mathrm{IIA}(\mathrm{I} 58)[\mathrm{I}], \mathrm{I} 4 \mathrm{~A}[2]$ \\
\hline & VI & $4 \mathrm{~A}, 24 \mathrm{~B}$ \\
\hline & VIP & $2 \mathrm{~A}, 4 \mathrm{~B}$ \\
\hline & VII & $7 B, 21 A(100)$ \\
\hline \multirow[t]{13}{*}{ C } & VIIIN & 2D, I5B (144) \\
\hline & IX & 22 **** $(280,277), 23$ (27I, 272 ***) \\
\hline & IXP & I7C, 20 ****, 22 ***, 23 **** [I] \\
\hline & & $27 \mathrm{~A} * * * *, 27 \mathrm{~B}$ \\
\hline & & $(20,22,23, \& 27 \mathrm{~A}$ NO Helicella itala $)$ \\
\hline & $x$ & $5 \mathrm{~A} *[\mathrm{I}], 5 \mathrm{~B}$ \\
\hline & $X I$ & $5 C[1], 15 C[4]$ \\
\hline & $X I N$ & I5B* (not I44). \\
\hline & $X I P$ & $2 \mathrm{~B}, 2 \mathrm{E}, 2 \mathrm{~F}, 26$ *⿻丷木 \\
\hline & $X I I$ & $2 \mathrm{C}, 17 \mathrm{~B} * *$ \\
\hline & $X I I N$ & $16 \mathrm{~B} *$ \\
\hline & $X I I P$ & $2 \mathrm{C}(59), 2 \mathrm{D}(57)$ \\
\hline & $X I I I N$ & $3 \mathrm{~B}, \mathrm{I} 4 \mathrm{~B} *$ \\
\hline \multirow[t]{6}{*}{ D } & $X I V$ & 6B, I IB [5], 24E [5] \\
\hline & $X V$ & $3 \mathrm{~A}[\mathrm{I}], 12,15 \mathrm{~A}, \mathrm{I5D}$ Burnt, 19A \\
\hline & $X V N$ & 19B Green \\
\hline & $X V P$ & $? 9$ \\
\hline & $X V I$ & $7 A[1], B 8,10$ \\
\hline & $X V I I N$ & $24 \mathrm{C}$ \\
\hline
\end{tabular}

Table 25. Baleshare. Faunal groups and faunal associations as defined by species characteristics. Key: [5] = number of small marine gastropods (from seaweed); * = wet land species from flooding (*** several; ** few; *very few)

of abundance, and the relative importance of the various terrestrial species encountered are listed in handwritten tables which can be found in the site archive Table 26 lists the stratigraphical blocks at Baleshare in their chronological order with the sub-blocks assigned to their faunal groups.

Hornish Point and Newtonferry have stratigraphic blocks which vary considerably in their faunas, often from layer to layer. At Hornish Point the great number of sub-blocks made clustering into faunal groups prohibitively complicated. Consequently a faunal matrix was employed with sub-blocks being plotted according to their terrestrial species characteristics. At Newtonferry, individual contexts were plotted on a slightly different faunal matrix. The method of construction of these faunal matrices, available as handwritten tables in the site archive, allows for intersite comparison.

The divisions between the assemblage groups and associations reflect natural variation in the proportions of the dominant species, ie adaptable species, forming the bulk of the faunas from most contexts, and the representation of the indicator species, ie less numerically important but more sensitive indicators of environmental differences.

\section{I4.4 DISCUSSION AND INTERPRETATION OF THE MOLLUSCAN FAUNAS}

\subsection{General observations}

Previous studies from coastal calcareous sands have yielded minimum counts of 50 individuals from 1.5 or $2.0 \mathrm{Kg}$ samples, occasionally reaching maxima of 5,000 or more (Evans 1971; Evans \& Spencer 1977; Evans \& Vaughan 1983; Spencer 1975). By comparison 20 kilo floated samples give values between 5 or less and 500 or more. However, as noted above, discussion and interpretation of the data proceeds from the premise that the floated fauna is as representative of the original fauna as that recovered by sieving and picking. Further investigations in the Western Isles will, however, be able to test these preliminary results and interpretations by analysing samples taken specifically for molluscan fauna.

Factors affecting the numbers of molluscs present within a context include original population size, rates of deposition (slower deposition allows more molluscs to accumulate), greater stability (which encourages richer vegetation and molluscan faunas) and preservation. Preservation of the floated snails remains fairly constant throughout the samples analysed; some assemblages being of remarkably fresh appearance while others although stained or discoloured having lost little of their microsculpture. Unfortunately no note of staining, possibly due to humus-rich layers, was made. It is hoped to investigate this phenomenon in future studies. The medium of deposition would appear to have been fairly constant (largely through burial by windblown sand, or incorporation in a deepening turf horizon); mechanical weathering may therefore reflect attrition by human or animal activity. Variation in human and animal use of the sites may be already reflected in differences in the contemporaneous snail faunas in the present study and could provide an interesting area for analysis in future investigations. Thus the majority of numerical variations within molluscan assemblages are attributable to differences in the original populations and the rate of layer accumulation. Even allowing for the small proportion of snails recovered by flotation the original populations would appear to have been fairly low and with restricted species diversity in comparison with previously published sites. Sites like Northton and Buckquoy have numbers of 'non-wet species' rising to 23 and 20 respectively, while at other sites numbers of greater than 12 or 13 normally indicated a greater degree of stability and shade; values of 15 and over often coincide with species indicative of true shade, perhaps rich, long, very stable grassland or perhaps even open woodland in the case of Northton and Buckquoy. Non-wet species counts of 11 were encountered only from four contexts at Baleshare and two from Hornish Point, these two sites having single higher values of 12 and 14 respectively. At Newtonferry the highest value was 9 while at Balelone it was only 8 . In all four cases, therefore, the molluscan counts indicate very open environments with almost no indication of true shade. interpretation depends upon discerning variations among faunas of restricted diversity which indicate environments with a greater or lesser degree of herbaceous cover and stability. Differences could be due to natural agencies like moisture or sand accumulation, both related to wind exposure, or to human agencies such as ploughing, fertilisation, deposition of rubbish or grazing. 
Late Bronze Age I

Late Bronze Age 2

Iron Age 4

Iron Age 5

Iron Age 6

Iron Age 7

Late Bronze Age 3

Age 5

\section{N Side}

B IX

C IXP

26 XIP

25 I P

$16 \mathrm{C} \mathrm{I}$

I5C XI
Centre

22 IX, IX P

$1335+/-60$ bc

20 IX P

$1020+/-65$ bc

27A IXP

27B IXP

$960+/-50$ bc

I7 A IV N

18 IP $790+/-60$ bc

$865+/-50$ bc

$16 \mathrm{~A} \quad \mathrm{I}, \mathrm{IP}$

I6B XII N

$15 \mathrm{~A} \times \mathrm{V}$

I5B XIN

I5D XV $425+/-55$ bc

I9A XV

$19 B \times V N 315+/-50 b c$

$12 X V$

9 XV P

29 II

I I P

2A VIP

2B XIP

2C XII

2C (59) XII P

2D VIII N

2D (57) XII P

$1080+/-50$ bc
$23 \mathrm{IX}, \mathrm{IXP}$

S Side

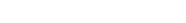

$10 \quad \mathrm{XVI}, \mathrm{XVIP}$

$8 \mathrm{XVI} \quad 7 \mathrm{~A} X \mathrm{VI}$

2IA VII $95+/-50$ bc

$7 \mathrm{~B}$ VII

IIA V 7C V

IIB XIV

IIC II H

IID II H

I I (II3) III N

8 (237) III N

I4A VN

I4B XIII N

2IB II

$3 A X V$

$4 \mathrm{~A} \mathrm{VI}$

$205+/-50$ bp

$4 \mathrm{~B}$ VIP

MACHAIR SAND

2E XI P

$2 \mathrm{~F} \times \mathrm{XIP}$

$290+/-55$ bc

24A V

24B VI

24C XVII N

24D II

24E XIV

$125+/-50$ bc

$5 A \times$

$5 B \times$

$5 \mathrm{C} X \mathrm{I}$

5D IV

$5 \mathrm{E} \quad \mathrm{II} \mathrm{H}$

$135+/-50$ bc

$6 \mathrm{~A} \mathrm{I}$

6B XIV

$160+/-$

Table 26. Baleshare. Stratigraphic Blocks with faunal groups in chronological order (chronological order determined by stratigraphy, ${ }^{14} \mathrm{C}$ dates and relative dating using the proportions of Hellica italia and Cochlicella acuta within the samples)

Small numbers of 'wet' species have been found in contexts from all four sites, together with odd specimens of freshwater aquatic snails. Flooding from nearby freshwater marshes must be considered; Baleshare, Hornish Point and Newtonferry are located on low-lying flat coastal machair plains liable to episodic winter flooding due to rising water tables (Ritchie 1979). This would account for these 'wet' species often coinciding with faunas suggestive of open, fairly dry environments. Consequently the 'wet' species have been omitted from the main number of species values used to interpret the local environment. Their significance will be dealt with in a subsequent section.

Another factor affecting the composition of the terrestrial molluscan faunas seems to have been that of time, in relation to the process of biological succession. The species Helicella itala and Cochlicella acuta arrived in the Outer Hebrides 
during the Later Bronze Age and became established at some stage after the Iron Age becoming the dominant faunal component in calcareous coastal dune and machair habitats and largely replacing other previously numerous species like Pupilla muscorum, Cochlicopa spp, and Vallonia spp. (A later section discusses how the ratio of these two species within molluscan assemblages can be used for relative dating of archaeological deposits both within and between sites not greatly separated by distance or ecological setting).

In the tables listing the molluscan counts there are included small numbers of marine species labelled as 'seaweed imports'. Most of these small marine gastropods seem to have been brought in with collected seaweed during the summer months, although at Newtonferry some may have been blown in. Leaving seaweed on the surface areas of the midden-site, for sheep fodder or for soil stabilisation, may have had some influence on the microenvironment but this is not reflected in the molluscan faunas. Sub-blocks showing closely similar molluscan assemblages can have quite different numbers of these marine gastropods. The numbers of these seaweed species seem to be more closely related to larger stratigraphic units and different areas of the sites, as at Hornish Point.

\subsubsection{Chronological implications from the molluscan data}

In all published studies of coastal calcareous sand systems of great duration, except those from Orkney, the species Helicella itala and Cochlicella acuta arrive some time after the start of sand deposition and replace the previously numerically important species to dominate the molluscan faunas. Most of these studies comprise columns through accreting sand bodies, and it would appear that the process of arrival, establishment and domination by the Helicella itala/Cochlicella acuta pairing was relatively rapid. Helicella itala may have arrived slightly before Cochlicella acuta in many areas, alternatively Cochlicella may have arrived at the same time, but in such small numbers as not to be recovered through sampling. Helicella itala being more adaptable became more rapidly established. Cochlicella, with a distribution today almost entirely confined to calcareous west coast sand systems (except in western Ireland) is a specialist species highly adapted to such conditions and though established slightly after Helicella itala, swiftly became the dominant species in many areas (Orkney and Shetland lie outwith their northern limit). In north-west Scotland and Lewis today the most northerly areas with calcareous coastal sands have very few Cochlicella, Helicella being far more important (cf Cain et al 1969). Cochlicella today is the dominant species in the Uists, Barra and Harris (Welch 1979).

At Baleshare the earliest levels are devoid of Helicella or Cochlicella; they appeared in very small numbers as odd specimens during phases two and three. In phase four Helicella became regularly present in small numbers, only becoming established as an important faunal element from phase five onwards. Cochlicella, however, was only ever present in very small numbers.

By contrast, Helicella itala was present in some numbers from the earliest levels at Hornish Point, together with occasional specimens of Cochlicella. During the later phases Cochlicella became important, tending to replace Helicella.
Block 20, the latest structure on the site, has one context typical of more modern faunas with Cochlicella completely dominant, having largely replaced the other previously common species like Pupilla muscorum, Cochlicopa spp and Vallonia spp.

All the contexts from Newtonferry demonstrate the same problem as the late context from Hornish Point, being similar to modern faunas with few Cochlicopa, Vallonia spp or Pupilla, these having been replaced by Helicella and especially Cochlicella. Significantly, the omnivorous group Vitrina pellucida, Vitrea contracta and Oxychilus alliarius seem to have been unaffected by changes in the representation of the dominant species, presumably because their life patterns were not in competition. Similarly Vertigo pygmaea and Lauria cylindracea seem not to have been competitively replaced by Helicella-Cochlicella: Lauria cylindracea appears in abundance in some of the lower levels of Newtonferry. This may be a similar phenomenon to that seen in Orkney where in the absence of Helicella/Cochlicella, Lauria seems to have broadened its ecological horizons some time in post-Roman or even post-Medieval times and adapted to more exposed and unstable open conditions among the fixed dune systems. Thus today in Orkney Lauria has competitively replaced Pupilla and Vallonia excentrica in many localities.

Another species which underwent a competitive decline seems to have been Cepaea hortensis. At Baleshare it was present throughout the sequence from the earliest to the latest deposits; only a single specimen was recovered from Hornish Point, and none from Newtonferry. Similarly, today Cepaea hortensis, like Vallonia costata and Pupilla muscorum, is rarely found in the Outer Hebrides, although it is more common in North East Scotland where Cochlicella acuta becomes scarce. In these areas Cepaea is in competition with Helicella itala, Cepaea being more common in richer, damper, more stable vegetation. (Cain et al 1969)

On the basis therefore of the molluscan faunas it would appear that of the four sites studied the earliest deposits are those of Phases 1 to 4 at Baleshare, followed by what would seem to be roughly contemporary levels from Phases 5 to 7 at Baleshare and all of the layers from Hornish Point except for Block 20; this Block, together with the sequence at Newtonferry could be interpreted as being rather later. The few contexts analysed from Balelone could be contemporary with the later phases from Baleshare and the deposits from Hornish Point.

The series of ${ }^{14} \mathrm{C}$ dates available, together with archaeological evidence, can be used to check the relative dating on the basis of the molluscan faunas. These suggest that Helicella itala became established earlier at Hornish Point than Baleshare.

The archaeological evidence from Block 20, Hornish Point, and the site of Newtonferry suggests that they are post-Medieval in date, considerably later than the rest of the deposits at Baleshare, Balelone and Hornish Point.

The only other comparative dating evidence for the arrival of Helicella and Cochicella in this area comes from the sites of Ardnave, Islay, and Northton, Harris. At Ardnave, Evans (1983) found a few specimens of Cochlicella and Helicella in earlier Bronze Age contexts dated to $3610 \pm 85$ uncal BP (GU-1371), by which time they appear to have become established. By contrast, at Northton (Evans 1971; 1972), there was no trace in earlier Bronze Age levels, dated 
to $3604 \pm 70$ uncal BP (BM-706) and $3481 \pm 54$ uncal BP (BM-707) (Burleigh et al 1973), or in the earlier of two Iron Age levels.

It is hoped that in future, the spread and ratios of these two species can be used as a relative dating tool, initially within single localities, and once their spread through the Scottish Isles has been dated, between sites, first ensuring that the rest of the faunal assemblages are broadly similar. This is the case for the sites of Baleshare, Balelone and Hornish Point. At Northton, however, another reason for their delay in becoming established may be that the background fauna indicates that the environment was considerably more shaded and moist than at Baleshare or Hornish Point.

The same two species may be useful, together with other Helicelid species like Cernuella virgata, in the relative dating of west coast calcareous sand locations further south. At Gwithian in Cornwall, Helicella and Cochlicella arrived some time after the Neolithic and were dominant by the Early Bronze Age (Spencer 1975).

\subsubsection{Indications of flooding and their implications for midden-site formation}

Possible explanations for the arrival of the 'wet' and aquatic species on the sites include flooding or the gathering of organic material from marshes for fertiliser, or other uses. The ecologies of the wet species and the freshwater species are listed in detail in appendices in the site archive. It seems likely that 'wet' species such as Vertigo antivertigo and Zonitoides as well as aquatic species arrived through episodes of flooding during the winter months: as during the summer months when water levels are low and the reeds in marshes, and weed in shallow water around the margins of the machair lakes could be cut, aquatic species like Armiger crista and Gyaulus laevis burrow into the mud to avoid drying out and Lymnaea peregra would have retreated with the dwindling water.

At Hornish Point 'wet' snails are found throughout the stratigraphy, although curiously with few from the earliest levels of the site (Blocks 1 and 26). By contrast, at Baleshare the earliest levels of Block 22 have a fairly high number of marsh snails but they are absent from the later levels. After layer [142] in Block 15 and [75] in Block 2 the only flood snails are a sequence of three in the fills $[173,172 \& 17]$ of a gulley or drain [174] in Block 15, cut into earlier deposits; a single shell in Block 5 lower down on the southern slope of the site, and a lone specimen in layer [109], Block 14, at about the same height as layers [142] and [75] within the circular structure cut into the earlier midden-site deposits. Layers [142, $75 \& 109]$ occur approximately halfway up the section through the midden exposed in the cliff face.

However, it is not impossible that these snails were introduced by human activity and here again we must note the tentative nature of the conclusions we have found on this first experiment in site-specific snail studies.

At Newtonferry the situation appears to lie in between that of Baleshare and Hornish Point, with a notable decrease in the number of 'wet' snails in the higher levels, but with odd specimens still being left, by presumed flood episodes.

At Baleshare the north and south of the site appear to have been subject to flooding though the confinement of Ver- tigo antivertigo to deposits in the northern half of the site may suggest that the vegetation of the marshes to the north may have been richer. At Hornish Point the 'wet' snails Oxgloma pfeifferi and Zonitoides nitidus indicate flooding from more permanent marshes to both north and south with the northern half of the site subject to greater flooding. The presence of two aquatic snails suggests that before coastal retreat a freshwater machair loch may have existed nearby to the north. The higher water table this implied helps to explain the greater flooding at Hornish Point.

The evidence for episodic flooding of these sites raises questions about site location and site formation processes. Some of these sites may have only been used seasonally and others permanently occupied, with provisions made to cope with seasonal flooding. Presumably, therefore, some system for protecting humans, animals and stored crops from flood damage would have been developed. The 'wet' snails in one of several gulley-like structures at Baleshare suggests that the function of at least some of them may have been drainage.

Block 22 at Baleshare has been interpreted as a deepened ploughsoil (above). Apart from the molluscan evidence suggesting that at least at some stages a reasonably stable grass-cover formed, the fairly large number of 'wet' snails in the sample from this deposit also indicate that the area was subject to quite severe winter flooding (at least in the lowest levels). The rest of the molluscan fauna, however, is indicative of reasonably dry conditions, so presumably by spring time the ground would have been dry enough for planting. The apparent severity of winter flooding in the very earliest levels, however, again raises the possibility that at least in its earliest stages Baleshare was a seasonal site. Moreover, the molluscan faunas indicate that between episodes of cultivation the ground was allowed to lie fallow. The great spatial extent of the earliest levels at Baleshare might be explicable therefore in terms of fairly large areas being subject to seasonal crop rotation. By continually building on the same location both the drainage would have been improved and the danger of flood damage lessened; this may, therefore, help to explain the existence of the numerous Iron Age and later midden-sites in low machair plain locations liable to episodic winter flooding.

Evidence of flooding from previously published sites is fairly rare. At Knap of Howar in Orkney, there are two horizons with Lymnaea truncatula. The first of these would appear to represent true marsh conditions, as the rest of the molluscan fauna changes to one which is indicative of this. The second, however, appears to represent flooding from a nearby marsh with a small number of L. truncatula coinciding with a much drier molluscan fauna. However, specimens of Vertigo substriata found unassociated with other 'wet' species from Knap of Howar, Buckhuoy and Skara Brae, seem rather to indicate damp and shady conditions as, unlike the other 'wet' species, Vertigo substriata is capable of living in normally damp locations and even surviving considerable periods of drying out. At Northton, Harris, the molluscan faunas contained small numbers of 'wet' species - including Carychium minimum, Oxyloma pfeifferi, Vertigo substriata, Vertigo angustior, Zonitoides nitidus and Lymnaea truncatula throughout most of the sequence in the sand cliff, except for the upper layers, including the horizons coinciding with Neolithic, Early Bronze Age and Iron Age occupation. These 'wet' species would seem to be incompatible with the rest of 
the faunas (as well as the occupation horizons), not only because of the dry, more open conditions indicated by prominent Pupilla, but also because Oxyloma pleifferi and Lymnaea truncatula would have avoided the more shaded areas, preferring open environments. The implication is therefore, that at Northton too the area around the site was subject to episodic winter flooding.

The advantages, in terms of the availability of good quality pasture and arable land, must evidently have outweighed the problems associated with inundation. But it is possible that the 'wet' snails preserved in the archaeological and natural deposits may only represent occasional flooding, once every ten or twenty years, the sites in fact being located in areas which avoided more regular inundation.

\subsubsection{Understanding the environment from the molluscan} data

Analysis of molluscan faunas from archaeological deposits differs from that from natural sediments in that interpretation of the environment becomes an interpretation of land use patterns around the archaeological sites. Thus ploughing, animal grazing and penning, and the disposal of different types of domestic rubbish create varying microenvironments in addition to the natural range of environments on which these human activities are superimposed.

Before it is possible to interpret the data in terms of environmental land-use variation, one must first discount other variable factors. Biological succession, and the superimposition of 'wet' species on the molluscan faunas through flooding have already been discussed. Climatic change is another potential factor. Some climatic deterioration seems to have occurred between circa $1000 \mathrm{bc}$, when the first deposits of Baleshare were accumulating, and $700 \mathrm{bc}$ after which most of the deposits at the other four sites were laid down. These large-scale changes seem not to have affected the faunas. Similarly all the species found at Baleshare and Hornish Point were present from Neolithic or Early Bronze Age times in the Outer and Inner Hebrides, with the exception of Helicella itala and Cochlicella acuta, so the differential presence of species on sites cannot be explained in terms of species availability. Other natural factors which can affect local environments independently of human activity include the height of an area above the water table, and thus the proximity to marshy or damp areas; aspect, relative to prevailing wind direction (thus salt spray, moisture, etc from the sea) or isolation; and underlying and nearby rocks and soils which would affect drainage, natural vegetation or the availability of standing rocks for rupestral snail species.

At the four sites studied here natural factors affecting the molluscan faunas can be allowed for after an examination of the data. Variation which cannot be explained in these terms can therefore be attributed to human activities; altering vegetation patterns by clearance, planting, burning, or the grazing of animals or controlling 'natural' factors such as the draining of land to lower water tables. Moreover, humans can create entirely new microenvironments such as standing structures which can act as habitats for rupestral snails and form shaded areas.

Layers seem to represent the product of various different processes, important factors for these sites being: the accumulation of wind blown sand; deepening turf horizons incor- porating organic material; the deposition of organic matter by grazing animals (although heavy sheep grazing will often prevent turf-lines from deepening); and finally the dumping of various types of domestic waste by the inhabitants of the archaeological site. Layer boundaries must therefore represent standstills in the processes of deposition.

As noted, most molluscan species live on or just below the surface, therefore molluscan faunas within layers must indicate, in the absence of a layer boundary, that deposition was gradual allowing the surface flora, fauna and layer accumulation to proceed without a noticeable break. Poor molluscan faunas within layers, therefore indicate rapid aggregation, and in natural conditions would be interpreted in terms of a rapid build up of wind-blown sand only ever covered with a restricted sparse herbaceous vegetation containing grass species adapted to unstable accumulating conditions. Thus, in a deepening turf horizon, a boundary before another similar layer, could mark a standstill perhaps caused by heavy grazing, or a series of severe frosts or droughts. A diffuse change to a sandier layer could merely mark the onset of more rapid sand aggregation. These changes, however, should be detectable by a continuous molluscan record, varying in abundance, and diversity. This is true also for surfaces grazed by animals.

The sedimentary mechanics of human dumping and ploughing are more complex. If dumping is in the nature of 'little and often' thin spreads can be incorporated into a single layer with a continuous molluscan record reflecting the nature of the surfaces of the spread material. If, however, dumping occurs in larger amounts then these will tend to form discrete layers with molluscan faunas and herbaceous floras only being able to colonise the surfaces of these deposits, there being no molluscan faunas inside the layers, thus helping to make boundaries more clear. These faunas and floras will reflect not only the nature of the dumped material below but also the amount of time that elapses before further dumping occurs or before natural aggregation begins. If dumped material is covered by naturally aggregated deposits the boundaries should be much more diffuse than those formed by repeated dumping.

One problem that remains in unravelling layer mechanics, is that of erosion and redeposition. Thus layer boundaries can mark episodes of erosion in an otherwise unbroken sequence of natural depositional events, while erosion can remove the faunas from the surface of colonised dump layers, leaving no indication of the dumped material except that which is naturally preserved. Eroded material can either be lost completely, or redeposited elsewhere on the site. Layers of naturally redeposited eroded material are more difficult to interpret than those in situ due to the mixing of faunas reflecting different environmental events. Redeposition can also result from human actions; material which has been accumulating in a rubbish dump can be removed and dumped. Such anthropically redeposited material could contain small numbers of derived snails which had previously colonised the rubbish tips.

Ploughing is a human activity that is difficult to detect in the molluscan faunas, it is akin to natural conditions of instability, and the molluscan faunas will reflect the vegetation cover and surface conditions that develop once ploughing has been completed. Thus, if the fallow period between ploughing episodes is great the molluscan faunas will tend to indi- 
cate a reasonably stable grass cover; with shorter intervals the fauna will indicate greater instability. Ploughing also destroys and mixes the faunas of all the fallow episodes thus producing an 'average' fauna. In ploughed deposits it is essential to know whether the surface or the body of the layer has been sampled. The surface fauna may simply indicate the greater stability associated with the final colonisation of an abandoned field.

\section{Dominant and indicator species}

At Baleshare, Balelone and Hornish Point the dominant species included Pupilla muscorum, Cochlicopa spp, and Vallonia spp which appear to have been in competition: rises in one species coinciding with decreases in other species (see Appendix 1 for the ecologies of the identified species).

The restricted number of species from the four study sites implies that extreme conditions with low diversity and poverty of habitats prevailed (cf Walden 1981, 370). This seems to have resulted both here and at other published sites, directly from human activities. Comparison with modern studies of faunas on grazed machair in Orkney (Evans \& Vaughan 1983) demonstrate their similarity with those from Baleshare, Balelone and Hornish Point.

The impact of man around these three archaeological sites severely limited the numbers of ecological niches available. The rise and fall in the proportionate representation of the dominant species should give some indication of the past environment. Pupilla muscorum for example is favoured by dry, exposed, unstable conditions; although it can survive more shaded moister conditions in which it is often paired with Vallonia excentrica. It seems to be unable to compete with more specialised species and hence only becomes abundant in fairly marginal environments. Stability is the key to the success of the vallonia species, though it is able to tolerate some fluctuations in both moisture and shade: Vallonia costata is more of a pioneer species than V. excentrica, favoured by fairly dry, stable grassland but declining markedly in the face of competition with $V$. excentrica. It can tolerate a wider range of conditions, retreating to wetter, more exposed, unstable or rupestral locations, though it would presumably encounter competition from other species. Rises in constata in conjunction with rising pupilla can therefore be seen as indicating an increase in instability or available rupestral locations; rises in $V$. excentrica may indicate a damp stable grassland, and with cochlicopa a rise may indicate damper more unstable conditions. Significantly, V. constata is also a well known coloniser of gardens and rubbish-midden locations, and it is possible that sudden peaks in this species might intimate the dumping of domestic rubbish.

Finally the two cochlicopa species seem to indicate, in the dune-machair system, a degree of instability, exposure and some dampness: C. lubrica favours damper, shadier, more sheltered habitats, while C. lubricella favours drier, more disturbed and exposed conditions.

At Newtonferry, and in a few late contexts at Hornish Point, however, the dominant species was Cochlicella acuta, with lesser amounts of Helicella itala. Today cochlicella is almost solely confined in its distribution to west coast calcareous sand system habitats: this specialist species successfully out-competed the previously dominant species, almost totally replacing Pupilla muscorum and causing a dramatic decline in the numbers of cochlicopa and vallonia. Vallonia excentrica in the most stable, regularly grazed grasslands and the cochlicopa species in damper habitats seem to have survived in some numbers. Vallonia costata, however today is virtually extinct from west coast sand systems.

In addition to the dominant species there are a number of numerically less important indicator species which provide finer detail of past environment. Cochlicella acuta and Helicella itala, for example, which when they first arrive at Baleshare, Balelone and Hornish Point are indicative of either dry, exposed, unstable conditions or reasonably dry, fairly short turf. These two Helicelid species although they are often found together would appear to be in competition to some degree. In the faunal matrix for Hornish Point, therefore, they are treated together as a Helicelid group. The third Helicelid species found during the study, Cepaea hortensis, would appear to be in competition with the other two. Today it seems to be favoured by locations with richer, denser, taller vegetation where Helicella is largely absent (Cain et al 1969). Where Cochlicella is present, however, it has all but eliminated Cepaea. This applies to all four sites studied here, with increasing quantities of Helicella and Cochlicella at Hornish Point relative to Baleshare leading to the virtual disappearance of Cepaea, which is totally absent from Newtonferry. The other indicator species seem to fluctuate independently of the dominant species groups (Pupilla, Cochlicopa, Vallonia, Helicella and Cochlicopa); they appear in similar numbers at Newtonferry, Baleshare, Hornish Point and Balelone. Vertigo pygmaea indicates stable, complete grassland, normally short-turfed and sheep-grazed; under these conditions it is often found with Vallonia excentrica, Vallonia costata and Pupilla muscorum. It seems to only reach slightly greater numbers in fairly moist stable turf. Similarly, if found in machair locations, the two species Punctum pygmaeum and Euconulus fulvus would seem to indicate fairly moist, stable, continuous grassland, possibly fairly rich in terms of abundance and diversity.

Lauria cylindricea is traditionally seen as a rupestral species living in woodland, among rocks, or less commonly in well established grassland in Orkney, however, it appears to have replaced Pupilla muscorum and Vallonia excentrica to a considerable extent. This change would appear to have taken place in post-Roman and even post-Medieval times; in other areas, it seems doubtful that Lauria could out compete Cochlicella. At Newtonferry the highest peaks of Lauria coincide with the highest frequencies of Oxychilus and other zonitids, seeming to indicate middening. At Baleshare, Balelone and Hornish Point, the smaller numbers of these may indicate the presence of nearby structures. At Iron Age Baleshare, for example, there seem to have been consistently more Lauria in the faunas from the northern than southern blocks; this phenomenon is perhaps associated with the large cairn which lies behind the northern half of the cliff section. From Hornish Point there is some evidence to suggest that peaks of Lauria do coincide with accumulation associated with structures, but other peaks in the southern half of the site are less easy to interpret.

The odd specimens of Clausilia bidentata and the single Leiostyla anglica are similarly difficult to interpret; both normally represent rupestral species but occasionally can be found in relatively damp grassland. Similarly, the single specimen of Columella edentala discovered implies a moderately damp environment, probably moist, stable grassland. 
All of the above indicator species help to refine the picture of the 'natural' environment in terms of the type and degree of vegetation cover. It is only with the zonitid group, however, that one can move closer to understanding direct human action in the processes of midden formation through dumping of various types of domestic waste. While human agricultural activity seems to have restricted the diversity of molluscan faunas, by decreasing the richness of the vegetation cover, it would appear that within and around settlements new micro-environments can be created - rupestral locations associated with walled structures and tips of various types of rubbish. The zonitid species and Vitrina pellucida are omnivores and thus tend to fluctuate independently of other species groups. All four species are also rapid colonisers, well placed to take advantage of plant and animal refuse, moreover, they are all species requiring dampness and shelter, and dumps of organic waste could provide, in addition to a food source, both moisture and a safe haven.

Oxychilus alliances can become locally abundant given favourable conditions, but in coastal dune-machair systems are only ever found in relatively low numbers (less than 5\%) in reasonably moist, stable, short-turf grassland grazed by sheep, avoiding turf grazed by cattle and unstable locations. In rich grassland, it is found with a variety of species including Punctum pygmaeum, Vitrina pellucida, Vitrea crystallina and Nesovitrea hammonis. At all four sites, Oxychilus regularly constituted around ten per cent of the context faunas, sometimes reaching as much as twenty per cent. By contrast Vitrina pellucida, and Nesovibea hammonis are only ever found in small numbers. Vitrina pellucida, in addition to moist stable grassland (when it is found in short-turf grazed by cattle), is also found in damp grassy hollows in the dune slacks of the coastal dune-machair system. When found without the other zonitid species, it may therefore, indicate cattle-grazed grassland or unstable conditions where some damp herbaceous vegetation is still available. Nesovitea hammonis is also found in moist stable grassland with Oxychilus and Vibira; intolerant of instability, it would appear to require more moisture than Vitrina and the other Zonitids.

Vitea contracta is also found only in small numbers. It can be found in moist stable shoreline turf, and appears to avoid unstable conditions or sandy grassland, preferring turf over a more compact substrate. At both Baleshare and Hornish Point odd specimens of Vitrea can be found in contexts with poor faunas and no other omnivorous species. Unlike Oxychilus and Nesovitrea, Vitrea can often be found crawling in open areas without vegetation as long as it has a reasonably sheltered place to retreat to such as stones or rocks. Vitrea contracta may have been able to colonise certain types of dumped material unsuited to Oxychilus. Oxychilus was the main coloniser of domestic rubbish, moving in from nearby moist, stable grassland where it would have been living with Vitrina and the other zonitids. Oxychilus alliarius is, with Vallonia costata, the only species normally found associated with domestic compost and midden heaps. More work needs to be done on modern analogues to understand the micro-ecological niches of these snail species in habitats associated with farms and small rural settlements.

Where Oxychilus does become relatively important in context faunal assemblages it is possible to say that this species is responding to the dumping of domestic organic refuse. However, in several sub-blocks, especially at Baleshare, peaks in the concentration of both preserved archaeological refuse (animal bone, carbonised seeds, sea shells and artefactual material) and soil organic are not reflected by rises in the number of Oxychilus alliarius. This raises the question of how different patterns of organic refuse disposal will be reflected in the molluscan faunas. The type, quantity, wetness, and mode of dumping will all affect the micro-environment. Organic, thinly spread over a surface, may not provide sufficient shelter or moisture to encourage colonisation by Oxychilus, and if this occurs regularly a thick uniform layer rich in organic and inorganic refuse may result; if this is rapidly followed by further dumping there may not be time for Oxychilus to colonise. Wet organic refuse will readily trap blown sand provoking rapid burial by natural aggregation, and again prevent Oxychilus from moving in. In these cases the rest of the molluscan faunas would also be very poor. Fertiliser which is rapidly ploughed in to an arable field need not be reflected by increased Oxychilus, although the molluscan faunas from fallow periods would still be present within the mixed up deposit.

Explanation is required when rich molluscan faunas indicative of stable conditions, but without any peak in Oxychilus, coincide with richly organic layers and abundant archaeological debris. Such contexts raise questions about the nature of both the organic and the archaeological material. Soil organic material could derive from a deepening moist turf horizon where grazing sheep contribute further organic matter. Similarly it would seem unlikely that manure of any type would be preferentially colonised by Oxychilus, as it would seem to have an advantage only with fresh animal and plant waste. Therefore, if rubbish were being allowed to collect in piles or as manure in byres, before being mucked out and spread on the midden, it would be in a partially decomposed or detrital state. This would also account for the occurrence of rich archaeological waste, as layers of rubbish piles were being periodically spread, rather than being regularly disposed of as smaller quantities of fresh waste deposited further from the settlement. Indeed many contexts poor in organic material do contain fairly rich artefactual assemblages indicating that organic waste had been disposed of separately or that it had accumulated and decomposed in rubbish piles before being spread. Conditions inside such refuse heaps would not have been conducive to exploitation of snails if decomposition in thick piles produced large amounts of heat or concentrates of organic acids. Perhaps small amounts of rubbish were regularly spread allowing total breakdown of soil organic and, thus insufficient material for Oxychilus to colonise. This idea is supported by a comparison of faunas from contexts at Baleshare, and Hornish Point. At Baleshare the naturally-eroded section seems to cut through deposits away from the centre of the site, while at Hornish Point the northern half of the section passes through a whole series of structures, presumably located near to the centre of the site. At Hornish Point the correlation between peaks in soil organic, archaeological material and Oxychilus alliances is good, whereas at Baleshare the correlation is good in the later blocks but falls down on some of the blocks from the middle Iron Age (Blocks 16, 15, 19 and 2A-D). The later blocks at Baleshare coincide with the central house structure while the middle Iron Age blocks have no contemporary domestic structures. It is therefore possible that peaks in Oxychilus reflect deposition of fresh domestic waste near the 


\section{BURNT SHELLS}

\begin{tabular}{|c|c|c|c|}
\hline \multirow[t]{4}{*}{ Baleshare } & 5A & 21 & I Pupilla muscorum \\
\hline & IIB & 126 & 2 Pupilla muscorum \\
\hline & $24 \mathrm{~A}$ & 39 & I Oxychiles alliarius \\
\hline & 24E & 37 & 2 Pupilla muscorum \\
\hline ale & 1017 & 804 & $\begin{array}{l}\text { All shells in this context } \\
\text { were burnt }\end{array}$ \\
\hline Tornish Poin & $5 E$ & 64 & I Nesovitrea hammonis \\
\hline
\end{tabular}

GREEN (Bronze or Copper) STAINED SHELLS

$\begin{array}{lrrl}\text { Baleshare } & \text { I5D } & \text { 215 } & \text { \} } \\ & \text { I6A } & \text { I49 } & \text { \} Many shells in these contexts } \\ & \text { I9B } & 212 & \text { \} were stained. } \\ \text { Hornish Point } & \text { IF } & 70 & \end{array}$

Table 27. Burnt and green-stained snails

centre of the site (for example in parts of Block 19, Hornish Point, much of which represents tipping into earlier abandoned structures) while absence of peaks of Oxychilus coincident with peaks in soil organic and archaeological material could in some cases represent redeposited rubbish further away from the centre of the settlement, in areas which may have represented a type of in-field.

Finally it should be mentioned that the small number of burnt snails listed in Table 27 may indicate either deliberate or accidental burning of areas around the midden (stubble burning, burning of turf in preparation for ploughing?). The few green-stained snails may result from the decay of bronze or copper objects among rubbish deposits. The bright, blotchy fixed nature of the staining would suggest this rather than organic staining from cess.

\subsubsection{Interpreting the faunal associations}

Detailed interpretations of the sub-blocks and individual contexts from the four sites studied here, are given within the main text with the archaeological Block descriptions. In order to compare and contrast faunas both within and between the sites, sub-blocks were clustered into faunal groups for the sites of Baleshare and Balelone, and plotted on faunal matrices for Hornish Point and Newtonferry. The advantage of using faunal groups is to facilitate recognition of closely related sub-blocks. The faunal matrices do not cluster sub-blocks and contexts categorically, so they have the advantage of being more flexible and accurate, describing the faunas from these smaller stratigraphic units, rather than their aggregates. Both methods demonstrate, that the molluscan faunas cluster into 'faunal associations' defined by the same species characteristics. These faunal associations have been labelled A-D. Within these associations the dominant species (Pupilla sp, Vallonia spp, Cochlicopa spp at Baleshare, Balelone and Hornish, and Lauria sp, and Cochlicopa sp at Newtonferry) vary in space according to local ecological conditions such as vegetation, dryness, stability and possibly animal grazing patterns, and through time due to biological succession and the competitive replacement of some species (eg Cochlicella acuta/Pupilla). The faunal associations are naturally defined, however, not by fluctuations in the most numerous 'dominant species' so much as by variation in the 'indicator species'.

The main division is between faunal associations A and B which have relatively important numbers of Oxychilus alliarius, and C and D which do not. The implications of this have been discussed in the previous sub-section. Vallonia costata, as well as Oxychilus is a species which sometimes colonises midden deposits, cf contexts 158 (sub-Block 11A), 112 (19A), 6 (6A), 11 and 9 (5D) from Baleshare where peaks of V. costata coincide with important Oxychilus; $V$ costata is also favoured by most grassland conditions (eg sub-Block 15B Baleshare, and sub-blocks in 26, I and also 19B, Hornish Point), so only where there are exceptional peaks of V. costata (Baleshare 143 (16B), Hornish 323 (20B) or rises in this species in an absence of moist grassland conditions (Baleshare 37 (24D)) can these phenomena be taken to indicate the deposition of some type of archaeological waste not colonised by Oxychilus.

The separation between faunal associations A and B on the basis of an absence of Helicella itala in association A may not be significant; the faunal matrix for Hornish Point shows how Helicella itala would appear to fluctuate relatively independently from Oxychilus alliarius within context and sub-Block molluscan faunas. Faunal associations $\mathrm{C}$ and D are divided by the absence of Oxychilus in $\mathrm{D}$, compared with a small number in C. At Baleshare this division is also reflected by the other species of the Zonitid group (Vitrea contracta and Nesovitrea hammonis), together with Vitrina pellucida, Punctum pygmaeum and a single Leiostyla anglica. Where found together, such assemblages would appear to indicate fairly moist, stable, grassland conditions. If Cepaea hortensis was also present this stable turf may have been longer, while if absent the turf may have been short and sheep-grazed. Where small numbers of Oxychilus were present without other grassland species this may indicate that small amounts of middening were taking place.

At Hornish Point, Punctum, Vitrina, Vitrea, and Nesovitrea are found in contexts regardless of the presence or absence of Oxychilus alliarius. Oxychilus tends to avoid turf grazed by cattle, while Vitrea is found in contexts where there is neither Oxychilus or Vertigo pygmaea (at both Hornish Point and Baleshare) indicating a fairly bare, open, although not unstable ground surface.

Within all four faunal associations there is a wide spectrum of degrees of dampness, exposure and stability, the crucial difference depending upon variations in human activity influenced vegetation through arable, pastoral and habitational land use but it is the deposition of various types of settlement waste which give rise to the differences on which the faunal associations can be constructed. This is hardly surprising since the layers which make up the excavated deposits consist of a mix of naturally accumulated blown sand and organic from the vegetation cover, archaeological material which was dumped or collected as a result of site occupation, and organic material deriving similarly from dumping, gradual accumulation and dung. 


\section{I4.5 CONCLUSIONS}

\subsection{Site formation processes}

The extent to which the snail faunas reflect at least in part, the materials and processes which go into the formation of the recorded layers has been discussed above. Sand within the layers has arrived either as a result of wind movement, or of being moved or dumped by man. Soil organic material may have derived from the decay of in situ vegetation, dung, decomposed rubbish or seaweed placed to stabilise surfaces or as animal fodder. Redeposited humic material eroded from older dune or machair areas should also be considered in an attempt to explain layers rich in humic material but with snail faunas which do not reflect the presence of plentiful available organic foodstuffs. The archaeological material, likewise, may have been dumped as fresh domestic refuse, as partially decomposed manure or compost or redeposited from accumulated heaps which have then totally decomposed.

The processes involved in layer accumulation can be considered as natural, anthropogenic, and mixed. To understand these process further, and their differential involvement in the formation of the sites studied here, one must understand the four sites in terms of their location within the dune-machair system.

\subsubsection{The dune-machair system and related geomorphological processes}

The formation of the machair system has been outlined by Ritchie (above). The deep sand stratigraphies of the high machair plains preserve sequences of all the natural and anthropic environments that had existed on the accreting surfaces, including buried soils and archaeological deposits. However, the flat low machair plains are prone to erosion and redeposition; old soil horizons are almost never found beneath these low plains (Ritchie 1979). It is on these low plains along the western coast of the Outer Hebrides that many midden-mounds are found. Consideration of the processes which contribute to the formation of these sites on the low machair plains and in other locations, taken in conjunction with the snail evidence from the four sites studied, suggest meaningful histories for the formation of these particular sites.

\section{Former site locations}

Hornish Point and Baleshare both have numerous contexts with molluscan faunas indicative of more or less stable fixed-dune pasture which could only be found in the machair region of the dune-machair system. Very similar faunas have been described from modern fixed-dune pasture locations in the Inner Hebrides (Colonsay and Oronsay; Paul 1976), Orkney (Evans \& Vaugan 1983) and the Outer Hebrides (from the extant turf of Northton, Harris; Evans 1971). The evidence from the snail faunas of dune-type conditions can, therefore, be interpreted as times of inland erosional sand-blows. Furthermore at both Hornish Point and Baleshare there are 'wet' snail species indicative of seasonal flooding from nearby lakes and marshes. Both these sites, therefore, were originally located on low machair deflation plains prone to wind-borne erosion and deposition; the former and modern presence of lakes and marshes suggesting that the sites were situated towards the landward margins of these plains (cf Ritchie 1979).

Balelone also has some evidence for former fixed-dune pasture, together with limited evidence for flooding. This site is situated some five metres higher than Baleshare and Hornish Point, and would appear to have been located on high machair plain. The former presence of marshes together with the modern machair rock or till is indicated (Ritchie 1979).

Newtonferry is different from the other sites in having molluscan faunas which are always typical of dune-type conditions. This site would appear to have been originally located among dunes near to the shore. The faunas suggest that the location was within the more stable part of the system rather than the active, mobile dune front. The presence of 'wet' and 'aquatic' snails within the assemblages suggest that there were freshwater lakes and marshes nearby. Today coastal recession has caused those freshwater bodies to become brackish.

The dune-machair systems now lost to the sea at Baleshare and Hornish Point may have exceeded a kilometre in width, though that at Balelone, with a steeper coastline, may have been less. At Newtonferry, rather less recession appears to have taken place, the site may have been a hundred metres or less from the beach.

\section{I4.6 THE MICROSCOPIC MARINE MOLLUSCA}

\section{Pain \& N Thew (1987)}

\subsection{Introduction}

The distribution of the microscopic marine mollusca vertically and spatially through the layer contexts of the individual sites is given in each site Chapter. The numbers of shells within each context or even within phases of these sites are too small to deal with separately. Table 28 therefore, gives the aggregate numbers of microscopic marine mollusca for the four sites.

As with the land snails, the numbers of sieve-recovered marine gastropods are under represented possibly by as much as a factor of ten because recovery was by flotation only, without subsequent sorting of the residues.

Despite this problem however, the microscopic marine gastropods seem to present coherent groups when their ecologies are considered. The ecological requirements for all the microscopic and species present on the four sites studied is listed at the end of this text. It is evident that the microscopic species were too small to have been originally deliberately collected by hand.

Table 29 shows that all the microscopic species, including juvenile Littorina littoralis and Littorina littorea, with the exception of Littorina neritoides and possibly Littorina saxatilis live attached to stones or seaweed. With the exception of few specimens which may have reached the sites during the gathering of beach stones for the construction of buildings or other structures, the majority appears to have been transported to the site attached to seaweed.

Birds and even the wind can act as agents for transporting both microscopic and larger mollusca inland (Evans 1983). None of the microscopic specimens recovered, however, were broken or noticeably abraded with the exception 


\begin{tabular}{|c|c|c|c|c|c|}
\hline & $\begin{array}{c}\text { Baleshare } \\
\text { Bronze Age }\end{array}$ & $\begin{array}{l}\text { Baleshare } \\
\text { Iron Age }\end{array}$ & $\begin{array}{c}\text { Hornish Pt } \\
\text { Iron Age }\end{array}$ & $\begin{array}{l}\text { Newtonferry } \\
\text { Post-med }\end{array}$ & $\begin{array}{l}\text { Balelo } \\
\text { Iron A }\end{array}$ \\
\hline \multicolumn{6}{|l|}{ Sieve collected } \\
\hline Onoba semicostata + & 0 & 0 & 0 & 2 & 0 \\
\hline Cingula semistriata + & 0 & I & 0 & 0 & 0 \\
\hline *Gibbula cineraria & 0 & 1 & 24 & 0 & \\
\hline Hydrobia ulvae+ & 2 & 2 & 0 & 0 & \\
\hline Zacuna pallidula+ & 0 & 0 & 0 & 2 & \\
\hline Lacuna vincta+ & 0 & I & 4 & 15 & \\
\hline *Littorina littoralis & 0 & 0 & 14 & 11 & \\
\hline *Littorina littorea & 0 & 3 & 16 & 3 & \\
\hline Littorina saxatilis & 0 & 0 & 2 & & 5 \\
\hline Littorina neritoides & 0 & 0 & 0 & & I \\
\hline Unidentified (broken) & 0 & 0 & I & & 0 \\
\hline Rissoa parva + & 3 & 20 & 321 & 98 & 5 \\
\hline Retusa obtusa+ & 0 & 0 & 0 & I & \\
\hline Total & (3) & (30) & (382) & $(132)$ & (II) \\
\hline No of contexts & 96 & 79 & $|7|$ & 36 & 10 \\
\hline Average per context & 0.03 & 0.38 & 2.23 & 3.67 & I.I \\
\hline
\end{tabular}

$\begin{array}{lrr}\text { Hand collected (this represents only those shells sent with the land shells) } & \\ \text { Buccinum undatum } & 2 & 6 \\ \text { Gibbula cineraria } & 7 & 53 \\ \text { Littorina littoralis } & 39 & 19 \\ \text { Littorina littorea } & 54 & 0 \\ \text { Nucealla lapillus } & 4 & 0 \\ \text { Patella aspersa } & (2) & \sim \\ \text { Patella vulagata } & 1 & \\ \text { Bivalves } & & \\ \text { Mytilus edulis } & 1 & \\ \text { Cerastoderma edule } & 2 & \\ \text { Pholadocea sp (?) } & I & \\ \text { Ensis arcuatus/Siliqua } & 1 & \\ \text { Mya Arenaria } & I & \end{array}$

Table 28. Marine mollusca from Baleshare, Hornish Point, Newtonferry and Balelone. Key: locally common: * includes apices broken from larger shells; + species most common, or only present in mature form in summer

of a specimen of Littorina saxatilis and a single Littorina neritoide from Balelone. Moreover, in the cases of Baleshare and Hornish Point, and possibly Newtonferry, it seems likely that the sites were located at some distance from the sea at their time of occupation thus reducing the possibility of accidental introduction. The Balelone site with its steep rocky coast may have been different and coastal erosion between the time of occupation and the present may have been much less severe. The single specimens of weathered Littorina neritoides and Littorina saxatilis, inhabitants of the higher rocky shore, may have been blown on to the site. A few of the microscopic shells had changed colour. As this was almost certainly due to the chemical action of the soil the phenomenon is not regarded as being of any archaeological significance.

In its unprocessed form, seaweed can be used as food for human and animal, and also as fuel and fertiliser. As most of the microscopic species recovered on the sites are only abundant or present in their mature forms in summer, it seems highly likely that seaweed collection occurred at this time of year. As many of the mollusca were present in cultivation layers it would seem that seaweed was used extensively as a fertiliser. Its use for the other purposes cannot be excluded but these are very difficult to demonstrate archaeologically. Col- lection could have been by cutting or collection from the shore in the wake of storms.

In addition to its use as a fertiliser, seaweed served as a stabiliser to the sandy soils of the machair which are particularly susceptible to wind erosion when under cultivation. Bell (1981) records that when left on the surface seaweed takes four months to a year to decompose. If deposited in May or June, it would keep the soil moist throughout the summer months making it less susceptible to wind erosion.

The majority of the marine gastropods present on these sites indicate harvesting of seaweed or collection of driftweed from rocky shores. The harvesting zone would appear to be the lower to middle shore as all the microscopic species can be found there. The predominance of Rissoa parva, a species which lives as high as the middle shore, over seaweed species which are confined to the lower shore may suggest that much of the seaweed was cut from the middle shore. Moreover, Rissoa parva is commonest on fine weeds suggesting that this was being harvested in preference to the larger Fucoid or Laminaria species. Such a preference might be explained by an awareness that finer seaweeds decompose more quickly, providing more enrichment for present rather than future crops. Some of the larger weeds were, however, undoubtedly being deposited and the presence of the large Fucoid species 
Onoba semicostate:

Cingula semistriata:

Gibbula cineraria:

Hydrobia ulvae:

Lacuna pallidula:

Lacuna vincta:

Littorina littoralis:

Littorina litorea:

Littorina saxatilis:

Littorina neritoides:

Rissoa parva:

Retusa obtusa:

Buccinum undatum:

Nucella lapillus:

Patella aspersa:

\section{Bivalves}

Mytilus edulis:

Cerastoderma edule:

Pholadacea: sp

Ensis arcuatus/arcuatus:

Mya arenaria:
Common in summer on all rocky and stony shores; under stones, among weeds and coralines; in silty crevices, and shelly gravel, always with a considerable quantity of silt. Near HWM - $100 \mathrm{~mm}$ sublittorally.

Not common in the $\mathrm{N}$; present in summer under stones and at the base of weeds on rock; especially silty places and common locally in muddy rock pools. LW - $100 \mathrm{~m}$ sublittorally.

Common on rocky shores under stones and on (top shell) seaweeds (Fucus, Laminari a, Bifurcata, + many small red algal species), in pools, and on rough surfaces; requires some shelter and avoids exposed locations; tolerant of sandy, stony shores but avoids mud and very weedy localities. LW - $130 \mathrm{~m}$.

Common in brackish and sheltere dintertidal locations with flat wet banks of firm mud or muddy sand, especially in estuaries; often found with Cerastoderma edul e; common also on weeds in muddy localities (ulvae, zostera and enteromorpha); tolerant of drying out by burrowing, but intolerant of direct wave action; salinities $2-42 \%$, normally $10-30 \%$ and average $22 \%$. HW - $20 \mathrm{~m}$.

Lives on holdfasts in the Laminaria zone, $L W-70+m$.

Common on seaweeds (especially Fucus sp, ceramium, zostera and polysiphonia, also Laminari a) - LW - c. $35 \mathrm{~m}$. Abundant on all rocky and stone shores; usually found on seaweed (Fucus, Ascophyllum); especially commo $n$ where these plants border rock pools. Lower, MW - upper LW.

?? Very common on rocky, stone, and sandy (and (edible winkl e) also muddy) beaches; lives on rocks and seaweeds. $M W-L W$

Abundant on all rocky coasts except the most exposed; usually in cracks, crevices and empty barnacle shells in asso ciation with the seaweed Pelvetica canaliculata. HW - middle MW.

Locally abundant on all rocky coasts; found in rock cracks and crevices; HW and above, but migrates to lower areas of the shore inbreeding season March - April.

Abundant in summer on rocky and stone shores among corallines and seaweeds (commo nest on base and fronds of smaller weeds with subdivided thallus - lamentaria, plumaria, callithamnion, Ceramium, Corallina; less commo $n$ on weeds with undivided fronds - Fucus, Enteromorphe, Rhodymenia, Ulva, and also commo $n$ on Laminaria hold especially fine weeds in rock pools; also under stones and in crevices. Middle MW $-2 \mathrm{~m}$ sublittorally.

Frequent in muddy estuaries and brackish water away from direct wave action; lives on flat wet banks of firm mud or muddy sand; tolerant of drying out through burrowing; commo $n$ also on weeds in muddy localities. Lower HW - 15 $m$.

Found on both rocky and sandy shores; a (whelk) large species, it is mobile and not confined to particular surfaces; lower LW - deep water sublittorally.

On all rocky coasts except very exposed (dog whelk) ones; locally abundant wherever barnacles and mussels are found (feeds on other mollusca); usually found under stones and in rock crevices. HW-sublittorally.

The dominant limpet on lower parts of (limpet) exposed rocky shores and higher where heavy wave action; avoids dryer and very sheltered areas and brackish water; prefers areas washed by waves and pools; found on open rocks, in gullies and on the underside of overhangs; feeds on seaweed (Fucus sp algae, and Corallina sp algae). LW -sublittorally; and lower MW where strong wave action. Patella vulgata The dominant limpe $t$ higher on all rocky shores from exposed to sheltered when there is a firm clean surface for attachment; lives on rocks and stones, in crevices, under overhangs and in pools; tolerant of brackish water locations (salinity down to 3\%) though normally lives in marine conditions (salinity > 25\%). HW - LW, though less commo $n$ on lower shore as replaced by $P$. aspersa, except in more sheltered or brackish water locations.

Very common on rocky and stone shores; (mussel) attached to rocks and usually in great local abundance; found in both sheltered and exposed locations. Lower HW - 15 m sublittorally.

Common in clean sand, muddy sand, mud or (commo n cockle) muddy gravel, in sandy bays, estuaries and tidal rivers; burrows to a depth of no more than $5 \mathrm{~cm}$; lives in water with salinity just below 20-35\%. MW - $10 \mathrm{~m}$ sublittorally. Burrowing species; into hard and softer (Piddock)rock, wood, peat, and firm sand.MW/LW - $10 \mathrm{~m}$ sublittorally. burrows into fine or coarse sand and also fine or coarse shell gravel. $L W-35 \mathrm{~m}$; siliqua burrows into fine sand, gen erally avoiding silty conditions. $L W-35 m$.

Very common in firm sand, mud, sandy mud and sandy gravel in seashore and estuaries. LW $-70 \mathrm{~m}$.

Table 29. The ecological requirements of the marine mollusc an species found at Baleshare, Hornish Point, Newtonferry and Baleshare 
is evidenced by the presence of juvenile species of Littorina littoralis and Littorina littorea.

Two species, Hydrobia alvae and Retusa obtusa, live on muddy shores, either on or within the mud, or on weeds in muddy localities. These species could indicate either the gathering of finer, smaller weeds on muddy shores, or alternatively accidental collection during the collection of cockles (Cerastoderma edule), with which they are commonly found.

\subsubsection{Balelone}

Only a small number of seaweed shells, all species from exposed rocky coasts, were found in the ten contexts sampled for snails. The single specimen of Littorina neritoides was abraded and could have been blown onto the site. This seems possible as the high rocky shore of its environs suggest that little coastal erosion occurred since the Iron Age. One example of the Littorina saxatilis was also abraded. The remaining Littorina saxatilis specimens, however, were undamaged. This appears to imply seaweed collection from the higher shore while collection of the weed from the lower and middle shore is evidenced by the few Rissoa specimens present.

\subsubsection{Baleshare}

The microscopic shells from Baleshare demonstrate collection from both rocky and sandy shores. The single specimen of Cingular semistriata shows that at least some of the rocky shore was rather sheltered and contained silty crevices or muddy rock pools. The rocky shore seaweeds could have been gathered from the exposed west-northwest-facing rocky and stony beaches, while the sandy species would have been brought with seaweed from the sheltered muddy and sandy lagoonal areas east of Baleshare Island. The nearest muddy and sandy beaches are less than $1 \mathrm{~km}$ to the north and east, whilst it would seem that in the Bronze Age and Iron Age a similar distance of $0.5-1.0 \mathrm{~km}$ separated Baleshare from the western rocky coast. Hydrobia Ulvae indicates the collection of seaweed from muddy, possibly estuarine, areas.

The frequency of microscopic gastropods indicates that seaweed gathering was at a relatively low level during the Bronze Age, increasing in importance during the Iron Age. The frequencies of seaweed mollusca at Baleshare, however, were generally less than $20 \%$ of that noted in contemporary contexts at Hornish Point. The differing nature of the contexts on the two sites rather than contrasting economic activities may account for this discrepancy (below).

\subsubsection{Hornish Point}

The high number of seaweed gastropods at Hornish Point implies that harvesting and collection of seaweed was a common summer activity at the site. The faunal composition is generally similar to that at Baleshare except that there are no indications of seaweed being gathered from sandy or muddy shores, with only species from rocky or stony shores being represented. Furthermore, there are no species like Cingula semistriata to indicate that there were any sheltered areas on this rocky shore. Hornish Point is presently flanked by a stony, rocky shore to the west, north and north-east, although there is evidence that like Baleshare, it may have been an inland site during the Iron Age.

Seaweed seems to have been collected from the lower and middle shores, although the two specimens of Littorina saxatilis may imply collection also from the higher shore. The dominance of Rissoa and the absence of certain species such as Onaba semicostate, presently common on Laminaria and Fucoid in the Outer Hebrides (Smith 1979), implies that the majority of weed collected may have been smaller, finer-leaved algal species. Lacuna vincta is also fairly common on smaller weed species but confined to the lower shore. It may have arrived, however, with larger Fucoid species (bladder wracks), the collection of which is implied by juvenile specimens of Littorina littoralis and Littorina littorea. These larger weeds would appear, however, to have been collected in small quantities.

The lower frequency of seaweed mollusca at Iron Age Baleshare has already been noted. The contexts sampled at Hornish Point came from the centre of activity on the site and are associated with buildings and midden-field immediately adjacent to them. Those excavated at Baleshare were located in the midden-field towards the periphery of the site away from the centres of activity. It is possible, therefore, that economic activities involving seaweed were practised more intensively at the centre than the periphery of these Iron Age sites. Seaweed species often seem to coincide with layers that have land snail indications of field middening or simply dumping of organic domestic refuse (Block 19). This may suggest that seaweed was deliberately incorporated into dung heaps and, more importantly, that the more intensively tilled and fertilised land was confined to the immediate vicinity of the settlement as predicted in central place models. Blocks 9, 11 and 12, however, have no land snail indication of middening but have significant numbers of seaweed species. In this case, it may be suggested that seaweed was deposited locally as animal fodder or more likely, that seaweed was the sole method of soil fertilisation. No burnt seaweed shells were noted at either Baleshare or Hornish Point. This would seem to suggest that seaweed was not used as fuel which is not surprising as extensive supplies of peat was available locally.

The presence in Block 9 of many Gibbula cineraria apices, in addition to Rissoa parva and a few Lacuna vincta, would suggest that both fine algal weeds and larger bladder wrack (Fucoid) and other weeds were left on the midden-fields.

The presence of seaweed mollusca in some of the building deposits at Hornish Point (eg Block 19) suggests that seaweed was exploited as food as it was dumped with other organic domestic refuse to fill old disused buildings from which it is unlikely to have been re-distributed as fertiliser. The seaweed shells were almost entirely Rissoa parva, indicating that finer, smaller weeds were preferred for human consumption, although a few Gibbula shells may suggest that larger weeds were also eaten.

\subsubsection{Newtonferry}

This post-Medieval site produced the highest frequency of seaweed species per context of the four sites studied, reflecting the importance of seaweed as a fertiliser in the past, a phenomenon clearly evidenced by the documentary sources. 
It appears that the excavated contexts are from near the centre of the site as the contexts were associated with buildings and midden-fields. The fauna are similar to those from Baleshare and Hornish Point in that they were largely derived from a rocky shore, from finer, smaller weeds, while some larger types were gathered from the lower and middle shores. The presence of Lacuna pallidula and Onoba semicostate suggests that Laminaria was also collected, possibly as driftweed. Onaba semicostate also indicates that some weed was collected from more sheltered rocky coasts. At present, such a coastal type is located immediately to the west and east of the site. The single specimen of Retusa obtusa, a mud-bank species, may show that weed was also being taken from the small, brackish Loch an Sticar $500 \mathrm{~m}$ south of the site or, possibly, from the sheltered bay where Newtonferry is situated. Alternatively, this specimen may have been introduced with collected cockles.

The distribution of seaweed species within the Newtonferry deposits indicates that whilst present in layers producing land-snail assemblages suggestive of middening, the highest concentrations were in layers devoid of such evidence, indicating that at Newtonferry seaweed was collected primarily as fertiliser and possible stabiliser for the midden-fields. 


\section{CHAPTER I5: THE PHYTOLITH ASSEMBLAGE}

A Powers (1987)

\section{I INTRODUCTION}

Phytoliths are silica particles which develop in plant tissue and their analysis is relatively new to British archaeology. Very few studies have been carried out with the exception of work by Armitage (1975), MacPhail (1981), Murphy (1986), Robinson \& Straker (1991) and the unpublished investigation of Scaife and Murphy. There have not been any previous studies in Britain or overseas of phytoliths in the modern and ancient sediments of coastal dune sequences.

Phytoliths may form within cellular tissues as a result of normal plant growth or as a response to water stress; microbial or insect attack, or mechanical damage (Powers \& Gilbertson 1987). The phytoliths assumed the shape of the host tissues in which they form and because of the diversity of cell morphologies, an identifiable range of phytolith morphotypes are produced (Figure 84).

On plant death the phytoliths may be incorporated into the sediments on site (Baker 1959 a \& b; Dimbleby 1967; Jones \& Beavers 1964 a \& b; Kalisz \& Stone 1984; Twiss 1983; Smithson 1956; 1958; 1961; Witty \& Knox 1964; Yeck \& Gray 1972), or they may be finally deposited elsewhere if the plants have been grazed or gathered for consumption or utilisation.

The study of phytoliths has considerable potential in the field of archaeology, both because of their unusual resistance to decay and the potential types information which they can yield (see Rovner 1983). The non-organic (silica) matrix of the phytoliths results in a microfossil that is comparatively resistant to microbial attack, decomposition, oxidation, leaching, attrition, breakage or disintegration. It appears to be chemically stable in a wide range of deposits from acid peats (Powers et al 1989) through to very alkaline sands, up to $\mathrm{pH} 9.8$ so far analysed, (Powers \& Gilbertson 1987). The wide range of conditions under which phytoliths are relatively inert is in contrast to the preservational behaviour of some other microfossils such as pollen. As a result of their carbon-based structure, pollen and spores are highly susceptible to microbial destruction and oxidation and the recovery of pollen grains is largely limited to depositional conditions which inhibit these destructive forces, eg peat bogs or lake sediments.

In conditions where pollen does not survive, for example in calcareous sand dune sequences at Baleshare and Hornish Point, phytoliths may be the only source of direct evidence for the presence of plants and hence for obtaining details concerning palaeoecological reconstruction of patterns of plant or land use. In addition, the preservation and recovery of phytoliths are potentially universal and not dependent on a specific combination of conditions, necessary for example for the accidental carbonisation of plant macrofossils.

Unlike pollen however, phytoliths are not species-specific and because of this they have to be studied not as single examples but as suites (assemblages) of the different phytolith shapes (phytolith morphotypes). Despite a general lack of individual specificity, in the study of one particular plant family - the Gramineae (grasses) - phytolith analysis is superior to pollen analysis. The recognition of wild and cultivated taxa in this family is neither simple nor totally reliable in standard palynological approaches, whereas phytolith analysis may, in certain circumstances, distinguish sub-families, genera and species (see Smithson 1958 and Piperno 1985).

Considerable effort has been undertaken in America in an attempt to rationalise phytolith suite analyses to obtain accurate correlations between phytolith suite components and the individual plant species from which they originate (see Brown 1984; Rovner 1983). With the exception of one or two species (eg maize) this approach is believed by Rovner (pers comm) to have been largely unsuccessful.

An alternative approach to the use of phytolith analysis is the basis of this account. Instead of attempting to distinguish separate species, we have attempted to encompass wider issues; the potential of phytolith analysis for the elucidation of coastal ecological zones; identification of anthropogenic levels in coastal machair and dune deposits; and the identification of the precise nature and origin(s) of the organic-rich layers.

It may be possible to make precise palaeo-geographical reconstructions based on ecological models or to investigate ancient pastoral or agricultural practices and the transport to, and consumption of, plant and animal remains within the fragile and ecologically important dune and machair systems which fringe the Atlantic seaboard of the Western Isles.

Phytoliths have been recovered from three different types of archaeological sources: from remnants in pottery (Dimbleby 1967; Fujiwara 1982), in food residue from teeth (Armitage 1975; Scaife 1984 unpub) and from the actual archaeological sediments themselves. This study uses Correspondence Analysis and Cluster Analysis to investigate the phytolith suites associated with modern analogue materials and archaeological sites in the machair of North and South Uist. It demonstrates that areas of ancient human occupation and activity are characterised by concentrations of phytoliths which are orders

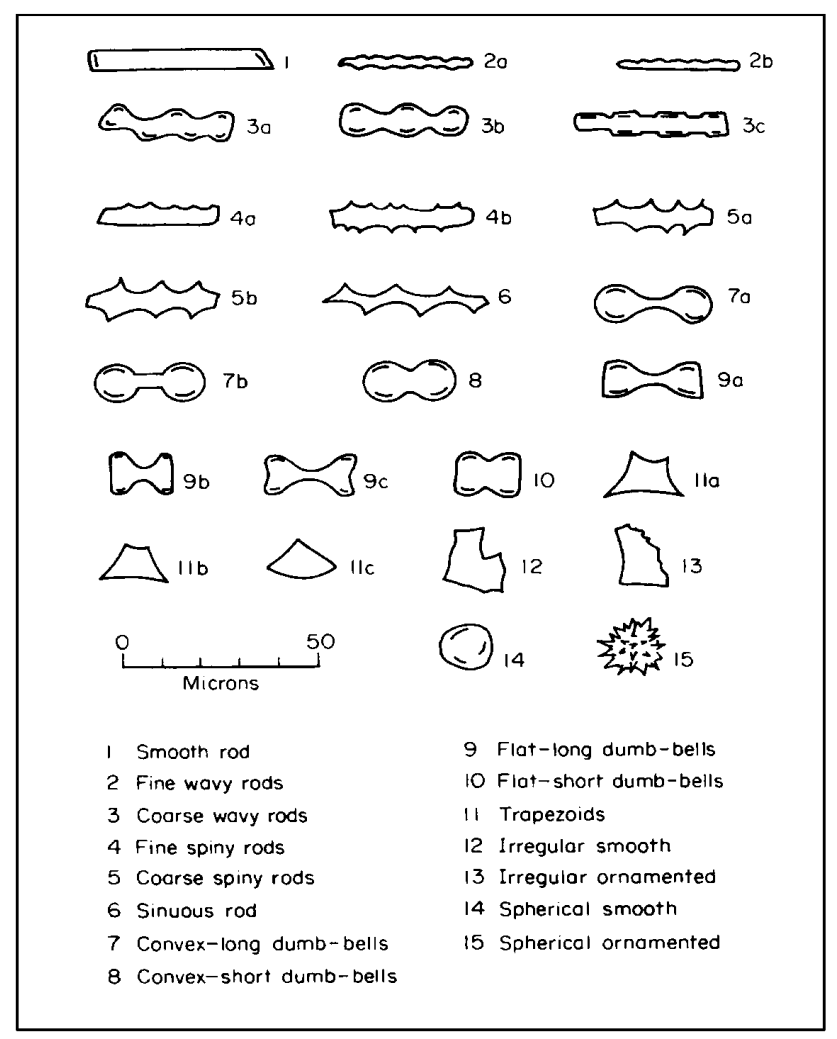

Figure 84. Phytolith morphotypes 


$\begin{array}{llll}\text { Block } & \text { Block type } & \text { Context No. Sample No. } \\ & & 001 & 3751 \\ 5 & \text { Windblown sand } & 004 & 3507 \\ & \text { Dumped deposits } & 011 & 3508 \\ & & 016 & 3512 \\ & & 035 & 3516 \\ 24 & & 027 & 3519 \\ & \text { Dumped deposits with } & 031 & 3526 \\ & \text { midden-site deposits } & 037 & 3521 \\ & & 032 & 3524 \\ & & 038 & 3537 \\ 2 & & 039 & 3533 \\ & & 055 & 3558 \\ & & 072 & 3562 \\ & & 059 & 3566 \\ & & 076 & 3570 \\ 1 & & 082 & 3599 \\ 23 & \text { Cultivated deposit } & 068 & 3574 \\ & & 267 & 3555 \\ & & 268 & 3544 \\ & & 269 & 3545 \\ & & 270 & 3546 \\ & & 272 & 3548 \\ & & 271 & 3547 \\ 22 & & 277 & 3554 \\ & & 278 & 3648 \\ & & 279 & 3649 \\ & & & 3650\end{array}$

Table 30. Baleshare. Provenance of phytolith samples

of magnitude higher than occur naturally in coastal dune systems. Some aspects of ancient human activity can be distinguished, ie the introduction of peat, turves, plant or animal waste, and possibly differences in grazing/pasture in the area.

\section{I5.2 RESEARCH QUESTIONS}

Initially two questions were posed by the excavator in the context of the excavations of the ancient coastal sand dunes at Baleshare and Hornish Point;

i) Whether or not it is possible to discriminate between different sedimentary origins on the basis of postulated differences in the likely frequencies of phytoliths. In particular to distinguish between assumed stable humic layers, believed to represent periods of soil formation and/or human occupation and non-humic sands, believed to represent the free accumulation of dune sand in a more open, less vegetated depositional environment.

ii) To what extent is it possible to recognise associations between the relative abundance of various phytolith morphotypes and deposits from dune environments?

Subsequently, a third question was also posed;

\begin{tabular}{|c|c|c|c|}
\hline Block & Block type & Context No. & Sample No. \\
\hline \multirow[t]{4}{*}{13} & Midden-site deposit & 002 & 5002 \\
\hline & & 003 & 5003 \\
\hline & & 075 & 5075 \\
\hline & & 304 & 5207 \\
\hline \multirow[t]{5}{*}{12} & Midden-site deposit & 306 & 5206 \\
\hline & & 305 & 4226 \\
\hline & & 015 & 5015 \\
\hline & & 134 & 5034 \\
\hline & & 52 & 5153 \\
\hline 10 & Cultivated deposit & 016 & 5016 \\
\hline \multirow[t]{11}{*}{09} & Midden-site deposit & 017 & 5017 \\
\hline & & 020 & 5020 \\
\hline & & 026 & 5026 \\
\hline & & 027 & 5027 \\
\hline & & 036 & 5036 \\
\hline & & 043 & 5043 \\
\hline & & 029 & 5029 \\
\hline & & 045 & 5045 \\
\hline & & 037 & 5037 \\
\hline & & 030 & 5030 \\
\hline & & 023 & 5023 \\
\hline \multirow[t]{5}{*}{05} & Cultivated deposit & 079 & 5148 \\
\hline & & 083 & 5083 \\
\hline & & 080 & 5080 \\
\hline & & 092 & 5092 \\
\hline & & 089 & 5089 \\
\hline 01 & Cultivated deposit & 057 & 5057 \\
\hline
\end{tabular}

Table 31. Hornish Point. Provenance of phytolith samples

iii) To what extent is it possible to identify the source of the humic material in the archaeological deposits on the basis of abundance and diversity of phytoliths?

Twenty seven samples were chosen from each of the two sites of Baleshare and Hornish Point. Their provenances are shown in Tables $30 \& 31$. The 'Block' and 'super-Block' terminology employed here is that employed in the field by the excavation team.

\section{I5.3 RESULTS}

Details of the raw data counts can be found in Powers et al 1986, Tables 10-23. Originally, relative abundance counts were plotted up from the raw data with the frequency of each morphotype expressed as a percentage of 250: the total phytolith count per sample (ibid, Figures $20 \& 21$, Table 25). However, despite the obvious advantage of being able to present the data in the form of two concise diagrams, relative abundances can be misleading. For example, an apparently significant variation in the overall frequencies of Trapezoids between the Baleshare and Hornish Point samples (ibid, Table 25 ) actually resulted from a depression of the percentage of Trapezoids in the Baleshare samples by a significant increase in the proportions of Medium Smooth Rods and Fine Spiny Rods. Therefore, absolute frequencies of phytoliths have been plotted (Figures $86 \& 88$ ) as a means of presenting the data. These bar charts can provide a means of making visual 


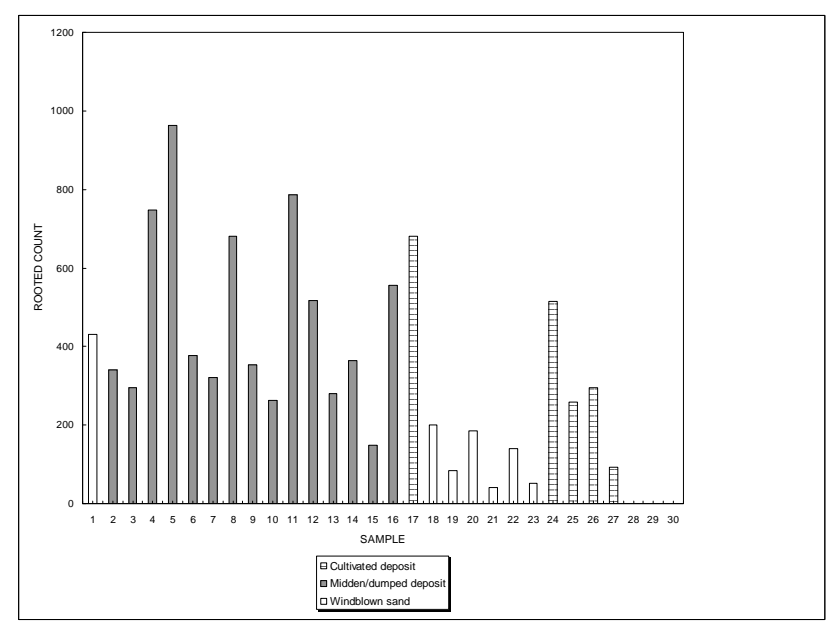

Figure 85. Baleshare; concentration of phytoliths per gram (rooted)

comparisons between samples within blocks, between blocks and between sites in order to attempt to identify any patterns of difference and/or similarity that may exist.

\subsection{Inter-, and intra-site variability}

This section provides a review of a statistical analysis of the results together with discussions of any patterns or trends in total abundance and composition of phytolith suits that are present. Intra-site variations are outlined first (Baleshare then Hornish Point), followed by details of inter-site variations on both a general then more detailed level. Included in the latter section is an investigation into the likelihood of isolating and defining 'Block-specific' phytolith suites. This is of interest in terms of equating archaeological deposits with their origins, after the unexpected results achieved from the modern analogues (Noltland and Ainsdale) which negated the present attempt to define different ecological zones from phytoliths because of the paucity of these particles in dune sands. The final part of this section deals with a comparison of the archaeological data with modern organic samples in an endeavour to determine the exact origins of the material recovered from the organic horizons.

\subsubsection{Statistical structure of phytolith data from archaeological deposits}

In addition to visual comparisons, the data was subject to statistical analysis by Ms Joanne Padmore, Department of Probability and Statistics, University of Sheffield (Padmore 1987). Two statistical analyses were performed;

i) Correspondence Analysis; essentially a scaling technique for displaying the rows and columns of a data matrix as points in corresponding low dimensional vector space.

The approach allows the different properties of samples spaces to be superimposed to obtain a joint display which may be interpreted visually (Greenacre 1984; Padmore 1987). ii) Cluster Analysis; using two separate techniques, Ward's Method and Iterative Relocation. The techniques were used to simplify the data by separating it into its constituent groups. Samples are clustered using the information for each sample given by its variable (for further details see Padmore 1987 and Powers et al 1989).

\subsubsection{Intra-site variations: Baleshare}

The range of phytolith concentration per one gram of sediment was 2,000 to 938,000 for the Baleshare samples (see Figure 85). It is possible to rank the Baleshare blocks according to the general total phytolith concentration (per one gram of sediment) of each Block (Table 32). With the exception of the single sample that constitutes Block 01, the ranking of blocks divides into two halves: (1) the windblown sands and cultivated (2) the midden-site and dumped deposits. The low frequencies of phytoliths in the windblown sands and cultivated deposits were expected from previous modern analyses (Powers \& Gilbertson 1987) and are unlikely to be an artefact of preservation or age.

Analysis of the compositions of the phytolith suites recovered form the Baleshare samples indicates that there is considerable overlap in the proportions of the various morphotypes that constitute the suites, for example large proportions of smooth rods and Trapezoids as compared with low proportions of Sinuous Rods (see Figure 86). However, a combination of visual appraisal of the bar charts and statistical analysis to support these observations, concluded that four Baleshare blocks possessed minor suite differences which could distinguish the samples from these blocks from the remaining samples. In addition to the standard patterns of common/uncommon morphotypes these four blocks had unusually high or low proportions of certain morphotypes (Table 33).

In addition to those blocks which had significantly different phytolith suites when compared with all blocks, there were a further number of separate Block comparisons where variations also appeared (Table 34). These relative differences in suite composition highlight the range of the variation within the Baleshare samples. Although all the samples overlap one another in terms of total suite composition, they possess differences in respect of one or two morphotypes that are only significant when the 'extremes' of the spectrum of values recovered for that particular morphotype are compared with one another.

$\begin{array}{llc}\text { Block } & \text { Block type } & \begin{array}{r}\text { Phytoliths } \\ \text { per gram }\end{array} \\ 23 & \text { Windblown sands } & \text { few } \\ 22 & \text { Cultivated deposit } & \hat{} \\ 06 & \text { Windblown sands } & \hat{} \\ 02 & \text { Midden-site deposit } & \hat{} \\ 01 & \text { Cultivated deposit } & \hat{} \\ 24 & \text { Dumped/midden-site deposit } & \text { many } \\ 05 & \text { Dumped deposit } & \end{array}$

Table 32. Baleshare. Ranking of Blocks based on phytolith concentrations 

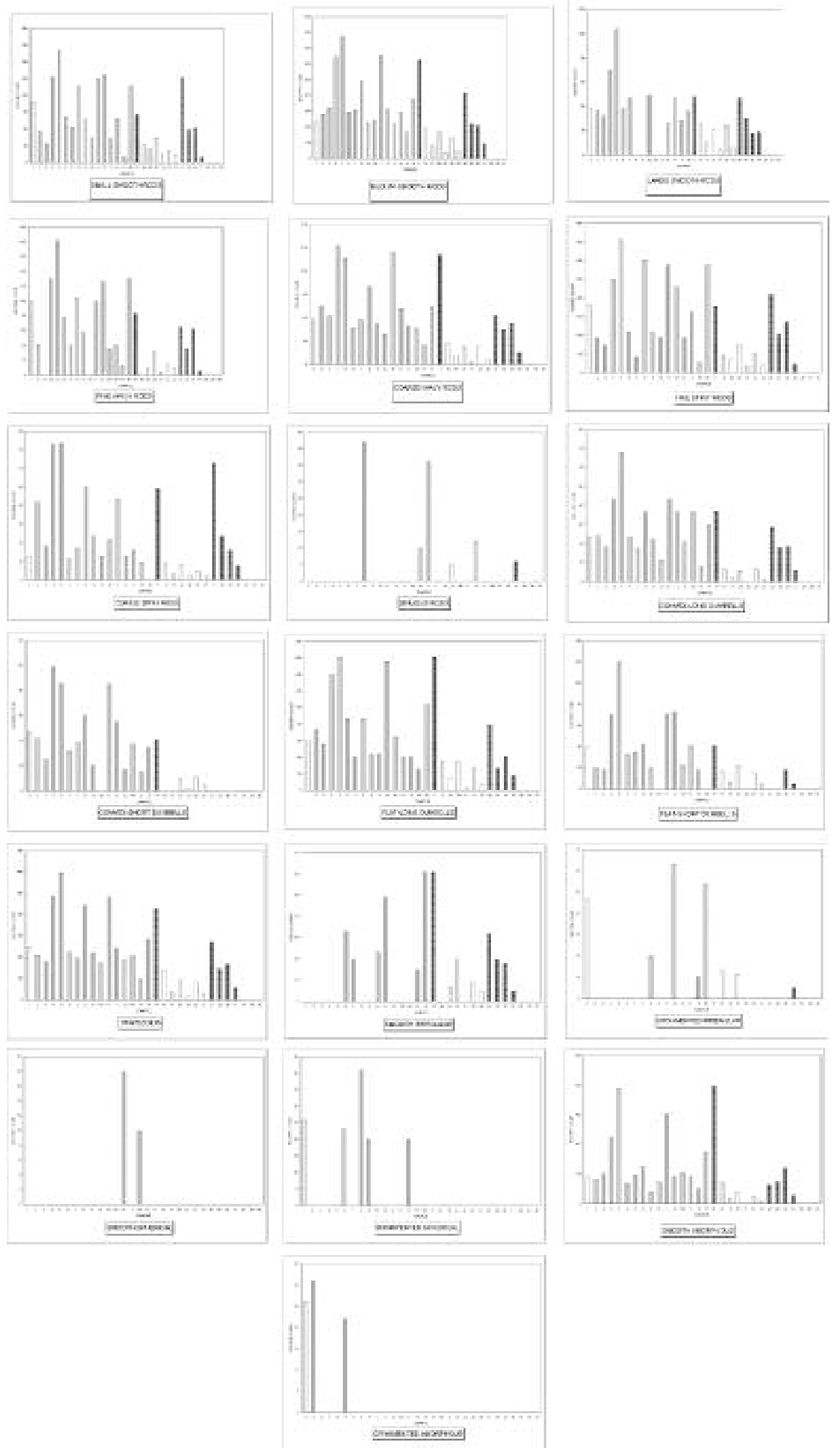

Figure 86. Baleshare; absolute phytolith frequencies (for key see Figure 85) 


\begin{tabular}{|c|c|c|}
\hline $\begin{array}{l}\text { Block } \\
\text { No. }\end{array}$ & Block type & $\begin{array}{l}\text { Component which is } \\
\text { significantly different } \\
\text { from norm }\end{array}$ \\
\hline 06 & Windblown sands & more Ornamented Irregulars \\
\hline 05 & Dumped deposit & fewer Fine Spiny Rods \\
\hline 23 & $\begin{array}{l}\text { Cultivated windblown } \\
\text { sand }\end{array}$ & fewer Trapezoids \\
\hline 23 & Cultivated windblown & \\
\hline 22 & $\begin{array}{l}\text { sand \& } \\
\text { cultivated deposit }\end{array}$ & $\begin{array}{l}\text { higher ratio of Fine Spiny Rods } \\
\text { to Coarse Wavy Rods }\end{array}$ \\
\hline
\end{tabular}

Table 33. Baleshare. Blocks with phytolith suites significantly different from other Baleshare samples

\section{Block no. \& type vs Block no. \& type}

$\begin{array}{ccc}\begin{array}{c}\text { I } \\ \text { Morphotype }\end{array} & \begin{array}{c}\text { 05 Dumped deposit } \\ \text { few Fine Spiny Rods }\end{array} & \begin{array}{c}23 \text { Windblown sands } \\ \text { many Fine Spiny Rods }\end{array} \\ \begin{array}{ccc}\text { Morphotype } \\ \text { 24 Dumped/midden } \\ \text { few Coarse Spiny Rods }\end{array} & \begin{array}{c}\text { 22 Cultivated deposit } \\ \text { many Coarse Spiny Rods }\end{array} \\ \begin{array}{c}\text { Morphotype } \\ \text { few Coarse Spiny Rods }\end{array} & \begin{array}{c}\text { 22 Cultivated deposit } \\ \text { many Coarse Spiny Rods }\end{array} \\ \begin{array}{c}\text { Morphotype } \\ \text { OI Cultivated deposit } \\ \text { few Fine Spiny Rods } \\ \text { many Coarse Wavy Rods }\end{array} & \begin{array}{l}\text { 06 Windblown sands } \\ \text { many Fine Spiny Rods } \\ \text { few Coarse Wavy Rods }\end{array}\end{array}$

Table 34. Baleshare. Blocks shown by Correspondence Analysis to have specific suite components that are at opposite extremes of the range of values recorded

$\begin{array}{lccc}\text { Block } & \text { GROUP I } & \text { GROUP 2 } & \text { GROUP 3 } \\ 06 & 001 & - & - \\ 05 & 027 & 004,011,016,035 & - \\ 24 & 037,032 & 031,038,039 & - \\ 02 & 055,059 & 072,076 & 082 \\ 01 & - & 068 & - \\ 23 & - & 267 & 268,269,270, \\ 272,271 & & & - \\ 22 & - & 277,278,279,280 & \end{array}$

Table 35. Baleshare. Cluster Analysis

$\begin{array}{llc}\text { Block } & \text { Block type } & \begin{array}{c}\text { Phytoliths } \\ \text { per gram }\end{array} \\ 01 & \text { Cultivated deposit } & \text { few } \\ 09 & \text { Midden-site deposit } & \hat{} \\ 13 & \text { Midden-site deposit } & \hat{} \\ 12 & \text { Midden-site deposit } & \hat{} \\ 10 & \text { Cultivated deposit } & \text { many }\end{array}$

Table 36. Hornish Point. Ranking of Blocks based on phytolith concentrations
The morphotypes exercising the greatest influence on the statistical Correspondence Analysis of the Baleshare samples were;

i) Fine Spiny Rods (correlating with low frequencies of Coarse Wavy Rods and Coarse Spiny Rods).

ii) Small and Medium Smooth Rods.

iii) Trapezoids.

iv) Ornamented Irregulars.

The cluster analysis of the Baleshare samples resulted in a three group solution that was essentially identical for both the Ward (Table 35) and the Relocate method. The only difference was a transposition of samples 22.227 (ie sample from Block 22, [277]) and 23.272 in the Relocate ordering.

Only one multi-sample Block (Block 22) lay entirely within one group, indicating substantial overlap between samples from different blocks. In addition the cluster analysis reveals that;

i) The Blocks are divided into three groups along general stratigraphic lines.

ii) Blocks 06, 05, 24, 02, 01 and 22 have phytolith suites whose composition share common features.

iii) Block 23 stands out as being significantly different from the rest of the Baleshare Blocks.

iv) Block 06 is significantly different from Block 23 .

v) Block 06 may be different from Blocks 5, 24 and 02 but it is impossible to be sure as the single sample from Block 6 overlaps with a few contexts from the other Blocks.

vi) The samples from Block 22 (all within group 2) are very homogeneous in terms of their phytolith suites.

vii) The samples from Block 23 (mainly within group 3) are very homogeneous in terms of their phytolith suites.

viii) The samples from Block 2 exhibit the least intra-Block homogeneity but the division into three groups orders the samples according to sample number ie the 50's, 70 's and 80 's. This may or may not be significant.

\subsubsection{Intra-site variations: Hornish Point}

The range of phytolith concentrations per 1 gram of sediment was 3,000 to 750,000 (Figure 87 ). It is possible to rank the Hornish Point samples according to the general total phytolith concentration (per 1 gram of sediment) of each Block (Table 36).

The relative absence of phytoliths from the single-sample Block 1 separates it from the remaining Hornish Point blocks. Block 9 is similarly separated from its neighbours by a low (but not as low as Block 1) phytolith concentration. 


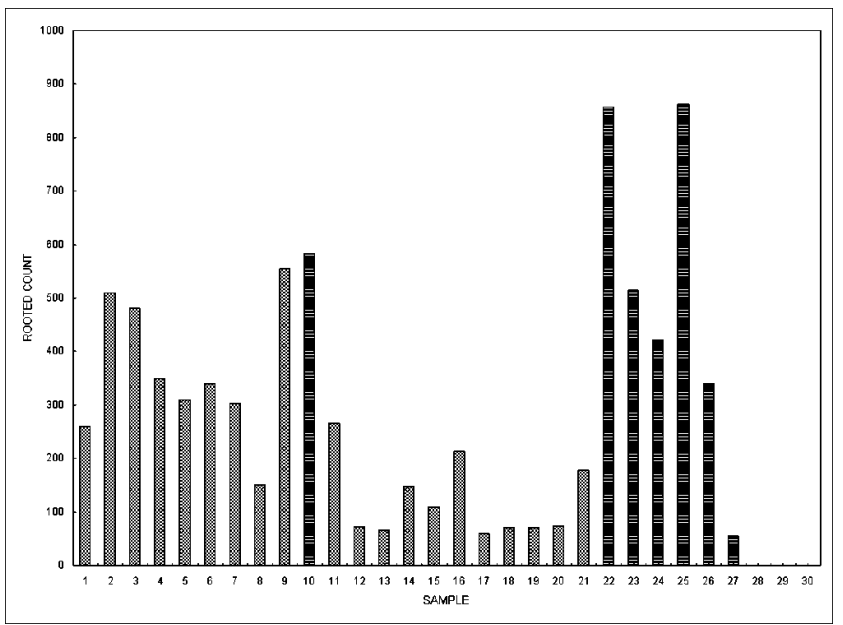

Figure 87. Hornish Point; concentration of phytoliths per gram (rooted) (for key see Figure 85)

Blocks 13, 12, 10 and 05 are grouped together on the basis of total phytolith concentrations which is not surprising since these form part of a 'super-Block' (Block 2). In general terms there is a decrease in phytolith concentration per gram of sediment with increasing age of the sediment.

However, this is far from a perfect correlation. For example Block 1, with the lowest concentration of phytoliths, is the oldest, but the richest samples were those derived from the next oldest Block, Block 5.

Variations in phytolith concentrations between samples are probably best explained not by age but by the origins of the samples themselves. The relative absence of phytoliths from Block 1, a cultivated deposit, was expected from the results of phytolith analyses of modern cultivated (vegetated) dune horizons (Powers et al 1989). The richness of the two remaining cultivation horizons (Blocks 5 and 10) from Hornish Point is less easy to understand, but it may stem from differences in type and/or density of vegetation cover and whether or not the vegetation cover was natural or managed.

As with the Baleshare samples, the Hornish Point samples share many components of their phytolith suites (see Figure 88); components that are similarly recovered in common proportions (eg many Trapezoids and Smooth Rods, few Sinuous Rods). This overlap in phytolith suites (see Padmore 1987) is not surprising because five out of the six blocks sampled for phytoliths constitute part of the Super-Block 2.
It has been possible however to recognise significant minor differences in the suites on the basis of visual appraisal and Correspondence Analysis. This has resulted in the division of the blocks into two groups on the basis of the proportions contained of the two morphotypes Medium Smooth Rods and Fine Spiny Rods;

Group 1 - Blocks 13, 12, and 10 few Medium Smooth Rods many Fine Spiny Rods.

Group 2 - Blocks 09, 05 and 01 many Medium Smooth Rods few Fine Spiny Rods

The samples from Block 12 actually overlap between the two groups, a not unexpected feature because the blocks belong to Super-Block 2, which has other Block elements from both groups.

As a result of the homogeneity of the Hornish Point samples only one Block, 01 , possessed a phytolith suite with elements which were significantly different from those of all the remaining Hornish Point blocks. This difference was in respect of two morphotypes, namely the presence of the Smooth Spherical morphotype and the fact that it possessed few Convex-long Dumb-bells. Block 1 however, possessed minor differences in its suite composition that made it stand out by comparison with other Hornish blocks, namely that it possessed the Smooth Spherical morphotype and that it had low frequencies of the Convex-long Dumb-bell. In addition to Block 01; which was different to the rest of the Hornish Point samples, there were two further Block comparisons involving four different blocks (see Table 37) indicating that in respect of several morphotypes the contrasting Block pairs represent the opposite extremes of a range of values.

Of great interest is the fact that the samples from Hornish Point blocks exhibit temporal ordering in respect of four morphotypes. The proportions of Fine Spiny Rods and Coarse Weavy Rods were seen to decrease with increasing age of sediment while those of Medium and Small Smooth Rods increase with increasing age. These changes through time are exemplified by the comparison of the two single-sample blocks, Block 1 being the oldest Block sampled for phytoliths and Block 10 originating from near the top of the stratigraphy (see above). Both of these blocks have been designated as cultivation deposits but their proportions of Fine Spiny and Coarse Wavy Rods to Medium and Small Rods are clearly reversed (see above).
Block no. \& type

$\begin{array}{cc}\text { I } & \text { I0 Cultivated deposit } \\ \text { morphotypes } & \text { many Coarse Wainy Rods } \\ & \text { few Medium Smooth Rods } \\ & \text { few Small Smooth Rods } \\ 2 & \text { I3 Midden-site deposit } \\ \text { Morphotypes } & \text { many Fine Spiny Rods } \\ & \text { few Medium Smooth Rods } \\ & \text { few Small Smooth Rods }\end{array}$

vs

Block no. \& type

0I Cultivated deposit
few Fine Spiny Rods
few Coarse Wavy Rods
many Medium Smooth Rods
many Small Smooth Rods
05 Cultivated deposit
few Fine Spiny Rods
many Medium Smooth Rods
many Small Smooth Rods

Table 37. Hornish Point. Blocks shown by Correspondence Analysis to have specific suite components that are at opposite extremes of the range of values recorded 


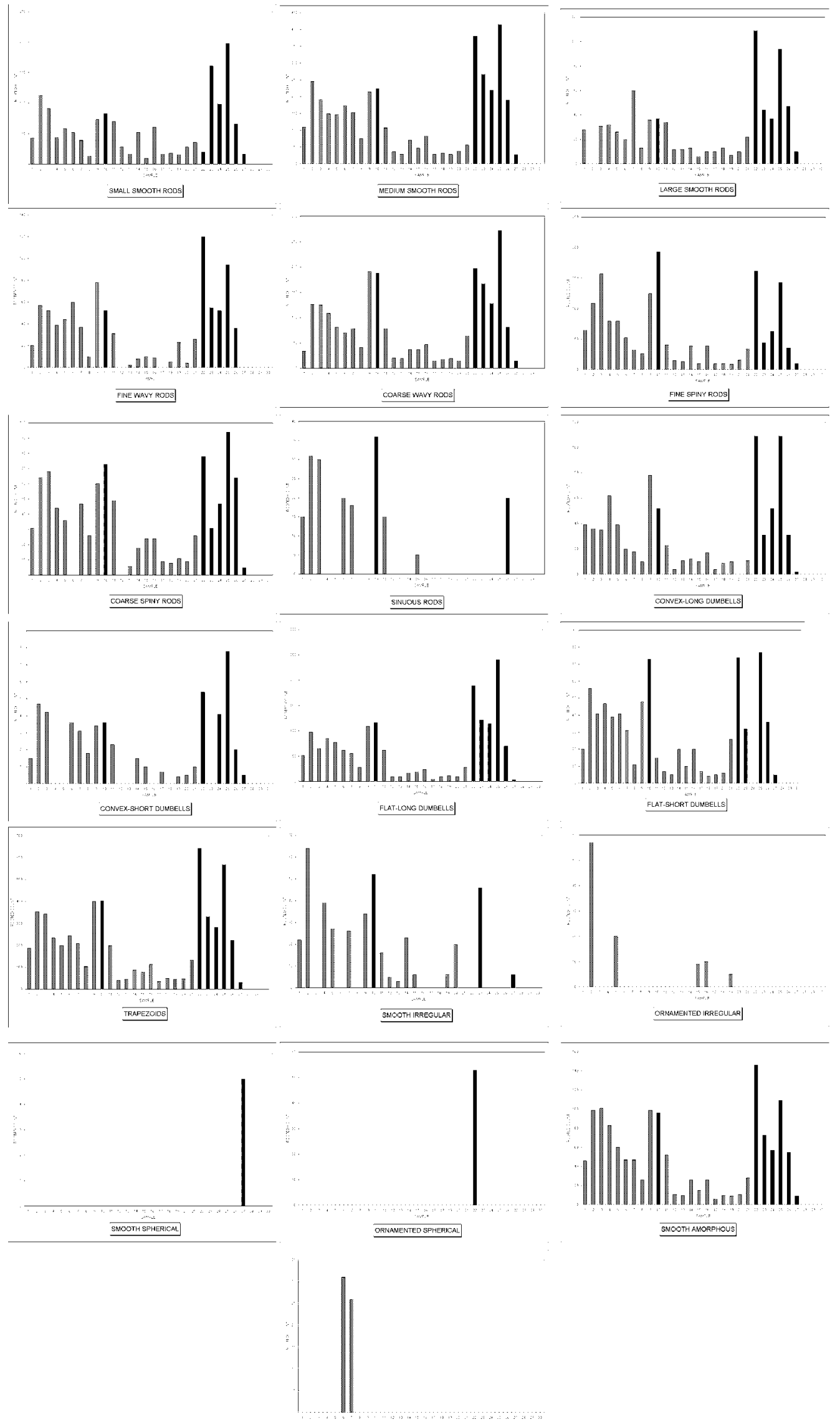

ORNAMENIED D AMORPRHOUS

Figure 88. Hornish Point; absolute phytolith frequencies (for key see Figure 85) 
a) Ward's method

$\begin{array}{lc}13 & 002,003,075,304 \\ 12 & 306,134,052 \\ 10 & 016 \\ 09 & 017,036,023 \\ 05 & 089 \\ 01 & - \\ \text { b) Relocate method } & \\ 13 & 002,003,075,304 \\ 12 & 306 \\ 10 & 016 \\ 09 & 017 \\ 05 & - \\ 01 & -\end{array}$

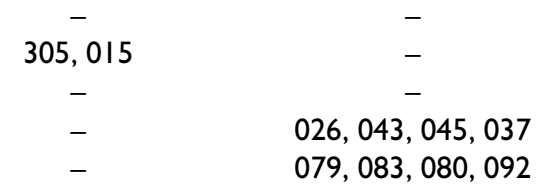

$079,083,080,092$

$-$
$-$

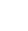

$020,027,029,030$

057

Table 38. Hornish Point. Cluster Analysis

The morphotypes that exercised greatest influence on the Correspondence Analysis of Hornish Point samples were;

i) Medium and Small Smooth Rods

ii) Fine Spiny Rods

iii) Coarse Wavy Rods

iv) Convex-long Dumb-bells

The cluster analysis of the Hornish Point data resulted in a four group solution. The results using the Relocate method and Ward's method produced slightly different four group solutions, with Groups 2 and 4 being identical in both cases but groups 1 and 3 being slightly different (Table 38 ).

The Cluster Analysis of the Hornish Point samples revealed that;

i) The Blocks may be divided into four groups in general stratigraphic order.

ii) Blocks 13, 12, 10, 9 and 5 have samples whose phytolith suites share common features.

iii) Block 1 may be very different from Blocks 13, 12, 10 and 5 although it consists of only one sample.

iv) Blocks 1 and 9 have certain samples with common suite features.

v) Block 13 may be very similar to Block 10 (although the latter consists of only one sample).

vi) Block 13 may be very different from Block 1 (although the latter consists of only one sample).

vii) Block 13 exhibits the greatest intra-Block sample homogeneity of all the Hornish Point blocks sampled. viii) Block 5 also exhibits considerable intra-Block sample homogeneity.

ix) Block 9 exhibits the least intra-Block homogeneity.

$x$ Samples 305 and 15 from Block 12 are not only distinctive from the rest of Block 12 but from all the remaining Hornish Point Blocks.

\section{Phytolith concentration}

There is considerable intra-site variation in the concentration of phytoliths in the Baleshare and Hornish Point samples, but the data indicates no significant inter-site separation. The sites exhibit extensive overlapping in the range of phytoliths recovered per gram of sediment; the results for Baleshare were 2,000 to 938,000 and those for Hornish Point 3,000 to 750,000 phytoliths per gram (Figures $85 \& 87$ ). Of the two sites, Baleshare possessed less within site homogeneity than Hornish Point in terms of concentration of phytoliths per sample. Baleshare produced both the sample with the least and with the most number of phytoliths per gram (contexts 270 windblown sand; and 05 - midden-site deposits respectively).

It is possible to rank all the blocks analyses on the basis of total phytolith concentration per gram of sediment (Table 39) but there is no direct and absolute correlation between sample origin (as indicted by the excavation team) and phytolith concentration per gram of sediment. If there were, one would expect an ordering of samples according to type. There is no evidence of a significant difference between those samples described by the excavator as 'dumped deposits' and those labelled 'midden-site'. In terms of phytolith concentrations the midden and dumped deposits greatly overlap with the dumped deposit blocks containing some samples with slightly more phytoliths than the plain midden-site blocks. Generally (though far from exclusively) there is a ranking of blocks according to type, ie windblown sand and cultivated deposits have few phytoliths per gram while midden-site and dumped deposits have many. However, an appraisal of Figures 85 and 87 soon highlights the many and various exceptions to this ranking. For example, Hornish Point Block 9, 


\begin{tabular}{|c|c|}
\hline Block & Block type \\
\hline $\begin{array}{l}\text { B } 23 \\
\text { HP 0I }\end{array}$ & $\begin{array}{l}\text { Windblown sands } \\
\text { cultivated deposit }\end{array}$ \\
\hline HP 09 & midden-site deposit \\
\hline B 22 & cultivated deposit \\
\hline В 06 & Windblown sands \\
\hline B 02 & midden-site deposit \\
\hline HP 13 & midden-site deposit \\
\hline HP 12 & midden-site deposit \\
\hline HP IO & cultivated deposit \\
\hline B Ol & cultivated deposit \\
\hline B 24 & Dumped/midden si \\
\hline HP 05 & cultivated deposit \\
\hline B 05 & dumped deposit \\
\hline
\end{tabular}

\begin{tabular}{|c|c|c|}
\hline Group & Block & Block type \\
\hline I & B 06 & Windblown sand \\
\hline \multirow[t]{4}{*}{2} & B 24 & Dumped/midden site deposit \\
\hline & B 02 & Midden-site deposit \\
\hline & B 23 & Windblown Sand \\
\hline & B 22 & Cultivated Deposit \\
\hline \multirow[t]{7}{*}{3} & B 05 & Dumped deposit \\
\hline & B Ol & Cultivated deposit \\
\hline & HP I3 & \\
\hline & HP 12 & \\
\hline & HP 10 & Cultivated deposit \\
\hline & HP 09 & \\
\hline & HP 05 & Cultivated deposit \\
\hline 4 & HP OI & Cultivated deposit \\
\hline
\end{tabular}

Table 40. Baleshare \& Hornish Point. Cluster Analysis of material

Samples from Baleshare have significantly higher proportions of three morphotypes in their suites';
a Fine Spiny Rods
b Small Smooth Rods
$c \quad$ Coarse Wavy Rods (less influential than $a \& b$ ) ern windblown sands versus ancient windblown sand) and parallel samples (ie modern organic deposits such as peat and faeces, versus ancient organics midden deposits see Powers et al 1989 for further details).

\section{Suite composition}

All the samples from the sites of Baleshare and Hornish Point have similar patterns in phytolith suite composition. The suites have high frequencies of Trapezoids and either Small or Medium Smooth Rods, with lesser numbers of the Edge Ornamented Rods. The four types of Dumb-bells are consistently present but at fairly low frequencies, while the less distinctive groups of irregular, spherical and amorphous morphotypes are intermittently represented at low frequencies, with an emphasis on the smooth rather than ornamented forms.

Despite these consistencies within suites, it is possible to differentiate between samples from Hornish Point and those from Baleshare. Two distinct differences between Baleshare and Hornish Point samples ('a' and 'b' below) were very obvious and noted easily by visual appraisal of the bar charts (Figures $86 \& 88$ ). These variations were confirmed as significant inter-site differences by Correspondence Analysis (see Padmore 1987 for full set of analyses) which also highlighted a further significant variation in suite composition ('c' below).

There is no evidence to suggest that samples of differing origins within each archaeological site have specific morphotypes associated with them. This is not true of samples which originate from natural as opposed to anthropogenically disturbed areas. This aspect is discussed below.

There is evidence to suggest that different archaeological sites may exhibit variations in the phytolith suites of their samples as noted by the variations between the frequencies of Fine Spiny Rods and Small Smooth Rods (Baleshare possessing higher frequencies of these morphotypes than Hornish Point). Similarly there is evidence from a pilot study of modern dune samples (see Powers et al 1989) that samples of similar age and type can vary in phytolith frequency and composition in comparison with similar samples taken from different geographical locations.

Such variations in suites from natural and archaeological samples whose type (or origin) is supposed to be the same may be a reflection of various factors. These include variations in seasonal availability of vegetation, local environment, micro-climate and degree of shelter (particularly important for coastal sites) affecting species colonisation, availability and phytolith production, access to plants and, or, grazing preferences of ruminants

Cluster analysis of the full data set

The Cluster Analysis (using Ward's method) of Baleshare and Hornish Point samples utilising mean proportional counts for each Block, resulted in a four group solution, see Table 40. There is no clear separation of blocks according to designated 
Sample type

Windblown sands

Vegetated surface deposits

Peat (not dessicated or

compacted)

Catttle faeces

Prehistoric middens
Sheep faeces

\section{Abundance of phytoliths}

very low
low
fairly high
high
high
very high

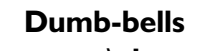
presentlabsent

absent
largely absent
present
generally present
generally present
present

Table 41. Characterisation of dune samples by concentration and types of phytoliths recovered

sediment type, with a mixture of midden-site deposits with windblown sand and cultivated deposits in the two multi-Block groups (numbers 2 and 3). It is difficult to assess the significance of the two single-Block groupings (numbers 1 and 4) as the blocks themselves are only single-sample blocks. Therefore, these two samples have not undergone the 'smoothing' effect of averaging the data, plus there is no way of assessing whether the results are 'typical' for their respective blocks. The breakdown of blocks into groups 2 and 3 appears more significant. In general terms the blocks are divided by site not sediment type. This is a direct result of the proportions of Fine Spiny Rods, which are more numerous in the majority of Baleshare samples as compared with the Hornish Point samples. The Cluster Analysis does not indicate a clear correlation between relative proportions of phytolith morphotypes and sediment type. Such a correlation may be resolved by further studies of the mechanics of deposition in dune systems and a refinement of phytolith classification.

\section{Clarification of the organic archaeological horizons}

In an attempt to answer the third question posed by the excavator namely, to determine the origins of the rich organic layers in the archaeological sites (those blocks designated 'midden-site' and/or 'dumped deposit'), phytolith analyses of modern comparative material were also performed (see Powers et al 1989 for full details). The samples originated from dune environments in the Uists and consisted of random samples collected by the excavator of windblown sands, cultivated (grassland) surface samples, cattle and sheep faeces and a peat core. Results of these analyses revealed that;

i) Modern windblown sand and vegetated surface layers contain very few phytoliths. This was quite unexpected and indicates that the cycling of silica within dune environments is not fully understood.

ii) Modern sub-surface sediments contain very few phytoliths ie there is no downwards movements of phytoliths on plant death to the sub-surface sediments.

iii) Modern 'natural' (ie non-anthropogenic) dune samples such as windblown sands and vegetated layers generally do not contain any of the four Dumb-bell phytolith morphotypes.

iv) Peat contains phytoliths in quite high numbers ranging from 3,000 and 58,000 per gram for the samples analysed.

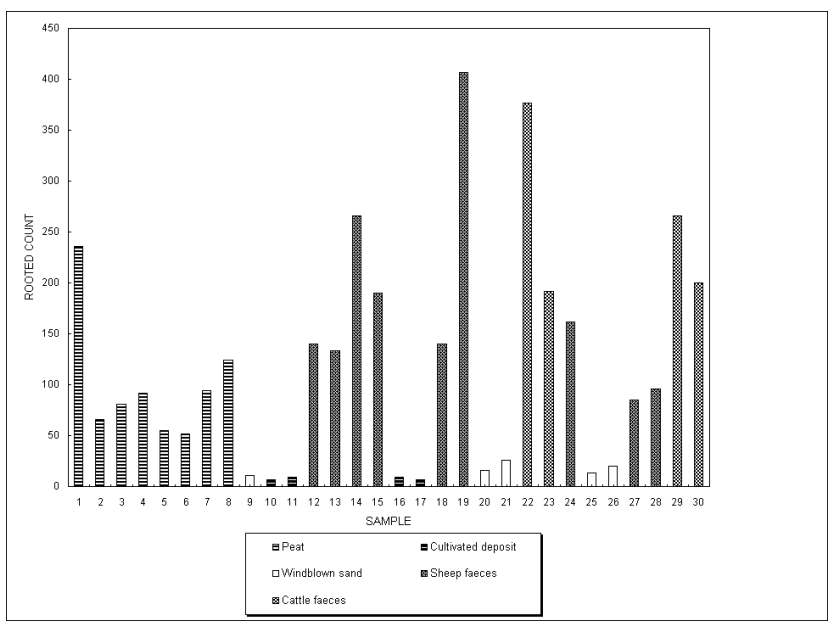

Figure 89. Modern samples; concentration of phytoliths per gram (rooted)

v) Phytoliths withstand chemical degradation and have been recovered from a wide range of sediment types, from acid peats to calcareous shell sands (up to $\mathrm{pH} 9.8$ analysed).

vi) Modern faecal remains from cattle and sheep grazed on dune systems produce high numbers of phytoliths, up to 171,500 per gram for the samples analysed.

vii) Whereas peat and sheep faeces do contain Dumb-bells, cattle faeces generally do not contain Dumb-bells.

It is theoretically possible therefore, to differentiate between samples of certain origins within the dune environment on the basis of total concentration, and variations within suites, of phytoliths. In addition to the standard composition of suites (eg many Smooth Rods and Trapezoids, few Ornamented Amorphous or Irregular) some types of samples are defined by the presence or absence of a particular group of morphotypes - the Dumb-bells (see Table 41).

A comparison of the results of phytolith analyses of modern samples with those from archaeological deposits (see Table 41 above and Powers et al 1989 for details) revealed many interesting points. It was immediately obvious that the archaeological samples possessed higher concentrations of phytoliths than their modern equivalents (compare Figures $85 \& 87$ with 89). Also, observations obtained from a series of Correspondence Analyses (see Padmore 1987 for discussion) revealed that the archaeological organic layers (eg midden-site deposits) were not exclusively, or even principally composed of faeces or 'fresh' (undried) peat (Figures $90 \&$ 91). That is not to say that the organic layers do not contain undried peat or faeces but the Correspondence Analysis indicates that there is a distinct separation of peat/faecal samples from midden samples on the basis of phytolith content.

The missing elements in the composition of the ancient organic deposits are likely to be introduced peat and once fresh plant material. The Correspondence Analysis (Figures $90 \& 91)$ illustrates that fresh peat is closest to the ancient midden samples in terms of phytolith content of all the modern analogue materials tested. This suggests that desiccated and compacted (rather than non-desiccated) peat is likely to 


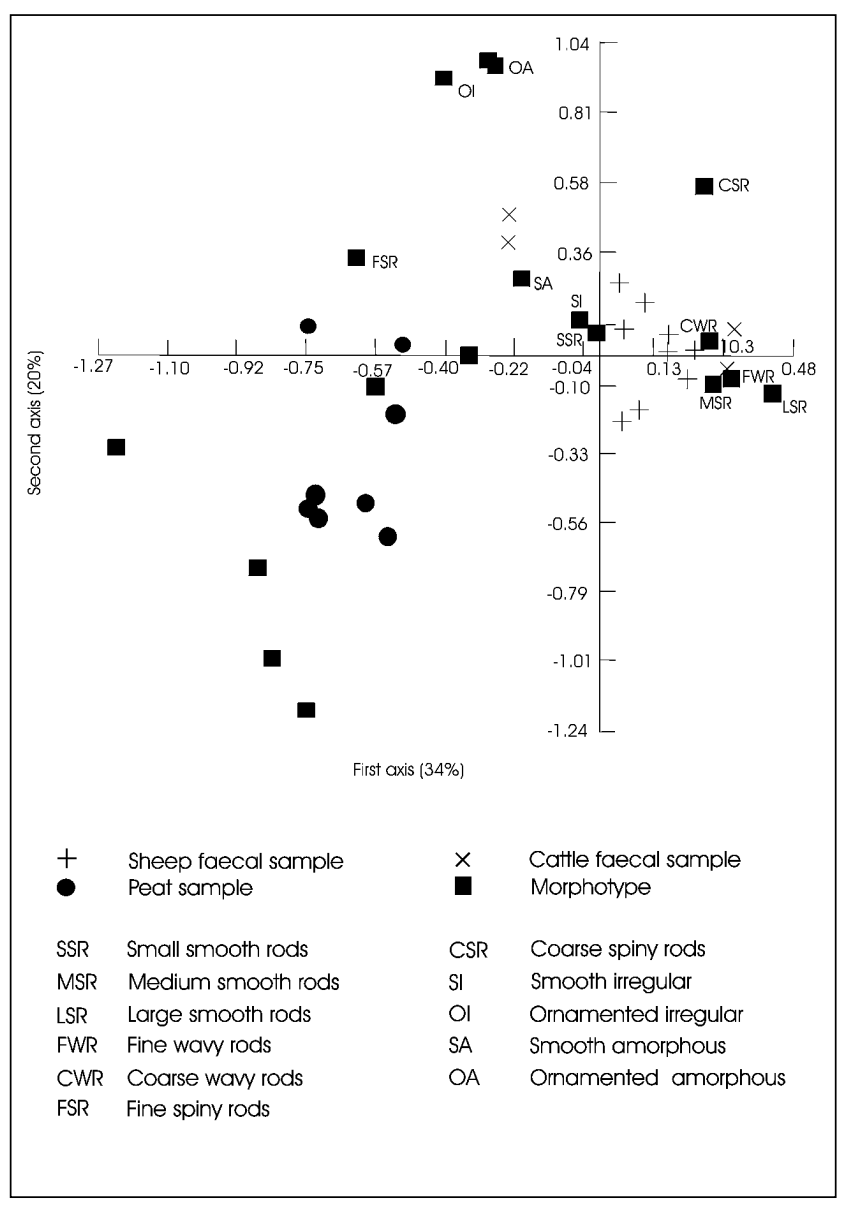

Figure 90. Correspondence Analysis of Baleshare midden and modern samples

be a constituent of the middens. Similarly, fresh plant material may have entered bedding, byreing, thatching, etc. All these forms of plant waste will have brought with them their own collections of phytoliths.

The results of analyses of the modern and ancient samples have illustrated that in machair sand dune environments, the presence of high concentrations of phytoliths, and more significantly, the presence of Dumb-bell morphotypes, may be used (nine times out of ten) to indicate anthropogenic activity. The very rich archaeological deposits clearly stand out from the background 'natural' dune sediments, the only reservations concerning the use of dumbbells as an indicator of past anthropogenic activity would occur for example when a natural peat or faecal remains were encountered in the sampling programme. Otherwise, total phytolith concentrations, when used in conjunction with presence or absence of Dumb-bell morphotypes should be an excellent method of determining in core samples the location of archaeological sites buried in machair sand dunes.

\section{I5.4 CONCLUSIONS}

As a result of this, and associated studies of phytoliths recovered from ancient and modern machair and sand dune samples (see Powers et al 1986; 1989), it is possible to advance the following conclusions;

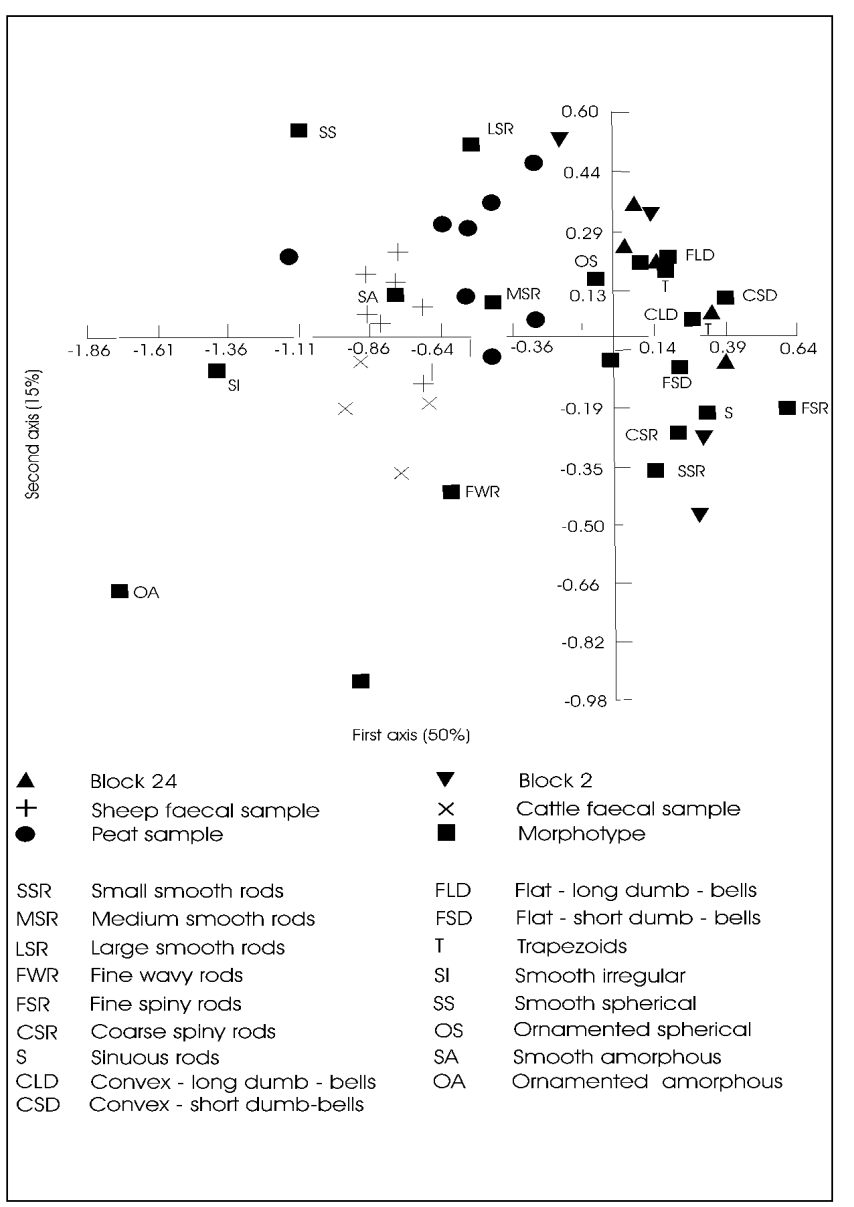

Figure 91. Correspondence Analysis of Hornish Point midden and modern samples

i) Phytoliths, silica particles formed within the tissues of certain plant species, are not species-specific and are therefore studied as suites of multi-morphological particles called morphotypes which have been ordered and recorded according to a simple and robust classification. On plant death the phytoliths are deposited either directly or indirectly within sediments.

ii) Phytoliths are highly resistant to decay and decomposition from biological and chemical agents, and have been recovered from a wide range of sediment types and pH's, from acid peats to calcareous shell sands (up to pH 9.8 so far analysed). However, phytoliths are not present in large numbers in natural machair and dune sediments such as windblown sands and vegetated surface layers and, for unknown reasons assumed to be concerned with the recycling of silica in dune systems, very few phytoliths were recovered from apparently stabilised vegetated layers.

iii) Phytoliths are present in large numbers in archaeological deposits. Therefore, some aspect of human activity on the site, possibly the concentration of plant debris and animal and human dung, shelter from strong winds, reduced rain dispersion or an interruption of the silica re-solution and cycling, has prevented the presumed normal loss of phytoliths from the deposit. 
Therefore, in ancient dune sediments the presence of very high concentrations of phytoliths in deposits may be taken to be indicative of past human activity. The sampled sediments must be shown to be neither natural peat or faecal remains.

iv) Most dune and machair samples share many common features in terms of suite composition, but it is possible to differentiate between archaeological and non-archaeological dune deposits on the presence or absence of dumb-bell morphotypes. Peat and sheep faeces also contain dumb-bells but their total phytolith concentration is generally less than that of anthropic organic deposits.

v) It has proved possible to differentiate between samples from Baleshare and Hornish Point on the basis of phytolith suite variations, which suggests either that some variation existed in the phytolith suites entering the deposits (ie different pattern of grazing, different use of plants), or that some mechanism has differentially influenced preservation on the two sites.

vi) There is no absolute correlation between archaeological sample origin, as defined by the excavator's definition of
Block types, and total concentration of phytoliths. But, there is a trend towards increasing concentrations from windblown sands (low numbers) to cultivated deposits to midden-site and dumped deposits (high numbers).

vii) While the midden-site samples from Baleshare and Hornish Point were similar in many ways, they did vary in richness both within and between sites. Thus, it may ultimately be possible to identify phytolith suites exclusive to particular sites, or to particular ecological zones which were exploited by people, or to particular activities carried out by ancient people at the site.

viii) The contexts within individual blocks exhibited variation in phytolith frequency and composition which in some cases may be seen as normal variation between samples but that in others particularly some of the middens, may point to the desirability of sub-sampling the very rich deposits.

ix) There is considerable potential for the use of phytolith analysis for the location of archaeological sites buried within sand dune systems. 
CHAPTER 16: POLLEN AND DIATOM DIAGRAMS FROM LOCH SCOLPAIG AND BALELONE FARM, NORTH UIST

A M Mannion \& S P Moseley (1987)

[Chapters 16 and 17 describe analyses of pollen, diatoms and the geochemistry of lake sediments on sites increasingly distant from the excavated areas. Our aim had been to investigate, if possible, the scale of landscape impact of the Bronze Age settlement of the islands, given that it seemed likely that the earlier deposits at Baleshare were of that age. We also wished to investigate the landscape impact of the Iron Age settlers which, on then current evidence, was on a much larger scale than the impact of earlier, or later, settlement in the Long Isle. The pollen and diatom work undertaken by Mannion and Moseley (this chapter) indicated that, following the development of the machair in this area, probably in the late Neolithic, its botanical signal largely obscured evidence for human activity. Hirons (Chapter 17) therefore undertook analyses to ascertain the usefulness of studying machair development and the environmental history of the

blacklands/machair ecotone using sediments from lake deposits on the machair margin and in the eastern catchment of the islands. J Barber]

\section{I POLLEN ANALYSIS}

\section{I. I Introduction}

The combination of an oceanic climate with the Machair plain of the Uists provides a niche for a floristically rich grassland with herbs (Dickinson \& Randall 1979) which is unparalleled elsewhere in Europe. The ecological significance of the Outer Hebrides, situated as they are at the Atlantic fringe of north-west Europe, is reflected in the presence of 4 National Nature Reserves (NNR's) and 35 Sites of Special Scientific Interest (SSSI's) (Ratcliffe 1977). North Uist has five SSSI's which are either coastal dune/machair sites or lochs. Overall, with the exception of scrub developments on many of the islands in the numerous lochs of the area, the islands present a tree-less landscape and apart from the machair vegetation and bare rock, peatland vegetation predominates. Although pollen diagrams are available from Lewis (Erdtman 1924; Birks \& Madsen 1979; Bohncke 1988), South Uist (Heslop-Harrison \& Blackburn 1946), Barra (Blackburn 1946), Benbecula (Ritchie 1966) and St Kilda (Walker 1984) no similar work had been done on North Uist at the time the analyses were undertaken. Therefore, samples for palynological analyses were collected from the nearby sites of Loch Scolpaig and a peat deposit at Balelone Farm (Figure 92) to provide an environmental context for the archaeological deposits.

\subsubsection{Site descriptions}

Loch Scolpaig (NF 733753 ) is a shallow lake approximately $7 \mathrm{~m}$ OD on the Machair plain of North Uist. To the west there are dune ridges which slope to the beach or coastal cliff and to the east there is blanket peat from which a fringing hydrosere of grasses, sedges, reeds and Menyanthes trifoliata extends into the lake, the open water of which supports a luxuriant growth of Nymphaea alba. In contrast, the blanket peat deposit near Balelone Farm (NF 731741) is at $25 \mathrm{~m} \mathrm{OD}$ above which the peat becomes thinner with outcrops of bare rock and below which the machair plain extends to the coast. In the vicinity of the coring site the present-day vegetation is dominated by Eriophorum angustifolium, Deschampsia flexuosa and Potentilla erecta. The stratigraphy of both cores is described in Tables 42 and 43.

\section{I.3 Results: Loch Scolpaig}

The results of the pollen analyses are given as pollen percentages (Figure 93a) and as pollen concentration data (Figure 93b) both of which reflect similar changes in the pollen spectra. To facilitate interpretation, the pollen diagrams from Loch Scolpaig have been divided into three local pollen assemblage zones (sensu West 1970) as follows:-

Zone Scl 2.60-2.35 m. Graminea e-Cyperaceae-Salix-Rumex zone Gramineae pollen values vary between 3\% and 27\% while Salix, Cyperaceae and Rumex acetosella maintain consistently high proportions of between $5 \%$ and $25 \%$. In addition, pol-

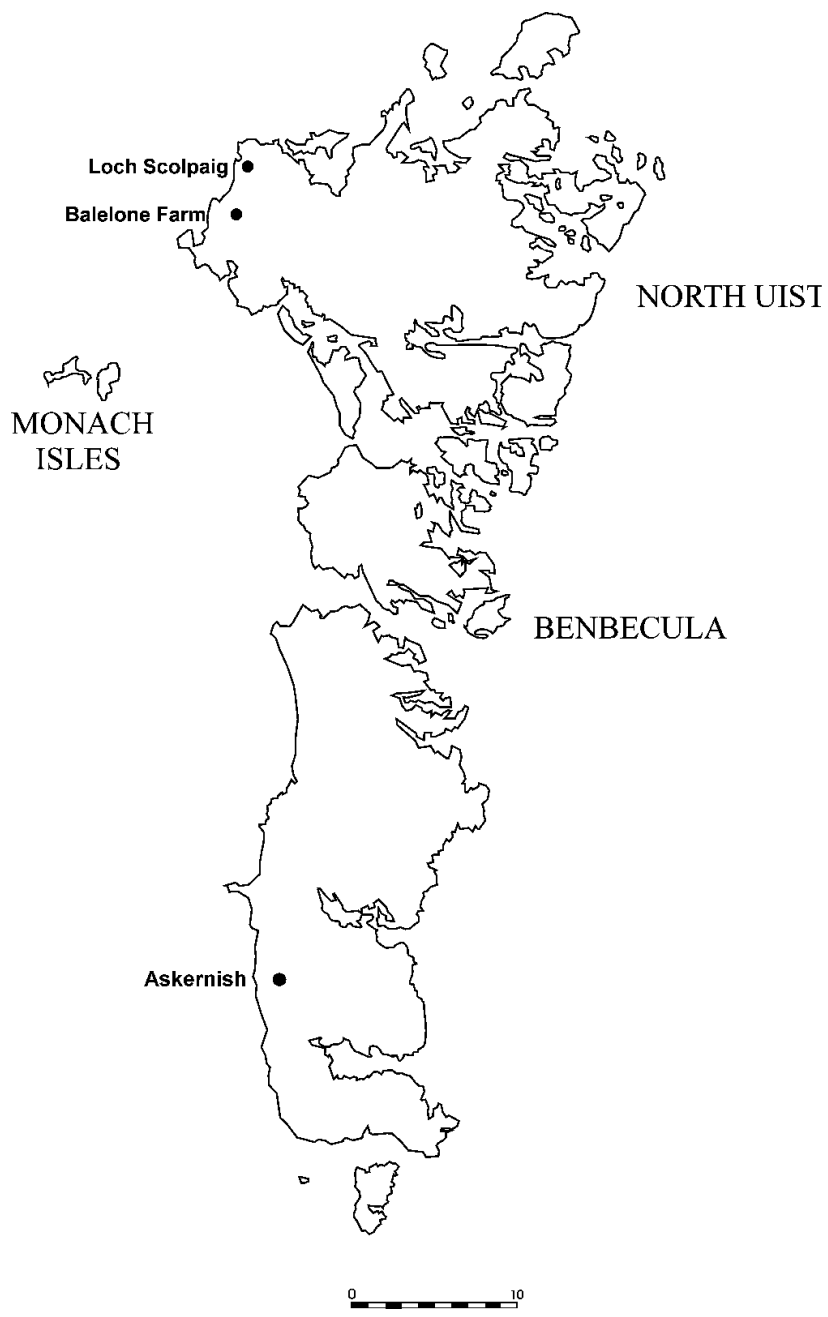

Figure 92. Location map showing sampling sites discussed in Chapters 16 \& 17 
LOCH SCOLPAIG PERCENTAGE POLLEN DIAGRAM

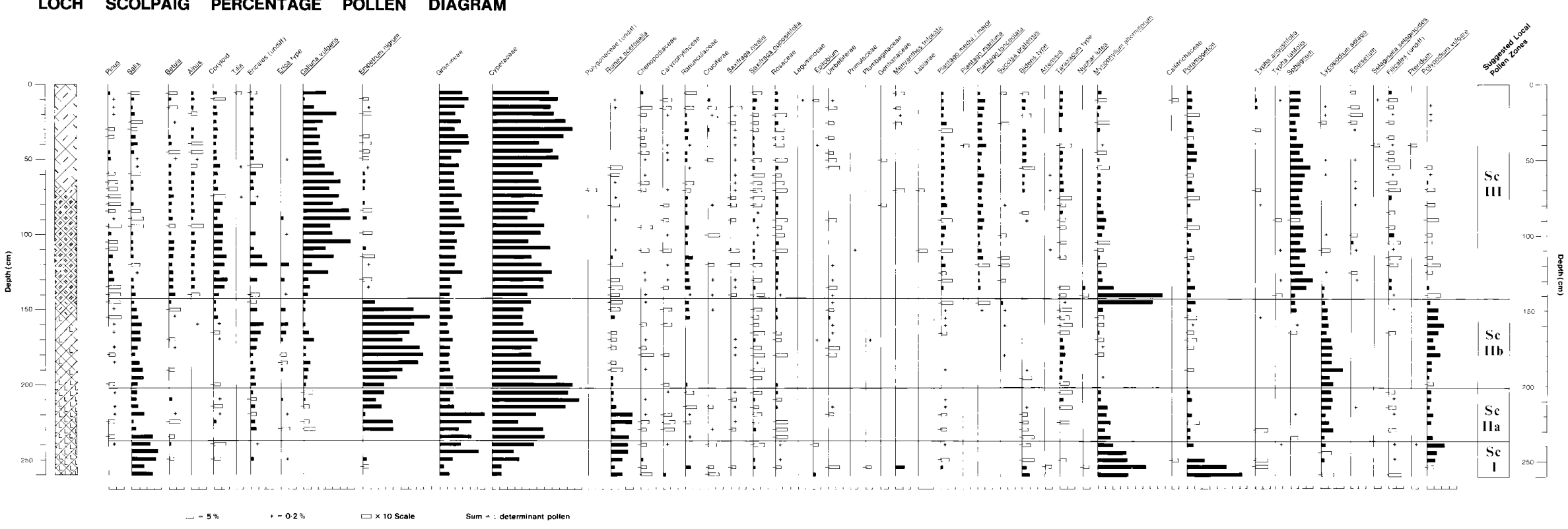

LOCH SCOLPAIG POLLEN CONCENTRATION DIAGRAM

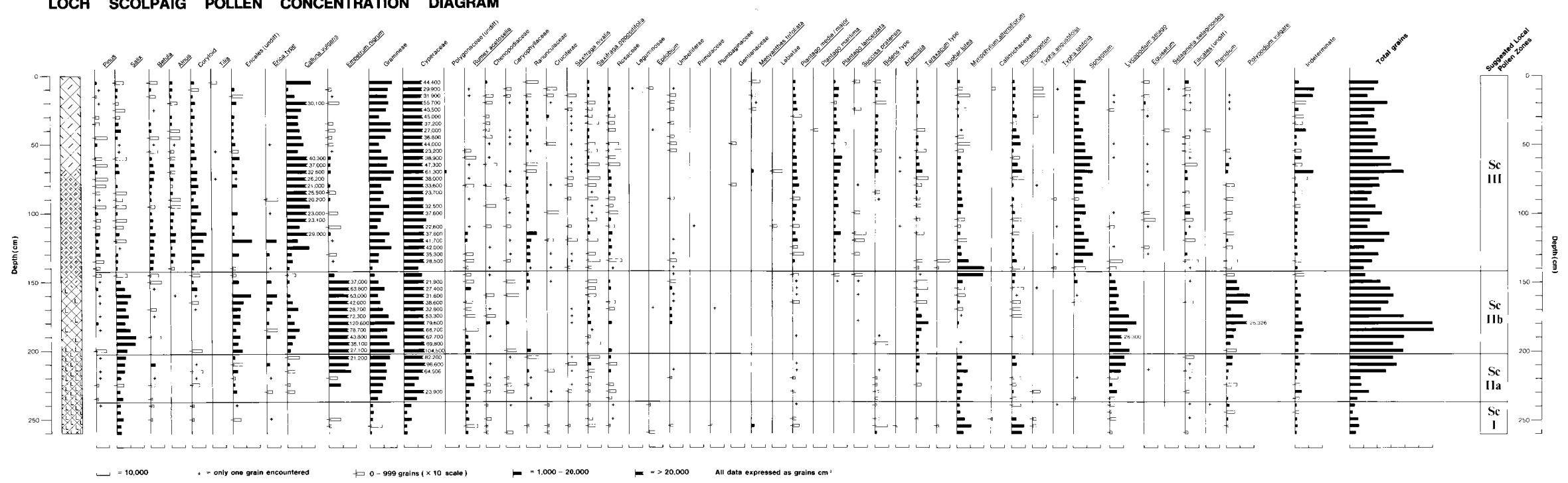

Figure 93. Loch Scolpaig; a) pollen percentages b) concentration data 


$\begin{array}{ll}\text { Depth }(\mathbf{c m}) & \text { Description (below sediment surface) } \\ 75-0 & \text { Very coarse detritus mud, with a dark brown matrix and root fragments. Dh2, DgI, Idl } \\ 148-75 & \text { Finer detrital mud with a dark brown to black matrix with a few plant fragments. Ld2, DhI, DgI } \\ 152-148 & \text { Transition between } 75-\mid 48 \mathrm{~cm} \text { and } 153-260 \mathrm{~cm} \\ 260-152 & \text { Fine detrital mud with a high clay content, few plant remains and mica plates. d2. As2. Agt } \\ 260+ & \text { Gravel }\end{array}$

Table 42. Loch Scolpaig. The stratigraphy of the core described using a modified Troels-Smith sediment classification scheme (Aaby 1979)

\section{Depth (m) Description (below sediment surface)}

0.06-0.0 Intertwined roots of Gramineae and herbaceous species.

0.12-0.05 Fine dark brown matrix with rootlets and sand grains. Th2, DII, DhI, Sh+.

0.34-0.12 As above but coarsening down profile, some mica plates and large quartz fragments (c. I cm diam) Th2, Dhl, Gal.

0.35-0.34 Coarse sand, few plant remains. Gs2, Ga2, Sh+.

0.45-0.34 As 0.34-0.12 but with fewer plant remains and less gritty. Th2, DhI, ShI, Ga+.

0.63-0.45 Darker more humified peat with obvious plant macroscopic remains. Th2, Sh2, $\mathrm{Dh}+, \mathrm{Ag}+$.

0.68-0.63 Coarse sand/silt. Ga2, Agl, Asl, Sh+.

0.77-0.68 Dark brown peat. Th2, DhI, Shl.

0.79-0.77 Matted fibrous plant remains. Dh2, Dg2, Sh+.

0.82-0.79 Dark brown peat. Th2, $\mathrm{Dhl}, \mathrm{Shl}, \mathrm{Ag}+$.

0.83-0.82 Coarse sand/silt. Ga2, AgI, AsI.

0.95-0.83 Dark brown peat with thin (c. 3-4mm). silt layers. Th2, DhI, ShI, Ag+.

I.03-0.95 Dark brown/black peat, little grit. Dh2, DII, ThI.

I.23-1.03 As I.03-0.95 but with coarser texture and lighter in colour. Dh2, DII, ThI.

I.46-I.23 Dark brown/black peat becoming gritty down profile. Dh2, DII, ShI, As+.

I.63-1.46 Black peat with very humified matrix but plant remains discernable. Dh2, ThI, ShI, DI+.

2.07-1.63 Coarse sand, few plant remains but well humified organic matrix. Ga2, GsI, ShI.

3.00-2.07 Black, almost amorphous peat with wood fragments at $2.23 \mathrm{~m}$ and silt band at 2.30-2.3Im. Sh2, ThI, DII.

Table 43. Balelone Farm. The stratigraphy of the core described using a modified Tro els-Smith sediment classification scheme (Aaby 1979)

len of aquatics is well represented, especially that of Myriophyllum alterniflorum.

Zone Scll 2.35-I.45 m. Salix-Empetrum-Gramineae-Cyperaceae zone Cyperaceae pollen predominates, achieving values of up to $50 \%$ of the total pollen. Empetrum nigrum pollen is also dominant with values of up to $38 \%$ of total whilst Gramineae pollen values are initially high at $25 \%$ declining to $10 \%$ at the close of the zone. Pollen of Salix is consistently recorded throughout the zone at between $5 \%$ and $10 \%$ of total and initially high values (between 5\% and 25\%) of Rumex acetosella decline from $2.05 \mathrm{~m}$ upwards when its record becomes sporadic.

This zone is divided into two subzones:

Subzone ScIIa 2.35-2.05 m: Empetrum nigrum pollen and Lycopodium selago spores increase markedly while Salix and Rumex pollen is consistently present and pollen of aquatics declines.

Subzone ScIIb 2.05-1.45 m: High values of both Empetrum nigrum and Lycopodium selago are maintained whilst the concentration of Salix pollen increases from ScI and ScIIa. Although proportions and concentrations of Gramineae and Cyperaceae pollen remain high they both decline toward the close of the subzone and the record of Rumex acetosella becomes discontinuous. The highest pollen concentration values for the entire core are achieved in this subzone.

\section{Zone ScIII 1.45-0.00 m. Calluna-Gramineae-Cyperaceae zone}

The opening of this zone is marked by a rise in Calluna and Alnus pollen proportions and concentrations and a sharp decline in Empetrum nigrum. Values for Sphagnum, Plantago lanceolata and Plantago major/media also increase. Gramineae and Cyperaceae values remain high and apart from that of Salix, tree pollen is almost entirely restricted to this zone. Pinus, Betula, Alnus and Coryloid pollen types are consistently recorded but only in low proportions $(5-10 \%$ of total pollen) and concentrations.

\subsubsection{Results: Balelone Farm}

Due to the hiatus in the pollen stratigraphic record of the Balelone Farm profile which, with the exception of the 2.15 $\mathrm{m}$ horizon, occurs between $2.40 \mathrm{~m}$ and $1.60 \mathrm{~m}$, zonation of the pollen diagrams (Figures 94a \& b) was considered fruitless and has not been attempted. However, the $2.55 \mathrm{~m}$ level 


\section{BALELONE FARM POLLEN PERCENTAGE DIAGRAM}

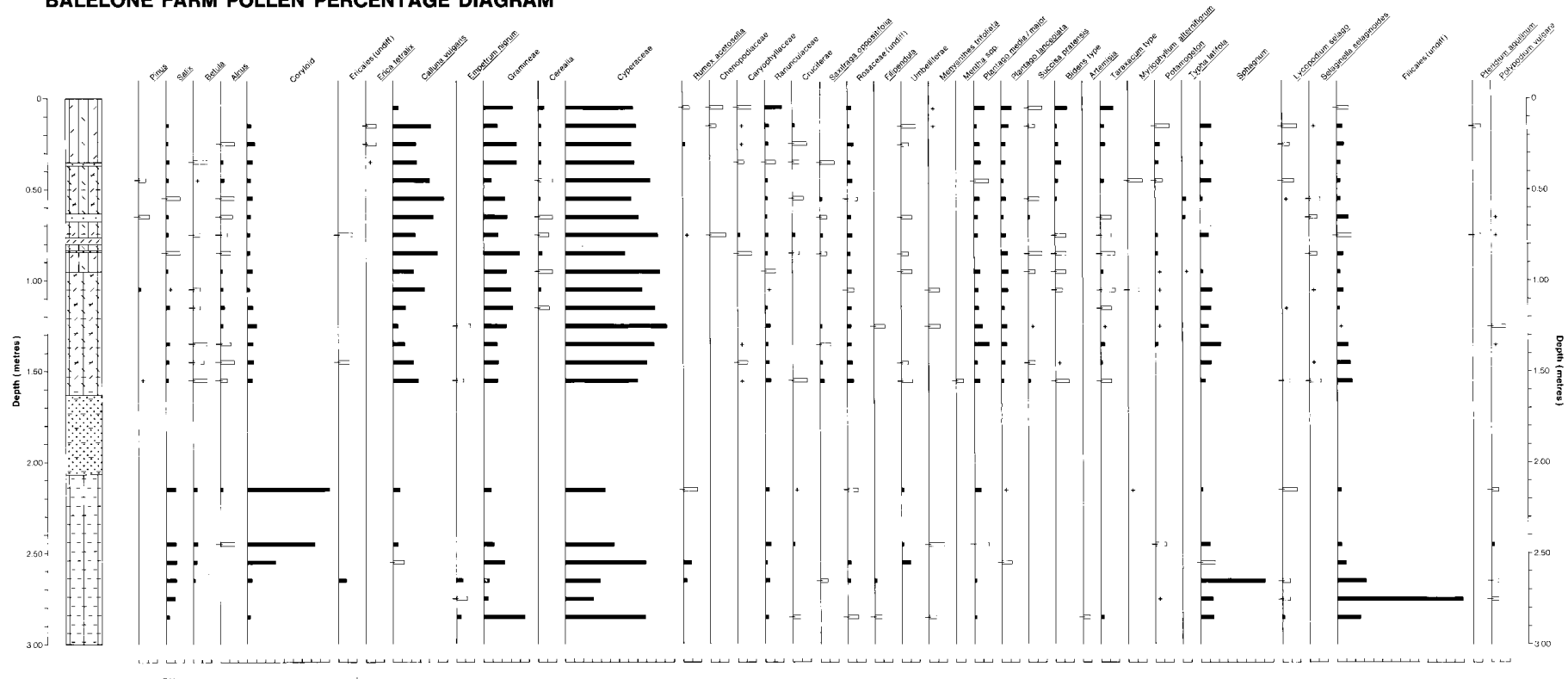

BALELONE FARM POLLEN CONCENTRATION DIAGRAM

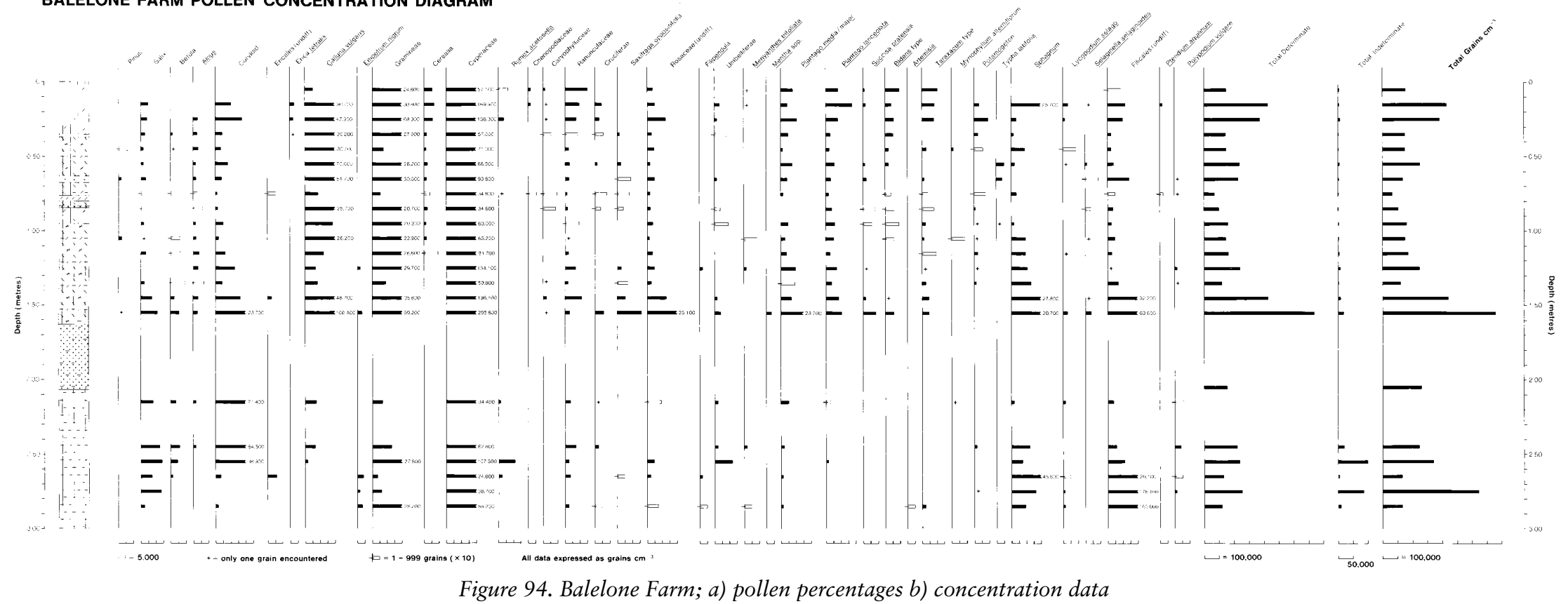




$\begin{array}{lcc}\text { Depth (cm) } & \text { Lab no. } & \begin{array}{c}\text { Date } \\ \text { (years BP) }\end{array} \\ 75 & \text { GU-1766 } & 2525 \pm 85 \\ 150 & \text { GU-1765 } & 2860 \pm 110 \\ 225 & \text { GU-1764 } & 7905 \pm 130 \\ 300 & \text { GU-1767 } & 8730 \pm 200\end{array}$

Table 44. Balelone Farm. Radiocarbon dates from the pollen core. All dates are calculated on a half-life of $5568 \pm 30$ and errors are expressed at the \pm one-sigma level of confidence

is of particular significance since it marks the decline in Empetrum and increases in Calluna and Coryloid-type followed by a rise in Alnus at $2.45 \mathrm{~m}$. Below $2.55 \mathrm{~m}$ Empetrum, Salix, Cyperaceae and Gramineae pollen, along with Sphagnum and Filicales spores dominate the assemblages. Above the hiatus from $1.60 \mathrm{~m}$ upwards Alnus, Salix and Coryloid-type are consistently recorded in low proportions with sporadic Betula and Pinus but the pollen spectra are dominated by Calluna vulgaris, Gramineae, Cyperaceae, Sphagnum and Filicales. In addition, there is a continuous record of Cerealia-type pollen from $1.15 \mathrm{~m}$ upward.

The results of the radiocarbon age determinations for the Balelone Farm profile are given in Table 44.

\subsubsection{Inferred vegetational history}

\section{Loch Scolpaig}

Zone ScI; The pollen spectra of this zone suggest that the vegetation was predominantly grassland with a mixture of herbs such as Plantago major/media. The abundance of Cyperaceae pollen, together with Salix and species such as Rumex and Bidens, probably reflects the vegetation at nearby wetter sites or at the edge of the lake itself where vegetation dominated by Myriophyllum alterniflorum and Potamogeton spp. was well established. Low pollen concentrations may reflect the presence of bare ground.

Sub Zone ScIIa; Vegetation similar to the previous zone persisted although increased pollen concentrations, especially of Gramineae and Cyperaceae, may reflect greater vegetation cover. Although Salix pollen percentages decline from the previous zone, it maintains its concentration values which imply that it maintains its status in the vegetation. Abundant spores of Lycopodium selago may reflect its colonisation of rock outcrops to the west of the lake basin where Empetrum was also becoming established either prior to or during initial peat accumulation (see below). These pollen spectra are similar to those recorded at the base of the Little Loch Roag core from Lewis which Birks and Madsen (1979) suggest may reflect a vegetation similar to present-day sub-alpine communities in Norway. In the lake itself Myriophyllum alternifolium and Potamogeton spp. continue to flourish.

Sub Zone ScIIb; Grassland communities with abundant herbs, notably Saxifraga oppositifolia and
Taraxacum-type maintained their dominance whilst Empetrum increased markedly and Lycopodium selago and Salix continued to be important components of the vegetation. Increased pollen concentration values and the decrease in Rumex acetosella may reflect the development of a more closed vegetation cover than in ScI or ScIIa although in the lake the declining and sporadic record of aquatics indicates some disruption of the hydrosere, possibly due to a high sediment input from the catchment.

Zone ScIII; The decline in both percentages and concentrations of Salix and Empetrum nigrum pollen corresponds with a marked increase in Calluna vulgaris pollen reflecting the expansion of Calluna heath and possibly peat forming communities. It can only be inferred that the earlier Empetrum nigrum dominance in ScII initiated soil acidification which allowed Calluna vulgaris to invade successfully. In addition, herb-rich grassland continued to persist, presumably on the machair plain which Ritchie (1979) suggests had been initiated sometime before 5700 uncal BP.

Moreover, the rise in Alnus pollen percentages and concentrations recorded at the ScII/ScIII boundary may mark the onset of the Flandrian climatic optimum even if, as has been suggested for Lewis (Birks \& Madsen 1979), Alnus pollen was derived by long-distance transport from the Inner Hebrides where the Alnus rise is well marked at 6500 uncal BP (Birks \& Williams 1983) or from the mainland. This may also be the origin of the low but consistent proportions of other tree pollen types, especially Betula, Pinus and Coryloid-type, which are almost entirely confined to zone ScIII. The pollen concentration data for all Arboreal Pollen (AP) types confirm that these low percentages are a true reflection of the status of the AP in the pollen assemblages and not simply an artefact of percentage calculations which may occur as a result of swamping by Non-Arboreal Pollen (NAP).

Pollen diagrams from elsewhere in the Outer Hebrides also show low AP frequencies as do some diagrams from the Inner Hebrides (Flenley \& Pearson 1967; Birks \& Williams 1983), the Shetlands (Hawksworth 1969; Johansen 1975); Orkney (Moar 1969) and north-east Caithness (Peglar 1979), indicating the presence of an almost treeless landscape in these areas throughout the Flandrian. However, Wilkins (1984) has described radiocarbon dated macroscopic tree remains of Pinus, Salix and Betula from blanket peat at forty sites on Lewis and suggests that Pinus at least grew extensively on the island prior to 4500 uncal BP; Wilkins (ibid) explains low AP counts as a consequence of wind blowing off the sea so that little pollen was carried westwards. In the authors' view this is an inadequate explanation and it seems more likely that the flowering capacity and hence pollen productivity of trees was impaired due to exposure to high winds or other, less than favourable environmental conditions such as impoverished soils. Indeed, Mathews (1975) has proposed impaired flowering capacity to explain the presence of abundant Betula macrofossils in association with low Betula pollen percentages at a glacial site in the Yukon and the occurrence of Alnus macrofossils in sediments 2000 years older than the Alnus pollen rise in the North West Territories, Canada. Whatever the explanation for low AP per- 
centages and concentrations it seems likely that the Outer Hebrides were more densely wooded than has hitherto been considered and confirms the molluscan evidence (Burleigh, Evans \& Simpson 1973) for woodland presence at Northton, South Harris prior to 4400 uncal BP.

The possibility that the ScII/ScIII boundary represents the onset of the climatic optimum is endorsed by increasing proportions and concentrations of Sphagnum spores which may also reflect wetter conditions. This, together with a simultaneous increase in Calluna vulgaris pollen attests to an increase in peatland vegetation in the vicinity of the lake giving rise to plant communities similar to those which exist today. The occurrence of Plantago lanceolata pollen in low but consistent concentrations and proportions is more difficult to interpret. A similar record was obtained by Birks \& Madsen (1979) from Lewis which they suggest may have resulted from long-distance transport from the mainland. Alternatively, $P$. lanceolata may have been as significant a constituent of coastal cliff and maritime grassland communities as it is in the Hebrides today (McVean 1961; Birks 1973; Dickinson \& Randall 1979) and elsewhere in Scotland it is recorded in significant amounts (Godwin 1975) in the early Flandrian prior to anthropogenic disturbance. In the absence of Cerealia-type pollen from the Loch Scolpaig core there is no indisputable evidence for human influence. Overall, there is little change in the pollen spectra indicating that the vegetation of North Uist has not changed significantly since the opening of Zone ScIII.

\section{Balelone Farm; pre-hiatus}

The radiocarbon date from the base of the peat profile indicates that peat formation began at approximately $8730 \pm$ 200 uncal BP from which time the pollen assemblages indicate the presence of grassland, stands of Salix and peat forming communities dominated by Empetrum nigrum and Sphagnum spp. The marked Coryloid-type pollen increase at the $2.55 \mathrm{~m}$ level may reflect the establishment of Myrica gale on the peat surface in association with Calluna vulgaris which appears to replace Empetrum nigrum. The Alnus rise at $245 \mathrm{~cm}$ is, as for Loch Scolpaig, again considered to represent the onset of the Flandrian climatic optimum.

Apart from the polleniferous horizon at $2.15 \mathrm{~m}$, which shows a similar pattern to the $2.45 \mathrm{~m}$ spectrum, the hiatus in the pollen stratigraphic record is difficult to explain as indeed is the radiocarbon date of $7905 \pm 130$ uncal BP at its base. This latter will be considered below in discussing the relationship between Loch Scolpaig, Balelone Farm and Little Loch Roag. Coarse sand is recorded in the stratigraphy which may be the result of changing hydrological conditions during the climatic optimum when wetter conditions may have increased run-off from higher areas above the site that gathered coarse particulate matter which was subsequently deposited in the hollow where peat was accumulating.

\section{Balelone Farm; post-hiatus}

Grassland communities with a mixture of herbs such as Plantago media/major and Taraxacum-type were important in the vegetation along with peat-forming communities of Calluna vulgaris and Sphagnum spp. The status of woodland in the area has already been discussed above and the same comments apply to the Balelone Farm record, although here the
AP percentages and proportions, especially for Betula and Pinus, are not so consistent. Of particular note is the relationship between the Plantago lanceolata pollen record and that of Cerealia-type. The former is well established before the latter which implies that the two are independent and lends support to the view (above) that $P$. lanceolata has indeed occurred as a component of the natural vegetation in North Uist. The Cerealia-type pollen occurs between the $150 \mathrm{~m}$ and $775 \mathrm{~m} \mathrm{lev}$ els dated at 2860 uncal BP and 2525 uncal BP respectively and reflects cereal cultivation in the area from about 2700 uncal BP. Despite this conclusive evidence for anthropogenic activity there is no other evidence to suggest that it affected the natural vegetation of North Uist in any significant way.

\section{I.6 The relationship between Loch Scolpaig, Balelone Farm and Little Loch Roag}

In general terms, the pollen diagrams from Loch Scolpaig and Balelone Farm show the same overall trends which are also similar to those at Little Loch Roag, Lewis (Birks \& Madsen 1979). The record from the former site, in common with Little Loch Roag, is longer than that at Balelone Farm, reflecting sedimentation in the lake for some time prior to peat initiation. Since the assemblages of the Loch Scolpaig ScI and ScIIa zones are similar to the basal assemblages for Little Loch Roag, sedimentation probably began at approximately the same time in both basins. A radiocarbon date from the latter indicates that this was about 9000 uncal BP. The most obvious similarity is the presence of low AP proportions, reasons for which have been discussed above. The hiatus in the Balelone Farm profile makes precise correlation between the sites difficult. However, the replacement of Empetrum nigrum by Calluna vulgaris at $255 \mathrm{~cm}$ and the Alnus rise at $245 \mathrm{~cm}$ in the Balelone Farm profile mirror the changes at the Loch Scolpaig ScIIb/ScIII boundary. The $225 \mathrm{~cm}$ horizon at Balelone Farm is radiocarbon dated (Table 44) to $7905 \pm$ 130 uncal BP which both these vegetational changes must therefore pre-date. However, similar changes at Little Loch Roag (Birks \& Madsen 1979) are dated to 7700 uncal BP and 6100 uncal BP respectively, indicating that either the changes were not synchronous between sites or that there is an error in either the Little Loch Roag date of 6100 uncal BP or the Balelone Farm date of 7900 uncal BP. Since the Alnus rise in the Inner Hebrides is dated to 6500 BP (Birks \& Williams 1983) and is similar to the Little Loch Roag date, it seems most likely that an error lies in the Balelone Farm date.

Apart from this anomaly, the similarity of the pollen diagrams from all three sites reflects a similar vegetation history.

\subsection{DIATOM ANALYIS}

\subsection{Introduction}

A $2.60 \mathrm{~m}$ core was collected with a Russian sampler from a central point in Loch Scolpaig, in July 1983. The stratigraphy is described in Table 42. Samples were extracted from the core for diatom analysis to examine the development of the lake ecosystem since its inception during the Late Devensian 

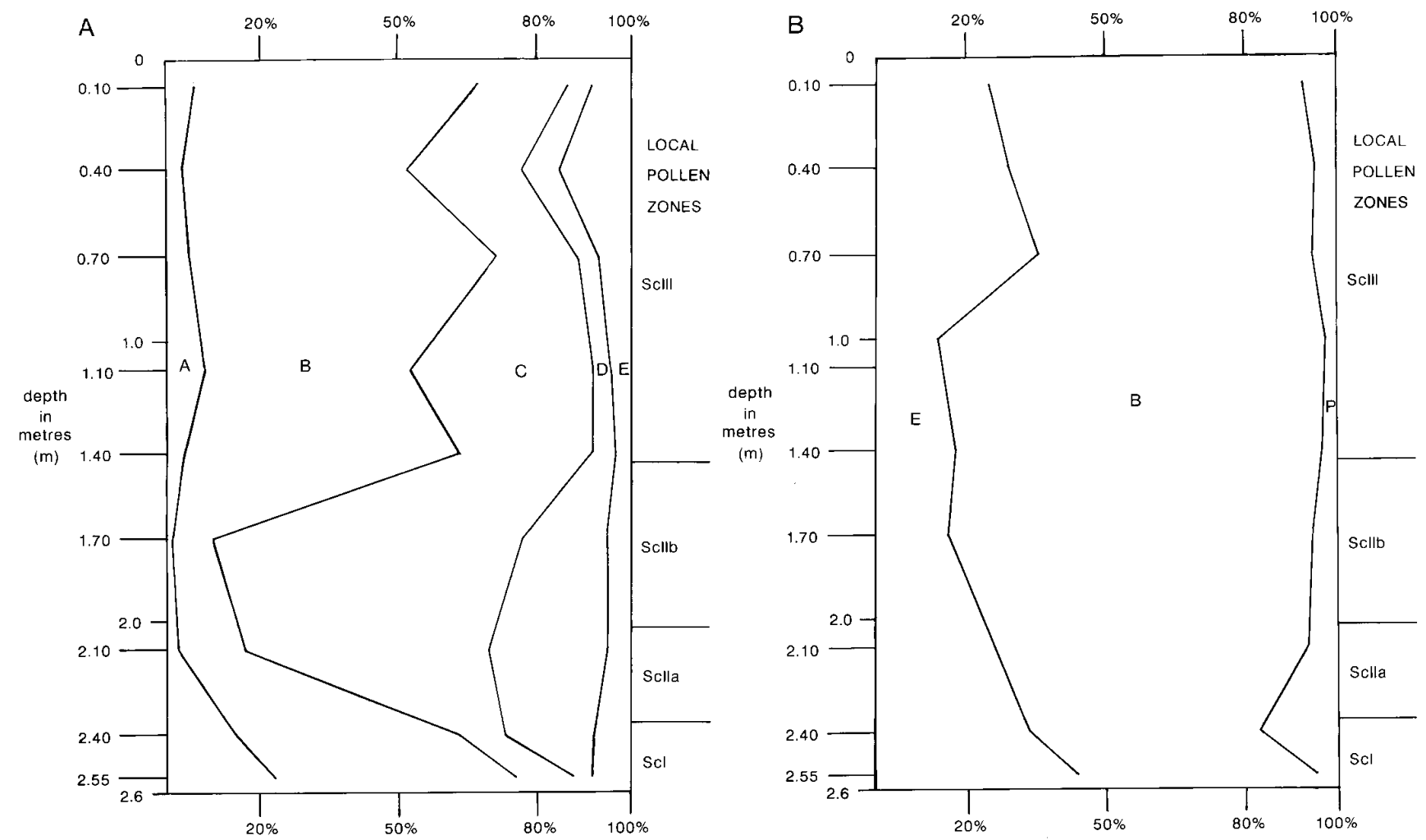

Figure 95. Loch Scolpaig; a) pH spectrum. The proportion of total ascribed to (A) alkalibiontic, (B) alkaliphilous, (C) indifferent, (D) acidophilous and (E) unknown; b) Ecological spectrum. The proportion of total ascribed to (E) epiphytes, (B) benthic species and $(P)$ planktonic species

(above) and to determine what effect prehistoric settlement in the catchment may have had on lake development.

\subsubsection{Results}

The results of the diatom counts, in terms of the incidence of all species and their percentage occurrence are given below. In addition, a $\mathrm{pH}$ spectrum (Figure 95a) has been constructed to provide an indication of how the $\mathrm{pH}$ status of the lake waters have changed over time.

The following categories (after Hustedt 1937-39) have been used:

ALKALIBIONTIC: Diatoms restricted to water of Ph greater than 7

ALKALIPHILOUS: Diatoms most frequently found in water of $\mathrm{pH}$ greater than 7

INDIFFERENT: Diatoms of equable occurrence at $\mathrm{pH}$ about 7

ACIDOPHILOUS: Diatoms most frequently found in water below $\mathrm{pH} 7$ but may also be found at higher $\mathrm{pH}$ values

The diatom species from the Loch Scolpaig sediments have been ascribed to these categories on the basis of the classifications of Foged (1947-1948; 1953; 1954; 1977), Jorgensen (1948; 1950), Round $(1957 ; 1964)$ and Florin (1970).
The ecological spectrum (Figure 95b) is based on the planktonic, benthic and epiphytic categories of Patrick (1948) and Round (1957) and has been constructed by determining the habitat requirements of individual species as given in the literature cited above.

Data for the $\mathrm{pH}$ and ecological spectra are summarised in Tables 45 and 46.

\subsubsection{Zonation}

Three local diatom assemblage zones (sensu Battarbee 1979 \& Mannion 1980) have been delimited as follows:

Zone Sc DI $2.60 \mathrm{~m}-2.35 \mathrm{~m}$

Epiphytic species show a decline as benthic species increase and the $\mathrm{pH}$ spectrum changes from dominance by alkalibiontic and alkaliphilous species to dominance by indifferent species. Acidophilous species also show an increase.

Zone Sc DI $2.35 \mathrm{~m}-1.55 \mathrm{~m}$

The ecological spectrum remains unchanged and the predominance of benthic species persists. The $\mathrm{pH}$ spectrum is dominated by indifferent and acidophilous species which decline toward the close of this zone to be replaced by alkaliphilous species.

Zone Sc DIII I.55 m-0.00 m

The diatom flora remains alkaliphilous and benthic with a slight increase in acidophilous species and epiphytes towards the surface. 


\begin{tabular}{|c|c|c|c|c|c|}
\hline Level (m) & $\begin{array}{c}\text { Alkalibiontic } \\
\text { (A) }\end{array}$ & $\begin{array}{l}\text { Alkaliphilous } \\
\text { (B) }\end{array}$ & $\begin{array}{l}\text { Indifferent } \\
\text { (C) }\end{array}$ & Acidophilous & Unknown \\
\hline 0.1 & 5.79 & 58.06 & 23.63 & 6.76 & 5.95 \\
\hline 0.4 & 4.46 & 47.29 & 26.12 & 7.56 & 14.08 \\
\hline 0.7 & 5.52 & 65.81 & 18.99 & 2.78 & 5.88 \\
\hline I.I & 7.3 & 47.42 & 39.8 & 2.79 & 2.47 \\
\hline 1.4 & 3.74 & 61.44 & 29 & 3.33 & 0.94 \\
\hline 1.7 & 0.15 & 10.76 & 65.4 & 19.35 & 4.75 \\
\hline 2.1 & 1.46 & 18.37 & 51.87 & 22.37 & 4.88 \\
\hline 2.4 & 13.87 & 53.25 & 7.82 & 16.96 & 7.86 \\
\hline 2.55 & 22.84 & 53.98 & 10.96 & 2.07 & 10.16 \\
\hline
\end{tabular}

Table 45. Loch Scolpaig. Summary of results for the pH spectrum (\%)

Since there is no generally accepted series of diatom zones of regional significance for relative dating as there is for pollen zones (Mannion 1980), the local diatom zones described above have been ascribed to a tentative chronology using the results of pollen analysis from the same core (see above). In addition two horizons on Figures 93 and 94 have been ascribed an approximate radiocarbon age which has been inferred, on the basis of pollen assemblage zones, from Little Loch Roag, Lewis (Birks \& Madsen 1979).

\subsubsection{Discussion}

The early stages of diatom community development, a preponderance of alkalibiontic and alkaliphilous species, is similar to that of many Late Devensian and early Flandrian profiles in Britain, eg in North Wales (Crabtree 1969) and the Lake District (Haworth 1976). This may be due to high base availability in drainage from relatively freshly weathered glacial material from which bases are often removed first. In addition, the calcareous machair environment in which Loch Scolpaig is situated, would provide a good supply of base-rich material. The dominance of benthic species is also to be expected in a predominantly minerogenic environment. The high proportion of epiphytes is a little surprising but the pollen diagram from Loch Scolpaig (above) shows high concentrations of pollen of aquatic species such as Myriopyllum alterniflorum and Potamogeton which would provide a suitable habitat for epiphytic species. Of the epiphytes recorded (below) the majority are Epithemie spp which are

$\begin{array}{lccc}\text { Level }(\mathbf{m}) & \text { Epiphytic } & \text { Benthic } & \text { Planktonic } \\ 0.1 & 23.61 & 70.62 & \\ 0.4 & 26.07 & 70.34 & 4.99 \\ 0.7 & 31.55 & 65.66 & 3.1 \\ 1.1 & 12.43 & 85.94 & 1.61 \\ 1.4 & 18.01 & 78.73 & 1.4 \\ 1.7 & 17.36 & 77.3 & 1.76 \\ 2.1 & 23.47 & 70.43 & 5.79 \\ 2.4 & 28.07 & 58.42 & 4.76 \\ 2.55 & 40.48 & 55.08 & 13.27 \\ & & & 3.18\end{array}$

Table 46. Loch Scolpaig. Summary of results for the ecological spectrum (\%) alkalibiontic and may have been particularly favoured by high $\mathrm{pH}$ values.

In local diatom zone Sc DII indifferent and acidophilous species increase at the expense of alkaliphilous species. This may have been a response to a reduction in base input into the lake ecosystem as the base content of glacial deposits and weathered bed rock was depleted. The pollen spectra also suggest the development of a more acidophilous vegetation in catchment which may have produced soil and humus acidification, drainage from which into Loch Scolpaig, influenced the diatom communities. However, alkaliphilous species are still well represented and this is probably a reflection of continued base-rich drainage from the machair sand. The predominance of benthic species indicates the persistence of a minerogenic environment which is borne out by the high clay content of the stratigraphy (above).

Above $1.55 \mathrm{~m}$ in diatom zone Sc DIII alkaliphilous species again increase and the diatom spectrum shows little overall change from this level to present, the stabilisation period having occurred in zone Sc DII. In view of the pollen analytical results, this is not surprising since the latter show that once blanket bog and moorland communities had established themselves at approximately 6900 radiocarbon years BP little change in the catchment vegetation has occurred to the present-day. Consequently, it is unlikely that drainage characteristics from the catchment have changed to influence the diatom populations in the lake. The predominance of alkaliphilous and benthic species throughout this zone reflect a minerogenic environment and the importance of base-rich drainage from the Machair sand which must, at least to some extent, neutralise the acid drainage from blanket bog and weathered, acid, gneiss bedrock in the catchment. There are no changes in the diatom spectra which can be unequivocally ascribed to the influence of human activity in the catchment although the increase in epiphytes at $0.7 \mathrm{~m}$ and the slight increase in acidophilous species at $0.4 \mathrm{~m}$ may well be a response to anthropogenic activity.

Two further points are also worthy of mention. Firstly, there are no marine diatom species recorded, indicating that there have been no marine incursions in the lake's history. There are however, a number of species which prefer brackish water and their presence has probably been encouraged by sea spray entering the lake. Secondly, the lack of planktonic development throughout the profile is unusual in comparison with published British data. This may be a response to lack of water depth since the core of only $2.6 \mathrm{~m}$ 
covers part of the Late Devensian and the entire Flandrian periods and today water depth does no exceed $1 \mathrm{~m}$. In addition, Loch Scolpaig occupies a unique environment in a lowland coastal position and receives drainage from both base-rich and base-poor sources. 


\section{CHAPTER I7: PRELIMINARY INVESTIGATION OF LAKE SEDIMENTS FROM THE MACHAIRS OF THE OUTER HEBRIDES}

\section{K R Hirons (1986)}

\section{I7.I INTRODUCTION}

Studies in the chronology and development of the west coast machair sand-dune systems of the Outer Hebrides have concentrated on organic materials from inter-tidal areas and archaeological sequences stratified within the blown sand (Elton 1938; Ritchie 1966; 1979; 1985; Simpson 1966; 1976; Evans 1971; Crawford \& Switsur 1977). Other deposits which may provide complimentary evidence of the development and environmental history of the machair and adjacent 'blacklands' are deposits preserved beneath the sand plains (eg Ritchie 1968) and lake sediments from lochs within the area of blown sand (see Brayshay \& Edwards 1996). There are two types of lake; machair lochs, here defined as lakes formed directly by the choking effect of encroaching sand (not necessarily equivalent to a limnological definition of Waterston et al 1979) and lakes confined by basins in rock or glacial deposits situated beyond the machair itself.

This project was undertaken to ascertain the usefulness of studying machair development and the environmental history of the blacklands/machair ecotone using sediments from lake deposits. The sites chosen were bog and former lake deposits near Balemore in North Uist and a core from Loch na Cuithe Moire, a rock-basin lake near Askernish, South Uist (Figure 92).

\subsection{RESULTS: ASKERNISH}

The small, circa $200 \mathrm{~m}$ diameter bog to the north-west of Loch na Cuithe Moire, near Askernish, South Uist lies at approximately 2-3 m OD, $1.2 \mathrm{~km}$ from the coastal dune system and behind a wet machair grassland. The site is in a basin in the Lewisian gneiss. The local vegetation was one of Phragmites and Scirpus spp. with Menyanthes trifoliata, Myriophyllum alterniflorum and Potamogeton spp. in the remaining shallow pool. The site was cored at its deepest point near the centre and somewhat to the north of the small area of open water. A $2.5 \mathrm{~m}$ core of peat, detritus mud, sand and clay was recovered using a narrow-bodied Russian-type corer (Jowsey 1966). The Askernish site is $6.25 \mathrm{~km}$ south-west of the pollen site on the island of Calvay and $9.5 \mathrm{~km}$ south/south-west of the peat sites at Stoneybridge studied by Heslop-Harrison and Blackburn (1946).

The stratigraphy of the core was examined in the laboratory and is recorded in Table 47.

\section{I7.2. I Sediments}

Sediment density, water content and loss on ignition (Figure 96) outline a trend of gradually increasing organic matter content up the core. Five layers are superimposed on this trend; a surface sandy layer, inorganic layers at 160-170 $\mathrm{cm}, 180-190 \mathrm{~cm}$ and $210-235 \mathrm{~cm}$, and a basal gritty layer. High temperature loss-on-ignition (HT-LOI) is generally low $(<15 \%)$ but suggests that some carbonates are present in certain parts of the core $(0-15 \mathrm{~cm}, 25-30 \mathrm{~cm}, 45-100$ $\mathrm{cm}, 151-180 \mathrm{~cm}$ and $220-240 \mathrm{~cm})$. Askernish $\mathrm{pH}$ profiles show peaks in three portions of the core; $0-10 \mathrm{~cm}, 80-180$ $\mathrm{cm}$ and $200-230 \mathrm{~cm}$.

On the basis of these results the Askernish core has been divided into nine sediment units for ease of description and as a basis for further analyses. The units are numbered 1-9 starting from the base of the core (Figure 96).

Two samples for total elemental analysis were taken to represent the variability of each of these sediment units. Results are plotted with depth in the core in Figure 97 on both a total sediment and mineral matter basis. Results of these analyses and duplicate analyses from one sand sample supplied by Mr J Barber are also presented in Table 47. One sample was chosen from each of units $1-5$ for preliminary numerological analysis in order to further characterise these basal layers. Samples were labelled A-E from the base of the core upwards and their depths were : A, 245-250 cm; B, 220-225 cm; C, 207-209 cm; D, 200-203 cm; E, 162-166 $\mathrm{cm}$ (samples for total elemental and mineralogical analyses are indicated on Figure 96).

Initial differential thermal analyses (DTA) of the untreated coarse fractions $(<63)$ of samples A, B, and E (Figure 98a) do not show the characteristic calcite or dolomite peaks at around $910{ }^{\circ} \mathrm{C}$ as might be expected from the HT-LOI; they have been swamped on the silt-fraction DTA trace by other minerals. Samples B and E exhibit broad endothermic reactions in the region of $250-500{ }^{\circ} \mathrm{C}$ region, both with double peaks. The initial suggestion is that these endortherms may be produced by dehydration reactions of iron oxide minerals or amorphous ferric oxide gels (MacKenzie 1957).

\section{Depth (cm) Description}

0-3

3-8

$8-11$

$11-12$

$12-50$

$50-70$

$70-78$

$78-100$

$100-104$

104-107

$107-12 \mid$

$12 \mid-125$

125-135

$135-185$

$185-187$

$187-195$

195-208

208-210

$210-213$

$213-216$

216-222

229-234

234-243

243-250
Fibrous, peaty mud, + sedge fragments with some sand

As above but with higher sand content

Fibrous, sedge peat

Sand layer

Sedge peat with occasional Phragmites rhizomes Coarse, amorphous detritus mud

Fine, detritus mud

Coarse detritus mud, some of sedge fragments

Fine detritus mud, some of sedge fragments

Pale, fine detritus mud with some clay content

Fine detritus mud; some cf. sedge fragments

As above but with some clay content

Fine detritus mud with few cf. sedge fragments

Fine gytta, darker colour than above

Organic-clay layer

Fine gytta

As above but with sand increasing down the core

Whitish clay-rich layer

Transition to fine organic gytta, clay reduced

Clay layer. 222-229 Organic gytta with clay

Transitional layer, clay increasing

Clay, very small organic faction

Sandy clay with angular, gritty fragments
Organic gytta layer, clay still present

Table 47. Askernish. Stratigraphy of core 


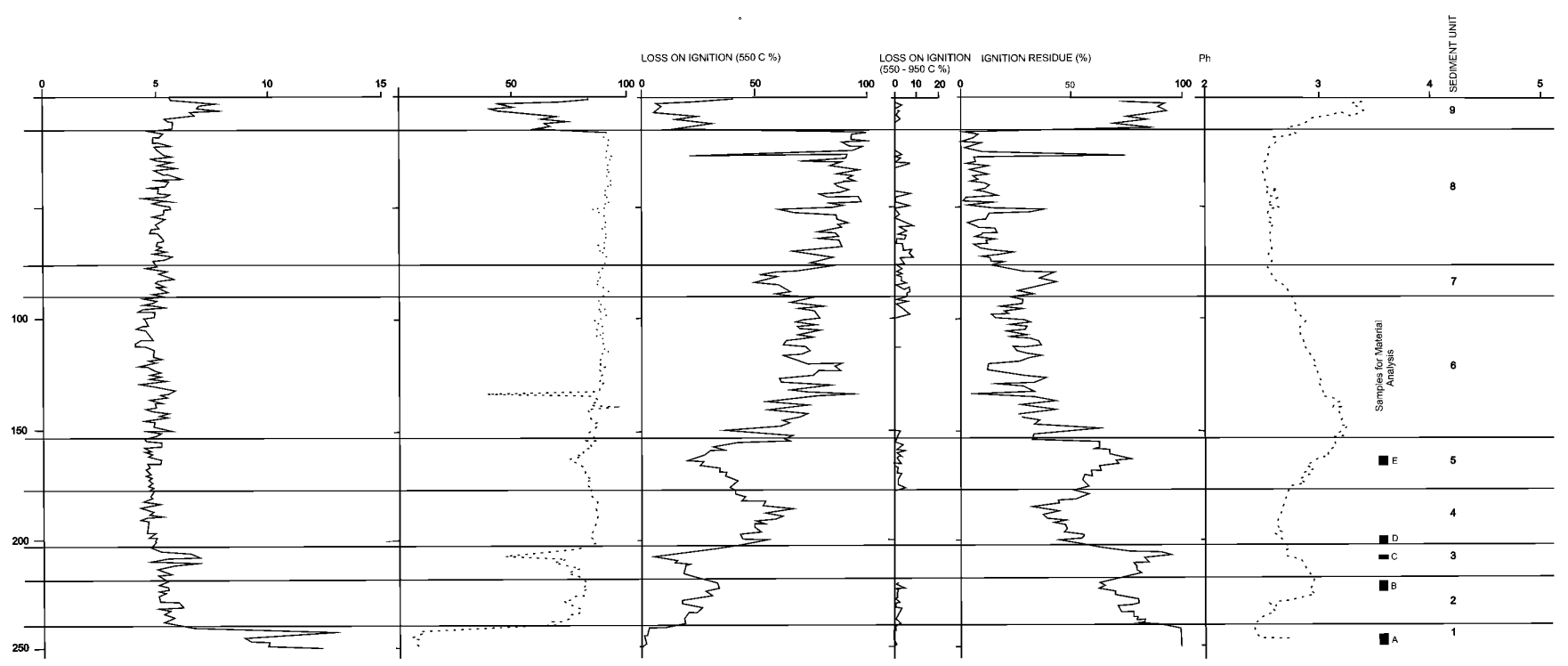

Figure 96. Askernish; sediment characterisation

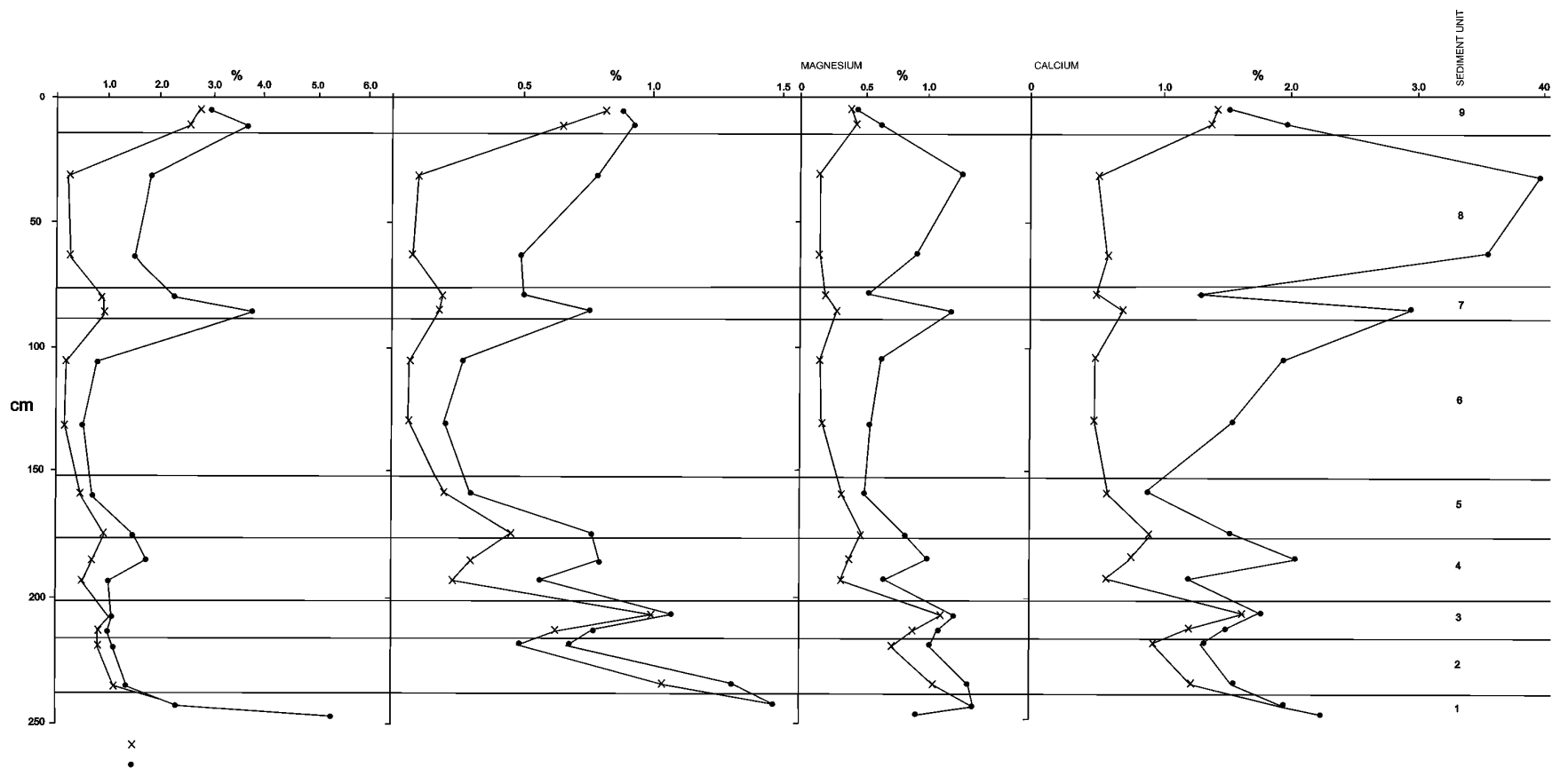

Figure 97. Askernish; chemical analysis

Further analyses were carried out on the clay-sized fraction after ammonium acetate extraction.

The mineralogical analyses distinguish between sediment units 1, 2 and 4 (samples A, B and D, Figure 98b) and 3 and 5 (samples C and E, Figure 98c). The difference may be the result of weathering processes and the different nature of iron deposition which is possibly related to erosional intensities or to a particle size effect causing a sorting of mineral assemblages.

\subsubsection{Pollen analyses}

Pollen data from Askernish are plotted in the form of a percentage pollen diagram with a column showing the boundaries of the sediment units (Figure 99), and a pollen concentration diagram including selected taxa only (Figure
100). No attempt has been made to zone the Askernish pollen diagram at this preliminary stage. The pollen data are discussed in terms of the depths of pollen spectra.

240-195 cm; The five basal spectra are dominated by Gramineae (17-53\%), Rumex (5-25\%) and Empetrum $(1-26 \%)$. Salix is initially high (34\%) but falls, whilst Cyperaceae increases from $2 \%$ at the base to $43 \%$ in the fifth spectrum. Juniperus has a peak (16\%) at $112 \mathrm{~cm}$.

195-145 cm; Betula increases to 10-16\%, Juniperus pollen becomes continuously higher here (7-10\%) and pollen of Plantago maritima becomes more frequent. In contrast, Empetrum and Rumex pollen is reduced and Lycopodium selago and Polypodium spores become less frequent. 


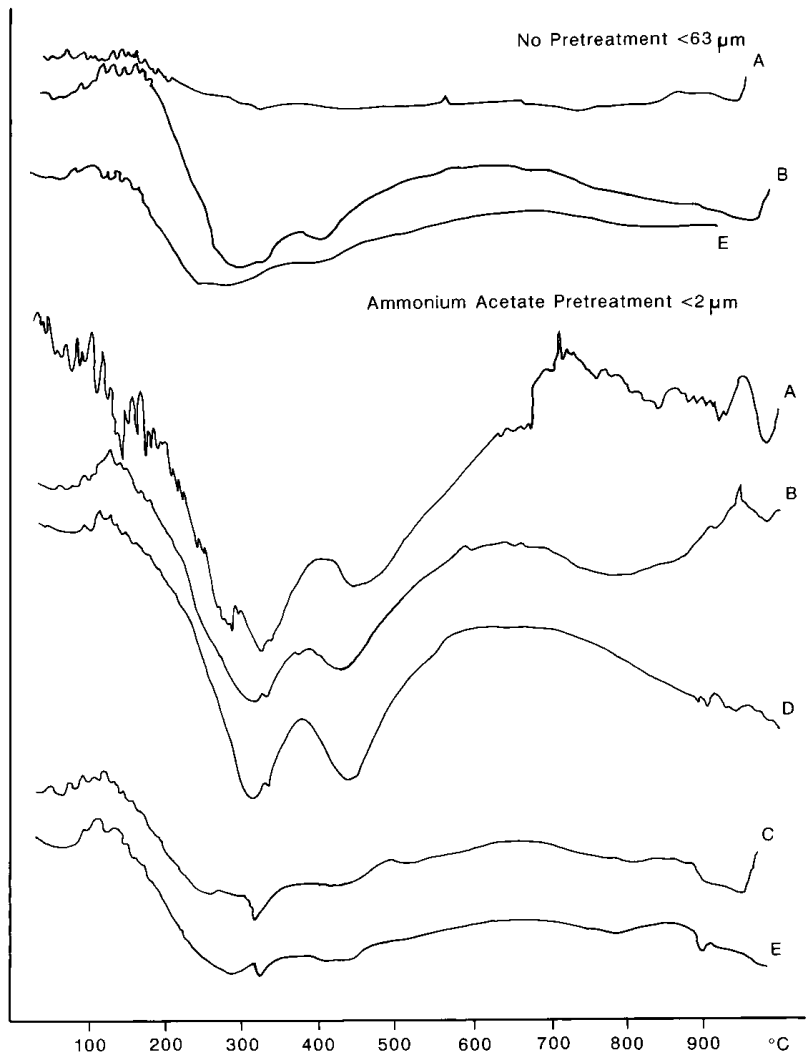

Figure 98. DTA (differential thermal analyses) traces: a) Samples A, B, and E; untreated coarse fractions $(<63) ; b)$ Samples A, B and D after ammonium acetate extraction; $c)$ Samples $C$ and $E$ after ammonium acetate extraction

145-65 cm; Calluna pollen percentages increase here to a peak of $24 \%$ and pollen of Coryloid, Fraxinus, Alnus, Quercus and Ulmus either make their first appearance or become more frequent. Gramineae and Cyperaceae pollen percentages are reduced and then Betula and Coryloid percentages expand and Calluna, Empetrum, Plantago maritima and Rumex become less frequent. Above $84 \mathrm{~cm}$ Betula and Coryloid decline whilst Gramineae, Cyperaceae and Calluna increase again. The charcoal curve becomes continuous above $150 \mathrm{~cm}$ and shows a major peak between 138-142 cm.

65-0 cm; The three uppermost assemblages are dominated by the pollen of Gramineae and Potentilla, with some Cyperaceae and Calluna. Charcoal frequencies are very high in all three spectra.

\subsubsection{Discussion}

More detailed pollen work is required for definitive correlations and therefore conclusions reached here are tentative. The grass-sedge assemblages with Salix, Empetrum, Rumex and Lycopodium selago and the double Juniperus peak are similar to assemblages interpreted as late-Devensian from Mainland Orkney, Skye and Mull (Moar 1969; Birks 1973; Walker \& Lowe 1982) but are not readily correlated with presumed late-glacial spectra from St. Kilda (Walker 1984).
On this basis the late to post-glacial climatic amelioration of circa 10,200 bp (Walker \& Lowe 1982) may occur between 200 and $210 \mathrm{~cm}$, at the beginning of the second expansion of Juniperus. Species of open ground and heathland were frequent below $150 \mathrm{~cm}$ at Askernish, especially Empetrum nigrum with Rumex spp., Thalictrum, Urtica and Epilobium. Lycopodium selago was also present suggesting the availability of local bare-rock substrates. Juniperus scrub increased for a brief period, was reduced and then recovered possibly replacing Empetrum and Rumex spp. as a scrubby heath. Filipendula, Ranunculaceae and Plantago maritima became more frequent, possibly as members of a tall-herb grassland community. Ferns were present, including Polypodium, as was Sphagnum witnessing the base-poor status of the local bedrock and substrates from the earliest postglacial birch pollen values of about 10-16\% suggest a local presence of scrub Betula in sheltered habitats (cf Birks \& Madsen 1979).

The pollen assemblages from $150 \mathrm{~cm}$ to the base of the Askernish core encompass sediment units 1-5. Chemical analyses indicate that the mineral matter found in the three sediment-units with low LOI values, units 1, 3 and 5 are all essentially similar and probably resemble local substrates. There is a general downward trend in elemental concentrations probably reflecting the onset of weathering processes and the loss of these relatively mobile elements by leaching. Results of mineral analyses support these conclusions with sample A having the most complex mineralogy, whereas $\mathrm{C}$ and $\mathrm{E}$ are considerably less complicated. An interesting feature of the Askernish core is the third inorganic layer, sediment unit 5, which occurs in the postglacial and suggests a return to an erosional regime for some reason during the Juniperus assemblages. Spores of Filicales and Polypodium, which are often present in terrestrial soils, increase in frequency at this time.

The increase in Calluna pollen at the expense of Juniperus at $145 \mathrm{~cm}$ is similar to the boundary between zones LLR1b-1c at Little Loch Roag, there dated to approximately $7700 \mathrm{bp}$. However, the Coryloid and Alnus curves begin together at Askernish unlike several local sites; Little Loch Roag, sites from the Inner Hebrides and sites on Western Mainland Scotland (Birks 1977; Birks \& Williams 1983; Walker \& Lowe 1985; Birks \& Madsen 1979). In combination with stratigraphic changes and suddenly increased frequencies of pollen of aquatics and of charcoal, a gap in sedimentation suggesting either erosion of sediments or an hiatus of deposition is indicated. This probably occurred from before the Juniperus decline and Coryloid rise dated to 7,900 bp at Little Loch Roag to after the Alnus expansion there dated to around $6000 \mathrm{bp}$. At Askernish, Calluna heath replaces Juniperus and herbs of open and broken ground, Plantago maritima, Rumex spp., grasses and sedges. Pollen concentration data indicate that Empetrum and Salix were also reduced. These events in the pollen record, reflecting the change to more organic sediments after unit 5 , suggest a stabilisation of soils occurred, after which soils were rapidly acidified and Calluna heath became established.

Attention may be drawn to the correspondence of increased frequencies of Calluna, Melampyrum, Rosaceae and Plantago lanceolata at the time of the major increase in charcoal content of the sediment. In combination these may suggest an early phase of open and broken ground and increased incidence of fire, showing similarities to periods of inferred anthropogenic activity. 


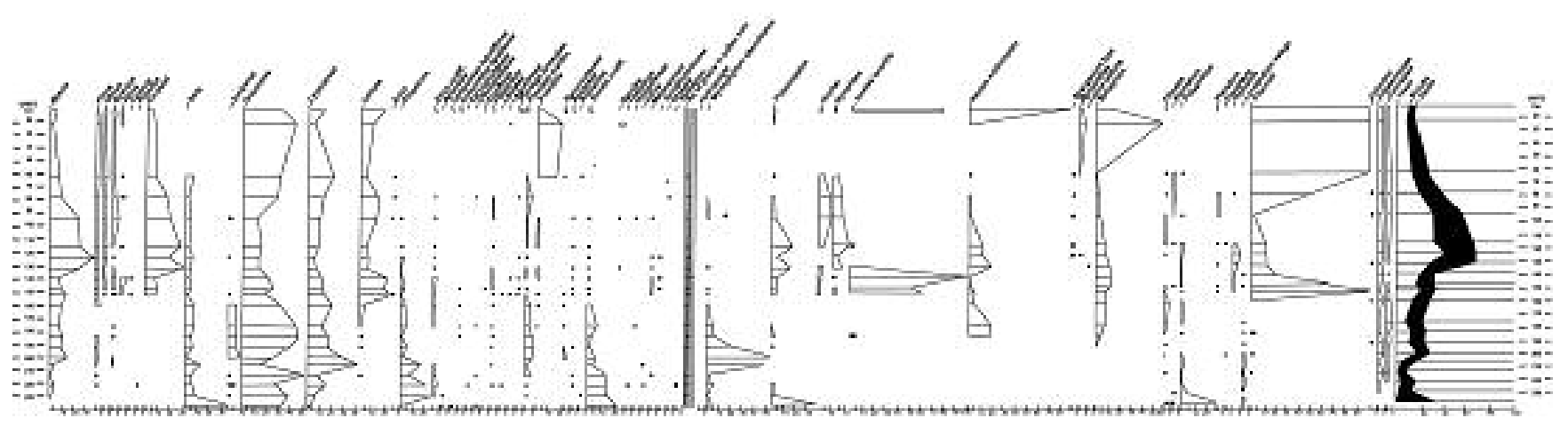

Figure 99. Askernish; pollen percentage diagram

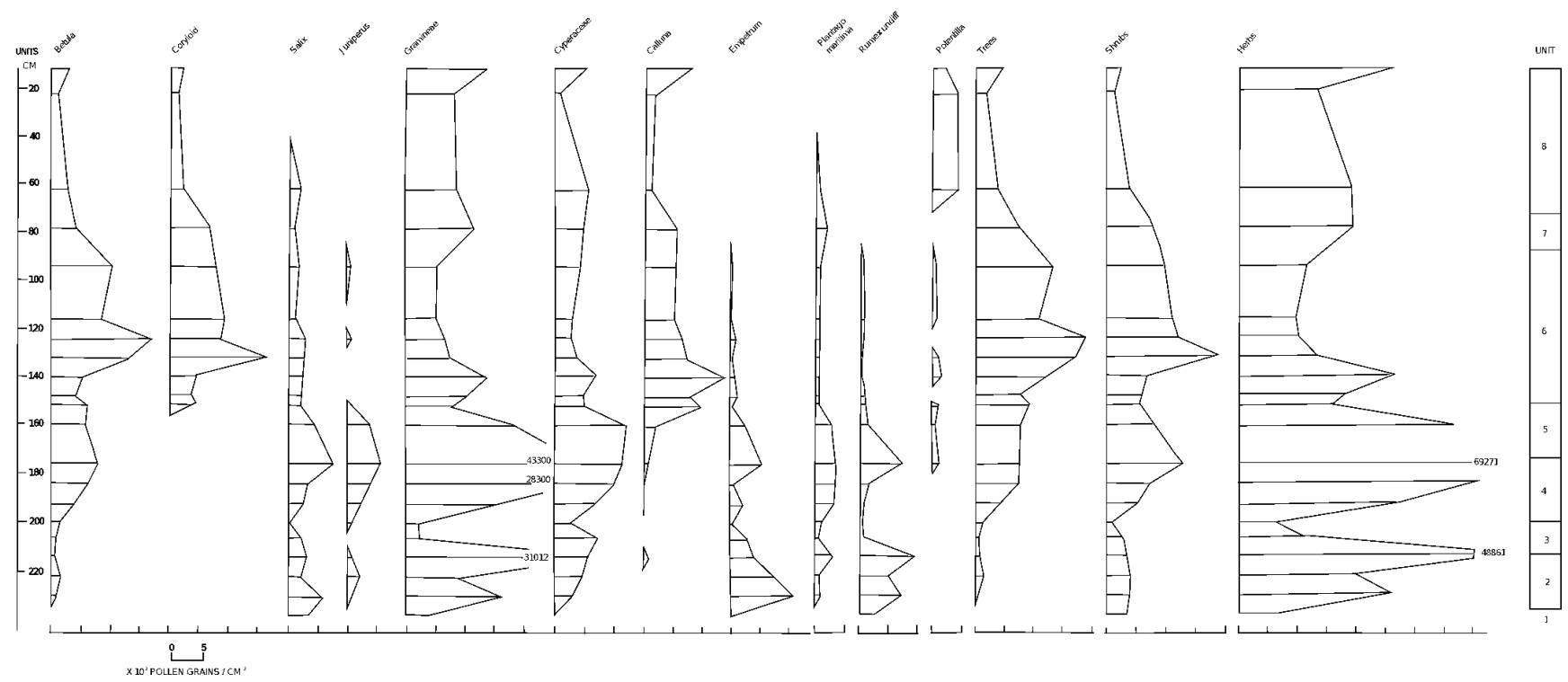

Figure 100. Askernish; pollen concentration diagram

The pollen of Alnus, Ulmus, Coryloid and Fraxinus first appears at $142 \mathrm{~cm}$ and Pinus and Quercus pollen is also present. Pollen of all these tree taxa is found in such low quantities that it is, perhaps, best explained as having been derived from trees present on the Inner Hebrides or the mainland. The expansion of Coryloid and Betula to a total in excess of $50 \%$ of total tree pollen between $84-132 \mathrm{~cm}$ almost certainly indicates a local expansion of birch-hazel scrub. This appears to have taken place at the expense of Gramineae, Cyperaceae, and Calluna all of which show a real reduction in concentration terms. Betula may have expanded to colonise damper, more acidic areas perhaps with Osmunda regalis, Pteridium aquilinum and other ferns with Filipendula, Succisa pratensis and Rumex spp. forming an open-herb community. Corylus scrub possibly colonised drier or less acidified soils and heath with Calluna vulgaris, Potentilla and Melampyrum completing the possible vegetation mosaic.

Sediment unit 7 is an inorganic layer which occurs at the time of a reduction in Betula and Coryloid percentages where first Gramineae and then Potentilla expand. Similar effects might be caused by clearance of birch and hazel and local agricultural activity which could result in the inwash of mineral material into the lake. The chemical data show an important change in the nature of the sedimentary mineral matter towards higher $\mathrm{K}, \mathrm{Na}, \mathrm{Mg}$ and especially $\mathrm{Ca}$ above $100 \mathrm{~cm}$, de- spite the fact that organic matter values increase above circa 75 $\mathrm{cm}$. One explanation for this paradox is the possibility that above about $100 \mathrm{~cm}$ the loch at Askernish came under the influence of greater aeolian sand and seaspray inputs. Hydroseral changes probably led to the increase in sedge content of the loch-mud and the increased organic content. Although lower in overall concentration, the mineral content is of a different nature to that found in the lower clay and sandy layers being much enhanced with respect to calcium but not potassium.

In sediment units 7 and 9 the chemical data show a closer affinity with the basal clay layers suggesting that these horizons relate to erosional episodes where predominantly till or bedrock substrates have been recruited to the sediments. These conclusions are supported by HT-LOI data which suggest that the major phase of carbonate deposition in the loch was between $45-100 \mathrm{~cm}$, with some evidence for episodic input above this.

The suggestion that aeolian sand was present nearer the site as indicated above $100 \mathrm{~cm}$ might have led to a reduction in Betula and Coryloid by, perhaps, causing changes in the water table. It is possible that the Potentilla increase represented the increased frequency of $P$. anserina a co-dominant or very frequent member of machair peatland or dune-slack communities (Dickinson \& Randall 1979). The alternative explanation, that man may have been responsible for the Betula-Coryloid reduction is feasible but there are no 


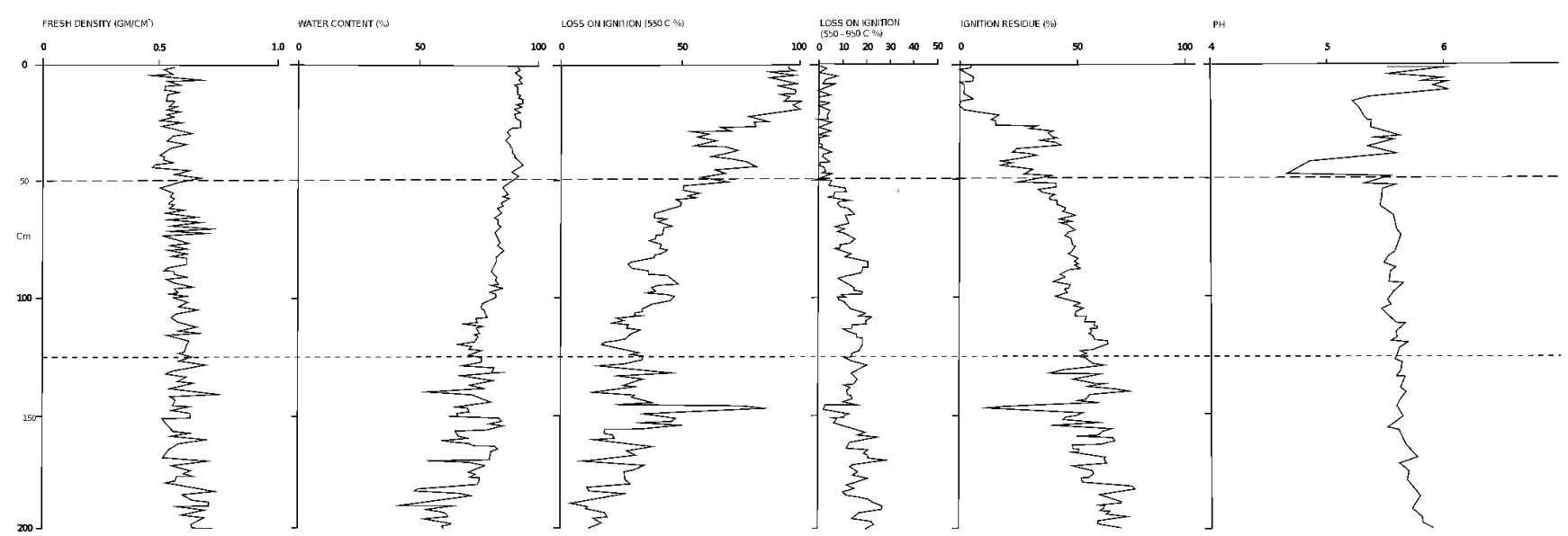

Figure 101. Balemore; sediment characterisation

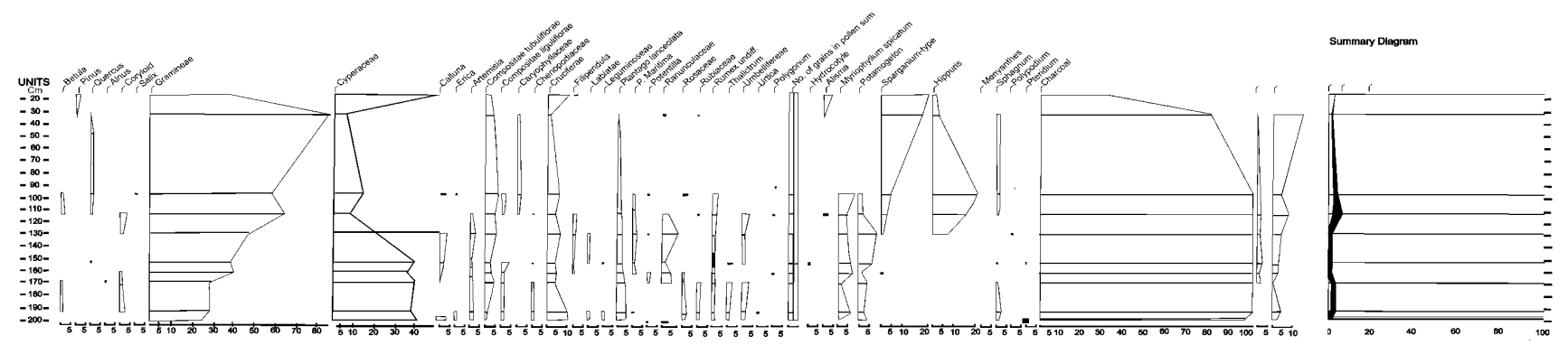

Figure 102. Balemore; pollen percentage diagram

definitive indications of man's impact in the pollen diagram other than, possibly, the charcoal evidence.

Rather similar pollen changes, dated to circa 5200 bp, are reported from Loch Cleat, Skye and there are also similarities with evidence from Little Loch Roag after circa 5000 bp. Although the causal factors for this change at Askernish cannot yet be determined and correlation with other sites is only tentative, it is interesting to note that Ritchie (1979) considers the major primary deposition of sand to have occurred before circa $4500 \mathrm{bp}$ and that redeposition of this material inland took place after circa $3500 \mathrm{bp}$. Independent dating evidence from the Askernish site may be able to tie in this major deflation period for one area of South Uist and provide a link with dated archaeological deposits. On the basis of the data accumulated so far there is no evidence to support the suggestions of several major episodes of sand instability each followed by stabilisation (Ritchie 1979).

\subsection{RESULTS: BALEMORE}

The reedswamp at about $15 \mathrm{~m}$ OD west of Balemore is about $1.2 \mathrm{~km}$ inland of the Rubna Mor dunes on North Uist (Figure 92). The site was found to comprise up to $2 \mathrm{~m}$ of sediment overlying a base of calcareous sand. The bog was cored approximately at the centre. It is about 300 by $200 \mathrm{~m}$ in size and lies south of a road running from the Balemore settlement across the machair. The site is one of a series of lochs and bogs occurring on the seaward flank of a north-west/south-east trending ridge of periodite intrusion running from Craig Hasten through Balranald at the land- ward edge of the Paible machair. Ritchie (1968) records evidence of recent sand-blowing from south to north in the form of partly-healed blowout scars on the south facing coast at Rubh Arnal. Other evidence for severe sand movements in the area come from accounts of arable farming on machair from Kirkibost Island, in the Statistical Account of 1837 and of large areas of sand lost from the south and west of Rubh Arnal (ibid). At the time of coring there was no open water at the sampling site and the vegetation consisted mainly of Phragmites and Scirpus reedswamp together with Iris pseudacorus. Caird (1979) provides evidence showing that arable agriculture has been important in the machair here since at least 1799 .

The stratigraphy of the core was examined in the laboratory and is recorded in Table 48.

\subsection{Sediments}

The core recovered from Balemore can be roughly divided into three sections for the sake of discussion (Figure 101).

i) $\quad 0-50 \mathrm{~cm}$. Sediment with the highest LOI of $>50 \%$ but lowest HT-LOI $(<10 \%)$. there is a layer of reduced organic content between about $20-38 \mathrm{~cm}$.

ii) $\quad 50-125 \mathrm{~cm}$. Organic matter gradually declines in this part of the core $(67-$ minimum of $17 \%)$ whilst HT-LOI increases to fluctuate between $8-21 \%$. 


\author{
Depth (cm) \\ Description \\ $00-50$ \\ $50-60$ \\ $60-90$ \\ $90-112$ \\ $112-12 \mid$ \\ $121-134$ \\ $134-140$ \\ $140-184$ \\ $184-185$ \\ $185-198$ \\ 198-200 \\ Coarse sedge peat becoming finer towards the base \\ Fine detritus mud \\ Fine detritus mud as above with some whole shells and many shell fragments \\ Fine detritus mud with some sand, fibres and many shells after $105 \mathrm{~cm}$ \\ As above but with more shell fragments and whole shells (large whole shell at $120 \mathrm{~cm}$ ) \\ Fine detritus mud with a few cf. sedge fragments, some clay and sand content with shells throughtout but increas- \\ ing after $125 \mathrm{~cm}$ \\ (large shell at $134 \mathrm{~cm}$ ) \\ As above but gradually increasing proportions of whole shells and sand \\ Sandy gytta with increased sand content and some cf. sedge detritus. (large whole shells at 147, 148, 163-4, 168, \\ 178 and $184 \mathrm{~cm})$ \\ Sand layer \\ Sandy gytta with increased sand content and some cf. sedge detritus. Paler in colour below $190 \mathrm{~cm}$ \\ Almost pure sand with humus
}

Table 48. Balemore. Stratigraphy of core

iii) $\quad 125-200 \mathrm{~cm}$. LOI fluctuates considerably in the bottom $75 \mathrm{~cm}$ of the core (5-90\%), probably due to the increased incidence of shells and shell fragments. There is a slight increase in HT-LOI, but again the range is large (2-30\%).

There is considerably more sand in the Balemore sediments than at Askernish, as might be expected. The sediment changes around $50 \mathrm{~cm}$ probably represent the encroachment of macrophytes and the change from open-water to reedswamp.

\subsubsection{Pollen analyses}

The land-pollen content of the Balemore core was found to be in very low concentrations and the time available for counting only allowed for sums between 100-200. The percentage pollen diagram from Balemore is presented in Figure 102.

Although pollen of Betula, Pinus, Quercus, Alnus, Coryloid and Salix are present in the Balemore core, the sum of these taxa never exceeds $10 \%$ of total pollen and makes the assemblages difficult to correlate with other pollen diagrams. The high grass and sedge frequencies (together never below circa 60\%) suggest that these assemblages may match those in the upper part of the Askernish core, say above 70 $\mathrm{cm}$ although much of the Balemore pollen is probably local.

The pollen data suggest that the immediate vicinity of the Balemore site has been completely open during the period of accumulation of the deposits, what little tree and shrub pollen there is present is most likely to have originated in other parts of the Hebrides or from the mainland. The pollen and stratigraphic record suggests a succession beginning with submerged macrophytes - Myriophyllum spicatum and Potamogeton spp. - a transitional phase of Hippuris vulgaris and finally a phase of Sparganium cf. erectum or emersum.

As Gramineae pollen increases then the records of many herb pollen types decline (eg Artemisia, Chenopodiaceae, Plantago maritima, Rumex spp., Potentilla, Thalictrum, Ranunculaceae and Umbelliferae). The increase in grass may be hydroseral and it is possible that the large amounts of Gramineae pollen may be reducing the percentages for other herb pollen taxa by swamping. The possibility that the change from Cyperaceae-Gramineae to

Gramineae-Compositae tubuliforae is due to other causes such as, for example, increased sand instability, cannot be ruled out. Dickinson and Randall (1979) describe two major types of machair vegetation, a type of unstable dune almost completely dominated by Ammophila arenaria, other grasses, sedges and Bellis perennis (a Compositae tubuliflorae-type), and a more stable grassland type with much less Ammophila and a different range of herbs. Further work involving the differentiation of Ammophila pollen from that of other grasses (cf Randall 1977) could contribute to the resolution of this problem here and at Askernish.

\subsubsection{Discussion}

The markedly different pollen records for the two sites makes comparisons of the Askernish and Balemore data very difficult. The Askernish site possibly reflects a more diverse environment at the machair/blackland transition, whilst local bog and machair grassland vegetation has dominated the pollen input to Balemore with only a limited base-poor blackland component. The much greater influence of shell sand at Balemore is evident from sediment data, especially HT-LOI, and from the aquatic pollen record.

No dating evidence is available for the profiles presented here although a crude outline chronology may be proposed for the Askernish core. Presumed late-glacial sediments at Askernish exhibit an apparently classical tri-partite lithological sequence, but without more pollen analyses these cannot be tied in to existing mainland biostratigraphic profiles. The Outer Hebrides are considered to be outwith the general area of Loch Lomond Advance Ice (Sissons 1977), thus there are no objections to the possible deposition or survival of complete late-glacial sequences in South Uist.

An inorganic layer in the early postglacial sediments at Askernish (unit 5) could relate to a change in local hydrological regime or in the balance between erosion and leaching of local soils. This feature is particularly interesting in view of the growing body of evidence for short-term climatic change in the early post-glacial which seems to be most evident in far-west European sites (Bradshaw 1985). To what extent this erosion episode relates to the postulated hiatus in sedi- 
mentation at Askernish and occurring sometime before 7,900 bp until after 6000 bp is difficult to suggest. At St. Kilda, Walker (1984) found an hiatus covering a period from the late glacial until shortly before $6000 \mathrm{bp}$.

The early phase of increased charcoal frequencies which accompanies pollen evidence suggesting possible anthropogenic activity deserves further attention. Closer pollen sampling, higher counts and secure dating are required to amplify events at that time.

After the stabilisation of soils and the establishment of birch and hazel scrub the pollen record from Askernish suggests a rich diversity of habitats along the machair/blackland ecotone. This period was succeeded by a more open environment as Betula, Salix and Coryloid pollen was reduced and grasses expanded with Potentilla. Changes in the sediments were also evident with a brief erosion phase (unit 7), a second major increase in charcoal frequency, and a general increase in the calcium content of the sediment mineral matter. These were suggested to relate, respectively, to possible clearance of birch and hazel with local agricultural activities initiating erosion, and to a possible movement of sand near to the Askernish site. Further work would be necessary to test the hypothesis that Betula and Coryloid were cleared for agriculture, but if so this might have implications for sand stability. Similar pollen changes at Loch Cleat, in northern Skye (Birks $\&$ Williams, 1983) have been attributed to clearance activities around $5000 \mathrm{bp}$, which dates them to soon after the initiation of major sand movements in the Outer Hebrides as suggested by Ritchie (1979). The sediments at Askernish are not excessively carbonate-rich, as are those at Balemore, and could be radiocarbon dated to provide an independent chronology for comparison with available archaeological dates.

Exposure and substrate instability may produce very open landscapes and a major problem of interpretation is that inferences regarding the impact of man cannot be based on the same criteria as are applied elsewhere. More information is needed on pollen dispersal (cf. Randall 1977) and critical indicator species which may reflect agricultural activities in this unique environment. For example Spence $e t$ al (1979) compared grazed fen and ungrazed islands at Loch Druidbeg and suggested a list of wetland species which are sensitive to grazing pressure, some of which may be useful 'negative' indicator species. Another species which is of prime importance is Ammophila arenaria. Its pollen is large and may be confused, on purely size criteria, with that of cereals (Andersen 1979). As Ammophila is a critical species in the distinction between the plant communities of stable and unstable sand environments (Dickinson \& Randall 1979) distinction of its pollen in deposits from such environments may be rewarding. Preliminary observations at Balemore suggest the continuous presence of Ammophila-type pollen but further work is required to complete these analyses.

\subsection{PROSPECT}

In general the prospect is very good for the use of rock-basin sites for environmental reconstruction of the machair/blackland ecotone. Dating should be possible as the sediments were not particularly calcareous and should be amenable to radiocarbon assay. At the Askernish site, periods of local sand deflation were not immediately obvious from the sediments and were only identifiable from chemical analyses. Presumably the degree of sand-influence on sediments from such rock-basin sites will vary with local sand stability.

Machair lochs such as that studied at Balemore are possibly not so easy to find and to sample. The use of piston corers might be more successful and these might also be able to penetrate sand to sample deeper stratified peat layers (cf Ritchie 1968). The study of deeper lochs to investigate the sediment characteristics might be profitable. Dating of lake sediments from such calcareous situations by radiocarbon is probably impractical. The linear accelerator makes it feasible to consider the possibility of dating macrofossils from terrestrial species whose tissues may not be prone to producing 'hard-water' errors. 


\section{CHAPTER I8: INTERPRETATION AND DISCUSSION}

\section{PART I: PROJECT REVIEW}

\section{I METHODOLOGY}

\section{I8.I.I Tapestry excavation}

The writer is grateful to Patrick Ashmore for suggesting the term 'tapestry' to describe excavations of this type. Following the project described here, tapestry excavations have been undertaken at the Viking site of Tuquoy (Owen 1993) and the Iron Age and Viking site at St Boniface (Lowe 1998), both in Orkney. Smaller-scale tapestry excavations were also undertaken by this writer at the broch site of Pool of Virkie, Shetland (Carter et al 1995). All of these sites are affected by coastal erosion and the principle benefit perceived in the use of tapestry excavations has been that the area of site exposed to the forces of erosion has not been increased by the excavation. However, one other advantage has emerged very clearly from these exercises and that is that the information yield from these exercises is enormous, in proportion to the actual costs of excavation. By providing cross-sections through the sites, tapestry excavations furnish evidence on chronology and 'process', albeit at the expense of revealing the full horizontal extents of structures and deposits.

The excavations at Buiston Crannog (Crone 2000) were conceived of as tapestry excavations and, in this case, a section across the width of the site was excavated down into the lake sediments. The intention had been to pursue the section faces outwards across each half of the site, excavating it in $1 \mathrm{~m}$ strips. The principal advantage perceived in this approach was that of stratigraphic control. With no feature ever lying more than 0.5 $\mathrm{m}$ from two recorded section faces, the stratigraphic control over the site would have been without parallel. The complex stratigraphy of crannogs was the stimulus for seeking a high level of rigour in the excavation and recording of Buiston. However, the excavations quickly showed that the bulk of the crannog had already been removed and while the tapestry excavation revealed the nature of the construction of the crannog very clearly, it was equally clear that the gains to be anticipated in pursuing the tapestries across the site would not have justified the necessary expenditure. Here then were two further strengths of the tapestry excavation; firstly, that it facilitated re-evaluation of the project at a much earlier stage, and therefore at much less cost than would have been possible with traditional area excavation; secondly, the survival of the remaining deposits had not been compromised by the tapestry excavation over the extensive areas of the site which would have been exposed to oxygenated waters, had a full scale horizontal excavation been undertaken. Despite its early abandonment, the exercise none-the-less provided a full chronology for the surviving remains and revealed the full constructional and structural history of the site.

In summary, tapestry excavations are appropriate for deeply stratified sites with complex stratigraphies, where the conservation of the unexcavated remains is a high priority, or is particularly difficult because of the nature of those remains. Thus, they provide an ideal mechanism for sampling excavations on such sites, eg coastal erosion sites, urban assessment sites, etc.

\section{I8.2 SPECIALISTS RECOMMENDATIONS}

Each of the specialists involved in this project was asked to make such recommendations as they thought necessary and useful for future exercises of this type and these are reported below.

\subsection{Carbonised plant remains}

\section{G Jones (1987)}

\section{On site sampling}

There are potential problems with the use of a Cambridge froth flotation machine. It has been demonstrated that certain categories of charred plant material, such as cereal chaff, pulse seeds and nut shell, do not always float and substantial losses may result (Jones 1981; 1983). The soils used in these trials ranged from heavy clays to light Mediterranean soils. It is possible that the midden deposits and sands of the Uist sites are such that they do not pose a problem for froth flotation but, until this proposition is tested, it should be recognised that it is not possible to say with any certainty whether the apparent lack of chaff (for instance) at these sites is real or due to the techniques used (but see Smith 1999, 332).

On-site bulk processing is necessary, however, in order to process large numbers of samples of adequate size. Fortunately there are machines which collect the sinking residue as well as the flot (see, for example, Kenward et al 1980). Small quantities of heavy residue can then be checked for plant remains (as well as small bones and artefacts) and sorted more completely if necessary (see Parker-Pearson \& Sharples 1999).

\section{Size and number of samples}

Many of the Baleshare samples were too small for analysis with only twenty-seven contexts having thirty or more cereal items and only three having ten or more fruits and seeds of wild taxa (cf Hornish Point with seventy-one and twenty-three contexts respectively). This could be improved by taking larger samples - for Baleshare, for instance, doubling the sample size would approximately double the number of contexts with thirty or more cereal grains, but it would also double the processing time.

One way of obtaining larger samples but minimising processing time, is to aim for a standard quantity of plant remains rather than taking a standard weight (or volume) of deposit. If an estimate can be made of the quantity of plant material in the coarse flot sieve (barley grains would be an obvious guide at these sites) then the quantity of deposit processed can be adjusted accordingly. If there are very few grains in the sieve, it is often not worth processing the rest of the sample. On the other hand, if grains are very abundant, a small volume of deposit will often give a sufficiently large sample. More time can then be spent processing larger volumes of intermediate samples.

If a choice has to be made between sample size and number of samples then a large number of smaller samples is preferable especially when, as at the Uist sites, samples can be grouped into blocks for later analyses. This does, however, reduce the number of units considerably - only fourteen of the blocks from Baleshare and twenty-one from Hornish Point had thirty or more cereal grains while seven and seventeen respectively had ten or more fruits and seeds of wild taxa. 


\section{Off site analysis}

It had been hoped that the contexts on the MCP would provide a useful summary of the plant remains from each site. However, only six contexts on the Baleshare MCP (nineteen for Hornish Point) had thirty or more cereal grains and no MCP contexts from Baleshare (four from Hornish Point) had ten or more seeds of wild taxa. [The MCP or 'maximum contigual path' (Barber 1986) was an interpretational device employed to target sample selection, but ultimately abandoned in the interpretation of these sites (ed)]

Clearly, it is necessary to analyse more samples than this from each site but this may become very time-consuming especially if larger samples are taken. Economies could be made, in the off-site study of the plant remains, at the expense of some loss of information. Given the rather uniform nature of most of the samples from these sites, it would be possible to 'scan' them, as they do at the York Environmental Archaeology Unit, where they have the much greater problem of dealing with waterlogged remains from an urban site (Hall pers comm).

For the Baleshare and Hornish Point samples, the most time-consuming operations are; (i) the examination of cereals, grain by grain, to determine whether the barley is hulled or naked, straight or twisted, indeterminate or simply too badly preserved to be sure whether it is barley or some other cereal; (ii) the subsequent counting of grains in these categories. It would be considerably faster to go through the sample picking out the wheat grains, chaff, seeds of wild taxa and other 'unusual' items. The quantity of barley and indeterminate cereal grains could then be estimated, say, by volume. This method would, however, fail to pick up any variations in the proportions of two-, to six-row barley and occasional naked grains might well go unobserved.

\subsubsection{Pollen analysis}

\section{K Hirons (1986)}

Although the following points are made specifically in respect of the current work at Loch Askernish, the observations have a more general relevance for future micro-fossil work in the Hebrides (see Gilbertson et al 1996).

More stratigraphic information is required from the lake at Askernish to test hypotheses about stratigraphical changes. It may be feasible to use rapid magnetic susceptibility equipment to help with these investigations.

More samples of background soils and sediments are required for chemical analysis. Any detailed study of sediment chemistry should take into account both the inherent variability of the machair sand (Ritchie 1967) and its susceptibility to rapid modification by sub-aerial weathering (Randall 1973). The mineralogical work should be extended further up the core to test hypotheses about carbonate inputs to the upper sediments.

Pollen data at both Balemore and Askernish should be supplemented by closer sampling to provide better pollen stratigraphic resolution.

Critical pollen identifications should be undertaken and means of relating these to specific geomorphological/anthropogenic problems considered.
The Askernish site should be supplemented with a site further back in the blacklands (cf blanket peat sites; Heslop-Harrison \& Blackburn 1946). This would help to test hypotheses about the spatial distribution of Betula and Coryloid scrubland and would provide a comparison by provision of a site with perhaps more conventional indicators of anthropogenic impacts and mechanisms of clearance.

\subsubsection{The terrestrial mollusca}

\section{N Thew (1987)}

In future work in the Hebridean machair sites, samples of 6.2 kilos, where possible, should be taken for molluscan analysis and passed through a series of sieves down to $0.5 \mathrm{~mm}$.

Attrition of molluscs by human and animal trampling is something that can be looked for in future studies when samples are wet sieved rather than floated. This would help in the characterisation of deposits and, more particularly, of the boundaries between them. It is now evident that greater attention must be paid to sampling and the recording the layer-boundaries themselves, if we wish to understand the nature of both layer accumulation, and change from one layer to another.

\section{I8.3 RELATIVE ARCHAEOLOGICAL VALUE OF THE VARIOUS STUDIES}

It seems both appropriate and helpful to continuing studies in the Hebrides to consider the relative value of the separate studies undertaken above for this archaeological project. It should at once be emphasised that these studies are, in the opinion of this writer, highly interesting in their own right and individually of great value to the separate professional areas of study that they embrace. Their value is neither in doubt nor in question. However, in the disbursement of limited archaeological funding the question to be addressed is not whether they are of value but whether they are of archaeological value in the sense that they address specific archaeological questions which are currently relevant to studies in the area.

Measured by this yardstick, the contribution of the snail analyses cannot be doubted. They clarified the natures of the several deposits, suggested refinement of the sub-division of blocks and provided bio-stratification markers for the Iron Age as well as highlighting the significant differences between the surface and the substance of individual deposits. This analysis was, we believe, the first attempt to use snails in the detailed interpretation of the microenvironments of sites. Furthermore, many of its conclusions are based on statistically inadequate samples. Therefore, the conclusions it offers must be treated with caution, until further work of this type establishes the strengths and weaknesses of the approach.

Conversely, we have not regretted our omission of the analysis of marine mollusca since nothing in the contemporary literature suggests that their analysis would assist in fleshing out the archaeological interpretations of the sites to any greater extent than that afforded by the simple observation of their presence. 
The phytolith analyses provided a useful insight into the recycling of silica in these soils and suggests that the phytolith count is a sensitive indicator of settlement. Beyond this, however, their contribution is very limited. Their detailed study on future excavations in the machair cannot be recommended but phytolith analysis, used in surveys of the machair, should provide a powerful prospecting device.

The study of carbonised plant remains proved useful not only for the insights it provides into site economies but also for its observation of the 'contextual sensitivity' of such remains. Clearly, carbonised plant remains are closely interrelated with human activities. In future excavations in such sites, Dr Jones' recommendations for on-site evaluation with flexible sampling is clearly a sine qua non. The animal, bird and fish bone analyses, equally clearly, bear directly on questions of site economy and resource exploitation and are signally important. They have each indicated important archaeological questions which should be addressed by targeted sampling, again assisted by identification and evalua- tion in the field leading to flexible sampling, in pursuit of specific goals.

The regional studies, particularly the pollen analyses, are of limited, direct archaeological value. This is particularly true of the period after the major sand movements of the Late Neolithic, around 2400 uncal BC when the pollen signal of the machair vegetation seems to dilute or mask the signals from anthropic sources. However, used in the study of landscape formation (Hirons infra; Mannion infra; Whittington \& Ritchie 1988, for examples) pollen studies may have a more significant contribution to make. It is disappointing to note from palynological studies in the Hebrides that the diagrams fail to portray anything of the dynamics of, for example, the Iron Age settlement of the area. This may be a common factor of all palynological studies but it is certainly exacerbated by the extreme catchment conditions of the Long Isle. Perhaps we shall one day evolve a set of practical or theoretical approaches that allow us to test the 'story-line' of the pollen profiles but until then we can have relatively little faith in them (see Taylor 1999; Brayshay 1999). 
CHAPTER I8: INTERPRETATION AND DISCUSSION

\section{PART 2: SITE FORMATION}

\section{I8.4 INTRODUCTION}

Any site is the sum of its deposits, if we take structures to be simply another form of deposit, albeit a rather special one. Archaeological sites are those which contain significant volumes of information on the human past. Archaeological sites and deposits are rarely completely anthropic in their formation; natural materials arrive into most deposits by means of purely natural, ie non-anthropic mechanisms. The role of the field archaeologist is to distinguish as clearly as possible between natural and anthropic effects in the formation process of the deposits and thence to approach the identification of the site's formation processes. This writer has argued elsewhere (Barber 1988) that deposits formed from soils should be interpreted in terms of three components; the natural soil matrix, the anthropic contribution and the non-soil but natural inclusions. Once the deposits' formation mechanisms are understood and a dating framework provided, the formation of the site, as an entity, can begin to be understood.

\section{I8.5 THE DEPOSIT: SOIL MATRIX, ANTHROPIC AND NON-SOIL NATURAL COMPONENTS}

\subsection{Soil matrix}

The coastal environment in which these sites lie greatly simplifies at least one of these components, the natural soil matrix, which would be exclusively shell sand were it not for the introduction of other materials by human agencies. Every stone encountered in the machair soil was brought there by humans. Indeed, even the bulk of the soil organic matter (SOM) was almost entirely introduced to the site by humans and associated species, domesticated or not (see O'Connor 1997).

\subsubsection{Soil organic matter (SOM)}

Soil chemistry, pollen and phytolith microfossils, the recovery of carbonised and uncarbonised peaty nodules and the abundant presence of peat ash throughout the examined section, all indicate that peat is a major constituent of the anthropic contribution to the SOM of the soil matrix. This is consistent with the results from the analysis of later farm mounds from Orkney (Davidson et al 1983) and from Scandinavia (Bertelsen 1979). Davidson draws on the ethnographic evidence for recent agricultural practices in the Northern and Western Isles (Fenton 1978) to suggest that peat used, initially, as byre floor covering is the major source of the organic component of the soil matrices of farm mounds. The snail evidence from the Bronze and Iron Age deposits of the Hebrides seems to confirm this specific use. However, it is unlikely to have been the only use and possibly not even the greatest one. The exclusive use of peat for fuel, evidenced in the observed ash deposits, and the deliberate introduction of peat to wind blown sand to create plaggen soils are clearly evidenced in these sites also. Whatever it's functions, peat was introduced to these sites in very large quantities indeed and became the second most abundant component of the soil matrix.

Animal faeces are less easily identifiable on the site and their presence can only be deduced from other strands of evidence. Phytolith analysis revealed that phytoliths were present in soils forming the deposits of these sites in concentrations of $10^{3}$ to $10^{6}$ per cubic centimetre (cc) of soil. This contrasts strongly with the results from naturally formed modern A-horizons on machair in the Hebrides and elsewhere where 20 phytoliths per cc was a typical concentration. Analyses of modern analogues indicate that peat and faeces contain phytolith concentrations comparable with those observed on the site and we may conclude that these provide a large part of the SOM and are the principal sources of much of the silica contained in the soil matrix. However, these sources alone cannot account for the particular photolith suites detected and we must look to other sources, like decaying vegetation from food for man and beast, to account for the remainder.

The presence of animal bones on the site provides the clearest evidence for the slaughter of animals on site, while the byre floor material itself and the presence of marine prosobranchs, small shellfish brought on site attached to seaweed collected for fodder, provide further strands of supporting inference. The phytolith concentrations also indicate the general possibility that animal (including human), faeces form part of the anthropic contribution to the SOM of these sites.

\subsubsection{The anthropic component}

These sites are exceptional in that even the soil matrix has a large anthropic component but here we consider the artefacts and ecofacts that became part of each of the sites.

\section{Macroscopic inclusions}

The structures and structural elements of the sites are the main anthropic contribution on the macroscopic scale. Most of these were dug into existing deposits; the internal faces of the voids thus created being lined with stone facings. The need to transport to the sites all of the stone used in construction probably encouraged the re-use of stone and this probably gave rise to further re-working of deposits. It has certainly led to the palimpsest nature of the structures, most clearly visible at Hornish Point where virtually every structure examined was formed of parts of pre-existing features, together with newly built elements. The re-used rotary quern at Baleshare (Plate 17) is symptomatic of the general curation of stone for buildings.

\section{Artefacts and ecofacts}

The most common artefacts recovered from these sites are pottery and burnt stone, the latter comprising a significant proportion of some individual deposits. Otherwise, the artefactual contribution to the sites' formations is relatively slight, measured as a proportion of the volume of the deposits. However, the numbers of potsherds recovered, even from these small sampling excavations, are counted in the thousands. This richness of artefactual material is exceptional for Iron Age sites in Scotland from which potsherd totals, at best, are counted in the hundreds. 
Ecofacts are also locally abundant within the sites. Not surprisingly, most contexts contained some marine shell and they constituted the greater part of some contexts. It is clear from their very abundance that these must be anthropic in origin even if some of them arrived on site by purely natural means. Butchery-, and food-waste, in the form of animal, bird and fish bone was similarly abundant, in contrast with most other Iron Age sites in Scotland. The high $\mathrm{pH}$ of the shell sand is the key factor in the preservation of bone and, indeed, of seashell and snails.

\section{Summary}

The materials of which the sites are formed comprise natural wind blown sand, principally shell sand. Clay-sized particles have been added to the shell sand. A large part of this addition comprises microscopic silicates derived from the decay of peat and faeces. The matrix also contains undecayed peat and other humified organic matter. Significant volumes of stone were imported for use in building and for heating water. Seashell, pottery and butchery and food waste of various types form smaller, but significant contributions.

\section{8.5.4 The (non-soils) natural component}

This element of the deposit contents is the most difficult to identify and quantify, for these sites. Some of the seashell will have been brought on site by, for example oyster catchers or other mollusc-eating birds. Very rough counts made by the writer on a somewhat ad hoc basis, revealed up to ten shells per ha on the current machair surface near the sites reported on here. Similarly, it is probable that the remains of bird species like thrush, starling, crow and rook became incorporated in these deposits on the deaths of birds living on the sites, quite independently of the sites' human occupants. Snails were incorporated into deposits partly as natural, in situ assemblages and partly as a result of the creation of specific ecological niches by humans, eg byre floor deposits.

In general, the non-soil, natural component of the deposits does not seem to have contributed significantly to the volume of the deposits.

\section{I8.6 SITE FORMATION PROCESSES}

\subsection{Introduction}

The formation of these sites was dynamic and comprised the interplay of natural and anthropic forces adding material to the sites, reworking the materials on site and, from time to time, removing some materials from the site also. In the case of the anthropic contribution there is also, perhaps, a distinction to be drawn between deposits on the basis of the 'intentionality' of their formation. This complexity requires the definition of terms used in its description, not least because the term 'midden' as applied to these site-types has become rather misleading.

\subsubsection{Terminology}

There are few technical terms universally agreed in respect of sites and landscape forms in sand and to avoid confusion and, hopefully, to assist the reader some 'definitions' are offered here of words used in the following text.

\section{Conflation}

Following the deflation of sandy deposits, the anthropic component of these deposits, eg bone, shell, pottery, etc and in the context of these sites, including stone also, does not blow away but comes to rest on some arbitrary surface, forming a deflation deposit. These remains may be of different origins and dates but can become incorporated together, either in a new deposit of wind blown sand or by incorporation, by bioturbation, in the surface on which they come to rest. The resulting deposit is known as a conflation deposit.

\section{Deflation}

The process of deflation means the removal of sand by the force of the wind alone. Used as an adjective the term can refer to the resultant landforms, eg 'deflation hollow' or 'deflation deposit'.

\section{Dump deposits or dumped deposits}

Dumped deposits are characterised by their clear boundaries and the low volume of the individual contributions. They will have been formed in discrete packages, such as could be carried on or in a shovel or basket or, perhaps, wheelbarrow or cart. They need not contain any anthropic materials but often do so in considerable quantity. They usually display large scale heterogeneity coupled with small scale homogeneity, ie while the single deposits may be quite homogenous, there can be considerable diversity between the individual deposits making up one dump deposit.

Needham and Spence (1997) and McOmish (1996) emphasise intentionality as an important consideration in the definition of dumps and the categorisation of dumping activities. Intentionality can be confidently attributed to the removal of material from its original source. The act of gathering it together and moving it to its find-location (archaeological context) is a necessary precondition to the deposit's formation and cannot be other than deliberate. The difficulty subsists in demonstrating intentionality in its disposal. Was its final resting place selected as an act of human will? Structured deposition, a heavily overworked concept, presumably consists of deposits for which we can be sure that their final resting place was not only selected as an act of human will, but was selected to the conscious exclusion of all other places.

\section{Midden}

The term 'midden', of Scandinavian origin, is composed of the elements møg (muck) and dynge heap and simply means muck heap or dung heap (OED). In the late nineteenth century it came to be used as an abbreviation for 'kitchen midden'. The latter term was a useful archaeological descriptor but the archaeological abuse of the term 'midden' has devalued it and caused some confusion (see Needham \& Spence 1997; McOmish 1996 for useful discussions). Here the term is reserved strictly for deposits that are interpreted as accumulations of refuse intended for reuse as manure. A 


\section{Deliberate}

\section{Dumped Primary dump}

Midden

Made soils (Plaggen soils)

Structured deposits

\section{Reworked Distributed on fields}

\section{Redeposited by later building}

Table 49. Categories of deposits evidenced on the excavated sites

midden may contain dumped deposits and incorporate midden-site deposits.

\section{Midden-site deposit}

A midden-site deposit is a deposit whose matrix has been enriched with relatively large amounts of anthropic material, artefactual and ecofactual, where the material has not entered the deposit as a result of deliberate dumping. Rather, the anthropic material arrived in these contexts by some combination of loss (accidental dumping), abandonment (of butchery waste, for example, at the butchery site), or incidental discarding (littering).

These contexts can be quite extensive and where sufficiently extensive are perhaps best described as midden-soils, rather than deposits. This distinction is based on the probability that anthropic material has been incorporated into an existing matrix or was progressively included into a matrix being formed by natural processes. Midden-site deposits can be created where dumped or other deposits have been cultivated and manured but these deposits are termed 'cultivated deposits' in this report (infra).

\section{Midden-site}

A midden-site is a site composed principally of midden-site deposits, but contains other types of deposit as well.

\section{Cultivated deposits}

Virtually all of the deposit types encountered on this site existed in hybrid or mixed forms also; cultivation being the most frequent cause of their hybridisation. Dumped deposits or midden-site deposits were the most commonly cultivated deposit types. The resulting cultivated horizon (it could include more than one original deposit) was usually so heterogeneous that it was not possible, unambiguously, to identify the nature of the parent deposits. Further, there seems to be a spectrum, more or less continuous, embracing cultivated dumped or midden-site deposits, highly manured cultivated sands and plaggen soils.

\section{I8.7 PROCESSES OF ACCUMULATION}

\subsection{Natural sedimentation}

Windblown sand is the major site-forming material on each of these sites. The process of its arrival is simply that of aeolian transport. Ritchie (1968) has shown that, in the absence of obstacles, like these sites, the high mean wind speed of the islands ensures that the transport of sand proceeds to the level of the local water table, thus creating the machair plain. Accumulations of humic matter in the vicinity of settlements facilitates the accretion of sand both by adhesion to soft wet humic material and, ultimately, by creating 'perched' water tables that, by keeping the sand wet, resist deflation.

The mere presence of walls and buildings can accelerate the processes of accumulation by providing nuclei for 'dune formation'; the wind blown sand coming to rest in the lee of the structures. Sand thus accreted, can in turn become stabilised by incorporation of dumped, humus-rich detritus from the structures and further trapping of blown sand may continue from that point.

\subsubsection{Deliberate dumping}

Our a priori suggestion that refuse dumping could be considered under a variety of headings seems to have facilitated a meaningful interpretation of the site deposits. The classification of Blocks used here distinguishes between dumped deposits, deposits that contain 'abandoned' or inadvertently dumped matter and reworked deposits of both types. In this there is a foreshadowing of Needham \& Spence's $(1997,87)$ contention that, 'We attempt to judge the intentional versus the inadvertent and to see what archaeological manifestations are created by their interaction.'

The evidence recovered in this study, however, has indicated the significance also of the reworking of deposits, however formed. Table 49 proposes a set of relationships between dumped and reworked deposits and the intentionality or inadvertence of their deposition.

\section{Primary dumps}

Dumps of refuse seem best illustrated at Balelone where humus rich strata and dumps of peat ash, for example, were commonly observed. The coherence of the deposits, their homogeneity, small volume and the clarity of their boundaries, indicates that these strata represent single episodes of dumping and their size suggests that the materials dumped could have been the waste products of a single household. This material can be viewed as primary dump deposits. Jones' analysis of the distribution of carbonised plant remains supports this classification of the relevant Blocks.

It has been argued above that the passage into the probable wheelhouse at Baleshare was used as a 'deliberate' dump for, inter alia, a skinned calf carcass. Use of abandoned structures for waste disposal seems probable (see Matthews 1993, for example) and one may wonder whether the multiple pits within the wheelhouse at Sollas (Campbell 1991) also, are post-abandonment features associated with dumping.

\section{Primary dumps in refuse pits}

The mere existence of refuse pits is not de facto evidence for structured deposition. Rotting debris and faecal matter lying about on the ground surface would have attracted vermin and formed a reservoir of disease vectors. In the late twentieth century it is easy to forget that only fifty years ago various forms of blood poisoning, tetanus and related conditions could be contracted from relatively trivial wounds and commonly resulted in death. Burial of at least some forms of refuse was a necessity on long term settle- 
ment sites. It may be supposed that among the materials most probably buried would be primary butchery waste, especially entrails and offal not kept for consumption, faeces and contaminated food.

\section{Middens}

Dumping of organic matter purely as waste disposal would have been an extremely short-sighted practice by machair residents given that machairs are severely deficient in humus. Some dump deposits on these sites constituted middening, or at least waste accumulation, for later distribution onto cultivated land. The vertical faces observed in the Balelone organic horizons, for example, are interpreted as evidence that middens of humic material from these locations had been dug out and, presumably, spread on cultivated areas.

\section{Plaggen soils}

Anthropic, or plaggen soils, are remarkable and consistent features of the prehistoric sites examined. These are considered in more detail elsewhere but the common, often abundant, presence of nodules of peat in the cultivated deposits indicates the possibility that peat was introduced directly to the machair sands to create fertile, arable soils. However, it is also possible that the peat arrived in the fields via byre floors or as ash and carbonised fuel via cooking fires. Whatever the mechanism of its introduction, the harvesting and delivery of peat to the sites represents a significant contribution to site formation process.

\section{Structured deposits}

Hill, from his study of Iron Age 'midden' deposits in Wessex, concluded that the original abundance of materials used on site is not reflected in the quantities surviving on archaeological sites and further that finds from later prehistoric sites are '...just as structured as those from graves or hoards.' (1995, 125). It is possible that some midden deposits, indeed that some middens are structured deposits. However, it is estimated that the roughly 70,000 tonnes of material in the Late Bronze Age midden at Baleshare rotted down from a total of something like 180,000 tonnes of freshly dumped refuse (I ignore here issues of the nature of the 'dumping'). It is hardly credible that this large mass of material was 'structurally' or ritually deposited.

There is at least one set of structured deposits at Hornish Point comprising the pits containing the partly articulated remains of one adolescent human and selected parts of two juvenile bovids and of two female sheep (Barber et al 1989, 775).

\subsubsection{Inadvertent dumping}

\section{Midden-type deposits}

Inadvertent dumping also seems to have occurred regularly, perhaps continuously, during the occupation of these sites. The deposits that have been styled 'midden-type' deposits are rich in domestic refuse but appear to have acquired this by incorporation from trample or by small scale abandonment of refuse close to structures. This could include small scale dumping of industrial by-products, or perhaps their simple abandonment at the production site.

\section{House floors}

Refuse has, similarly, become incorporated in some house floors, most probably by trample and by burial in shallow pits scooped out of the sand. In the case of Block 11 at Baleshare, black, humus rich levels interpreted as house floors were sealed under layers of clean sand apparently introduced to bury surfaces that had become noisome and unhealthy.

The house floors visible in the small structure at Baleshare had crisply clear boundaries, so clear that the writer wonders if anyone ever walked on them. The alternating bands of dark humic matter and white wind blown sand would surely have become very intermixed, had humans or animals walked on them. Perhaps these 'floor deposits' are in reality post-abandonment dump deposits that were occasionally buried with clean sand to discourage flies, suppress the associated smells, discourage vermin or remove a health hazard.

\subsubsection{Reworked material}

\section{Manured cultivation areas}

Middened material was spread on fields and ploughed-in to maintain or improve fertility and, on machair, to resist deflation. Given the proximity of large seaweed deposits on the nearby beaches it is probably necessary to point out here that seaweed would have contributed little by way of nutrients that the shell sand did not already possess. It would have helped to stem erosion but, unless burned and applied in great quantities, seaweed alone could not have made up the deficiencies of machair soils.

In considering middens as accumulations of mainly organic matter, ie 'provisional refuse' in Schiffer's terminology $(1987,64)$ Needham and Spence suggest that '...the practice of accumulating refuse does not automatically point to the practice of manuring' $(1997,84)$. But the practice of manuring does point to the fact that refuse was accumulated.

\section{Reworked material, cultivated dumps}

Deposits of all kinds were reworked by subsequent episodes of ploughing. The deep and highly stratified deposits on the south side of Hornish Point provide a particularly striking example of the process by which sand accretion coupled with repeated cycles of cultivation following dumping, midden-site deposit formation or extensive manuring led to rapid accumulations up to $2 \mathrm{~m}$ deep. These formed in periods of time so short that the radiocarbon method cannot resolve the chronology of the separate formation episodes. Indeed the radiocarbon method is only just capable of resolving between the earliest and latest episodes.

\section{Reworking for new construction}

Baleshare and Hornish Point both contain structures that are dug into the accumulated sediments of the site. Removal of the considerable volume of material needed to prepare the house-stances caused massive reworking of some deposits. At Baleshare this resulted in one significant radiocarbon dating reversal, ie the determinations identified younger deposits underlying older deposits. In the large farm-mound site type, of the Hebrides and Orkneys, this must be a relatively common phenomenon and should encourage caution in the interpretation of individual dates or of small numbers of dates from such complex sites. The radiocarbon-dating of 

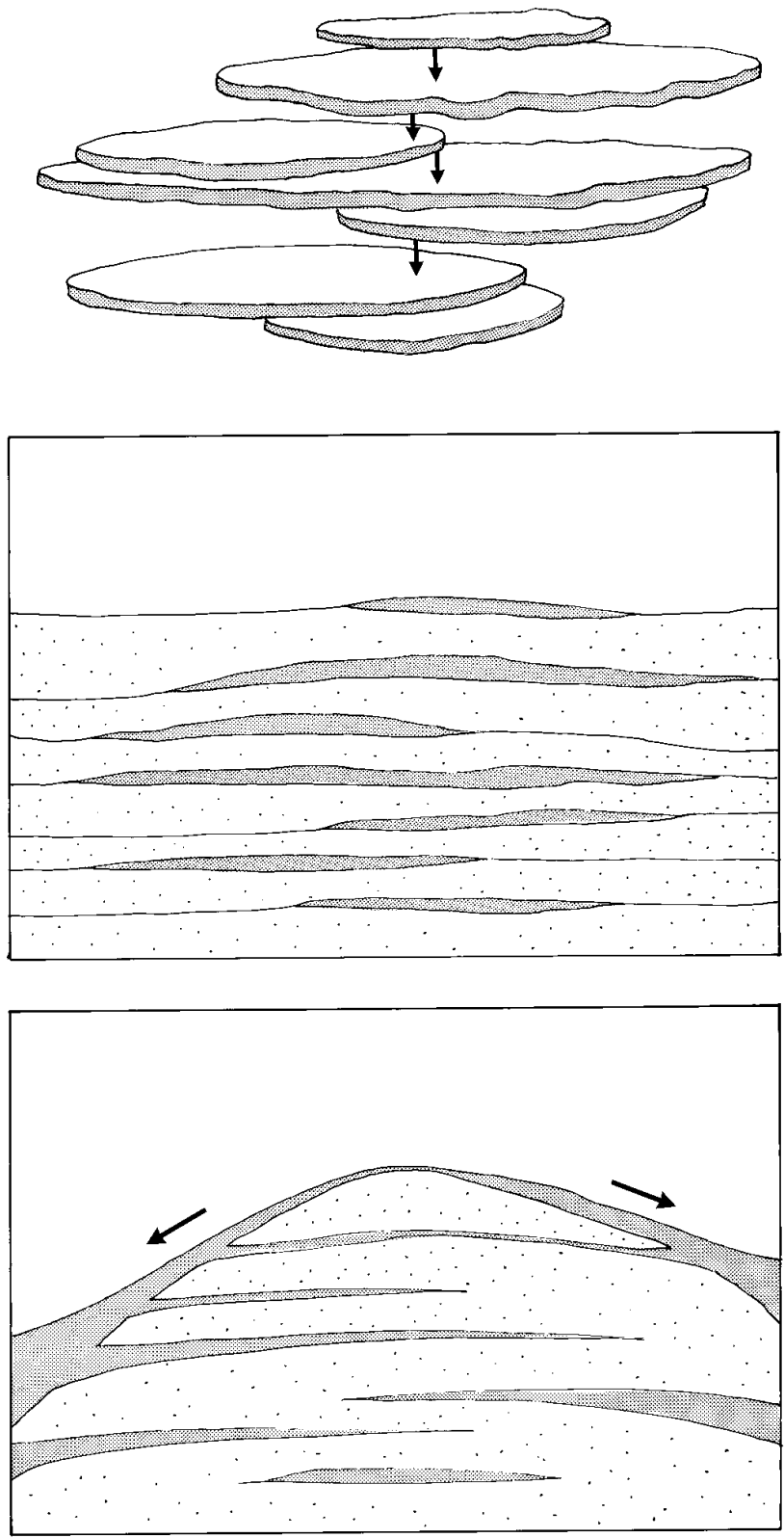

Figure 103. Margins of sites interdigitated with peat

the broch and associated features at Scalloway, Shetland provides a clear example of this problem (Sharples 1998, 83-8). Despite the use of twenty-four dates there is one inversion in each of the three periods identified among securely stratified contexts.

\section{I8.8 NEGATIVE ACCUMULATION: LOSS OF SEDIMENTS}

\subsection{The overall physical form of the sites}

If the sites and their immediate environments were accreting sand at roughly comparable rates, we should expect to find the margins of each site interdigitated with the machair deposits (Figure 103). This expectation prompted the coring and trial pitting in the hinterland of Balelone, in an attempt to relate the site deposits to the surrounding landscape. However, observations at Balelone, at all the other excavated sites and the sites visited in the course of the initial surveys, has shown that all of the machair sites are roughly hemispherical or domical in form (Plate 9). This must necessarily mean that the machair around these sites has, itself, deflated (on more than one occasion) and, therefore, that the contiguous sand deposits are not contemporaneous with the juxtaposed site deposits. This observation is consistent both with Ritchie's model for the evolution of the machair and with the observation of early modern travellers, who like Martin Martin in 1703, saw not a blade of grass growing on the bare sand of the machair.

The erosion pits on the south edge of Balelone and the erosional slipping of a mass of strata at the northern end of the Hornish Point section also demonstrate that these bodies of deposits were episodically exposed to erosion on a scale large enough to isolate entire sites from their enveloping machair deposits.

\section{8.8.2 Conflation horizons}

At Baleshare, the presence of strata or surfaces spanning the full extent of the revealed section (Blocks 23 and the surface of Blocks 15 and 1, for example) indicate large scale erosional events. These isolated the sites from their machair hinterlands more than once during the sites' formation. These layers are conflation horizons and are particularly problematic for the archaeologist. They are formed by the following processes:

i) Deflation; Wind erosion of sandy deposits removes the sand particles of the deposits but the larger particles, including stone, artefacts and ecofacts cannot be removed by the wind and simply drop down the profile and lie, mixed together as a conflated assemblage, on the exposed deflation surface. The deflation surface may cut through deposits of different ages.

ii) Stabilisation; Erosion stops because strata are reached which resist further erosion, eg humus enriched deposits or the local water table. Vegetation invades the revealed surfaces and a biologically active A-horizon develops.

iii) Conflation; Bioturbation incorporates into the A-horizon the mixture of materials lying on the deflation surface, further mixing them with the contents of the deposits in which the new A-horizon has formed, the latter constituting a conflation horizon. Thus, the conflation horizon contains materials from each of the contexts removed by aeolian erosion as well as the materials in the contexts (usually more than one) forming the deflation surface. These are clearly not synchronous deposits. Their contents are diachronic and may contain strange juxtapositions of materials, sometimes sufficiently strange to invite the interpretation that they are ritual deposits or structured deposits.

\subsubsection{Missing deposits}

Smaller scale erosion is also well attested in the excavations. Plate 20 shows ard marks, revealed in underlying deposits. 
The material that enters an ard mark at the time of its creation should be a mixture of the soil of the overlying deposit and that of the 'subsoil' into which it is cut. However, as Plate 20 shows, the material in these ard marks is significantly different from both the underlying and overlying strata. This is interpreted as indicative of the loss of the A-horizon, or surface soil, through which the cultivation took place. As noted above, summer drought exposes the cultivated soils of the machair to the hazard of wind erosion. It seems reasonable to conclude that droughty summers in the Bronze and Iron Ages may have led to the loss of exposed areas of the cultivated surface soils and very probably of the cultivated crops in those areas as well.

\section{I8.9 DEPOSITIONAL RATES AND PRESERVATION CONDITIONS}

The quality of preservation of remains like animal bones or carbonised plant remains is affected by the rates at which they are incorporated into the sediments of the sites. Faster deposition at Hornish Point, for example, has resulted in a lower absolute volume of bones, per unit volume of sediment, but the quality of the preserved bones is much better than that of those from Baleshare. The same observation has been made about the relatively fragile carbonised plant remains (Jones infra).

In general, the conditions in these sites are excellent for the preservation of a wide range of archaeological materials.
The high $\mathrm{pH}$ of the soils has ensured the survival even of the most fragile bones of bird and fish. These conditions should also facilitate the preservation of metals. Hammerscale was recovered from many of the deposits. This consists of small metallic scales dislodged from the surface of iron objects when these were hot-worked by hammering for forming and hammer-welding. The survival of these tiny scales indicates quite clearly that iron could and did survive on the site and that its absence from the sampled deposits is real and not just an artefact of preservation.

\section{I0 SUMMARY}

The machair sites were formed by sand accretion, facilitated by human activities ranging from construction to refuse disposal and cultivation. Their formation was intermittent and they underwent episodes of major erosion, isolating the sites from the landscape mass of the machair sands. Areas of the sites were also subject to smaller scale erosion, particularly to the loss of cultivated topsoils. The implications of these observations for the chronologies of the sites are considered below. Despite the vigorous dynamics of their formation the sites are good preservational environments and the recovered artefactual and ecofactual material can be taken as truly representative of the original inputs to the deposits. 
CHAPTER I8: INTERPRETATION AND DISCUSSION

\section{PART 3: RADIOCARBON DATING}

\section{I8. I DATING THE SITES}

\section{I I.I Inherent problems}

Despite their apparent wealth of suitable materials, the dating of Hebridean coastal erosion sites presents special problems. Radiocarbon dating of carbonised wood or charcoal, is rendered suspect by three factors which may on occasion act in combination. The first of these is the presence in these islands of significant volumes of driftwood which originated in the Americas or elsewhere, the growth of which may have been completed a considerable time before its deposition as charcoal (Dickson 1992).

The second factor is the possible inclusion of charcoal derived from peat. Peat ash is clearly visible in almost all of the exposed profiles, often containing unburnt peat particles, occasionally in association with charcoal. The woody stems of the Ericaceae or of Myrica gale or some of the Salix species are clearly visible in many peat cuttings on the islands and can be seen in the cut peats. Sub-fossil tree-stumps of pine are also locally abundant in the peat. There is therefore a danger that the charcoal from such contexts is carbonised sub-fossil wood from the peat deposits.

Even if the exotics and the peat-derived material can be identified and eliminated from dating samples, the heirloom status of construction timbers in these treeless islands poses a severe problem. Large timbers, such as those suitable for use as rafters or ridge-poles, are likely to have been conserved in the islands and to have assumed the status of heirlooms. In consequence, they are unlikely ever to have been discarded for use as firewood and, when consumed in accidental conflagrations, they may pre-date the currency of the structures they are found in by several centuries. Oral tradition in the isles tends to confirm this view in that members of the older generation can remember, or recall their parents or grandparents remembering the often lengthy, and invariably tortuous, history of their roof trusses. It must of course, be remembered that these comments may only apply to the periods which fall after the deforestation of the islands.

Smaller carbonised remains, seeds and fruits, etc are also susceptible to contamination from peat-derived material (Jones supra). It could be argued that the only reliable carbonised dating material is carbonised cereal grains from clearly identified and well understood contexts. However, relatively few contexts contained carbonised cereals and only a handful contained sufficient to provide the standard radiocarbon dates available to this project.

The radiocarbon dating of humic matter from these sites is also fraught with difficulties. Fragments of peat were found in large numbers in most contexts, some of them carbonised or partly carbonised. These alone rule out the possibility of using the soil organic matter (SOM) to date contexts, quite apart from the uncertainty arising from the unknown mean residence time of humus in these soils, or the potential relict carbonate effect of shell sand dissolved in humic acids.

\section{I I.2 Dating sea shell}

Sea shells were available from most contexts and occurred in sufficient quantity to provide radiocarbon dates. However, radiocarbon dates of seashells are felt by some authorities to be somewhat older than the shells themselves because of the marine reservoir effect (Harkness 1983). This effect arises from the slow and uneven rates of incorporation and mixing of carbon isotopes in the oceans' waters. Thus, in oceanic areas characterised by the upwelling of deep water the radiocarbon content of the water is lower than the radiocarbon content of contemporaneous terrestrial materials. However others point out that the relative amounts of carbon isotopes (notably of ${ }^{13} \mathrm{C}$ and ${ }^{14} \mathrm{C}$ ) fixed in the formation of marine bicarbonate, are different from the ratio in which they occur in terrestrial materials. They argue that the order of difference is such as to approximately cancel out the marine reservoir effect. In other words,

'.... the increase in ${ }^{14} \mathrm{C}$ activity due to isotopic fractionation during the formation of bicarbonate, and the decrease due to mixing with deep water, almost cancel. This has long been utilised in the dating of marine shells which are in close isotopic equilibrium with bicarbonate of the surrounding water.' (Tauber 1976).

This conclusion is apparently contradicted by experimental work undertaken in Australia (Huebbers 1978, A5.2). The radiocarbon dates of shells of four different species were compared with dates from charcoal from archaeologically associated contexts. In total ten pairs of dates were compared and in every case the shell dates were older than the charcoal dates. The differences ranged from $240 \pm 141$ to $1400 \pm$ 114 years. Significant differences between species were noted, and Hormomya erosa (the rough beaked mussel) proved consistently to have the greatest errors, with a pooled mean error of $1360 \pm 95$ years. The scale of these errors was attributed to Hormomya's habitat; sheltered bays and lagoons, where relict carbonates leached from ancient shell sands on the coast become concentrated, in the absence of adequate circulation of tidal waters. These carbonates become fixed by the mollusca and produce dates over 1000 years too old (Heubbers 1978, A341-2).

There is clearly a danger that machair sands produce relict carbonates which enter the Atlantic, off the Hebrides, in solution. However, there are few sheltered bays or lagoons along the west Hebridean coastline and so the problem may not be as acute for these sites as it seems to be for the Australian sites noted above.

\section{The calibration curve}

It seemed clear that most of the prehistoric sediments on these sites would date to the first millennium BC, and this poses a further problem because the calibration curve is particularly flat and unvarying in the interval 800-200 BC (Baillie \& Pilcher 1983). Single dates, or small numbers of dates from individual sites would not, therefore provide an adequate basis for intra-, and more particularly, inter-site comparisons. 


\begin{tabular}{|c|c|c|c|c|c|c|c|}
\hline \multirow[t]{2}{*}{ Lab No. } & \multirow{2}{*}{$\begin{array}{l}\text { Context } \\
\text { No. }\end{array}$} & \multirow[t]{2}{*}{ Block } & \multirow{2}{*}{$\begin{array}{l}\text { Sample } \\
\text { type* }\end{array}$} & \multirow[t]{2}{*}{ Date bp } & \multirow[t]{2}{*}{ SD } & \multicolumn{2}{|c|}{ Calibrated dates } \\
\hline & & & & & & |-sigma & 2-sigma \\
\hline \multicolumn{8}{|c|}{ Baleshare } \\
\hline GU-1968 & 100 & 21 & $\mathrm{a}$ & 2045 & 50 & 166 BC-AD 16 & 200 BC-AD 57 \\
\hline GU-1975 & 29 & 24 & $\mathrm{a}$ & 2075 & 50 & $172-3 \mathrm{BC}$ & 348 BC-AD 48 \\
\hline GU-1972 & 2 & 5 & $\mathrm{a}$ & 2085 & 50 & 198-44 BC & 35 I BC-AD 46 \\
\hline GU-1964 & $\mathrm{I}$ & 6 & $\mathrm{a}$ & 2110 & 80 & $350-4 \mathrm{BC}$ & 390 BC-AD 54 \\
\hline GU-1962 & 46 & 4 & $\mathrm{a}$ & 2155 & 50 & $354-120 \mathrm{BC}$ & 380-72 BC \\
\hline GU-1974 & 33 & 28 & a & 2210 & 50 & $385-203$ BC & $400-121 \mathrm{BC}$ \\
\hline GU-1960 & 42 & 2 & $\mathrm{a}$ & 2240 & 55 & $393-209$ BC & $400-131 \mathrm{BC}$ \\
\hline GU-2166 & 265 & 11 & $\mathrm{a}$ & 2250 & 50 & $394-211 \mathrm{BC}$ & $400-174 \mathrm{BC}$ \\
\hline GU-1970 & 212 & 19 & $\mathrm{a}$ & 2265 & 50 & $397-214$ BC & 407-200 BC \\
\hline GU-2। 65 & 113 & II & $\mathrm{a}$ & 2320 & 50 & $406-386$ BC & $510-233$ BC \\
\hline GU-1963 & 239 & 15 & $\mathrm{a}$ & 2375 & 55 & $516-396 \mathrm{BC}$ & $76 I-380 \mathrm{BC}$ \\
\hline GU-1961 & 68 & 1 & $\mathrm{a}$ & 2390 & 55 & $752-399$ BC & $764-390 \mathrm{BC}$ \\
\hline GU-1965 & 127 & 18 & $a, b$ & 2740 & 60 & $973-828$ BC & $1072-800$ BC \\
\hline GU-197| & 148 & 26 & $\mathrm{a}$ & 2815 & 50 & 1072-904 BC & 1209-833 BC \\
\hline GU-1973 & 132 & 27 & $\mathrm{a}$ & 2910 & 50 & $|24|-10 \mid 4 B C$ & $1314-935$ BC \\
\hline GU-1967 & 196 & 20 & $a, b$ & 2970 & 65 & $1370-1054$ BC & $1410-976$ BC \\
\hline GU-1969 & 272 & 23 & $\mathrm{a}$ & 3030 & 50 & $1392-1135$ BC & $1430-1110 \mathrm{BC}$ \\
\hline GU-1966 & 280 & 22 & $a, b, c$ & 3285 & 60 & $1686-1496$ BC & I734-I430 BC \\
\hline \multicolumn{8}{|c|}{ Hornish Point } \\
\hline GU-2024 & 257 & 19 & $\mathrm{a}$ & 2170 & 50 & $357-128$ BC & 390-74 BC \\
\hline GU-20I5 & 3 & 13 & $\mathrm{a}$ & 2170 & 50 & $357-128$ BC & 390-74 BC \\
\hline GU-2026 & 332 & 22 & $\mathrm{a}$ & 2185 & 50 & $362-172 \mathrm{BC}$ & $390-90$ BC \\
\hline GU-2016 & 16 & 10 & $\mathrm{a}$ & 2220 & 50 & $387-206$ BC & $400-126$ BC \\
\hline GU-2028 & 351 & 22 & $\mathrm{a}$ & 2270 & 50 & $398-233$ BC & $407-200$ BC \\
\hline GU-2025 & 272 & 19 & $\mathrm{a}$ & 2285 & 50 & $400-235$ BC & $410-208$ BC \\
\hline GU-2022 & 218 & 7 & $b$ & 2310 & 50 & $405-380 \mathrm{BC}$ & $484-212$ BC \\
\hline GU-2023 & 231 & 8 & $\mathrm{a}$ & 2320 & 50 & $406-386$ BC & $510-233 \mathrm{BC}$ \\
\hline GU-202I & 87 & 5 & $b$ & 2325 & 50 & $407-387$ BC & $515-233$ BC \\
\hline GU-2018 & 33 & 12 & $\mathrm{a}$ & 2330 & 50 & $408-388$ BC & $733-234$ BC \\
\hline GU-20I7 & 24 & 4 & $\mathrm{a}$ & 2335 & 50 & $409-389$ BC & $74 I-235$ BC \\
\hline GU-2019 & 37 & 9 & $\mathrm{a}$ & 2345 & 50 & $4|I-39|$ BC & $752-263$ BC \\
\hline GU-2027 & 339 & 26 & a & 2370 & 50 & $509-396$ BC & $758-384$ BC \\
\hline GU-216I & $79 / 464 / 465$ & 27 & $a, b$ & 2410 & 50 & $756-403 \mathrm{BC}$ & $767-390$ BC \\
\hline GU-2020 & 74 & 1 & $\mathrm{a}$ & 2500 & 50 & 789-446 BC & $800-410$ BC \\
\hline \multicolumn{8}{|l|}{ Balelone } \\
\hline GU-I802 & 339 & 9.00 & not ID & 2290 & 60 & $403-234$ BC & $483-210 \mathrm{BC}$ \\
\hline GU-I80I & 113 & 3 & not ID & 2330 & 70 & $411-382 \mathrm{BC}$ & $757-210 \mathrm{BC}$ \\
\hline GU-I803 & 166 & 4 & not ID & 2440 & 80 & $768-403$ BC & $800-390$ BC \\
\hline \multicolumn{8}{|c|}{ Newtonferry } \\
\hline GU-2163 & 19 & 3 & $\mathrm{a}$ & 700 & 50 & AD 1264-1377 & AD |220-139| \\
\hline GU-2164 & 33 & 3 & $\mathrm{a}$ & 710 & 50 & $A D \mid 262-1285$ & AD $1220-1389$ \\
\hline GU-2162 & 8 & 3 & $a, b, d$ & 1150 & 70 & AD 777-982 & AD 680-1019 \\
\hline \multicolumn{8}{|c|}{ South Glendale } \\
\hline GU-2159 & 108 & Area 2 & $b, d$ & 540 & 50 & $A D$ I327-1427 & AD I297-|44| \\
\hline GU-2160 & 212 & Area 2 & b, c & 550 & 50 & $A D \mid 325-1424$ & AD $1280-1440$ \\
\hline
\end{tabular}

Table 50. Radiocarbon dates from marine shell. * $a=$ periwinkle; $b=$ limpet; $c=$ cockle; $d=$ razor

\section{I I.3 Towards a dating strategy}

The complexity of the larger sites was such that dating single events or structures would require a very large number of dates. It was, in consequence, decided to abandon the usual strategy of providing single dates for specific events and to try, rather, to provide a dating framework for each site by se- lecting samples which would date the depositional sequences, ie the Blocks, defined for each site. The dates of archaeologically significant events could then be arrived at by extrapolation. This strategy would also allow for the estimation of depositional rates for each Block which would help in their final interpretation. 


\begin{tabular}{|c|c|c|c|c|c|c|c|}
\hline \multirow[t]{2}{*}{ Lab No. } & \multirow{2}{*}{$\begin{array}{r}\text { Context } \\
\text { No. }\end{array}$} & \multirow[t]{2}{*}{ Block } & \multirow[t]{2}{*}{ Sample type } & \multirow[t]{2}{*}{ Date bp } & \multirow[t]{2}{*}{ SD } & \multicolumn{2}{|c|}{ Calibrated dates } \\
\hline & & & & & & I-sigma & 2-sigma \\
\hline \multicolumn{8}{|c|}{ Baleshare } \\
\hline GU-2554 & 146 & 15 & Hordeum sp. & 1970 & 80 & $92 B C-A D \mid 26$ & 197 BC-AD 226 \\
\hline GU-2555 & 42 & 2 & Bos sp. & 2260 & 80 & $40 \mathrm{I}-208 \mathrm{BC}$ & $511-117 \mathrm{BC}$ \\
\hline \multirow[t]{2}{*}{ GU-2558 } & 1.03 & 18 & Bos sp. & 2900 & 140 & 1370-903 BC & 1489-800 BC \\
\hline & $\& 139$ & 26 & & & & & \\
\hline GU-2556 & various & 22 & Bos sp. & 3360 & 80 & I743-3480 BC & I883-3409 BC \\
\hline \multicolumn{8}{|c|}{ Hornish Point } \\
\hline GU-2550 & various & 5 & Hordeum sp. & 2160 & 80 & $363-95 \mathrm{BC}$ & 400 BC-AD 2 \\
\hline GU-2549 & various & 19 & Hordeum sp. & 2090 & 50 & $200-48$ BC & $35 I B C-A D 21$ \\
\hline
\end{tabular}

Table 51. Radiocarbon dates from bone and carbonised seeds

Lab No. Block no. Date bp Pair? Group?

\begin{tabular}{lrllll} 
GU-1968 & 21 & $2045 \pm 50$ & & & Period III \\
GU-1975 & 24 & $2075 \pm 50$ & yes & yes & b \\
GU-1972 & 5 & $2085 \pm 50$ & yes & yes & ----- \\
GU-1964 & 6 & $2110 \pm 80$ & yes & yes & c \\
GU-1962 & 4 & $2155 \pm 50$ & yes & no & ----- \\
GU-1974 & 28 & $2210 \pm 50$ & yes & yes & b \\
GU-1960 & 2 & $2240 \pm 55$ & yes & yes & \\
GU-2166 & 11 & $2250 \pm 50$ & yes & yes & \\
GU-1970 & 19 & $2265 \pm 50$ & yes & yes & \\
GU-2165 & 11 & $2320 \pm 50$ & yes & no & ----- \\
GU-1963 & 15 & $2375 \pm 55$ & no & & a \\
GU-1961 & 1 & $2390 \pm 55$ & yes & & \\
& & & & & \\
\hline
\end{tabular}

\begin{tabular}{llllll} 
GU-1965 & 18 & $2740 \pm 60$ & no & & Period II \\
GU-197I & 26 & $2815 \pm 50$ & yes & yes & \\
GU-1973 & 27 & $2910 \pm 50$ & yes & no & \\
GU-1967 & 20 & $2970 \pm 65$ & yes & yes & \\
GU-1969 & 23 & $3030 \pm 50$ & yes & no & \\
\hline & & & & & \\
\hline GU-1966 & 22 & $3285 \pm 60$ & no & & Period I
\end{tabular}

Table 52. Baleshare. Pairwise analysis of the radiocarbon dates. NB: Phase IIIc consists of redeposited material

Should the dated networks prove internally consistent, ie consistent with the stratigraphy, we could be confident that the resolution of the dates was not hopelessly compromised by the variability in the ${ }^{14} \mathrm{C}$ content in the first millennium $\mathrm{BC}$, or rather, by its lack of variability over most of that millennium. Analysis of the chronological sequence of dates could also be used to try to distinguish between events and processes and to indicate the phasing of the sites.

It was decided to use sea shells to construct the dating frameworks for the deep sites, and to date carbonised cereal grains, which had been reliably identified, to provide an estimate of the scale of the reservoir effect on the shell dates. In an attempt to limit other variables, like the inter-specific differences noted by Huebbers (1978) in carbon isotope fixation, the shells of periwinkle were used exclusively for dating
Lab No. Block no. Date bp Pair? Group?

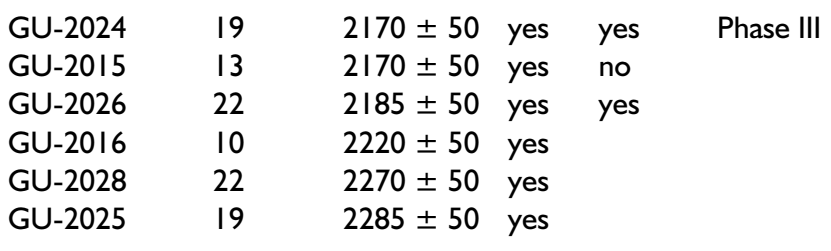

$\begin{array}{lrllll}\text { GU-2022 } & 7 & 2310 \pm 50 & \text { yes } & \text { no } & \text { Phase II } \\ \text { GU-2023 } & 8 & 2320 \pm 50 & \text { yes } & \text { yes } & \\ \text { GU-2021 } & 5 & 2325 \pm 50 & \text { yes } & \text { yes } & \\ \text { GU-2018 } & 12 & 2330 \pm 50 & \text { yes } & \text { yes } & \\ \text { GU-2017 } & 4 & 2335 \pm 50 & \text { yes } & \text { no } & \\ \text { GU-2019 } & 9 & 2345 \pm 50 & \text { yes } & \text { yes } & \\ \text { GU-2027 } & 26 & 2370 \pm 50 & \text { yes } & \text { yes } & \\ & & & & & \\ \text { GU-216I } & 27 & 2410 \pm 50 \text { yes } & \text { yes } & \text { Phase I } \\ \text { GU-2020 } & 1 & 2500 \pm 50 \text { yes } & \text { yes } & \end{array}$

Table 53. Hornish Point, Period II. Pairwise analysis of the radiocarbon dates

wherever sufficient of them survived. Where an adequate weight was not retrieved, limpet shells were added to the total, and, in the few cases where even these did not suffice, cockle shells were also added.

\section{I I.4 Results}

Tables 50 and 51 list the results of the radiocarbon dating programmes for seashell and other organics, respectively, for the sites of Balelone, Baleshare, Hornish Point, Newtonferry and South Glendale.

In the case of Balelone, no attempt was made to construct a dating framework. Preliminary dates from the earliest and latest strata on that site proved to span such a small period that radiocarbon dates of the intervening deposits would not be sufficiently precise to resolve between 


\begin{tabular}{|c|c|c|c|c|c|c|c|}
\hline Lab no. & date & SD & I3C & Lab No. & date & SD & 130 \\
\hline \multicolumn{8}{|l|}{ Baleshare } \\
\hline GU-1960 & 2240 & 55 & 1.54 & GU-2555 & 2260 & 80 & -22.5 \\
\hline GU-1963 & 2375 & 55 & 4.35 & GU-2554 & 1970 & 80 & -23.4 \\
\hline **⿻丷木 & 2780 & 50 & & GU-2558 & 2900 & 140 & -22.5 \\
\hline (GU-1965 & 2740 & 60 & (.36) & & & & \\
\hline (GU-197I & 2815 & 50 & $1.72)$ & & & & \\
\hline GU-1966 & 3285 & 60 & 2.12 & GU-2556 & 3360 & 80 & -26.4 \\
\hline \multicolumn{8}{|c|}{ Hornish Pt } \\
\hline **⿻丷木 & 2230 & 50 & & GU-2549 & 2090 & 50 & -24.6 \\
\hline (GU-20I5 & 2170 & 50 & I.30) & & & & \\
\hline (GU-2025 & 2285 & 50 & $0.95)$ & & & & \\
\hline *⿻丷木 & 2320 & 50 & & GU-2550 & 2160 & 80 & -23.9 \\
\hline (GU-202I & 2325 & 50 & I.17) & & & & \\
\hline (GU-2025 & 2285 & 50 & $0.95)$ & & & & \\
\hline
\end{tabular}

Table 54. Radiocarbon dates - the marine reservoir effect. ** indicates an interpolated date based on the pair of dates immediately below and their stratigraphic inter-relationships

$\begin{array}{lcccc}\text { Very rapid } & \text { Rapid } & \text { Average } & \text { Slow } & \text { Very slow } \\ 100(+) \mathrm{mm} / \mathrm{Ry} & 30 \mathrm{~mm} / \mathrm{Ry} & 20 \mathrm{~mm} / \mathrm{Ry} & 5-10 \mathrm{~mm} / \mathrm{Ry} & <5 \mathrm{~mm} / \mathrm{Ry}\end{array}$

Table 55. Approximate sedimentation rates, in mm per radiocarbon year (Ry), for Baleshar e and Hornish Point, based on radiocarbon determinations and the volumes of the excavated deposits

successive events. In any event, the extent of the first trial excavation at Balelone was so small and the results so tentative that the costs of a large dating framework would not have been justified.

In analysing the site chronologies of Baleshare and Hornish Point (Tables 52 and 53) the statistical procedures outlined by Long and Rippeteau (1974) were followed. The first hypothesis tested for each site was that all the dates represent separate estimates of the same age, ie that the accumulation of all the site deposits was a short lived process and that the dates represent a span of time which is not significant with respect to the precision of the analyses. The simplest test of this hypothesis is a test of the legitimacy of averaging all the dates using Chauvenet's rejection criterion for the exclusion of 'unaverageable' dates. This criterion suggests that dates with a probability of less than $1 / 2 \mathrm{n}$ of being included in the averaged distribution (group mean \pm weighted standard deviation) may not be averaged.

Even a brief examination of the spread of dates from these sites shows that this is a trivial hypothesis and the statistics readily confirm this. The dates must therefore represent a number of events, the intervals between some of which must be significant in respect of the precision of the analyses. The next approach was therefore to list the dates in simple chronological order and to test the legitimacy of averaging adjacent pairs. Where consecutive pairs cannot be averaged legitimately, the interval between them is significant with re- spect to the precision of the radiocarbon dating method. Thus, we can say that there is a significant hiatus in the depositional sequence at this point. This process divided the sequence for Baleshare into four distinct groups of Blocks which have been treated as the main Periods of the site.

Once defined by this means, each event may be tested for non-coaevalness which allows us '...to evaluate whether a series of seemingly close radiocarbon dates represent an instant of time, or rather a duration of time significant with respect to the precision of analyses' (Long \& Rippeteau 1974, 210).

Where a group of dates representing a single event, as defined above, are shown to represent a duration of time, there may well be archaeological grounds for dividing or subdividing the group. Similarly, archaeological grounds may exist for combining groups, but, in either event the duration of the events, and the gaps between successive events must be taken into account in the overall interpretation of the chronology.

\section{8. I I.5 Baleshare; chronology (refer to Tables 50 and 5 I for Lab Numbers)}

Period I

The first group consists of a single determination, $3285 \pm 60$ (GU-1966), for Block 22. This later Bronze Age Block is the earliest set of deposits investigated on the site, although there 


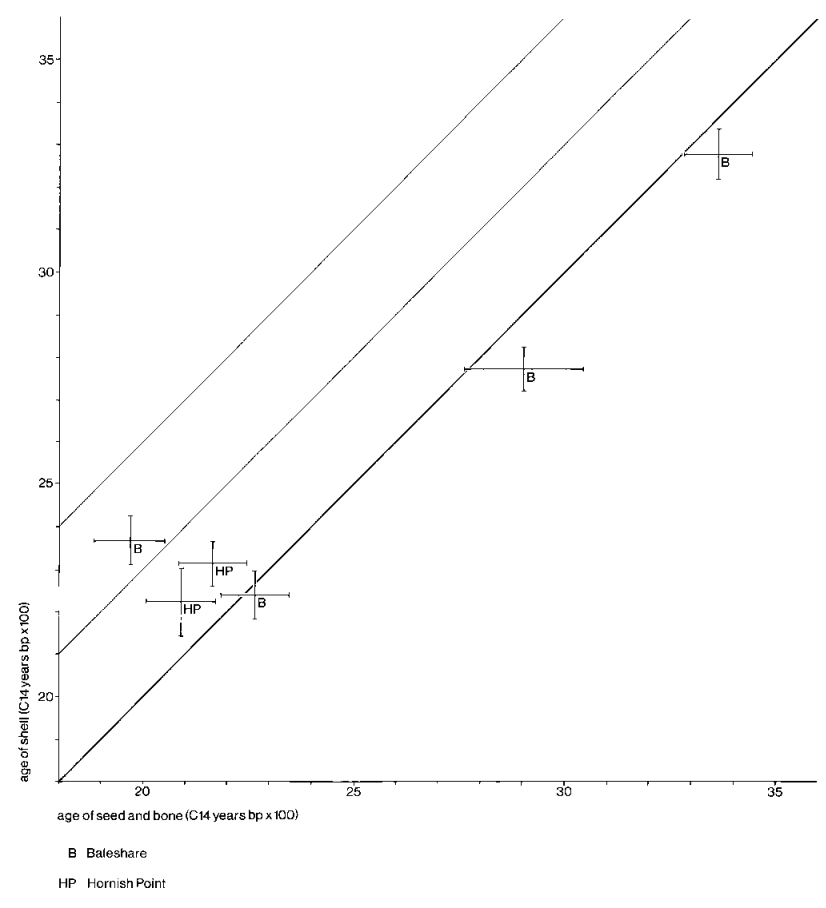

Figure 104. Calibration of the marine effect

are even earlier deposits beneath them. It constitutes the Period I excavated sequence for Baleshare.

\section{Period II}

The next group of determinations ranges from $3030 \pm 50$ (GU-1969) to $2740 \pm 60$ (GU-1965) and includes Blocks 23, 27, 20, 18 and 26, all dated. Block 17, undated, must also be included, on stratigraphic grounds. The inversion of the dates here (Block 26, dated to $2815 \pm 50$ [GU-1971], overlies Block 18, $2740 \pm 60$ [GU-1965]), is statistically without significance, as there are only 75 radiocarbon years between the determinations.

Block 25 is included in this phase, Phase 2, because of its similarities to Block 26, both are cultivation layers, and its differences from overlying Blocks, 16 and 15 which are both midden-site deposits.

Further analysis of the dates shows that Period II need not be further subdivided, on the grounds that all the dates it encompasses could be legitimately averaged together. This is hardly surprising, given that the four determinations involved span less than 200 years.

\section{Period III}

The determinations of the remainder of the Blocks follow each other in such close succession that it is legitimate to average each pair of dates, implying that the differences between them are not significant with respect to the precision of the analyses. Thus, Period III includes Blocks 15, 1, 19, 2, $28,11,24,5,21,4$ and 6 , all dated, and, on stratigraphic grounds, the following undated Blocks; 16, 9, 12, 10, 8, 7, 14 and 3.

Further analysis shows that Period III can be subdivided into three phases, IIIa, containing Blocks 16, 9, 15, 29 and 1; Phase IIIb, containing Blocks 19, 2, 12, 28, 10, 8, 7, 11, 14, 21, 5, 24, and 3; Phase IIIc containing Blocks 4 and 6 . The validity of these sub-divisions rests in part on the archaeolog- ical evidence. Were we to alter the order of analysis, from top-down to bottom-up, for example, the analysis would offer slightly different results.

\section{I I.6 Hornish Point; chronology}

The Hornish Point determinations were analysed in the same fashion as those from Baleshare but with rather different results. It transpired that all of the successive pairs of determinations from this site can, in fact be legitimately averaged together. Thus, from the radiocarbon dated deposits there is no evidence for any interval in the depositional sequence which is significant with respect to the precision of the analyses. The site is thus considered to be all of one period, lasting some 330 radiocarbon years, measured between the means. There are no clear statistical grounds for grouping the Blocks into phases and this has been done solely on the basis of their archaeological interpretations.

\section{I I.7 Newtonferry; chronology}

There are three dates from Newtonferry, two virtually identical dates calibrating to the thirteenth to fourteenth centuries and one to the Dark Age period between the late seventh and early eleventh centuries. The two medieval dates are consistent with the general character of the bulk of the deposits. These seem to comprise settlement debris and waste material. The context from which the Dark Age date is drawn lies at the base of the Block of medieval sediments. There is no $a$ priori reason to dismiss the radiocarbon date as aberrant but neither was any diagnostically Dark Age material retrieved from the context. Given the possibility that two local burials were of Norse origin (see Chapter 8.1), it is not inherently improbable that some Dark Age activity took place at the site. Whether this constituted settlement may be doubted, given the paucity of the dated remains. More probably, this may have simply been a temporary anchorage at the head of a sheltered bay.

\section{I I.8 South Glendale; chronology}

The radiocarbon dates from South Glendale indicate occupation in Area 2 sometime between the thirteenth and fifteenth centuries $\mathrm{AD}$. The closeness of the two determinations suggests that despite the lengthy spans indicated by the calibrated range the occupation was probably of a single period and also probably quite short. However, the finds of post-medieval reduced wares in the uncontexted spreads on the deflation surface indicates that further activity, perhaps not associated with occupation, persisted at the site. Its use as a ferry terminus for traffic to Barra and the small isles to the south would account for these later artefacts.

Although untested by radiocarbon dating it is important to recall past surface finds of Beaker shreds. The undated and stratigraphically lower activity in the midden deposits of Area 1 has been described above as 'of prehistoric character'. The stratified assemblage of fifty-five potsherds is essentially undiagnostic as is the flint assemblage. However, on balance these confirm the excavator's interpretation of the frag- 
mented and truncated remains as prehistoric, probably Early Bronze Age in date.

\section{I 2 CALIBRATING THE MARINE RESERVOIR EFFECT}

As noted above, the dating of these deep middens was undertaken using marine shell because it was ubiquitous (or relatively so) and allowed us to date the depositional sequence for the sites. A further set of ten samples of carbonised material or large mammal bone was submitted for dating in an attempt to quantify the scale of the marine reservoir effect. This effect should make dates from marine materials 'too old' by $405 \pm 40$ (Harkness 1983).

In the event, four of the samples failed to produce sufficient datable material and six dates were assayed; three of bone and one of carbonised seed from Baleshare and two of carbonised seed from Hornish Point (Table 51).

Ideally, the non-marine materials should have been selected from the contexts from which the shell dates were taken. However, this only proved possible with one of the samples from Baleshare. For the other four samples, material was selected from a stratigraphically close context or it was amalgamated from a number of such contexts. In the latter case we tried to ensure that the group of contexts selected lay between dated contexts which established that they had not been formed over a period of time which was significant in terms of the precision of radiocarbon dating. In such cases we estimated the Interpolated Date (Table 54) as the mean of the two dates whose source-contexts bracketed these newly sampled contexts.

The Blocks referred to in the tabulated data and below are groups of contexts, ie deposits, which are contiguous and which, it is believed, share a common formation process. It seems therefore, reasonable on archaeological grounds also, to average the dates that bracket them, or to interpolate between them on the basis of their mean sedimentation rates (Table 55).

The differences between the seashell and the bone and seed dates are presented in Table 54 and range from +121 to -405 years, ie the shell dates range from 121 years younger than expected to 405 years older than expected. This distribution is not what was expected on Harkness's model and the data were examined by a statistician to test the hypothesis that the differences between the determinations from the two classes of material (marine and terrestrial organics) are not significantly different from zero.

\section{I 2. I Statistical comparison of the radiocarbon dates from marine shell with those from terrestrial organic material}

\section{Scott}

The radiocarbon dates from Hornish Point and Baleshare were subjected to a Student's t-test to examine the significance of the differences between the radiocarbon dates obtained from marine shell and those from other organic materials, ie bone and carbonised barley. The results are presented in Figure 104.
The shell dates were matched with corresponding organic dates and the difference in age calculated (the standard deviations were not considered). A 95\% confidence interval was constructed for the average difference between the shell and bone dates. This interval $(-286,123)$ includes 0 , and thus we find that statistically there is no evidence of a difference between dates on the different materials.

There is a large spread in the results, the differences ranging between -400 years to 120 years. The variation between the Baleshare dates is greater, with the bone dates being older and the seed date being younger by 405 Rys, a difference of circa 425 Rys. In both the samples from Hornish Point the seed date is younger by approximately 160 years.

Although the sample size involved is small, it would appear that the differences between the samples is not significantly different from zero and secondly that while the shell dates may be up to 300 years 'too old', some may be up to 100 years 'too young'.

\section{8.|2.2 The archaeological implications of the seashell calibration}

Dr Scott's conclusion is rightly qualified by the small size of the sample on which it is based. Comparative dates from shell and terrestrial organics have been assayed from the site at St Boniface, Papa Westray, Orkney (Lowe 1998, 97). There the author simply applied the conventional correction for the marine reservoir effect (MRE) indicating perhaps that no reason had been encountered to do otherwise. Another comparative date is available from Dun Vulan where an auk skeleton was dated to $2330 \pm 60$ bp (AA-10498) and carbonised barley in the same layer was dated to $1905 \pm 45$ bp (AA-22911) (Parker-Pearson \& Sharples 1999, Table 9.1).

However, on the basis of the dates from the sites reported upon here, the validity of routinely applying Harkness's 405 \pm 40 correction factor must be questioned. We can be reasonably sure, for example, that the animal bone dates are free from MRE because their ${ }^{13} \mathrm{C}$ values are clearly those associated with terrestrial organisms (Table 54). It is generally agreed that molluscs selectively take up carbon isotopes and that, coincidentally, the differences in isotopic uptake just about cancels out the MRE. Australian researchers have shown that fossil carbonate, leached from geological deposits and concentrated in sheltered bays, affect the $14^{\mathrm{C}}$ dates of molluscs from those bays, creating 'errors' of over a millennium (Gillespie \& Polach 1976).

Drs G Cook of SURRC and A Dugmore of Edinburgh University and this writer have embarked on a research programme to explore this problem and its archaeological consequences. For now, the interpretation of the radiocarbon determinations from marine or mixed contexts must be treated cautiously. Whatever the uncertainties created by the marine reservoir effect, the relative sequence of the seashell radiocarbon dates from both sites is remarkably consistent.

\section{Baleshare; internal consistency of the chronology}

At Baleshare, two apparent inversions have been noted. Block 18 underlies Block 26 but postdates it by 75 radiocarbon years (Ry). The difference here is not statistically significant. Similarly, Block 24 underlies but is younger than Block 5, by a mere 10 Rys. However, Blocks 4 and 6 are apparently 'too 
old' by up to 110 Rys. In these cases the differences partly relate to the fact that these samples came from the top of conflation horizons. In practice both of these dates should be discounted.

\section{Hornish Point; internal consistency of the chronology}

The sequence at Hornish Point is much shorter in overall duration than that at Baleshare; 330 Rys as compared to 1240 Rys. Thus, given that contiguous separate deposits are more nearly contemporaneous there is a higher incidence of trivial reversals in the site's radiocarbon chronology. Block 26 is stratigraphically lower than Block 27 but is 40 Rys younger than it. The implication to be taken here is that the two Blocks are very nearly contemporaneous.

The $2 \mathrm{~m}$ deep series of deposits revealed in the southern half of the site were formed, on the radiocarbon evidence, over a period of, at most, 165 Rys. It subsumes two trivial dating inversions: Block 7 underlies but is 10 Rys younger than Block 8 while Block 8 underlies but is 15 Rys younger than Block 4. It is not impossible that these deposits have been disturbed, ie dug out from the area to the north into which the wheelhouses have been inserted, but the radiocarbon evidence cannot be cited in support of this possibility because the differences between the dates are too small to be significant with respect to the precision of the analyses.

Similarly, there are two dates each for Blocks 19 and 22 and the means of these pairs of dates are identical. Here again it is the near contemporaneity of the dumped deposits of Block 19 with the use of the structure of Block 22 which seems indicated.

\section{Other chronological indicators}

The use of artefacts in the dating of archaeological contexts is central to traditional archaeological methodology. However, in Scotland this is a tradition more honoured in the breach than the observance for studies of the greater part of the nation's prehistory. The gradual breakdown of typological dating in archaeology in general (partly as a consequence of the emerging radiocarbon chronologies) is exacerbated in Scotland by the paucity of typologically dateable material, in the first place, and the possible persistence of archaic features in that which does occur. At any rate, no suitable chronologically sensitive material can be shown to exist in these sites and it is probable that in the provision of radiometrically-dated, well-stratified assemblages of materials this project may contribute more to the study of the artefacts than the latter are likely to contribute to the site chronologies.

Nonetheless, the principal element of the artefact assemblage, the pottery, was subjected to a series of studies de- signed to explore its value as a chronological indicator. Firstly, an attribute analysis of the assemblage was undertaken and then various groupings of the assemblage based on a range of attributes were examined. The groups based on fabric and firing technology are those closest to traditional archaeological taxonomies and these are discussed further elsewhere in this volume (Chapter 10). Sherds of virtually all types occurred in contexts of all ages. While this was perhaps not surprising at Hornish Point, given the short duration of the site, it was certainly surprising at Baleshare where some 1400 Rys separate the earliest and latest features.

Lest the problem here was caused by the use of an analytical device which is too mechanistic, a traditional analysis of the assemblage was commissioned from Dr A Lane. This was based on a study of the rim, base and decorated sherds and interpreted in the light of Dr Lane's (1990) typology for later prehistoric pottery in the Hebrides. Like the first analysis, Dr Lane's was undertaken in ignorance of the stratigraphic record and like the first study it also failed the test for chronological sensitivity, ie pottery of all the types recognised by the analysts were found spread throughout the stratigraphic sequence (Chapter 10).

Finally, an analysis of the assemblages which was undertaken in full knowledge of the stratigraphic sequence produced groupings of sherd types which appear to be chronologically significant. However, the writer is convinced by this sequence of analyses that the typologies of Hebridean pottery, of all periods, are subjective constructs that are chronologically unreliable.

\section{8.| 2.3 Depositional rates}

The close dating of the deposits facilitates at least a rough determination of sedimentation rates over the excavated deposits. This is calculable in litres per annum for some areas of the excavated deposits. However, this would be a spurious accuracy, not least because we do not know how far back into the surviving deposits the individual contexts or Blocks may extend, ie we do not know how representative of the full deposits are the portions sampled in this exercise. Radiocarbon determinations for the tops and bottoms of sequences of deposits do at least provide an indication of the duration of the period over which they accumulated and this can be expressed in broad classes, five of which are used here, viz very rapid, rapid, average, slowly and very slowly. The operational definitions of these rates are set out in Table 55 . 


\section{CHAPTER I8: INTERPRETATION AND DISCUSSION}

\section{PART 4: SITE INTERPRETATIONS}

The interpretations offered here are based on the conclusions reached for each Block of strata and are couched in terms of the human activities, and where relevant the natural processes, which have contributed to the formation of these deposit groups. These interpretations are expressed solely in terms of the evidence from the sites themselves. Inter site comparanda and the wider implications of these interpretations are considered in Part 5.

The Blocks in each site are discussed in what is believed to be the order of their deposition, from earliest to most recent. The following should perhaps be read with the site descriptions in Volume 1 alongside.

\section{I 3 BALESHARE}

\subsection{Period I}

\section{Block 22}

The conclusion that this very extensive deposit $(300 \times 100$ $\times 1 \mathrm{~m})$ is a cultivated soil can be accepted with confidence. The presence in it of ard marks, at different levels throughout the deposit, suggest that it was an A-horizon being progressively deepened, mainly by wind blown sand deposition. Capture and retention of the sand was, no doubt, helped by the inclusion in the soil of manure. Indeed, without the organics from this manure the soil would not have been cultivable in any case. The anthropic materials included with the manure are typical of domestic refuse.

The distribution of pot-sherd sizes indicates that ploughing was continued over a relatively lengthy period, during which manuring continued, ie while many sherds were reduced to small fragments the addition of new material from the manure ensured that small numbers of larger sherds also survived. Given that the viability of the soil depended almost completely on the materials added by man, it is not unreasonable to view this as a plaggen-, or man-made-soil.

Coring revealed what has been interpreted as a settlement nucleus in the south-east of the cored deposit. It is noteworthy that, discounting the unknown volume of the deposit removed by the sea, the settlement drew upon at least three hectares of arable land and was capable of sustaining this with manures, implying that livestock were relatively abundant and probably seasonally confined, facilitating the accumulation of their manure.

\section{I 3.2 Period II}

Following a period of abandonment whose duration was roughly 200 radiocarbon years, the deposits of the next phase were formed. These form Blocks 23, 20, 27, 18, 26 and 25 . The excavated tapestry did not reveal any structures associated with this period. However, Block 23 is separated from the other Blocks of this period by a deep ditch (Figure 23). The walls of the structure comprising Block 8 sit within this ditch, but at a relatively high level. It is not impossible, on the available evidence, that the ditch forms part of the activities of this period and the differences between the deep and highly stratified deposits on its north side and the single Block on its south side suggest that some significant demarcation of activities occurred at this point. If the ditch represents that demarcation, then the deposits of Block 9, the primary infilling of the ditch (Figure 24) probably belong in this period also but, on the available evidence it is not possible to confidently attribute Block 9 to either Period. It is therefore treated separately below.

The Blocks in this period fall into two groups on the basis of stratigraphy and of their constituents. The lower Blocks, 20,23 , and 27 were all interpreted in the field as windblown sands but proved to contain modest amounts of anthropic materials giving them IHI values of 7,000, 15,000 and 13,000 respectively. These contrast with the higher IHI values, ranging from 23,500 to 36,500 returned from the contexts of the stratigraphically higher group of Blocks.

\section{Reoccupation and cultivation of marginal windblown sands}

Post-excavation analyses suggest that Blocks 20, 23, and 27 were initially deposits of windblown sand, which were cultivated, and into which a restricted range of materials, in relatively small amounts, was introduced during manuring from farmyard middens. The condition of this material, particularly the potsherds, is such as to suggest that the material had already been reworked and redeposited before it became included in these Blocks. These then appear to represent an initial phase of cultivation of wind-blown sands which had accumulated above the Period I deposits. The low IHI values, and the snail evidence both suggest that this cultivation was intermittent and probably sited at some distance from the associated settlement. Peak sedimentation rates here are almost $2 \mathrm{~m}$ of deposits formed in a period of 120 Rys $(16.7 \mathrm{~mm} / \mathrm{Ry})$. However, half of this figure would be more representative of the bulk of the deposits.

\section{Dumping and cultivation in the vicinity of settlemen $t$}

The stratigraphically earliest of these Blocks, 17, comprised a set of dumped deposits rich in burnt material. The high degree of heterogeneity in the contexts which comprise this Block and the richness, variability and condition of their contents suggest that it was a primary dump. It seems reasonable to assume that the structures or activities with which it was associated were sited nearby.

The overlying Blocks, 18, 26 and 25, seem also to have originated as dumped deposits but, unlike Block 17, these were subsequently cultivated. The balance of the evidence suggests that this cultivation was short lived. The existence of three distinct Blocks encourages us to suspect that cultivation was also intermittent because continuous cultivation would have resulted in a deepened A-horizon without internal horizonation.

Sedimentation rates are harder to assess for this group of Blocks because of the inversion of the dates of Blocks 26 and 18. If, however, we take the maximum duration represented in the radiocarbon dates and the maximum depth of deposits formed in the period, some $1.2 \mathrm{~m}$ of deposits formed in 170 Rys, ie just under $10 \mathrm{~mm}$ per annum $(70 \mathrm{~mm} / \mathrm{Ry})$. 


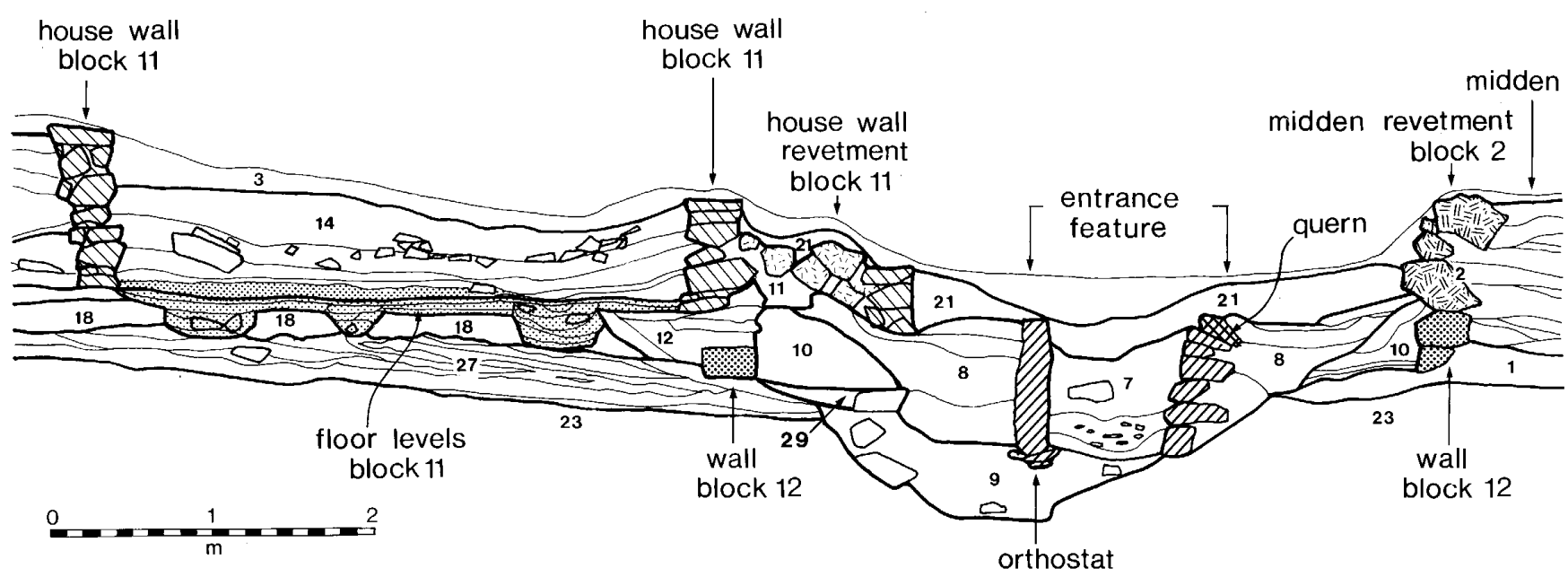

Figure 105. The major structural elements at Baleshare

\section{Summary}

Somewhat more than two centuries after the abandonment of the earliest excavated deposits, Period II opened with the intermittent cultivation of what were essentially wind-blown sands with some degree of manuring. The paucity of anthropogenic materials, indicative of low levels of manuring suggest that this cultivation was relatively small scale and distant from settlement. The area was accreting windblown sand throughout the period at relatively high sedimentation rates. We may, therefore, envisage this activity as the cultivation of areas of relatively open or lightly grass-covered sands on the margins of a settlement area.

With no break in deposition within Period II sufficiently lengthy to be resolved with the precision of the radiocarbon method, the settlement seems to have moved nearer to the excavated locus because there is an abrupt transition to dumped deposition of settlement detritus. This was also cultivated, intermittently, as it accumulated.

There are conflicts in the snail evidence for the deposits of this phase of activity which can be explained by consideration of the difference between the substance of deposits and their surfaces. A dumped deposit can contain the snail assemblage representative of its primary formation locus, ie material from a byre floor can contain the snails characteristic of that environment. Once dumped however, it will develop a grassland cover on its upper surface and acquire the snails appropriate to that environment. The admixture of the two assemblages over a period of time can lead to a misleading or uninterpretable pseudo-assemblage. When the dumped deposit consists primarily of household or other detritus which is free of snails, or nearly so, only the grassland assemblage formed on its surface will be recovered from the deposit. This will be equally misleading in its import for the deposit.

Period II, then, is represented by marginal cultivation associated with an initial recolonisation of the abandoned site followed by dumping and subsequent cultivation of materials in the vicinity of a settlement, which in the later phase has moved closer to the excavated area. This settlement must be assumed to have been lost to the sea because the coring did not reveal its presence inland.

\section{I8.| 3.3 Period III}

The chronological analysis suggests that Period III can be subdivided into three phases, IIIa, containing Blocks 16, 15, and 1; Phase IIIb, containing Blocks 19, 2, 12, 28, 10, 8, 7, 11, 14, 21, 5, 24, and 3; Phase IIIc containing Blocks 4 and 6 .

\section{Introduction}

The hiatus between Periods II and III extended over a minimum period of 350 radiocarbon years and yet, when it ended the differences in deposition between the north and south ends of the site mirror the differences evidenced in the Period II deposits, at least during the earliest phase, IIIa.

Phase IIla

The deposits of this phase comprise Blocks 1, 16 and 15 . Block 1 lies to the south of the ditch feature (Block 9) and with ard marks in its base it has been interpreted as a cultivated deposit. It is shallow, 0.10 to $0.30 \mathrm{~m}$ deep, and relatively extensive but it contains little in the way of anthropogenic material. Its IHI value of 5,000 is among the lowest from the site. The deposit is a dark brown loamy sand and the colour and texture suggest the possibility that this is a cultivated A-horizon that originally formed the surface of the Period II deposits. The paucity of anthropogenic materials suggests that, like the earliest deposits of Period II, Block 1 was a cultivated plot at some distance from its associated settlement.

To the north of the Block 9 Ditch the other two sets of deposits of this Phase, Blocks 16 and 15, are both midden-site deposits, ie deposits which had formed in the immediate vicinity of a settlement. Their southern end is truncated by the wall of the structure in Block 11 but this structure cannot be the source of the materials they contain. It survives as a segment of a simple circular hut created by building a stone lining inside a circular space cut into pre-existing deposits (Figures $25 \& 26$ ). The wall cannot have stood on its own and therefore, the use of this structure postdates the deposits of Blocks 16 and 15, into which it was cut. However, among the lowest of the deposits of Block 16, [252] consists of a spread of stones which could represent structural debris from the construction or destruction of a hut, which preceded that in Block 11. This is consistent with the radiocarbon dating 
evidence and could explain the nature of the differences between the northern and southern deposits of this phase. The deposits of Block 16 are strongly heterogeneous, lack ard marks (although, on the snail evidence they may have been briefly and infrequently cultivated) and contain large volumes of a wide range of materials (mean IHI value of 29,000). Thus, they have the characteristics of deposits accumulating in the immediate vicinity of a settlement structure.

The deposits of Block 15 are of very much the same character as those of Block 16, which they overly, but with an IHI value of 55,000 for the soil deposits, are if anything even richer. The excavated strip of deposits was crossed by some five ditch-like features whose nature and function could not be explored in the small exposure. None the less, their occurrence reinforces the interpretation that these represent deposits formed close to active settlements.

That the settlement with which these Blocks should be associated is missing does not weaken the interpretation offered here, even though it is freely admitted that the indications contained in [252] are far from conclusive evidence for a precursor to the hut in Block 11. If future excavations discount this possibility we should simply have to accept that the associated settlement lay to the seaward side of the excavated strip and is now lost forever.

Sedimentation rates for these deposits are extremely high. The difference between the earliest and latest radiocarbon dates is a mere 15 Rys during which a minimum of $0.50 \mathrm{~m}$ and a maximum of $1.55 \mathrm{~m}$ of deposits were laid down, implying sedimentation rates of 30-100 $\mathrm{mm}$ per annum.

\section{Phase IIlb}

Phase IIIb encompasses the Blocks of strata and walling associated with the group of structures close to the centre of the site (Figure 105). The close stratigraphic control afforded by tapestry excavation allowed us to unravel a sequence of at least three structures, of which only one was excavated to any extent. To the north of this complex, the deposits of this phase comprise a single midden-site deposit and a terminal conflation horizon. To the south, however, a series of Blocks of deeply stratified deposits were noted. The description which follows starts with the structures and deals then with the deposits to the south and north respectively.

Structure 1; The evidence for the existence of the structure referred to here consists of the ditch (Block 9) and the revetted space over it formed by the walls of Block 12 (Figure 105). Block 9 was filled with virtually sterile sand and over this an A-Horizon had formed (Block 29). Over this windblown sand (Block 10) accumulated between drystone walls (Block 12). These seem to mark a higher level extension to the structure, possibly revetting the deeper sediments to keep them from eroding down into the passageway, which it is assumed, ran along the ditch. Evidence for the actual structure itself has been removed by the insertion of Structure 2 . The upper levels of the revetment walls (Block 12) have been slighted by and underlie Structure 4.

Structure 2; The evidence for this structure consists of a pair of parallel walls erected in a recut of the earlier ditch and revetted with redeposited sand (Block 8). The walls extend into the sand cliff and make between them a passage some $0.70 \mathrm{~m}$ wide and $0.90 \mathrm{~m}$ high (Figure 105). The outer face of the northern is demarcated by an orthostat and very slight signs of a socket at the foot of the corresponding position on the southern wall suggest that an orthostat brought the latter to a fair face also. This suggests that these are the outer ends of an entrance passage leading into the structure that is still preserved beneath the sand, or was when these excavations took place. There was no evidence for the roofing of this passage. Rather the space between the walls had been used as a primary dump, presumably after the abandonment of the structure.

The upper levels of the walls and the, by now infilled, passage were covered in a deposit of windblown sand which contains very little anthropic material. It is, in effect sterile. The revetment to the deposits of Block 2 and that found partly underlying the south wall of Structure 3 appear to be upper level revetments for this structure.

Structure 3; Only the rear part of this structure survived (Block 11), consisting of a chord of about one third of the area of the structure, assuming that it was originally circular, or roughly so (Figure 105). Its wall, one stone thick, was no more than a revetment to the deposits into which it had been cut. It survived to a height of $0.95 \mathrm{~m}$. It contained three distinct floor levels, separated from each other by clean sand. Pits were found in each of the floor levels that contained burnt sand and carbonised peat and spreads of peat ash were also noted. No clear evidence was recovered for the function of this structure. It is assumed that it formed part of a domestic residence because the pit contents suggest that fires had been lit within it and because the floor had been kept clean.

\section{Phase IIlc}

The Blocks of this phase are both problematical. Block 4 is a human interment and the radiocarbon dated material associated with it is almost certainly derived. Block 6 is largely windblown sand in a conflation horizon and the radiocarbon-dated material is clearly derived from some other source. Whatever the original sources of the dated materials, the sub-block is of interest because, on the radiocarbon evidence, it bears witness to sediments that have been removed from this part of the site.

\section{14 HORNISH POINT}

\subsection{Period I}

The face of the site exposed by coastal erosion at Hornish Point was found to have relatively extensive spreads of masonry and structures lying in and in front of it. The examination of these was continued only to the current beach level but it was perfectly clear that structures and associated deposits underlie the current beach. The title 'Period I' has been applied to these, unexcavated structures to emphasise the fact that the chronological start point for the excavated sequence is an arbitrary one. 


\section{I8. I4.2 Period II, Phase I}

Block I

The earliest deposits excavated at Hornish Point are those of Block 1, dating to $2500 \pm 50$ bp (GU-2020). It consisted of a series of deposits, dumped during a period of natural sand accumulation, and intermittently cultivated. The rate of natural sand accumulation was high, as the evidence from the snail analysis and the dilution of the anthropic inputs indicate. Some effort may have been made to contain the southward spread of these deposits by a revetment wall (Figure 45). However, it is not impossible that this wall (Block 7) was later associated with the deposits of Blocks 2, 3 and 8. The scale and character of the Block 1 deposits suggest that it was an infield area, receiving regular supplies of domestic refuse, albeit somewhat diluted by the accretion of windblown sand.

No clear evidence of the structures associated with this cultivation episode was recovered in the excavation. It is possible that these structures lay before the excavated face, and are lost to coastal erosion or lie behind the face and have yet to suffer that fate. Structural remains were noted beneath those excavated on the northern side of the site and it is most probably among these that we might seek the settlement associated with this phase of cultivation.

\section{I8.14.3 Phases II to IV - summary}

\section{Introduction}

Some 130 Rys intervened before Block 26, a cultivated deposit, was formed at the northern end of the site. Dated to $2370 \pm 50 \mathrm{bp}$ (GU-2027), this is not significantly different from the initial dates from the deeply stratified series of deposits that comprise the site's southern end. This series covers the radiocarbon period $2325 \pm 50 \mathrm{bp}$ (Block 5) to 2170 \pm 50 (Block 13), a span of some 140 Rys.

The structures of the northern end cover a similar span, viz $2370 \pm 50 \mathrm{bp}$ (Block 26 forming against and over the structure of Block 23) and $2230 \mathrm{bp}$ (the average of the four dates from Blocks 19 and 22), a span of 140 Rys. However, there is an hiatus in the sequence of dates from the structures, which is significant with respect to the precision of the analyses and which is not mirrored in the soft deposits at the south end. This is the interval between $2410 \pm 50$ (Block 27) and the mean date of 2230 , returned from the structures of Blocks 19 and 22.

\subsubsection{Phase II}

Blocks 2, 3, 5, 7, 8, 6, 4, 9, 23, 24 and 25

The first eight Blocks at the south end of the site (Blocks 2, 3, $5,7,8,6,4$ and 9) have returned five radiocarbon dates the means of which cover a span of only 35 Rys. This short sequence is replete with chronological inversions but, given its short duration, these are of no statistical significance. Rather, the general implication must be that this substantial set of deposits was formed over a period too short for the dates of its component parts to be resolved from each other, given the precision of the radiocarbon method. It is probably safer to consider that these deposits formed over a very short period of time indeed, the best estimate of which is provided by the mean of the five determinations, viz $2327 \pm 22 \mathrm{bp}$.

The wheelhouse structure of Block 23 (Figures $60 \& 61$ ) is contemporary with or slightly earlier than the deposits of Block 26. In practice it appears cut into the lower deposits of that Block and parts of its walling are overlain by the uppermost deposits. Block 23 is also overlain by the masonry structure and floor levels of Block 27 (Figure 66). Blocks 26 and 27 are dated to $2370 \pm 50$ and $2410 \pm 50$ respectively; an inversion of the observed stratification but one covering only a period of 40 Rys. It is not unreasonable to suggest that all three deposits are approximately contemporaneous, ie that they occurred over a time span too short to be resolved by the radiocarbon method. Making this assumption, we shall represent the approximate date of these events by the mean of the two radiocarbon determinations, viz $2390 \pm 50 \mathrm{bp}$.

The structural fragments identified in Blocks 24 and 25 (Figures 62-64) were in situ when the deposits of Block 4 accumulated against Block 24, or, alternatively, the Block 24 structure was cut into the deposits of Block 4. However, the surviving wall head of Block 24 was overlain by the deposits of Block 9, the uppermost Block of the lower sequence. The structures in Blocks 24, 25 and 23 are infilled with Blocks 16,17 and 19, respectively, and all of these are dumped deposits of one sort or another; Block 16 is structural debris, Block 17, rubble and midden-site deposits and Block 19, dumped deposits. All of these factors suggest that the structures of Blocks 24, 25 and 23 were in contemporaneous use or in use over a period of time too short to be resolved by the radiocarbon method.

While the radiocarbon determinations certainly do not prove the case, it is arguable on the basis of the assumptions made above that the deposits formed in Blocks 2, 3, 5, 7, 8, 6, 4 and 9 were formed while the wheelhouse of Block 23 and the associated structures of Blocks 24 and 25 were occupied and the deposits were formed, in part, of materials dumped from those sources.

\section{I4.5 Phase III}

\section{Blocks 15/18, 16, 17, 19, 21 and 22}

The large wheelhouse of Block 15/18 (Figure 54) overlay and masked the masonry of Block 24. Its chronological position can only be inferred because of its distance from the recorded face and the major rubble dump which separated it therefrom. It is assumed here that the rubble infill between the wheelhouse and the recorded face is contemporaneous with the other major rubble and dump infills of Blocks 16, 17 and 19. The infill of boulders behind the Block $15 / 18$ structure are integral to its stability and from this we deduce that this structure is contemporaneous with the infilling of the abandoned structures of Period 2. One of these infills, Block 16, subsumes part of Block 9, the uppermost of the first series of soil deposits on the south side of the site. In so far as this can be treated as a synchronic event, it implies that Structure 5 probably dates to the end of the first series of southern deposits.

There is an apparent hiatus of about 100 Rys between the first and second series of soil deposits on the south side of the site, between say 2327 (the mean of the first series) and $2220 \pm 50 \mathrm{bp}$, the earliest of the dates from the second se- 
ries. However, the mean of the two dates from the Block 19 infill is 2227 while that of the two dates from Structure 6, cut into Block 19 is also 2227. Clearly then, the sequence of events which comprised the infilling of the Period 2 structures and the erection of Structures 5 and 6 all occurred over a period of time too short to be resolved by the radiocarbon method. The stratigraphic and radiocarbon evidence then suggest that Structures 5 and 6 are roughly contemporaneous and that the materials recovered from the infill deposits came, at least in part from activities associated with the erection and subsequent occupation of these structures. Structure 6 , Block 22 may have been associated with, or even the source of the undated dumped deposits of Block 21. At any rate these deposits are prehistoric in their associations and are not associated with the post-medieval blackhouse, Block 20 (Figures $56 \& 57$ ).

\section{I4.6 Phase IV}

\section{Blocks $10,11,12$ and 13}

The upper series of deposits on the south of the site comprise Blocks 10, 11, 12 and 13, and the stone wall of Block 14 which seems to have revetted the northern end of the Block 10 and lower Block 12 deposits. Two radiocarbon dates suggest that these deposits formed over a span of only 50 Rys, ie over a span to short to be resolved by the radiocarbon method. The date for these deposits are later, not significantly later than the dates from Structure 6 in Block 22 from which they may have derived, albeit that they are removed from it by the greater part of the length of the site. It is not improbable that they were formed in association with some further structure, possibly that whose presence can be deduced from the shallow depression in the current ground surface some short distance inland from the excavated area.

\section{I4.7 Summary of the prehistoric sequence at Hornish Point}

The radiocarbon dates from Hornish Point form such a coherent sequence when considered simply as a numerical progression regardless of the events they represent, that their subdivision into Phases seems folly. However, the stratigraphic evidence, taken in conjunction with the dates, clearly indicates a sequence of main events, construction, abandon- ment, infilling and renewed construction of buildings and the successive deposition of associated soils. Even in the one structure of which sufficient remained to facilitate its analysis, Structure 5 (Blocks 15 and 18), it was clear that this incorporated elements of earlier structures and had itself been considerably modified during its use, albeit that the period of its use was quite short. Thus, we have stratigraphic and structural heterogeneity within a broadly homogeneous chronological framework. This suggests that settlement on this site may have been truly continuous.

In particular, the subdivision of the soils at the south end is relatively arbitrary. All were formed over a very short time and all comprised varying combinations of domestic refuse and windblown sand which were intermittently cultivated. This succession of surfaces would have been highly fertile because of their constant manuring with organic refuse. They could have supported cereal growing or may have been a kitchen garden plot supporting other vegetables.

At Hornish Point then, we appear to have had an early group of structures (Period I) which were unexplored, followed by a group of wheelhouse structures and associated dumped and cultivated deposits (Period II, Phase I), followed, in turn by a further group of wheelhouse structures and associated cultivation areas (Phase II), and a further set of cultivated deposits with which further but unobserved structures were probably associated (Phase III). Settlement on the site was probably continuous for a period of some 300 radiocarbon years.

\section{I4.8 The post-medieval blackhouse}

\section{Blocks 20 and 31}

A blackhouse of characteristic Lewisian form had been cut into the settlement mound at its northern end (Figure 57). The interior did not contain any structural debris which suggests that its roof had been removed and any useful fixtures or fittings stripped out at the time of its abandonment. The primary butchering waste from a sheep was found among the infill deposits. This use of the sheltered space provided by an abandoned building for aesthetically unacceptable activities like butchery and waste disposal has many parallels among the contexts from both Hornish Point and Baleshare and, indeed, from prehistoric sites in general. 
CHAPTER I8: INTERPRETATION AND DISCUSSION

\section{PART 5: THE PHYSICAL ARCHAEOLOGY OF THE SITES}

\subsection{STRUCTURES}

\subsection{Prehistoric structures}

\section{Baleshare}

The stone-built structures of Baleshare comprised:

i) Block 12; two revetment walls (Figure 27), dated to the period between $2260 \pm 80 \mathrm{BP}$ (GU-2555; an animal bone date from Block 2) and $2250 \pm 50 \mathrm{BP}$ (GU-2166; the shell date from Block 11).

ii) Block 8; subsequently, within the same interval, two walls of an entrance passage were inserted between these revetment walls (Figure 23).

iii) Block 11; finally, a house was dug into the deposits north of the northern revetment wall and partly overlying the latter (Figures $25 \& 26$ ). The abandonment of the house is not closely dated, but it underlies Block 6 , dated to $2110 \pm 80 \mathrm{BP}$ (GU-1964).

Block 12: the revetment walls; It has been argued elsewhere that the revetment walls may have been a constructional device used in the building of the structure for which Block 8 provided an entrance.

Block 8: the entrance feature; This feature, it has been argued, is the entrance to a structure, possibly an aisled- or wheel-house. In the absence of further excavation little more can be said about it but the orthostats used to define the entrance terminals speak of some measure of architectural pretension.

Block 11: the round house; The only structure of which sufficient was exposed to characterise it, Block 11, seems to have been a simple round house, dug into pre-existing midden deposits. It did not contain any evidence for radial segmentation and is not in the wheelhouse tradition.

It contained a series of apparent floor levels in each of which pits had been dug. Carbonised peat formed a large component of the fills of these pits, especially of the pits of the first floor. The complete body of a neonatal lamb was buried in Pit [152], also in the first floor, together with part of a second neonatal lamb. This, together with the unusually high volumes of carbonised plant remains form the pits, and the absence of a hearth setting, suggests that this structure may have had a specialised function and was probably not a simple domestic structure.

If roofed, and no evidence for its roofing has been observed, it could have served as a smoke-house for smoking meat and fish. Open to the elements, it could have served as an animal pen, perhaps as a lambing stall. However, the clarity of the fragile layers of the floor levels militates against the latter suggestion because trample by animals would have greatly disturbed the sandy surfaces. Indeed, the clarity of their boundaries suggests that the layers may be dumped de- posits with sand introduced either naturally or, more probably, to cover up stinking refuse.

\section{Duration of use}

Determining the duration of use of the structures is hampered by the anomalous shell date from the house floor of Block 11. If, instead, we take the animal bone date from this floor, $2260 \pm 80 \mathrm{BP}$ (GU-2555) and the date of $2240 \pm 55$ BP (GU-1960), from the midden-site deposits immediately underlying the revetment walls of Block 12, clearly the construction phase at Baleshare is of very short duration. These elements were built, used and abandoned in a period of time too short to be resolved by the radiocarbon method, even allowing for the fact that Block 11 was built after Block 12 had, itself, been abandoned.

\section{Hornish Point}

Structures 1, 2 and 3 (Blocks 23, 27 and 24 respectively) were the earliest structures revealed at Hornish Point, but they all overlay further structures and deposits.

Structure 1; Structure 1 (Figures $56 \& 57$ ) was erected after the deposits of Block 26 had begun to form, but before the dated context, [F339] had been laid down. This context was dated to $2370 \pm 50 \mathrm{bp}$ (GU-2027) and it provides a terminus ante quem for Structure 1. However, the structure cannot pre-date [339] by any significant interval given the rapid sedimentation of this site, and the coherence of Block 26. Thus Structure 1 can be said to date from roughly $2370 \pm 50$ BP (GU-2027).

Structure 1 is a radially segmented house, roughly half of which was uncovered. It contained four radial piers, three of them abutting the encircling wallface, the fourth standing free of it in its lower courses and keyed into it by a massive lintel about $1 \mathrm{~m}$ above the apparent floor level. The encircling wallface, which was one stone thick, was built from large slabs and was slightly corbelled, inwards. This corbelling was most probably employed for its resistance to the pressure of the surrounding deposits; the so-called 'horizontal arch' effect (Barber 1992). The internal diameter of the house, at floor level, was $7.5 \mathrm{~m}$. This was a wheelhouse, one of whose piers has an aisle, separating it from the enclosing wall.

Structure 2; A drain running south-west from Structure 1 was incorporated into and blocked off by the wall of Structure 2. This implies that Structure 2 (Block 27) was built after Structure 1 had ceased to require a drain to assist its functioning. However, both structures could have overlapped in their use, or even been largely contemporaneous; Structure 1 functioning without its drain.

Only a fragment of Structure 2 survives, comprising an arc of walling, the circuit of which indicates a building roughly $8 \mathrm{~m}$ in diameter (Figure 66). It may have been part of a radially segmented structure but the evidence for its original form has been removed by coastal erosion. On balance, this was probably a wheelhouse also.

Structure 3; Structure 3 (Block 24) overlay Structure 2 and like the latter was fragmentary, indeed so ruinous is it that it is not possible to say whether it comprises parts of more than one building (Figure 62). Structure 3 is overlain by the structural debris of Block 16 and by the deposits of Block 4, the 


\begin{tabular}{|c|c|c|c|c|c|c|c|}
\hline \multirow{2}{*}{\multicolumn{2}{|c|}{ Site/structure Structure type }} & \multirow[t]{2}{*}{ TAQ (BP) } & \multirow[t]{2}{*}{ TPQ (BP) } & \multirow[t]{2}{*}{ Probable } & \multicolumn{2}{|c|}{ Calibrated dates } & \multirow{2}{*}{$\begin{array}{c}\text { MRE-adjusted } \\
\text { @ 2-sigma }\end{array}$} \\
\hline & & & & & I-sigma & 2-sigma & \\
\hline \multicolumn{8}{|l|}{ Baleshare } \\
\hline Structure I & $\begin{array}{l}\text { Revetment walls and } \\
\text { ditched entrance (?) }\end{array}$ & $2250 \pm 55$ & $2260 \pm 50$ & $2256 \pm 37$ & $393-214$ BC & $40 \mathrm{I}-207 \mathrm{BC}$ & $A D 75-315$ \\
\hline Structure 2 & Entrance passage & $2250 \pm 55$ & $2260 \pm 50$ & $2256 \pm 37$ & $393-214$ BC & $40 \mathrm{I}-207 \mathrm{BC}$ & $A D 75-315$ \\
\hline Structure 3 & Circular structure & $2110 \pm 80$ & & $2110 \pm 80$ & $350-4 \mathrm{BC}$ & 390 BC-AD 54 & AD $24 I-538$ \\
\hline \multicolumn{8}{|l|}{ Hornish Point } \\
\hline Structure I & Wheelhouse & $2370 \pm 50$ & & $2370 \pm 50$ & $509-396$ BC & $758-384$ BC & $86 B C-A D|3|$ \\
\hline Structure 4 & & & & $2350 \pm 50$ & $412-392 \mathrm{BC}$ & $753-264$ BC & 45 BC-AD 208 \\
\hline Structure 2 & & & & $2350 \pm 50$ & $412-392 \mathrm{BC}$ & $753-264$ BC & 45 BC-AD 208 \\
\hline Structure 3 & Wheelhouse? & $2335 \pm 50$ & & $2335 \pm 50$ & $409-389 \mathrm{BC}$ & $74 I-235 B C$ & 4 I BC-AD 220 \\
\hline Structure 5 & & $2170 \pm 50$ & $2370 \pm 50$ & $2270 \pm 35$ & $395-235$ BC & $403-210 \mathrm{BC}$ & $A D$ 69-240 \\
\hline Structure 6 & Circular structure & $2270 \pm 50$ & $2370 \pm 50$ & $2320 \pm 35$ & $404-389$ BC & $411-264 B C$ & $A D 5-210$ \\
\hline
\end{tabular}

Balelone

Block 5

wall fragments

$$
2330 \pm 70 \quad 2330 \pm 70 \quad 4 I I-382 B C \quad 757-210 B C
$$

86 BC-AD 242

Table 56. The absolute ages of the 'wheelhouse complex'

latter dating to $2335 \pm 50 \mathrm{BP}$ (GU-2017). The difference of 35 radiocarbon years between this and the derived date for Structure 1 implies that the first three structures were erected, used and abandoned within a time interval too short to be resolved by radiocarbon dating.

Structure 4; Structures 2 and 3 both underlay the small fragment of Structure 4 (Block 25) revealed at the foot of the excavated section (Figures $63 \&$ 64). It is not impossible that its construction contributed to their destruction. Given the size of the exposure, it is not possible to indicate the nature or function of the structure of which it forms part but it is possible that this was rectilinear in plan.

Structure 5; Structure 5 comprises two Blocks, one of which, Block 18, lies seaward of the recorded section while Block 15, which makes up its southern end, is recorded in section. It was only in plan that it became clear that together these make up a single radially segmented structure (Figure 54). However, it was clear also that this structure was not of one build and that the $2 \mathrm{~m}$ high, corbelled vault of Block 15 had had a separate existence in a structure now lost either to the sea or to later clearance and rebuilding on the site.

Structure 5 overlies Structures 2, 3 and 4, whose destruction was a precondition of its erection. Its construction may have required little more that extending the pre-existing fragments of Block 15 and adding internal radial piers to a gap between other existing structures. Certainly, in plan and general appearance it has more than a little of the ad hoc about it.

While unequivocal evidence is wanting, it is possible that the rubble of Block 16 relates either to the new construction of Structure 5 or to the modification of the earlier elements that it subsumes.

The rubble and midden deposits of Block 17 overly Structure 5 and are, in turn overlain by Block 13, which has been radiocarbon dated to $2170 \pm 50 \mathrm{bP}$ (GU-2015). This provides a terminus ante quem for Structure 5, a terminus post quem for which is provided by the derived date for Structure 1 , ie $2370 \pm 50 \mathrm{BP}$ (GU-2027).
Structure 6; Structure 6, (Block 22) comprises two sections of wall, interpreted as a circular structure, seen in section, and the deposits contained within it (Figure 59). The latter yielded dates of $2270 \pm 50 \mathrm{BP}$ (GU-2028) and $2185 \pm 50$ BP (GU-2026). It contained an apparent hearth and is interpreted as a simple domestic structure with post abandonment deposits. The dates provide a terminus ante quem and so Structure 6 predates the older of the two, ie it predates 2270 $\pm 50 \mathrm{BP}$. It post-dates the determination of $2370 \pm 50 \mathrm{BP}$ (GU-2027) from Block 26, which it overlies.

Other structural elements; Block 7 was identified as a revetment wall with associated deposits (Figure 45) from which a radiocarbon date of $2310 \pm 50 \mathrm{BP}$ (GU-2022) was returned. Block 14, identified as masonry could have been either a revetment wall or part of a structure (Figure 51 ). It lies between Blocks 9 (2345 $\pm 50 \mathrm{BP}$; GU-2019) and 10 (2220 \pm 50; BP GU-2016). Both of these walls were constructed during the period within which the principal structures on the site were erected.

\section{South Glendale}

Pottery collected from this site in the past had included Beaker sherds (Shepherd \& Maclean 1978) and although the bulk of the surviving midden proved to be medieval, this was underlain by deposits of prehistoric character. In these stake holes were noted which may have formed part of a tent, hut or shelter. However, ard marks and spade marks in the deposits suggest that more permanent structures may also have been used at this site, but are now lost to coastal erosion.

\section{Balelone}

The earliest structural remains at Balelone, in Block 5, are later than the radiocarbon dated deposits of Block 3, $2330 \pm$ 70 BP (GU-1801), which they overlie. The remains consist of two un-interpretable pieces of masonry overlain by a thick curving wall fragment, the latter probably part of a round house, possibly of radially segmented type although no direct evidence for this was observed.

A group of postholes was noted in the base of Block 6, stratigraphically higher than Block 5, together with, but not 
demonstrably associated with a $1.1 \mathrm{~m}$ high drystone wall. The latter could have revetted the clear space within which the post-hole structure was erected. In any event, the stone structure of Block 5 seems to have been succeeded by the wooden structure of Block 6.

\subsubsection{Medieval structures}

\section{South Glendale}

A fragment of the corner of a rectangular structure was uncovered in Area 2, at South Glendale (Figure 70). Within the angle enclosed by its walls, an organic layer contained shells dated to $540 \pm 50 \mathrm{BP}(\mathrm{GU}-2159)$, while a date of $550 \pm 50$ BP (GU-2160) was returned from material in the layer beneath this. These dates are indicative of use in the medieval period. Pottery from the deflation surface surrounding the site indicates use of the area in the medieval and post-medieval periods.

The walls, of which $2.3 \mathrm{~m}$ and $5 \mathrm{~m}$ lengths formed the surviving corner, were formed of inner and outer stone faces retaining a core of peat or peaty soil.

South Glendale's sheltered bay, within living memory, served as a ferry terminus for a service to the islands in the sound and to the small isles to the south. The structure may represent the home of a ferryman at an earlier date.

\subsubsection{Post-medieval structures}

\section{Hornish Point}

Block 20, at Hornish Point, consists of the greater part of a simple rectangular structure of 'blackhouse' type. It was internally divided by a row of low slabs set on edge and the southern part contained a central hearth defined by a circular setting of radially set, rounded pebbles (Figure 57). The structure consisted of an inner wallface, revetting the deposits into which the blackhouse had been dug. It is possible that the northern end was free standing. The structure was remarkable free of occupation debris and its attribution to the post-medieval period is based solely on its form.

\section{Newtonferry}

A right-angled setting of stone with two cetacean vertebrae was recorded west of the section line (Figure 72). This was interpreted, on the basis of its linearity as part of a medieval, or more probably post-medieval/pre-clearance house. A second such structure was noted in the isolated sand tallard (Figure 72). The midden deposits of Block 3 returned two radiocarbon dates roughly indicative of the medieval or early post-medieval period, viz $700 \pm 50 \mathrm{BP}$ (GU-2163) and 710 $\pm 50 \mathrm{BP}$ (GU-2164) and it is not inconceivable that these structures are of this, or slightly more recent date.

\section{I5.4 Discussion}

Bronze Age structures are rare in the Hebrides and none were observed in the excavated levels at Baleshare, albeit that the existence of stone structures was revealed by coring (see above). It could well be that Hebridean structures of this period were largely of wood or perhaps built of turves, as
Crone has argued for the Neolithic structures at Carinish (Crone 1993), and so largely transparent to survey approaches. Structures of stone have been excavated at the Udal (Crawford nd) and at Killelan Farm, on Islay (Burgess 1976, 181) but these Early and Middle Bronze Age structures are curiously ephemeral and may represent no more than seasonal shelters. The later Bronze Age hut circle at $\mathrm{Cul} \mathrm{a}$ Bhaile, on Jura (Stevenson 1984), like those at An Sithean, Islay (Barber \& Brown 1984) and many more throughout the Inner Hebrides, represent more permanent settlement. The exposed and cored deposits of Bronze Age date at Baleshare represent extensive, manured, cultivated fields. It seems reasonable to anticipate that buildings found in association with them would also be of a permanent character, thus the field interpretation of the stone concentrations identified by coring as houses may well prove to have been correct. The examination of LBA settlements in the Islands should be a high priority for students of settlement in the Western Isles.

The Iron Age structures examined in these excavations are remarkable for their palimpsest nature and their very short chronologies. By their palimpsest nature is meant the extent to which subsequent buildings subsume elements of earlier structures, incorporating them intact or in greater or lesser degree of modification. Nowhere is this clearer than in the complex of structures at Hornish Point but even where the structures are less numerous, as at Baleshare, earlier buildings are founded upon or cut into by later buildings.

Within structures that are apparently single period or which functioned as single period occupations, there is much evidence of remodelling and rebuilding. This is clearest, perhaps, in the radial piers of the Hornish Point structures. Twentieth century expectations of the permanence of structures, lasting at least over periods of many decades and typically over several centuries, seem wholly inappropriate in the context of the Hebridean Iron Age. The Iron Age occupants seemed to have regarded their homes as dynamic envelopes rather than as lasting statements of some architectural ideal. For instance, House 401 at Cladh Hallan, South Uist was in use over a period of about half a millennium during which time it was rebuilt eight times (Parker-Pearson pers comm; Marshall et al 1998). Thus, the average duration of a structure on that site was about 55 years. Recent research suggests that this order of duration for a structure lies at the upper end of the range (Barber \& Crone forthcoming).

Dendrochronological analyses reveal durations as short as a single generation for individual prehistoric structures (ibid).

The rates of change in the dynamics of the architecture may have been heightened artificially by the accreting depositional environment in which these structures are set. Accumulating deposits around the buildings may have encouraged frequent modification for the simple reasons of ease of access or safety or the relative level of the water table. Whatever its genesis, the rapidity of construction, reconstruction and replacement have improved the resolution with which structures on these sites may be examined.

The chronology of their construction has proved somewhat surprising, at least to this writer, and before addressing the matter it may prove useful to offer a comment on the relevance and security of the dating samples. The matter of dating subsumes two topics; the duration and relative ages of the observed structures, on the one hand, and their absolute cal- 
endar age, on the other. The latter is considered later while their duration and relative ages are considered here. For the purposes of this discussion the raw radiocarbon determinations are cited throughout and all the dates are derived from seashell, unless otherwise stated.

The radiocarbon determinations have been shown to have a very high degree of internal consistency when judged against the stratigraphic record from the sites. This fact is interpreted as validation of the relative sequencing of the radiocarbon dates as well as supporting the taphonomic interpretation of the sites' formation processes. The taphonomy of the sediments has been rigorously addressed and the relationship between the samples and contexts, from which they are derived, is generally well understood.

The sequences of dates indicate astonishingly high sedimentation rates, particularly for the Iron Age sediments on the sites. Thus, even if there were some doubt about the relationship between an individual sample and its context, the high rates of sedimentation mean that the errors should be minimal, for all but conflation horizons. If, for example, a sample contained material from the overlying or underlying layers, the difference in date between contiguous layers is so small that the error thus introduced would be negligible. This is one of the benefits of dating the sedimentary sequence rather than seeking to date specific archaeological 'events'.

Table 56 sets out the dating evidence for the structures. Referring only to the mean dates of the determinations, all of the Iron Age structures from the three relevant sites were built, used and abandoned within a period of roughly 250 Rys and all three probably had structures in contemporaneous use over parts of this period.

In reality, the duration of settlement is probably significantly less than that indicated by the termini dates. Taking into account the sedimentation rates and the volumes of sediments separating the structures from the dated deposits, it seems likely that their chronology should be further compressed into the earlier part of the span. On balance, it is argued that the chronology of these Iron Age structures is compressed into one to one-and-a-half radiocarbon centuries following $2370 \mathrm{BP}$.

While the general applicability of this chronology to other comparable structures remains to be discovered, the fact that it applies to the three excavated sites with relevant deposits, at least raises this possibility and it is hoped that future work may help to elucidate this problem. The conventional chronology (Armit 1992, 127) envisages the construction of wheelhouses during the later centuries BC and into the first century $\mathrm{AD}$, and seems to imply a duration of perhaps three to four calendar centuries, or more.

Very short chronologies are not a feature of machair settlements alone. A very short chronology has been proposed for the Early Historic crannog at Buiston, Ayrshire (Crone 2000). There, the chronology is securely founded on the dendrochronological analysis of many timbers from the houses and palisades of the site. Dr Crone has revealed a bewildering succession of building and re-building all taking place over a period of roughly 50 calendar years.

Barber \& Crone (1993) have suggested that the site chronologies of crannogs may be fractal in their organisation, with multiple periodicity, on a macroscopic scale, being replicated by multiple rebuilding during each period of occupation and multiple replacement during the currency of single rebuilds. This theory seems equally applicable to the Iron Age farm mounds of the Hebrides and, in principle, may be a feature of all prehistoric settlement.

On crannogs, as on machair sites, preservation in rapidly forming deposits is a feature of site formation and the deep sediments provide sufficient resolution to reveal the structured chronology of the settlements. However, such sites are exceptional. Almost all other sites survive only as truncated and conflated assemblages of relict features, deposits and artefacts. In the absence of sequences of diagnostic artefacts, a regrettable feature of the earlier Iron Age periods, the sites can be misunderstood as single period sites, or where a single exotic occurs, the entire site can be dated to the currency of that artefact (Clarke 1971).

Poor chronological resolution, small numbers of radiocarbon dates and over-reliance on single, or small numbers of, diagnostic ('exotic') artefacts have bedevilled the study of the sites of the 'Castle Complex'. This matter is considered further below.

Given the brief phases of occupation implied by the short chronology, does the absence of settlements immediately before or after imply that the population left the islands? The coring evidence has shown that other settlement nuclei may exist in the preserved hinterlands of the sites. Furthermore, the presence of earlier and later sediments indicate use of the sites, even if settlements for these periods were not found. However, the chronology for Baleshare does display significant lacunae between the main periods, indicative of abandonment, and the possibility that the sites were abandoned between successive phases must also be considered. Given the fragility of settlement in the islands the possibility of occasional abandonment cannot be discounted.

The relative abundance of the bones of young sheep and cattle at Baleshare and Hornish Point indicates that the sites were occupied during the spring and early summer, and during the autumn and winter (Halstead infra). The real abundance of microscopic marine mollusca, introduced to the site on seaweed, suggests that the sites were occupied during the summer, when such mollusca are abundant. It further implies occupation during the winter, because seaweed gathered for fodder would be used during that season. The bird species represented on the site indicate collection, and probably consumption during the late spring and early summer

(Serjeantson infra). Intensively commensal pig rearing implies continuous occupation of the sites throughout the year. In all then, these sites were permanent settlements occupied all year long or, at least there is no clear evidence to indicate seasonal use.

The structures of the wheelhouse complex at Hornish Point were all built, used and abandoned in a very short period of time: in raw radiocarbon determinations, between $2270 \pm 35 \mathrm{BP}$ and $2370 \pm 50 \mathrm{BP}$. Dr Scott's report (Section 18.12.1) makes clear that the differences between matched pairs of samples from terrestrial and marine environments are not significantly different from zero. The number of matched pairs is small but even so, the results of her analysis counsels' caution in the use of the correction for MRE developed by Dr Harkness. This writer and others are currently researching this problem by dating a much larger sample of matched pairs of dates and we may be able to clarify this position in the next three to five years. Until then, the Scottish verdict of 'not proven' 


\section{Type of deposit}

\section{Midden site}

Dumped

Dumped and midden

Cultivated and midden

Structural

Totals
Cultivated

\section{Hornish Pt Baleshare}

Total

$\begin{array}{rr}6 & 14 \\ 9 & 2 \\ 0 & 1 \\ 4 & 0 \\ 2 & 3 \\ 1 & 1 \\ 22 & 21\end{array}$

20

II

I

4

5

2

43

Table 57. Block types from which worked bone and antler have been recovered

should apply to the MRE correction factor of 405 years or thereto.

Clearly, this creates something of a problem for the absolute dating of the sites. Table 56 sets out the radiocarbon determinations and their calibrated ranges, for the structures at Baleshare, Hornish Point and Balelone. At the three-sigma level, these imply construction at Baleshare between 401 BC and AD 54; at Hornish Point between 750 BC and 264 BC and at Balelone between $757 \mathrm{BC}$ and $210 \mathrm{BC}$ (all in calendar years). It is vital to note that the excavated evidence and the primary analysis of the radiocarbon deteminations imply strongly that the construction on each site took place over a very short period within these ranges.

If we apply the 405-year MRE correction and recalibrate the determinations, at 2 sigma, we arrive at the ranges set out in the righthand column in Table 56. The dated structures lie apparently in the span $86 \mathrm{BC}$ to $538 \mathrm{AD}$ but mainly in the span $85 \mathrm{BC}$ to AD 240. Unfortunately, the effect of calibration at the sorts of ages we are here considering is amplified by the topography of the calibration curve. Slightly earlier radiocarbon determinations calibrate early and are spread over 500 calibrated years. Conversely, if the determinations are slightly later, they calibrate late and the ranges within which they occur are spread over only two centuries.

The other major problem for the absolute dating of the sites arises from the fact that the calibrated date ranges, without adjustment for MRE, lie at the younger end of what Baillie \& Pilcher (1983) have called the 'first millennium BC radiocarbon disaster'. Flattening of the calibration curve in the range roughly 200 to $800 \mathrm{BC}$ (calendar years) spreads the radiocarbon determinations across the whole of the range. For example, four of the Hornish Point calibrated ranges and one of those from Balelone (Table 56) span roughly 750 to $200 \mathrm{cal}$ BC. Correspondingly, the calibration ranges for dates at or just below the younger end of this range are 'compressed' into the interval 400 to $250 \mathrm{cal} \mathrm{BC}$. Thus it is possible that all of the construction phases are roughly contemporary (other than as evidenced by stratigraphy) and date to a short period at or just before about $200 \mathrm{AD}$ (calendar years).

In South Uist the emerging ceramic sequence sees coarse plain wares earlier than $400 \mathrm{BC}$ with finger impressed decoration later and then cordon and incised decoration from the second century at the latest (M Parker-Pearson pers comm). On this basis, it is unlikely that the structures at Hornish Point are earlier than the second century cal BC. However, it is salutary to reflect that the pottery sequences for the Hebridean Iron Age are re-written on a site-by-site basis. There is at present nothing even approaching a consensus position. Our own attempts to test the rigor of taxonomies founded on attribute analysis and on traditional typological seriation indicate that neither approach generated classifications that were stratigraphically coherent (see 18.16.1 below).

Several writers have identified a date of approximately $200 \mathrm{cal} \mathrm{BC}$ as a key date for the architecture and pottery of the Hebrides. Armit, by and large would prefer to see the wheelhouses as earlier than this date while Parker Pearson (pers comm) thinks it unlikely that pottery from Baleshare, and by inference Hornish Point are earlier than $200 \mathrm{cal} \mathrm{BC}$. We have at present no basis for selecting between these options. In reality, the significance of the $200 \mathrm{cal}$ BC date may simply be that it is a toggle point that spits out dates either to the earlier period (750-250 or 400-250 all cal BC) or the later period (100 cal BC to AD 250). Thus, the dichotomy may prove an artefact of the calibration curve with little or no real world significance.

\subsection{ARTEFACTS}

\subsection{Pottery}

Dr Ann MacSween has reported above on the pottery assemblages from the sites examined in this project. Her work is in part a summary of the reports prepared earlier by the named contributors to her own report. The history of these studies is not without interest. When these excavations were undertaken and before the formal analysis of the pottery assemblages we provided Dr Peter Topping with some sherds from Balelone for elemental analysis of their clays. Topping's study (1987) included ceramic material from a wide range of sites in the Outer Hebrides and concluded in effect that all the pottery was produced locally. His results did not support any suggestion of local, regional or wide scale trade. A subsequent analysis of the larger mineral inclusions in the sherds

\section{Hornish Point}

Artefact type
Complete artefacts
Broken artefacts
Broken points and awls
Offcuts and roughouts
Fragments
Utilised fragments
Totals

$\begin{array}{lr}\text { Sample No } & \text { No } \\ \text { H7, HI2, H23 } & 2 \\ \text { HIO, HII, HI3, HI4, HI5 } & 5 \\ \text { HI, H2, H3, H4, H6, H8 } & 6 \\ \text { H9, HI9, H22 } & 3 \\ \text { HI6, HI7, HI8, H2O } & 4 \\ \text { H5, H2I } & 2 \\ & 23\end{array}$

\section{Baleshare}

$\begin{array}{lr}\text { Sample No } & \text { No } \\ \text { BI4, BI7, B I8 } & 3 \\ \text { BI, B4, B5, B6 } & 4 \\ \text { B3, BI2 } & 2 \\ \text { B7, B8, B9, BI0, BI3, BI9 } & 6 \\ \text { BII, BI5, BI6, B20, B2I } & 9 \\ \text { B2 } & \text { I } \\ \end{array}$

Table 58. Baleshare \& Hornish Point. Categories of worked bone and antler 


\section{Deposit type}

Mean score

$\begin{array}{ll}\text { Structure } & 146.34 \\ \text { Ditch fill } & 500 \\ \text { Backfill } & 833.33 \\ \text { Cultivated windblown sand } & 1053.57 \\ \text { Dumped } & 1308.77 \\ \text { Midden site } & 1340.77 \\ \text { Cultivated midden/dump } & 2300 \\ \text { Conflation } & 2500\end{array}$

\section{Table 59. Baleshare. Types of deposits with burnt stone}

from all sites was undertaken by the late Geoff Collins, then of the BGS. This simply reaffirmed Dr Topping's conclusion that all sherds were locally produced.

The first analysis of the pottery assemblages, an attribute analysis, is detailed above (Chapter 9). We had agreed in advance of this analysis that its success would be measured by its goodness of fit with the stratigraphic details. Therefore, the taxonomies based on measured attributes were developed in ignorance of the chronological details of site phasing and radiocarbon dates. In all cases, regardless of the attributes selected and the weightings applied to them, the resultant taxonomies failed this test. Sherds of many classes commonly occurred in single contexts and sherds from individual classes were distributed almost randomly throught the stratified contexts. In almost all cases also, the resultant classifications were too fine grained and contained large numbers of groups and sub-groups.

The rim sherds and decorated sherds were then analysed by Drs Alan Lane and Ewan Campbell, also without access to details of site phasing and chronologies. This produced a taxonomy that was more manageable and more recognisably 'archaeological' in character. However, this also was remarkably unsympathetic to the site chronologies and failed the test of chronological coherence almost as convincingly as had the taxonomies resulting from attribute analysis.

Finally, Dr Ann MacSween, with access to the earlier reports and to the stratigraphic details and radiocarbon results, prepared the report presented above. It must be noted that where this report refers to Bronze Age or Iron Age pottery it does so by virtue of access to independent chronological information, not by virtue of information inherent to the potsherds themselves. While it is clear that there are many potsherds that can be identified unambiguously to say the Iron Age or Beaker sherds that are clearly Early Bronze Age in date, there is a great deal of pottery in these assemblages that cannot be attributed to any period with confidence. This conclusion is not without its significance.

\section{The 'Laura Ashley school of archaeology'}

A goodly proportion of processual archaeology is founded on the identification of patterns in the past (see the works of Binford for examples). However, the inherent weakness in developing a disciplined body of information from pattern identification is that the mere existence of a pattern does not establish its significance, much less test the truth of the causality it is usually said to imply. In the case of the Hebridean pottery, it is possible that pattern can only be detected by ignoring a very large component of 'noise' in the data set. That noise may have resulted from scale effects in the heterogene- ity/homogeneity of the assemblages. This is a characteristic of the midden sites themselves. On a large enough scale, the site deposits and their contents can appear remarkably homogenous while viewed on smaller scales there is considerable heterogeneity in evidence. The writer has taken this to indicate, in the case of the sediments, that their formation is either largely random or, if originally deliberate, has been rendered random by re-working.

In the case of the pottery, we may wonder whether a large proportion of the sherds represent 'traditional' forms and fabrics with only a small part of the assemblage, perhaps the decorated vessels, used to express cultural value. MacSween has noted that the use of rows of impressed decoration, at Baleshare, is a continuation from later Early Iron Age ceramic ornamentation. Her conclusion is that the sequence for the area for the first millennium $\mathrm{BC}$ and into the first part of the first millennium $\mathrm{AD}$ is created by '...the addition of new decorative elements rather than the discontinuation of earlier styles as new ones developed.' This implies the formation of assemblages that may not be responsive to unilinear taxonomic analysis. Rather, they may prove more appropriately analysed by techniques based on the use of fuzzy mathematics.

\subsubsection{Metalwork}

No metal objects were recovered from these excavations and their absence would clearly be a significant factor both in determining the date of the onset of the local Iron Age and in gauging the status of the sites. However, the absence of evidence in this instance is certainly not evidence of absence. The worked bone and antler provide evidence for an extensive metal tool kit. This had contained awls, punches, coarse and fine saws, knives, hand-drills and bow-drills and cleavers or possibly axes, ie heavy, chopping tools. Similarly, the butchery marks on animal, bird and fish bone confirm the use of metal knives and choppers. One piece of antler had served as a handle or haft for the tang of an iron implement, probably a knife. Two potsherds bear the impressions of projected ring-headed pins (Plate 33). Thus, in the assemblages of the site there is abundant evidence for the use of metal tools.

In pursuit of the missing metal and assuming that in the later periods at least, this would be iron, the standard bulk samples were tested for the presence of iron hammer scale and other by-products of iron working. In all of the samples from Iron Age deposits that were examined, hammer scale was recovered while none was recovered from Bronze Age deposits and small pieces of ferrous slag were recovered from deposits of both periods. This was an unstructured test, not least because the samples had already been worked on for other purposes and the possibility of some cross contamination could not be ruled out. However, the results were sufficiently encouraging to suggest that samples should be collected specifically to test for the first presence of iron hammer scale on site. A suitable programme of sampling should give a close approximation to the on-site availability of iron and, spread over several sites might indicate the local initiation of the Iron Age.

Slag has also been recovered, from eleven of the twenty-eight Blocks at Baleshare and five of the sixteen Blocks at Hornish Point (Blocks 1-12 being treated as one 
Block). The combined weight of slag from both sites is somewhat less than $1 \mathrm{~kg}$ (334.9 g from Baleshare, $566 \mathrm{~g}$ from Hornish Point). The slag from Baleshare comes from three Blocks which are essentially Bronze Age in date, Blocks 22, 23 and 17 and from eight Blocks which lie in the date range $2390 \pm 55 \mathrm{BP}$ to $2057 \pm 50 \mathrm{BP}$, Blocks 2, 3, 5, 9, 15, 16, 19 and 24. It is assumed that the slag from the three earlier Blocks represents bronze working. Blocks 1-13, 19 and 22 at Hornish Point also produced slag and this lies in the date range $2500 \pm 50 \mathrm{BP}$ to $2170 \pm 50 \mathrm{BP}$.

Bronze working is indicated by small amounts of slag from the earlier deposits at Baleshare. In the absence of ores of copper or tin in the islands it must be assumed that the bronze was introduced to the islands in metallic form and that the slag results from subsequent working or re-working and repair of existing artefacts.

\section{Technology}

The small amounts of slag from a small number of contexts in the Iron Age deposits, taken together with the rather more widespread distribution of hammer scale suggests that iron working was undertaken at these sites. There is no unequivocal evidence for the smelting of iron. Indeed the evidence for iron working on these sites is so similar to that from the Bronze Age deposits that it invites the conclusion that iron was imported to the sites in its metallic form and was subsequently re-worked or repaired on site. Thus, iron working on these sites was at the level of local blacksmithing. The absence of any finished objects of iron suggests that the metal was scarce enough to warrant heirloom status and it was not lightly discarded or lost.

\section{I6.3 Bone and antler}

In contrast, objects of bone and antler were relatively frequently discarded or lost. A total of forty-three pieces of worked bone and antler has been recovered from Baleshare and Hornish Point. At the former, all but two of the twenty-one pieces were recovered from Phase III Blocks and these are broadly contemporaneous with the twenty-two pieces from Hornish Point. The concentration of these artefacts in the later phases again emphasises the differences between the earlier and later phases at Baleshare.

The nature of the contexts from which these artefacts have been recovered is of some interest (Table 57). Twenty pieces, just under half of the total, were recovered from midden-site deposits where they may have been discarded or lost. Twelve more come from dumped or dumped and midden-site deposits, where they were probably discarded deliberately. Cultivated midden-site deposits account for another four while five more were found in cultivated deposits to which they were probably introduced by manuring. Only two came from within structures. In general, and again allowing for a small measure of circularity in the logic, this distribution tends to confirm the definition of the Block types. It also makes the point that the resources, ie bone and antler, were sufficiently freely available not to have acquired heirloom status but to remain subject to casual loss and discard. Nonetheless, two pieces of antler (H9 and B10) were fashioned from older artefacts and may indicate that antler, at least, was somewhat harder to come by and so was somewhat more intensively used.

The bone and antler objects are principally pins, awls, points and spatulas (Table 58) and the majority are polished, some highly polished, from use. It is probable that they were used in leather working. The perforated antler plate from Hornish Point (H12; Figure 77c) could have functioned as a tensioning device for ropes on boats or tents.

Bone and antler artefacts were clearly fashioned on site, as the presence of the offcuts and rough-outs and fragmentary debris suggests. Their emergence after $2300 \mathrm{BP}$ and their apparent association with skin working may be seen to support the tentative suggestion discussed above, that the emphasis in this period was on animal husbandry, at the expense of tillage. Certainly their proliferation after that time is indicative of some significant change in the agricultural economy of the site.

\section{I6.4 Lithics}

If the bone and antler artefacts had their floruit in the later deposits on these sites, the use of chipped stone shows the reverse trend. Only the Early Bronze Age deposits at South Glendale produced a relatively large non-quartz assemblage consisting of eighteen pieces of flint and one piece of chert, while a further six pieces of flint were recovered from the deflation surface surrounding the site. The lithic assemblages from the other sites are small and the material is undiagnostic. Some sixteen pieces of flint and fourteen pieces of quartz were recovered from Baleshare of which only four come from the later, essentially Iron Age deposits. Only five pieces were found at Hornish Point and these are essentially uncontexted.

There is no known source of flint in the isles and the identification of a fossil belemnite suggests that it may have been imported together with flint, from Skye, the nearest source of both belemnites and flint. Presumably the availability of iron in the later periods obviated the need for knapped stone implements and killed off this trade.

\subsubsection{Pumice}

Some sixteen pieces of unmodified pumice have been recovered from the Phase I and II deposits at Baleshare while twenty-four pieces have come from the Phase III, Iron Age, levels of that site. Analysis suggests that all of the pumice is derived from a single volcanic system, albeit that it need not all be of the same date. Its concentration on these sites suggests that it may have been deliberately mined from beach or raised beach deposits. It was clearly identified, and exploited, as a resource, especially at Baleshare.

Fashioned objects are rare and only the perforated piece from Baleshare can be ascribed a function, that of net- or line-float. The other two modified pieces simply display worn surfaces and facetting from use as abrasives. The use of pumice as an abrasive in the preparation of skins might account for the relative abundance of this material in the later levels at Baleshare, at a time when animal husbandry may have become the predominant agricultural pursuit. 


\subsubsection{Burnt stone; burnt mound material}

Writing in 1990 about burnt mound material from settlement sites in Scotland, this writer (Barber 1990, 92-6) noted its ubiquity on settlement sites of the Iron Age. However, deposits of burnt stones are but rarely mentioned in the literature and the accounts of its occurrence are under-represented in the Scottish literature. Owen \& Lowe (1990, 84-6) have noted burnt mound material on the site of Kebister, Shetland while Lowe $(1998,77-8)$ has also noted burnt stones in Block 228 at St Boniface on Papa Westray, Orkney, also dating to the Iron Age. Hedges noted burnt material at $\mathrm{Bu}$ $(1987,18)$ while this writer made the same observation at East Shore broch, Shetland (albeit that this observation is not repeated in the published account of that site: see Carter et al 1995). Its absence, confirmed by the excavators from Neolithic midden sites like Links of Noltland, Skara Brae and Knap of Howar (see Barber 1990, 94) suggest that burnt mound material is an introduction of Bronze Age or later date. Radiocarbon dating of roughly seventy sites in Ireland and Scotland suggests that burnt mounds, per se, were introduced in the Early Bronze Age while accumulating evidence suggests that the appearance of deposits of fire shattered stones, or 'pot boilers' on settlement sites is principally an Iron Age phenomenon.

Analysis of the burnt stone component from Baleshare (ibid, 94-6) revealed that it occurred in 62\% of the depositional blocks. An index was calculated, based on the product of the percentage of contexts in the block containing burnt stone and the average percentage of burnt stone in the context. These were averaged over block type and the results are presented in Table 59.

It seems reasonable to conclude from this and from field observation that the small amounts of burnt stone contained in structures, ditch fills and backfills of other features represent residual material. Conversely, the high proportions in midden and dump deposits have been concentrated by the dilution of other, mainly organic inclusions and the destruction of more fragile remains like pottery and macro-plant remains. The cultivated, dumped and midden site deposits were truly rich in burnt stone and this implies a reliance on the production of hot water by the immersion of roasted stones. The hot water was probably used for a range of functions including cooking, bathing and saunas or steam bathing and medicinal uses. 
CHAPTER I8: INTERPRETATION AND DISCUSSION

\section{PART 6: CULTURAL ARCHAEOLOGY; SOME INDICATIONS}

\subsection{SITE ECONOMY}

\subsection{Agricultural economy}

These excavations have produced evidence for the agricultural economy indicative of the exploitation of three resource bases; arable agriculture, animal husbandry and hunting and gathering. The evidence for arable agriculture comes principally from the direct observation of cultivation marks in the soils and indirectly from the carbonised plant remains recovered from sieving and floatation.

At the site of Baleshare, some eleven of the twenty eight recorded Blocks from here have been interpreted as cultivated deposits or as deposits of some other character that had been, secondarily, cultivated. Of these, four (Blocks 1, 18, 20 and 22) contained ard marks with one (Block 20) also containing spade marks. Three (Blocks 25, 26 and 28) were interpreted as cultivated soils on the basis of some combination of soil colour, texture, extent, homogeneity, and inclusions (including the pot sherd size distribution). One, Block 23, was interpreted in the field as wind-blown sand deposits but the snail evidence suggests that this was also cultivated. Block 16 displayed the wavy lower boundary typical of obliquely cut ard marking while Block 24, principally a set of dumped and midden site deposits, and Block 27, principally wind blown sand, both also contained ard marks.

Block 22, in Phase I at Baleshare consists solely of a deepened plough soil in which successive levels of ard marking can be seen. Some seven of the eight Blocks in Phase II display some evidence of cultivation while only three of the nineteen Blocks in Phase III contain evidence of cultivation and two of these three simply present evidence for episodes of cultivation of dumped and midden site deposits. Thus, only one set of deposits (Block 1) can be said to be principally cultivated deposits.

It must be accepted that the ratio of $3: 19$ cultivated to non-cultivated deposits is misleading, because five of the remaining Blocks are structural and could not have been cultivated. Nonetheless, the sampled sediments indicate heavy reliance on cultivation of the site's deposits in the earlier phases of settlement, from say 3300 to $2300 \mathrm{BP}$. This was followed by a considerable reduction in the importance of cultivation in the later phase, say from 2300 to $2100 \mathrm{BP}$ (in radiocarbon years).

At Hornish Point, only eight of the twenty seven interpretable Blocks have produced evidence for cultivation, all but one of them in the sedimentary sequence of Blocks 1 to 13 at the south end of the site. These dumped and midden site deposits were cultivated intermittently over the period $2500 \mathrm{bp}$ to 2170 BP. The remaining Block (Block 26) dates to 2370 BP and evidence for its cultivation exists in the soil characteristics listed above; there were few if any convincing ard marks.

While the emphasis on cultivation reduced in the later phase at Baleshare, the southern part of Hornish Point seems to have continued in cultivation, intermittently, during the same period. Unlike Baleshare also, the area to be cultivated seems to have had a 'formal' existence in that it was restricted to the southern part of the site and demarcated by walls from time to time.

The sites at Baleshare and Hornish Point are truncated by the sea and we know that substantial parts of them have been lost to erosion. Thus, the validity of the pattern we observe at Baleshare may be questioned on the basis that deposits in some other part of the site may have formed part of the 'formal' fields of that site.

\section{Plaggen soils}

The later Bronze Age soils at Baleshare and those of the succeeding phase (Phase II) are plaggen, or man-made soils. They consist essentially of wind blown shell sand to which humus has been added to create a fertile, cultivable soil. The humus appears to have been manure, included in which are large volumes of domestic refuse and peat, many small nodules of which were visible in the exposed profiles and recovered in sieving and floatation. Adding humus to the sands is clearly the reverse of the current practice of adding sand to the peat to create the famous contemporary plaggen soil known as Lewisian black earths (Whittow 1977, 282-6). The cultivated areas at Hornish Point may have served only secondarily as areas of cultivation, their primary function being that of dumps or midden site deposits. Nonetheless they did function as cultivated areas and the soils that comprise them are plaggen soils.

In Britain, plaggen soils are well known from sub-Roman (MacPhail 1981), Dark Age (Barber 1981; Davidson \& Simpson 1994, 68-71) and medieval (Romans in Barber 1981, 359) contexts and many examples of these dates are also known from European sites (Groenman-van Waateringe \& Robinson 1988). However, instances of prehistoric plaggen soils have been noted. Davidson and Simpson (1994, 71-73) describe manuring systems giving rise to plaggen soils at Tofts Ness, Sanday, Orkney, as early as the Late Neolithic/Early Bronze Age period. By the later Bronze Age and the Early Iron Age periods, wind-blown calcareous sands had covered the area and these sands were stabilised and cultivated by the addition of ash and manures with 'enhanced' faecal matter (ibid). In one area of Tofts Ness turves and organic material had been imported onto the sands to facilitate cultivation (ibid). Dockrill reports plaggen soils of Bronze Age date from Scatness in Shetland (BA 1997, 5).

Groenman-van Waateringe (1988) has argued that the pollen assemblage from the soils of Elp $(1300-800 \mathrm{bc}$, radiocarbon years) and similar sites in eastern Netherlands show evidence of plaggen soil formations. Sites in west Friesland occupied between 1200 and 700 bc) are said by Ijzereef (1981) to display signs of deliberate plaggen soil formation. Byre floor material was mixed with mineral sands from large pits, some of them $8 \mathrm{~m}$ and more in diameter, to be spread on the surrounding land. The presence of small, comminuted potsherds in the ard marks of those fields is at least indicative of manuring and multiple cultivation episodes (Barker 1985, 181-3). By 500 bc, the 'Celtic fields' at Vlassen were being fertilised by the deliberate addition of organic matter providing the first irrefutable evidence for plaggen soil formation (ibid, 186-7). By the end of the first millennium bc plaggen soils were being worked in northern Germany, at Flogeln (Zimmerman 1978, 149) and on Sylt, an island west of Jutland (Kroll 1975 ) and, no doubt elsewhere in northern Europe where 
pressure on land was forcing the intake of relatively infertile mineral sands.

Coined to describe the Netherlands medieval practice of mixing byre floor material and soil for spreading on fields, plaggen is not a precise term. Heavily manured soils, for example, seem to be those now argued for as the earliest European plaggen soils but these are qualitatively different from the made soils which occur in the later periods. In the former, land fertility is merely improved by the addition of missing nutrients but plaggen soils are wholly artificial and their fertility is an artefact whose very existence is conditional on human intervention. In this sense, the extensive, deepened and heavily manured top-soils of the earlier phase at Baleshare are probably not plaggen soils, sensu stricto, while the artificial Iron Age soils of the later phase clearly are.

\section{Cultivation strategies}

Prior to these excavations the writer was struck by the fact that the machair sites were formed in large part by humic material or humus-enriched sands. This seemed strange because the local hoarding of humic matter deprived the surrounding machair of the specific nutrient in which it is virtually totally deficient, viz humus. If the settlements were dependent on arable agriculture for their subsistence, this waste of humic matter seemed inexplicable.

Excavation of the later Bronze Age levels at Baleshare revealed what might be described as the anticipated situation. There, relatively large areas, at least 3 ha in extent were under continuous cultivation and their fertility was maintained by consistent manuring with midden material and peat.

Subsequently, at Baleshare and at Hornish Point, very much smaller areas were cultivated. Their linear exposures can be measured in tens of metres and their maximum area coverage amounts to only fractions of a hectare, based on the coring evidence. However, their humic content is much higher than that of the Bronze Age soils and in many instances cultivation was carried out directly on dumped deposits of byre floor material and domestic refuse. What this cultivation may have lacked in area it may have compensated for in intensity. Long term experiments at Rothamstead and Woburn have shown that the continuing use of manure can sustain fertility, even on sandy soils. Yields in the region of 1.5 to 2.5 tonnes per hectare have been sustained over a century (Catt 1994). In the terminal Bronze Age/earliest Iron Age deposits on the machair sites examined in this project, intensive cultivation, probably largely or exclusively of barley, was carried out in market garden sized plots whose fertility was maintained by constant manuring on a scale sufficient to produce true plaggen soils.

Later still, there is a marked reduction in the amount of cultivation revealed in the sediments at Baleshare. Acceleration in deposition rates may, by dilution of the evidence, have contributed to this apparent decline. However, these sedimentation rates are exceeded at Hornish Point without loss of the evidence for cultivation, albeit intermittent, in the contemporary deposits. Furthermore, at Baleshare some five of the later Blocks are characterised as midden-site deposits or dumped deposits. These deposits were a wasted resource because, cultivated in situ or spread on the machair sands, their humus could have produced useful crops. Their relative abundance seems to confirm the notion that the absence of cultivated areas in the later sediments represents a real change in agricultural economy after, say, $2300 \mathrm{BP}$, in shell-derived radiocarbon years.

\section{Crops}

Throughout the whole of the period from the later Bronze Age to the abandonment of these sites in prehistory, barley was the principal crop consumed, from which we conclude that it was the main cultivar. As Jones (infra) has shown, this was hulled barley of the six-row variety. A very little emmer wheat seems to have been grown, possibly as a contaminant of the barley crop. Because we cannot distinguish between the carbonised remains of wild seeds and fruits brought onto the site in or with fuel (peat), it was not possible to identify unambiguously, the weeds of cultivation or, indeed, other cultivars.

The distribution of carbonised macroplant remains throughout the excavated profiles shows that barley continued in consumption during the later, Iron Age phases at Baleshare and the coeval phases at Hornish Point. However, the distribution is so strongly correlated with deposit type that it cannot be usefully employed to explore the perceived change in agricultural economy in these later deposits. At both Baleshare and Hornish Point, carbonised seeds were recovered in large numbers from midden-site deposits and in relatively small numbers from windblown sand and from 'features', like structures, pits, etc. The main difference between the sites lies in the small totals from cultivated soils at Baleshare and the very large totals from the cultivated deposits at Hornish Point; 308 barley fragments against 3559, respectively. This difference is almost certainly caused by taphonomic differences. At Baleshare, the cultivated soils are mainly windblown sands to which midden material has been added, while at Hornish Point, it is mainly dumped and midden-site deposits that have been subsequently cultivated in situ. Thus, the richness of the midden-site deposits is reflected in the high totals from these cultivated levels. Furthermore, given the high sedimentation rates at Hornish Point, the episodes of cultivation become spatially separated as the body of deposits rapidly deepens. Thus, the individual deposits were not disturbed by the plough so frequently as were those at Baleshare. In consequence, the relatively fragile carbonised remains were also better preserved at Hornish Point.

Jones has shown that the carbonised plant remains discriminate powerfully between the deposit types, at the Block level. There is, of course, some small measure of circularity in this because, where plant remains were visible in the field, the fact of their existence contributed to the classification of the Blocks in which they occurred. However, they were, in this writer's experience, only rarely visible in the field and certainly their relative incidence remained unknown until after the floatation, sieving and sorting were completed. Thus, it is argued, they provide independent confirmation of the Block designations.

\section{Yield}

Mercer (1981, 232-3) argues that the unmanured fields at Butzer produce an average of 1.85 tonnes per hectare of emmer and argues that manuring might well double this yield. In fact, the Butzer soils are re-fertilised by the nutrient rich parent material brought into the plough soil at every ploughing and so the fields are not really unmanured (Romans pers comm). Nonetheless some improvement in 
yield would probably result from manuring, perhaps something of the order of a $50 \%$ increase is indicated by the Rothamsted experimental plots (Catt 1994, fig 10.1, 121) and something in the region of 2.5 tonnes per hectare of barley might not be wildly optimistic.

The three hectare extent of the later Bronze Age settlement at Baleshare might thus have provided say 7.5 tonnes per annum of which, allowing for wastage and retention of seed grain, might provide about 5 tonnes per annum, for consumption. Application of the Roman Army allowance of one third of a tonne per man per annum (Mercer 1981) indicates a population of fifteen persons. This is probably more indicative of twenty, or so, allowing for females, the very old and babies and small children whose requirements are somewhat less than those of a soldier on active service. While the reader will appreciate that these calculations are fraught with massive uncertainty, they still provide an indication of the scale of settlement likely to have been supported, accepting that errors of up to $50 \%$ may be involved. The use of other food resources and the land lost to the sea, both conspire to increase the estimate of the settlement's population and these factors will be discussed later.

The same rough calculations for the Iron Age deposits, allowing for more intensive cultivation, could be argued to indicate a population that was one third to half that indicated for the Bronze Age, perhaps six to ten persons. Clearly the same grave uncertainties apply to this estimate, albeit that at all periods the populations are likely to have been higher, not lower than the estimated figures.

\subsubsection{Animal husbandry}

Moderate numbers of animal bones have been recovered from these excavations. It is clear from these remains that cattle and sheep were the main domesticates, with sheep accounting for almost $60 \%$ of the identifiable anatomical units at Baleshare and Hornish Point and cattle representing 34\% and $28 \%$, pigs accounted for $6 \%$ and $12 \%$ respectively.

Halstead suggests that the severe cull of calves, evidenced on both sites, is a clear indication of a specialised dairy economy. The age-at-death pattern for sheep, on the other hand, reveals that they were principally kept for their meat and most killed off towards the end of their first year. The predominance of females among the adult sheep supports this view and suggests further that wool production was not the primary interest in sheep herding at this time.

The relatively high proportion of pig remains is somewhat surprising. In Early Christian Ireland, for example, the pig was as important or more important, in the diet of the population but there, at least, pig husbandry was closely related to the availability of mast, a relationship whose survival elsewhere into the medieval period is evidenced in the laws of pannage (Rackham 1980,155). That the relationship was overtly known to the Early Christians is evidenced in the many annalistic references to good, or exceptional mast crops. Thirteen such references are to be found between AD 576 and $\mathrm{AD} 1310$, in the Annals of Inisfallen, for example (MacAirt 1977). Pig husbandry, therefore in Ireland, and lowland Britain, was largely dependent on the availability of oak woodlands with their seasonal acorn 'crops'.

McCormick (pers comm) has suggested that pig husbandry in the Isles would have been limited by the absence of mast from the Hebrides and the damage their foraging would cause on the machair. While there is some doubt as to the status of Hebridean woodlands in the Bronze and Iron Ages (see Chapter 3.2.2) few would argue that oak woodlands existed in the islands during these periods. Pig husbandry must therefore have assumed something like the fully commensal role with which we are familiar from the more recent past, in post-medieval and early modern urban situations. If they did not actually keep their pigs in their parlours at least they kept them firmly penned or carefully herded. Foraging on the margins of machair-lochs, or in machair outfield, together with food supplement from domestic wastes, may have formed the husbandry strategy.

However, with one in eight anatomical units from Hornish Point identified as pig, there can be no doubt that pig husbandry was practised on a significant scale. Frequent farrowing, large brood size and highly efficient food-to-meat conversion make pigs an ideal 'emergency ration' and one that may have been needed in the marginal conditions of machair settlements. This alone may have encouraged the settlers to evolve appropriate husbandry practices. Parker Pearson et al $(1996,65)$ argue that the high percentages of pig present in 'midden' deposits at the broch site of Dun Vulan (first to third centuries $\mathrm{AD}$ ) indicate the selection of joints of meat for the inhabitants and are proxy-indicators of high status (see, however, Gilmour \& Cook 1998 for refutation).

The major constraint on the husbandry of sheep, cattle and pigs was, and remains, the problem of providing winter fodder. Here, uniquely, the climate of the machair was a positive help because frost is rare and snow even rarer. Thus there is some, limited, growth of grass all year round and animals can be left outdoors for the greater part of the winter. The evidence from the abundant byre floor material from these sites is that some beasts, possibly gravid animals or those still in milk,- were overwintered either indoors or sheltered among the standing buildings, and these animals must have been supplied with some form of provender.

The byre floor material observed on all the sites is almost exclusively peat derived and we may wonder what became of the barley straw resulting from the ubiquitous barley cultivation. Even in recent farming, some barley straw was fed to cattle (Lockhart \& Wiseman 1983, 105) and it may be that it was used more extensively in the Bronze and Iron Ages.

At all five sites examined in this project there is clear, even abundant evidence for the harvesting of seaweed. At the largely post-Medieval settlement at Newtonferry this material was principally added to the fields. However, in the prehistoric deposits, peat, probably deposited via byre floors, seems to have provided the necessary organic material. At the earlier sites, the distribution of the microscopic mollusca suggests that seaweed was used as fodder. The observation of dental calculus, characteristic of seaweed eating, on sheep teeth (Halstead infra) supports this view, albeit that only a single instance of it was observed. There is then some support for the idea that seaweed was used as fodder in the overwintering of animals. Pain and Thew (infra) have noted that the use of seaweed seems to have increased markedly through time on the sites of Baleshare and Hornish Point. However, as we have noted a reduction in the area of land being cultivated through this period, it is unlikely that the principal use of the seaweed was for manuring fields and this further supports the idea that it was used as fodder. 
The geomorphology of the machairs may also have helped to 'shorten the winter' by providing natural water meadows. The lochs at the landward margins of the machair are, even now, subject to great seasonal variation in extent, while the water table of the machair itself lies at or near the ground surface throughout the winter. Thus, areas of grass and the rootmass of the sward would have been maintained at temperatures above freezing, even during the coldest winters, and early spring grass production in these areas would have reduced the period over which fodder was necessary. Local access to the fodder source of the sea and the early grazing of the machair may have been potent factors in determining the location of the sites in and on machair. This is a siting which on many other grounds would seem most improbable and one that, long since, has been abandoned for the ecotonal strip between machair and blackland.

Apart from the evidence of the byre floor material, the presence of deciduous teeth of cattle and sheep, naturally shed, indicates the presence of calves on site, probably during the spring and early summer. These were found in dumped deposits; cattle in Blocks 5, 23 and 24, and sheep in Block 2, at Baleshare. The retention of the calves on site may provide support for the theory that cattle husbandry was orientated toward milk production. McCormick (1992) following Lucas (1989) argues quite convincingly that even in the recent past, the presence of the calf was necessary to enable the mother to let down her milk. Thus, calves and cattle may have been kept, separately but nearby, during the spring and early summer and for part of that time were housed at or near the excavated settlements. If this hypothesis is accepted, perhaps we can see some of the revetting and retaining walls as part of the penning necessary to achieve successful dairying. Clearly, further excavation would be required to explore this adequately.

McCormick $(1992,208)$ argues that dairy farming only really becomes a dominant husbandry strategy during the Dark Ages or at the earliest in the Irish Late Iron Age, ie the first few centuries AD, on the basis of evidence from Dun Ailinne, Co Kildare (Crabtree 1986). He, McCormick, suggests that it would be dangerous to '...project the existence of dairying further back into prehistory...' (ibid). Direct evidence exists for dairying at this time in Scotland. Radiocarbon dates from bog butter indicate that dairying was practised in Morvern in the mid-second to mid-third century AD and at Kyleakin, on Skye, a century later (Earwood 1991, 233).

On balance, the evidence from the machair sites suggests that dairying was practised in the Outer Hebrides almost a millennium earlier. Furthermore, given that all but one of the deciduous calf-teeth were found in the Blocks of the later phase at Baleshare we may also wonder whether the decline in the emphasis on cultivation is related to the rise in the importance of dairying. Halstead (infra) rightly observes that the small numbers of bones recovered from each of the sampled Blocks militate against direct comparisons of husbandry practices between Blocks or even between groups of Blocks. Thus, while acknowledging the slender basis for this hypothesis, it is offered here in the hope that future researchers may specifically address this problem.

\section{I7.3 The wildscape}

Apart from the cultivated crops, dairy products, beef, mutton and pork the inhabitants of these sites also exploited the natural resources of the islands. The surviving evidence for this is largely the result of hunting and trapping animals, birds and fish and the collection of shellfish but the seeds and fruits and other parts of uncultivated vegetation were probably also gathered. The difficulty of distinguishing between such deliberately introduced 'weed' species and the weeds of cultivation or vegetable matter introduced to the sites in fodder or fuel has already been touched upon. Although drawn from a much later period, Margaret Bennett's Plant lore in Gaelic Scotland (1991) records some of the traditional uses of wild plants of the Hebrides. The stinging nettle Deanntag is often now observed on old midden sites because of its attraction to phosphate-, and nitrate-rich soils and it may well have flourished in such locations in the past from which nettletops could have been collected for soups and teas. Silverweed, whose pollen may occur but are included in the taxon Rosaceae was known to the Gael as Brisgean and, 'Before the introduction of the potato...[it]...was commonly boiled, roasted on a fire or dried and ground into meal for bread-making or porridge.' (ibid, 56). Similarly, white and pink stonecrop were considered a delicacy and, no doubt many other naturally occurring plant foods were exploited. Medicines for the treatment of scurvy included nettles and scurvy grass, both rich in ascorbic acid while fevers were treated with feverfew or a tea decocted from violets, while tansy was used in the treatment of worms. Dye plants included sundew, bog myrtle, yellow flag and lady's bedstraw while heather (Calluna vulgaris) was used as a dye, for roofing, as bedding and for tanning and brewing. The multiple uses of the ling heather may account for its relatively frequent appearances in pollen and macro-plant samples. Certainly, in the absence of oaks for 'tanbark' other sources of vegetable tannins must have been pressed into use. While we have no direct evidence for these uses of the vegetation of the ambient wildscape, it seems useful to recall their existence not least because their exploitation may always have been essential for the provision of trace elements and vitamins in a diet that otherwise lacked them.

In contrast, direct evidence for the exploitation of wild animals is provided by the recovery of bone and antler from the machair sites. Bones of red deer, roe deer, common seal and otter have been recovered from Baleshare and Hornish Point, albeit in small numbers. Serjeantson (infra) has noted that wild fowl were exploited as a casual, rather than a major resource. Fish, however, seem to have been rather more systematically exploited. Jones (infra) has noted the presence of sharks, large gadoids, wrasse, mackerel and a variety of flat fishes. These were identified from the retent of the $5 \mathrm{~mm}$ mesh sieves and examination of the smaller fraction would clearly expand the list of species taken and enhance our perception of the part played by fish in the prehistoric diet of these settlements. Jones suggests that the larger fish were taken on hand lines and the shoaling fish, probably by hand netting. Clearly boats were used in this process, albeit that no other evidence for their existence has been noted.

The paucity of the remains of wild animal species is not very surprising given the restricted landmass of the Uists and the restricted range of wild species available. However, the 
low level of exploitation of the bird population, especially the migratory fowl, is surprising, given their seasonal abundance and the ease with which the young, in particular, can be taken. The extensive cropping of the gannets of St Kilda, for example, may well have been a reaction in extremis to an extremely poor environment (a view shared by many who have tried to eat one) but at least it shows the potential input these creatures could have made. Perhaps further excavation will change this picture but, on the present evidence the failure to exploit the seasonal abundance of protein represented by the migratory fowl, suggests that although the domestic economy of the sites was a subsistence economy, it was not a poor one. Alternatively, perhaps the fowl were harvested but formed part of the 'invisible exports' of the sites.

\section{I7.4 Landholdings}

The bones of the domesticated animals did not display any of the dietary deficiency diseases which confinement to the machair would have entailed (Chapter 2.3.1). This implies that the settlements each had access to the grazings of the central and eastern heath and moorlands. The large volumes of peat evidenced at the sites confirm rights of access and of exploitation. Each site also had access to the shore for shellfish, seaweed and fishing and it must be remembered that the contemporaneous shorelines probably lay up to 500 to 750 $\mathrm{m}$ west of their present positions (Chapter 2.2). Taken together these imply that the landholding of each site should be envisaged as a strip of land running from the sea, over the machair, up the eastern hillslopes and down the other side to the east coast. It is not impossible that the eastern moorlands were held in common but prudent husbandry, based it is assumed on herding, militates against this.

It is not surprising that the individual holdings ran across the ecological zones of the islands. It maximises access to the range of available resources and is a common response to areas of high ecological gradients, from the earliest times. The Neolithic fields at Ceide, Co Mayo (Mitchell \& Ryan 1997, 185-6), the Bronze Age reaves on Dartmoor (Fleming 1988) and the medieval and post-medieval settlements of west coast Ireland (Mitchell \& Ryan 1997) and Scotland all provide examples of landholdings of this type.

Landholding in the Hebrides in the Dark Ages seems to have been based on the davach (dabhach), of gaelic Celtic origin, and the ounceland (tirunga), of Norse origin. The term davach means a vat or tub and, applied to landholdings, may have meant the area of arable land which yielded sufficient seed to fill such a vessel, or perhaps which required a davach full of seed to plant (Jackson 1972, 116). Dodgshon $(1981,75)$, while acknowledging that the term may have been used originally as a measure of agricultural productivity, suggests that it could also represent the output from an area of land which contained other non-productive parts or that it might represent the disposable product available for taxation, from a given area of land. Oram $(1987,49)$ has noted that the davach of the west of Scotland and the Hebrides was transmuted to the Norse ounceland and, as such, contained twenty pennylands, in contrast with the eighteen pennylands in the ouncelands of the east and north of Scotland. He equates these twenty sub-units with the groups of twenty households which formed units for naval assessment and recruitment in the Senchus Fer nAlban (Bannerman 1974), and imputes a Goidelic origin to the Dabhach. This implies that while the davach became either, or both, a specific unit of areal measure or a conceptual, financial, instrument, its origins are to be sought in the simple hierarchical relationships of twenty households to one overlord.

It is to the first millennium BC that Bangor-Jones (1987) looks for the origin of the landholding systems which, to paraphrase him, subsequently acquired Goidelic and Norse nomenclature. In this context, the Bronze Age seems to be the period when land management systems, like the Dartmoor reaves first give evidence for large scale control and organisation of the British landscape. However, we have so little evidence for Later Bronze Age settlements in the Outer Hebrides that this phenomenon is simply not observable there. By the later half of the first millennium bc, on the other hand, the Iron Age sites investigated in this project indicate that settlements controlling east-west strips of land were in contemporaneous occupation for at least part of the duration of occupation at each site. This is evidence for land management on a significant scale. Even relatively simple geographical modelling, using Tiessen polygons, tends to confirm this observation (Armit 1992, Ills 12.8). There is, therefore, evidence for the existence of a settlement hierarchy, in which the machair sites function, generally at the level of family farms, or perhaps as clachans, small groups of up to three or four households, practising mixed arable and dairy husbandry.

\subsubsection{Food storage and preparation}

No evidence was recovered for the bulk storage of cereal grain, fish or meat. Experimental evidence from Butser suggests that beehive shaped storage silos made from straw ropes could contain just over 1 tonne of seed grain; these could have coped with the needs even of the Bronze Age levels of Baleshare. We need not, therefore, be too surprised at not recovering evidence for bulk storage.

It was noted that the tops of the rim sherds of Iron Age vessels of the larger size range are commonly ground flat. It is suggested that this results from the use of stone lids for the vessels. The use of lids on the vessels further implies that they were used for the storage of some commodity and their size and fragility militate against their routine use for cooking. They could have been used to store food but even fresh water for these porous sites must have required some form of container and, no doubt, a number of other commodities that could have been stored in these vessels, ranging from shellfish to milk.

Sherds of the smaller pottery vessels are predominantly soot-encrusted and seem often to contain food residues. It seems reasonable to conclude that these are simple cooking vessels. The abundance of fragments of heat shattered stone on the sites' deposits has been noted by Collins (infra) as has its co-occurrence with other domestic refuse. These seem no more than the pot-boilers characteristic particularly of Iron Age sites like Stackpole Warren in Pembrokshire (Williams 1990) and which this writer has also identified on broch sites in Scotland (Barber 1990, 92-6). Collins noted the deliberate selection of rock types other than gneiss for this function. 
Even brief experience of heating gneiss in beach barbecue fires shows how this rock type disintegrates on roasting. While direct evidence for cooking troughs or pits is lacking, the abundance of heat shattered stone spalls demonstrates quite clearly that boiling of large volumes of water was routinely undertaken on the site. Of course, the uses to which the heated water could be put are many and varied, ranging from boiling large joints of meat through de-hairing skins to steam bathing or saunas.

Only one quern stone, the upper stone of a rotary quern was recovered from Baleshare. It was made from gneiss and where found, was re-used in the walling of the Block 8 entrance passage. This context dates from between 2260 and $2045 \mathrm{bp}$ and the date of the quern is much more likely to lie closer to the earlier than the later boundary of this range. It provides evidence for the milling of barley, which, even had it been absent we might reasonably have anticipated. Bere bannocks and similar unleavened breads (Lerche 1975) were no doubt cooked on heated slabs beside the hearth.

Caulfield $(1978,137)$ suggests that replacement of the saddle type of quern by rotary types had taken place in the Hebrides before the brochs were built. The example from Baleshare does not contradict this hypothesis.

\section{I8 THE ATLANTIC SETTLEMENTS OF THE WESTERN ISLES}

Dennis Harding described the settlers of the Atlantic Iron Age as a 'community of economy and culture' that could be clearly distinguished from the cultures of regions to the south and east with traditions that lay within the Hallstatt and La Tène mainstream of central and western Europe $(1984,206)$. In suggesting this he was giving voice to what can be described as the insular view of the Atlantic Iron Age. It is a feature of many papers written before Harding's 1984 paper and of virtually all papers written since, that discussion of the Atlantic Iron Age is confined to the sites attributed to the Atlantic Iron Age, virtually without reference to developments in Europe and in Britain south of Scotland's central belt. Harding (ibid) clearly includes Ireland in his Atlantic Iron Age suggesting that '...we should be emphasising the relationships between brochs, duns and Irish cashels or cathairs as regional variants on a similar theme...'

Writing in 1990, Harding had asserted that '...what the Atlantic Iron Age emphatically is not is either 'peripheral' or 'marginal'...' and founded this assertion on two factors; firstly, that the resource diversity of the Atlantic zone would render settlement there non-marginal while social and cultural peripherality was avoided by the existence of a '...maritime continuum, at least from the Northern Isles to southern Ireland, if not from Scandinavia to the Iberian peninsula...' (ibid, 16).

In essence then, Harding suggests that the current typologies were too inflexible to encompass the heterogeneity of the group of monuments attributed to the Atlantic Iron Age and too parochial to embrace comparanda in Ireland and elsewhere on the Atlantic rim. He suggests that the Atlantic rim formed a 'maritime continuum' in which Scotland's Western Isles would have had a central rather than a peripheral role and he asserts that the settlements were not marginal.

In suggesting that 'We are out of the claustrophobic little net of Victorian typology...' in our studies of brochs and re- lated structures, Hedges was more than a little optimistic $(1990,31)$. Harding had, in 1984, gone some way to agreeing with Hedge's proposition, at least in so far as he argued for the abandonment of formal typologies based on architectural detailing in favour of systems based on '...function within the settlement systems and economic strategies of Iron Age communities in Atlantic Scotland...' (Harding 1984, 206). However, by 1992, the confusing profusion of typologies was reduced to simplicity itself by Armit's declaration that sites previously described as brochs, galleried duns, island duns and forts were all in fact of one class, the class of Atlantic roundhouses $(1992,22)$.

Typologically coherent or not, the structures of the Atlantic Iron Age share a repertoire of architectural forms of which the most characteristic include deep narrow entrance passages with door jambs, bolt holes and guard cells, thick walled or sunken structures, intra-mural cells and galleries, scarcements and radial segmentation of the enclosed spaces. In varying combinations of all or parts of this list, these architectural symbols provide the syntactical elements of the semiotics of the structures of the Atlantic Iron Age (sensu Eco 1991, 1-13). The freedom with which their builders constructed 'statements' about themselves by selection of what they deemed appropriate syntactical elements is at the root of the failure of all attempts to provide classical typologies of these structures. The creation of the portmanteau class of Atlantic roundhouse is the final step towards the shedding of classical taxonomies and the acceptance that while homogeneous on one very large scale, the sites of this period in the north and west display such small scale heterogeneity that their further classification rapidly becomes meaningless. The continuing exclusion of the wheelhouses from this portmanteau class is illogical, based as it seems to be on the distinction between freestanding and dug-in structures, and these also should be seen as part of the more general scheme.

The chronology of Atlantic roundhouses of the Western Isles is very poorly understood. Largely on the basis of Orcadian evidence, Armit suggests that they were built over the period $400 \mathrm{BC}$ to $100 \mathrm{AD}$, in calendar years (Armit 1992). The chronology of the wheelhouses of the Western Isles is equally poorly understood. Stevenson had attributed wheelhouses to the period between the third and seventh centuries $\mathrm{AD}$, on the basis of a rather weak argument for a late date for projecting, ring headed pins, and of pottery stamped therewith (Stevenson 1955). Foster (1990, 153-4) has included the projected ring-headed pins in her Group C which she seems to date to the Middle Iron Age to Late Iron Age II (her terminology) which, in turn, she dates to the first half of the first millennium AD, though this is by no means clear. Rejecting Stevenson's dating, Armit (1992, 69-70) suggests that wheelhouses date to the period between the fourth or third century BC and the first century AD. Note, however, that this is based in part on radiocarbon dates from the sites of Baleshare and Hornish Point and should not be interpreted as independent support for the dates they indicate. Our reservations about the chronological sensitivity of projecting ring-headed pins must persist despite Euan Campbell's (1998) suggestion that they can be treated as chronologically sensitive indicators if only we can ignore the early, disputed dates from Dun Mor Vaul and the late dates already rejected by Armit, as deriving from secondary uses of brochs and wheelhouses. 
Outside of the Western Isles, wheelhouses are said only to have been noted in Shetland, at Jarlshof and at Ward Hill (Armit 1992, 71) and are apparently absent from Orkney. However, this may be somewhat misleading. The secondary use of the broch at Howe, for example (Ballin Smith 1994, 84 ) involved the radial segmentation of the enclosed space in a fashion similar to the construction of wheelhouses. This writer has noted similar segmentation in the broch at the Pool of Virkie, but is of the opinion that there, the segmented interior was a primary feature of the broch. None the less, the absence of wheelhouse structures from Orkney may be more apparent than real. This writer has suggested elsewhere that the absence of small chambered tombs from the better lands in Orkney is an artefact of survival (Barber 1992, 29). Continuous cultivation has resulted in the removal of the smaller structures from the cultivated areas of Orkney leaving only the truly massive sites, like Maes Howe, while lesser sites survive only in the more marginal areas and islands of the archipelago. If, as the evidence from the current excavations suggests, the wheelhouses are farmsteads they may only have been built on the better land available and may, in Orkney, have been preferentially removed or slighted and concealed by ploughing.

\subsection{Cognate structures and their relationships}

Various authors have addressed the question of the origins of the Atlantic roundhouse and currently seek their predecessors within north and west Scotland, in the simple roundhouses of the early first millennium BC. Cellular structures with a clear central area, often containing a hearth, and surrounded by a series of cells of corbelled construction usually contained within an oval structure, occur from the Neolithic Period to the Dark Ages in the Northern and Western Isles. Houses 7, 8 and 9 at Skara Brae, Orkney and the houses at Staneydale and Gruting School, Shetland are Neolithic examples of this type (see Ritchie \& Ritchie 1981, 36, for summary) while elements of radial segmentation can be seen even in the Neolithic houses at Knap of Howar, Holm of Papa Westray and Rinyo (ibid). The later, Iron Age, structures at a number of Hebridean sites are also described as cellular (Armit 1992, Chapter 7) and some cellular structures of dates ranging from the first to the eighth centuries $\mathrm{AD}$ also fall into this category (ibid). The so called 'Pictish' houses of Buckquoy (Ritchie 1977), Pool (Hunter 1990) and elsewhere in the Northern Isles are also of this general type.

The outstanding difference between cellular structures and the wheelhouse appears to be that the wheelhouse is a radially segmented circular structure while the cellular structure is oval or irregular in overall plan. The existence of a long and continuing tradition of cellular construction prompts the speculation that the wheelhouse is little more than a mid-first millennium $\mathrm{BC}$ rectification of the basic building style of the north and west of Scotland. It invites the further conclusion that there is a continuity of architectural tradition over this very long time span. However, it is important to be aware of the limitations that constrained the architectural possibilities of both areas. To begin with, wood was either not available or was in severely short supply and so providing roofs for structures presented grave difficulties. In practice earth and stone were the only constructional ma- terials that were readily available and in neither area was the quality of the available stone ideal for building (contrary to common perception, the stone of the northern mainland and the islands is very weak in tension and is a poor building material). Thus corbelling emerged as the basic constructional technique.

This writer has shown elsewhere (Barber 1992, 18) that corbelled structures, when free standing, require an enclosing wall whose thickness amounts to some $60 \%$ or more of the width of the enclosed floor. Corbelled structures, if they are to provide sufficient head room for normal activities also need to be very high in proportion to the width of the floor. Thus relatively large volumes of stones must be used to acquire relatively modest volumes of internal space. Dry stone structures provide ideal mechanisms for the condensation of water vapour from moisture laden winds and, from personal observations on Ireland's south-west coast, can be damp or even wet, on a mild summer's day. Their permeability to winds is best demonstrated by their use as drying sheds for gannet carcasses on St Kilda, in the more recent past (Emery 1996, 182). The addition of a turf covering, held in place by an outer stoneface has been noted at corbelled structures of the Early Christian period in Ireland (at Reask, for example; Fanning 1981). This would have provided damp-, and draft-proofing but its existence, taken together with the common observation of drains in the floors of these structures, attests to their dampness. Armit observed midden packed into the upper parts of Wheelhouses 1 and 2 at Cnip which undoubtedly fulfilled the same function (1990, 84-5).

High, thick-walled, drafty and damp, freestanding corbelled structures clearly did not appeal to the Early Iron Age settlers of the north and west of Scotland. As noted above, the Hebrides have the second highest recorded mean wind speeds on earth and high humidity all year round. While occasional corbelled cells occur, the ubiquitous clochain of the Irish mid-, and south-west coasts was clearly inappropriate to the settlers of the Scottish north and west coasts and their exploitation of the principles of corbelling has led them along quite another path.

In the absence of adequate building material and especially in the absence of an adequate supply of timber for roofing, one response in the west and north of Scotland has been to create structures by digging them into appropriate sediments for shelter and damp-proofing and by creating within them smaller spaces that were individually roofed by corbelling, thus avoiding the need to roof a large void. Corbelling was also used in revetting the enclosing sediments, exploiting its 'horizontal arch' effect. Given the severe physical conditions and the equally severe limitations on constructional possibilities, the commonality of response in most periods from the Neolithic to the recent past is neither surprising nor indicative of continuity of tradition. Bronze Age cellular structures need not be seen as the evolutionary forebears of the 'cellular structures' of the Atlantic Iron Age, whether this description is restricted to Armit's use thereof or to the entire class of Atlantic round houses.

Harding has argued that the brochs and duns with diameters of less than fifty feet (roughly $15 \mathrm{~m}$ ) were roofed (1984, 218-9). He suggests that apart from driftwood, supplies of timber may have been imported from the mainland or the inner Hebrides. Certainly, by the sixth century AD this was possible, with wattles from Mull and timbers from the main- 
land being imported to Iona, if Adomnan's Life of Columba is to be believed (Anderson \& Anderson 1961). However, in the Iron Age Hebrides, timber would have been a scarce and valuable resource. The restriction of this resource to the brochs and duns may provide evidence for the lowly status of wheelhouses which had to use corbelled radial cells to reduce their dependence on large timbers.

This writer has suggested elsewhere that there are grounds for viewing the whole of the complex, including the wheelhouses, as providing evidence for social stratification (Barber 1985). Given the scales of difference in bulk, in enclosed areas, in enclosed volumes, in man-hours of work required in construction and in 'monumentality' these sites simply cannot have all served the same class of occupant. This statement is implicit to Fojut's conclusion that the answer to the question 'Is Mousa a broch?' must be yes but no other broch is a Mousa $(1981,227)$, implying that there is some stratification even within the restricted class of brochs. The emergence of nucleated settlements around many of the Orcadian and Shetland brochs like the Howe (Ballin Smith 1994) and Jarlshof (Hamilton 1956) suggests that some, at least, of the larger sites continued to serve as focal centres up to and perhaps after the advent of the Norse. That such developments apparently did not take place in the Western Isles is not without its significance for our understanding of social developments in this area.

\subsection{SETTLEMENTS AND MARGINALITY}

\section{I9.I Marginality of cultivation}

Harding's assertion (above) that the settlements of the Western Isles were not marginal is unsupported by any evidence. It may simply be an emotional rejection of an apparently unacceptable judgement made on the lives and conditions of Iron Age Hebrideans. However, that is not what is implied by the term marginality in its use here. Rather areas are deemed marginal if they incur a high probability of failure of the subsistence basis on which settlement depends. The work of Parry on the abandonment of Mediaeval farmsteads in the Lammermuirs, in the face of the deteriorating climate during the Little Ice Age, provides us with a potentially quantifiable definition of this type of marginality (Parry 1978).

Parry first established the limiting conditions for the growth of the main cereal crop, measured in day-degrees, centigrade above a given base $\left(4^{\circ} \mathrm{C}\right)$, millimetres of potential soil water deficit and exposure, measured in wind rates in metres per second. Sites, or areas which lie at or close to these limiting conditions can be said to be marginal for cultivation. Parry identified the conditions under which two out of three crops would fail (at the $95 \%$ probability level), and he postulated that abandonment of settlement would necessarily occur at this level of marginality. Thus, marginality is a measure of settlement potential, not a value judgement. On this objective measure, the Western Isles is certainly and demonstrably marginal at the present time, and was perhaps more so during the Atlantic Iron Age (pace Harding).

However, resource diversity goes some way to limiting the affects of the physical marginality of their cultivation. Fishing, fowling and hunting were all practised, on the evidence of the current excavations. The reduction of the scale of agriculture to market gardening may well have been a response to the marginalisation of cultivation in the more severe climatic conditions of the Atlantic Period and the shelter provided by existing structures or by the mound of the sites' deposits could have made the difference between success and failure in bringing in a crop. However, the small scale of cultivation, limited hunting and gathering and the limited exploitation of domesticates for meat may be interpreted as supporting the idea that dairying had emerged as the principal subsistence strategy, ie that the secondary products revolution had at last reached the Hebrides.

\subsubsection{Marginality of technology}

The absence of metalwork, especially of iron, from the sites' deposits has been shown to be an absence of evidence rather than evidence of absence. Hammer scale attests to blacksmithing on these sites and the butchery marks of animal, bird and fish bone attest to the use of edged metal implements while the worked bone and antler prove the existence of a relatively extensive tool-kit. Therefore, the material marginality of these sites during the Iron Age period is not really a marginality of technology, but of resource availability.

The restriction on availability seems to have affected the whole of Scotland and to have persisted into the first millennium $\mathrm{AD}$. Writing in the first quarter of the third century AD, the Greek historian Herodian observed that the people of Scotland valued iron as highly as gold (Histories, iii, 14,7) and, for once, the archaeological and historical records seem in accord. Manning (1981) cites the report by Callendar and Grant (1934) on the excavations at the broch of Midhowe to show that some brochs suffer a similar mismatch of evidence for iron working but no surviving ironwork. In the case of Midhowe, large amounts of iron slag, indicative of iron smelting on site, were recovered. Indeed, Manning goes further (ibid, 57-61) by suggesting that the three hoards discussed by Piggott (1955) as the only undoubtedly 'native' hoards from Scotland were not in fact native but the possessions of auxiliaries or mercenaries gained in service in southern England.

In his listing of seventeen wheelhouses in the Outer Hebrides Armit (1992 Chapter 6) does not record a single instance of finds of iron objects or of slags or mould fragments associated with iron working. In contrast, three of the thirteen sites in his portmanteau class of Atlantic roundhouse (ibid, Chapter 5) contained some such evidence, viz Rudh a Duin, Vallay, fragments of an iron sword with scabbard; Dun a Ghallain, iron rivets, dirk and curved knife; Buaile Risary, rivets; in addition a whetstone was recovered from Eilean a Ghallain and triangular crucibles from Dun Barabhat and Buaile Risary. Excavated brochs in the Northern Isles have produced abundant evidence for iron smelting and iron working, as well as for the production of relatively high status bronze objects. The Howe (Ballin Smith 1994, 228-234) produced over 200 iron objects and almost $200 \mathrm{~kg}$ of slag, including nine plano-convex slag cakes together with fragments of furnace linings and tuyeres. Some five furnace bottoms were recovered from Crosskirk, together with further slags and some iron, the latter poorly preserved because of the adverse depositional environment, and two crucible fragments (Fairhurst 1984, 118-9). Similar assemblages were recorded from the broch at $\mathrm{Bu}$ (Hedges 1987). 
It has been argued above that the chronologies of brochs, or Atlantic roundhouses and wheelhouses probably overlap significantly. This writer has argued elsewhere that these various structures may reflect an hierarchy of settlement with the broch placed higher than the wheelhouse in that hierarchy (Barber 1985). Given the presence of iron smelting on brochs and its absence from wheelhouses, we may wonder whether the control of the supply of iron was part of the mechanism by which political and social control was exercised by the broch occupiers, or some other 'overlords', over the farms of the wheelhouse dwellers. Legitimising the relationship between tenant and landlord by the gifting of equipment is characteristic of one of the forms of clientship practised during the later, Dark Age periods of Scotland and Ireland (Kelly 1988, 29). Charles-Edwards (1993, 522) comments on an early Welsh law on inheritance, that required that '...the youngest son gets the special homestead and eight acres and all the equipment and the cauldron and the wood-axe and the coulter'. This suggests that the gifting of equipment and its attendant obligations possibly extended over successive generations. Perhaps we should consider the relationship between the dwellers in brochs and those in wheelhouses as a precursor to base clientship. Extending 'known' Dark Age social institutions into the Iron Age is always dangerous but we do have some other indications in its favour. Among these the survival of the twenty pennyland ouncelands discussed in Chapter 18.17.4 may be noted.

The use of iron as a medium of exchange between tenant and landlord emphasises the scarcity of the raw metal and, even among the brochs, the volume of recovered iron objects is very small. The scarcity of ironwork and of high-status, ornamented bronzes on sites of the Early Iron Age in Scotland is also reflected in the distribution of artefacts bearing $\mathrm{La}$ Tène ornament. Such artefacts are found in a sparse scatter across the central belt of Scotland and into the Southern Uplands with none in the north or west of the mainland nor in the Hebrides (see Cunliffe 1978, fig 14:13, for a typical example). This contrasts with the Irish distributions of similar materials which show concentrations in the northern half to two-thirds of the country with few or none in the south (Raftery 1994, passim).

\subsubsection{Marginality of culture}

The Ritchies, among many other authors, have noted the profound changes in the archaeological record of Scotland in the middle of the first millennium BC, to which period they also attribute the introduction of P-Celtic (1981, Chapter 5). In neighbouring Ireland, save only for the linguistic change, the same scale of change is clearly detectable (Raftery 1994) and in the southern half of Scotland and northern half of Ireland these changes are associated with the cultural group characterised by the title 'La Tène' because the diagnostic artefacts of the period bear artistic motifs of the La Tène tradition. These Iron Age, possibly Celtic, peoples had emerged in central Europe as an identifiable archaeological cultural grouping designated the Hallstatt culture. In these islands, Hallstatt forms appear in bronze, in a limited range and without replacing the existing later Bronze Age implements. There is cause, therefore, to suggest that these Halstatt additions to an existing culture represent the arrival of influences and the diffusion of styles and ideas. However, the changes noted by the Ritchies (1981), including the alteration of language, introduction of a new technology, use of the technology to alter social control over landholding, and the evolution of new settlement forms, all seem to this writer to be explicable only in terms of an actual movement of some people.

This writer is aware of just how unfashionable this interpretation of events may prove, not least because of Raftery's recent exegesis on this subject $(1994,224)$. Despite changes to material objects and settlement forms some orders of magnitude greater than those observable in Scotland, despite the existence of a strong hagiographical tradition in support of invasion, despite the presence on Ptolemy's map of Ireland (arguably based on first century AD information) of the names of European tribes (Cauci and Menapii from north Europe, Brigantes from the north of England) and despite a long sanguinary history, replete with large-scale migrations, in the succeeding period, Raftery suggests that all the observed changes are due to the diffusion of ideas rather than the movement of peoples. It is not impossible that this is the correct interpretation of events and, certainly, invasions have been invoked in archaeological interpretations in the past to account for relatively trivial changes but to deny all possibility of invasion does not seem wise. Similarly, in the Outer Hebrides, it would not be wise to dismiss the possibility of invasion given the later movement of the Norse to that area (most of the placenames in the Hebrides are Norse in origin). However, the invocation of invasion to explain changes in material culture does not deny the observable continuity of indigenous people and the artefacts of their existences. MacSween (above) suggests that the considerable differences between the ceramic assemblages of the Bronze and Iron Ages arise by accumulation of new traits rather than by any single dramatic change. Similarly, we have noted above the continuity in architectural styles based on corbelling throughout the prehistoric period in the islands albeit that this can be attributed to the paucity of good building materials. However, the fact that we can explain change as incremental or continuity as imposed does not rule out the possibility, indeed the likelihood, of what the indigenes would have regarded as invasion even if we interpret that as no more than the alternation of one ruling elite with another.

\subsubsection{Marginal but not meagre}

The wheelhouses then may be seen as the habitations of farmers practising mixed dairy farming in a socially and politically managed landscape and receiving the necessary iron implements of their trade as part of their 'tenancy' or clientship agreement. The physical marginality and resource poverty of their environment facilitated their social and political control but their settlements clearly cannot have been at subsistence level. A subsistence level settlement produces all that it consumes, and usually, vice versa also. However, metalwork was brought to these sites as finished products, manufactured elsewhere. Thus some tradeable surplus must have existed and it is most probable that this comprised organic materials, amongst which butter and cheese are likely to have been included. Thus, although marginal, these sites were not individual subsistence settlements but formed part of a larger polity. 


\section{BIBLIOGRAPHY}

Alcock, L 1972 'The Irish Sea zone in the pre-Roman Iron Age', in Thomas, C (ed) The Iron Age in the Irish Sea Province, 99-112. CBA Res Rep No 9.

Andersen, S Th 1979 'Identification of wild grasses and cereal pollen’, Danmarks Geologiske Undersögelse Årbog 1978, 69-92.

Anderson, A O \& Anderson, M O 1961 Adomnan's Life of Columba. London. Nelson \& Sons.

Anderson, J 1883 Scotland in Pagan Times: The Iron Age. Edinburgh.

Armit, I 1987 Excavation of a Neolithic island settlement at Loch Olabhat, North Uist 1987. Edinburgh: Edinburgh Univ Dept Archaeol Occ Paper No 8.

Armit, I 1988 Excavations at Loch Olabhat, North Uist, 1988. Edinburgh: Edinburgh Univ Dept Archaeol Occ Paper No 10.

Armit, I (ed) 1990 Beyond the brochs: changing perspectives on the Later Iron Age in Atlantic Scotland. Edinburgh: EUP.

Armit, I 1992 The Later Prehistory of the Western Isles of Scotland. Oxford: BAR British Series (= Brit Archaeol Rep Brit Ser, 221).

Armit, I 1993 'Baleshare, North Uist', Discovery Excav Scot 1993, 113.

Armit, I 1996 The archaeology of Skye and the Western Isles. Edinburgh: EUP.

Armitage, P L 1975 'The extraction and identification of opal phytoliths from the teeth of ungulates' J Archaeol Sci 2, 187-195.

Ashmore, P J 1995 Callanais. The standing stones. Inverness: Highland Printers.

Avery, B W 1980 Soil classification for England and Wales. Soil Survey Technical Monog 14. Harpenden.

BA 1997 'Man-made fields in Bronze Age Shetland', British Archaeol 21, 5.

Baden-Powell, D \& Elton, C 1937 'On the relation between a raised beach and an Iron Age midden on the Island of Lewis, Outer Hebrides’ Proc Soc Antiq Scot 71, 347-365.

Baillie, M G L \& Pilcher, J R 1983 'Some observations on the high-precision calibration of routine dates', in Ottaway, B S (ed), Archaeology, dendrochronology and the radiocarbon calibration curve, 51-63. Edinburgh: Univ Edinburgh Dept Archaeol Occ Paper No 9.

Baker, G 1959a 'Fossil opal phytoliths and phytolith nomenclature' Australian J Sci 21, 305-306.

Baker, G 1959b ‘Opal phytoliths in some Victorian soils and “red rain” residues’, Australian J Botany 7, 64-87.

Baker, J R \& Britt, D P 1984 'Dental calculus and periodontal disease in sheep', Veterinary Record 20, 411-12.

Baldwin, J R 1982 'Fishing the sellag: hand netting traditions from Caithness, the Northern and Western Isles', in Baldwin, J R (ed) Caithness: A cultural crossroads, 161-212. Edinburgh: Edina Press Ltd.

Ballin Smith, B 1994 Howe: four millennia of Orkney Prehistory. Soc Antiq Scot Monog 9. Edinburgh.

Bangor-Jones, M 1987 'Ouncelands and Pennylands in Sutherland and Caithness', in Macgregor, L J \& Crawford, B E (eds) 1987, 13-23.

Bannerman, J 1974 Studies in the History of Dalriada. Edinburgh: Scottish Academic Press.

Barber, H G \& Haworth, E Y 1981 A Guide to the Morphology of the Diatom Frustule. Freshwater Biological Association Scientific Publication 44.

Barber, J 1981 'Excavations on Iona, 1979’, Proc Soc Antiq Scot 111, 282-380.

Barber, J 1985 Innsegall. Edinburgh: John Donald. 
Barber, J 1986 'A comment on Dalland and Harris’, Scot Archaeol Rev 4.1, 49-52.

Barber, J 1987 'The Western Isles project: coring at Baleshare', CEU \& AML Annual Report, 51-4.

Barber, J 1988 'Isbister, Quanterness and the Point of Cott: the formulation and testing of some middle range theory', in Barrett, $\mathrm{J} \&$ Kinnes, I (eds) The archaeology of context in the Neolithic and Bronze Age: recent trends, 57-62. Sheffield: Collis Publications.

Barber, J 1990 'Burnt mound material on settlement sites in Scotland', in Buckley, V (comp) 1990, 92-7.

Barber, J 1992 'Megalithic Architecture', in Sharples, N \& Sheridan, A (eds) Vessels for the Ancestors, 1-31. Edinburgh: EUP.

Barber, J (ed) 1993 Interpreting Stratigraphy. Edinburgh: AOC (Scotland) Ltd.

Barber, J 1997 The archaeological investigation of a prehistoric landscape: excavations on Arran 1978-81. Edinburgh: STAR.

Barber, J \& Brown, M 1984 ‘An Sithean, Islay’, Proc Soc Antiq Scot 114, 161-188

Barber, J, Halstead P, James, H \& Lee, F 1989 'An unusual Iron Age burial at Hornish Point, South Uist', Antiquity 241, 773-8.

Barber, J \& Crone, A 1993 'Crannogs; a diminishing resource? A survey of the crannogs of southwest Scotland and excavations at Buiston Crannog', Antiquity 67, 520-33.

Barber, J W \& Crone, B A forthcoming 'The duration of structures, settlements and sites: some evidence from Scotland', Proceedings WARP 1998 conference. Dublin.

Barker, G 1985 Prehistoric Farming in Europe. Cambridge: CUP.

Basset, J A \& Curtis, T G 1985 'The nature and occurence of sand-dune machair in Ireland', Proc Roy Irish Acad 85B, 1-20.

Battarbee, R W 1979 'Diatoms in lake sediments', in Berglund, B E (ed) Paleohydrological changes in the Temperate Zone in the last 15,000 years. Sweden: Univ Lund.

Bennett, M 1991 Plant lore in Gaelic Scotland. Edinburgh: Polygon.

Benninghoff, W S 1962 'Calculation of pollen and spore density in sediments by addition of exotic pollen in known quantities', Pollen et Spores 4, 332-333.

Berggren, G 1969 Atlas of seeds: Part 2 Cyperaceae. Stockholm.

Bernas, B 1978 'Acid pressure decomposition for interference-free A.A analysis', Spectroscopy Ser II, 48-51.

Berry, A C \& Berry, R J 1967 'Epigenetic variations in the human cranium’, J Anatomy 101 (2), 361-379.

Berry, R J 1979 'The Outer Hebrides: where genes and geography meet’ in Boyd, J M (ed) 1979, 21-43.

Bertelsen, R 1979 'Farm mounds in Norway: a review of recent research', Norwegian Archaeol Rev 12, 48-56.

Bevan, B (ed) 1999 Northern exposure: interpretative devolution and the Iron Ages in Britain . Leicester: Leicester Univ Archaeol Monog 4.

Beveridge, E 1911 North Uist, its Archaeology and Topography. Edinburgh. William Brown.

Beveridge, E \& Callander, J G 1931 'Excavations of an earth-house at Foshigarry, and a fort, Dun Thomaidh, in North Uist', Proc Soc Antiq Scot 65, 299-357.

Beveridge, E \& Callander, J G 1932 'Earth-houses at Garry Iochdrach and Bac Mhic Connain in North Uist', Proc Soc Antiq Scot $66,32-66$.

Binford, L R 1981 Bones. Ancient men and modern myths. New York: Academic Press. 
Binford, L R \& Bertram, J B 1977 'Bone frequencies and attritional processes' in Binford, L R (ed) For Theory Building in Archaeology, 77-153. New York: Academic Press.

Birks, H J B 1973 The past and present vegetation of the the Isle of Skye - a palaeological study. Cambridge: CUP.

Birks, H J B 1977 'The Flandrian forest history of Scotland: a preliminary synthesis', in British Quaternary Studies - Recent Advances, 119-135. Oxford: Clarendon Press.

Birks, H J B \& Madsen, B J 1979 'Flandrian vegetational history of Little Loch Roag, Isle of Lewis, Scotland', J Ecol 67, 825-842.

Birks, H J B \& Birks, H H 1980 Quaternary Paleoecology. London: Edward Arnold.

Birks, H J B \& Williams, W 1983 'Late Quaternary vegetational history of the Inner Hebrides', Proc Royal Soc Edin 83, 269-292.

Blackburn, K B 1946 'On a peat from the island of Barra, Outer Hebrides. Dates for the study of post-glacial history', New Phytol 45, 44-49.

Boardman, S 1987 .. with unquenchable fire: Re-evaluating the evidence for more recent approaches to archaeobotanical data . Univ Sheffield: unpubl BA diss.

Boerboom, H J A 1963 'Het verband tussen bodemen vegetatie in de Wasssenaarse duinen' Boor en Spade 13, 120-55.

Boessneck, J, Muller, H-H, Teichert, M 1964 'Osteologische Unterscheigungsmerkmale zwischen Schaf (Ovis aries Linne) und Ziege (Capra hircus Linne)', Kuhn-Archiv 78, 1-29.

Bohncke, S J P 1988 'Vegetation and habitation history of the Callanish area, Isle of Lewis, Scotland', in Birks, H H, Birks, H J B, Laland, P E \& Moe, D (eds) The Cultural Landscape - Past, Present and Future, 445-61. Cambridge: CUP.

Bohncke, S J P \& Cowie, T G forthcoming 'Excavation and palaeoecological study of walls buried in peat near Callanish, Isle of Lewis, 1977-79'.

Bonny, A P 1972 ‘A method for determining absolute pollen frequencies in lake sediments’, New Phytologist 71, 393-405.

Bonsall, C (ed) 1989 The Mesolithic in Europe: Papers presented to the 3rd International Mesolithic Symposium 1985 Edinburgh. Edinburgh: John Donald.

Boorman, L A 1977 'Sand-dunes’, in Barnes, R S K (ed) The Coastline, 161-197. Chichester: John Wiley \& Sons.

Boulton, G S, Jones, A S, Clayton, K M \& Kenning, M J 1977 'A British ice sheet model and patterns of glacial erosion and deposition in Britain', in Shotton, F W (ed) 1977 British Quaternary Studies - Recent Advances, 231-46. Oxford: OUP.

Bowen, H C \& Fowler, P J (eds) 1978 Early Land Allotment in the British Isles: A survey of recent work. Oxford: BAR British Series (= Brit Archaeol Rep Brit Ser, 48).

Boyd, J M (ed) 1979 The Natural Environment of the Outer Hebrides. Proc Roy Soc Edinb 77B.

Boyd, J M 1979 'The Natural Environment of the Outer Hebrides', in Boyd, J M (ed) 1979, 3-19.

Bradshaw, R H W 1985 'Paleoecology: General Review', in Thorn, R H (ed) Sligo and West Leitrim, 16-21. Dublin: Irish Association for Quaternary Studies Field Guide 8.

Brady, N C 1974 The Nature and Properties of Soils. 8th edition. London: Macmillan.

Braithwaite, M 1982 'Decoration as ritual symbol: a theoretical proposal and an ethnographic study in southern Sudan', in Hodder, I (ed) 1982, Symbolic and structural archaeology, 80-88. Cambridge: CUP.

Branigan, K \& Foster, P 1995 Barra. Archaeological research on Ben Tangaval. Sheffield: Sheffield Academic Press.

Brayshay, B 1999 'The pollen analysis of the gallery deposits', in Parker-Pearson \& Sharples, N 1999, 91. 
Brayshay, B \& Edwards, K 1996 'Late-glacial and Holocene vegetational history of South Uist and Barra', in Gilbertson et al (eds) $1996,13-26$.

Brothwell, D R \& Powers, R 1968 'Congenital malformations of the skeleton in earlier man', in Brothwell, D (ed) The Skeletal Biology of Earlier Populations, 172-203. London: Pergamon Press.

Brothwell, D R 1972 Digging up Bones. London: British Museum.

Brown, D A 1984 'Prospects and limits of a phytolith key for grasses in the central United States', J Archaeol Sci 11, 345-368.

Buckley, V (comp) 1990 Burnt Offerings - International Contributions to Burnt Mound Archaeology. Dublin: Wordwell Ltd.

Burgess, C \& Miket, R (eds) 1976 Settlement and Economy in the third and second millenia BC. Oxford: BAR British series (=Brit Archaeol Rep Brit Ser, 33).

Burl, A 1976 The Stone Circles of the British Isles. Yale: Yale Univ Press.

Burleigh, R, Evans, J G \& Simpson, D D A 1973 'Radiocarbon dates for Northton, Outer Hebrides', Antiquity 47, 61-64.

Cain, A J, Cameron, R A D \& Parkin, D T 1969 'Ecology and variation of some Helicelid snails in Northern Scotland', Proc Malac Soc Lond 38, 269-99.

Caird, J B 1979 'Land use in the Uists since 1800', Proc Roy Soc Edin 77B, 505-526.

Callander, J G 1921 'Report on the excavation of Dun Beag, a broch near Struan, Skye', Proc Soc Antiq Scot 55, 110-131.

Callander, J G \& Grant, W G 1934 ‘The Broch of Midhowe, Rousay, Orkney’, Proc Soc Antiq Scot 68, 444-516.

Campbell, R N \& Williamson, R B 1979 'The fishes of inland waters in the Outer Hebrides', in Boyd, J R (ed) 1979, $377-393$.

Campbell, E 1991 'Excavation of a wheelhouse and other Iron Age structures at Sollas, North Uist, by R J C Atkinson in 1957', Proc Soc Antiq Scot 121, 117-173.

Cannell, R Q, Belford, R K \& Gales, K 1980 'Effects of waterlogging at different stages of development on growth and yield of winter wheat', J Sci Food Agric 31, 117-32.

Carter, S P, McCullagh, R P J \& MacSween, A 1995 'The Iron Age in Shetland: excavations at five sites threatened by coastal erosion', Proc Soc Antiq Scot 125, 429-482.

Catt, J A 1994 'Long-term consequences of using artificial and organic fertilisers: the Rothamsted Experiments', in Foster, S \& Smout, C (eds) 1994 The History of Soils and Field Systems, 119-134. Aberdeen: Scottish Cultural Press.

Caulfield, S 1978 'Neolithic fields: the Irish evidence' in Bowen, H C \& Fowler, P J (eds) 1978, 137-143.

Caulfield, S 1978 'Quern replacement and the origin of the brochs', Proc Soc Antiq Scot 109, 129-39.

Charles-Edwards, T M 1993 Early Irish and Welsh Kinship. Oxford: OUP.

Childe V G 1935 Prehistory of Scotland. Edinburgh: EUP.

Clapham, A R, Tutin, T G \& Warburg, E F 1962 Flora of the British Isles. 2nd edition. Cambridge: CUP.

Clarke, A D 1960 'Report on the Animal Remains in A Cheardach Mhor, Drimore, South Uist', in Young, A \& Richardson, K M 1960, 169-171.

Clarke, D L 1973 'Archaeology: the loss of innocence', Antiquity 47, 6-18.

Clarke, D V 1971 'Small finds in the Atlantic Province: problems of approach', Scott Archaeol Forum 3, $22-54$.

Clarke, D V \& Sharples, N 1985 'Settlements and subsistence in the 3rd millennium BC', in Renfrew, C (ed) The Prehistory of Orkney, 54-82. Edinburgh: EUP. 
Close-Brooks, J 1976 'New finds of late bronze-age spearheads from Scotland', Proc Soc Antiq Scot 107, 310-11.

Close-Brooks, J \& Maxwell, S 1974 'The Mackenzie Collection', Proc Soc Antiq Scot 105, 287-93.

Coles, J M 1960 'Scottish late bronze age metalwork: typology, distributions and chronology', Proc Soc Antiq Scot 93, 16-34.

Colley, S 1983 'Interpreting prehistoric fishing strategies: an Orkney case study', in Grigson, C \& Clutton-Brock, J (eds) Animals and archaeology: 2 Shell middens, fishes and birds, 157-171. Oxford: BAR International Series (= Brit Archaeol Rep Int Ser, 183).

Coward, M P 1977 'Anomalous glacial erratics in the southern part of the Outer Hebrides', Scot J Geol 13, $185-188$.

Cowles, G S 1978 'The bird bones', in Mercer, J 1978 'The investigation of the King's Cave, Isle of Jura', Glasgow Archaeol J 5 , 44-70.

Crabtree, K 1969 'Post-glacial diatom zonation of limnic deposits in North-Wales', Mitteilungen Internationale Vereininigung für Theoretische und Angewandte Limnologic 17, 163-171.

Crabtree, KP 1986 'Dairying in Irish prehistory', Expedition 28, 59-62.

Crawford, I A nd The West Highlands and Islands: A view of 50 centuries. The Udal (North Uist) Evidence. Cambridge: Great Auk Press.

Crawford, I A 1964 'Baleshare, N Uist', Discovery Excav Scot 1964, 33.

Crawford, I 1978 'Archaeological prospect and practical technique in an environmental region: the Western Isles machairs', World Archaeol 10, 51-62.

Crawford, I A 1980 Excavation and research at Coileagan an Udail, North Uist 1980. unpubl interim report.

Crawford, I A 1981 Excavation and research at Coileagan an Udail, North Uist 1981. unpubl interim report.

Crawford, I A 1983 'Contributions to a history of domestic settlement in North Uist', in O’Connor, A \& Clarke, D V (eds) 1983, 34-63.

Crawford, I A 1996 'The Udal', Current Archaeol 147 (3), 84-94.

Crawford, I A \& Switsur, R 1977 'Sandscaping and C-14; the Udal, North Uist', Antiquity 51, 124-136.

Crone, B A 1993 'Excavation and Survey of sub-peat features of Neolithic and Bronze Age date at Bharpa Carinish, North Uist, Scotland', Proc Prehist Soc 59, 361-382.

Crone, B A 2000 The history of a Scottish lowland crannog; excavations at Buiston, Ayrshire 1989-90. Edinburgh: STAR Monog 4.

Cunliffe, B 1978 Iron Age Communities in Britain. London: RKP.

Cunningham, W A J 1979 'Birds of the Outer Hebrides: terrestrial birds and raptors', in Boyd, J M (ed) 1979, $407-417$.

Currie, A 1979 'The vegetation of the Outer Hebrides', in Boyd, J M (ed) 1979, 219-65.

Darling, F F 1955 West Highland Survey. Oxford: OUP.

Darling, F F \& Boyd, J 1964 The Highlands and Islands. 2nd edition. London: Collins.

Davidson, D A, Lamb, R G \& Simpson, I A 1983 'Farm mounds in North Orkney: a preliminary report', Norwegian Archaeol Rev 16, 39-44.

Davidson, D A \& Simpson, I A 1994 'Soils and landscape history: case studies from the Northern Isles of Scotland', in Foster, S \& Smout, C (eds) 1994, 66-74. 
Davies, H C, Dobson, M R \& Whittington, J R 1984 'A revised seismic stratigraphy for Quaternary deposits on the inner continental shelf west of Scotland between $55^{\circ} 30^{\prime} \mathrm{N}$ and $57^{\circ} 30^{\prime} \mathrm{N}$ ', Boreas 13, 49-66.

Dean, W E 1974 'Determination of carbonate and organic matter in calcareous sediments and sedimentary rocks by loss on ignition: comparison with other methods', J Sedim Petrol 44, 242-248.

Deniz, E \& Payne, S 1982 'Eruption and wear in the mandibular dentition as a guide to ageing Turkish Angora goats', in Wilson, B, Grigson, C \& Payne, S (eds) 1982, 155-205.

Dickinson, G \& Randall, R E 1979 ‘An interpretation of machair vegetation’, in Boyd, J M (ed) 1979, 267-278.

Dickson, C A \& Dickson J H 1984 'The botany of the Crosskirk Broch site', in Fairhurst, H 1984, 147-155.

Dickson, J H 1992 'North American driftwood, especially Picea (spruce), from archaeological sites in the Hebrides and Northern Isles of Scotland', Rev Palaeobotany \& Palynology 73, 49-56.

Digerfeldt, G 1972 'The postglacial development of Lake Trummen’, Folia Limn Scand 16, 1-96.

Dimbleby, G W 1967 Plants and archaeology. London: John Baker.

Dodgshon, R A 1981 Land and Society in Early Scotland.Oxford: Clarendon Press.

Downes, J \& Badcock, A 1998 'Berneray Causeway', Discovery Excav Scot 1998, 101.

Dunwell, A, Johnson, M \& Armit, I forthcoming 'Excavations at Geirisclett chambered tomb, North Uist, 1996-7’.

Eco, U 1991 Semiotics and the philosophy of language. London: Macmillan

Earwood, C 1991 ‘Two Early Historic bog butter containers', Proc Soc Antiq Scot 121, 231-40.

Elton, C 1938 'Notes on the ecological and natural history of Pabbay, and other islands in the Sound of Harris, Outer Hebrides', J Ecol 26, 275-297.

Emery, N 1996 Excavations on Hirta 1986-90. Edinburgh: HMSO.

Erdtmann, G 1924 'Studies in the micropalaeontology of postglacial deposits in northern Scotland and the Scottish isles, with especial reference to the history of woodlands', J Linn Soc, 46 449-504.

Evans, J G 1971 'Habitat change on the calcareous soils of Britain: the impact of Neolithic man', in Simpson, D D A (ed), Economy and Settlement in Neolithic and Early Bronze Age Britain and Europe. 27-75. Leicester: Leicester Univ Press.

Evans, J G 1972 Land Snails in Archaeology. London: Seminar Press.

Evans, J G 1979 'The Paleo-environment of coastal wind-blown sand deposits in Western and Northern Britain', in Thomas, L M (ed), Early Man in the Scottish Landscape. Scott Archaeol Forum 9, 16-26.

Evans, J G 1983 'Appendix 2: Mollusca and other invertebrates from Ardnave, Islay', in Ritchie, G \& Welfare, H 'Excavations at Ardnave, Isaly', Proc Soc Antiq Scot 113, 350-358.

Evans, J G \& Spencer, P 1977 ‘Appendix 4: The Mollusca and environment, Buckquoy, Orkney’, in Ritchie, A 1977, $215-219$.

Evans, J G \& Vaughan 1983 'Appendix 8: The Molluscs from Knap of Howar,Orkney', in Ritchie, A, 'Excavation of a Neolithic farmstead at Knap of Howar, Papa Westray, Orkney', Proc Soc Antiq Scot 113, 106-114.

F M A 1981 Fertilisers and Our Environment. Fertilisers Manufacturers Association.

Fairhurst, H 1971 'The wheelhouse site A Cheardach Bheag on Drumnore Machair', Glas Archaeol J, 2, 72-106.

Fairhurst, H 1984 Excavations at Crosskirk Broch, Caithness. Soc Antiqs Scot Monog Ser No 3. Edinburgh.

Fairhurst, H \& Ritchie, W 1963 'Baleshare Island, North Uist', Discovery Excav Scot 1963, 31. 
Fanning, T 1981 'Excavation of an Early Christian cemetery and settlement at Reasc, Co Kerry', Proc Roy Irish Acad 81C, 3-172.

Fenton, A 1963 'Early and traditional cultivation implements in Scotland', Proc Soc Antiq Scot, 96, 264-317.

Fenton, A 1978 The Northern Isles: Orkney and Shetland. Edinburgh. John Donald.

Fettes, D J, Mendum, J R Smith, D I \& Watson, J V 1992 'The geology of the Outer Hebrides', in Memoir for 1:000,000 (Solid edition) Geological sheets, Lewis, Harris, Uist and Barra, (Scotland). Edinburgh: HMSO.

Finnegan, M 1973 'Non-metric variation of the infracranial skeleton', J Anatomy 125 (1), 23-37.

Fleming A 1988 The Dartmoor Reaves: investigating prehistoric land divisions. London: Batsford.

Flenley, J R \& Pearson, M C 1967 'Pollen analysis of a peat from the Island of Canna (Inner Hebrides)', New Phytol 66, 299-306.

Fletcher, M R \& Clapham, J W B 1974 'Sediment density and the limits to the repeatability of absolute pollen frequency determinations', Geoscience \& Man IX, 27-35.

Flinn, D 1978 'The glaciation of the Outer Hebrides', Scott J Geol 13 (2), 195-219.

Flinn, D 1980 'The glaciation of the Outer Hebrides: reply', Scott J Geol 16 (1), 85-86.

Florin, M B 1970 'Lateglacial diatoms of Kirchner Marsh, southeastern Minnesota', Nova Hedwigia 31, 667-746.

Foged, N 1947-48 'Diatoms in fresh water courses in Funen', Dansk Botanisk Arkiv 12.

Foged, N 1953 'Diatoms from western Greenland’, Meddelelser Gronland 147, 1-86.

Foged, N 1954 On the diatom flora of some Funen lakes. Folia Limnologica Scandinavia 6.

Foged, N 1977 'Freshwater diatoms in Ireland', Bibliotheca Phycologia 34, 1-221.

Fojut, N 1981 'Is Mousa a broch?', Proc Soc Antiq Scot 111, 220-228.

Forbes of Culloden, D 1737 'Letter concerning the Duke of Argyll's Estates in Tiree, Morvern and Mull, 24th Sept, 1737'. Reprinted 1884 in Report of the Commission of Inquiry in the Condition of Crofters and Cottars in the Highlands and Islands.

Foster, S M 1990 'Pins, combs and the chronology of later Atlantic Iron Age settlement', in Armit, I (ed) 1990, $143-174$.

Fretter, V \& Graham, A 1976 A functional anatomy of invertebrates. London: Academic Press.

Fujiwara, H 1982 'Detection of plant opals contained in pottery walls of the Jonon period in Kunamoto prefecture', Archaeol Nat Sci 4, 55-66.

Fuller, R J, Wilson, J R \& Coxon, P 1979 'Birds of the Outer Hebrides: the waders', in Boyd, J M (ed) 1979, 419-430.

Gilbert, B \& Mckern, W 1973 'A method for ageing the female os pubis', American J Phys Anthropology 38, 31-38.

Gilbertson, D, Kent, M \& Gratton, J (eds) 1996 The Outer Hebrides: the last 14,000 years. Sheffield: Sheffield Academic Press.

Gillespie, R \& Polach, H A 1976 'The suitability of marine shells for radiocarbon dating of Australian prehistory', in Berger, R $\&$ Suess, H E (eds) $9^{\text {th }}$ International Radiocarbon Conference Proceedings, Los Angeles and La Jolla, 404-21. Los Angeles: Univ California Press.

Gilmour, S \& Cook, M 1998 'Excavations at Dun Vulan: a reinterpretation of the reappraised Iron Age', Antiquity 72, $327-37$.

Glentworth, R 1979 'Observations on the soils of the Outer Hebrides', in Boyd, J M (ed) 1979, 123-137. 
Glentworth, R \& Muir, J W 1963 The soils of the country round Aberdeen, Inverurie and Fraserburgh. Memoirs Soil Survey Great Britain. Scotland. Edinburgh: HMSO.

Godden, Mr \& Mrs 1980 'Eochdar (S Uist)', Discovery Excav Scot 1980, 42.

Godwin, H 1975 The History of the British Flora. 2nd edition. Cambridge: CUP.

Graham, A 1971 British prosobranch and other operculate gastropod molluscs: keys and notes for the identification of the species . Synopses of the British Fauna New Series 2. London: Academic Press.

Grant, A 1975 'The animal bones', in Cunliffe, B Excavations at Portchester Castle. 1: Roman, 378-408. London: Soc Antiq.

Grant, A 1982 'The use of tooth wear as a guide to the age of domestic ungulates', in Wilson, B, Grigson, C \& Payne, S (eds) 1982, 91-108.

Grant, J W 1979 'Cereals and grass production in Lewis and the Uists', Proc Roy Soc Edinburgh 77B, 527-33.

Greenacre, M J 1984 Theory and applications of correspondence analysis. London: Academic Press.

Grigson, C 1982 'Sex and age determination of some bones and teeth of domestic cattle', in Wilson, B, Grigson, C \& Payne, S (eds) 1982, 91-108.

Groenman-van Waateringe, W \& Robinson, M (eds) 1988 Man-made Soils. Oxford: BAR International Series (= Brit Archaeol Rep Int Ser, 410).

Groenman-van Waateringe, W 1988 'Palynology of plaggen soils on the Veluwe, central Netherlands', in Groenman-van Waateringe, W \& Robinson, M (eds) 1988, 55-65.

Guido, M 1978 The glass beads of the Prehistoric and Roman Periods in Britain and Ireland. London: Soc Antiq.

Gwilt, A \& Haselgrove, C 1997 Reconstructing Iron Age societies. Oxford: Oxbow Monog 71.

Hall, D G , Reeve, M J, Thomasson, A J \& Wright, V F 1977 Water retention, porosity and density of field soils. Harpenden: Soil Survey Technical Monog No 9.

Halstead, P 1985 'A study of mandibular teeth from Romano-British contexts at Maxey', in Pryor, F, French, C, Crowther, D, Gurney, D, Simpson, G \& Taylor, M (eds) Archaeology and environment in the Lower Welland Valley, 219-24. East Anglian Archaeology 27.

Hamilton, J R C 1956 Excavations at Jarlshof, Shetland. Edinburgh: HMSO.

Hamilton, J R C 1968 Excavations at Clickhimin, Shetland. Edinburgh: HMSO.

Harding, D W 1984 'The function and classification of brochs and duns', in Miket, R \& Burgess, C (eds) Between and Beyond the Walls. Edinburgh: John Donald. 206-220.

Harding, D W 1990 'Changing perspectives in the Atlantic Iron Age’, in Armit, I (ed) 1990, 5-16.

Harding, D W 1997 'Forts, duns, brochs and crannogs: Iron Age settlements in Argyll', in Ritchie, J N G (ed) 1997 The archaeology of Argyll, 118-140.

Harkness, DD 1983 'The extent of natural ${ }^{14} \mathrm{C}$ deficiency in the coastal environment of the United Kingdom', ${ }^{14} \mathrm{C}$ and archaeology. Proceeding of the Radiocarbon conference, Groningen 1981, 351-364.

Harris, E 1979 Principles of archaeological stratigraphy. London: Academic Press.

Harrison, C J O \& Cowles, G S 1977 'The extinct large cranes of the north-west Palaearctic', 4, 25-27.

Hawksworth, D L 1969 'Studies on the peat deposits of the islands of Foula,Shetland', Trans \& Proc Bot Soc Edinb 40, 576-591. 
Haworth, E Y 1976 'Two lateglacial (Late Devensian) diatom assemblage profiles from Northern Scotland', New Phytol 77, $227-256$

Hedges, J W 1987 Bu, Gurness and the brochs of Orkney I. Oxford: BAR British Series (= Brit Archaeol Rep Brit Ser, 163).

Hedges, J W 1990 'Surveying the foundations: life after 'Brochs” in Armit, I (ed) 1990, 17-31.

Hedges, J W \& Bell, B 1980 'That tower of Scottish prehistory - the broch', Antiquity 54, 87-94.

Henshall, A S 1972 The Chambered Tombs of Scotland. Vol 2. Edinburgh: EUP.

Heslop-Harrison, J W \& Blackburn, K B 1946 'The occurrence of a unit of Trapens natans L. in the outer Hebrides with some account of the peat bogs adjoining the Loch in which the discovery was made', New Phytol 45, 124-131.

Hickling, C F 1935 The hake and the hake fishery: the Buckland Lectures for 1934. London: Edward Arnold.

Hill, J D 1995 Ritual and rubbish in the Iron Age of Wessex: a study on the formation of a specific archaeological record . Oxford: BAR British Series (= Brit Archaeol Rep Brit Ser, 242).

Hillman, G C 1981 'Reconstructing crop husbandry practices from charred remains of crops', in Mercer, R J (ed) 1981, $123-162$.

Hillman, G C 1984 'Interpretation of archaeological plant remains: the application of ethnographic models from Turkey', in Van Zeist, \& Casparie, W A (eds) 1984, 1-41.

Hodder, I 1982 The present past: an introduction to anthropology for archaeologists . London: Batsford.

Hodgson, J M (ed) 1976 Soil Survey Field Handbook. Harpenden: Soil Survey Tech Monog 5.

Hopkins, P G \& Coxon, P 1979 'Birds of the Outer Hebrides: waterfowl', in Boyd, J M (ed) 1979, 431-44.

Hudson, G, Towers, W, Bibby, J \& Henderson 1982 Soil and Land Capability for Agriculture: The Outer Hebrides. Aberdeen: Macaulay Institute.

Hunter, J R 1990 'Pool, Sanday: a case study for the Late Iron Age and Viking periods’, in Armit, I (ed) 1990, $175-193$.

Hustedt, F 1930 Die Süsswasser Flora Mitteleuropas Heft 20. Bacillsriophyta (Diatomeae). Jena: Fischer.

Hustedt, F 1937-1939 'Systematische und ökologische Untersuchungen über die Diatomeen - flora von Java, Bali und sumatra', Archiv fur Hydrobiologie Supplement 15, 16, 1-153.

Hutchison, C S 1974 Laboratory Handbook of petrographic techniques. New York: Wiley.

Ijzereef, G F 1981 Bronze Age Animal Bones from Bovenkarspel. Amersfort: ROB.

Illingworth, C \& Dick, B M 1979 A Textbook of Surgical Pathology. Edinburgh: Churchill Livinstone.

Jackson, K 1972 The Gaelic notes in the Book of Deer. Osbert Bergin Memorial Lectures. Cambridge: CUP.

Jarman, H N, Legge, A J \& Charles, J A 1972 'Retrieval of plant remains from archaeological sites by froth flotation', in Higgs, E S (ed), Papers in Economic Prehistory, 39-48. Cambridge: CUP.

Jehu, J T \& Craig, R M 1923a 'The Barra Isles', Trans R Soc Edinb Vol 53, 419-441.

Jehu, J T \& Craig, R M 1923b 'S Uist and Eriskay', Trans R Soc Edinb Vol 54, 467-489.

Jehu, J T \& Craig, R M 1926 'Geology of the Outer Hebrides III. North Uist and Benbecula', Trans Roy Soc Edinb 54, $467-489$.

Johansen, J 1975 'Pollen diagrams from the Shetland and Faroe Islands', New Phytol 74, 369-387. 
Jones, A K G 1986 'Fish bone survival in the digestive systems of the pig, dog, and man: some experiments' in Brinkhuizen, D C \& Clason, A T (eds) Fish and archaeology: studies in osteometry, taphonomy, seasonality and fishing methods, 53-61. Oxford: BAR International Series (= Brit Archaeol Rep Int Ser, 294).

Jones, G E M 1981 'The carbonised plant remains', in Orme, B J, Caseldine, A E \& Bailey, G N (eds) 'Meare Village West 1979'. Somerset Levels Papers 7, 33-5.

Jones, G E M 1983 The Use of Ethnographic and Ecological Models in the Interpretation of Archaeological Plant Remains . Univ Cambridge: unpubl $\mathrm{PhD}$ thesis.

Jones, G E M 1984 'Interpretation of archaeological plant remains: ethnographic models from Greece', in Van Zeist, W \& Casparie, W A (eds) 1984, 43-61.

Jones, G E M 1987 'A statistical approach to the archaeological identification of crop processing', J Archaeol Sci 14, 311-323.

Jones, R L \& Beavers, A H 1964a 'Aspects of catenary and depth distribution of opal phytoliths in Illinois soils', Proc Soil Sci Soc America 28 (3), 413-416.

Jones, R L \& Beavers, A H 1964b 'Variation of opal phytolith content among some great soil groups in Illinois', Proc Soil Sci Soc America 28 (5), 711-712.

Jorgensen, E G 1948 'Diatom communities in some Danish lakes and ponds', Kongelige danske Videskabernes Selskabs Biologiske Skrifter 5, 1-140.

Jorgensen, E G 1950 'Diatom communities in some Danish lakes and ponds', Danske Botanisk Arkiv 14, 1-18.

Jowsey, P C 1966 'An improved peat sampler', New Phytol 65, 245-248.

Kalisz, P J \& Stone, E L 1984 'The Longleaf Pine Islands of the Ocala National Forest, Florida: a soil survey', Ecology 65 (6), 1743-1754.

Kelly, F 1988 A Guide to Early Irish Law. Dublin: Inst Advanced Studies.

Kenward, H K, Hall, A R \& Jones, A 1980 'A tested set of techniques for the extraction of plant and animal macrofossils from waterlogged deposits', Sci \& Archaeol 22, 2-15.

Kerney, M P \& Cameron, R A D 1979 A field guide to Land Snails in Britain and North-West Europe. London: Collins.

Klein, R G \& Cruz-Uribe, K 1984 The analysis of animal bones from archaeological sites. Chicago: Univ Chicago Press.

Lacaille, A D 1954 The Stone Age in Scotland. London: Oxford Univ Press.

Lamb, H H 1982 Climate, history and the modern world. London: Methuen.

Lane, A 1990 'Hebridean pottery: problems of definition, chronology, presence and absence', in Armit, I (ed) 1990, 108-30.

Legge, A J 1981 'The agricultural economy', in Mercer, R J (ed) Grimes Graves Excavations 1971-72, 79-103. London: HMSO.

Lerche, G 1975 'Notes on different types of “bread” in 'Northern Scotland: Bannocks, Oatcakes, Scones and Pancakes', in Arnott, M L Gastronomy; The anthropology of food and food habits, 327-336. The Hague: Mouton Publishers.

Lockhart, J A R \& Wiseman, A J L 1983 Introduction to Crop Husbandry. Oxford: Pergamon Press.

Long, A \& Rippeteau, B 1974 'Testing contemporaneity and averaging Radiocarbon dates', American Antiq 39 (2), $205-215$.

Lowe, C 1998 St Boniface Church, Orkney. Coastal erosion and archaeological assessment. Stroud: Suttons.

Lowe, J J \& Walker, M J C 1984 Reconstructing Quaternary Environments. London: Longman.

Lucas, A T 1989 Cattle in Ancient Ireland. Kilkenny: Boethius Press.

MacAirt, S 1977 The Annals of Inisfallen. Dublin: Inst Advanced Studies. 
MacDonald, A 1904 The Clan Donald. Inverness.

Macgregor, A 1974 'The Broch of Burrian, North Ronaldsay', Proc Soc Antiq Scot 105, 63-118.

MacGregor, A 1985 Bone, antler, ivory and horn. London: Croom Helm.

Macgregor, L J \& Crawford, B E (eds) 1987 Ouncelands and Pennylands. St Andrews: Univ St Andrews.

Mackenzie, RC 1957 The differential thermal investigation of clays. London: Mineral Society.

Mackereth, F J H 1966 'Some chemical observations on postglacial lake sediments', Phil Trans Roy Soc 250B, $165-213$.

MacKie, E W 1965a 'Brochs and the Hebridean Iron Age', Antiquity 39, 266-278.

MacKie, E 1965b 'Origin of the broch and wheelhouse building cultures of the Scottish Iron Age', Proc Prehist Soc 31, 93-144

MacKie, E W 1971 'English migrants and Scottish brochs', Glas Archaeol J 2, 39-71.

MacKie, E 1972 'Continuity in Iron Age fort building traditions in Caithness', in Meldrum, E (ed) The Dark Ages in the Highlands, 5-23. Inverness: Inverness Field Club.

MacKie, E W 1974a Dun Mor Vaul: An Iron Age broch on Tiree. Glasgow: Glasgow Univ Press.

MacKie, E W 1974b 'A dwelling site of the earlier Iron Age at Balevullin, Tiree’, Proc Soc Antiq Scot, 155-183.

Maclean, C, Shepherd, I \& Shepherd, A 1978 'Paible', Discovery Excav Scot 1978, 35.

Macleod, F T 1915 'Notes on Dun Iardhard, a broch near Dunvegan, excavated by Countess Vincent Baillet de Latour, Uignish Lodge, Skye', Proc Soc Antiq Scot 51, 57-70.

MacPhail, R I 1981 'Soil and botanical studies of the 'dark earth”, in Dimbleby, D \& Jones, M (eds) The environment of man, 309-331. Oxford: BAR British Series (= Brit Archaeol Rep Brit Ser, 87).

Manley, G 1979 'The climatic environment of the Outer Hebrides', in Boyd, J M (ed) 1979, 47-59.

Manning, W H 1981 'Native and Roman metalwork in Northern Britain: a question of origins and influences', in Kenworthy, J (ed) Early technology in North Britain, 52-61. Scott Archaeol Forum 11.

Mannion, A M 1980 'Pollen Analysis: a technique in palaeoenvironmental reconstruction', Univ Reading Dept Geography Paper 73,62 .

Mannion, AM 1982 'Diatoms: their use in physical geography', Progress in Physical Geography 6, 233-259.

Marshall, D N 1964 'Report on the excavations at Little Dunagoil' Trans Bute Nat Hist Soc 16, 1-69.

Marshall, P, Mulville, J, Parker-Pearson, M \& Gidlow, J 1998 ‘Cladh Hallan’, Discovery Excav Scot 1998, 102.

Marshall, T J \& Holmes, J W 1979 Soil Physics. Cambridge: CUP.

Martin Martin 1703 A description of the Western Islands of Scotland. London.

Martlew, R 1985 'The excavation of Dun Flodigarry, Staffin, Isle of Skye', Glasgow Archaeol J 12, 30-48.

Matthews, J V 1975 'Incongruence of macrofossil and pollen evidence: a case from the Late pleistocene of the northern Tukon coast', Geological Survey of Canada Paper 75-1 Part B, 139-146.

Matthews, K 1993 'A futile occupation? Archaeological meanings and occupation deposits' in Barber, J (ed) 1993, 55-61.

McCormick, F 1981 'The animal bones from Ditch 1', in Barber, J 1981, 313-318.

McCormick, F 1992 'Early faunal evidence for dairying', Oxford J Archaeol 11 (2), 201-209. 
McOmish, D 1996 'East Chisenbury: ritual and rubbish at the British Bronze Age-Iron Age transition', Antiquity 70, 68-76.

McVean, D N 1961 'Flora and vegetation of the islands of St Kilda and North Rona in 1958', J Ecol 49, 39-54.

Megaw, J V S \& Simpson, D D A 1961 'A short cist burial on North Uist and some notes on the prehistory of the Outer Isles in the second millennium BC', Proc Soc Antiq Scot 74, 62-78.

Mellars, P A \& Wilkinson, M R 1980 'Fish otoliths as indicators of seasonality in prehistoric shell middens; the evidence from Oronsay (Inner Hebrides)', Proc Prehist Soc 46, 19-44.

Mellars, P 1987 Excavations on Oronsay; prehistoric human ecology on a small island. Edinburgh: EUP.

Mercer, J 1979 'The Palaeolithic and Mesolithic occupation of the Isle of Jura, Argyll, Scotland', Almogaren 9-10, 347-67.

Mercer, J 1980 'Lussa Wood I: the Late-glacial and early Post-glacial occupation of Jura', Proc Soc Antiq Scot 110, 1-31.

Mercer, J 1978 'The Kings Cave, Jura', Glasgow Archaeol J 5, 44-70.

Mercer, R J (ed) 1981 Farming Practice in British Prehistory. Edinburgh. EUP.

Mills, C M, Crone, A, Edwards, K J \& Whittington, G 1994 'The excavation and environmental investigation of a sub-peat stone bank near Loch Portain, North Uist, Outer Hebrides', Proc Soc Antiq Scot 124, 155-171.

Milne-Edwards, H 1856 A manual of zoology. London: H Renshaw.

Mitchell, F \& Ryan, M 1997 Reading the Irish Landscape. Dublin: Town House.

Mithen, S J 1989 'New evidence for Mesolithic settlement on Colonsay', Proc Soc Antiq Scot 119, 33-41.

Moar, N T 1969 'Two pollen diagrams from the Mainland, Orkney Islands', New Phytol 68, 201-208.

Moar, N T 1969 'A radiocarbon-dated pollen diagram from north-west Scotland', New Phytol 68, 209-214.

Moe, D 1983 'Palynology of sheep's faeces: relationship between pollen content, diet and local pollen rain', Grana 22, $105-113$.

Moisley, H A 1961 'North Uist in 1799', Scott Geog Mag 77, 89-92.

Movius, H L 1942 The Irish Stone Age. Cambridge: CUP.

Mulville, J A 1999 'The mammal bones', in Parker-Pearson \& Sharples 1999, 234-74.

Murphy, P 1986 'Botanical evidence', in Lawson, A D Barrow excavations in Norfolk 1950-82, 43-44. East Anglian Archaeol Rep No 29.

Murray, R \& Ratcliffe, R A S 1969 Met Mag Lond 98, 201-219.

Needham, S \& Spence, T 1997 'Refuse and the formation of middens', Antiquity 71, 77-90.

Newell, P J 1989 ‘A buried wall in peatland by Sheshader, Isle of Lewis’, Proc Soc Antiq Scot 118, 79-93.

Newton, A J forthcoming 'Report on pumice pieces found at Papa Stour'.

Newton, A J \& Dugmore, A 1995 'The pumice; analytical report', in Barra: archaeological research on Ben Tangaval, $145-148$. Sheffield: Sheffield Academic Press.

Nilsson, O \& Helmqvist, H 1967 'Studies on the nutlet structure of south Scandinavian species of Carex', Botaniska Notiser 120, 460-85.

O’Connor, A \& Clarke, D V (eds) 1983 From the Stone Age to the '45. Edinburgh: John Donald.

O’Connor, T P 1997 'Working at relationships: another look at animal domestication', Antiquity 71, $149-56$. 
Oram, R D 1987 'Davachs and Pennylands in South-West Scotland: a review of the evidence', in Macgregor, L J \& Crawford, B E (eds) $1987,46-59$.

Owen, O 1993 'Tuquoy, Westray, Orkney. A challenge for the future?', in Batey, C, Jesch, J \& Morris, C D (eds) The Viking Age in Caithness, Orkney and the North Atlantic, 318-339. Edinburgh: EUP.

Owen, O \& Lowe, C 1990 'Kebister: burnt mounds and burnt mound material', in Buckley, V (comp) 1990, 84-86.

Padmore, J 1987 Analysis of the phytolith abundance of coastal sand dune systems in the Outer Hebrides. Univ Sheffield Dept Probability \& Statistics Res Rep 291/87.

Parker Pearson, M, Sharples, N \& Mulville, J 1996 'Brochs and Iron Age society: a reappraisal', Antiquity 70, 57-67.

Parker-Pearson, M \& Sharples, N with Mulville, J \& Smith, H 1999 Between land and sea: excavations at Dun Vulan, South Uist. Sheffield: Sheffield Academic Press.

Parkin, R A, Rowley-Conwy, P \& Serjeantson, D 1986 'Late palaeolithic exploitation of horse and red deer at Gough's Cave, Cheddar, Somerset', Proc Univ Bristol Speleological Soc 17 (3), 311-30.

Parry, M L 1978 Climatic change, agriculture and settlement. Connetticutt: Dawson.

Patrick, R 1948 'Factors affecting the distribution of diatoms', Botanical Review 14, 473-524.

Patrick, R \& Reimer, C 1966 The Diatoms of the United States exclusive of Alaska and Hawaii. Volume 1. Fragilariaiaceace, Eunotiaceae,Achnantheceae, Naviculaceae. Philadelphia: Philadelphia Acad Nat Sci Monog 13, 1-213.

Paul, C R C 1975a 'The Ecology of Mollusca in ancient woodland. I: The fauna of Hayley Wood, Cambridgeshire', J Conch 28, 301-327.

Paul, C R 1975b ‘Columella in the Britsh Isles', J Conch 28, 371-383.

Paul, C R 1976 'The non-marine mollusca of Colonsay and Oronsay', J Conch 29, 107-110.

Payne, S 1973 'Kill-off patterns in sheep and goats', Anatolian Studies 24, 281-303.

Payne, S 1987 'Reference codes for wear states in the mandibular cheek teeth of sheep and goats', J Archaeol Sci 14, 609-614.

Payne, S 1984 'The use of early 19th century data in ageing cattle mandibles from archaeological sites, and the relationship between eruption of $\mathrm{M}_{3}$ and $\mathrm{P}_{4}$, Circaea 2 (2), 77-82.

Payne, S 1985 'Morphological distinctions between the mandibular teeth of young sheep, Ovis, and goats, Capra', J Archaeol Sci 12, 139-47.

Payne, S \& Munson, P 1985 'Ruby and how many squirrels? The destruction of bones by dogs', in Feiller, N R J, Gilbertson, D D \& Ralph, N G A (eds), Palaeobiological Investigations: Research Design, Methods and Data Analysis, 31-48. Oxford: BAR British Series (= Brit Archaeol Rep Brit Ser, 266).

Peacock, J D 1984 'Quaternary geology of the Outer Hebrides’, Rep Brit Geol Survey, 16, 2.

Peacock, J D \& Ross, D L 1984 'Anomalous glaical erratics in the southern part of the Outer Hebrides', Scott J Geol 14, 262.

Peglar, S M 1979 'A radiocarbon dated pollen diagram from the Loch of Winless, Caithness, northeast Scotland', New Phytol $78,245-263$.

Pennant, T 1774 A Tour in Scotland; and Voyage to the Hebrides, MDCCLXXII. Chester.

Pethick, J S 1984 An introduction to coastal geomorphology. London: Arnold.

Piggott, S 1955 'Three metalwork hoards of the Roman Period from southern Scotland', Proc Soc Antiq Scot 87, 1-50.

Piperno, D 1985 'Phytolith taphonomy and distribution in archaeological sediments from Panama', J Archaeol Sci 12, $247-267$. 
Powers, A H, Gilbertson, D D \& Jones, G 1986 The prospects for environmental discrimination in coastal sand dunes on the basis of studies of phytolith type and abundance. unpubl report for SDD.

Powers, A H \& Gilbertson, D D 1987 'A simple preparation technique for the study of opal phytoliths from archaeological and Quaternary sediments', J Archaeol Sci 14, 529-535.

Powers, A H, Padmore, J \& Gilbertson, D D 1989 'Studies of late prehistoric and modern opal phytoliths from coastal sand dunes and machair in northwest Britain', J Archaeol Sci 16, 27-45.

PSAS 1912 'Donations to the museum and library', Proc Soc Antiq Scot 46, 327-343

PSAS 1916 'Donations to the museum and library', Proc Soc Antiq Scot 50, 12-16.

PSAS 1922 'Donations to the museum and library', Proc Soc Antiq Scot 56, 10-21

Rackham 1980 Ancient woodland; its history, vegetation and uses in England. London: Edward Arnold.

Raftery 1994 Pagan Celtic Ireland; the enigma of the Irish Iron Age. London:

Randall, R E 1972 Vegetation in a Maritime Environment: the Monarch Isles. Cambridge: unpubl PhD thesis.

Randall, R E 1973 ‘Calcium carbonate in dune soils: evidence for geomorphic change', Area 5, 308-310.

Randall, R E 1976 'Machair zonation in the Monarch Isles, NNR, Outer Hebrides', Trans Proc Bot Soc Edinb 42, $153-162$.

Randall, R E 1977 'Pollen catchments in relation to local vegetation: Cann Ear, Monach Isles NNR, Outer Hebrides', in Ranwell, D S (ed) Sand Dune Machair 2, 16-21.

Ranwell, D S 1972 Ecology of salt marshes and sand dunes. London: Chapman Hall.

Ratcliffe, D A 1977 A Nature Conservation Review, vols 1 and 2. Cambridge: CUP.

RCAHMS 1928 The Outer Hebrides, Skye and the Small Isles. Edinburgh: HMSO.

RCAHMS 1980 Argyll Vol 5. Islay, Jura, Colonsay and Oronsay. Edinburgh: HMSO.

RCAHMS 1984 Argyll Vol 3. Mull, Tiree, Coll and north Argyll. Edinburgh: HMSO.

Reid Survey 1799 Plan of the Island of North Uist by Robert Reid. Register House Plan No 1306.

Ritchie, A 1977 'Excavation of Pictish and Viking-Age farmsteads at Buckquoy, Orkney', Proc Soc Antiq Scot 108, $174-277$.

Ritchie, J N G \& Lane, A M 1980 'Dun Cul Bhuirg, Iona, Argyll', Proc Soc Antiq Scot 110, 209-29.

Ritchie, J N G \& Ritchie, A 1981 Scotland; archaeology and early history. London: Thames \& Hudson.

Ritchie, W 1966 'The post-glacial rise in sea level and coastal changes in the Uists', Trans Inst Brit Geographers 38, 79-96.

Ritchie, W 1968 The Coastal Geomorphology of North Uist. O’Dell Memorial Monog 1. Aberdeen: Univ Aberdeen Dept Geog.

Ritchie, W 1971 The beaches of Barra and the Uists. Geography Department. Aberdeen: Univ Aberdeen.

Ritchie, W 1979 'Machair development and chronology in the Uists and adjacent islands', in Boyd, J M (ed) 1979, 107-122.

Ritchie, W 1985 'Inter-tidal peats and sub-tidal organic deposits and sea level changes in the Uists, Outer Hebrides', Scott J Geol $21,161-176$.

Roberts, H W, Kerr, D H \& Seaton, D 1959 'The machair grasslands of the Hebrides', J Br Grassl Soc 14, 223-8.

Robertson, A S 1970 'Roman finds from non-Roman sites in Scotland', Britannia I, 198-226. 
Robinson, M \& Straker, V 1991 'Silica skeletons of macroscopic plant remains from ash', in Renfrew, J (ed) New light on early farming, 3-13. Edinburgh: EUP.

Round, F E 1957 'Studies on bottom-living algae in some lakes of the English Lake District', J Ecol 45, 343-360.

Round, F E 1964 'The diatom sequence in lake deposits: some problems of interpretation', Mitteilungen Internationale Vereininigung für Limnologie 15, 1012-1020.

Rovner, I 1983 'Plant opal phytolith analysis: major advances in archaeobotanical research', in Schiffer, M B (ed) Advances in archaeological method and theory, 225-266. London: Academic Press.

Salisbury, E J 1952 Downs and Dunes. London: Bell.

Scaife, R unpubl 'Plant biogenic (phytolith) remains impacted in equine incisors'.

Schiffer, M B 1987 Formation processes of the archaeological record. Albuquerque: Univ New Mexico Press.

Scott, W L 1935 'The chambered cairn of Clettraval, North Uist', Proc Soc Antiq Scot 69, 480-536.

Scott, W L 1948 'The chambered tomb of Unival, North Uist', Proc Soc Antiq Scot 82, 1-48.

Scott, W L 1951 'Eilean an Tighe; a pottery workshop of the 2nd millennium BC', Proc Soc Antiq Scot 85, 1-37.

Serjeantson, D nd 'The mammal, bird and fish remains from Udal North'. Interim Report.

Serjeantson, D 1988 'Archaeological and ethnographic evidence for seabird exploitation in Scotland', Archaeozoologia II, 209-224.

Sharples, N 1998 Scalloway. A broch, Late Iron Age settlement and Medieval cemetery in Shetland. Oxbow Monog 82. Oxford.

Shepard, A O 1965 Ceramics for the Archaeologist. Washington: Carnegie Institute.

Shepherd, I A G 1976 'Preliminary results from the Beaker settlement at Rosinish, Benbecula', in Burgess, C \& Miket, R (eds) 1976, 209-220.

Shepherd, I AG \& Shepherd, A N 1978 Machair sites survey: Uists and Benbecula. HBMD internal report.

Silver, I A 1969 'The ageing of domestic animals', in Higgs, E S \& Brothwell, D R (eds) Science in Archaeology, $283-302$. London: Thames \& Hudson.

Simpson, D D A 1966 'A Neolithic settlement in the Outer Hebrides', Antiquity 40, 137-139.

Simpson, D D A 1976 'The later Neolithic and Beaker settlement site at Northton, Isle of Harris', in Burgess, C \& Miket, R (eds) 1976, 221-232.

Sissons, J B 1977 The geomorphology of the British Isles. London: Methuen.

Sissons, J B 1981 'The last Scottish ice-sheet: facts and speculative discussion', Boreas 10, 1-17.

Sissons, J B 1983 'The quaternary geomorphology of the Inner Hebrides: a review’, Proc Geol Assoc 94, 165-175.

Smith, D I \& Fettes, D J 1979 'The geological framework of the Outer Hebrides', in Boyd, J M (ed) 1979, 75-83.

Smith, H 1999 'The plant remains', in Parker-Pearson \& Sharples 1999, 297-336.

Smith, S M 1979 'The mollusca of rocky shores: Lewis and Harris, Outer Hebrides', in Boyd, J M (ed) 1979, $173-187$.

Smithson, F 1956 'Silica particles in some British soils', J Soil Sci 7 (1), 122-129.

Smithson, F 1958 'Grass opal in British soils', J Soil Sci 9 (1), 148-159.

Smithson, F 1961 'The microscopy of the silt fraction', J Soil Sci 12 (1), 145-157. 
Spence, D H N, Allen, E D \& Fraser, J 1979 'Macrophytic vegetation of fresh and brackish waters in and near Loch Druidibeg National Nature Reserve, South Uist’, in Boyd, J M (ed) 1979, 307-328.

Spencer, P 1975 'Habitat change in coastal sand-dune areas: the molluscan evidence', in Evans, J G, Limbrey, S \& Cleere, H (eds) The Effect of Man in the Highland Zone, 96-103. CBA Res Rep 11.

SPSS Inc 1983 SPSSx Users Guide. New York.

Stevenson, R B K 1955 'Pins and the chronology of brochs', Proc Prehist Soc 21, 282-94.

Stevenson, J B 1984 'The excavation of a hut circle at Cùl a'Bhaile, Jura', Proc Soc Antiq Scot 114, 127-160.

Stockmarr, J 1971 'Tablets with spores used in absolute pollen analysis', Pollen et Spores 13, 615-621.

Stockmarr, J 1972 'Determination of spore concentrations with an electronic particle counter', Danmarks Geologiske Undersogelse 89, 1-69.

Sutherland, D G, Ballantyne, C K \& Walker, J C 1984 'Late Quaternary glaciation and environmental change on St Kilda, Scotland, and their paleoclimatic significance', Boreas 13 (3), 261-272.

Synge, F M 1977 'Records of sea levels during the Late Devensian', Trans R Soc London B 280, 211-228.

Tabraham, C 1977 'Excavations at Dun Carloway broch, Isle of Lewis', Proc Soc Antiq Scot, 156-167.

Tauber, H $1976{ }^{114} \mathrm{C}$ activity of Arctic marine mammals', in Berger, R \& Suess, H E (eds) $9^{\text {th }}$ International Radiocarbon Conference Proceedings, Los Angeles and La Jolla, 447-52. Los Angeles: Univ California Press.

Taylor, M 1999 'The wood', in Parker-Pearson \& Sharples, N, 188-92.

Thomas, S 1960 'Studien zu den Germanischen kammen der romischen kaiserzeit', Arbeits und Forschungsberichte zur Sachsischen Bodenkmalpflege 8, 54-215.

Thorpe, O N \& Thorpe, R S 1984 'The distribution and sources of archaeological pitchstone in Britain', J Archaeol Sci 11, 1-31.

Topping, P G 1987 'Typology and chronology in thelater prehistoric pottery assemblages of the Western Isles', Proc Soc Antiq Scot 117, 67-84.

Trotter, M \& Gleser, G C 1952 'Stature white females', American J Phys Anthropol 10 (4), 463-514.

Turner, J 1965 'A contribution to the history of forest clearance', Proc Roy Soc B161, 343-54.

Tutin, T G, Heywood, V H, Burges, N A, Valentine, D H, Walters, SM \& Webb, D A 1964 Flora Europaea. Cambridge. CUP.

Twiss, P C 1983 'Dust deposition and opal phytoliths in the Great Plains', Trans Nebraska Academy Sciences XI, 73-82.

Tylecote, R F 1986 The prehistory of metallurgy in the British Isles. London: Inst Metals.

Van Zeist, \& Casparie, W A (eds) 1984 Plants and Ancient Man: Studies in Palaeoethnobotany. Rotterdam: Balkema.

von den Driesch, A \& Boessneck, A 1975 ‘Schnittspuren an neolithischen Tierknochen’, Germania 53, 1-23.

Von Weymarn, J A 1974 Coastal development in Lewis and Harris, Outer Hebrides, with particular reference to the effects of glaciation. Univ Aberdeen: unpubl PhD thesis.

Von Weymarn, J A 1979 ‘A new concept of glaciation in Lewis and Harris’, in Boyd, J M (ed) 1979, 97-105.

Walden, H W 1981 'Communities and diversity of land molluscs in Scandinavian woodlands, I. High diversity communities in taluses and boulder slopes in SW Sweden', J Conch 30, 351-372.

Walker, M J C \& Lowe, J J 1982 'Lateglacial and early Flandrian chronology of the Isle of Mull, Scotland', Nature 296, $558-561$. 
Walker, M J C 1984 'A pollen diagram from St Kilda, Outer Hebrides, Scotland', New Phytol 97, 99-113.

Walker, M J C \& Lowe, J J 1985 'Flandrian environmental history of the Isle of Mull, Scotland. I Pollen stratigraphic evidence and radiocarbon dates from Glen More, south-central Mull', New Phytol 99, 587-610.

Warner, R B 1983 'Ireland, Ulster and Scotland in the earlier Iron Age', in O’Connor, A \& Clarke, D V (eds) 1983, $160-85$.

Waterson, A R, Holden, A V, Campbell, R N \& Maitland, P S 1979 'The inland waters of the Outer Hebrides', in Boyd, J M (ed) $1979,329-351$.

Waterson, A R \& Lister, I H J 1979 'The macrofauna of brackish and fresh waters of the Loch Druidibeg National Nature Reserve and its neighbourhood, South Uist', in Boyd, J M (ed) 1979, 353-376.

Waterston, A R, Holden, A V, Campbell, R N \& Maitland, P S 1979 'The inland waters of the Outer Hebrides', in Boyd, J M (ed) $1979,329-351$.

Welch, R C 1979 'Survey of the invertebrate fauna of sand dune and machair sites in the Outer Hebrides during 1976', in Boyd, J M (ed) 1979, 395-404.

West, R G 1970 'Pollen zones in the Pleistocene of Great Britain and their correlation', New Phytol 69, 1179-1183.

Whittington, G \& Ritchie, W 1988 Flandrian environmental evolution of Northeast Benbecula and southern Grimsay, Outer Hebrides, Scotland. O’Dell Memorial Monog 21. Aberdeen: Univ Aberdeen Dept Geog.

Whittow J B 1977 Geology and Scenery in Scotland. London: Penguin.

Wickham-Jones, C 1990 Rhum: Mesolithic and Later Sites at Kinloch, Excavations 1984-86, Soc Antiqs Scot Monog Ser No 7.

Wickham-Jones C \& Collins, CR 1978 ‘The sources of flint and cherts in northern Britain’, Proc Soc Antiq Scot 109, 7-22.

Wilkins, D A 1984 'The Flandrian woods of Lewis', J Ecol 72, 251-258.

Williams, G 1990 'Burnt mounds in south-west Wales', in Buckley, V (comp) 1990, 129-140.

Wilson, B, Grigson, C \& Payne, S (eds) 1982 Ageing and sexing animal bones from archaeological sites. Oxford: BAR British Series (= Brit Archaeol Rep Brit Ser, 109).

Wilson, G 1998 'The worked bone and antler', in Lowe, C 1998, 139-142.

Wishart, D 1978 Clustanz User Manual. Edinburgh.

Witty, J E \& Knox, E G 1964 'Grass opal in some chestnut and forested soils in north central Oregon', Proc Soil Sci Soc America $28,685-688$.

Woodman, P C 1978 The Mesolithic in Ireland. Oxford: BAR 58.

Yeck, R D \& Gray, F 1972 'Phytolith size characteristics between Udolls and Ustolls', Proc Soil Sci Soc America 36, 639-641.

Young, A 1953 'An aisled farmhouse at the Allasdale, Isle of Barra', Proc Soc Antiq Scot 87, 80-105.

Young, A 1956 'Excavations at Dun Cuier, Isle of Barra, Outer Hebrides', Proc Soc Antiq Scot 89, 290-327.

Young, A 1966 'The sequence of Hebridean pottery', in Rivet, A L F (ed), The Iron Age in Northern Britain, 45-58. Edinburgh: EUP.

Young, A \& Richardson, K M 1960 ‘A Cheardach Mhor, Drimore, South Uist', Proc Soc Antiq Scot 93, 135-173.

Zimmerman, H W 1978 'Economy of the Roman Iron Age settlement at Flogen (Kr Cuxhaven)', in Cunliffe, B \& Rowley, T (eds), Lowland Iron Age communities in Europe. 147-65. Oxford: BAR International Series (= Brit Archaeol Rep Int Ser, 48). 


\section{INDEX}

A Cheardach Bheag 29, 30, 31

A Cheardach Mhor 29, 30

Adabrock hoard 31

agriculture 19, 203, 205, 235, 236, 242

Aird An Runair 6

aisled house 74

Allasdale 29, 30, 31

Allt Christal 27

Alnus 192, 194, 195, 201, 202, 204

Ammophila arenaria 204, 205

Annals of Inisfallen 237

ard marks $27,34,35,46,62,63,66,67,70,83,105,213$, 214, 222, 223, 224, 228, 235

Ardivacher Point 72

Ardkenneth 14

Ardnave 163, 167

Armada 109

Armiger crista 168

Arran 21

Artemisia 204

Askernish 199, 200, 201, 202, 203, 204, 205, 207

Atlantic Roundhouses 28

atriplex sp. 153

augers 4,6

awls 138, 139, 231, 232, 233

axes 4,232

Bac Mhic Connain 29, 30

Bagh Mor 104

Bagh nam Faoilean 72

Baile Mhic Cumhais 110
Balelone 1, 8, 15, 17, 18, 32, 33, 36, 37, 39, 114, 117, 120, $121,126,127,130,131,132,133,134,138,159,160$, $161,162,163,164,165,167,168,170,172,173,174$, 176, 190, 192, 193, 194, 195, 211, 212, 213, 216, 217, $218,228,231$

Balemore 199, 203, 204, 205, 207

Baleshare 3, 4, 6, 8, 10, 11, 20, 22, 33, 43, 44, 45, 51, 53, $56,66,91,110,116,117,119,120,121,122,124$, $126,127,128,129,130,131,132,133,134,135,136$, $138,139,140,142,143,144,145,146,147,148,149$, $150,151,152,153,154,156,157,158,161,163,164$, $165,166,167,168,169,170,171,172,173,174,175$, $176,177,178,179,180,181,182,183,185,186,187$, $188,189,190,206,207,209,211,212,213,214,216$, 217, 218, 219, 220, 221, 223, 226, 227, 228, 229, 230, $231,232,233,234,235,236,237,238,239,240$

Balgarva estate 72

Balliviconen 109

barley 19, 27, 153, 154, 155, 156, 157, 206, 207, 220, 236, 237,240

Barra 12, 13, 15, 27, 30, 132, 138, 167, 190, 219

Barvas 12

Beinn Bhreac 109

Beinn Mhor 109

Bellis perennis 204

Benbecula 12, 19, 20, 26, 27, 72, 190

Betula 192, 194, 195, 200, 201, 202, 204, 205, 207

Bharpa Carinish 21

Bidens 194

Bilderdykia convolvulus 153

bindweed 153

birch 25, 26, 201, 202, 205

birds of prey 26

blackbird 26

bladder wrack 176

Bleau 110

blockhouses 30

bloodstone 21 


\section{bluebells 26}

boat 109, 120, 233, 238

\section{bog myrtle 238}

\section{bone}

angel shark 67,149

animal 10, 19, 22, 25, 26, 34, 43, 47, 52, 58, 72, 90, 91, $92,95,115,116,118,119,121,122,142,144,145$, $146,147,148,156,157,159,160,161,162,165,168$, $169,171,172,173,174,176,178,179,188,207,208$, $209,210,212,214,220,227,232,233,235,237,238$, 239,242

ballan wrasse 50

bird 23, 26, 35, 41, 47, 50, 54, 58, 63, 64, 80, 85, 99, $115,120,148,150,151,152,208,210,214,230,232$, $238,239,242$

bovid 90,212

calf $52,119,144,211,238$

cattle $15,23,35,36,38,41,46,47,48,50,52,54,55$, $59,61,62,63,64,65,66,67,68,69,70,76,77,78$, $79,80,81,82,83,85,86,87,88,89,91,93,96,98$, $99,100,102,119,138,142,143,144,145,146,147$, $148,161,162,163,171,172,187,230,237,238$

$\operatorname{cod} 23,46,55,61,62,63,65,67,68,69,76,80,92,93$, $98,119,148,149$

common scouter 69

cormorant 67

crab $23,41,77$

crane 150,152

dab $28,31,69,239$

deer $26,35,38,46,47,48,58,61,62,63,66,67,69,79$, 92, 93, 118, 119, 138, 142, 145, 147, 238

fallow $118,123,142,168,169,171$

red $26,38,46,47,48,58,61,62,63,66,67,69,79,92$, 93, 119, 138, 142, 143, 144, 145, 147, 238

roe $138,164,167,169,192,207,235,238$

$\operatorname{dog} 17,18,21,35,41,61,67,68,69,86,91,92,93$, $119,142,143,144,145,147,175$

dulin 70

fish $23,26,41,42,60,61,63,72,76,79,80,85,87,93$, 103, 116, 120, 138, 148, 149, 150, 208, 209, 210, 214, $227,232,238,239,242$

flatfish $60,61,63,103,148,149$

fulmar 52, 150

gadoid $60,65,69,148,238$

gannet $55,69,239,241$

goat $118,119,142$

great auk 47, 48, 68, 83, 85, 93, 150, 151, 152

greylag goose 62

guillimot 47

gull $32,61,64,85,168,175$

hake $46,50,55,58,62,69,76,148,149$

human 9, 10, 19, 23, 25, 27, 47, 90, 92, 109, 114, 116, $121,122,123,140,141,142,144,146,147,150,153$, $157,164,165,168,169,170,171,172,174,176,178$, 179, 188, 189, 190, 195, 197, 207, 208, 209, 210, 212, $214,222,224,236$

lamb 52, 58, 95, 119, 140, 144, 227

ling $62,63,80,93,148$ mackerel 50, 148, 149, 238

mallard 68, 87, 95, 151

manx shearwater 62,81

otter $4,6,10,21,26,27,29,30,31,33,38,43,51,67$, $92,104,106,109,110,116,117,118,126,127,128$, $129,130,131,132,133,140,142,145,178,209,210$, $221,228,229,231,232,234,238,239,240$

pig $34,38,41,47,48,49,50,52,54,55,58,59,60,61$, $62,63,64,65,66,67,68,69,70,71,76,77,78,79$, $80,81,82,83,85,86,87,88,89,93,96,98,99,100$, $102,119,140,142,145,147,230,237$

plaice 50,68

pollock 23, 48, 50, 76, 80, 148

puffin 47,151

rabbit $15,44,124$

raven 79

rook/crow 89

saithe $23,55,89,93,148,149$

seal $8,23,26,36,38,47,50,52,55,57,62,67,78,80$, $85,86,92,95,98,103,113,119,140,141,142,143$, $145,146,212,238$

shark $65,67,148,149,238$

sheep 15, 19, 23, 26, 35, 36, 38, 41, 42, 47, 48, 49, 50, $52,54,55,59,60,61,62,63,65,66,68,69,70,76$, $77,79,80,90,91,95,103,118,119,124,127,142$, $143,144,145,146,147,148,160,161,162,163,167$, $169,170,171,172,187,189,212,226,230,237,238$ starling 50, 210

thrush $60,63,210$

tope $61,62,63,69,148,215,217,220$

Turdinae family 50

Turdus sp. 47

whale 139,143

whooper swan 61,150

wigeon 61

worked 137-9, 232, 233, 242

wrasse $50,148,238$

Borve 26

bow-drills 232

Bowermadden 137, 139

Brassicao Sinapis 153

brassicas 153, 160

Brigantes 243

British Geological Survey 12

brochs 22, 28, 29, 30, 132, 142, 240, 241, 242, 243

Bronze Age 4, 21, 22, 23, 26, 27, 28, 31, 132, 139, 150, $163,166,167,168,169,174,176,190,212,218,229$, $232,233,234,235,236,237,239,241,243$

Bu 234, 242

Buaile Risary 242 
Buckhuoy 168

Buiston 206, 230

burials 43, 109, 145, 146, 147, 219

burnt

mounds 234

stones $9,58,61,62,63,64,68,69,83,89,90,93,134$, $135,209,232,234$

butter 238, 243

Butzer 236

cairn

chambered 20, 22, 27, 44

kerb 27

long 27

navigation 43

round 27

Caithness 137, 139, 194

Callanish 21, 22, 25

Calluna vulgaris 159, 162, 194, 195, 202, 204, 238

Calvay Island 25

Cambridge froth flotation tank 8

Canada 135, 194

Caolais Newton 109

Caolas 109

Caravat Barp 27

carbonate $12,18,31,120,124,125,199,202,205,207$, 215,220

Carex

binervis 153

demissa 153

distans 153

flacca 153

hostiana 153

lasiocarpa 153

oederi 153

pallescens 153

panicea 153

pilulifera 153

rostrata 153

Carinish 12, 21, 22, 27, 28, 229

Carnan nan Long 44 carragheen 23

Carychium minimum 168

Cauci 243

Ceardach Ruadh 43, 135

Ceide 239

Cepaea hortensis 121, 164, 167, 170, 172

Cerastoderma edule 174, 175, 176

Cerealia 160, 194, 195

Cernuella virgata 168

Central Excavation Unit 1

charclock 153

charr 43, 105, 120, 153, 154, 155, 156, 157, 158, 206

cheese 243

Chenopodiaceae 204

Chenopodium album 153

chickweed 153

choppers 138, 232

Christian period 241

church 44

Cingular semistriata 176

cists $6,43,44,109$

Clausilia bidentata 163, 170

clay $18,21,27,31,36,47,108,117,125,126,127,128$, 129, 131, 159, 192, 197, 199, 200, 202, 206, 231

clearance 26, 109, 110, 169, 202, 205, 207, 228, 229

cleavers 232

Clettraval ware $27,30,115,118,131,174,219,231,241$, 243

Clickhimin 29

climate $19,186,190,237,242$

Cnip 241

Cnoc Raineach 109 
coal $23,38,49,50,58,105,124,201,203,205,215$

cobalt $19,142,147$

Cochlicella acuta 122, 163, 164, 166, 167, 169, 170, 172

Cochlicopa spp 122, 163, 167, 170, 172

lubrica 122, 170

lubricella 122, 170

cockles 176,177

$\operatorname{cod} 23,46,55,61,62,63,65,67,68,69,76,80,92,93$, $98,119,148,149$

coffin 43,48

Colonsay 173

Columella edentala 163, 170

comb 6, 9, 15, 23, 91, 95, 117, 126, 128, 130, 131, 132, $139,148,162,178,180,190,201,211,215,218,226$, $233,235,240$

Compositae 161, 204

conflation 48, 50, 86, 133, 134, 210, 213, 221, 224, 230

copper 19, 31, 142, 147, 172, 233

copper ore 31

corbelling 86, 87, 227, 241, 243

coring 1, 4, 6, 66, 116, 190, 203, 213, 223, 229, 230, 236

Coryloid 124, 192, 194, 195, 201, 202, 204, 205, 207

Corylus 202

crabs 23

Craig Hasten 203

crannogs 206, 230

Crois Mhic Jamain 109

Crosskirk 242

Cruachan 104

crucibles $30,31,242$

Cruciferae 160

Cul a Bhaile 229 cultivated deposits $34,42,62,67,68,75,76,81,83,84$, $102,108,116,180,185,187,189,211,212,226,233$, 235,236

Cyperaceae 153, 156, 159, 162, 190, 192, 194, 200, 201, 202, 204

Dalriadic migration 28

settlement 30

Dark Ages 31, 238, 239, 241

Deanntag 238

deflation $1,6,15,43,67,104,109,111,173,203,205$, 210, 211, 212, 213, 219, 229, 233

Deschampsia flexuosa 190

diatoms 124, 190

Dik Mor 26

dirk 242

dock 153, 175

drills 138, 139, 232

dulse 23

Dun

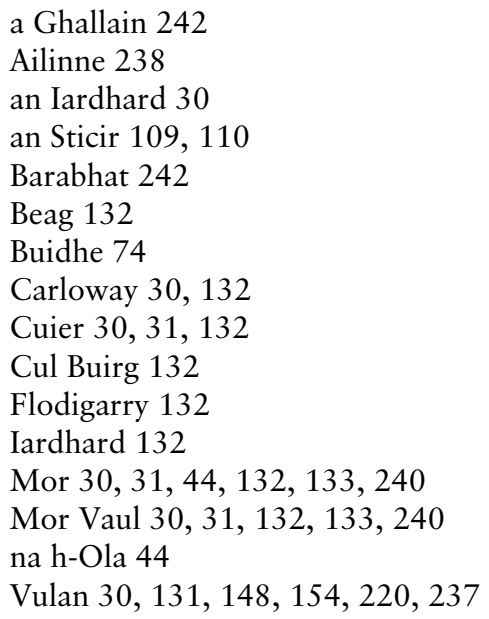

Dunagoil ware 30

Dunamich 110

dunes $1,12,13,15,17,18,43,72,124,136,173,179,188$, 203

duns

galleried 28, 109, 240 
East Lothian 139

East Shore 29, 234

Edinburgh University 109, 220

eel $6,17,18,26,28,29,30,31,38,43,44,58,74,87,90$, 92, 97, 98, 99, 103, 109, 114, 131, 132, 142, 194, 210, $211,215,221,224,225,226,227,228,230,231,233$, 240, 241, 242, 243

Eilean an Tighe 21, 27

emmer 27, 153, 236

Empetrum nigrum 192, 194, 195, 201

England 30, 31, 242, 243

Eocher 74

Epilobium 201

Erica $25,153,156,157,215$

Ericaceae 215

Eriophorum angustifolium 190

Euconulus fulvus 170

excavation methodology 114-25

sampling $1,8,61,120,121,150,163,167,188,189,203$, 205, 206, 207, 208, 209, 232

Eye Peninsula 13, 22, 26

fat hen 153

feverfew 238

field madder 153

Filicales 194, 201

fish $23,26,41,42,60,61,63,72,76,79,80,85,87,93$, $103,116,120,138,148,149,150,208,209,210,214$, $227,232,238,239,242$

flint 12, 27, 43, 104, 117, 133, 134, 135, 219, 233

Flogeln 235

forts

$$
\text { promontory 30, 43, } 109
$$

Foshigarry 29, 30

Fraxinus 201, 202
Friesland 235

Fucoid 174, 176

Gadwell 26

Galston 26, 31

Garry Iochdrach 30, 31

Garry Tigharry 26

Geirisclett 20, 27

geology 12,13

Germany 235

Ghegan Rock 139

Gibbula cineraria 174, 175, 176

glaciation 12

Glastonbury 150

Glen Valtos 12

Gorstan 104

Gramineae 156, 159, 160, 162, 178, 190, 192, 194, 200, 201, 202, 204

grasses 13, 127, 153, 178, 190, 201, 204, 205

Grimsay 26

Gruting School 241

Gyraulus laevis 163

haematite 30,31

Hallstatt 240, 243

hammerstones 43

hand-drills 232

\section{Harris}

Sound of 3, 12, 104

matrices 11

hazel 25, 202, 205

heath grass 153

heather 104, 153, 238

heathland 25, 201 
Helicella itala 122, 163, 165, 166, 167, 169, 170, 172

Herodian 242

\section{Hippuris vulgaris 204}

Historic Scotland 1

Hoglan Bay 12

Holm of Papa Westray 241

\section{Hordeum}

\section{distichum 153}

vulgare 153

Hornish 6, 8, 12, 26, 33, 72, 73, 74, 75, 76, 85, 87, 91, 97, $101,110,117,119,120,121,122,124,129,130,131$, $132,133,134,138,139,140,141,142,143,144,145$, $146,147,148,149,150,151,152,153,155,156,157$, $158,163,164,165,166,167,168,169,170,171,172$, $173,174,175,176,177,178,179,180,182,183,184$, $185,186,187,188,189,206,207,209,212,213,214$, $216,217,218,219,220,221,224,225,226,227,228$, $229,230,231,232,233,235,236,237,238,240$

house floors 212

Howe 1, 18, 19, 21, 23, 26, 28, 29, 30, 31, 33, 35, 42, 44, $66,71,77,84,98,100,114,117,118,120,122,123$, $126,132,138,139,140,148,149,150,153,157,163$, $165,168,171,173,179,180,183,185,188,192,194$, 195, 197, 201, 206, 207, 208, 209, 212, 213, 214, 215, $219,220,221,222,223,225,226,227,228,230,231$, $232,234,235,236,237,238,239,240,241,242,243$

Hydrobia alvae 176

Ulvae 176

diversity index 10

Illeray 43

Inner Hebrides 22, 26, 163, 169, 173, 194, 195, 201, 202, 229

Iona 132

Ireland 17, 28, 31, 135, 136, 163, 167, 234, 237, 239, 240, 241,243

Iris pseudacorus 203

iron

rivets $30,31,109,242$

Iron Age 4, 6, 21, 22, 23, 26, 27, 28, 29, 30, 31, 72, 109, $114,126,131,132,135,139,142,150,154,163,166$, $167,168,170,171,174,176,190,206,207,208,209$,
$210,212,214,229,230,231,232,233,234,235,236$, $237,238,239,240,241,242,243$

Islay 22, 163, 167, 229

Jarlshof 29, 241, 242

Judicial Rental 32, 110

Juniperus 200, 201

Jura 22, 135, 150, 229

Jutland 235

Kebister 234

kelp burning stances 6

Kettleburn 139

Killelan Farm 229

Killin 26

kiln 27

Kilpheder 29, 31

Kings Cave 150

Kirkibost Island 203

Knap of Howar 168, 234, 241

knives 139, 232

knotgrass 153

Kyleakin 238

Kyles Bernera 109

La Tène 240, 243

Lacuna

pallidula 174, 175, 177 vincta $174,175,176$

lake sediments 124, 159, 178, 190, 199, 205, 206

Laminaria 174, 175, 176, 177

Lammermuirs 242

Lang Gorm 43

Langbank Crannog 139

Later Broch Features 29 
Lauria sp.

cylindraea 122,163

Leiostyla anglica 170, 172

Lewis

Butt of 12,19

limonite 31

limpet 23, 66, 102, 111, 175, 216, 217

ling 238

Links of Noltland 26, 123, 234

lithics 135

Little Grebe 26

Little Ice Age 21, 242

Little Loch Roag 21, 25, 194, 195, 197, 201, 203

\section{Littorina}

littoralis 173, 174, 175, 176

neritoides 173, 174, 175, 176

saxatilis $173,174,176$

Loch

an Duin Bhig 72

an Duin Mhoir 72

an Duin Mor 44

an Phobaill 27

an Sticir 109

Askernish 207

Bee 72

Cleat 203, 205

Eport 26

Erisort 26

Lomond Advance Ice 204

Mor 44

na Cuithe Moire 199

na Paisg 44

nan Geireann 27

Olabhat 27, 44

Portain 22

Scolpaig 120, 190, 192, 194, 195, 196, 197, 198

Seaforth 26

Lochmaddy 12, 109

Long Isle 1, 9, 27, 28, 116, 190, 208

Lycopodium

selago 192, 194, 200, 201

spore tablets 120,161
Lymnaea truncatula 168, 169

Maari 27

machair $1,6,9,10,12,13,15,16,17,18,19,21,22,23$, $24,25,26,27,29,32,33,43,72,74,104,105,109$, $110,114,115,116,121,122,123,124,127,142,147$, $150,153,156,160,161,162,166,167,168,170,171$, 173, 174, 178, 188, 189, 190, 194, 197, 199, 202, 203, 204, 205, 207, 208, 209, 210, 211, 212, 213, 214, 215, 230, 236, 237, 238, 239

Machair Lathan 29

MacKenzie Collection 109

macroplant 8, 9, 10, 11, 26, 33, 34, 54, 84, 92, 116, 236

Maes Howe 241

magnesium 18

maize 178

marine mollusca 116, 173, 175, 207, 230

Marrogh 27

Medicago sp. 153

medick 153

Medieval 26, 44, 111, 113, 131, 163, 167, 170, 176, 229, 237

megaliths 27,30

Melampyrum 201, 202

Menapii 243

Menyanthes trifoliata 190, 199

Mesolithic 23, 26, 28, 135

metalwork 30, 242, 243

metalworking 30-1

bronze 30, 31, 43, 109, 172, 233, 242, 243

iron $30,31,33,214,232,233,242,243$

midden-type deposits 212

Midhowe 242

Minch 13, 31

Ministry

of Defence 74

of Works 74 
Monach Islands 12

Moorhen 26

Morvern 238

Mousa 242

Mull 201, 241

Mute Swan 26

mylonite 12,21

Myrica gale 195, 215

Myriophyllum

alterniflorum 194, 197, 199

spicatum 204

National Museum of Scotland 43

Neolithic 20, 21, 22, 23, 26, 27-8, 44, 168, 169, 190, 208, $229,234,235,239,241$

fields 239

Nesovitraea hammonis 164, 171, 172

Netherlands 235, 236

nettle 238

Newton House 109

Newtonferry 6, 8, 12, 27, 109, 110, 111, 112, 117, 121, $122,131,135,163,164,165,166,167,168,170,172$, $173,174,175,176,177,216,217,219,229,237$

National Nature Reserve 124

Norse 26, 33, 43, 109, 219, 239, 242, 243

North

Bay 72

Dell 22

Ronaldsay 147

Uist Estates 109

West Territories 194

Northern Isles 28, 29, 240, 241, 242

Northferry 161, 162

Northton 12, 21, 27, 28, 121, 163, 165, 167, 168, 169, 173

Norway 135, 136, 160, 162, 194

Nymphaea alba 190 oaks 238

oats $19,135,138,233,238$

Office of Works 1

Onaba semicostate 176, 177

orache 153

Orkney Islands 23

Oronsay 23, 173

Osmunda regalis 202

Outer Hebrides 1, 12, 15, 17, 21, 22, 23, 24, 26, 27, 28, 127, 148, 163, 166, 167, 173, 176, 190, 194, 199, 204, 205, 231, 238, 239, 242, 243

Oxychilus alliarius 167, 171, 172

Oxyloma pfeifferi 121, 168

oyster 23,210

Oystercatchers 26

Panicea Carey 153

Papa Westray 139, 220, 234, 241

peats

inter-tidal 20

surface 20

persicaria 153, 156, 157

phosphorus 19

Phragmites 199, 203

phytoliths $123,124,178,179,180,182,183,185,186$, 187, 188, 189, 209

pins

ring-headed 31, 131, 232, 240

Pintail 26

Pinus 162, 192, 194, 195, 202, 204

pitchstone 21

plaggen soil 23, 209, 211, 212, 235, 236

Plantaginaceae 161

Plantago 
lanceolata 153, 192, 195, 201

major/media 192, 194

maritima 200, 201, 204

plough share 31

Pobull Fhin 27

Pochard 26

pollen $8,25,26,116,120,121,124,159,160,161,162$, 178, 190, 192, 193, 194, 195, 197, 199, 200, 201, 202, 203, 204, 205, 207, 208, 209, 235, 238

pollock $23,48,50,76,80,148$

Polygonaceae 153, 156

Polygonum 153, 156, 157

Polypodiaceae 161

Polypodium 200, 201

Pool of Virkie 206, 241

Port Nan Long 6, 109

post-medieval $6,74,95,108,111,113,151,219,226,229$, 237,239

Potamogeton spp. 194, 199, 204

potassium 19, 202

potato 238

\section{Potentilla erecta 190}

pottery $4,10,21,31,33,43,51,67,92,104,106,109$, $110,116,117-18,126-33,178,209,210,221,228$, $229,231-2$

Beaker 27, 104

decoration $27,30,33,72,104,117,118,126,127,128$, $129,130,131,132,133,139,221,231,232$

Iron Age 29, 30, 131, 231, 232, 233, 234, 235, 236, 237, $238,239,240,241,242,243$

Neolithic 27, 28, 44, 168, 169, 190, 208, 229, 234, 235, 239, 241

Roman 30

primary dump 51, 52, 63, 211, 222, 224

Pteridium aquilinum 202

Ptolemy 243

pumice $9,47,48,59,61,63,67,69,70,104,134,135,136$, 138,233

punches 139, 232
Punctum pygmaeum 170, 171, 172

Pupilla muscorum 122, 163, 167, 170, 172

Potential Water Surplus 19

Quercus 201, 202, 204

quern $33,53,54,209,240$

radiocarbon dating $8,120,121,212,215,217,218,219$, $220,223,228$

rainfall 18,19

Ranunculaceae 201, 204

reeds $72,168,190,203,204$

research questions

methodology 120, 121, 123, 124, 126, 142, 144, 221

Retusa obtusa 174, 175, 176, 177

Rhum 21

ribwort 153

rig-and-furrow cultivation 21

Ringed Plovers 26

rings $19,31,132$

Rinyo 241

Rissoa parva 174, 175, 176

Roman army 237

rookeries 23

Rosaceae 201, 238

Rosinish 21, 26, 27

Rothamstead 236

Routine Soil Sample 8

Ru Cuinafenagh 72

Ru Hornish 72

Rubh Arnal 203

Rubha na Traghead 109

Rubna Mor 203

Rudh a Duin 242 
Rumex acetosella 190, 192, 194

saithe $23,55,89,93,148,149$

Salix 190, 192, 194, 195, 200, 201, 204, 205, 215

salmon 26

Sanday 13, 235

sand-cliffs 1

saws $138,139,232$

Saxifraga oppositifolia 194

Scalloway 213

Scandinavia 26, 135, 209, 210, 240

Scatness 235

Scaup 26

Scirpus spp. 199

Scolpaig 32, 120, 190, 192, 194, 195, 196, 197, 198

Scottish Lowlands 19

Screvan 109

scurvy grass 238

\section{SDD Ancient Monuments 1}

seal

common 23, 143, 145, 146, 238

grey 23

seaweed 19, 23, 116, 147, 154, 165, 167, 173, 174, 176, $177,209,212,230,237,239$

sedges 153, 190, 201, 204

semi-brochs 28, 30

Sgeir na Galtun 43

SEARCH 114,115

Shelduck 26

shell $1,4,6,8,9,10,12,13,21,23,27,33,35,36,38,43$, $44,47,48,49,60,61,65,67,68,72,75,76,79,84$, $87,92,93,94,96,104,105,109,110,113,116,120$, $121,127,135,164,168,171,172,173,174,176,187$, $188,204,206,209,210,212,215,216,217,220,227$, 229, 235, 236, 238, 239

Sherardia arvensis 153
Sheshader 22, 26

Shoveller 26

Sithean 26, 229

Skara Brae 168, 234, 241

Skiport 133

Skye 30, 109, 132, 133, 134, 201, 203, 205, 233, 238

slag 4, 6, 8, 9, 10, 31, 33, 43, 55, 109, 232

bronze $30,31,109,233$

iron $30,33,232,242$

Sloc Sabhaidh 43, 44

snails $121,122,163,164,165,166,168,169,171,172$, $173,176,207,210,223$

Society of Antiquaries of Scotland 33

Soil Survey Handbook 8

soils $9,10,17,18,19,21,22,23,25,27,29,43,61,62,63$, $64,65,66,114,122,123,156,169,173,174,194$, 201, 202, 204, 205, 206, 207, 208, 209, 210, 211, 212, $214,215,226,235,236,238$

Sollas 29, 31, 131, 132, 133, 211

Sound of Eriskay 104

South Clettraval 27

South Glendale 6, 8, 27, 104, 105, 117, 131, 133, 134, 135, $216,217,219,228,229,233$

South Lewis 26

South Uist 1, 6, 12, 13, 14, 25, 26, 27, 28, 30, 72, 74, 104, $131,132,157,161,162,178,190,199,203,204,229$, 231

Sparganium emersum 204

spear-butts 31

Sphagnum 192, 194, 195, 201

St Boniface 139, 206, 220, 234

St Kilda 190, 239, 241

Standard Bulk Sample 8

Staneydale 241

Stellaria media 153, 156 
stone $4,6,8,9,10,12,18,21,27,29,30,32,33,34,35$, $36,38,43,44,47,48,50,51,52,53,54,55,56,58$, $59,60,61,62,63,64,65,67,68,69,72,75,76,77$, $78,80,81,83,84,85,86,87,88,89,90,92,93,94$, 96, 98, 99, 100, 102, 103, 104, 105, 106, 108, 109, $110,111,113,132,134,135,171,173,209,210,213$, $223,224,226,227,229,232,233,234,238,239,240$, 241,242

Stoneybridge 25, 199

Stornoway 12, 19

structured deposition 90, 211

Suenish 109

sundew 238

Switzerland 6

Sylt 235

tallard 32, 104, 109, 110, 111, 229

tansy 238

'tapestry' excavation

advantages $8,19,148,169$

procedure $8,120,148,156,157,161,218$

Taraxacum-type 194, 195

Teampull Chriosd 44

Thalictrum 201, 204

$\operatorname{tin} 31,233$

Tiree 19, 30, 132

Tob Nan Leobag 22

Tofts Ness 235

Traigh Luskentyre 12

Tregaron Bog 19

Triticum diccoccum 153

trout 26

Tufted Duck 26

Tuquoy 206

Udal 21, 27, 28, 29, 30, 148, 161, 162, 229

Ulmus 201, 202
Umbelliferae 204

Unival 21, 27

Unstan ware 27

Urtica 201

Usinish 29

Vallaquie 109

Vallay 26, 30, 242

Vallay Strand 30

Vallonia spp

costata $163,167,170,171,172,174$ excentrica 167,170

Valtos 12, 133

Varlish Point 33

Vatersay 12

vegetation $15,18,21,23,25,26,113,114,121,122,123$, $128,131,160,162,163,165,167,168,169,170,171$, $172,173,183,186,190,194,195,197,199,202,203$, 204, 208, 209, 238

\section{Vertigo}

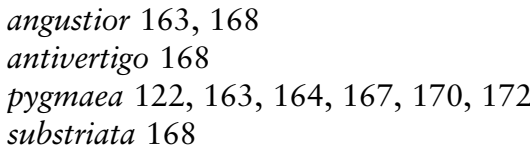

Vigdale 26

Viking 23, 26, 43, 74, 109, 132, 206

violets 238

Vitrea

$$
\begin{aligned}
& \text { contracta } 167,171,172 \\
& \text { crystallina } 171
\end{aligned}
$$

Vitrina pellucida 121, 122, 163, 164, 167, 171, 172

Vlassen 235

waders 26,150

Ward Hill 241

Water Rail 26

Wessex 212 


\section{West Lewis 25}

Western Isles 13, 15, 18, 19, 21, 23, 24, 26, 27, 28, 29, 30, $31,117,138,151,154,165,178,209,229,240,241$, 242

wheat $153,157,207,236$

wheelhouses $28,29,30,44,74,221,230,231,240,241$, 242, 243

Wigeon 26, 151

wildcat 26 winkle $23,36,46,48,49,50,55,60,63,64,65,66,67,69$, $70,71,74,77,80,81,82,84,92,96,100,102,111$, $175,216,217$

Woburn 236

wood sorrel 26

woodland 25, 26, 121, 165, 170, 195, 237

wrack 23, 176

yellow flag 109, 238

zinc 18,124

Zonitoides nitidus 163, 168 


\section{TABLES}

TABLES FOR CHAPTER 4

BLOCK I (see p.34)

$\begin{array}{rll}\text { Context } & \text { Pot } & \text { Macro } \\ 8 & 0 & 0 \\ 10 & 0 & 0 \\ 205 & 2 & 0.13 \\ \text { Total } & 2 & 0.13\end{array}$

BLOCK 2 (see p.34)

$\begin{array}{rrrr}\text { Context } & \text { Bone } & \text { SeaSh } & \text { Slag } \\ 4 & 4 & 95 & 30 \\ 280 & 0 & 100 & 0 \\ \text { Total } & 4 & 195 & 30\end{array}$


BLOCK 3 (see p.35)

\begin{tabular}{|c|c|c|c|c|c|}
\hline Context & Bone & Pot & SeaSh & Macro & Stone \\
\hline 26 & I & 17 & 0 & 0 & 0 \\
\hline 27 & 0 & 10 & 0 & 0 & 0 \\
\hline 28 & 0 & 1 & 0 & 0 & 0 \\
\hline 33 & 0 & I & 0 & 0 & 0 \\
\hline 43 & 0 & 0 & 72 & 0 & 0 \\
\hline 44 & 149 & 0 & 14.1 & 0 & 0 \\
\hline 45 & I & 0 & 2 & 0 & 0 \\
\hline 49 & 3 & 0 & 43 & 591 & 0 \\
\hline 54 & 4 & 0 & 48.6 & 0 & 0 \\
\hline 58 & 4 & 0 & 394 & 0 & 0 \\
\hline 60 & I & 0 & 24.6 & 0 & 0 \\
\hline 62 & 0 & 0 & 26.1 & 0 & 0 \\
\hline 63 & 2 & 0 & 31.8 & 0 & 0 \\
\hline 71 & 0 & 10 & 0 & 0 & 0 \\
\hline 72 & 7 & 2 & 0 & 0 & 0 \\
\hline 74 & 0 & 4 & 0 & 0 & 0 \\
\hline 86 & 0 & 1 & 34 & 0 & 0 \\
\hline 106 & 65 & 2 & 60 & 0 & 0 \\
\hline 107 & 250 & 9 & 156 & 0 & 0 \\
\hline 113 & 514 & 19 & 349 & 39.5 & 9 \\
\hline 120 & 0 & 101 & 0 & 0 & 0 \\
\hline 121 & 16 & I & 32 & 0 & 0 \\
\hline 122 & 0 & 1 & 0 & 0 & 0 \\
\hline 307 & 0 & 24 & 0 & 0 & 0 \\
\hline 329 & 10 & 4 & 385 & 0 & 0 \\
\hline 330 & II & 4 & 100 & 0 & 0 \\
\hline 331 & 5 & 2 & 43 & 0 & 0 \\
\hline 333 & 5 & 2 & 43 & 0 & 0 \\
\hline 345 & 0 & 0 & 10 & 0 & 0 \\
\hline 346 & 0 & 0 & 7 & 0 & 0 \\
\hline 504 & 0 & 0 & 2 & 0 & 0 \\
\hline 664 & 0 & 14 & 2 & 0 & 0 \\
\hline 667 & 0 & 26 & 0 & 0 & 0 \\
\hline Total & 1,043 & 253 & 1,840 & 645 & 9 \\
\hline
\end{tabular}


BLOCK 4 (see p.36)

\begin{tabular}{|c|c|c|c|c|c|}
\hline Context & Bone & Pot & SeaSh & Macro & Stone \\
\hline 148 & 0 & 3 & 0 & 0 & 0 \\
\hline 155 & 0 & I & 0 & 0 & 0 \\
\hline 156 & 4 & 0 & 0 & 0 & 0 \\
\hline 162 & 0 & 1 & 0 & 0 & 0 \\
\hline 166 & 0 & 14 & 0 & 0 & 0 \\
\hline 262 & 0 & 29 & 0 & 0 & 0 \\
\hline 264 & 0 & 0 & 92.4 & 0 & 0 \\
\hline 265 & 0 & 0 & 250 & 0 & 0 \\
\hline 266 & 20 & 0 & 400 & 0 & 38 \\
\hline 268 & 7 & 0 & 11.8 & 0 & 15.2 \\
\hline 271 & 0 & 3 & 0 & 0 & 0 \\
\hline 281 & 12 & 0 & 221 & 0 & 92 \\
\hline 282 & 9 & 0 & 33.5 & 0 & 33 \\
\hline 283 & 16 & 4 & 74 & 0 & 203 \\
\hline 284 & 5 & 3 & 24.3 & 0 & 61.8 \\
\hline 285 & 0 & 0 & 0 & 0 & 78.4 \\
\hline 286 & 0 & 2 & 0 & 0 & 0 \\
\hline 288 & 14 & 1 & 53.2 & 4.2 & 29.9 \\
\hline 289 & 25 & 0 & 0 & 0 & 32.8 \\
\hline 291 & 0 & 10 & 0 & 0 & 0 \\
\hline 292 & 3 & 0 & 57.2 & 0 & 188.8 \\
\hline 293 & 4 & 0 & 21.5 & 0 & 36.2 \\
\hline 294 & 9 & 8 & 35 & 0 & 12 \\
\hline 295 & 11 & 0 & 60 & 0 & 0 \\
\hline 560 & 0 & 3 & 0 & 0 & 0 \\
\hline 613 & 0 & 3 & 0 & 0 & 0 \\
\hline 614 & 15 & 0 & 1,391 & 3.6 & 0 \\
\hline 622 & 0 & 4 & 0 & 0 & 0 \\
\hline 784 & 0 & 4 & 0 & 0 & 0 \\
\hline 797 & 0 & 1 & 0 & 0 & 0 \\
\hline Total & 154 & 94 & 2,725 & 7.75 & 821.1 \\
\hline
\end{tabular}


BLOCK 5 (see p.36)

\begin{tabular}{|c|c|c|c|c|c|}
\hline Context & Bone & Pot & SeaSh & Macro & Stone \\
\hline 20 & 918 & $|4|$ & 2,101 & 14.7 & 519 \\
\hline 21 & 84 & 22 & 308 & 8 & 173 \\
\hline 22 & 0 & 118 & 0 & 0 & 0 \\
\hline 39 & 224 & 15 & 2,060 & 40.5 & 865 \\
\hline 89 & 0 & 17 & 0 & 0 & 0 \\
\hline 92 & 0 & 9 & 0 & 0 & 0 \\
\hline 93 & 0 & 9 & 0 & 0 & 0 \\
\hline 145 & 48 & 60 & 130 & 9.8 & 0 \\
\hline 149 & 3 & 0 & 4 & 0 & 0 \\
\hline 150 & 6 & 1 & 8 & 0 & 0 \\
\hline 301 & 0 & 12 & 0 & 0 & 0 \\
\hline 309 & 0 & 6 & 0 & 0 & 0 \\
\hline 311 & 0 & 1 & 0 & 0 & 0 \\
\hline 316 & 0 & 5 & 0 & 0 & 0 \\
\hline 320 & 0 & 3 & 0 & 0 & 0 \\
\hline 340 & 224 & 11 & 2,060 & 40.5 & 865 \\
\hline 513 & 0 & 4 & 0 & 0 & 0 \\
\hline 515 & 0 & 180 & 0 & 0 & 0 \\
\hline 526 & 0 & 9 & 0 & 0 & 0 \\
\hline 527 & 0 & 57 & 0 & 0 & 0 \\
\hline 528 & 0 & 12 & 0 & 0 & 0 \\
\hline 529 & 0 & 28 & 0 & 0 & 0 \\
\hline 639 & 0 & 0 & 48 & 0 & 0 \\
\hline 651 & 0 & 2 & 0 & 0 & 0 \\
\hline 652 & 10 & 18 & 25 & 0 & 0 \\
\hline 656 & 0 & 0 & 11 & 0 & 0 \\
\hline 657 & 32 & 0 & 45 & 0 & 0 \\
\hline 658 & 0 & 0 & 24 & 0 & 0 \\
\hline 659 & 0 & 0 & 14 & 0 & 0 \\
\hline 662 & 1 & 58 & 221 & 3.6 & 15.4 \\
\hline 663 & 121 & 10 & 63 & 3.6 & 0 \\
\hline 669 & 2 & 0 & 0 & 0 & 0 \\
\hline 671 & 12 & 0 & 9 & 0 & 0 \\
\hline 672 & 0 & 1 & 0 & 0 & 0 \\
\hline 673 & 4 & 0 & 35 & 0 & 0 \\
\hline 763 & 0 & I & 0 & 0 & 0 \\
\hline 771 & 0 & 0 & 19 & 0 & 0 \\
\hline 801 & 0 & 7 & 0 & 0 & 0 \\
\hline 802 & 0 & 10 & 0 & 0 & 0 \\
\hline 803 & 0 & 0 & 0 & 60 & 0 \\
\hline 804 & 0 & 0 & 0 & 6.9 & 0 \\
\hline 805 & 0 & 0 & 0 & 39.8 & 0 \\
\hline 885 & 0 & 1 & 0 & 0 & 0 \\
\hline Total & 1,689 & 828 & 7,185 & 227.44 & 2,437 \\
\hline
\end{tabular}


BLOCK 6 (see p.38)

\begin{tabular}{|c|c|c|c|c|c|c|c|}
\hline Context & Bone & Pot & SeaSh & Macro & Stone & Snail & Slag \\
\hline 239 & 4 & 0 & 0 & 0 & 0 & 0 & 0 \\
\hline 240 & 3 & 0 & 1,983 & 0 & 0 & 0 & 0 \\
\hline 249 & 0 & 0 & 225 & 0 & 0 & 0 & 0 \\
\hline 250 & 0 & 0 & 266 & 0 & 0 & 0 & 0 \\
\hline 305 & 0 & 5 & 0 & 0 & 0 & 0 & 0 \\
\hline 309 & 200 & 0 & 103 & 105 & 787 & 0 & 7.6 \\
\hline 311 & 0 & 0 & 3,086 & 0 & 0 & 0 & 0 \\
\hline 315 & 0 & 0 & 0 & 0 & 0 & 0 & 0 \\
\hline 316 & 0 & 0 & 0 & 0 & 0 & 0 & 0 \\
\hline 317 & 0 & 2 & 188 & 0 & 0 & 0 & 0 \\
\hline 325 & 0 & 0 & 291 & 0 & 0 & 0 & 0 \\
\hline 704 & 0 & 0 & $\mathrm{I}, 470$ & 417 & 20 & 0 & 0 \\
\hline 708 & 0 & I & 71 & 0 & 0 & 0 & 0 \\
\hline 710 & 235 & 33 & 4,224 & 70 & 2,965 & 0 & 9 \\
\hline 716 & 0 & 1 & 0 & 0 & 0 & 0 & 0 \\
\hline Total & 442 & 42 & 11,907 & 592 & 3,772 & 0 & 16.6 \\
\hline
\end{tabular}

Pit fills

$\begin{array}{lrl}520 & 0 & 0 \\ 531 & 0 & 0 \\ 534 & 0 & 0 \\ 712 & 0 & 0 \\ 714 & 0 & 0 \\ 716 & 12 & 1 \\ 720 & 0 & 0 \\ 722 & 0 & 0\end{array}$

3.58

34.21

0
0

$\begin{array}{lr}0.01 & 0 \\ 0.07 & 0 \\ 0 & 108 \\ 0 & 0 \\ 0 & 0 \\ 0 & 0 \\ 0.01 & 0 \\ 0 & 0\end{array}$

To-tal

12

5,972

120.03

147

0.09

108 
BLOCK 7 (see p.4I)

\begin{tabular}{|c|c|c|c|c|c|c|}
\hline Context & Bone & Pot & SeaSh & Macro & Stone & Slag \\
\hline 15 & 3 & 0 & 159 & 0 & 0 & 0 \\
\hline 17 & 0 & 9 & 0 & 0 & 0 & 0 \\
\hline 18 & 0 & 55 & 0 & 0 & 0 & 0 \\
\hline 19 & 12 & 6 & 18 & 0 & 19 & 0 \\
\hline 91 & 0 & 3 & 0 & 0 & 0 & 0 \\
\hline 94 & 5 & I & 0 & 0 & 0 & 0 \\
\hline 128 & 11 & 5 & 167 & 0 & 11 & 0 \\
\hline 129 & 4 & 4 & 17 & 0 & 0 & 0 \\
\hline 130 & 3 & 1 & 82 & 0 & 0 & 0 \\
\hline 133 & 7 & 0 & 123 & 0 & 0 & 0 \\
\hline 134 & 0 & 7 & 0 & 0 & 0 & 0 \\
\hline 135 & 0 & 0 & 0 & 0 & 0 & 0 \\
\hline 136 & 0 & 0 & 0 & 0 & 0 & 0 \\
\hline 138 & 3 & 0 & 18 & 0 & 0 & 0 \\
\hline 140 & 25 & 0 & 463 & 7.3 & 2,538 & 0 \\
\hline $14 \mid$ & 0 & 0 & 73 & 0 & 0 & 0 \\
\hline 143 & 0 & 0 & 12 & 0 & 0 & 0 \\
\hline 225 & 5 & 0 & 163 & 0 & 0 & 0 \\
\hline 226 & 0 & 0 & 1,180 & 0 & 0 & 0 \\
\hline 228 & 0 & 0 & 288 & 0 & 0 & 0 \\
\hline 229 & 45 & 15 & 5,107 & 6.7 & 0 & 69.4 \\
\hline 230 & 3 & 2 & 71 & 0 & 0 & 0 \\
\hline 231 & I & 0 & 78 & 0 & 0 & 0 \\
\hline 232 & 4 & 0 & 167 & 0 & 0 & 0 \\
\hline 233 & 15 & 0 & 0 & 0 & 0 & 0 \\
\hline 237 & 0 & 3 & 3 & 0 & 0 & 0 \\
\hline 238 & 0 & 0 & 703 & 0 & 0 & 0 \\
\hline 244 & 4 & 0 & 42 & 0 & 0 & 0 \\
\hline 245 & 12 & 0 & 2,723 & 0 & 0 & 0 \\
\hline 302 & 0 & 0 & 2 & 0 & 0 & 0 \\
\hline 303 & 5 & 0 & 152 & 0 & 0 & 0 \\
\hline 304 & 59 & 18 & 6,849 & 20 & 394 & 71.8 \\
\hline 306 & 3 & 4 & 440 & 0 & 0 & 0 \\
\hline 308 & 0 & 3 & 0 & 0 & 0 & 0 \\
\hline 505 & 0 & 70 & 58 & 0 & 0 & 0 \\
\hline 506 & 4 & 11 & I,789 & 86 & 0 & 0 \\
\hline 517 & 0 & 3 & 0 & 0 & 0 & 0 \\
\hline 519 & 0 & 3 & 0 & 0 & 0 & 0 \\
\hline 522 & 0 & 52 & 0 & 0 & 0 & 0 \\
\hline 523 & 0 & 4 & 0 & 0 & 0 & 0 \\
\hline 525 & 0 & 18 & 0 & 0 & 0 & 0 \\
\hline 624 & 12 & 0 & 119 & 2.6 & 13 & 0 \\
\hline 625 & 6 & 0 & 123 & 0 & 0 & 0 \\
\hline 627 & 7 & 0 & 327 & 4.4 & 23 & 0 \\
\hline 628 & 13 & 2 & 37 & 7.8 & 0 & 0 \\
\hline 629 & 0 & 6 & 0 & 0 & 0 & 0 \\
\hline 631 & 14 & 0 & 1,166 & 178 & 200 & 30.7 \\
\hline 640 & 2 & I & 55 & 0 & 0 & 0 \\
\hline 642 & 0 & 0 & 1,317 & 0 & 0 & 0 \\
\hline 650 & 3 & 0 & 119 & 0 & 0 & 0 \\
\hline 751 & 12 & 0 & 979 & 10 & 21 & 0 \\
\hline 787 & 0 & 0 & 19 & 0 & 0 & 0 \\
\hline 810 & 0 & 0 & 48 & 0 & 0 & 0 \\
\hline Total & 302 & 306 & 25,256 & 322.8 & 3,219 & 171.9 \\
\hline
\end{tabular}


BLOCK 8 (see p.4I)

$\begin{array}{rrrrr}\text { Context } & \text { Bone } & \text { Pot } & \text { SeaSh } & \text { Macro } \\ 166 & 15 & 0 & 1,391 & 3.55 \\ 181 & 4 & 3 & 0 & 0 \\ \text { Total } & 19 & 3 & 1,391 & 3.55\end{array}$


TABLES FOR CHAPTER 5

BLOCK IA (see p.46)

$\begin{array}{cccccccccc}\text { Context } & \text { Bone } & \text { Pot } & \text { Snail } & \text { SeaSh } & \text { Macro } & \text { Stone } & \text { IHI } & \text { pH } & \text { Phos } \\ 68 & 553 & 37 & 0.01 & 382 & 0.06 & 528 & 5000 & 7.5 & 3\end{array}$

\section{BLOCK IB (see p.46)}

Context

68

\section{Species}

Cochlicopa lubrica

Cochlicopa lubricella

Cochlicopa sp

Vertigo antivertigo

Pupilla muscorum

Vallonia costata

Vallonia excentrica

Vitrea contracta

Nesovitrea hammonis I

Oxychillus alliarius

Helicella itala

Cepaea hortensis

\section{Total-terrestrial}

(including wet species)

No. of species

(including wet species) 
BLOCK 2A (see table p.46)

\begin{tabular}{|c|c|c|c|c|c|c|c|c|c|c|c|c|c|}
\hline Context & Bone & Pot & Snail & SeaSh & Macro & Slag & Stone & IHI & $\mathbf{P h}$ & Phos & $\begin{array}{l}\% \text { Burnt } \\
\text { stone }\end{array}$ & $\begin{array}{l}\text { Pumice } \\
\text { frags }\end{array}$ & $W t(g)$ \\
\hline 42 & 1594 & 149 & 29.00 & |957| & 71.32 & 98 & 1169 & 36000 & 7.21 & 4 & 20 & 0 & 0 \\
\hline 43 & 265 & 26 & 14.00 & 568 & 0.14 & 0 & 793 & 4500 & 7.31 & 2 & $<5$ & 0 & 0 \\
\hline 44 & 22 & 4 & 0.001 & 185 & 0.23 & 0 & 51 & 15000 & 7.48 & 5 & $<5$ & 0 & 0 \\
\hline 51 & 0 & 0 & 0.00 & 0 & 0.00 & 0 & 0 & 0 & 7.12 & 4 & 0 & 0 & 0 \\
\hline 52 & 137 & 34 & 0.00 & 678 & 7.37 & 0 & 73 & 13000 & 7.28 & 2 & $<5$ & 0 & 0 \\
\hline 55 & 343 & 22 & 0.01 & 2881 & 0.21 & 0 & 223 & 21000 & 7.55 & I & 20 & 0 & 0 \\
\hline 56 & 0 & 3 & 0.00 & 55 & 0.1 & 0 & 0 & 31000 & 7.18 & 3 & 0 & 0 & 0 \\
\hline 57 & 1173 & 95 & 11.01 & 12282 & 23.11 & 0 & 1222 & 29500 & 7.29 & 3 & 10 & 0 & 0 \\
\hline 58 & 10 & 0 & 0.00 & 393 & 0.11 & 0 & 36 & 30000 & 7.37 & 4 & $<5$ & 0 & 0 \\
\hline 59 & 831 & 42 & 0.01 & 2000 & 7.18 & 0 & 146 & 13000 & 7.21 & 2 & $<5$ & 0 & 0 \\
\hline 60 & 0 & 0 & 0.01 & 18 & 0.09 & 0 & 0 & 6000 & 7.39 & 4 & 0 & 0 & 0 \\
\hline 61 & 51 & 32 & 6.00 & |475 & 0.00 & 0 & 210 & 80000 & 7.26 & 3 & 10 & 0 & 0 \\
\hline 62 & 74 & 6 & 0.01 & 426 & 0.08 & 0 & 214 & 22000 & 7.38 & 2 & $<5$ & 2 & 1.0 \\
\hline 63 & 513 & 19 & 0.06 & 493 & 7.15 & 0 & 339 & 20000 & 7.55 & 3 & $<5$ & 0 & 0 \\
\hline 64 & 0 & 0 & 0.01 & 30 & 0.13 & 0 & 14 & 17000 & 7.25 & 3 & 100 & 0 & 0 \\
\hline 65 & 0 & I & 0.00 & 7 & 0.17 & 0 & 129 & 17000 & 7.23 & I & 50 & I & 2.2 \\
\hline 66 & 19 & 5 & 0.01 & 29 & 0.08 & 0 & 0 & 4500 & 7.18 & 4 & 0 & 0 & 0 \\
\hline 67 & 47 & 4 & 0.01 & 98 & 0.26 & 0 & 123 & 8500 & 7.41 & 5 & 0 & 0 & 0 \\
\hline 69 & 74 & 13 & 16.01 & 227 & 0.19 & 7 & 94 & 12000 & 7.37 & 2 & 10 & 0 & 0 \\
\hline 70 & 57 & 7 & 4.02 & 1002 & 0.08 & 0 & 128 & 23000 & 7.46 & 4 & $<5$ & 0 & 0 \\
\hline 71 & 4 & 1 & 71.00 & 110 & 1.10 & 0 & 188 & 25000 & 7.38 & 5 & 10 & 0 & 0 \\
\hline 72 & 11 & 3 & 0.23 & 113 & 0.14 & 0 & 201 & 27500 & 7.20 & 5 & $<5$ & 0 & 0 \\
\hline 73 & 114 & 14 & 0.09 & 792 & 0.20 & I & 287 & 18000 & 7.55 & 5 & $<5$ & I & 24.4 \\
\hline 75 & 32 & 0 & 0.1 & 1464 & 0.21 & 0 & 608 & 73000 & 7.24 & 2 & 20 & 0 & 0 \\
\hline 76 & 44 & 2 & 0.05 & 33 & 0.37 & 0 & 70 & 9000 & 7.30 & 5 & 10 & 0 & 0 \\
\hline 80 & 0 & 6 & I.74 & 13 & 0.17 & 0 & 2 & 6000 & 7.15 & 3 & 0 & 0 & 0 \\
\hline 81 & 0 & 0 & 0.01 & 6 & 0.17 & 0 & 0 & 2500 & 7.65 & 2 & 0 & 0 & 0 \\
\hline 82 & 0 & 0 & 0.01 & 0 & 0.01 & 0 & 6 & 2000 & 7.05 & 2 & 0 & 0 & 0 \\
\hline 84 & 0 & 0 & 0.00 & 0 & 0.00 & 0 & 0 & 0 & 7.63 & 2 & 0 & 0 & 0 \\
\hline 200 & 11 & 7 & 0.02 & 36 & 0.10 & 0 & 327 & 27000 & 7.31 & 4 & 10 & 0 & 0 \\
\hline Total & 5426 & 495 & $|53.42|$ & 44985 & 125.47 & 106 & 6653 & & & & & & 0 \\
\hline Mean & & & & & & & & 21000 & & & & & 0 \\
\hline
\end{tabular}


BLOCK 2B (see table p.46)

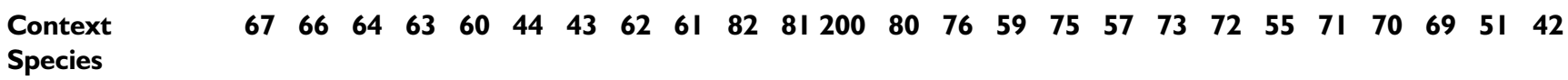

Cochlicopa lubrica

Cochlicopa lubricella

Cochlicopa sp

Vertigo antivertigo

Pupilla muscorum

Vallonia costata

Vallonia excentrica

Vitrea contracta

Oxychillus alliarius

Helicella itala

Cepaea hortensis

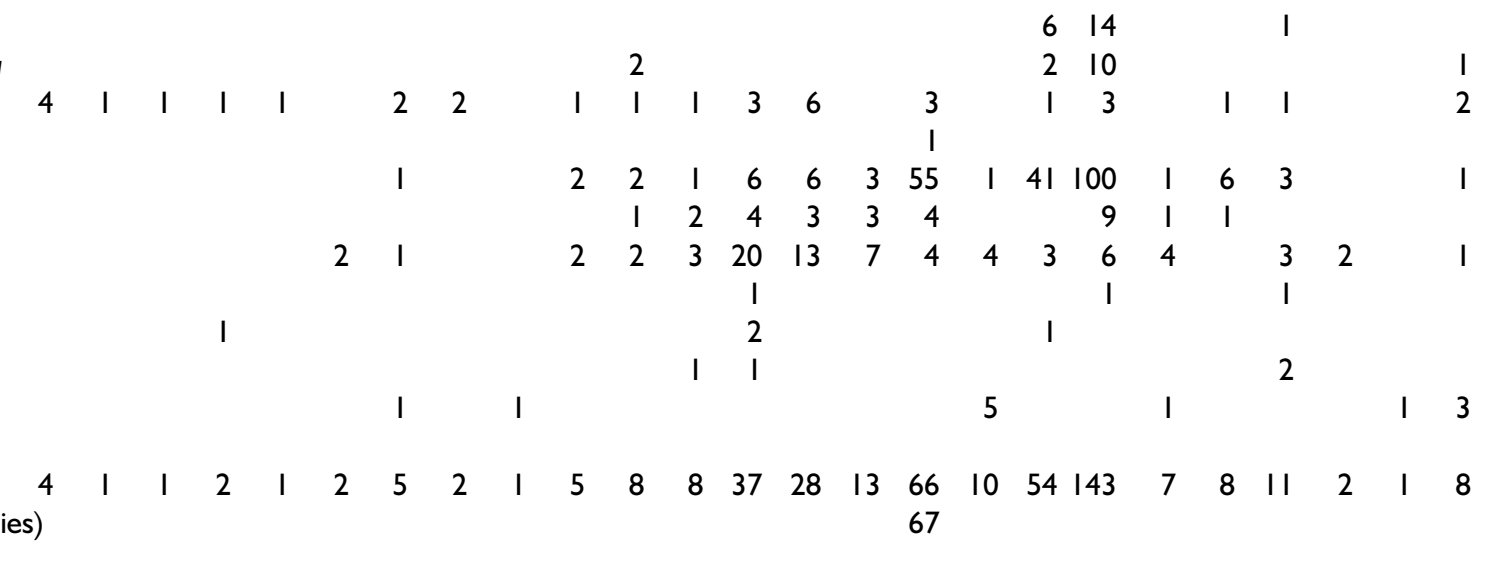

No. of species

(including wet species)

BLOCK 3A (see table p.47)

\begin{tabular}{|c|c|c|c|c|c|c|c|c|c|c|c|c|c|}
\hline Context & Bone & Pot & Snail & SeaSh & Macro & Slag & Stone & IHI & pH & Phos & $\begin{array}{c}\% \text { Burnt } \\
\text { stone }\end{array}$ & $\begin{array}{l}\text { Pumice } \\
\text { frags }\end{array}$ & Wt \\
\hline 5 & 876.8 & 93 & 32.1 & 8855.7 & 0.47 & 1.7 & 1986.6 & 150000 & $7.2-7.7$ & $2-4$ & 25 & $2^{\circ}$ & 9.6 \\
\hline 13 & 8.00 & 0 & 0.06 & 13.0 & 0.21 & 0 & 7.0 & 4000 & 7.7 & 3 & 0 & 0 & 0 \\
\hline Total & 884.8 & 93 & 32.16 & 8868.7 & 0.68 & 1.7 & 1993.6 & & & & & & \\
\hline
\end{tabular}


BLOCK 3B (see table p.47)

\section{Context}

Species

Cochlicopa lubrica

Cochlicopa lubricella

Cochlicopa sp

Vertigo pygmaea

Pupilla muscorum

Lauria cylindracea

Vallonia costata

Vallonia excentrica

Vittrina pellucida

Vitrea contracta

Oxychilus alliarius

Helicella itala

Cepaea hortensis

Total-terrestrial

(including wet species)

No. of species

(including wet species)

Seaweed imports

Rissoa parva

BLOCK 4A (see table p.48)
13

4

3

18

2

4

I

3

35

7
$5(I I) \quad 5(3 \mid 4)$

2

I

2

6

3

8

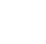

\section{2}

13

16

5

\section{5}

I

6

12

13
5(476)

5(484)

1 I

7

2

I

$\begin{array}{lccccccccc}\text { Context } & \text { Bone } & \text { Pot } & \text { Snail } & \text { SeaSh } & \text { Macro } & \text { Stone } & \text { IHI } & \text { PH } & \text { Phos } \\ 46 & 112 & 0 & 0.36 & 181 & 0.04 & 0 & 13 & 7.58 & 5 \\ 47 & 56 & 1 & 0 & 220 & 0.02 & 30 & 0 & 6.67 & 5 \\ \text { Total } & 168 & 1 & 0.36 & 401 & 0.06 & 30 & 0 & 0 & 0\end{array}$

\section{BLOCK 4B (see table p.48)}

\section{Context}

Species

Cochlicopa lubrica

Cochlicopa lubricella

Pupilla muscorum

Vallonia costata

Oxychilus alliarius

Hellicella itala

Total-terrestrial

(including wet species)

No. of species

(including wet species) 
BLOCK 5A (see p.49)

\begin{tabular}{|c|c|c|c|c|c|c|c|c|c|c|c|}
\hline Context & Bone & Pot & Snail & SeaSh & Macro & Slag & Stone & IHI & $\mathrm{pH}$ & Phos & $\begin{array}{c}\% \text { Burnt } \\
\text { stone }\end{array}$ \\
\hline 2 & 33.1 & I & 0.001 & 477 & 6.18 & 2 & 23 & 76000 & 7.54 & 3 & 0 \\
\hline 3 & 0 & 0 & 1 & 15 & 0 & 0 & 0 & 1000 & 7.33 & 5 & 0 \\
\hline 4 & 23.1 & 5 & 0 & 161 & 0 & 0 & 24 & 8000 & 7.46 & 4 & 0 \\
\hline 7 & 10 & 2 & 0.01 & 133 & 0.13 & 0 & 0 & 6000 & 7.69 & 3 & 0 \\
\hline 8 & 3 & 0 & 3 & 120 & 0.03 & 0 & 17 & 1000 & 7.78 & 2 & 0 \\
\hline 9 & 1 & 0 & 0.02 & 5 & 0.12 & 0 & 2 & 2700 & 7.62 & 3 & 0 \\
\hline 11 & I & 0 & 0.03 & 10 & 0.04 & 0 & 7 & 1000 & 7.46 & 2 & 0 \\
\hline 12 & 61 & 3 & 0.03 & 768 & 0.14 & 5 & 83 & 13000 & 7.63 & 3 & $<5$ \\
\hline 14 & 22 & 0 & 0 & 0 & 0 & 0 & 0 & 6500 & 7.35 & 2 & 0 \\
\hline 16 & 44 & 0 & 3.05 & 4 & 0.11 & 0 & 8 & 3500 & 7.68 & 2 & 0 \\
\hline 19 & 1 & 0 & 0.09 & 4 & 0.14 & 0 & I & 1500 & 7.59 & 3 & 0 \\
\hline 20 & 15 & 0 & 0.04 & 9 & 0.16 & 0 & 2 & 1500 & 7.41 & 4 & 0 \\
\hline 21 & 23 & 0 & 1.04 & 15 & 28.21 & 0 & 122 & 19500 & 7.44 & 3 & 0 \\
\hline 24 & 285 & 0 & 0 & 20 & 22.66 & 0 & 21 & 98500 & 7.74 & 2 & 0 \\
\hline 27 & 30 & 0 & 0.03 & I & 18.15 & 0 & I & 13000 & 7.56 & 4 & 0 \\
\hline 28 & 2 & 0 & 0.13 & 2 & 2.21 & 0 & 10 & 4500 & 7.07 & 5 & 0 \\
\hline 35 & 19 & 0 & 0.02 & 56 & 1.24 & 0 & 4 & 7000 & 7.43 & 2 & 0 \\
\hline 201 & 11 & 2 & 0.05 & 505 & 0 & 0 & 2 & 18000 & 7.74 & 3 & 0 \\
\hline Total & 584.2 & 13 & 8.541 & 2305 & 79.52 & 7 & 327 & & & & \\
\hline Mean & & & & & & & & 15500 & & & \\
\hline
\end{tabular}

\section{BLOCK 5B (see p.49)}

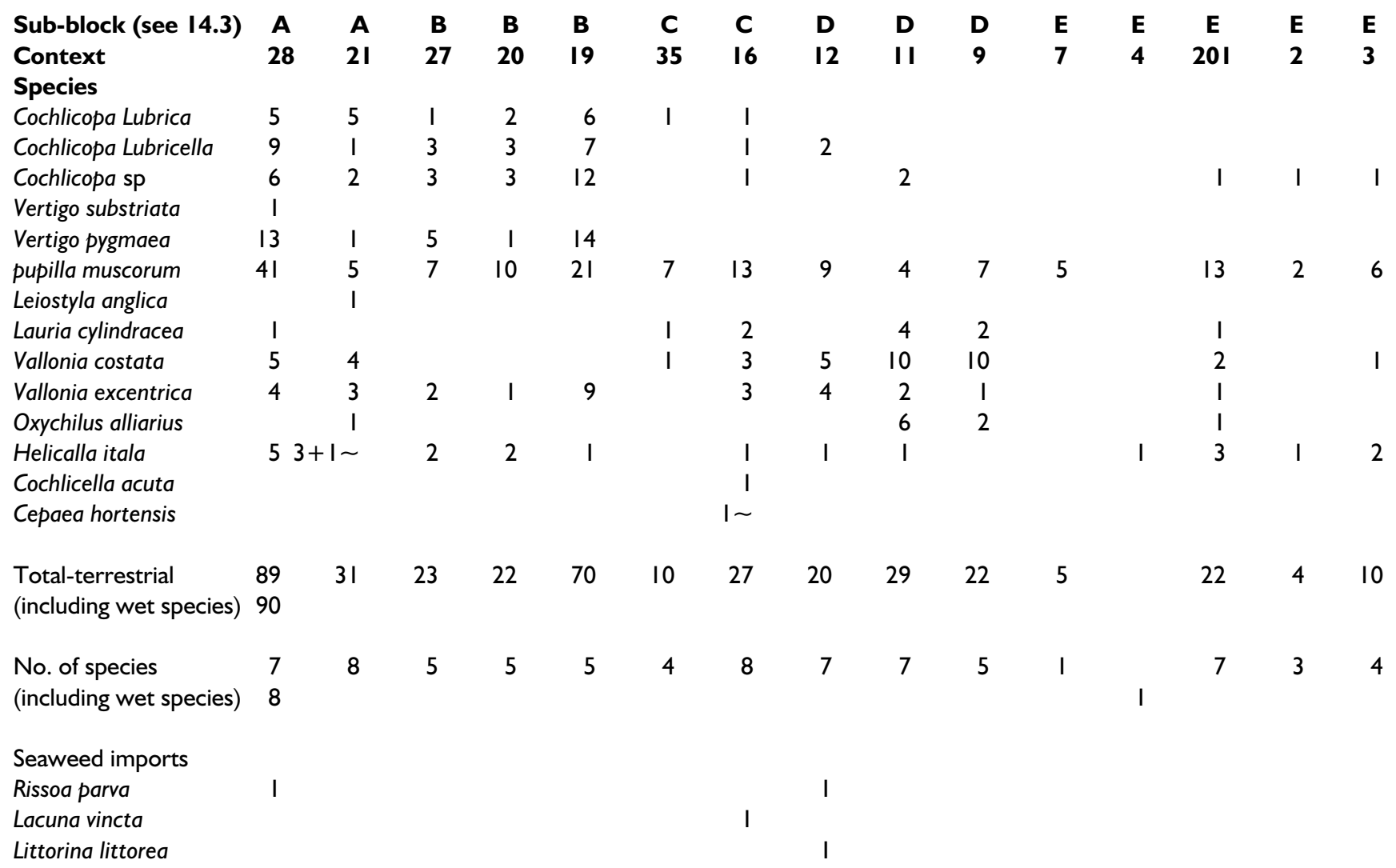


BLOCK 6A (see p.50)

\begin{tabular}{lrrrrrrrrrr} 
Context & Bone & Pot & Snail & SeaSh & Macro & Stone & IHI & $\begin{array}{c}\text { pH } \\
\text { Phos }\end{array} \begin{array}{c}\% \text { Burnt } \\
\text { stone }\end{array}$ \\
\hline & 342 & 97 & 32.18 & 7134 & 68.15 & 819 & 20.5 & 7.76 & 3 & 0 \\
6 & 1 & 0 & 0.06 & 7 & 0.14 & 0 & 1 & 7.61 & 2 & 0 \\
Total & 343 & 97 & 32.24 & 7141 & 68.29 & 819 & 0 & 0 & 0 & 0
\end{tabular}

\section{BLOCK 6B (see p.50)}

Sub-block (see 14.3)

Context

\section{Species}

Cochlicopa lubrica

Cochlicopa lubricella

Cochlicopa sp

Vertigo pygmaea

Pupilla muscorum

Lauria cylindraea

Vallonia cylindracea

Oxychilus alliarius

Helicella itala

Cepaea hortensis

Total-terrestrial

(including wet species)

No. of species

(including wet species)

BLOCK 7A (see p.5I)

$\begin{array}{cr}\text { A } & \text { B } \\ 6 & \text { I } \\ 3 & 9 \\ 4 & 13 \\ 3 & 6 \\ & 2 \\ 3 & 28 \\ 1 & \\ 5 & 1 \\ 3 & \\ & 1 \\ & 10 \wedge \\ 37 & 70\end{array}$

6

6

\begin{tabular}{|c|c|c|c|c|c|c|c|c|c|c|}
\hline Context & Bone & Pot & Snail & SeaSh & Macro & Stone & IHI & $\mathrm{pH}$ & Phos & $\begin{array}{c}\% \text { Burnt } \\
\text { stone }\end{array}$ \\
\hline 83 & 376 & 13 & 8.04 & 422 & 0.05 & 132 & 56500 & 7.3 & 4 & 0 \\
\hline 97 & 381 & 26 & 0.15 & 380.1 & 17 & 0 & 15500 & 6.5 & 3 & 0 \\
\hline 98 & 1008 & 32 & 7.11 & 630 & 7.05 & 199 & 69000 & 2 & $<5$ & $<5$ \\
\hline Total & 1765 & 71 & 15.3 & 1432.1 & 24.1 & 331 & & & & \\
\hline Mean & & & \multicolumn{8}{|c|}{47000} \\
\hline
\end{tabular}


BLOCK 7B (see p.5 I)

Sub-block (see 14.3)

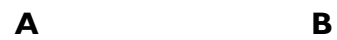

Context

83

C

C

\section{Species}

Cochlicopa sp

3

98

97

97*

Pupilla muscorum

Lauria cylindracea

15

2

2

Vallonia costata

Vallonia excentrica

Vitrina pellucida

Oxychilus alliarius

Helicalla itala

Cepaea hortensis

Total-terrestrial

(including wet species)

No. of species

5

(including wet species)

Sea weed imports

Rissoa parva

I

Other marine

BLOCK 8A (see p.52)

$\begin{array}{lrrrrrrrrr}\text { Context } & \text { Bone } & \text { Pot } & \text { Snail } & \text { SeaSh } & \text { Macro } & \text { Stone } & \text { IHI } & \text { PH } & \text { Phos } \\ 88 & 0 & 0 & 0 & 0 & 0 & 0 & 0 & 35587 & 2 \\ 89 & 0 & 0 & 0.07 & 0 & 0.19 & 9 & 200 & 35587 & 4 \\ 90 & 5 & 1 & 5.05 & 44 & 0.09 & 0 & 1000 & 35468 & 4 \\ 103 & 22 & 0 & 0.89 & 58 & 0.03 & 123 & 8000 & 35648 & 2 \\ 104 & 16 & 0 & 3 & 64 & 5.09 & 0 & 2000 & 35587 & 4 \\ 105 & 172 & 5 & 0.05 & 126 & 0.06 & 85 & 18000 & 35468 & 1 \\ 237 & 5 & 0 & 3.25 & 63 & 0.08 & 14 & 2500 & 7 & 2 \\ \text { Total } & 220 & 6 & 12.31 & 355 & 5.54 & 231 & & & \end{array}$


BLOCK 8B (see p.52)

\section{Context}

Species

Cochlicopa sp.

Vertigo pygmaea

Lauria cylindracea

Vallonia costata

Vallonia excentrica

Vitrina pellucida

Vitrea contracta

Helicella itala

Cepaea hortensis

Total-terrestrial

(including wet species)

No. of species

(including wet species)

Seaweed imports

Rissoa parva

BLOCK 9A (see p.54)

Context Bone

99

200

Pot

Snail Macro

Slag Stone IHI

4.0I $\quad 707$

3

341

1000
Pupilla muscorum

Oxychilus alliarus

103

237

14

15

2

1

69

2

8

2

9

I

3

$2+2 *$

23

23

II

5

\section{BLOCK 9B (see p.54)}

\section{Context}

Species

Pupilla muscorum

Total-terrestrial

BLOCK IOA (see p.55)

$\begin{array}{lrrlrlrrrr}\text { Context } & \text { Bone } & \text { Pot } & \text { Snail } & \text { SeaSh } & \text { Macro } & \text { Stone } & \text { IHI } & \text { pH } & \text { Phos } \\ 74 & 0 & 0 & 0 & 0 & 0 & 0 & 0 & 7.8 & 4 \\ 77 & 0 & 0 & 0 & 0 & 0 & 0 & 0 & 6.3 & 2 \\ 91 & 3 & 2 & 0.01 & 57 & 0.01 & 20 & 4000 & 6.5 & 5 \\ 93 & 0 & 0 & 0 & 0 & 0 & 0 & 0 & 7.1 & 2 \\ 106 & 24 & 2 & 0.09 & 213 & 0.13 & 9 & 3000 & 6.7 & 3 \\ \text { Total } & 27 & 4 & 0.1 & 270 & 0.14 & 29 & & & \end{array}$


BLOCK IOB (see p.55)

\section{Context}

Species

Cochlicopa sp

Vertigo pygmaea

Pupilla muscorum

Helicella itala

Total-terrestrial

(including wet species)

No. of species

(including wet species)

\section{BLOCK I IA (see p.55)}

Pits Diameter

(in $\mathbf{~ m m}$ )

225

0.6

264

0.56

152

0.55

157

0.35

Depth

0.15

0.09

0.3

0.14

91

106

I

3

14

4
Shape

Flat-bottomed with undercut

Round-bottomed

U-shaped

U-shaped
Fills

158

159

265

266

124

125

223

229

156 (in descending order)

Grey sand

Brown sand with two large stones Brown sand with carbonized peat Carbonized peat

Grey sand

Brown \& grey sand with carbonized peat Grey sand

Grey sand

Brown \& grey sand with carbonized peat

\section{BLOCK I I B (see p.55)}

\begin{tabular}{|c|c|c|c|c|c|}
\hline Pits & $\begin{array}{c}\text { Diameter } \\
\text { (in } \mathbf{~ m m} \text { ) }\end{array}$ & Depth & Shape & Fills & (in descending order) \\
\hline$|5|$ & 0.55 & 0.13 & Flat-bottomed & $\begin{array}{l}121 \\
122\end{array}$ & $\begin{array}{l}\text { Mottled grey \& brown sand } \\
\text { " }\end{array}$ \\
\hline 253 & 0.32 & 0.12 & U-shaped & $\begin{array}{l}257 \\
258\end{array}$ & $\begin{array}{l}\text { Light grey sand } \\
\text { Black sand }\end{array}$ \\
\hline 254 & 0.6 & 0.14 & Flat-bottomed concave sides & $\begin{array}{l}259 \\
260\end{array}$ & $\begin{array}{l}\text { Brown sand } \\
\text { Dark brown sand }\end{array}$ \\
\hline 226 & 0.35 & 0.05 & Flat-bottomed & 153 & Grey brown sand \\
\hline
\end{tabular}

\section{BLOCK I IC (see p.55)}

$\begin{array}{ccclcl}\text { Pit } & \begin{array}{c}\text { Diameter } \\ \text { (in } \mathbf{~ m m})\end{array} & \text { Depth } & \text { Shape } & \text { Fills } & \text { (in descending order) } \\ 230 & 0.15 & 0.04 & \text { Round-bottomed } & 255 & \text { White sand } \\ & & & & 256 & \text { Dark brown sand }\end{array}$


BLOCK I ID (see p.55)

Bone

Pot

Snail

SeaSh

Macro

Stone

IHI

FLOOR I

Layers

$100 \quad 103$

101

37

2.84

412

0.02

$\begin{array}{ll}0.01 & 78\end{array}$

0.01

0.01

67

0.5

0.53

0.09

2.87

I. 14

20
98

4000

136

Total

232

589

1486

182

1786

16000

10000

Pits

225/160

1159

0

38

205000

0.12

0.35

25000

$\begin{array}{lll}0.24 & 17 & 0.25\end{array}$

$\begin{array}{lll}1.6 & 100 & 5.2\end{array}$

3.2

6500

$264 / 265$

0

139

$152 / 124$

2.05

0.27
0.42

51500

154

$/ 126$

20.2

Total

57.2

4.03

337.49

$\begin{array}{rr}0 & 205000 \\ 151 & 25000 \\ 12 & 6500 \\ 20 & 51500 \\ 0 & 0 \\ 69 & 38500 \\ 266 & 61500 \\ 0 & 0 \\ 518 & 0\end{array}$

FLOOR 2

Layers

224

135

115

Total

1.1
0

0.06

0

0.07

5500

$0.03 \quad 0$

0.13

20
0

157

177

11000

$1.13 \quad 52$

90

0

486000

0.11

II

0.2

61000

0.02

0.38

113

21500

0.02

19

1122

$/ 123$

0

0

319

30000

1.2

80

0
18000

$0 \quad 0$

0

432000

226/153

0

182.78

0

Total

51

$19 \quad 5.16$

25

$5.17 \quad 58$

0.03

9000

0

58

0 


\section{BLOCK I IE (see p.55)}

$\begin{array}{lllllllllllllllllllllll}\text { Sub-block (see 14.3) } & \text { A } & \text { A } & \text { A } & \text { A } & \text { A } & \text { A } & \text { B } & \text { B } & \text { B } & \text { C } & \text { C } & \text { C } & \text { C } & \text { C } & \text { C } & \text { C } & \text { C } & \text { D } & \text { D } & \text { D } & \text { E }\end{array}$ Context

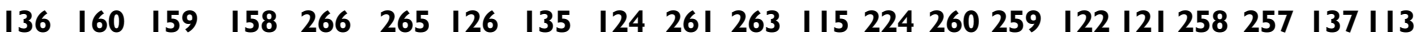

Species

Cochlicopa sp

Vertigo pygmaea

Pupilla muscorum

Lauria cylindracea

Vallonia costata

Vallonia excentrica

Vitrina pellucida

Vitrea contracta

Nesovitrea hammonis

Oxychilus alliarius

Clausila bidentata

Helicella itala

Cepaea hortensis

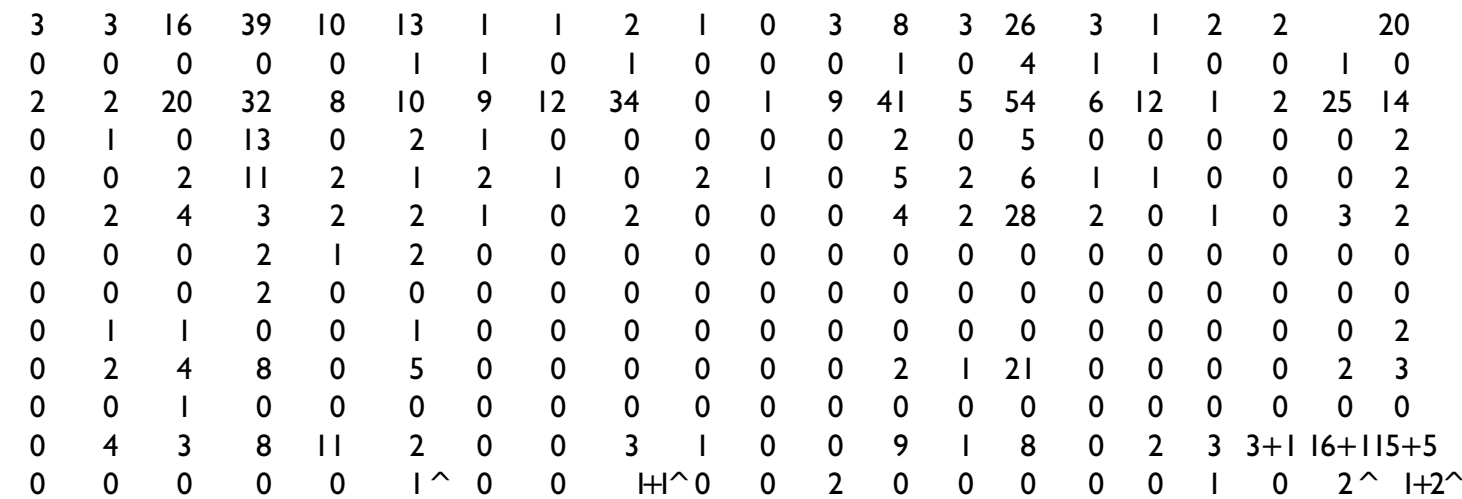

Total-terrestrial

(including wet species)

No. of species

(including wet species)

Seaweed imports

Hydrobia ulvae

Gibula cneraria

Rissoa parva

$\begin{array}{lllllllllllllllllllll}0 & 0 & 0 & 0 & 0 & 0 & 0 & 0 & 0 & 0 & 0 & 0 & 0 & 0 & 0 & 0 & 0 & 0 & 0 & 0 & 2 \\ 0 & 0 & 0 & 0 & 0 & 0 & 1 & 0 & 0 & 0 & 0 & 0 & 0 & 0 & 0 & 0 & 0 & 0 & 0 & 0 & 0 \\ 0 & 0 & 0 & 1 & 1 & 0 & 3 & 1 & 0 & 0 & 0 & 0 & 0 & 0 & 0 & 0 & 0 & 0 & 0 & 0 & 0\end{array}$

BLOCK I2A (see p.59)

$\begin{array}{rrrlrlrrrrrc}\text { Context } & \text { Bone } & \text { Pot } & \text { Snail } & \text { seaSh } & \text { Macro } & \text { Stone } & \text { IHI } & \text { pH } & \begin{array}{c}\text { Phos } \\ \text { Pumice } \\ \text { frags }\end{array} \\ 119 & 15 & 3 & 0.06 & 36 & 0.28 & 57 & 12500 & 6.5 & 4 & 2 & 20.3 \\ 222 & 0 & 0 & 0 & 0 & 0 & 0 & 0 & 6.5 & 4 & 0 & 0\end{array}$

\section{BLOCK I 2B (see p.59)}

\section{Context}

\section{Species}

Cochlicopa sp

Pupilla muscorum

Lauria cylindracea

Vallonia costata

Vallonia excentrica

Helicella itala

Total-terrestrial

(including wet species)

No. of species 
BLOCK I4A (see p.59)

$\begin{array}{rrrrrrrrrr}\text { Context } & \text { Bone } & \text { Pot } & \text { Snail } & \text { SeaSh } & \text { Macro } & \text { Stone } & \text { IHI } & \text { pH } & \text { Phos } \\ 109 & 230 & 7 & 5.43 & 867 & 0.23 & 0 & 7000 & 7.3 & 4 \\ 110 & 201 & 8 & 8 & 711 & 0 & 3 & 0 & 0 & 0 \\ 111 & 80 & 4 & 4.19 & 176 & 0.63 & 107 & 4500 & 7.4 & 3 \\ 112 & 114 & 11 & 0.38 & 243 & 0.25 & 127 & 10000 & 7.2 & 4 \\ \text { Total } & 625 & 45 & 18 & 1988 & 1.11 & 237 & & & \\ \text { Mean } & & & & & & & & & \end{array}$

\section{BLOCK I4B (see p.59)}

\section{Context}

Species

Cochlicopa sp

Vetigo pygmaea

Pupilla muscorum

Lauria cylindracea

Vallonia costata

Vallonia excentrica

Punctum pygaeum

Vitrina pellucida

Vitrea contracta

Nesovitrea hammonis

Oxychilus alliarius

Helicella itala

Cochlicella acuta

Cepaea hortensis

Total-terrestrial

(including wet species)

No. of species

(including wet species)

Seaweed imports

Rissoa parva

Littorina littoralis

BLOCK I5A (see p.60)

$\begin{array}{rll}\text { Context } & \text { Width } & \text { Dept } \\ 174 & 1.2 & 0.6 \\ 217 & 0.35 & 0.38 \\ 243 & 0.23 & 0.06 \\ 246 & 0.4 & 0.05 \\ 218 & 0.9 & 0.25\end{array}$

112

51

6

75

11

43

II

I

2

II

22

17

14

$1+I^{\wedge}$

109

9
110

109

143

2

19

3

6

57

I

I

8

4

1

$2^{\wedge}$

247

248

13
Fills

$17 \mid, 172,173$

216

244

246

218
Cut from

within $\mathrm{BI} 15$

$21 \mathrm{I}(\mathrm{BI}$ I6)

247 (B| I6)

247 (BI I6)

247 (BI I6)
Orientation

NW-SE

NE-SW

$-$

NW-SE 
BLOCK I5B (see p.60)

\begin{tabular}{|c|c|c|c|c|c|c|c|c|c|c|c|c|}
\hline & Bone & Pot & Snail & SeaSh & Macro & Stone & IHI & pH & Phos & $\begin{array}{c}\% \text { Burnt } \\
\text { stone }\end{array}$ & $\begin{array}{l}\text { Pumice } \\
\text { frags }\end{array}$ & $\begin{array}{c}\text { Pumice } \\
\text { Wt }\end{array}$ \\
\hline \multicolumn{13}{|c|}{ Layers } \\
\hline 144 & 554.3 & 29 & 12.11 & 4142 & 8.46 & 851 & 19000 & 7.2 & 4 & 10 & 0 & 0 \\
\hline 145 & 667 & 48 & 9.94 & 9271 & 4.18 & 1608 & 37500 & 7.8 & 1 & 10 & 0 & 0 \\
\hline 146 & 99 & 26 & 8.02 & 19239 & 116 & 690 & 243000 & 7 & 3 & $<5$ & 0 & 0 \\
\hline 147 & 107 & 2 & 16.04 & 777 & 10.31 & 145 & 4000 & 7.5 & 2 & 20 & 0 & 0 \\
\hline 170 & 40 & 5 & 0.03 & 350 & 3.76 & 217 & 16500 & 7.5 & 2 & 0 & 0 & 0 \\
\hline 176 & 55 & 2 & 0.63 & 178 & 25 & 195 & 15000 & 7.6 & 2 & 0 & I & 2.4 \\
\hline 177 & 409 & 64 & 10.04 & 2482 & 10 & 1473 & 37000 & 7.8 & 2 & 10 & 2 & 13.5 \\
\hline 178 & 517.6 & 60 & 5.19 & 1292 & 4.3 & 1069 & 14000 & 7.2 & 3 & 10 & 0 & 0 \\
\hline 206 & 16 & 5 & 0.11 & 10 & 7.52 & 111 & 1500 & 6.6 & 2 & 0 & 0 & 0 \\
\hline 207 & 124 & 14 & 0.08 & 30 & 9.24 & 214 & 10000 & 6.4 & 2 & $<5$ & 0 & 0 \\
\hline 208 & 2 & 2 & 0.01 & 0 & 0.18 & 25 & 6500 & 7.4 & 2 & $<5$ & 0 & 0 \\
\hline 215 & 269 & 38 & 5 & 575 & 1.83 & 2407 & 13500 & 7.4 & 2 & 15 & 0 & 0 \\
\hline 239 & 141 & 33 & 0.01 & 246 & 6.48 & 903 & 7000 & 6.5 & 3 & 40 & 0 & 0 \\
\hline 251 & 459 & 0 & 0 & 56 & 6.7 & 334 & 342500 & 6.4 & 3 & 0 & 0 & 0 \\
\hline Total & 3459.9 & 328 & 67.21 & 38648 & 213.96 & 10242 & & & & & & \\
\hline Mean & & & & & & & 55000 & & & & & \\
\hline \multicolumn{13}{|c|}{ Ditches } \\
\hline 171 & 57 & 3 & 0.16 & 86 & 0.63 & 71 & 31500 & 7.09 & 3 & 0 & 0 & 0 \\
\hline 172 & 28 & 4 & 0.13 & 102 & 1.4 & 11 & 51500 & 7.66 & 2 & 0 & 0 & 0 \\
\hline 173 & 4 & 2 & 0.06 & 34 & 0.62 & 12 & 16500 & 7.45 & 1 & 0 & 0 & 0 \\
\hline 216 & 18 & 4 & 22.03 & 103 & 0.24 & 253 & 10500 & 7.4 & 4 & 10 & I & 2.9 \\
\hline 218 & 27 & 3 & 0.07 & 19 & 0.16 & 61 & 3000 & 7.3 & 2 & 10 & 0 & 0 \\
\hline 244 & 0 & 0 & 0 & 0 & 0 & 0 & 3000 & 6.5 & 3 & 0 & 0 & 0 \\
\hline 245 & 0 & 1 & 0.02 & 0 & 0.22 & 0 & 3000 & 6.7 & 3 & $<5$ & 0 & 0 \\
\hline Total & 134 & 17 & 22.47 & 344 & 3.27 & 408 & & & & & & \\
\hline Mean & & & & & & & 19500 & & & & & \\
\hline
\end{tabular}


Cochlicopa lubrica

Cochlicopa lubricella

Cochlicopa sp

*Vertigo antivertigo

Vertigo pygmaea

Pupilla muscorum

Lauria cylindracea

Vallonia costata

Vallonia excentrica

Punctum pygmaeum

Vitrina pellucida

Vitrea contracta

Nesovitrea hammonis

Oxychilus alliarius

Hydrobia ulvae

Cochlicella acuta

Cepaea hortensis

* Lymnaea truncatula

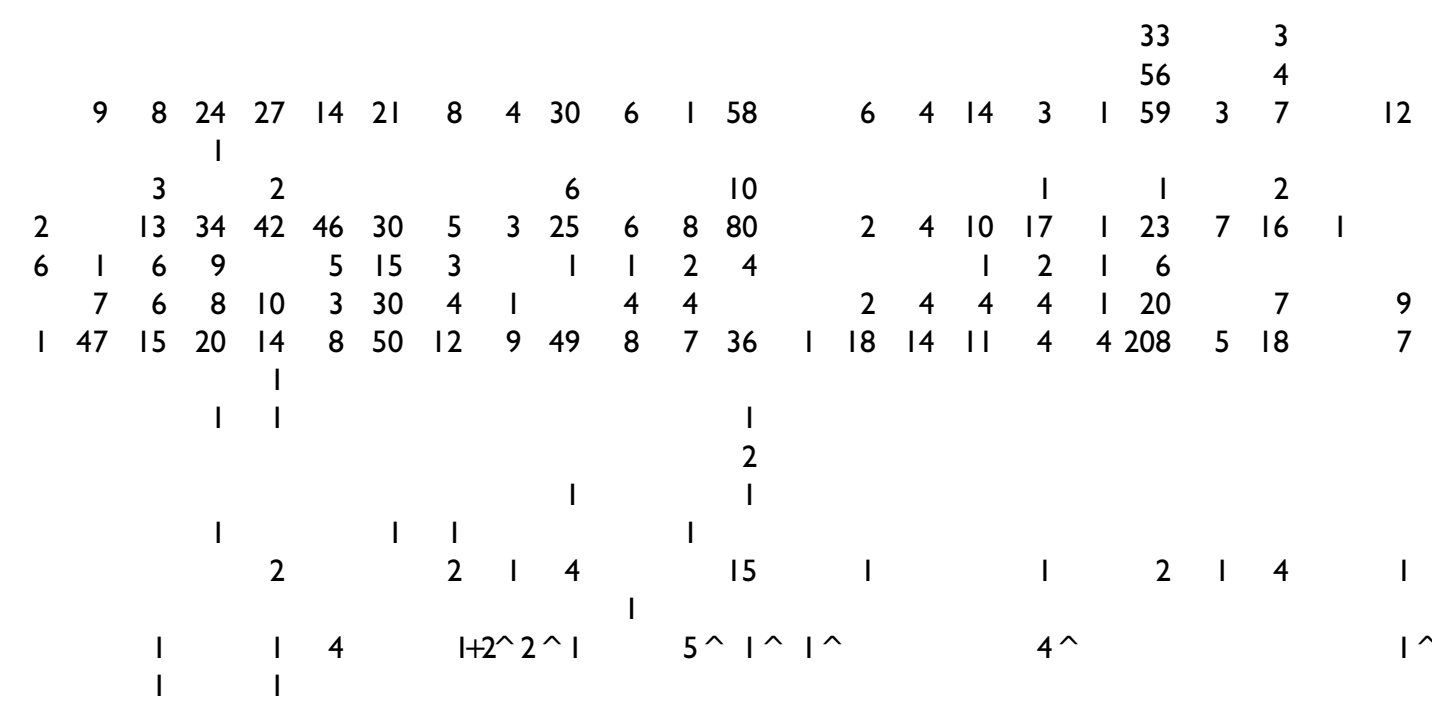

Total-terrestrial

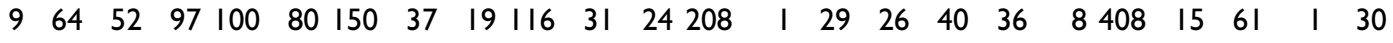

(including wet species) $\begin{array}{llll}53 \quad 98 & 101\end{array}$

No. of species

(including wet species)

$\begin{array}{lllll}3 & 4 & 7 & 7 & 9\end{array}$

$\begin{array}{llll}6 & 7 & 8 & 6\end{array}$

Seaweed imports

Hydrobia ulvae

Rissoa parva

Littorina littoralis

\section{BLOCK I6A (see p.6I)}

\begin{tabular}{|c|c|c|c|c|c|c|c|c|c|c|c|}
\hline Pot & Snail & SeaSh. & Macro & Slag & Stone & IHI & pH & Phos & $\begin{array}{c}\% \text { Burnt } \\
\text { stone }\end{array}$ & $\begin{array}{c}\text { Pumice } \\
\text { frags }\end{array}$ & $\begin{array}{c}\text { Pumice } \\
\text { wt }\end{array}$ \\
\hline 274 & 0.25 & 826 & 43 & 2 & 5011 & 13000 & 7.2 & 3 & 15 & I & 5.1 \\
\hline 2 & 0.22 & 756 & 0.12 & 0 & 292 & 93000 & 7.4 & 2 & 10 & 0 & 0 \\
\hline 269 & 0 & 789 & 43.35 & 30.9 & 2414 & 148500 & 7.2 & 4 & 15 & 2 & 10.3 \\
\hline 10 & 0.01 & 0 & 0.41 & 0 & 677 & 10000 & 7 & 2 & 10 & I & 20 \\
\hline 0 & 0.01 & 0 & 0.07 & 0 & 0 & 500 & 7.3 & 2 & 0 & 0 & 0 \\
\hline 0 & 0.01 & 9 & 0.31 & 0 & 20 & 7000 & 6.8 & 2 & 10 & 0 & 0 \\
\hline 134 & 0.04 & 344 & 3.19 & 47 & 6247 & 13500 & 7.3 & 4 & 50 & 0 & 0 \\
\hline 39 & 0.02 & 244 & 0.35 & 0 & 1717 & 14000 & 6.9 & 3 & 50 & 0 & 0 \\
\hline 12 & 0.02 & 565 & 0.05 & 0 & 2621 & 21000 & 6.9 & 2 & 30 & 4 & 43.1 \\
\hline 6 & 0.7 & 181 & 4.01 & 0 & 54 & 21000 & 7.3 & 2 & 0 & 0 & 0 \\
\hline 6 & 0.14 & 79 & 0.23 & 0 & 0 & 35000 & 7.2 & 4 & 0 & 0 & 0 \\
\hline 16 & 0.01 & 281 & 7.32 & 0 & 1725 & 15500 & 7.4 & 2 & 50 & 2 & 5.1 \\
\hline 13 & 0.02 & 183 & 0.21 & 0 & 580 & 12500 & 7.3 & 2 & 70 & 0 & 0 \\
\hline 0 & 0.03 & 5 & 0.94 & 0 & 118 & 4000 & 7.2 & 3 & 25 & 0 & 0 \\
\hline 12 & 4.04 & 420 & 0.11 & 0 & 3821 & 12500 & 7.3 & 2 & 50 & 4 & 25.8 \\
\hline 91 & 0 & 0 & 0 & 0 & 0 & 0 & 0 & 0 & 0 & 0 & 0 \\
\hline 17 & 0 & 32 & 0 & 0 & 189 & 42000 & 7.4 & 1 & 10 & 0 & 0 \\
\hline
\end{tabular}

90 


\section{BLOCK I6B (see p.6I)}

\begin{tabular}{|c|c|c|c|c|c|c|c|c|c|c|c|c|c|c|c|}
\hline $\begin{array}{l}\text { Context } \\
\text { Species }\end{array}$ & 203 & 204 & $219=$ & 247 & $24 I$ & 214 & 240 & 150 & \#149 & 142 & 143 & 235 & 236 & $211=$ & 242 \\
\hline Cochlicopa sp & 0 & I & 2 & 4 & 2 & 1 & 1 & I & 4 & 52 & 33 & 107 & 11 & 5 & 3 \\
\hline Vertigo pygmaea & 0 & 0 & 0 & 0 & 0 & 1 & 0 & 0 & 0 & 1 & 8 & 4 & I & 0 & 0 \\
\hline Pupilla muscorum & 0 & 0 & 12 & 8 & 3 & 12 & 0 & 0 & 6 & 5 & 47 & 60 & 66 & I & I \\
\hline Lauria cylindracea & 0 & 0 & 0 & 1 & 0 & I & 0 & 0 & I & 35 & 44 & 12 & I & 0 & 0 \\
\hline Vallonia costata & 0 & 1 & 0 & 6 & 0 & 0 & I & 0 & 3 & 16 & 43 & 23 & 6 & I & 10 \\
\hline Vallonia excentrica & 3 & 2 & 2 & 5 & 0 & 0 & 2 & 0 & 4 & 67 & 21 & 66 & 13 & 18 & 19 \\
\hline Nesovitrea hammonis & 0 & 0 & 0 & 0 & 0 & 0 & 0 & 0 & 0 & 0 & I & 0 & 0 & 0 & 0 \\
\hline Oxychilus alliarus & 0 & 0 & 2 & 0 & 2 & I & 0 & 0 & 0 & 2 & 2 & 0 & I & 0 & 2 \\
\hline Helicella itala & 0 & 0 & 0 & 0 & 0 & 0 & 0 & 0 & 0 & 3 & 0 & 0 & 0 & 0 & 0 \\
\hline *Lymnaea truncatula & 0 & 0 & 0 & 0 & 0 & 0 & 0 & 0 & 0 & I & 0 & 0 & 0 & 0 & 0 \\
\hline $\begin{array}{l}\text { Total-terrestrial } \\
\text { (including wet species) }\end{array}$ & 3 & 4 & 18 & 24 & 7 & 16 & 4 & I & 18 & $\begin{array}{l}181 \\
182\end{array}$ & 199 & 272 & 99 & 25 & 35 \\
\hline $\begin{array}{l}\text { No. of species } \\
\text { (including wet species) }\end{array}$ & I & 3 & 4 & 5 & 3 & 5 & 3 & 1 & 5 & $\begin{array}{l}8 \\
9\end{array}$ & 8 & 6 & 7 & 4 & \\
\hline
\end{tabular}

\section{BLOCK I7A (see p.62)}

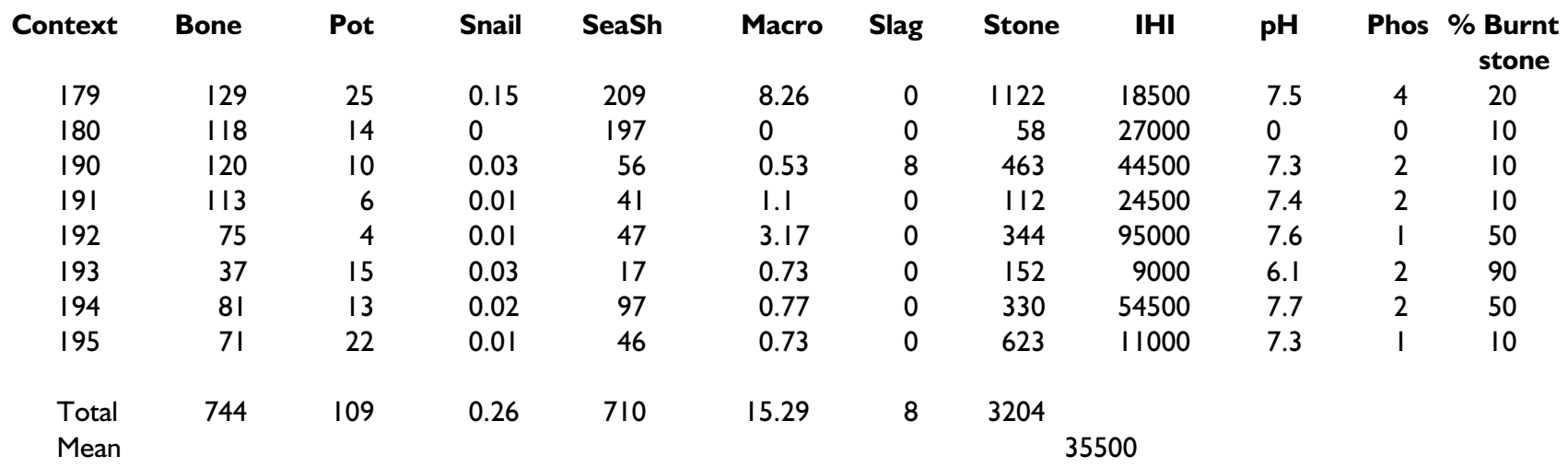

\section{BLOCK I7B (see p.62)}

\section{Context}

\section{Species}

Cochlicopa sp

*Vertigo antivertigo

Pupilla muscorum

Lauria cylindracea

Vallonia costata

Vallonia excentrica

Vitrina pellucida

Oxychilus alliarius

Helicella itala

Total-terrestrial

(including wet species)

No. of species

(including wet species)$$
27
$$

194

193

10

2

10

2

4

5

0

$$
\text { I }
$$

32

34

19

20
192

191

195

$$
\begin{aligned}
& 0 \\
& 0 \\
& 1 \\
& 0 \\
& 0 \\
& 0 \\
& 0 \\
& 0 \\
& 0
\end{aligned}
$$

$$
\begin{aligned}
& 6 \\
& 7
\end{aligned}
$$

$\begin{array}{ll}1 & 2 \\ 0 & 0 \\ 2 & 1 \\ 0 & 0 \\ 0 & 0 \\ 0 & 0 \\ 0 & 0 \\ 0 & 0 \\ 0 & 0\end{array}$

33


BLOCK I8A (see p.63)

$\begin{array}{ccccccccccc}\text { Pot } & \text { Snail } & \text { SeaSh } & \text { Macro } & \text { Stone } & \text { IHI } & \text { pH } & \text { Phos } & \begin{array}{c}\% \text { Burnt } \\ \text { stone }\end{array} & \begin{array}{c}\text { Pumice } \\ \text { frags }\end{array} & \begin{array}{c}\text { Pumice } \\ \text { wt }\end{array} \\ 87 & 17.03 & 1738 & 1.16 & 3014 & 28,000 \text { (mean) } & 6.5 & 3 & <5 & 2 & 11.7\end{array}$

\section{BLOCK I8B (see p.63)}

\section{Context}

Species

Cochlicopa sp

Vallonia excentica

Total-terrestrial

(including wet species)

No. of species

(including wet species)

BLOCK I9A (see p.64)

\begin{tabular}{|c|c|c|c|c|c|c|c|c|c|c|c|}
\hline Context & Bone & Pot & Snail & SeaSh & Macro & Slag & Stone & IHI & pH & Phos & $\begin{array}{c}\% \text { Burnt } \\
\text { stone }\end{array}$ \\
\hline 175 & 170 & 5 & 4.08 & 589 & 0.12 & 0 & 3437 & 6000 & 7.5 & 3 & $<5$ \\
\hline 198 & 91 & 2 & 0.06 & 43 & 4.4 & 0 & 348 & 36000 & 7 & 5 & 10 \\
\hline 212 & 228.1 & 38 & 2.28 & 883 & 14.3 & 0 & 1955 & 9,5000 & 6.7 & 1 & 15 \\
\hline 213 & 95 & 3 & 2 & 175 & 1.55 & 10 & 332 & 11000 & 6.8 & 3 & 15 \\
\hline Total & 584.1 & 48 & 8.42 & 1690 & 20.37 & 10 & 6072 & & & & \\
\hline Mean & & & & \multicolumn{8}{|c|}{15500} \\
\hline
\end{tabular}

\section{BLOCK I9B (see p.64)}

\section{Context}

Cochlicopa sp

Vertigo pygmaea

Pupilla muscorum

Lauria clylinracea

Vallonia costata

Vallonia excentrica

Helicella itala

Cepaea hortensis

Total-terrestrial

(including wet species)

No. of species

(including wet species)
7

24

0

2

3

18

2

$1^{\wedge}$

51

7
220

8

112
1
1
5
28
70
2
1

77
3
4
12
14
59
2
1

172

8
147
1
6
2
58
228
2
1
445

8 


\section{BLOCK 20A (see p.64)}

\begin{tabular}{|c|c|c|c|c|c|c|c|c|c|c|}
\hline Context & Bone & Pot & Snail & SeaSh. & Macro & Stone & IHI & $\mathrm{pH}$ & Phos & $\begin{array}{c}\% \text { Burnt } \\
\text { stone }\end{array}$ \\
\hline 196 & 445.2 & 27 & 0.01 & 204 & 4.48 & $|40|$ & 16000 & 6.5 & 2 & 50 \\
\hline 209 & 22 & 3 & 0.01 & 27 & 0.01 & 28 & 13000 & 6.8 & 2 & $<5$ \\
\hline 210 & 322 & 24 & 0 & 277 & 0.6 & 1036 & 10000 & 6.4 & 2 & 10 \\
\hline Total & 789.2 & 65 & 0.02 & 508 & 5.22 & 2465 & & & & \\
\hline Mean & & & & & & & 13000 & & & \\
\hline
\end{tabular}

\section{BLOCK 20B (see p.64)}

\section{Context}

196

209

Species

Cochlicopa sp

*Vertigo antivertigo

Pupilla muscorum

Vallonia costata

Vallonia excentrica

Total-terrestrial

(including wet species)

No. of species

(including wet species)

BLOCK 2 IA (see p.65)

$\begin{array}{ccccccccccc}\text { Context } & \text { Bone } & \text { Pot } & \text { Snail } & \text { SeaSh } & \text { Macro } & \text { Slag } & \text { Stone } & \text { IHI } & \text { PH } & \text { Phos } \\ 86 & 134 & 3 & 0.03 & 496 & 0.21 & 0 & 69 & 6500 & 7.4 & 2 \\ 100 & 103 & 0 & 2.84 & 412 & 0.02 & 0 & 20 & 4000 & 7.5 & 4 \\ \begin{array}{r}\text { Total } \\ \text { Mean }\end{array} & 237 & 3 & 2.87 & 908 & 0.23 & 0 & 89 & & & \end{array}$

BLOCK 2 I B (see p.65)

\section{Context}

100

86

Species

Cochlicopa sp

Pupilla muscorum

Lauria cylindracea

Vallonia costata

Vallonia excentrica

Oxychilus alliarius

Helicella itala

Cepaea hortensis

Total-terrestrial

(including wet species)

No. of species

(including wet species)
2

2

2

7

4

2

3

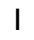

6

7

8

5000

\section{5}

17

2

$2+1 \wedge$

$1 \wedge$

35

25

8

4 
BLOCK 22A (see p.66)

\begin{tabular}{|c|c|c|c|c|c|c|c|c|c|c|c|c|c|c|}
\hline Context & Bone & Pot & Snail & SeaSh & Macro & Slag & Stone & IHI & LOI & pH & Phos & $\begin{array}{c}\% \text { Burnt } \\
\text { stone }\end{array}$ & $\begin{array}{c}\text { Pumice } \\
\text { frags }\end{array}$ & $\begin{array}{c}\text { Pumice } \\
\text { wt }\end{array}$ \\
\hline Total & 3358 & 443 & 0.08 & 2925 & 0.59 & 2 & 4503 & & $1 \%$ & 7.5 & 3 & 20 & 2 & 12.8 \\
\hline Mean & & & & & & & & 16000 & & & & & & \\
\hline
\end{tabular}

BLOCK 22B (see p.66)

\section{Context}

\section{Species}

Cochlicopa lubrica

Cochlicopa sp

Vertigo pygmaea

Pupilla muscorum

Vallonia costata

Vallonia excentrica

*Lymnaea truncatula

Total-terrestrial

(including wet species)

No. of species

(including wet species)

\section{BLOCK 23A (see p.67)}

\begin{tabular}{|c|c|c|c|c|c|c|c|c|c|c|c|c|c|}
\hline Context & Bone & Pot & Snail & SeaSh & Macro & Slag & Stone & IHI & $\mathbf{p H}$ & Phos & $\begin{array}{l}\% \text { Burnt } \\
\text { stone }\end{array}$ & $\begin{array}{c}\text { Pumice } \\
\text { frags }\end{array}$ & $\begin{array}{c}\text { Pumice } \\
\text { wt }\end{array}$ \\
\hline 267 & 106 & 9 & 0.01 & 71 & 0.01 & 0 & 234 & 5500 & 7.2 & 4 & $<5$ & 0 & \\
\hline 268 & 416 & 0 & 0.16 & 101 & 0 & 0 & 916 & 16000 & 6.5 & 2 & 5 & 0 & \\
\hline 269 & 5 & 2 & 0.02 & 10 & 0.08 & 0 & 8 & 500 & 6.8 & 2 & 0 & 0 & \\
\hline 270 & 209 & 3 & 0.01 & 184 & 0.02 & 0 & 1082 & 11000 & 7.1 & 3 & 10 & 3 & 18.7 \\
\hline 271 & 63 & 8 & 0.06 & 72 & 0.01 & 0 & 236 & 4000 & 7 & 2 & $<5$ & 0 & \\
\hline 272 & 133 & 19 & 0.02 & 226 & 0.07 & 3 & 326 & 9000 & 6.4 & 2 & 0 & 0 & \\
\hline 273 & 40 & 0 & 0.01 & 72 & 0 & 0 & 42 & 2000 & 7.1 & 3 & 10 & 0 & \\
\hline Total & 972 & 41 & 0.29 & 736 & 0.19 & 3 & 2844 & & & & & & \\
\hline Mean & & & & & & & & 7000 & & & & & \\
\hline
\end{tabular}

BLOCK 23B (see p.67)

\section{Context}

Species

Cochlicopa sp

Vertigo pygmaea

Pupilla muscorum

Lauria cylindracea

Vallonia excentrica

Cochlicella acuta

*Lymnaea truncatula

Total-terrestrial

(including wet species)

No. of species

(including wet species)
276

275

274

280

279+

278

277

2

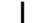

5

13

6$$
\begin{aligned}
& 1 \\
& 8
\end{aligned}
$$$$
\text { I }
$$

2

7

14

3

2

4
5

$\begin{array}{lll}1 & 3 & 9 \\ 1 & 2 & 9 \\ & & 3 \\ & 2 & 6 \\ & & \\ 3 & 5 & 27 \\ & 7 & \end{array}$

$\begin{array}{ll}3 & 2 \\ & 3\end{array}$
9
9
3
6 
BLOCK 24A (see p.67)

\begin{tabular}{|c|c|c|c|c|c|c|c|c|c|c|c|c|c|}
\hline Context & Bone & Pot & Snail & SeaSh & Macro & Slag & Stone & IHI & $\mathrm{pH}$ & Phos & $\begin{array}{c}\% \text { Burnt } \\
\text { stone }\end{array}$ & $\begin{array}{c}\text { Pumice } \\
\text { frags }\end{array}$ & $\begin{array}{c}\text { Pumice } \\
\text { wt }\end{array}$ \\
\hline 18 & 69 & 9 & 3.02 & 798 & 0.29 & 3 & 108 & 15000 & 7.4 & 2 & 25 & 0 & \\
\hline 29 & 429 & 22 & 10 & 5061 & 225 & 4 & 357 & 29500 & 7 & 2 & 0 & 0 & \\
\hline 30 & 119 & 5 & 1.01 & 343 & 5.02 & 0 & 37 & 29500 & 7.3 & 2 & 0 & 0 & \\
\hline 31 & 53 & 0 & 0.05 & 110 & 0.47 & 0 & 72 & 28700 & 0 & 0 & 0 & 0 & \\
\hline 32 & 980 & 115 & 20.59 & 8123 & 0.13 & 4 & 1530 & 17000 & 7.5 & 5 & 10 & I & 2.7 \\
\hline 34 & 0 & 0 & 0 & 106 & 0 & 0 & 0 & 21000 & 7.4 & 3 & 0 & 0 & \\
\hline 36 & 68 & 3 & 0.01 & 345 & 0.13 & 0 & 233 & 18000 & 7.3 & 0 & 0 & 0 & \\
\hline 37 & 82 & 4 & 3 & 302 & 57.9 & 0 & 25 & 25500 & 7.2 & 3 & 0 & 0 & \\
\hline 38 & 144.3 & 7 & 6.03 & 1474 & 9.45 & 0 & 128 & 117500 & 7.6 & 2 & $<5$ & 0 & \\
\hline 39 & 90 & 1 & 0.03 & 5394 & 0.41 & 0 & 223 & I |49000 & 7.6 & 2 & 10 & 0 & \\
\hline 40 & 276 & 43 & 5.05 & 1542 & 22.76 & 0 & 211 & 29000 & 7.6 & 3 & $<5$ & 0 & \\
\hline 41 & 175 & 0 & 0.02 & 640 & 12.4 & 7 & 37 & 11500 & 7.6 & 4 & $<5$ & 0 & \\
\hline 45 & 224 & 32 & 4.05 & 1909 & 16.19 & 0 & 966 & 35500 & 7.7 & 3 & 5 & 0 & \\
\hline 49 & 13 & 2 & 0.08 & 66 & 1.07 & 0 & 3 & 5000 & 7.1 & 2 & 0 & 0 & \\
\hline 50 & 16 & I & 0 & 66 & 0 & 2 & 0 & 16500 & 7.4 & 2 & 0 & 0 & \\
\hline Total & 2738.3 & 244 & 52.94 & 26729 & 351.22 & 20 & 3930 & & & & & & \\
\hline Mean & & & & & & & & 103000 & & & & & \\
\hline
\end{tabular}

BLOCK 24B (see p.67)

\begin{tabular}{|c|c|c|c|c|c|c|c|c|c|c|c|c|c|c|}
\hline $\begin{array}{l}\text { Context } \\
\text { Species }\end{array}$ & 41 & 40 & 39 & 38 & 36 & 45 & 34 & 32 & 18 & 49 & 37 & 31 & 30 & 29 \\
\hline Cochlicopa lubrica & 1 & $\mathrm{I}$ & 2 & 2 & $\mathrm{I}$ & 6 & I & 96 & I & 2 & 2 & 4 & 3 & \\
\hline Cochlicopa lubricella & 1 & 3 & I & I & & 3 & & 38 & 2 & 2 & I & I & & \\
\hline Cochlicopa sp & 1 & 6 & 1 & 4 & 2 & 19 & & 173 & 2 & 2 & 2 & 4 & 7 & \\
\hline Vertigo pygmaea & & & & & & & & & & I & 1 & & 1 & \\
\hline Pupilla muscorum & 1 & 9 & 6 & 5 & I & 2 & & 5 & 3 & 21 & 9 & 14 & 2 & I \\
\hline Lauria cylindracea & & & I & I & & & & & & 2 & & & & \\
\hline Vallonia costata & 5 & 5 & I & 3 & 3 & 2 & & 5 & 2 & I & 4 & 2 & I & \\
\hline Vallonia excentrica & 1 & 9 & 3 & 3 & 4 & & & 8 & I & 2 & 3 & 1 & 1 & I \\
\hline Vitrina pellucida & I & & 2 & 3 & & 3 & & 6 & & & & & & \\
\hline Oxychilus alliarus & 2 & 2 & 2 & 3 & 2 & 8 & & & I & 2 & & & & \\
\hline Helicella itala & & 4 & I & 2 & & & $10+1^{\wedge}$ & & & 4 & 6 & & I & \\
\hline Cepaea hortensis & & & & $\mathrm{I} \sim$ & & $\mathrm{I} \sim$ & $2+7^{\wedge}$ & $I^{\wedge}$ & $\mathrm{I}$ & $I+I^{\wedge}$ & & & & $2^{\wedge}$ \\
\hline $\begin{array}{l}\text { Total-terrestrial } \\
\text { (including wet species) }\end{array}$ & 9 & 39 & 20 & 28 & 13 & 44 & I & 351 & 13 & 40 & 30 & 26 & 16 & 4 \\
\hline $\begin{array}{l}\text { No. of species } \\
\text { (including wet species) }\end{array}$ & & 5 & 10 & II & 6 & 8 & I & 9 & 8 & 11 & 9 & 6 & 7 & 3 \\
\hline Seaweed imports & & & & & & & & & & & & & & \\
\hline Rissoa parva & & 1 & & & & & & & & & 1 & & & \\
\hline Littorina littorea & & & & & & & & & & & 2 & & & \\
\hline
\end{tabular}

BLOCK 25A (see p.69)

$\begin{array}{ccccccccccccc}\text { Context } & \text { Bone } & \text { Pot } & \text { Snail } & \text { SeaSh } & \text { Macro } & \text { Stone } & \text { IHI } & \text { pH } & \begin{array}{c}\text { Phos } \\ \% \text { Burnt } \\ \text { stone }\end{array} \begin{array}{c}\text { Pumice } \\ \text { frags }\end{array} \begin{array}{c}\text { Pumice } \\ \text { wt }\end{array} \\ 140 & 1074 & 135 & 7.01 & 575 & 7.63 & 1660 & 23500 & 7.1 & 2 & 30 & 1 & 10.3\end{array}$


BLOCK 25B (see p.69)

\section{Context}

Species

Cochlicopa sp

Vertigo pygmaea

pupilla muscorum

Vallonia costata

Vallonia excentrica

Oxychilus alliarus

*Lymnaea truncatula

Total-terrestrial

(including wet species)

No. of species

(including wet species)

\section{BLOCK 26A (see p.69)}

\begin{tabular}{|c|c|c|c|c|c|c|c|c|c|c|c|c|c|}
\hline Context & Bone & Pot & Snail & SeaSh & Macro & Slag & Stone & IHI & pH & Phos & $\begin{array}{c}\% \text { Burnt } \\
\text { stone }\end{array}$ & $\begin{array}{l}\text { Pumice } \\
\text { frags }\end{array}$ & $\begin{array}{l}\text { Pum-ice } \\
\text { wt }\end{array}$ \\
\hline 139 & 726.9 & 178 & 4.01 & 904 & 12.59 & 0 & 2282 & 34000 & 6.4 & 2 & 50 & 3 & 19.9 \\
\hline 148 & 299 & 49 & 5.01 & 363 & 6.52 & 0 & 1049 & 33000 & 6.9 & 2 & 70 & 4 & 17.6 \\
\hline 181 & 10 & 0 & 0.01 & 4 & 0.07 & 0 & 67 & 3500 & 6.2 & 2 & 10 & 0 & \\
\hline Total & 1035.9 & 227 & 9.03 & $137 \mid$ & 19.18 & 0 & 3398 & & & & & & \\
\hline Mean & & & & & & & & 23500 & & & & & \\
\hline
\end{tabular}

\section{BLOCK 26B (see p.69)}

\section{Context}

139

\# 148

Cochlicopa sp

*Vertigo antivertigo

Pupilla muscorum

Vallonia costata

Vallonia excentrica

Helicella itala

Cepaea hortensis

Total-terrestrial

(including wet species)

No. of species

(including wet species)
\# 140

18

\section{6}

23500

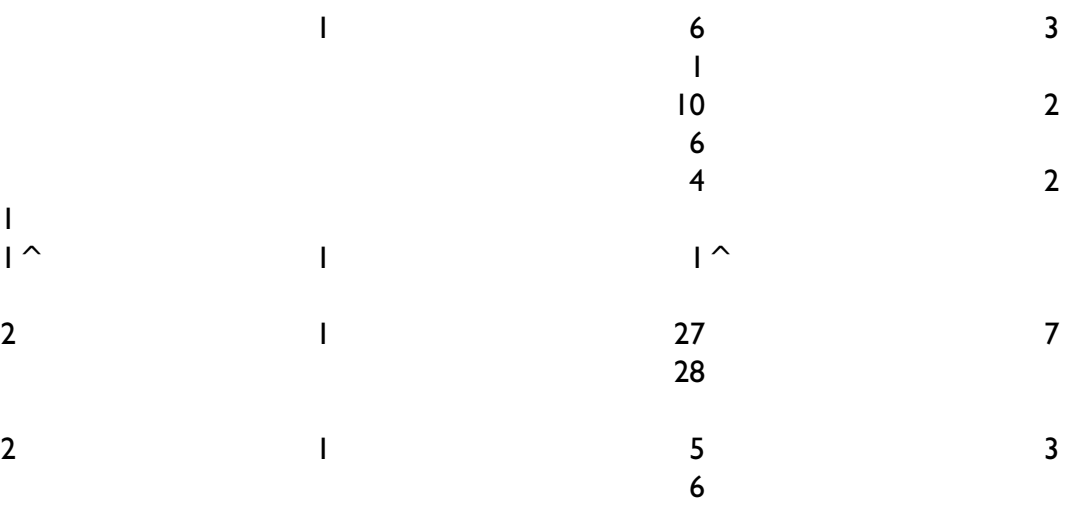


BLOCK 27A (see p.70)

\begin{tabular}{|c|c|c|c|c|c|c|c|c|c|c|c|c|c|}
\hline Context & Bone & Pot & Snail & SeaSh & Macro & Slag & Stone & IHI & pH & Phos & $\begin{array}{c}\% \text { Burnt } \\
\text { stone }\end{array}$ & $\begin{array}{c}\text { Pumice } \\
\text { frags }\end{array}$ & $\begin{array}{c}\text { Pumice } \\
\text { wt }\end{array}$ \\
\hline 54 & 20.9 & - & - & 23 & 0.07 & - & 44 & 9000 & 6.7 & 4 & - & - & \\
\hline 128 & 19 & - & 0.01 & 28 & 0.36 & - & 26 & 10000 & 6.6 & 3 & 25 & - & \\
\hline 129 & 85.0 & 15 & 0.01 & 20 & 11.13 & - & 30 & 35000 & 6.8 & 4 & $<5$ & - & \\
\hline 130 & 31.0 & - & 0.01 & 14 & 8.04 & - & 58 & 11000 & 6.8 & 5 & - & - & \\
\hline $13 \mid$ & 76.0 & 2 & 0.01 & 47 & 7.11 & - & 138 & 21000 & 6.5 & I & 10 & - & \\
\hline 132 & 244.0 & 12 & 3.01 & 250 & 14.04 & - & 66 & 29500 & 7.3 & 5 & - & - & \\
\hline 133 & 278.8 & 19 & 0.01 & 180 & 0.04 & - & 1129 & 6000 & 6.6 & 4 & 25 & - & \\
\hline 231 & 19.1 & - & 0.01 & 16 & 0.08 & - & 51 & 9000 & 7.6 & 5 & 20 & I & 10.6 \\
\hline 232 & 24.0 & 2 & 0.01 & 59 & 0.03 & - & 528 & 3000 & 6.6 & 3 & 70 & I & 9.6 \\
\hline 238 & 21.0 & 5 & 0.0125 & & 0.12 & - & 227 & 18000 & 6.7 & 2 & 15 & - & \\
\hline Total & 818.8 & 55 & 3.09 & & 41.29 & & & & & & & & \\
\hline Mean & & & & & & & & 15000 & & & & & \\
\hline
\end{tabular}

\section{BLOCK 27B (see p.70)}

\section{Context}

Species

Cochlicopa sp

*Vertigo antivertigo

Vertigo pygmaea

Pupilla muscorum

Vallonia costata

Vallonia excentrica

Oxychilus alliarius

Helicella itala

Cepaea hortensis

*Lymnaea truncatula

Total-terrestrial

(including wet species)

No. of species

(including wet species)

BLOCK 28 (see p.7I)

\section{Context}

\section{Bone}

38
238

133

232

132

231

I31

130

129

128

$\begin{array}{lll}2 & & 3 \\ 1 & & \text { I } \\ 3 & 4 & 1 \\ 1 & & \\ 2 & 1 & 1\end{array}$

2

8

5

2

4
5
33

BLOCK 29A (see p.7I)

\section{Context}

234

\section{Bone}

39

Snail

21.03
Pot

16

SeaSh
53

SeaSh

175
Stone

82
IHI

6000
0.6 
BLOCK 29B (see p.7I)

Context

Species

Cochlicopa sp

Vertigo pygmaea

Pupilla muscorum

Vallonia costata

Vallonia excentrica

Oxychilus alliarius

Helicella itala

Total-terrestrial

(including wet species)

No. of species

(including wet species)

\section{Seaweed imports}

Rissoa parva
234

8

2

2

3

21

7

2 
BLOCKIA (see p.74)

$\begin{array}{rrrrrrrrrrrr}\text { Context } & \text { Bone } & \text { Pot } & \text { Snail } & \text { SeaSh } & \text { Macro } & \text { Slag } & \text { Stone } & \text { IHI } & \text { PH } & \text { Phos } & \text { \%Burnt } \\ 48 & 7 & 2 & 1.05 & 65 & 0.01 & 0 & 780 & 5500 & 7.5 & 5 & <5 \\ 55 & 21 & 0 & 0.03 & 15 & 6.27 & 0 & 50 & 21500 & 7.2 & 3 & <5 \\ 56 & 33 & 3 & 3.37 & 209 & 0.01 & 0 & 3323 & 12000 & 7.3 & 4 & 0 \\ 57 & 108 & 2 & 0.62 & 82 & 0.01 & 0 & 2342 & 0 & 7.1 & 3 & 0 \\ 70 & 13 & 1 & 1.14 & 42 & 0.12 & 0 & 140 & 350 & 7.4 & 4 & 0 \\ 71 & 3 & 0 & 0.01 & 0 & 0.41 & 0 & 97 & 119000 & 7 & 3 & 0 \\ 72 & 4 & 3 & 0.01 & 5 & 0.08 & 0 & 79 & 0 & 7.4 & 3 & 5 \\ 74 & 328.4 & 23 & 0.8 & 1796.4 & 0.07 & 0 & 3045 & 8000 & 7.4 & 4 & 30 \\ 96 & 7 & 0 & 0.02 & 0 & 0.18 & 0 & 17 & 1500 & 7.4 & 3 & 0 \\ 132 & \text { not sampled } & & & & & & & & & & \\ 210 & 9.5 & 2 & 4.11 & 272.3 & 0.12 & 4 & 300 & 2000 & 7.4 & 2 & <5 \\ 211 & 35 & 2 & 0.15 & 52 & 0.4 & 0 & 785 & 1500 & 7.4 & 4 & 5 \\ 213 & 107 & 7 & 0.09 & 310 & 17.09 & 0 & 36 & 2000 & 7.4 & 4 & <5 \\ \text { Total } & 675.9 & 45 & 11.4 & 2848.3 & 24.77 & 4 & 10994 & & & & \end{array}$

\section{BLOCKIB (see p.74)}

Sub-block (see I4.3)

\section{Context}

Species

* Oxyloma pfeifferi Cochlicopa lubrica Cochlicopa lubricella Cochlicopa sp.

*Vertigo substriata

Vertigo pygmaea

Pupilla muscorum Lauria cylindracea

Vallonia costata

Vallonia excentrica

Punctum pygmaeum

Vitrina pellucida

Nesovitrea hammonis

Oxychilus alliarius

Euconulus fulvus

Helicella itala

Total-terrestrial

No. of species

Seaweed imports

Gibula cineraria

Rissoa parva

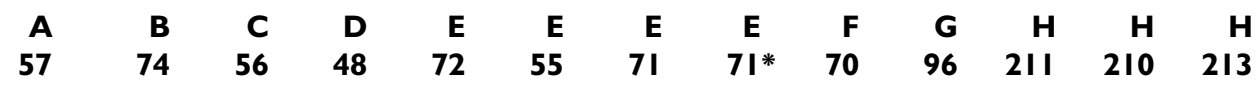

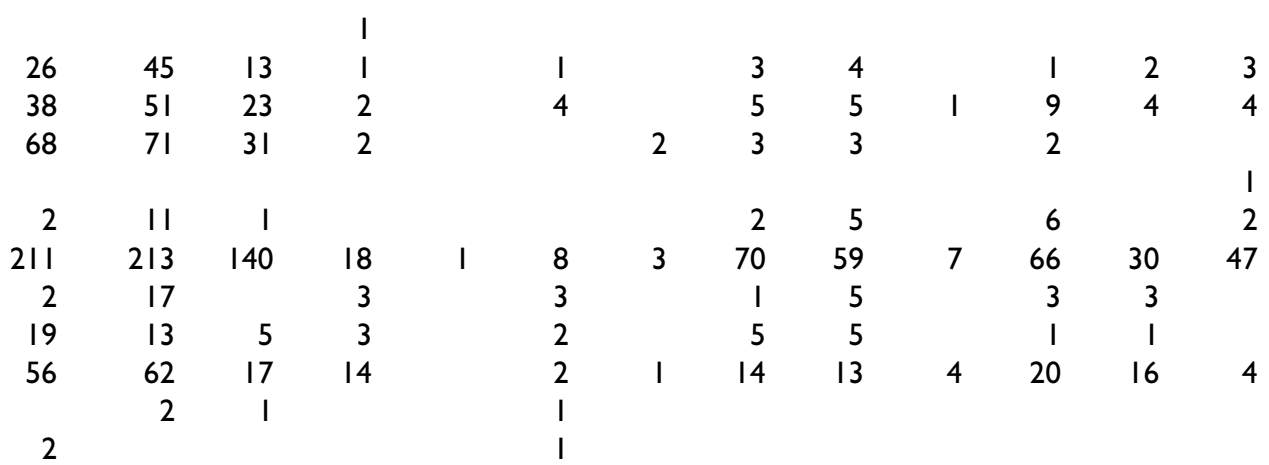

$\begin{array}{rrr}2 & 1 & \\ 13 & 31 & 38 \\ 439 & 518 & 269 \\ 11 & 12 & 9\end{array}$

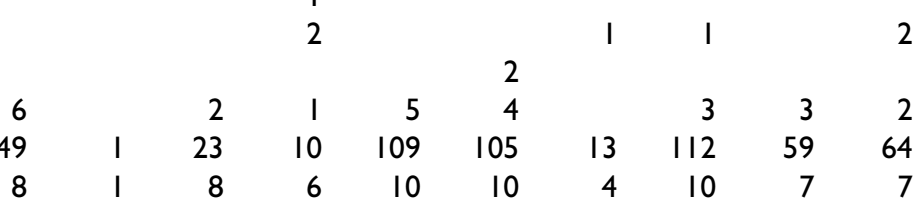


BLOCKS 2-I2 (see p.76)

\begin{tabular}{|c|c|c|c|c|c|c|c|c|c|c|c|c|c|}
\hline Context & Bone & Pot & Snail & SeaSh & Macro & Slag & Stone & IHI & pH & Phos & $\begin{array}{c}\% \text { Burnt } \\
\text { stone }\end{array}$ & $\begin{array}{c}\text { Pumice } \\
\text { frags }\end{array}$ & $\begin{array}{c}\text { Pumice } \\
\text { wt }\end{array}$ \\
\hline 4 & 98 & 15 & 0.01 & 669 & 0.22 & 0 & 2626 & 10000 & 7.8 & 4 & 10 & 0 & \\
\hline 5 & 2 & 0 & 0.01 & 33 & 0.1 & 0 & 85 & 2500 & 7.7 & 4 & 0 & 0 & \\
\hline 6 & $\mathrm{II}$ & 4 & 0.02 & 73 & 0.13 & 0 & 786 & 4000 & 7.5 & 4 & $<5$ & 0 & \\
\hline 7 & 32 & 4 & 6.02 & 234 & 0.2 & 0 & 746 & 5500 & 7.7 & 3 & 0 & 0 & \\
\hline 8 & 9 & 0 & 0.01 & 268 & 0.08 & 0 & 722 & 3000 & 7.6 & 1 & 0 & 0 & \\
\hline 9 & 71 & 0 & 4.01 & 329 & 6.4 & 0 & 922 & 5000 & 7.5 & 4 & 0 & 0 & \\
\hline 11 & 12 & 0 & 3 & 163 & 0 & 0 & 127 & 3000 & 0 & 0 & 0 & 0 & \\
\hline 12 & 26 & 0 & 10.01 & 279 & 0.08 & 0 & 902 & 2500 & 7.5 & 4 & $<5$ & 0 & \\
\hline 15 & 0 & 0 & 0 & 0 & 0 & 0 & 0 & 0 & 7.5 & 3 & 0 & 0 & \\
\hline 16 & 70 & 7 & 0.01 & 400 & 48.55 & 0 & 1500 & 16000 & 7.5 & 2 & $<5$ & 0 & \\
\hline 17 & 0 & 0 & 0 & 0 & 0 & 0 & 0 & 0 & 7.5 & 4 & 0 & 0 & \\
\hline 18 & 0 & 0 & 0 & 0 & 0 & 0 & 0 & 0 & 7.5 & 2 & 0 & 0 & \\
\hline 19 & 3 & 0 & 0.08 & 24 & 0.22 & 0 & 44 & 700 & 7.5 & 2 & 0 & 0 & \\
\hline 20 & 6 & 0 & 0.04 & 59 & 0.66 & 0 & 425 & 2000 & 7.7 & 3 & 0 & 0 & \\
\hline 21 & 0 & 0 & 0 & 0 & 0 & 0 & 0 & 0 & 7.7 & 2 & 0 & 0 & \\
\hline 23 & 2 & 0 & 0.07 & 24 & 0.12 & 0 & 0 & 100 & 7.7 & 3 & 0 & 0 & \\
\hline 24 & 213 & 18 & 7.01 & 1295 & 0.86 & 0 & 2726 & 3000 & 7.5 & 3 & 5 & 0 & \\
\hline 25 & 67 & 3 & 0.03 & 167 & 0.24 & 0 & 751 & 1500 & 7.3 & 2 & 10 & 0 & \\
\hline 26 & 11 & 1 & 0.01 & 36 & 0.01 & 0 & 30 & 400 & 7.3 & 4 & 0 & 1 & 0.64 \\
\hline 27 & 21 & 1 & 3.12 & 83 & 0.07 & 0 & 41 & 200 & 7.1 & 5 & 0 & 0 & \\
\hline 28 & 5 & 0 & 4.08 & 178 & 0.04 & 0 & 269 & 13500 & 7.1 & 3 & 0 & 0 & \\
\hline 29 & 0 & 0 & 0.02 & 5 & 0 & 0 & 95 & 2500 & 7.3 & 3 & 0 & 0 & \\
\hline 30 & 5 & 0 & 0.03 & 24 & 0.09 & 0 & 57 & 3000 & 7.3 & 1 & 0 & 0 & \\
\hline 31 & 29 & 2 & 2.06 & 10 & 0.18 & 0 & 402 & 4000 & 7.2 & 1 & $<5$ & 0 & \\
\hline 32 & 9 & 0 & 0.07 & 43 & 0.26 & 0 & 0 & 100 & 7.3 & 3 & 0 & 0 & \\
\hline 33 & 14 & 2 & 0.01 & 234 & 0.12 & 0 & 605 & 3000 & 7.3 & 4 & $<5$ & 0 & \\
\hline 34 & 0 & 0 & 0 & 0 & 0 & 0 & 0 & 0 & 7.3 & 3 & 0 & 0 & \\
\hline 35 & 1 & 0 & 0.03 & 45 & 0.46 & 0 & 1233 & 10500 & 7.2 & 5 & 0 & 0 & \\
\hline 36 & 0 & 0 & 0.01 & 0 & 0.01 & 0 & 0 & 30 & 7.3 & 3 & 0 & 0 & \\
\hline 37 & 92 & 7 & 3.06 & $|462|$ & 24.23 & 82 & 1517 & 70500 & 7.2 & 4 & 10 & 0 & \\
\hline 38 & 0 & 0 & 0 & 0 & 0 & 0 & 0 & 0 & 7.3 & 3 & 0 & 0 & \\
\hline 39 & 0 & 0 & 0.01 & 34 & 0.08 & 49 & 88 & 7500 & 7.3 & 4 & 0 & 0 & \\
\hline 41 & 0 & 0 & 0 & 0 & 0 & 0 & 0 & 0 & 7.4 & 3 & 0 & 0 & \\
\hline 42 & 9 & 0 & 0.01 & 0 & 0.12 & 0 & 0 & 500 & 7.3 & 2 & 0 & 0 & \\
\hline 43 & 0 & 0 & 0 & 0 & 0 & 0 & 0 & 0 & 7.2 & 3 & 0 & 0 & \\
\hline 44 & 0 & 0 & 0 & 4 & 0 & 0 & 22 & 1000 & 0 & 0 & 0 & 0 & \\
\hline 45 & 0 & 0 & 0 & 0 & 0 & 0 & 0 & 0 & 6.8 & 2 & 0 & 0 & \\
\hline 47 & 0 & 0 & 0 & 0 & 0 & 0 & 0 & 0 & 7 & 3 & 0 & 0 & \\
\hline 51 & 0 & 0 & 0 & 0 & 0 & 0 & 0 & 0 & 7.1 & 2 & 0 & 0 & \\
\hline 52 & 0 & 0 & 0 & 0 & 0 & 0 & 0 & 0 & 7.6 & 2 & 0 & 0 & \\
\hline 53 & 0 & 0 & 0 & 0 & 0 & 0 & 0 & 0 & 7.1 & 2 & 0 & 0 & \\
\hline 54 & 0 & 0 & 0 & 0 & 0 & 0 & 0 & 0 & 0 & 4 & 0 & 0 & \\
\hline 58 & 15 & 1 & 0.01 & 407 & 36.25 & 0 & 0 & 500 & 7.6 & 2 & 0 & 0 & \\
\hline 59 & 4 & 2 & 0.01 & 138 & 0.94 & 0 & 32 & 0 & 7.3 & 3 & 0 & 0 & \\
\hline 60 & 70 & 0 & 5.03 & 1094 & 0.77 & 0 & 2644 & 0 & 7.1 & 2 & 5 & 0 & \\
\hline 61 & 6 & 0 & 0.01 & 255 & 0.24 & 0 & 52 & 0 & 7.5 & 4 & 5 & 0 & \\
\hline 62 & 0 & 0 & 0 & 0 & 0 & 0 & 0 & 0 & 7.5 & 2 & 0 & 0 & \\
\hline 63 & 19 & 0 & 0.01 & 3 & 0.26 & 0 & 337 & 35000 & 7.1 & 2 & 0 & 0 & \\
\hline 64 & 360 & 0 & 6.01 & 165 & I.4 & 0 & 1470 & 8500 & 7.6 & 2 & 20 & 0 & \\
\hline 65 & 8 & 0 & 0.04 & 372 & 0.4 & 0 & 451 & 6000 & 7.4 & 3 & 20 & 0 & \\
\hline 66 & 9 & 1 & 0.01 & 5 & 0.28 & 0 & 14 & 48500 & 7.5 & 2 & 10 & 0 & \\
\hline 67 & 15 & 7 & 0.01 & 138 & 7.12 & 0 & 1005 & 14000 & 7.3 & 2 & 10 & 0 & \\
\hline 68 & 5 & 0 & 0.05 & 16 & 0.33 & 0 & 91 & 0 & 7.1 & 3 & $<5$ & 0 & \\
\hline 69 & 174 & 7 & 0.03 & 235 & 2 & 18 & 1398 & 0 & 7.5 & 1 & 5 & 0 & \\
\hline 73 & 0 & 0 & 0 & 0 & 0 & 0 & 0 & 0 & 7.4 & 4 & 0 & 0 & \\
\hline 76 & 45 & 4 & 2.07 & 209 & 0.42 & 0 & 1743 & 14500 & 7.5 & 3 & 30 & 0 & \\
\hline 77 & 93 & 10 & 0.02 & 1674 & 0.7 & 0 & 318 & 600 & 7.6 & 3 & 40 & 0 & \\
\hline 79 & 0 & 0 & 0 & 0 & 0 & 0 & 0 & 0 & 7.6 & 3 & 0 & 0 & \\
\hline
\end{tabular}


Context Bone Pot Snail SeaSh Macro Slag Stone IHI pH Phos \% Burnt Pumice Pumice stone frags wt

\begin{tabular}{|c|c|c|c|c|c|c|c|c|c|c|c|c|}
\hline 80 & 18 & 0 & 0 & 0 & 0 & 0 & 19 & 1000 & 7.3 & 3 & 0 & 0 \\
\hline 81 & 0 & 0 & 0.01 & 37 & 0.04 & 0 & 15 & 400 & 7.4 & 1 & 0 & 0 \\
\hline 82 & 0 & 0 & 0 & 0 & 0 & 0 & 0 & 0 & 7.2 & 3 & 0 & 0 \\
\hline 83 & 0 & 0 & 0 & 0 & 0 & 0 & 0 & 0 & 7.5 & 2 & 0 & 0 \\
\hline 86 & 0 & 0 & 0.01 & 6 & 0.01 & 0 & 0 & 4 & 7.4 & 3 & 0 & 0 \\
\hline 87 & 53 & I & 5.05 & 313 & 5.85 & 0 & 364 & 49500 & 7.6 & 2 & 20 & 0 \\
\hline 88 & 0 & 0 & 0 & 0 & 0 & 0 & 0 & 0 & 7.4 & 2 & 0 & 0 \\
\hline 89 & 95 & 19 & 0 & 54 & 0 & 0 & 51 & 600 & 0 & 0 & 0 & 0 \\
\hline 90 & 0 & 0 & 0 & 7 & 0.81 & 0 & 13 & 0 & 7.6 & 2 & 0 & 0 \\
\hline 91 & 7 & I & 0.07 & 65 & 0.11 & 0 & 16 & 300 & 7.6 & 2 & 0 & 0 \\
\hline 92 & 128 & 0 & 0.02 & 267 & 0.31 & 0 & 55 & 3500 & 7.1 & 1 & 0 & 0 \\
\hline 93 & 0 & 0 & 0 & 0 & 0 & 0 & 0 & 0 & 7.5 & 3 & 0 & 0 \\
\hline 94 & 50 & 12 & 3.01 & 678 & 0.33 & 0 & 384 & 1500 & 7.3 & 4 & 0 & 0 \\
\hline 99 & 29 & 10 & 0.01 & 459 & 0 & 0 & 1746 & 6000 & 7.4 & 2 & 80 & 0 \\
\hline 100 & 17 & 15 & 0.01 & 1770 & 9.92 & 93 & 799 & 33500 & 7.6 & 2 & 10 & 0 \\
\hline 201 & 132 & 0 & 0.03 & 981 & 1.21 & 0 & 5446 & 15500 & 7.3 & 3 & 10 & 0 \\
\hline 202 & 70 & 9 & 0.01 & 160 & 0.13 & 0 & 3132 & 10500 & 7.4 & 2 & 5 & 0 \\
\hline 204 & 22 & 13 & 2.01 & 281 & 2.86 & 0 & 624 & 9500 & 7.3 & 4 & 10 & 0 \\
\hline 205 & 45 & 8 & 0.01 & 202 & 0.72 & 0 & 294 & 3000 & 7.3 & 4 & 10 & 0 \\
\hline 206 & 34 & 0 & 0.01 & 1055 & 1.65 & 0 & 410 & 350 & 7.4 & 3 & 5 & 0 \\
\hline 207 & 25 & 0 & 0.06 & 17 & 0.89 & 0 & 195 & 3000 & 7.4 & 0 & 0 & 0 \\
\hline 208 & 0 & 0 & 0.01 & 8 & 0.07 & 0 & 37 & 500 & 7.3 & 2 & $<5$ & 0 \\
\hline 212 & 36 & 3 & 3.07 & 148 & 0.23 & 0 & 1042 & 3000 & 7.4 & 4 & 5 & 0 \\
\hline 214 & 6 & 0 & 0.05 & 28 & 0.95 & 0 & 36 & 2000 & 7.2 & 5 & $<5$ & 0 \\
\hline 215 & 18 & 0 & 0.03 & 238 & 2.13 & 0 & 330 & 3000 & 7.3 & 3 & $<5$ & 0 \\
\hline 216 & 0 & 0 & 0 & II & 0.08 & 0 & 34 & 1000 & 7.4 & 3 & $<5$ & 0 \\
\hline 217 & 24 & 2 & 0.01 & 65 & 0.27 & 0 & 954 & 16000 & 7.3 & 3 & 0 & 0 \\
\hline 218 & 95 & 5 & 0.02 & 584 & 0.68 & 0 & 2647 & 10500 & 7.2 & 3 & 5 & 0 \\
\hline 219 & 8 & 0 & 0.01 & 732 & 13.7 & 0 & $34 I$ & 1500 & 7.3 & 3 & $<5$ & 0 \\
\hline 220 & 29 & I & 0.01 & 470 & 1.6 & 0 & 198 & 2000 & 7.4 & 3 & $<5$ & 0 \\
\hline 221 & 240 & 0 & 0.01 & 521 & 18.07 & 5 & 838 & 0 & 7.3 & 4 & $<5$ & 0 \\
\hline 222 & 31 & 2 & 0.03 & 504 & 0.58 & 0 & 804 & 8500 & 7.1 & 3 & $<5$ & 0 \\
\hline 224 & 37 & 1 & 4.01 & 199 & 0.39 & 0 & 298 & 2500 & 7.2 & 3 & 10 & 0 \\
\hline 225 & 62 & 7 & 0.03 & 2750 & 31.33 & 0 & 923 & 65500 & 7.4 & 3 & 10 & 0 \\
\hline 223 & 5 & 0 & 0.01 & 207 & 0.03 & 0 & 265 & 6500 & 7.4 & 2 & $<5$ & 0 \\
\hline 226 & 8 & 4 & 0.01 & 177 & 1.05 & 0 & 17 & 0 & 7.4 & 2 & 0 & 0 \\
\hline 228 & 2 & 0 & 0.01 & 243 & 0.13 & 0 & 197 & 0 & 7.4 & 3 & $<5$ & 0 \\
\hline 231 & 4 & 2 & 0.07 & 843 & 0.55 & 0 & 89 & 0 & 7.3 & 3 & 0 & 0 \\
\hline 234 & 5 & 9 & 0.05 & 26 & 0.35 & 0 & 67 & 2000 & 7.4 & 3 & 0 & 0 \\
\hline 235 & 0 & I & 0 & 0 & 0 & 0 & 0 & 0 & 7.4 & 3 & 0 & 0 \\
\hline 237 & 136 & 0 & 0.06 & 0 & 0.33 & 0 & 24 & 0 & 0 & 0 & 0 & 0 \\
\hline 238 & 10 & 0 & 0.01 & 48 & 0.32 & 0 & 167 & 0 & 7.3 & 4 & $<5$ & 0 \\
\hline 239 & 13 & 0 & 0.3 & $|14|$ & 0.7 & 0 & 762 & 0 & 7.4 & 3 & 20 & 0 \\
\hline 244 & 51 & 2 & 0.01 & 633 & 0.1 & 0 & 905 & 11500 & 7.3 & 3 & $<5$ & 0 \\
\hline 305 & 0 & 0 & 0 & 26 & 0 & 0 & 270 & 4500 & 7.6 & I & 0 & 0 \\
\hline 306 & 0 & 0 & 0 & 0 & 0 & 0 & 0 & 0 & 7.1 & 3 & 0 & 0 \\
\hline 307 & 0 & 0 & 0.01 & 25 & 0.21 & 0 & 12 & 4000 & 7.6 & 2 & 0 & 0 \\
\hline 308 & 8 & 0 & 0.01 & 68 & 0.46 & 0 & 693 & 12000 & 8.1 & 2 & 5 & 0 \\
\hline 309 & 0 & 0 & 0 & 0 & 0 & 0 & 0 & 0 & 7.1 & 2 & 0 & 0 \\
\hline 310 & 0 & 0 & 0 & 0 & 0 & 0 & 0 & 0 & 7.9 & 4 & 0 & 0 \\
\hline 448 & 0 & 0 & 0 & 0 & 0 & 0 & 0 & 0 & 7.6 & 4 & 0 & 0 \\
\hline Total & 3162 & 223 & 72.23 & 40127 & 247.23 & 247 & 51868 & & & & & \\
\hline Mean & & & & & & & & 8500 & & & & \\
\hline
\end{tabular}


BLOCK 2 (see p.77)

Context

Species

Cochlicopa lubrica

Cochlicopa sp

*Vertigo antivertigo

Pupilla muscorum

Vallonia costata

Vallonia excentrica

Nesovitrea hammonis

Oxychilus alliarius

*Zonitoides nitidus

Helicella itala

Total-terrestrial

(including wet species)

No. of species

(including wet species)

Seaweed imports

Rissoa parva

\section{BLOCK 3 (see p.77)}

\section{Context}

Species

Pupilla muscorum

Helicella itala

Total-terrestrial

(including wet species)

No. of species

(including wet species)

Seaweed imports

Gibula cineraria

\section{BLOCK 4 (see p.77)}

Context

$6 \quad 7$

$7-8$

\section{Species}

Cochlicopa lubrica

Cochlicopa sp

Vertigo pygmaea

Pupilla muscorum

Vallonia costata

Vallonia excentrica

Helicella itala

Total-terrestrial

(including wet species)

No. of species

3

(including wet species)

Seaweed imports

Rissoa parva 


\section{BLOCK 5 (see p.78)}

\begin{tabular}{|c|c|c|c|c|c|c|c|c|c|c|c|c|c|c|c|c|c|c|c|c|c|c|c|c|}
\hline Context & 90 & 69 & 68 & 878 & $7 \sim$ & 223 & 91 & 92 & 86 & 94 & 81 & 67 & 63 & 66 & 64 & 205 & 65 & 208 & 207 & 204 & 99 & 202 & 217 & 216 \\
\hline \multicolumn{25}{|l|}{ Species } \\
\hline Cochlicopa lubrica & & 2 & I & 2 & & & & & I & & & & & & & & $I$ & & & I & & & I & \\
\hline Cochlicopa lubricella & & & I & & I & & 4 & I & & & & & & & & & $I$ & & $I$ & & & 2 & & \\
\hline Cochlicopa sp & & 2 & 3 & I & I & & I & 2 & & & & & & $I$ & & 2 & & & $l$ & & 2 & & I & \\
\hline Columella edentula & & & & & & & & & & I & & & & & & & & & & & & & & \\
\hline *Vertigo antivertigo & & $I$ & & & & & & & & & & & & & & & & & $I$ & & & & & \\
\hline *Vertigo substriata & & & & & I & & & & & & & & & & & & & & & & & & & \\
\hline Vertigo pygmaea & & 2 & I & & I & & l & & & & & & & & 3 & I & I & & 4 & & & & I & \\
\hline Pupilla muscorum & 5 & 13 & 18 & 25 & 22 & 2 & 40 & 11 & 3 & 5 & 10 & 4 & 3 & 2 & 11 & 2 & 26 & & 29 & 1 & II & 5 & & \\
\hline Lauria cylindracea & & & & I & I & & & & & & & & & & 3 & & I & & 3 & & & & & \\
\hline Vallonia costata & 2 & & 2 & 2 & 2 & I & & & & I & & & I & & & & I & & 3 & & & & & I \\
\hline Vallonia excentrica & 3 & I & 8 & 3 & 4 & & 3 & 3 & & & 2 & I & & & 4 & I & 2 & & 2 & & I & & & \\
\hline Nesovitrea hammonis & & I & & I & I & & & & & & & & & & 3 & I & & & 2 & & & & & \\
\hline Oxychilus alliarius & & & & I & I & & & & & & & & & & 2 & & & & 3 & & 3 & & I & \\
\hline Helicella itala & 5 & I & 4 & 3 & I & & & & & 7 & & & I & & & & 2 & & & & & & & \\
\hline Cochlicella acuta & & & I & & & I & & & & & I & & & & & 1 & & & & & & & & \\
\hline *Lymnaea truncatula & & & & & & & & & & & I & I & & & & & & & I & & & & & \\
\hline Total-terrestrial & 15 & 22 & 39 & 39 & 35 & 4 & 49 & 17 & 4 & 14 & 13 & 5 & 5 & 3 & 26 & 8 & 35 & & 48 & 2 & 17 & 7 & 4 & I \\
\hline (including wet species) & & 23 & & & 36 & & & & & & 14 & 6 & & & & & & & 50 & & & & & \\
\hline No. of species & 4 & 7 & 9 & 9 & 10 & 3 & 5 & 4 & 2 & 4 & 3 & 2 & 3 & 2 & 6 & 6 & 8 & & 10 & 2 & 4 & 2 & 4 & I \\
\hline (including wet species) & & 8 & & & II & & & & & & 4 & 3 & & & & & & & II & & & & & \\
\hline \multicolumn{25}{|l|}{ Seaweed imports } \\
\hline Gibula cineraria & & & & & & & & & & & & I & & & & & I & & & & & & & \\
\hline Rissoa parva & 1 & I & & 4 & & & l & I & & & & & & & I & 3 & $I$ & I & 3 & & 2 & & 4 & I \\
\hline Littorina littorals & $I$ & & & & & & & & & & & & & & & & & & & & & & & \\
\hline Littorina littorea & & & I & & & & & & & & & & & & & & I & & & & & & I & \\
\hline
\end{tabular}


BLOCK 6 (see p.79)

\section{Context}

Species

Cochlicopa lubrica

Cochlicopa lubricella

Cochlicopa sp

*Vertigo antivertigo

*Vertigo substriata

Vertigo pygmaea

Pupilla muscorum

Lauria cylindradea

Vallonia costata

Vallonia excentrica

Punctum pygmaeum

Nasovitrea hammonis

Oxychilus alliarius

*Zonitodes nitidus

Helicella itala

Cochlicopa acuta

*Lymnaea truncatula

Total-terrestrial

(including wet species)

No. of species

(including wet species)

Seaweed imports

Gibula cineraria

Rissoa parva

Lacuna vincta

Littorina littorea

\section{BLOCK 7 (see p.80)}

\section{Context}

\section{Species}

Cochlicopa sp

*Vertigo substriata

Pupilla muscorum

Vallonia excentrica

Nesovitrea hammonis

Oxychilus alliarius

Total-terrestrial

(including wet species)

No. of species

(including wet species)

Seaweed imports

Rissoa parva

\begin{tabular}{|c|c|c|c|c|c|c|c|c|c|c|c|c|}
\hline 201 & 215 & 234 & 100 & 237 & 76 & 77 & 228 & 206 & 221 & 226 & 220 & $220 *$ \\
\hline I & I & & & & I & & & & & 2 & & \\
\hline \multirow[t]{2}{*}{ I } & $I$ & 2 & & I & 3 & & $I$ & & & I & & \\
\hline & I & 3 & I & & & 1 & & & & & & \\
\hline \multirow[t]{3}{*}{1} & & & I & & & & & & & & & \\
\hline & & & & & I & & & & & & & \\
\hline & & & & & & 2 & & & & & & \\
\hline 6 & 6 & 16 & 7 & 12 & 15 & 7 & I & 4 & 4 & 4 & $I$ & I \\
\hline \multirow[t]{2}{*}{ I } & $I$ & & & & & I & & & & $I$ & & I \\
\hline & 2 & 2 & & & 4 & I & & & & & I & \\
\hline \multirow[t]{2}{*}{$I$} & $I$ & 3 & I & $I$ & 2 & I & 2 & & & & & \\
\hline & & & & & I & & & & & & & \\
\hline \multicolumn{13}{|l|}{ I } \\
\hline \multirow[t]{3}{*}{1} & & I & I & 2 & & I & & & & & & \\
\hline & & & I & & & & & & & & & \\
\hline & I & $I$ & I & $I$ & & & & & & & $I$ & \\
\hline
\end{tabular}

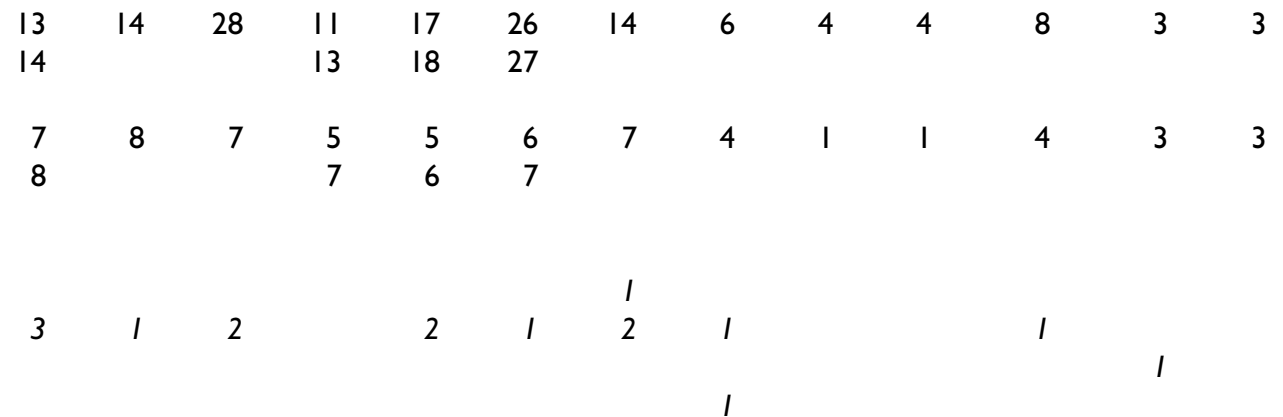

218

I

1

8

1

1

2

13

14

5

6

4 
BLOCK 8 (see p.80)

\section{Context}

\section{Species}

Cochlicopa lubrica

Cochlicopa lubricella

Cochlicopa

*Vertigo substriata

Vertigo pygmaea

Pupilla muscorum

Lauria cylindracea

Vallonia costata

Vallonia excentrica

Nesovitrea hammonis

Oxychilus alliarius

*Zonitoides nitidus

Helicella itala

Cochlicopa acuta

Total-terrestrial

(including wet species)

No. of species

(including wet species)

Seaweed imports

Rissoa parva

Littorina littoralis

BLOCK 9 (see p.8I)

Sub-block (see 14.3)

\section{Context}

Species

Cochlicopa lubrica

Cochlicopa lubricella

Cochlicopa sp

Vertigo pygmaea

Pupilla muscorum

Lauria cylindracea

Vallonia costata

Vallonia excentrica

Punctum pygmaeum

Nesovitrea hammonis

Helicella itala

* Lymnaea truncatula

Total-terrestrial

(including wet species)

No. of species

(including wet species)

Seaweed imports

Gibula cineraria

Rissoa parva

Lacuna vincta

Other marine

Littorina littoralis

Littorina littorea
244

224

238

222

239

239*

225

231

\begin{tabular}{|c|c|c|}
\hline I & $I$ & \\
\hline & 5 & I \\
\hline 2 & 3 & I \\
\hline
\end{tabular}

$1 \quad 1$

20

4

13

2

I

6

2

2

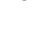

7

3

7

$4 \quad 30$

19

20

4

40

2

3

4

6

$\begin{array}{lll}5 & 2 & 10\end{array}$

8

3

$12 \quad 1$

3 $\begin{array}{rrrrrrrrrrrr}\text { A } & \text { B } & \text { B } & \text { B } & \text { B } & \text { C } & \text { D } & \text { E } & \text { E } & \text { E } & \text { E } & \text { F } \\ 23 & 30 & 28 & 37 & 29 & 44^{*} & 43 & 36 & 19 & 27 & 26 & 20\end{array}$

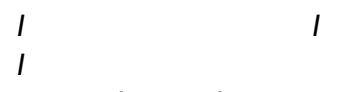

$\begin{array}{rrr} & I & 1 \\ 43 & 9 & 38 \\ 1 & & 23 \\ 1 & 4 & 2\end{array}$

5

52

6

$14 \quad 43$

3

43

$23 \quad 8$

80

$\begin{array}{llll}1 & 3 & 1 & 1 \\ 1 & 4 & 3 & 1\end{array}$

$\begin{array}{llllll}80 & 5 & 20 & 83 & 4 & 23\end{array}$

1

$\begin{array}{llll}1 & & 1 \\ 5 & 1 & 1 & 3\end{array}$

$\begin{array}{llll}20 & 2 & 2 & 2\end{array}$

$\begin{array}{lllll} & 1 & 4 & 2 & \\ 2 & 6 & 4 & 7 & 1\end{array}$

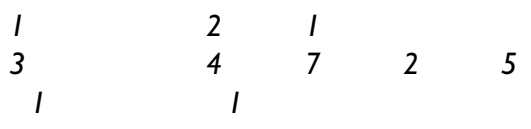


BLOCK 10 (see p.82)

\section{Context}

Species

* Oxyloma pfeifferi

Cochlicopa sp.

Pupilla muscorum

Oxychilus alliarus

Total-terrestrial

(including wet species)

No. of species

(including wet species)

\section{BLOCK I I (see p.82)}

Sub-block (see 14.3)

Context

A

6I

60

Species

Cochlicopa lubricella

Cochlicopa sp.

Pupilla muscorum

Vallonia costata

Vallonia excentrica

Oxychilus alliarius

Helicella itala

Cochlicella aucta

Total-terrestrial

(including wet species)

No. of species

(including wet species)

Seaweed imports

Rissoa parva 
BLOCK 12 (see p.82)

Sub-blocks (see 14.3)

Context

$\begin{array}{rrrrrrrrrrrrr}\text { A } & \text { A } & \text { B } & \text { C } & \text { D } & \text { D } & \text { D } & \text { E } & \text { E } & \text { E } & \text { F } & \text { F } & \text { F } \\ 35 & 33 & 12 & 32 & 42 & 9 & 8 & 7 & 6 & 308 & 5 & 4 & 307\end{array}$

Species

Oxyloma pfeifferi

Cochlicope lubrica

Cochlicopa lubricella

Cochlicopa sp.

*Vertigo antivertigo

Vertigo pygmaea

Pupilla muscorum

Lauria cylindracea

Vallonia costata

Vallonia excentrica

Vitrina pellucida

Vitrea contracta

Oxychilus alliarius

Hellicella itala

Cepea hortensis

Total-terrestrial

(including wet species)

No. of species

(including wet species)

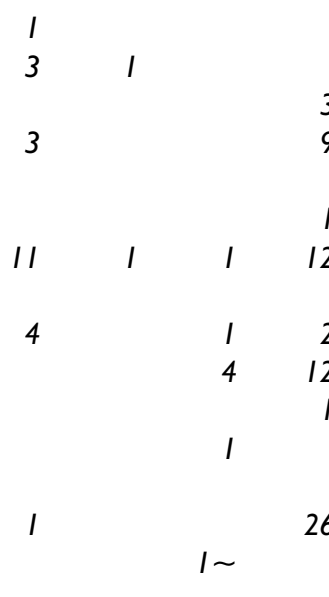

$22 \quad 2 \quad 8 \quad 66$

23

$\begin{array}{llll}2 & 5 & 8 & 1\end{array}$

$\begin{array}{llll}3 & 8 & 5 & 8\end{array}$

33

Seaweed imports

Gibula cineraria

Rissoa parva

BLOCK I3A (see p.84)

\begin{tabular}{|c|c|c|c|c|c|c|c|c|c|c|c|}
\hline Context & Bone & Pot & Snail & SeaSh & Macro & Slag & Stone & IHI & pH & Phos & $\begin{array}{r}\% \text { Burnt } \\
\text { stone }\end{array}$ \\
\hline 2 & 0 & 0 & 0 & 0 & 0 & 0 & 0 & 0 & 7.5 & 3 & 0 \\
\hline 3 & 702 & 25 & 0 & 43.4 & 0 & 0 & 906 & 1500 & 7.3 & 4 & 0 \\
\hline 75 & 71 & 10 & 3.01 & 754 & 0.07 & 169 & 1978 & 7500 & 7.5 & 2 & 20 \\
\hline 304 & 0 & 0 & 0 & 0 & 0 & 0 & 0 & 0 & 7.7 & 2 & 0 \\
\hline 354 & 115 & 0 & 0 & 0 & 0 & 0 & 0 & 0 & 0 & 0 & 0 \\
\hline 436 & 0 & 0 & 0 & 0 & 0 & 0 & 0 & 0 & 7.3 & 4 & 0 \\
\hline 437 & 0 & 0 & 0 & 0 & 0 & 0 & 0 & 0 & 7.5 & 3 & 0 \\
\hline 439 & 0 & 0 & 0 & 0 & 0 & 0 & 0 & 0 & 7 & I & 0 \\
\hline 442 & 0 & 0 & 0 & 0 & 0 & 0 & 0 & 0 & 8.2 & 3 & 0 \\
\hline 448 & 0 & 0 & 0 & 0 & 0 & 0 & 0 & 0 & 7.6 & 4 & 0 \\
\hline Total & 888 & 35 & 3.01 & 1188 & 0.07 & 169 & 2884 & & & & \\
\hline Mean & & & & & & & & & & & \\
\hline
\end{tabular}


BLOCK I3B (see p.84)

\section{Context}

Species

Cochlicopa lubrica

Cochlicopa lubricella

Cochlicopa sp.

Pupilla muscorum

Vallonia costata

Oxychilus alliarius

Helicella itala

Total-terrestrial

(including wet species)

No. of species

(including wet species)

Seaweed imports

Rissoa parva

\section{BLOCK I5A (see p.86)}

\begin{tabular}{|c|c|c|c|c|c|c|c|c|c|c|}
\hline Context & Bone & Pot & Snail & SeaSh & Macro & Slag & Stone & $\mathbf{p H}$ & Phos & $\begin{array}{c}\% \text { Burnt } \\
\text { stone }\end{array}$ \\
\hline 101 & 280 & - & - & - & - & - & 15 & & & \\
\hline $14 \mid$ & 2 & - & 0.09 & 197 & 0.04 & - & 11 & 7.5 & 4 & - \\
\hline 142 & 4 & 1 & 0.18 & 106 & 0.62 & - & 27 & 7.4 & 2 & - \\
\hline 143 & 44 & - & 0.21 & 37 & 0.59 & - & 67 & 7.4 & 4 & - \\
\hline 144 & 251 & 5 & 4.02 & 165 & 0.35 & - & 40 & 7.4 & 2 & - \\
\hline 147 & 8 & 4 & 0.01 & 41 & 0.97 & - & 170 & 7.1 & 2 & - \\
\hline 148 & 126 & - & $16.4 \mid$ & - & 0.18 & - & - & 7.3 & 5 & - \\
\hline 149 & 14 & - & - & - & - & - & - & 7.3 & 2 & - \\
\hline 155 & 19 & - & 0.01 & 23 & 0.15 & - & 616 & 7.5 & 2 & $<5$ \\
\hline 164 & 5 & - & 0.02 & 582 & 0.07 & - & 12 & 7.5 & 4 & - \\
\hline 166 & - & - & - & - & - & - & - & 7.4 & 2 & - \\
\hline 168 & - & - & 0.07 & - & 0.11 & - & - & 7.3 & 3 & - \\
\hline 190 & - & - & - & - & - & - & - & 7.1 & 3 & - \\
\hline 191 & - & - & - & - & - & - & - & 7.1 & 3 & - \\
\hline 192 & - & - & - & - & - & - & - & 7.3 & 2 & - \\
\hline
\end{tabular}

3

4

1

44

2

I

57

7

2

$3.08-958$ 


\section{BLOCK I5B (see p.86)}

Sub-block (see 14.3)

Context

$\begin{array}{rrrrrrrrr}A & B & C & C & D & E & E & F & G \\ 148 & 168 & 147 & 155 & 144 & 143 & 142 & 164 & 141\end{array}$

Species

*Oxyloma pfeifferi

Cochlicopa lubrica

Cochlicopa lubricella

Cochlicopa sp.

$\begin{array}{ll}3 & 4 \\ 8 & 3 \\ 9 & 3\end{array}$

*Vertigo antivertigo

*Vertigo substriata

Vertigo pygmaea

Pupilla muscorum

Lauria cylindracea

Vallonia costata

298

Vallonia excentrica

Punctum pygmaeum

Vitrina pellucida

Vitrea contracta

Nesovitrea hammonis

Oxychilus alliarius

Helicella itala

Cochlicella acuta

* Lymnaea trucatula

Total-terrestrial

(including wet species)

No. of species

7

(including wet species)

Seaweed imports

Rissoa parva

3

Littorina littoralis

BLOCK I7A (see p.88)

\begin{tabular}{|c|c|c|c|c|c|c|c|c|c|}
\hline Context & Bone & Pot & Snail & SeaSh & Macro & Stone & pH & Phos & $\begin{array}{r}\% \text { Burnt } \\
\text { stone }\end{array}$ \\
\hline 135 & 117 & 5 & 0 & 53 & 0 & 135 & 0 & - & - \\
\hline 245 & 30 & 6 & 0 & 314 & 0 & 222 & 7.8 & 4 & - \\
\hline 246 & 410 & 39 & 11.01 & 1633 & 23.58 & 3555 & 7.6 & 3 & 10 \\
\hline 247 & 0 & I & 0.01 & 14 & 0.01 & 0 & 8 & 3 & - \\
\hline 248 & 64 & I & 0.03 & 53 & 0.34 & 505 & 7.6 & 3 & 5 \\
\hline 249 & 9 & 0 & 0.01 & 96 & 0.42 & 727 & 7.7 & 3 & 10 \\
\hline 250 & 5 & 0 & 0.06 & 18 & 0.31 & 121 & 8.2 & 2 & - \\
\hline 251 & 5 & 0 & 0.05 & 50 & 0.49 & 49 & 7.6 & 4 & - \\
\hline 414 & 26 & 2 & 8.01 & 212 & 0.81 & $|54|$ & 7.6 & 2 & 30 \\
\hline Total & 666 & 99 & 19.2 & 2443 & 25.96 & 2884 & 0 & & \\
\hline
\end{tabular}


BLOCK I7B (see p.88)

Sub-block (see 14.3)

\section{Context}

Species

*Oxyloma pfeifferi

Cochlicopa lubrica

Cochlicopa lubricella

Cochlicopa sp.

*Vertigo antivertigo

Vertigo pygmaea

Pupilla muscorum

Lauria cylindracea

Vallonia costata

Vallonia excentrica

Vitrina pellucida

Vitrea contracta

Nesovitrea hammonia

Oxychilus alliarius

Hellicella itala

Cochliella acuta

*Lymnaea truncatula

Total-terrestrial

(including wet species)

No. of species

(including wet species)

Seaweed imports

Gibula cineraria

Rissoa parva

Littorina littoralis

Littorina littorea

BLOCK I8A (see p.89)

$\begin{array}{lrr}\begin{array}{l}\text { Context } \\ \text { Layers }\end{array} & \text { Bone } & \text { Po } \\ 123 & 219 & 46 \\ 124 & 224 & 2 \\ 169 & 0 & 21 \\ 170 & 157 & 0 \\ 185 & 76 & 0 \\ 186 & 0 & 0 \\ & & \end{array}$

Total

676

69

Pits

Pit I/138 $1978 \quad 0$

Pit $2 / 178 \quad 719 \quad 0$

Pit $3 / 174 \quad 1024 \quad 0$

Pit 4/48I

1418

Total

5139
A

249

B

248

\section{C}

25I

$C$
250

D

246

E

414

E

247

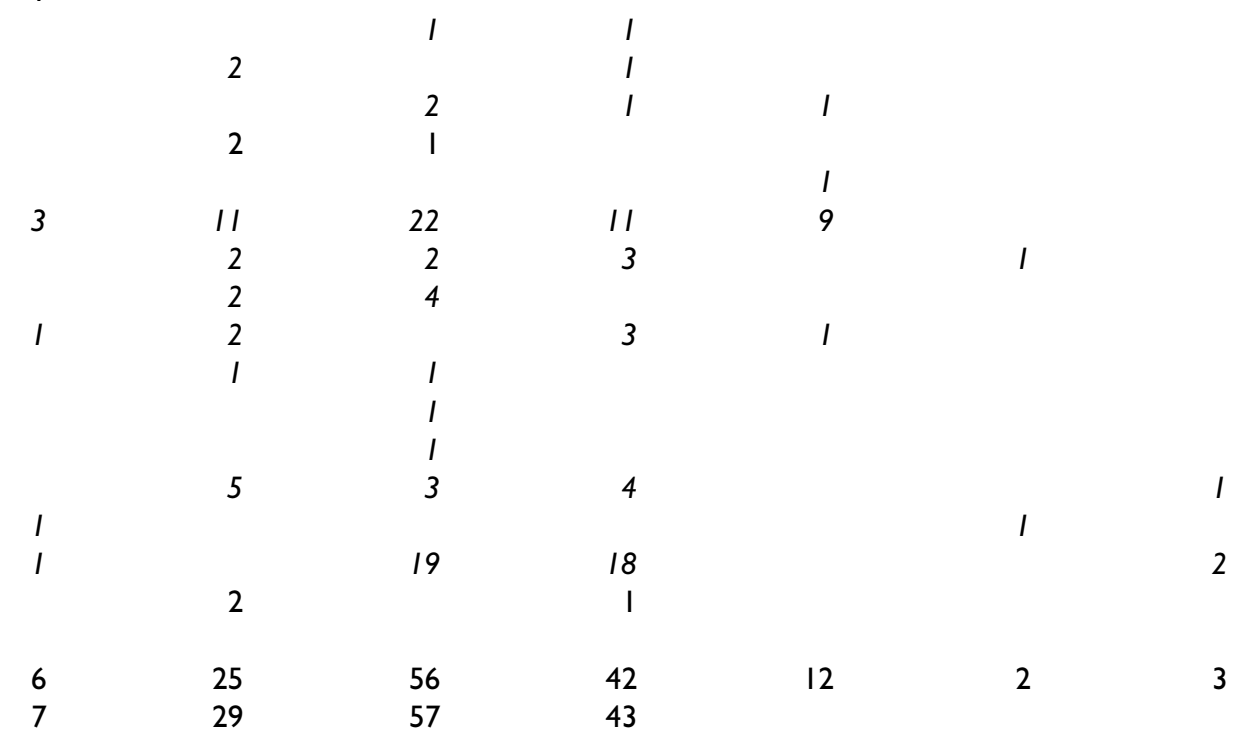

4

10

8

4

2

2

119

2

$$
\text { I }
$$

$\begin{array}{lr}\text { Snail } & \text { SeaSh } \\ 0 & 0 \\ 0.01 & 948 \\ 0.02 & 0 \\ 0 & 28 \\ 0 & 0 \\ 0.01 & 21 \\ 0.04 & 997\end{array}$

Macro
0
1.56
0.12
0
0
0.34

Stone

Ph

Phos
0
2
2
4
4
0

$\%$ Burnt

stone

$\begin{array}{rl}0 & 0 \\ 11 & 7.6 \\ 0 & 7.8 \\ 213 & 7.6 \\ 0 & 7.1 \\ 9 & 0\end{array}$

0

0

0

0

0

0

0

$233 \quad 0$

0

0
$<5$
0
0

$34.68 \quad 255$

$\begin{array}{rl}0 & 0 \\ 118 & 7.6 \\ 137 & 7.3 \\ 0 & 0\end{array}$

0
4
2
0

0

0 
BLOCK I8B (see p.89)

\section{Sub-block (see 14.3)}

Context

Species

Cochlicopa lubrica

Cochlicopa lubricella

Cohclicopa sp.

*Vertigo antivertigo

*Vertigo substiata

Vertigo pygmaea

Pupilla muscorum

Vallonia costata

Vallonia excentrica

Oxychilus alliarius

Helicella itala

Cochlicella acuta

Total-terrestrial

(including wet species)

No. of species

(including wet species)

Seaweed imports

Rissoa parva

$$
\text { A }
$$

178

B

186

B

169

24

3

2

2

I

2

2

l

34

6

I

47

8

3

I

I

2

3

I

17

6

5

10

I

2

I

2

I 
BLOCK I9A (see p.92)

\begin{tabular}{|c|c|c|c|c|c|c|c|c|c|c|}
\hline Context & Bone & Pot & Snail & SeaSh & Macro & Slag & Stone & pH & Phos & $\begin{array}{r}\% \text { Burnt } \\
\text { stone }\end{array}$ \\
\hline 252 & 30 & 0 & 0.09 & 261 & 1.64 & 0 & 268 & 7.8 & 3 & 5 \\
\hline 253 & 5 & 0 & 0.01 & 110 & 0.73 & 0 & 82 & 7.6 & 3 & 10 \\
\hline 254 & 5 & 0 & 0.01 & 56 & 0.31 & 0 & 35 & 7.6 & 3 & 0 \\
\hline 255 & 24 & 0 & 0.11 & 46 & 1.2 & 0 & 57 & 0 & 0 & 0 \\
\hline 256 & 5 & 0 & 0.12 & 35 & 0.39 & 0 & 23 & 7.8 & 2 & 0 \\
\hline 257 & 105 & 13 & 0.02 & 273 & 0.23 & 0 & 1705 & 7.6 & 2 & $<5$ \\
\hline 258 & 7 & 4 & 0.02 & 44 & 0.32 & 0 & 229 & 7.7 & 2 & 0 \\
\hline 259 & 38 & 0 & 5 & 220 & 1.14 & 0 & 469 & 7.7 & 2 & 0 \\
\hline 260 & 3 & 2 & 0.01 & 99 & 0.1 & 0 & 296 & 7.6 & 3 & 0 \\
\hline 261 & 33 & 6 & I & 250 & 0 & 0 & 1402 & 7.6 & 2 & $<5$ \\
\hline 262 & 39 & 10 & 9.01 & 619 & 6.23 & 0 & $116 \mid$ & 7.6 & 2 & $<5$ \\
\hline 263 & 31 & 5 & 9 & $|13|$ & 9.79 & 0 & 710 & 7.6 & 2 & 0 \\
\hline 264 & 20 & 0 & 0.06 & 1477 & 13.91 & 0 & 108 & 7.6 & 2 & 0 \\
\hline 265 & 116 & 8 & 0.01 & 2032 & 1.24 & 26 & 1738 & 7.6 & 2 & $<5$ \\
\hline 266 & 0 & 0 & 0 & 0 & 0 & 0 & 0 & 7.5 & 5 & 0 \\
\hline 267 & 244 & 7 & 4.07 & 819 & 11.82 & 0 & 1207 & 7.5 & 2 & $<5$ \\
\hline 268 & 242 & 13 & 0.11 & 1118 & 9.54 & 0 & 3932 & 7.5 & 2 & $<5$ \\
\hline 269 & 18 & I & 0.22 & 247 & I.0I & 0 & 1250 & 7.8 & 2 & 0 \\
\hline 270 & 62 & 0 & 2.1 & 561 & 1.01 & 8 & 1693 & 7.7 & 4 & 0 \\
\hline 271 & 20 & 2 & 2.01 & 140 & 0.02 & 0 & 530 & 7.8 & 3 & $<5$ \\
\hline 272 & 94 & 8 & 0.1 & 263 & 0.99 & 7 & 576 & 7.8 & I & 5 \\
\hline 273 & 62 & 0 & 0.19 & 80 & 1.24 & 0 & 224 & 7.8 & 0 & 0 \\
\hline 274 & 14 & 0 & 2.13 & 31 & 0.34 & 0 & 1236 & 7.9 & 3 & $<5$ \\
\hline 275 & 22 & 0 & 0 & 10 & 1.41 & 0 & 7 & 7.9 & 2 & 0 \\
\hline 276 & 3 & 1 & 0.33 & 16 & 0.38 & 0 & 504 & 7.7 & 2 & 0 \\
\hline 277 & 0 & 0 & 0 & 0 & 0 & 0 & 0 & 7.5 & 2 & 0 \\
\hline 278 & 0 & 1 & 0.01 & 0 & 0.1 & 0 & 0 & 7.9 & 2 & 0 \\
\hline 279 & 0 & 0 & 0 & 0 & 0 & 0 & 0 & 7.6 & 3 & 0 \\
\hline 280 & 0 & 0 & 0.03 & 0 & 0.66 & 0 & 11 & 8.1 & 2 & 0 \\
\hline 294 & 0 & 0 & 0 & 0 & 0 & 0 & 0 & 7.8 & 2 & 0 \\
\hline 295 & 3 & 1 & 0.09 & 18 & 0.3 & 0 & 24 & 7.8 & 3 & 0 \\
\hline 296 & 11 & 0 & 0.06 & 5 & 0.08 & 0 & 395 & 8.1 & 4 & 0 \\
\hline 297 & 0 & 0 & 0 & 0 & 0 & 0 & 0 & 8.1 & 2 & 0 \\
\hline 298 & 0 & 0 & 0 & 0 & 0 & 0 & 0 & 8.1 & 3 & 0 \\
\hline 299 & 8 & 0 & 0.08 & 177 & I & 0 & 216 & 7.8 & 4 & 0 \\
\hline 300 & 2 & 0 & 0.01 & 19 & 0.22 & 0 & 726 & 0 & 2 & $<5$ \\
\hline 301 & 624 & 0 & 0 & 0 & 0 & 0 & 0 & 0 & 0 & 0 \\
\hline 355 & 3 & 0 & 0.01 & 16 & 0.23 & 0 & 52 & 0 & 0 & 0 \\
\hline 372 & 13 & 4 & 0.03 & 71 & 1.26 & 0 & 1389 & 7.7 & 0 & 0 \\
\hline 373 & 12 & 4 & 0.03 & 93 & 0.8 & 0 & 302 & 7.6 & 0 & 0 \\
\hline Total & 1918 & 90 & 36.08 & 10337 & 69.64 & 41 & 22557 & 0 & 0 & 0 \\
\hline
\end{tabular}




\section{BLOCK I9B (see p.92)}

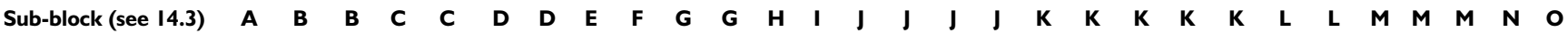
Context 280276274296255254253252278273272271355372373299300270269295268267265264262258257256260

\section{Species}

\begin{tabular}{|c|c|c|c|c|c|c|c|c|c|c|c|c|c|c|c|c|c|c|c|c|c|c|c|c|c|c|c|}
\hline Cochlicopa lubrica & 3 & 16 & 5 & 3 & 2 & & & 1 & & 11 & 1 & & 1 & & 2 & 4 & & 2 & 8 & 7 & 4 & & 1 & 1 & & & I \\
\hline Cochlicopa lubricella & 2 & 7 & 8 & 2 & 1 & I & & 3 & & 10 & 19 & & & & & & & 5 & 8 & 4 & 4 & 4 & & 2 & & & I \\
\hline Cochlicopa sp & & 16 & 5 & 1 & 6 & 1 & & 6 & 1 & 26 & 21 & & & 2 & 1 & 1 & & 5 & 8 & 2 & 4 & 8 & & 2 & & & I \\
\hline *Vertigo antivertigo & & & & & & & & 1 & & 1 & & & & & 2 & & 1 & & & I & 3 & 2 & 1 & & & & \\
\hline *Vertigo substriata & & & & & & & & 1 & & & & & & & & & & & & & & & & & & & \\
\hline Vertigo pygmaea & & & & & 1 & & & 1 & & & & & & 1 & 1 & & & & 1 & & 1 & 2 & & & & & \\
\hline Pupilla muscorum & & 141 & 50 & 18 & 22 & 7 & 4 & 28 & 4 & 87 & 37 & 1 & 7 & 15 & 15 & 40 & 5 & 18 & 48 & 20 & 42 & 18 & 1 & 11 & 1 & 4 & 16 \\
\hline Lauria cylindracea & & 9 & 4 & I & 1 & & & 5 & 1 & 3 & 4 & & I & & 2 & 4 & & 5 & 10 & 9 & 3 & 3 & & 7 & & & 1 \\
\hline Vallonia costata & & 8 & 4 & I & 2 & & & 4 & & & 7 & & & & & & & & 3 & & 2 & 2 & & 3 & & & 2 \\
\hline Vallonia excentrica & & 2 & 1 & 2 & 4 & & & & & 3 & 3 & & 1 & & & 1 & 1 & & 2 & & 2 & 2 & & 2 & & & \\
\hline Vitrina pellucida & & & & & & & & & & 1 & & 1 & & & & & & 1 & 1 & & & & & & & & \\
\hline Vitrea contracta & & & & & & & & & & & & & & 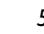 & & & & & & & & & & & & & \\
\hline
\end{tabular}

Nesovitrea hammonis

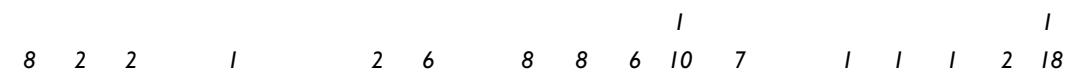

Oxychilus alliarius

*Zonitoides nitidus

Helicella itala

Cochlicella acuta

* Lymnaea truncatula

Total-terrestrial

(including wet species)

No. of species

(including wet species)

\section{Aquatic species}

Armiger crista

Seaweed imports

Gibula cineraria

Rissoa parva

Littorina littoralis

Littorina littorea

\section{BLOCK 20A (see p.93)}

$\begin{array}{rrrrrrrrrrr}\text { Context } & \text { Bone } & \text { Pot } & \text { Snail } & \text { SeaSh } & \text { Macro } & \text { Slag } & \text { Stone } & \begin{array}{r}\text { pH } \\ \text { Phos }\end{array} \begin{array}{c}\text { \% Burnt } \\ \text { stone }\end{array} \\ 189 & - & 2 & - & - & - & - & - & - & - & - \\ 314 & 621 & - & - & - & - & - & - & - & - & - \\ 323 & 3 & 2 & 0.01 & 32 & 0.01 & - & 24 & 7.6 & 3 & - \\ 324 & - & - & - & - & - & - & - & 7.7 & 2 & - \\ 331 & 4 & - & 0.52 & 39 & 0.03 & - & 90 & 7.6 & 4 & - \\ 335 & - & 1 & - & 3 & - & - & 32 & 7.8 & 3 & - \\ 336 & - & 2 & 2.01 & - & 0.01 & - & 6 & 7.7 & 4 & - \\ 343 & - & 3 & 0.01 & 17 & 0.04 & - & - & 7.8 & 3 & - \\ 413 & 145 & 4 & 0.08 & 74 & 0.63 & 24 & 867 & 7.4 & - & - \\ 435 & 2 & - & 0.05 & - & 0.1 & - & 58 & 7.4 & - & < \\ 447 & 53 & - & 6.05 & 97 & 0.08 & - & 369 & 7.4 & 3 & -\end{array}$

$\begin{array}{llllllll}\text { Total } & 828 & 14 & 8.73 & 262 & 0.9 & 24 & 1446\end{array}$


BLOCK 20B (see p.93)

\section{Sub-block (see 14.3)}

Context

Species

* Oxyloma pfeifferi

Cochlicopa lubrica

Cochlicopa lubricella

Cochlicopa sp

Vertigo pygmaea

Pupilla muscorum

Lauria cylindracea

Vallonia costata

Vallonia excentrica

Nesovitrea hammonis

Oxychilus alliarius

Helicella itala

Cochlicella acuta

*Lymnaea truncatula

Total-terrestrial

(including wet species)

No. of species

(including wet species)

Aquatic species

Gyraulus laevis

Seaweed imports

Rissoa parva

Littorina littoralis

Littorina littorea
447

A

336

B

323

C

331

35

435

413

2

2

2

1

5

3

6

1

3

104

2

20

22

4

4

9

6

III

22

23

27

28

5

7

II

12

I

2

2

4

3

3

4

I

I

1

31

5

4 
BLOCK 2 IA (see p.95)

\begin{tabular}{|c|c|c|}
\hline Context & Pot & Snail \\
\hline 357 & 0 & 0.14 \\
\hline 371 & 0 & 0.01 \\
\hline 375 & 0 & 0 \\
\hline 377 & 0 & 0 \\
\hline 378 & 0 & 0 \\
\hline 379 & 0 & 0 \\
\hline 380 & 0 & 0 \\
\hline 381 & 0 & 0 \\
\hline 382 & 0 & 0 \\
\hline 383 & 0 & 0 \\
\hline 384 & 0 & 0 \\
\hline 385 & 0 & 0 \\
\hline 386 & 0 & 0 \\
\hline 387 & 0 & 0 \\
\hline 389 & 0 & 0 \\
\hline 390 & 0 & 0 \\
\hline 391 & 0 & 0 \\
\hline 392 & 0 & 0 \\
\hline 393 & 4 & 0 \\
\hline 394 & 0 & 0 \\
\hline 395 & 0 & 0 \\
\hline 396 & 0 & 0 \\
\hline 400 & 0 & 0 \\
\hline 402 & 0 & 0 \\
\hline 404 & 0 & 0 \\
\hline 405 & 0 & 0 \\
\hline 406 & 0 & 0 \\
\hline 407 & 0 & 0 \\
\hline 411 & 0 & 0 \\
\hline 421 & 0 & 0 \\
\hline 422 & 0 & 0 \\
\hline 423 & 0 & 0 \\
\hline 425 & 0 & 0 \\
\hline
\end{tabular}

SeaSh

Macro

pH

Phos

0.14

0.53

$\begin{array}{ll}0.16 & 7.2\end{array}$

$\begin{array}{ll}0.16 & 7.8\end{array}$

7.7

7.6

7.6

7.6

7.7

7.7

7.7

7.6

7.7

7.6

7.7

7.5

7.6

7.6

7.6

7.5

7.6

7.6

7.6

7.6

0

0
0

3

3

3
-3
-3

$\begin{array}{lll}\text { Total } 4 & 0.15\end{array}$

17

0

Species

Cochlicopa lubrica

Cochlicopa Lubricella

Cochlicopa sp

Pupilla muscorum

Lauria cylindracea

Oxychilus alliarius

Helicella itala

Total-terrestrial

(including wet species)

No. of species

(including wet species)

Seaweed imports 
BLOCK 22A (see p.96)

$\begin{array}{rrrrrrrrrrr}\text { Context } & \text { Bone } & \text { Pot } & \text { Snail } & \text { SeaSh } & \text { Macro } & \text { Slag } & \text { Stone } & \text { pH } & \begin{array}{r}\text { Phos } \\ \text { \% Burnt } \\ \text { stone }\end{array} \\ 332 & 51 & 14 & 0.03 & 723 & 0.2 & 6 & 2956 & 7.6 & 3 & - \\ 333 & 78 & 2 & - & 105 & 0.12 & - & 1155 & 7.5 & 3 & - \\ 337 & 33 & - & 0.01 & 6 & 0,41 & - & 56 & 7.7 & 3 & - \\ 341 & 63 & 12 & 0.12 & 244 & 0.74 & - & 1312 & 7.7 & 3 & - \\ 344 & - & - & 0.01 & 6 & 0.55 & - & 44 & 8.2 & 4 & - \\ 345 & - & - & 0.01 & - & -0.01 & - & - & 7.8 & 3 & - \\ 346 & - & - & - & - & - & - & - & 7.5 & 4 & - \\ 350 & - & - & - & - & - & - & - & 7.5 & 3 & - \\ 351 & 27 & 4 & 0.04 & 395 & 0.54 & 4 & 1532 & 7.8 & 3 & - \\ 352 & 5 & 3 & - & 65 & - & - & 198 & 7.5 & - & 5 \\ 353 & - & - & - & - & - & - & - & 7.6 & 3 & - \\ 412 & 16 & 5 & 0.01 & 29 & 0.35 & - & 275 & 7.3 & 2 & -\end{array}$

\section{BLOCK 22B (see p.96)}

\section{Sub-block (see 14.3)}

Context

\section{Species}

Cochlicopa lubrica

Cochlicopa lubricella

cochlicopa sp

Pupilla muscorum

Lauria cylindracea

Vallonia costata

Vallonia excentrica

Oxychilus alliarius

Helicella itala

*Lymnaea truncatula

Total-terrestrial

(including wet species)

No. of species

(including wet species)

Seaweed imports

Gibula cineraria

Rissoa parva

Littorina littorea

BLOCK 23 (see p.98)

\section{Context}

Bone

115

84
A

344

A

337

A

412

C

332

5

1
24

I

3

2

2

6

37

8

4

6

5 
BLOCK 26A (see p. 100)

\begin{tabular}{|c|c|c|c|c|c|c|c|c|c|c|}
\hline Context & Bone & Pot & Snail & SeaSh & Macro & Slag & Stone & pH & Phos & $\begin{array}{r}\text { \% Burnt } \\
\text { stone }\end{array}$ \\
\hline 326 & 18 & I & 0.06 & 70 & 0.24 & - & 666 & 7.4 & 4 & - \\
\hline 327 & - & - & - & - & - & - & - & 7.6 & 3 & - \\
\hline 338 & 31 & 3 & 0.05 & 969 & 0.15 & - & 4322 & 7.8 & 4 & - \\
\hline 339 & 42 & 6 & 2.04 & 470 & 0.52 & - & 4542 & 7.8 & 4 & - \\
\hline 340 & 34 & - & 0.04 & 170 & 0.92 & - & 505 & 7.8 & 2 & - \\
\hline 342 & 4 & - & 0.37 & - & 0.01 & - & 7 & 8 & 4 & - \\
\hline 347 & 14 & - & 0.01 & 49 & 0.23 & - & 218 & 7.4 & 4 & - \\
\hline 348 & 4 & - & 0.14 & 102 & 0.02 & - & 10 & 7.4 & 2 & - \\
\hline 349 & 6 & - & 0.08 & 68 & 0.35 & - & 124 & 7.5 & 4 & - \\
\hline 369 & 20 & - & 0.39 & - & 0.01 & - & - & 7.3 & 2 & - \\
\hline 370 & - & - & - & - & - & - & - & 7.4 & 3 & - \\
\hline 376 & - & - & - & - & - & - & - & 7.6 & 4 & - \\
\hline
\end{tabular}

$\begin{array}{llllllll}\text { TOTAL } & 173 & 10 & 3.18 & 1898 & 2.45 & - & 10394\end{array}$

BLOCK 26B (see p. I 00)

\begin{tabular}{|c|c|c|c|c|c|c|c|c|c|}
\hline Sub-block (see I4.3) & $\mathbf{A}$ & B & C & D & D & D & $\mathbf{E}$ & $\mathbf{E}$ & $\mathbf{F}$ \\
\hline Context & 369 & 342 & 326 & 340 & 347 & 339 & 348 & 338 & 349 \\
\hline \multicolumn{10}{|l|}{ Species } \\
\hline Cochlicopa lubrica & 54 & 23 & 3 & 3 & 3 & 9 & 6 & 49 & 4 \\
\hline Cochlicopa lubricella & 42 & 25 & 3 & 2 & & & 9 & 35 & 3 \\
\hline Cochlicopa sp. & 37 & 23 & 7 & 4 & 4 & 12 & 12 & 37 & 11 \\
\hline *Vertigo substriata & 1 & & & & & & & & \\
\hline Vertigo pygmaea & & & & & & & & I & \\
\hline Pupilla muscorum & 38 & 119 & 17 & 6 & 3 & 8 & 33 & 156 & 24 \\
\hline Lauria cylindracea & & & 2 & & & & & 6 & 1 \\
\hline Vallonia costata & 7 & 3 & 6 & 2 & 2 & 5 & 2 & 27 & 7 \\
\hline Vallonia excentrica & 58 & 34 & 6 & 6 & 2 & 8 & 7 & 46 & 8 \\
\hline Vitrina pellucida & & & & & & & & 1 & \\
\hline Nesovitrea hammonis & & & 1 & & & & & & \\
\hline Oxychilus alliarius & & & 2 & & & I & & & 3 \\
\hline Helicella itala & I & 16 & 3 & & & I & 5 & 14 & 6 \\
\hline Cochlicopa acuta & & & & & & & I & I & \\
\hline *Lymnaea truncatula & & & 1 & & & & & & \\
\hline Total-terrestrial & 237 & 243 & 50 & 23 & 14 & 44 & 75 & 375 & 67 \\
\hline (including wet species) & 238 & & 51 & & & & & & \\
\hline No. of species & 7 & 7 & 10 & 6 & 5 & 7 & 8 & II & 9 \\
\hline (including wet species) & 8 & & II & & & & & & \\
\hline \multicolumn{10}{|l|}{ Seaweed imports } \\
\hline Rissoa parva & I & & I & & & I & I & l & 3 \\
\hline
\end{tabular}


BLOCK 27A (see p. I 02)

$\begin{array}{crrlrlrrrr}\text { Context } & \text { Bone } & \text { Pot } & \text { Snail } & \text { SeaSh } & \text { Macro } & \text { Stone } & \text { pH } & \begin{array}{r}\text { Phos } \\ \text { \% Burnt } \\ \text { stone }\end{array} \\ 125 & 6 & 6 & 0 & 0 & 0 & 0 & 0 & 0 & 0 \\ 126 & 211 & 4 & 0 & 0 & 0 & 0 & 0 & 0 & 0 \\ 130 & 56 & 19 & 0 & 0 & 0 & 0 & 0 & 0 & 0 \\ 172 & 34 & 0 & 0.02 & 109 & 0.65 & 123 & 0 & 0 & 0 \\ 175 & 0 & 0 & 0 & 8 & 0.04 & 40 & 7.2 & 3 & 0 \\ 464 & 53 & 2 & 0.05 & 106 & 0.01 & 917 & 7.3 & 5 & 5 \\ 465 & 42 & 0 & 0.03 & 94 & 0.31 & 1420 & 7.3 & 5 & 0 \\ \text { Total } & 402 & 31 & 1 & 317 & 1.01 & 2500 & 0 & 0 & 0\end{array}$

BLOCK 27B (see p. I 02)

Sub-block (see 14.3)

Cochlicopa lubrica

Cochlicopa lubricella

Cochliocpa sp

*Vertigo antivertigo

Pupilla muscorum

Vallonia costata

Vallonia excentrica

Vitrina pellucida

Oxychilus alliarius

Helicella itala

Cochlicella acuta

Total-terrestrial

(including wet species)

No. of species

(including wet species)

Seaweed imports

Rissoa parva

BLOCKS 28-3I (see p. I03)

\section{Context}

\section{0}

\section{Species}

Cochlicopa lubrica

Vertigo pygmaea

Pupilla muscorum

Lauria cylindradea

Vallonia costata

Oxychilus alliarius

Cochlicella acuta

Total-terrestrial

(including wet species)

No. of species

(including wet species)

Seaweed imports

Rissoa parva
A

464

$\begin{array}{cc}\text { B } & \text { C } \\ 465 & 172\end{array}$

31

$$
3
$$

1

10

2 
TABLES FOR CHAPTER 7

BLOCK IA (see p.| 05)

\begin{tabular}{|c|c|c|c|c|c|c|c|c|c|c|}
\hline Layers & Bone & SeaSh & $\begin{array}{l}\text { Pot } \\
\text { frags }\end{array}$ & $\begin{array}{l}\text { Pot } \\
\text { wt }\end{array}$ & Qtz & Flt & Stn & Slag & $\begin{array}{c}\text { Pumice } \\
\text { frags }\end{array}$ & $\begin{array}{c}\text { Pumice } \\
\text { wt }\end{array}$ \\
\hline 4 & 27.6 & 604.9 & 26 & 466.8 & 16 & 6 & 16 & I & I & 2.4 \\
\hline 13 & I.I & 0 & 0 & 0 & 0 & 2 & 0 & 0 & 0 & 0 \\
\hline 19 & 1.7 & 0 & 2 & 7.7 & 4 & 0 & I & 0 & I & 14.3 \\
\hline 21 & 0 & 0 & 1 & 4.1 & I & 0 & 0 & 0 & 0 & 0 \\
\hline 25 & 0 & 0 & 14 & 177.7 & 2 & 0 & 0 & 0 & 0 & 0 \\
\hline 27 & 0 & 0 & I & 3.9 & 0 & 0 & 0 & 0 & 0 & 0 \\
\hline 71 & 0 & 0 & 7 & 33 & 2 & 0 & 0 & 0 & 0 & 0 \\
\hline 101 & 65 & 39 & 0 & 0 & 0 & 1 & 0 & 0 & 0 & 0 \\
\hline 104 & 11 & I44.I & 4 & 31.7 & 0 & 2 & 0 & 0 & 0 & 0 \\
\hline 109 & 10 & 53 & 0 & 0 & 0 & 0 & 0 & 0 & 0 & 0 \\
\hline 122 & 77.7 & 0 & 0 & 0 & 0 & 0 & 0 & 0 & 0 & 0 \\
\hline 124 & 0 & 0 & 0 & 0 & I & 1 & 0 & 0 & 0 & 0 \\
\hline 142 & 221.3 & 6.4 & 0 & 0 & 0 & 0 & 0 & 0 & 0 & 0 \\
\hline 157 & 0 & 0 & 2 & 17.9 & 0 & 0 & 0 & 0 & 0 & 0 \\
\hline 198 & 0 & 0 & 0 & 0 & I & 0 & 0 & 0 & 0 & 0 \\
\hline Total & 415.4 & 847.4 & 57 & 742 & 27 & 12 & 12 & 17 & 12 & 16.7 \\
\hline
\end{tabular}

BLOCK IB (see p. I 05)

\begin{tabular}{|c|c|c|c|c|c|c|}
\hline Pits & Bone & SeaSh & $\begin{array}{l}\text { Pot } \\
\text { frags }\end{array}$ & $\begin{array}{c}\text { Pot } \\
\text { wt }\end{array}$ & Qtz & Flt \\
\hline 2 & 0 & 0 & 2 & 43 & 0 & 0 \\
\hline 3 & 0 & 0 & 9 & 54.4 & 0 & 0 \\
\hline 5 & 0 & 0 & 0 & 0 & 0 & 1 \\
\hline 38 & 0 & 0 & 0 & 0 & 1 & 0 \\
\hline 48 & 0 & 0 & 1 & 2.5 & 0 & I \\
\hline 68 & 0 & 0 & I & 1.7 & 1 & 0 \\
\hline 93 & 0 & 6.7 & 0 & 0 & 0 & 0 \\
\hline 119 & 0 & 0 & I & 11.3 & 0 & 0 \\
\hline 95 (fill of II9) & 0 & 0 & 1 & 32 & 0 & 0 \\
\hline 150 & 102.2 & 10.4 & 0 & 0 & 0 & 0 \\
\hline 207 & 0 & 0 & 0 & 0 & 20 & 0 \\
\hline 222 & 0 & 0 & 0 & 0 & 0 & I \\
\hline 224 (fill of 222) & 0 & 0 & I & 76 & 0 & 0 \\
\hline Total & 102.2 & 17.1 & 16 & 220.9 & 22 & 3 \\
\hline
\end{tabular}

BLOCK 2 (see p. | 06)

$\begin{array}{cccc}\text { Context } & \begin{array}{c}\text { Pot } \\ \text { frags }\end{array} & \begin{array}{c}\text { Pot } \\ \text { wt }\end{array} & \text { Stn } \\ 103 & 1 & 3 & 1\end{array}$


BLOCK 3 (see p. | 08)

\begin{tabular}{|c|c|c|c|c|c|c|c|}
\hline Context & Bone & SeaSh & Qtz & Flt & St & $\begin{array}{c}\text { Pumice } \\
\text { frags }\end{array}$ & $\begin{array}{c}\text { Pumice } \\
\text { wt }\end{array}$ \\
\hline 83 & 0 & 0 & 0 & 0 & I & 0 & 0 \\
\hline 108 & 20.6 & 1012.7 & 6 & 0 & 8 & I & 8 \\
\hline 112 & 1.3 & 9.2 & 0 & 0 & 0 & 0 & 0 \\
\hline 180 & 46.9 & 12.1 & 0 & 2 & 0 & 0 & 0 \\
\hline 212 & 0 & 100 & 17 & 0 & I & 0 & 0 \\
\hline 233 & 0 & 0 & 1 & 0 & 0 & 0 & 0 \\
\hline Total & 68.8 & 1134 & 24 & 2 & 10 & I & 8 \\
\hline
\end{tabular}


TABLES FOR CHAPTER 8

BLOCK I (see p.III)

$\begin{array}{ccccccc}\text { Context } & \text { Bone } & \text { Snail } & \text { SeaSh } & \text { Stone } & \text { pH } & \text { Phos } \\ 1 & 9.14 & 6 & 123.8 & 334 & 2 & 7.4\end{array}$

BLOCK 2 (see p. I I I)

Context

50

BLOCK 3 (see p. I I I)

\begin{tabular}{|c|c|c|c|c|c|c|c|c|c|}
\hline Context & Bone & Snail & SeaSh & Mcp & Pot & Stone & Iron & pH & Phos \\
\hline 5 & 0 & 0 & 68 & 0 & 0 & 0 & 0 & 7.3 & 4 \\
\hline 6 & 9 & 0 & 215 & 0 & 0 & 0 & 0 & 7.5 & 4 \\
\hline 7 & 61 & 0 & 818 & 6 & 0 & 437 & 0 & 7.5 & 4 \\
\hline 8 & 6 & 0 & 128 & 0 & 4.7 & 164 & 0 & 7.5 & 3 \\
\hline 11 & 0 & 0 & 0 & 0 & 0 & 0 & 0 & 7.5 & 3 \\
\hline 12 & 2 & 1.4 & 96 & 0 & 0 & 298 & 0 & 7.5 & 5 \\
\hline 13 & 13 & 0 & 93 & 0 & 0 & 73 & 0 & 7.5 & 3 \\
\hline 14 & 0 & 0 & 0 & 0 & 0 & 0 & 0 & 7.6 & 2 \\
\hline 15 & 0 & 0 & 0 & 0 & 0 & 0 & 0 & 7.5 & 2 \\
\hline 17 & 43 & 10.2 & 96 & 0 & 0 & 70 & 0 & 7.5 & 5 \\
\hline 19 & 72 & 11 & 707 & 18 & 0 & 288 & 0 & 7.6 & 5 \\
\hline 20 & 4 & 0 & 191 & 0 & 0 & 108 & 0 & 7.6 & 5 \\
\hline 21 & 7 & 0 & 600 & 0 & 0 & 405 & 0 & 7.7 & 2 \\
\hline 22 & 20 & 0 & 132 & 0 & 8.1 & 99 & 0 & 7.1 & 5 \\
\hline 23 & 0 & 4 & 118 & 0 & 0 & 17 & 0 & 7.5 & 4 \\
\hline 24 & 12 & 7 & 148 & 0 & 16.7 & 30 & 0 & 7.5 & 3 \\
\hline 27 & 11 & 0 & 917 & 0 & 0 & 0 & 0 & 7.7 & 4 \\
\hline 28 & 4 & 0 & 51 & 0 & 0 & 0 & 0 & 7.6 & 3 \\
\hline 29 & 2 & 0 & 31 & 0 & 20.6 & 17 & 0 & 7.7 & 5 \\
\hline 30 & 0 & 0 & 186 & 0 & 0 & 7 & 0 & 7.1 & 5 \\
\hline 31 & 20 & 0 & 160 & 0 & 0 & 20 & 0 & 7.6 & 2 \\
\hline 32 & 9 & 2.8 & $|3|$ & 0 & 0 & 0 & 0 & 7.5 & 4 \\
\hline 33 & 28 & 7.6 & 0 & 0 & 0 & 0 & 0 & 7.5 & 3 \\
\hline 35 & 0 & 0 & 0 & 0 & 0 & 0 & 0 & 7.6 & 3 \\
\hline 37 & 3 & 5.3 & 0 & 0 & 0 & 0 & 0 & 7.1 & 2 \\
\hline 38 & 79 & 2.1 & 775 & 0 & 0 & 174 & 0 & 7.6 & 5 \\
\hline 41 & 39 & 7 & 563 & 0 & 0 & 554 & 10 & 7.7 & 4 \\
\hline 42 & 0 & 0 & 30 & 0 & 0 & 0 & 0 & 7.5 & 4 \\
\hline 47 & 0 & 0 & 130 & 0 & 0 & 0 & 0 & 7.1 & 5 \\
\hline 48 & 85 & 0 & 253 & 0 & 0 & 95 & 0 & 7.7 & 5 \\
\hline 49 & 0 & 0 & 22 & 0 & 3.8 & 0 & 0 & 7.8 & 4 \\
\hline Total & 529 & 58.4 & 6,659 & 18 & 53.9 & 2,856 & 10 & 0 & 0 \\
\hline
\end{tabular}

SeaSh
27 
BLOCK 4 (see p.II3)

$\begin{array}{lrrrrrrrrr}\text { Context } & \text { Bone } & \text { Snail } & \text { SeaSh } & \text { Mcp } & \text { Pot } & \text { Stone } & \text { Glass } & \text { PH } & \text { Phos } \\ 51 & 5 & 6 & 163 & 0 & 0 & 12 & 0 & 0 \\ 52 & 86 & 8 & 474 & 7 & 4.1 & 286 & 4 & 0 \\ 53 & 52 & 6 & 707 & 0 & 0 & 157 & 0 & 7.5 \\ 56 & 0 & 0 & 0 & 0 & 0 & 0 & 0 & 7.5 \\ 58 & 2 & 3 & 26 & 0 & 0 & 0 & 0 & 7.5 \\ \text { Total } & 145 & 23 & 1370 & 7 & 4.1 & 455 & 4 & 3 \\ \end{array}$

\section{BLOCK 5 (see p.II3)}

$\begin{array}{cccccccc}\text { Context } & \text { Bone } & \text { Snail } & \text { SeaSh } & \text { Mcp } & \text { Stone } & \text { Phos } & \text { pH } \\ 43 & 19 & 6 & 340 & 18 & 68 & 7.7 & 3 \\ 46 & 35 & 0 & 3,369 & 0 & 0 & 7.9 & 3\end{array}$

BLOCKS I-5 (see p.III, II3)

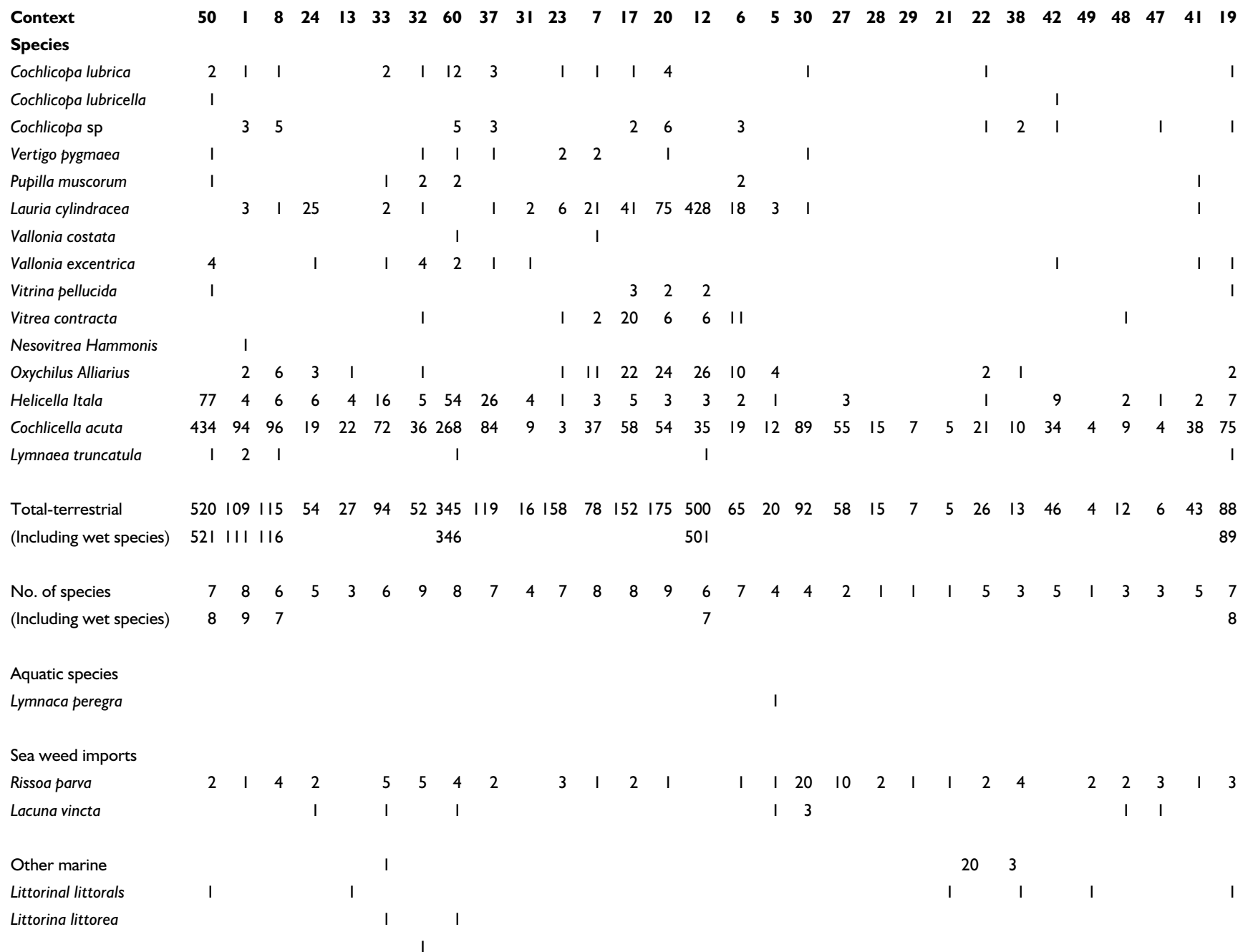

